\title{
Instruction and attitudes in EFL: A focus on recognition and production of conventional expressions
}

DOCTORAL DISSERTATION

Presented by: María José Arrufat Marqués

Supervised by: Dr. Eva Alcón Soler 


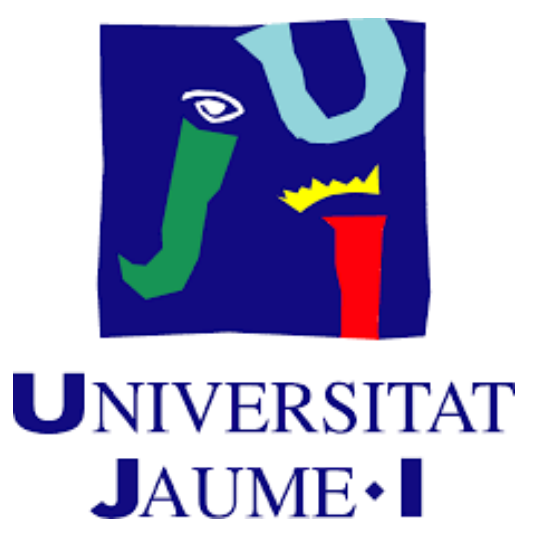

Programa de Doctorat en Llengües Aplicades, Literatura i Traducció

Escola de Doctorat de la Universitat Jaume I

Instruction and attitudes in EFL: A focus on recognition and production of conventional expressions

Memòria presentada per María José Arrufat Marqués per a optar al grau de doctora per la Universitat Jaume I

María José Arrufat Marqués

Eva Alcón Soler

María del Pilar Safont Jordà

Castelló de la Plana, maig 2019 



\section{Finançament rebut}

La doctoranda María José Arrufat Marqués ha gaudit d'un contracte predoctoral per la Generalitat Valenciana, en particular per la Conselleria d'Educació, Cultura i Ciència, amb una beca predoctoral VALi+D amb identificació ACIF/2016/237. 



\section{ACKNOWLEDGEMENTS}

First and foremost, I would like to express my sincere gratitude to my two supervisors, Dr. Eva Alcón and Dr. Pilar Safont. Thank you both for your support, interest for, and guidance in this $\mathrm{PhD}$ dissertation. This study would never have been accomplished without both of you and your valuable comments and insights all throughout the research and writing processes. I am immensely indebted to the two of you for sharing your vast experience and extensive knowledge in the fields of pragmatics, teaching pragmatics, and language attitudes. Your personal qualities and good advice have been of great help throughout the past four years.

My heartfelt thank you goes to Dr. Marta González-Lloret. Huge thanks to you, for your invaluable help, your constant academic, professional, and personal support throughout the eight months I spent with you at the University of Hawai'i at Mānoa. It has been an honor for me to work with you and learn from you. You made me feel at home when I was so far away from mine.

Special thanks are due to all members in the LAELA research group at Universitat Jaume I (UJI). Thanks for your support and encouragement in this dissertation. I also wish to thank the Valencian Government, specially the Generalitat Valenciana Conselleria d'Educació, Cultura i Ciència for the VALi+D grant which enabled me to complete this dissertation.

I do owe more than thanks to Dr. Alicia Martínez-Flor. You have been my academic mom since I first became an undergraduate student at UJI back in 2008. I am indebted to you as well, since you were the one who introduced me to pragmatics in the first place. Thank you for believing in me. It all started with you. 
I would also like to truly thank Dr. Naoko Taguchi for being not only one of my professors in my time at Carnegie Mellon University, but also -and most importantlyfor being a mentor to me even years after I graduated. Thank you for all your support, your insights on this dissertation, and your help during all these years. You always had time to sit down with me and talk about school and more. You have been an example of hard work and dedication, an inspiration, a role model to me.

A big thanks goes to Dr. Fernando de La Torre for allowing me to do a research stay at his Human Sensing Lab in the Robotics Institute at Carnegie Mellon University during the Spring semester of 2017. Thank you for allowing me to use IntraFace for educational purposes and thus proving the importance of interdisciplinary research for the development of any field of study.

Thanks are also due to all native speakers who helped me throughout this process. Thanks to Patrick and Bria for their help in the early stages of this dissertation when I was designing the instruments to test them in the pilot study. Thanks to Tara and Dian for their help rating the qualitative data of this dissertation and therefore providing their insights as native speakers and help me with the interrater reliability process.

I also wish to thank the seven students that participated in the pilot study, as well as the 48 students that conformed the sample of this study. This dissertation would have never come to life without you.

I would like to thank my friends here in Spain and overseas for their support and understanding my long periods of absences. I would like to make a special mention to some of you. First, Melissa and Yuuki, thank you for allowing me to use the video we created for our Language and Technology class back in 2015 when we were graduate students at Carnegie Mellon University. Using our video two years later reminded me of 
the good old times we spent together, not only while filming the video but also during that wonderful academic year. Second, thank you to Mery, Mar, Caty, Cindy, and Luke at the University of Hawai' $i$ at Mānoa for welcoming me so warmly and supporting me all throughout the final stages of this dissertation. You guys are incredibly amazing. Third, Sofía, our long conversations and your pieces of advice when I most needed them helped me get through the most difficult moments during this long journey, from its beginning to its end. A zillion thanks to you, my dear. Fourth, Silvia, not only have you been a true friend, but you have also supported me in this crazy adventure I call PhD life. Thank you so much for all your help, your ideas and suggestions, your knowledge of statistics, and your thoughtful comments all along the process. Pittsburgh let me meet two wonderful people: one was Marc and the other one was you. Fifth, Dani, life brings you the opportunity to meet amazing people sometimes. And one of these very few I have met is you. Thank you for all these years of being not only a good friend but also my therapist, giving me advice on all sorts of academic and $\mathrm{PhD}$-related issues. Finally, Bego, thank you for being there since 2008, when our paths crossed in our undergraduate studies at UJI. You are one of those very few souls I cannot live without. Thank you for inspiring me, for rooting for me, for believing in me.

I do owe more than thank you to my parents Pascual and Loles, not only for the past four years, but for my entire life. Letting me see and experience the world has helped me get to where I am now. I would have never become who I am without your limitless patience, love, and support. Saying thank you to you both is the understatement of the century, but I hope these words help me express the honor it is for me to be your daughter. 
And last but not least, I would like to thank my husband. Marc, thank you for being the rock I have held on to since we first met five years ago. Thank you for your unconditional love, your endless patience, and your help with the technical/computer part of this study. Thank you for cheering me up at all times, for encouraging me to keep moving forward, for being there at every moment we have been through during our times together across the pond, and our FaceTime connections when we were far way apart from each other. Thank you for understanding that this $\mathrm{PhD}$ craziness meant one of the milestones in my life. I love you with all my soul. This dissertation would have never been the same without you. To you, to our life together, forever, wherever the wind takes us. 
TO MY PARENTS,

TO MARC 

TABLE OF CONTENTS

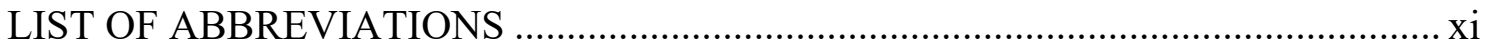

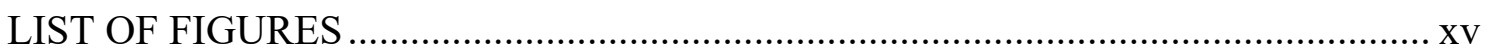

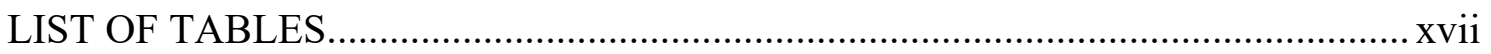

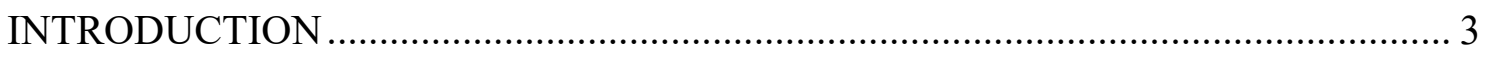

PART I: LITERATURE REVIEW ….............................................................. 9

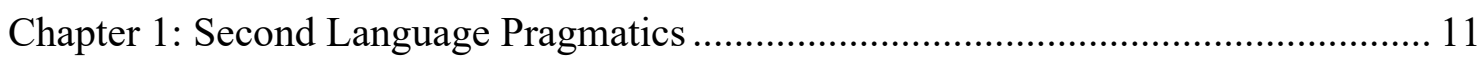

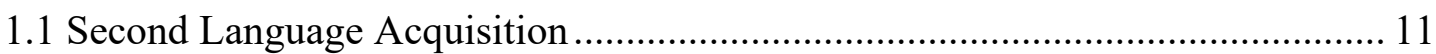

1.1.1 Defining second language acquisition......................................................... 11

1.1.2 Theories of second language acquisition.................................................. 13

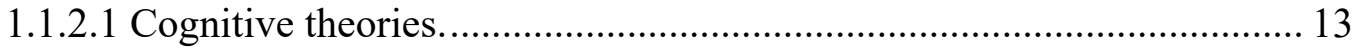

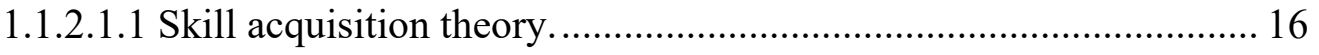

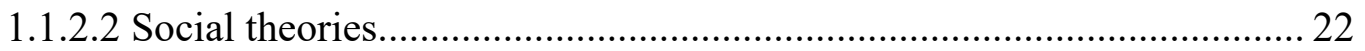

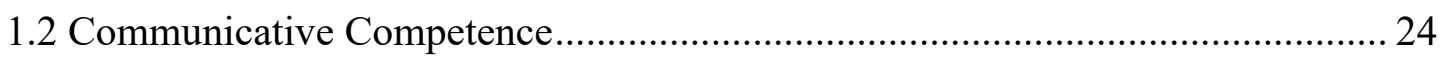

1.2.1 Defining communicative competence. …................................................ 24

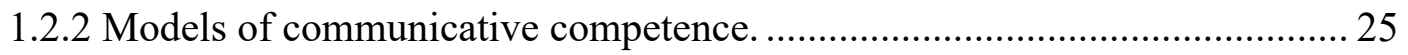

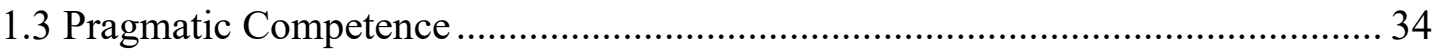

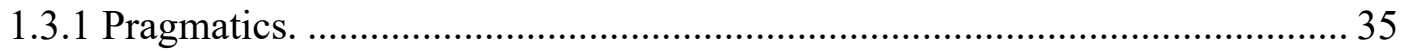

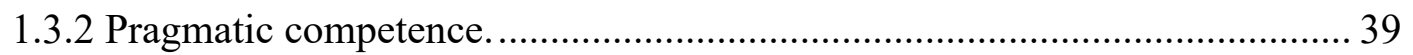

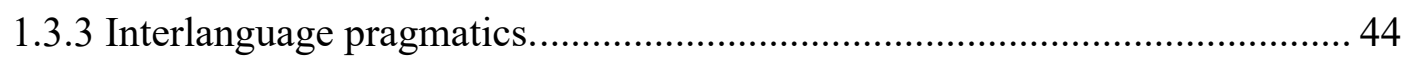

1.3.3.1 Defining interlanguage pragmatics.............................................. 44

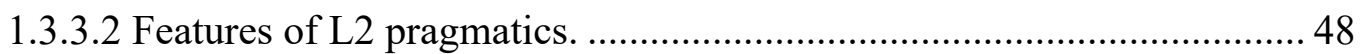

1.3.3.3 ILP studies: cross-sectional and longitudinal. ..................................... 49

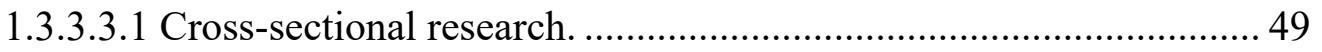

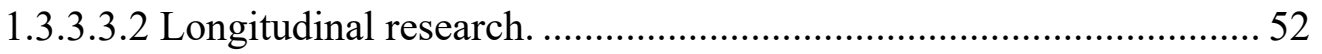

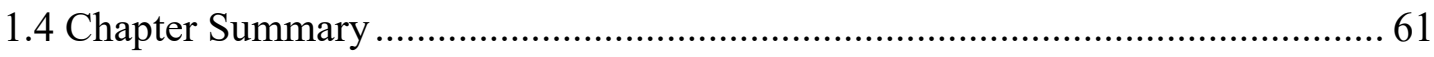

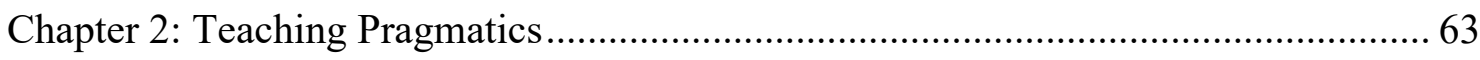

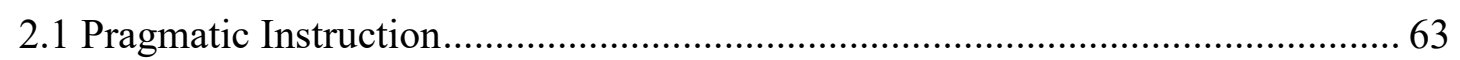

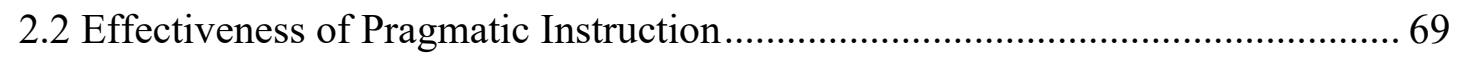

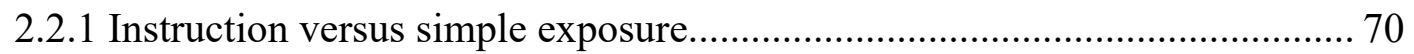

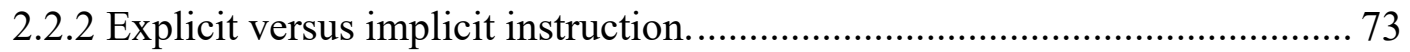

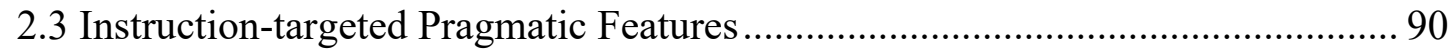

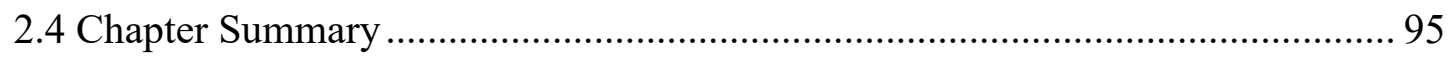

Chapter 3: Attitudes in Language Learning .............................................................. 97

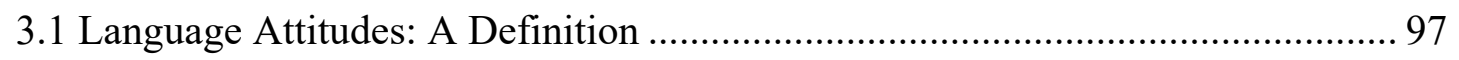

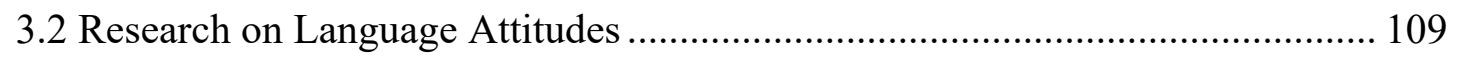

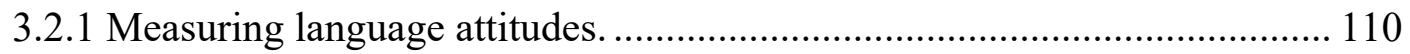


3.2.2 Research on language attitudes in instructed classrooms. 114

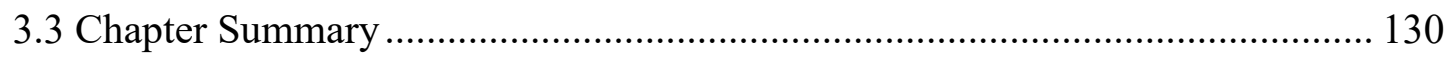

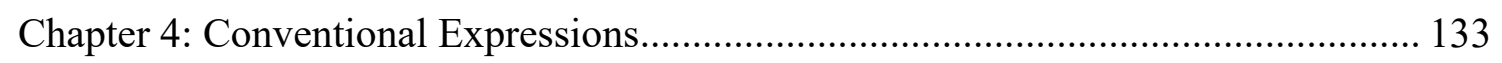

4.1 Conventional Expressions and Formulaic Language ........................................ 133

4.1.1 Operationalization of conventional expressions..................................... 134

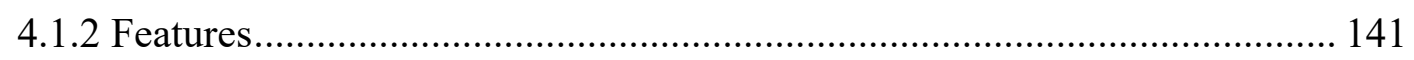

4.2 Research on Conventional Expressions.......................................................... 144

4.2.1 Research on recognition and production of conventional expressions........ 148

4.3 Target Conventional Expressions .................................................................. 157

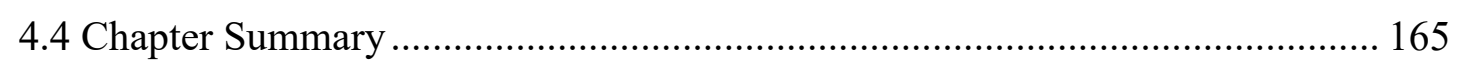

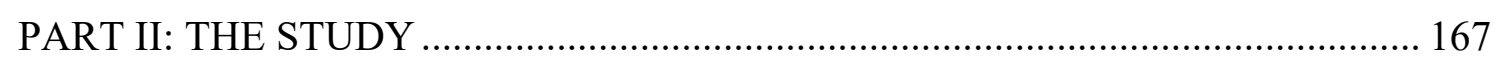

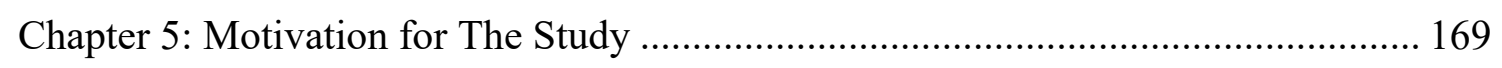

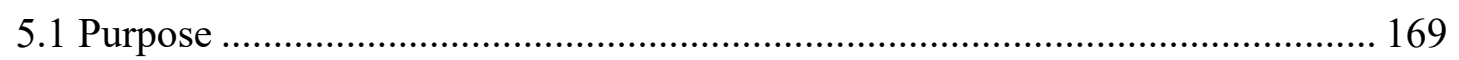

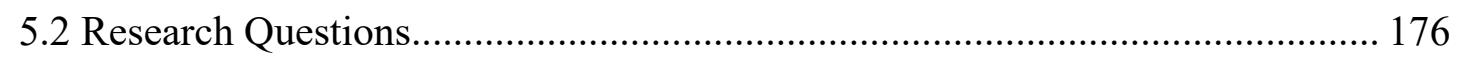

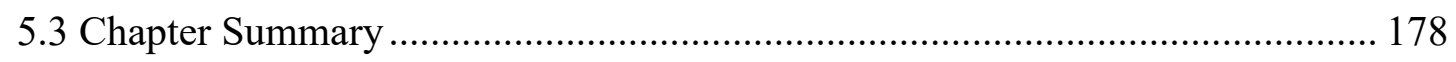

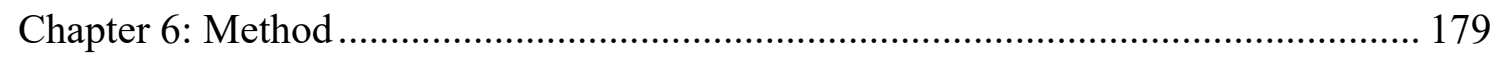

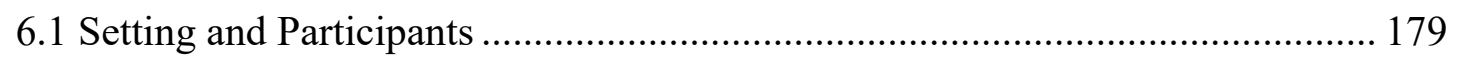

6.2 Target Conventional Expressions ................................................................. 184

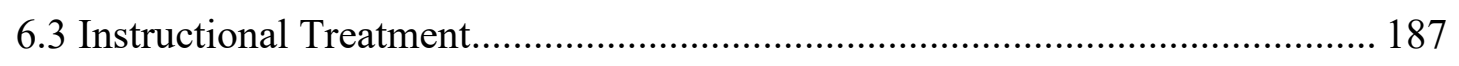

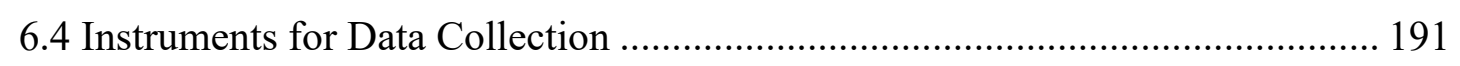

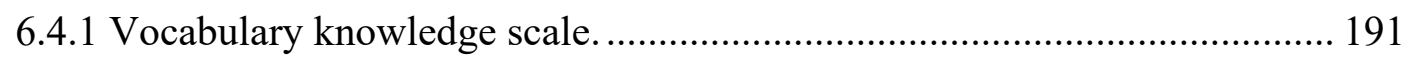

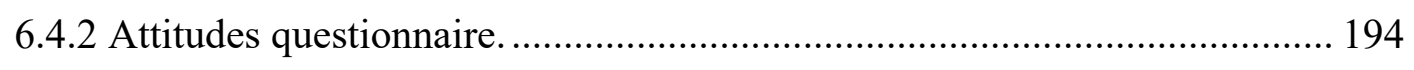

6.4.3 Computer-delivered oral discourse completion task............................... 196

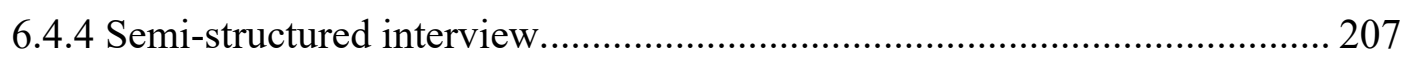

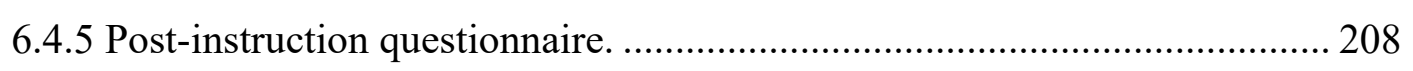

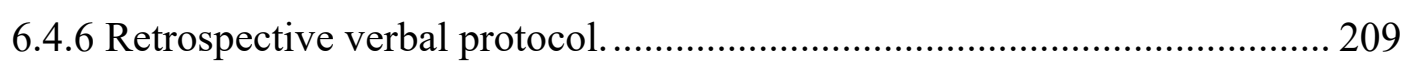

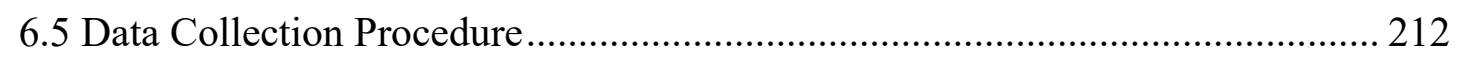

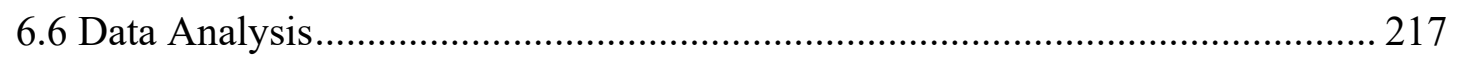

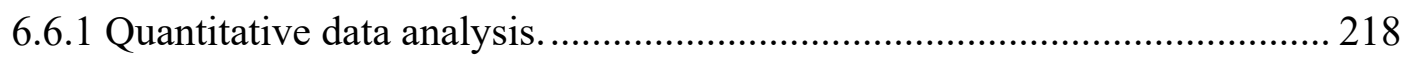

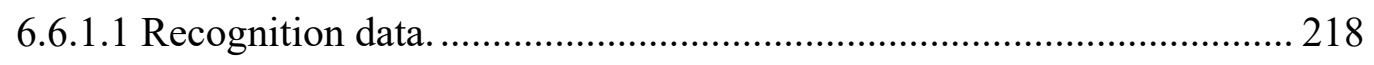

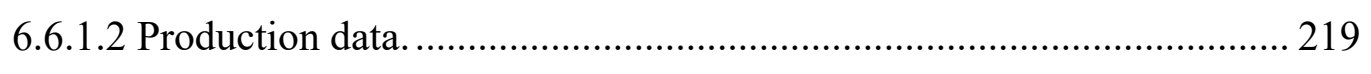

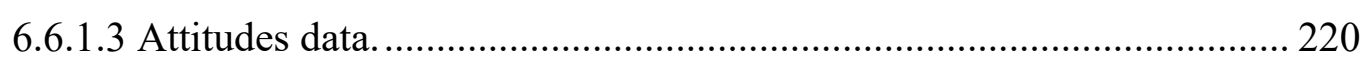

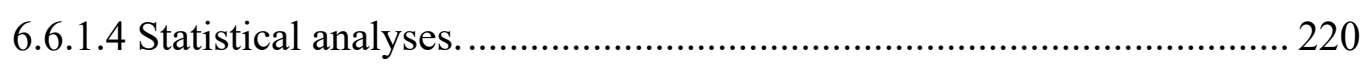

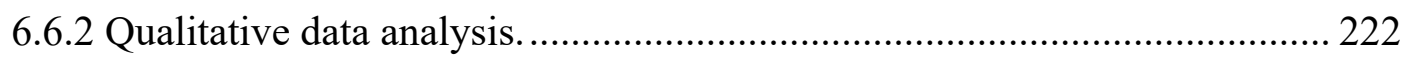

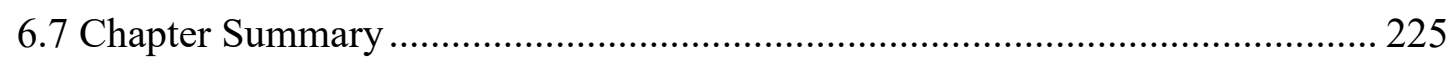

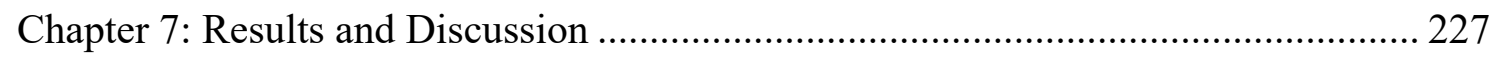

7.1 Results and Discussion Related to Hypothesis 1 .......................................... 227 
7.2 Results and Discussion Related to Hypothesis 2 2............................................ 253

7.3 Results and Discussion Related to Hypothesis 3 …........................................ 282

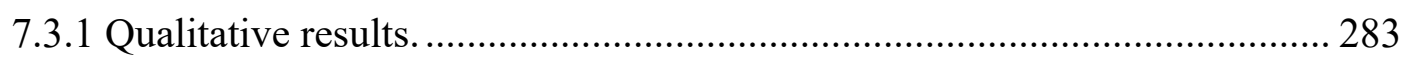

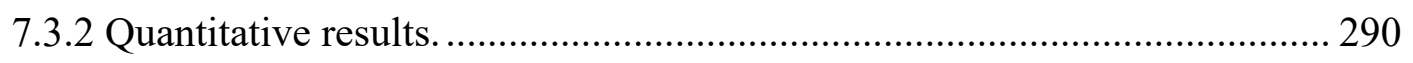

7.4 Results and Discussion Related to Hypothesis 4 ............................................. 295

7.5 Results and Discussion Related to Hypothesis 5 ............................................. 305

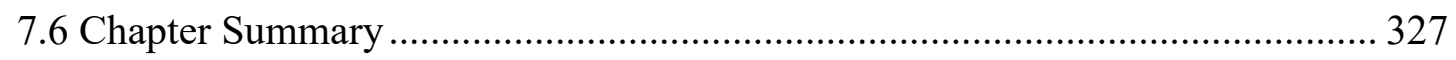

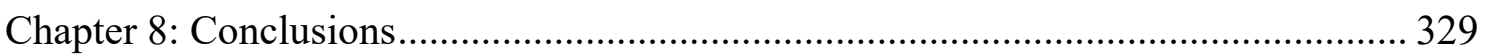

8.1 Originality of The Study and Summary of Main Findings............................... 329

8.2 Limitations of The Study and Directions for Further Research ........................ 335

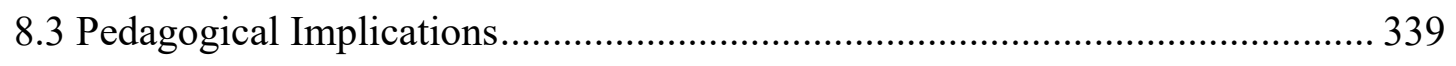

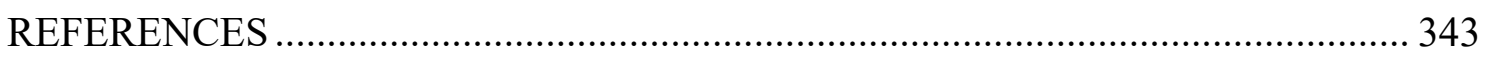

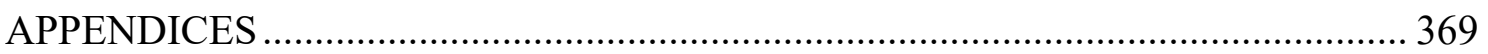

Appendix 1. PowerPoint Presentation Session 1 Instructional treatment ................. 369

Appendix 2. Appropriateness Judgment Task Session 1 Instructional treatment .... 383

Appendix 3. PowerPoint Presentation Session 2 Instructional treatment ................ 391

Appendix 4. Role-play Task Session 2 Instructional treatment .............................. 393

Appendix 5. Post-instruction Questionnaire........................................................... 401

Appendix 6. Vocabulary Knowledge Scale Pretest Version ................................... 407

Appendix 7. Vocabulary Knowledge Scale Posttest Version.................................... 413

Appendix 8. Vocabulary Knowledge Scale Delayed Posttest Version .................... 419

Appendix 9. Lasagabaster and Huguet's (2007) Attitudes Questionnaire ............... 425

Appendix 10. Attitudes Questionnaire employed in this dissertation at Pretest,

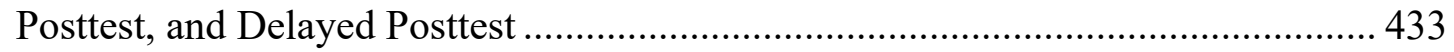

Appendix 11. Rationale for modifications to Lasagabaster and Huguet's (2007)

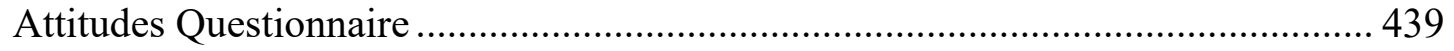

Appendix 12. Computer-delivered ODCT and RVP Pretest Version ..................... 443

Appendix 13. Computer-delivered ODCT and RVP Posttest Version..................... 459

Appendix 14. Computer-delivered ODCT and RVP Delayed Posttest Version ...... 475

Appendix 15. Quick Placement Test (Oxford University Press, 2001).................... 491

Appendix 16. Extended description of descriptive statistics for experimental and

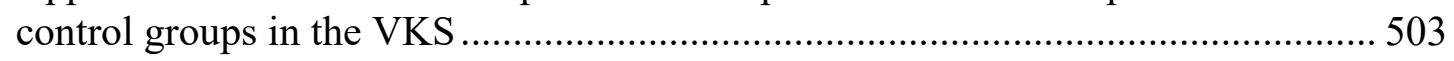

Appendix 17. Extended description of descriptive statistics for experimental and control groups in the computer-delivered ODCT and RVP .................................511

Appendix 18. Test of between-subjects effects across topics ................................ 519

Appendix 19. Extended description of descriptive statistics for experimental and control groups in the Attitudes Questionnaire. 



\section{LIST OF ABBREVIATIONS}

ACT-R: Adaptive Control of Thought-Rational

ACT: Adaptive control of Thought

AJT: Appropriateness judgment task

ANOVA: Analysis of variance

AWK: Awkward

BAC: Basque Autonomous Community

CAPD: Computer-animated production task

CD: Concept definition

CEFR: Common European Framework of Reference

CFL: Chinese as a foreign language

CI: confidence interval

CLIL: Content and language integrated learning

COPT: Cartoon oral production task

d: Effect size

DCT: Discourse completion task

DCT: Discourse completion task

DIF: Difficult

DLY-P10-Sit4: Participant 10 in Situation 4 at Delayed Pretest.

DLY-P11-Sit14: Participant 11 in Situation 14 at Delayed Posttest.

DLY-P13-Sit13: Participant 13 in Situation 13 at Delayed Posttest.

DLY-P5-Sit10: Participant 5 in Situation 10 at Delayed Posttest.

DLY-P6-Sit13: Participant 6 in Situation 13 at Delayed Posttest.

DPT: Dialogue production task

e.g.: exempli gratia, for example

EAP: English for academic purposes

EFL: English as a Foreign Language

EMI: English-medium instruction

ESL: English as a Second Language

ESP: English for specific purposes

F: The Greenhouse-Geisser correction is used to report statistical differences in MANOVA tests.

FcL: Formulaic language 
FDCT: Free discourse completion task

GLK: General life knowledge

H1: Hypothesis 1

H2: Hypothesis 2

H3: Hypothesis 3

H4: Hypothesis 4

H5: Hypothesis 5

i.e.: id est, in other words

IDCT: Interactive discourse completion task

IDK: I don't know

IIR DLY: Instruction-Induced Reason at Delayed Posttest

IIR PST: Instruction-Induced Reason at Posttest

IIR: Instruction-Induced Reason

ILP: Interlanguage Pragmatics

ISLA: Instructed second language acquisition

KFT: Knowledge from test

L1: First language

L1SK: L1-specific knowledge

L2: Second language

L3: Third language

LR DLY: Logical Reasoning at Delayed Posttest

LR: logical reasoning

M: Mean

MANOVA: Multivariate analysis of variance

MET: Multimedia elicitation task

MGT: Matched-guise technique

$\mathrm{n}$ : the number of participants in a sample (e.g.: a group)

$\mathrm{N}$ : the total number of a population in a study

NA: Not applicable

NNSs: Non-native speakers

NS: Native speaker

NSs: Native speakers

ODCT: Oral discourse completion task

$\mathrm{p}$ : the statistical value of a test 
P1: Participant 1

P11: Participant 11

P12: Participant 12

P14: Participant 14

P19: Participant 19

P2: Participant 2

P20: Participant 20

P22: Participant 22

P24: Participant 24

P25: Participant 25

P27: Participant 27

P29: Participant 29

P29Pret: Participant 29 at the pretest

P3: Participant 3

P36: Participant 36

P41: Participant 41

P48: Participant 48

P5: Participant 5

P6: Participant 6

P7: Participant 7

P7Pret: Participant 7 at the pretest

P9: Participant 9

PB: Participant's beliefs

PE: Previous experience

PLT: Pragmatic listening test

POL DLY: Politeness at Delayed Posttest

POL PST: Politeness at Posttest

POL: politeness

PPT: PowerPoint

PRT-P11-Sit12: Participant 11 in Situation 12 at Pretest.

PRT-P19-Sit12: Participant 19 in Situation 12 at Pretest.

PRT-P2-Sit7: Participant 2 in Situation 7 at Pretest.

PRT-P21-Sit2: Participant 21 in Situation 2 at Pretest.

PRT-P23-Sit6: Participant 23 in Situation 6 at Pretest. 
PRT-P3-Sit2: Participant 3 in Situation 2 at Pretest.

PRT-P35-Sit13: Participant 35 in Situation 12 at Pretest.

PRT-P37-Sit6: Participant 37 in Situation 6 at Pretest.

PRT-P4-Sit4: Participant 4 in Situation 4 at Pretest.

PRT-P5-Sit3: Participant 5 in Situation 3 at Pretest.

PST-P2-Sit5: Participant 2 in Situation 5 at Posttest.

PST-P23-Sit13: Participant 23 in Situation 13 at Posttest.

PST-P31-Sit13: Participant 31 in Situation 15 at Posttest.

RQ: Research question

RQ1: Research question 1

RQ2: Research question 2

RQ3: Research question 3

RVP: Retrospective verbal protocol

SA: Study abroad

SD: Situation description

SD: standard deviation

SE: Something established

SitD PST: Situation Description at Posttest

SitD: Situation description

SLA: Second Language Acquisition

STM: Short-term memory

T1: Time 1

T2: Time 2

T3: Time 3

TL: Target Language

TOEIC: Test of English for International Communication

VKS: Vocabulary knowledge scale

WDCT: Written discourse completion task

ZPD: Zone of Proximal Development 


\section{LIST OF FIGURES}

Figure 1. Chronological evolution of communicative competence models (adapted

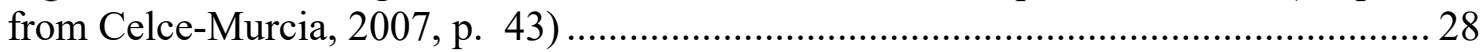
Figure 2. Bachman's model of pragmatic competence (adapted from Bachman, 1990, p. 87) 29

Figure 3. Bachman and Palmer's (1996, 2010) model of pragmatic competence ..... 31 Figure 4. Usó-Juan and Martínez-Flor's (2006) model of communicative competence (adapted from Usó-Juan \& Martínez-Flor, 2006, p. 16) .............................................. 33

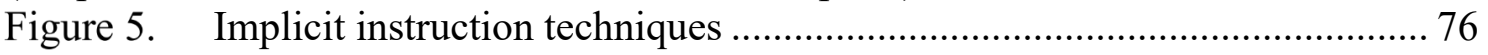

Figure 6. Relationship between attitudes and their components (adapted from Baker, 1992, p. 13) 106

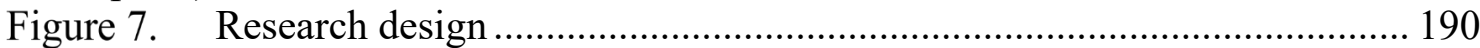

Figure 8. Bardovi-Harlig's (2008, p. 222) modification of VKS ............................ 193

Figure 9. Example of item included in the VKS version used in this dissertation. . 194

Figure 10. Item illustration in computer-delivered ODCT and RVP.................... 206

Figure 11. CEFR proficiency levels as delimited in Quick Placement Test .......... 213

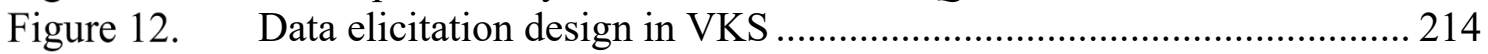

Figure 13. Data elicitation design in computer-delivered OCDT …..................... 216

Figure 14. Boxplot for control and experimental groups performance of VKS .... 228

Figure 15. Box plot for Mean difference between control group and experimental

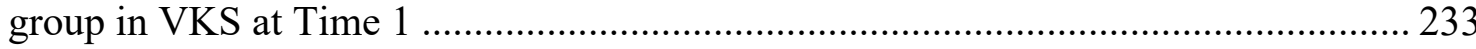

Figure 16. Box plot for Mean difference between control group and experimental

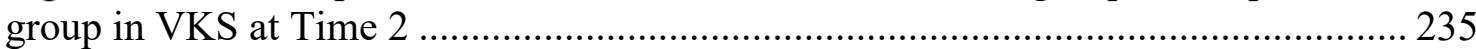

Figure 17. Box plot for Mean difference between control group and experimental group in VKS at Time 3 ..................................................................................... 237

Figure 18. Boxplot for control and experimental groups performance of computerdelivered ODCT . ....

Figure 19. Box plot for Mean difference between control group and experimental

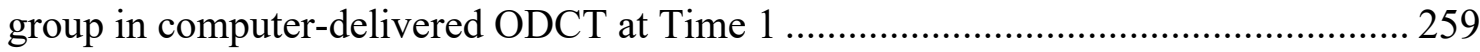

Figure 20. Box plot for Mean difference between control group and experimental

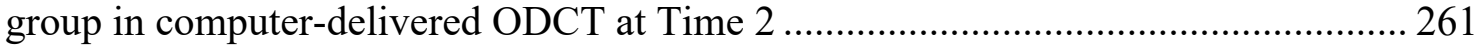

Figure 21. Box plot for Mean difference between control group and experimental group in computer-delivered ODCT at Time 3 ......................................................... 263

Figure 22. Boxplot for control and experimental groups performance of Attitudes Questionnaire 306

Figure 23. Box plot for Mean difference between control group and experimental group in Attitude Questionnaire at Time 1 ................................................................... 311

Figure 24. Box plot for Mean difference between control group and experimental group in Attitude Questionnaire at Time 2 ............................................................ 313

Figure 25. Box plot for Mean difference between control group and experimental group in Attitude Questionnaire at Time 3 ........................................................ 316 Figure 26. Distribution of the scores by the control group in the VKS at Time 1.504 Figure 27. Distribution of the scores by the experimental group in the VKS at Time 1 505

Figure 28. Distribution of the scores by the control group in the VKS at Time 2.506 Figure 29. Distribution of the scores by the experimental group in the VKS at Time 2 507

Figure 30. Distribution of the scores by the control group in the VKS at Time 3.508 
Figure 31. Distribution of the scores by the experimental group in the VKS at Time 3

Figure 32. Distribution of the scores by the control group in the computer-delivered ODCT at Time 1

Figure 33. Distribution of the scores by the experimental group in the computer-

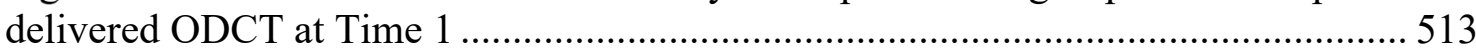
Figure 34. Distribution of the scores by the control group in the computer-delivered

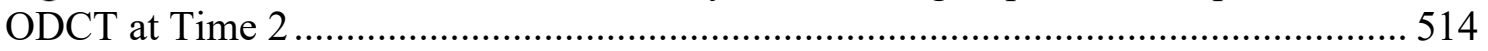
Figure 35. Distribution of the scores by the experimental group in the computer-

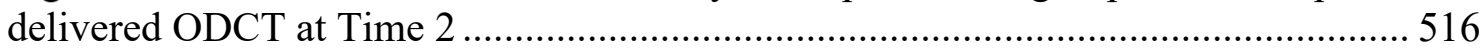
Figure 36. Distribution of the scores by the control group in the computer-delivered

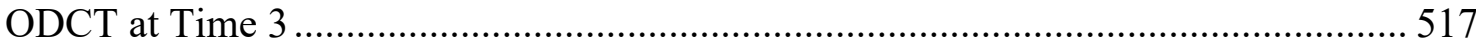

Figure 37. Distribution of the scores by the experimental group in the computer-

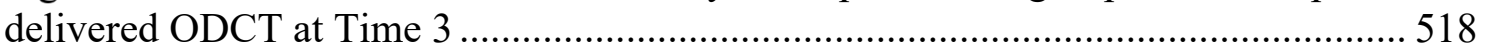
Figure 38. Distribution of the scores by the control group in the Attitudes

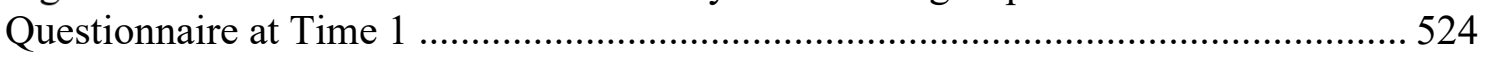

Figure 39. Distribution of the scores by the experimental group in Attitudes

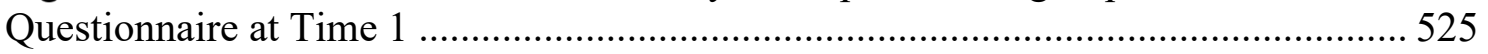

Figure 40. Distribution of the scores by the control group in the Attitudes

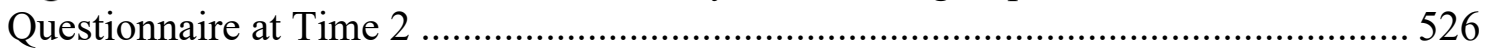

Figure 41. Distribution of the scores by the experimental group in Attitudes

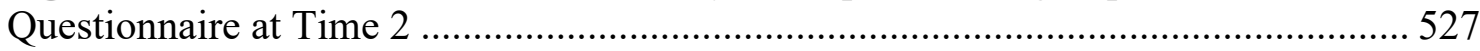

Figure 42. Distribution of the scores by the control group in the Attitudes

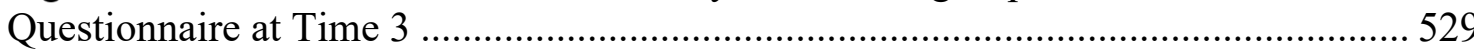

Figure 43. Distribution of the scores by the experimental group in Attitudes

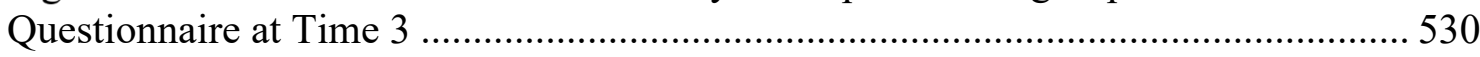




\section{LIST OF TABLES}

Table 1. Alcón-Soler's (2000, p. 262) model of communicative competence .......... 32

Table 2. Cohen et al.'s (2007, p. 220) strengths and weaknesses in cross-cultural research 50

Table 3. Cohen et al.'s (2007, p. 221) strengths and weaknesses in longitudinal research 54

Table 4. Terms used to provide my definition of conventional expressions for the present study.....

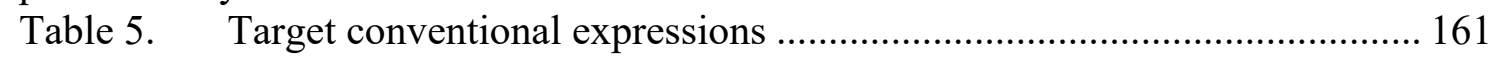

Table 6. Conventional expressions used as distractors in instructional treatment . 164

Table 7. Number of students per level of proficiency in English ........................... 182

Table 8. Target conventional expressions .............................................................. 185

Table 9. Wesche and Paribakht's (1994, p. 23) five multiple-choice options outline 192

Table 10. Summary of data collection procedure

Table 11. Summary of the data collection instruments, data collection time points,

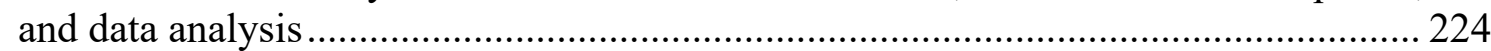

Table 12. Descriptive statistics for experimental group across times in VKS ........ 229

Table 13. Descriptive statistics for control group across times in VKS ................... 230

Table 14. Descriptive statistics for group Mean comparison in the VKS at Time 1231

Table 15. Independent samples t-test both groups in VKS at Time 1 ..................... 232

Table 16. Descriptive statistics for group Mean comparison in the VKS at Time 2233

Table 17. Independent samples t-test both groups in VKS at Time 2 ..................... 234

Table 18. Descriptive statistics for group Mean comparison in the VKS at Time 3236

Table 19. Independent samples t-test both groups in VKS at Time 3 ..................... 236

Table 20. Paired samples t-test descriptive statistics for VKS control group from

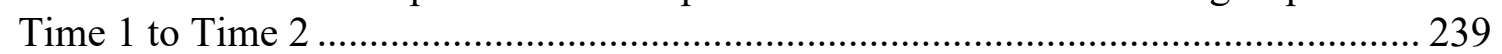

Table 21. Paired samples t-test for VKS control group from Time 1 to Time 2 ...... 239

Table 22. Paired samples t-test descriptive statistics for VKS control group from

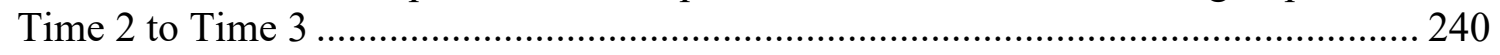

Table 23. Paired samples t-test for VKS control group from Time 2 to Time 3 ...... 240

Table 24. Paired samples t-test descriptive statistics for VKS control group from

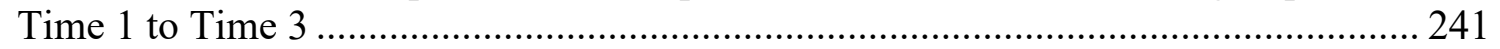

Table 25. Paired samples t-test for VKS control group from Time 1 to Time $3 \ldots . . .241$

Table 26. Paired samples t-test descriptive statistics for VKS experimental group

from Time 1 to Time 2 ........................................................................................... 243

Table 27. Paired samples t-test for VKS experimental group from Time 1 to Time 2

243

Table 28. Paired samples t-test descriptive statistics for VKS experimental group

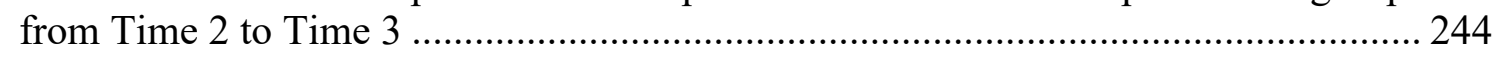

Table 29. Paired samples t-test for VKS experimental group from Time 2 to Time 3 244

Table 30. Paired samples t-test descriptive statistics for VKS experimental group

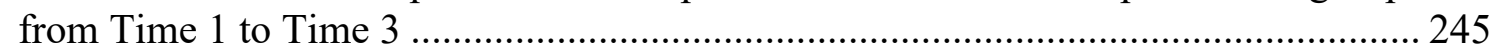

Table 31. Paired samples t-test for VKS experimental group from Time 1 to Time 3 245

Table 32. Descriptive statistics for control group across times in computer-delivered ODCT 255 
Table 33. Descriptive statistics for experimental group across times in computerdelivered ODCT

Table 34. Descriptive statistics for group Mean comparison in the computer-delivered

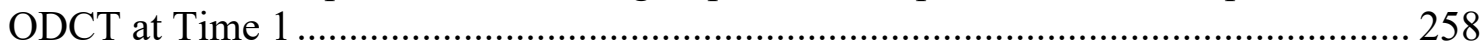

Table 35. Independent samples t-test both groups in computer-delivered ODCT at Time 1258

Table 36. Descriptive statistics for group Mean comparison in the computer-delivered

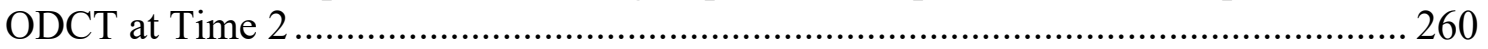

Table 37. Independent samples t-test both groups in computer-delivered ODCT at Time $2 \quad 260$

Table 38. Descriptive statistics for group score comparison in the computer-delivered

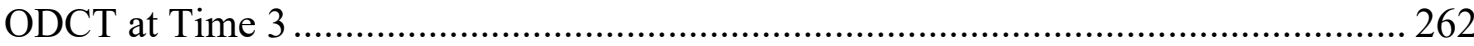

Table 39. Independent samples t-test both groups in computer-delivered ODCT at Time 3262

Table 40. Paired samples t-test descriptive statistics for computer-delivered ODCT control group from Time 1 to Time 2

Table 41. Paired samples t-test for computer-delivered ODCT control group from Time 1 to Time 2 .

Table 42. Paired samples t-test descriptive statistics for computer-delivered ODCT control group from Time 2 to Time 3 .... 266

Table 43. Paired samples t-test for computer-delivered ODCT control group from Time 2 to Time 3 . 266

Table 44. Paired samples t-test descriptive statistics for computer-delivered ODCT control group from Time 1 to Time 3 . .

Table 45. Paired samples t-test for computer-delivered ODCT control group from Time 1 to Time 3 .....

Table 46. Paired samples t-test descriptive statistics for computer-delivered ODCT experimental group from Time 1 to Time 2

Table 47. Paired samples t-test for computer-delivered ODCT experimental group

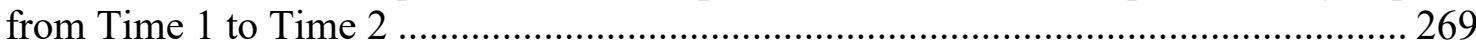

Table 48. Paired samples t-test descriptive statistics for computer-delivered ODCT

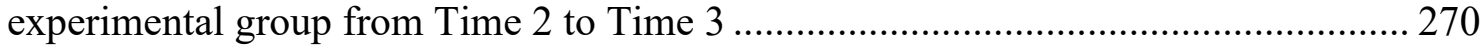
Table 49. Paired samples t-test for computer-delivered ODCT experimental group

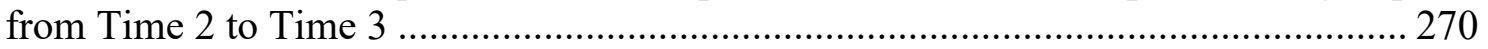
Table 50. Paired samples t-test descriptive statistics for computer-delivered ODCT experimental group from Time 1 to Time 3

Table 51. Paired samples t-test for computer-delivered ODCT experimental group

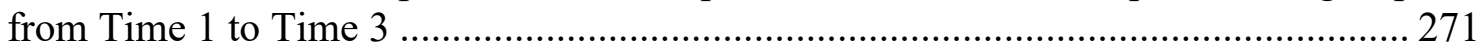

Table 52. Topics and their meanings in RVPs classification ................................. 283

Table 53. Participants' use of IIR in RVPs............................................................... 293

Table 54. Descriptive statistics for experimental group across times in VKS ......... 307

Table 55. Descriptive statistics for control group across times in Attitudes Questionnaire.....

Table 56. Descriptive statistics for group Mean comparison in the computer-delivered ODCT at Time 1

Table 57. Independent samples t-test both groups in the Attitudes Questionnaire at Time 1310

Table 58. Descriptive statistics for group Mean comparison in the computer-delivered ODCT at Time 2 .... 
Table 59. Independent samples t-test both groups in the Attitudes Questionnaire at Time 2. 312

Table 60. Descriptive statistics for group score comparison in the computer-delivered ODCT at Time 3 .

Table 61. Independent samples t-test both groups in the Attitudes Questionnaire at Time $3 \quad 315$

Table 62. Paired samples t-test descriptive statistics for Attitudes Questionnaire control group from Time 1 to Time 2 ......

Table 63. Paired samples t-test for Attitudes Questionnaire control group from Time 1 to Time 2318

Table 64. Paired samples t-test descriptive statistics for Attitudes Questionnaire control group from Time 2 to Time 3 ....

Table 65. Paired samples t-test for Attitudes Questionnaire control group from Time

2 to Time 3319

Table 66. Paired samples t-test descriptive statistics for Attitudes Questionnaire control group from Time 1 to Time 3 .

Table 67. Paired samples t-test for Attitudes Questionnaire control group from Time 1 to Time 3320

Table 68. Paired samples t-test descriptive statistics for Attitudes Questionnaire experimental group from Time 1 to Time 2

Table 69. Paired samples t-test for Attitudes Questionnaire experimental group from

Time 1 to Time 2 .

Table 70. Paired samples t-test descriptive statistics for Attitudes Questionnaire experimental group from Time 2 to Time 3 ....

Table 71. Paired samples t-test for Attitudes Questionnaire experimental group from

Time 2 to Time 3

Table 72. Paired samples t-test descriptive statistics for Attitudes Questionnaire experimental group from Time 1 to Time 3

Table 73. Paired samples t-test for Attitudes Questionnaire experimental group from

Time 1 to Time 3

Table 74. Hypotheses, data collection methods, data collection time points, data analyses, and hypotheses confirmation .................................................................... 328

Table 75. Descriptive statistics for control group in the VKS at Time 1 ................ 503

Table 76. Descriptive statistics for experimental group in the VKS at Time 1........504

Table 77. Descriptive statistics for control group in the VKS at Time 2 ................ 505

Table 78. Descriptive statistics for experimental group in the VKS at Time 2........506

Table 79. Descriptive statistics for control group in the VKS at Time 3 ................. 507

Table 80. Descriptive statistics for experimental group in the VKS at Time 3....... 508

Table 81. Descriptive statistics for control group in the computer-delivered ODCT at

Time $1 \quad 511$

Table 82. Descriptive statistics for experimental group in the computer-delivered

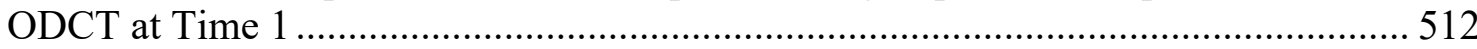

Table 83. Descriptive statistics for control group in the computer-delivered ODCT at

Time 2513

Table 84. Descriptive statistics for experimental group in the computer-delivered

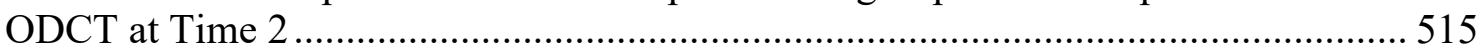

Table 85. Descriptive statistics for control group in the computer-delivered ODCT at Time $3 \quad 516$

Table 86. Descriptive statistics for experimental group in the computer-delivered 
Table 87. Descriptive statistics for control group in the Attitudes Questionnaire at Time 1523

Table 88. Descriptive statistics for experimental group in the Attitudes Questionnaire at Time $1 \quad 524$

Table 89. Descriptive statistics for control group in the Attitudes Questionnaire at Time 2525

Table 90. Descriptive statistics for control group in the Attitudes Questionnaire at Time $2 \quad 527$

Table 91. Descriptive statistics for control group in the Attitudes Questionnaire at Time 3528

Table 92. Descriptive statistics for experimental group in the Attitudes Questionnaire at Time $3 \quad 529$ 


\section{INTRODUCTION}





\section{INTRODUCTION}

A renewed interest in formulaic language has arisen since the early $21^{\text {st }}$ century. In the globalized world where we live, it is essential to communicate successfully in a foreign language, as is the case with English, which represents the most extensively spoken language and the lingua franca of much of the communication worldwide. Therefore, English as a foreign language (EFL) learners need to be able to behave appropriately in the target language (TL) community. It is in the social interactions where a series of recurrent expressions are used every day, i.e., conventional expressions (BardoviHarlig, 2009), which are included within formulaic language. Conventional expressions are the target pragmatic feature under investigation in this study. The exploration of the learning and use of these expressions is essential because they carry a great deal of social and cultural meaning that EFL learners need to be aware of and know in order to master different communicative situations. The application of the knowledge learnt to future situational interactions is a concern that needs to be addressed in ILP research (Taguchi, 2015b). Taking into consideration the research that points out the impoverished nature of EFL contexts when it comes to pragmatic learning (e.g., Eslami \& Eslami-Rasekh, 2008), the need to provide students with the knowledge to behave pragmatically competent in the TL community is at stake. In order to address these needs, the present study provides students with a pedagogical intervention that features a combination of metapragmatic instruction targeting real-life and research based situations by means of audiovisual aids, together with metapragmatic discussion, ample opportunities to practice both recognition and production skills, and feedback. These are the features that the literature shows are key in successful explicit teaching interventions (e.g., Taguchi \& Roever, 2017). Additionally, this study considers language attitudes, thus acknowledging the essential role they play in language learning and use (e.g., 


\section{Introduction}

Garrett, 2010; Lasagabaster \& Huguet, 2007; Nightingale, 2016; Portolés, 2011, 2015; Safont \& Portolés, 2016; Safont, 2007).

Finally, the present investigation is undertaken from a Skill Acquisition Theory perspective (Anderson, 1993; DeKeyser, 1997, 1998, 2001, 2003, 2007a), which explains language acquisition from a cognitive stance. Following the cognitive viewpoint of this particular theory, the learning and use of conventional expressions is investigated in terms of the gradual learning process that develops in three stages. First, in the cognitive stage, the learning of new pragmatic rules by means of explanations becomes declarative knowledge. Second, the proceduralization process is activated by means of extensive meaningful practice, which finally becomes procedural knowledge in the third and last stage: the autonomous stage. This final phase is characterized by fluent speech and automatic knowledge of the rules, as well as by de less frequent appearance of mistakes.

Being concerned about the importance of pragmatics learning, this dissertation explores the pragmatic development of adult EFL learners for use in social contexts outside the classroom setting in English-speaking communities. More specifically, the aims in the present dissertation are (1) to explore the development of the recognition and production of conventional expressions; (2) to investigate the effect of instruction; and (3) to observe participants' language attitudes from pretest to delayed posttest. These aims are achieved exploring EFL students' recognition and production of conventional expressions taking into consideration the effects of instruction and attitudes. In doing so, several research gaps are covered. First, studying conventional expressions, an under-researched area. Second, exploring both recognition and production of conventional expression, which scant attention has received in comparison to the investigation of these two skills separately. Third, examining the 


\section{Introduction}

development of both skills in an EFL setting, whereas most of the research on conventional expressions has been undertaken in ESL and SA contexts. Fourth, including a delayed posttest data collection time point which, to date, no other study on conventional expressions has included. Fifth, exploring the effect of instruction on both the recognition and production of conventional expressions by means of an explicit pedagogical intervention composed of (1) metapragmatic information, (2) metapragmatic discussion, and (3) ample opportunities to practice both skills: recognition and production. Sixth, including the effect of language attitudes. In other words, exploring the effect of instruction and language attitudes on the recognition and production of conventional expressions, which no study to date has researched. Seven, undertaking this study from a Skill Acquisition Theory (Anderson, 1993; DeKeiser, 1997, 1998, 2001, 2003, 2007a), which has received less attention in pragmatics in general, and in the literature of conventional expressions more specifically, compared to, for example, Schmidt's (1983, 1990, 1993, 1994, 1995, 2001, 2010) Noticing Hypothesis, or Long's (1985, 1990, 1996, 2015) Input Hypothesis.

To sum up, the gaps discussed above: (1) conducting research on conventional expressions; (2) focusing on both recognition and production skills of this pragmatic feature; (3) from an EFL perspective; (4) including a delayed posttest data collection time point; considering (5) the effect of instruction, and (6) the development of language attitudes; and finally (7) conceiving this piece of research from a Skill Acquisition theory (Anderson, 1993) perspective are tackled in this dissertation that focuses on classroom research pragmatics more generally.

The present study is divided into eight chapters. The first four chapters review the existing literature and provide the basis for this dissertation. The remaining four 


\section{Introduction}

chapters tackle different parts of the study. A chapter summary, where the main highlights of each chapter are encompassed, is included in each of the chapters.

Chapter 1 presents the theoretical framework on which this dissertation is based.

Section 1.1 provides a general overview of second language acquisition (SLA), reviewing the cognitive and socially grounded language learning theories in this field of research. Section 1.2 examines the concept of communicative competence together with the models of communicative competence proposed through the years. Section 1.3 deals with pragmatic competence and examines the notions of pragmatics and pragmatic competence. Section 1.4 reviews the concept and features of interlanguage pragmatics (ILP) together with the research carried out in this field of study from both viewpoints: cross-sectional and longitudinal. Section 1.5 tackles the Chapter Summary.

Chapter 2 focuses on research in second language (L2) pragmatic instruction. Section 2.1 presents the definitions and features that characterize instructional treatments in ILP. Section 2.2 provides an in-depth discussion about the effectiveness of pedagogical intervention provision dealing with two main issues: (1) instruction provision versus simple exposure; and (2) explicit versus implicit instruction. Section 2.3 reviews the research conducted on the most frequently researched target pragmatic features in ILP contexts, with a focus on the pragmatic feature under investigation in this study: conventional expressions. Section 2.4 brings together the main issues raised in this chapter in the Chapter Summary.

Chapter 3 explores language attitudes and its relation to L2 pragmatics, because research shows that language attitudes constitute a central component that influence L2 language learning. In order to comprehend the role that language attitudes play in the acquisition of the L2 pragmatic system, Section 3.1 presents a general understanding of what language attitudes are. Section 3.2 reviews the techniques employed to measure 


\section{Introduction}

language attitudes, together with the research undertaken in EFL contexts similar to the one where this dissertation was conducted. In so doing, the rationale for the present investigation is provided. The main highlights in Chapter 3 are encompassed in the Chapter Summary.

Chapter 4 focuses on conventional expressions. As research evidence reveals, conventional expressions are facilitators of communicative acts. Therefore, their relation to L2 pragmatics is also investigated in this chapter to comprehend the role that conventional expressions play in L2 pragmatic learning. Section 4.1 provides a detailed description of the conceptualization and characterization of conventional expressions. Section 4.2 reviews the instruments used to measure conventional expressions, as well as the research undertaken in ILP regarding recognition and production of conventional expressions. Section 4.3 reviews the main takeaways of Chapter 4 in the Chapter Summary.

Taking into consideration the research gaps identified and the main findings from the studies reported in Chapter 1, 2, 3, and 4, Chapter 5 presents the motivations underlying the present dissertation in Section 5.1, as well as the research questions and hypotheses by which the present investigation is driven in Section 5.2. To conclude this chapter, the Chapter Summary is presented in Section 5.3.

Chapter 6 discusses the method designed to conduct the present dissertation.

Section 6.1 explores the setting where the study took place and the participants that took part in this study. Section 6.2 reports on the pilot study and Section 6.3 on the target conventional expressions. Section 6.4 explains the instructional treatment and Section 6.5 the instruments used to collect data. Section 6.6 details the data collection procedure and Section 6.7 the data analysis for both quantitative and qualitative instruments. Section 6.8 presents the Chapter Summary. 


\section{Introduction}

Chapter 7 encompasses the outcomes of the two research questions and five hypotheses formulated in Section 5.2. The analysis and discussion of the results for the three first hypotheses under RQ1: Effect of instruction are explored first. These hypotheses are: the effect of instruction on the recognition task (H1); the effect of instruction on the production task (H2); and participants' perceptions about their knowledge of conventional expressions (H3). The following two sections encompass the analysis and discussion of the results for the two last hypotheses, which are included under RQ2: Students' attitudes. They explore to the effect of instruction on learners' attitudes (H4) and the effect of attitudes towards English (H5). To conclude, Section 7.6 presents the Chapter Summary.

Finally, Chapter 8 presents the main findings in this study together its contributions to the literature on pragmatics, teaching pragmatics, conventional expressions, and language attitudes in Section 8.1. Section 8.2 is devoted to explain the limitations and discuss the lines for further research that could be adopted from this study. Lastly, some pedagogical implications are proposed based on the results obtained in this study. 
PART I: LITERATURE REVIEW 



\section{Chapter 1: Second Language Pragmatics}

The aim in Chapter 1 is to provide the theoretical framework in which the present study is based. It is encompassed within the field of second language acquisition (SLA) more broadly, and within the field of interlanguage pragmatics (ILP') more specifically. The first section provides a general overview of SLA, which also includes a presentation of cognitively and socially grounded theories of language learning proposed in this field of study. The second section is devoted to reviewing the notion of communicative competence as well as the models of communicative competence proposed in the literature. The third section explores the concept of pragmatic competence. First, the concept of pragmatics is discussed. After that, the notion of pragmatic competence and its two components, namely pragmalinguistics and sociopragmatics, are presented. Finally, the nature and research of ILP is explored, discussing the definition of this concept and the features that characterize it, followed by a revision of the research conducted in ILP, from a cross-sectional point of view, and from a longitudinal perspective. Chapter 1 concludes with a Chapter Summary.

\subsection{Second Language Acquisition}

In general terms, SLA refers to the study of the acquisitional progress of a second or further language. This first subsection is devoted to defining the concept and theories behind SLA from a cognitive and social standpoint.

\subsubsection{Defining second language acquisition.}

The field of SLA was born in the 1960s and was focused on theoretical underpinnings in different research fields, such as psychology, anthropology, and education. Applied linguists and researchers in the field of English as a Second Language (ESL) were part

\footnotetext{
${ }^{1}$ In the present dissertation, the terms ILP and L2 pragmatics will be used interchangeably. See Bardovi-Harlig (1999) for the origin of the concept: 'acquisitional pragmatics' and its relation to L2 pragmatics and ILP.
} 
of this new research movement, namely SLA (Long, 1990). Culpeper, Mackey, and Taguchi (2018, p. 209) defined SLA broadly as "the field of research concerning the acquisition/learning of second or additional languages." On the other hand, Norris and Ortega (2003, p. 717) added to that idea the notion that SLA is "interested in describing and understanding the dynamic processes of language learning (...) under conditions other than natural, first language acquisition." Norris and Ortega's (2003) definition is interpreted as if formal instruction is one of those conditions they mention. Therefore, based on the definitions mentioned above, I attempt to provide my own, as I perceive SLA to be the field of study that accounts for the cognitive and social processes that learners go through when learning or acquiring ${ }^{2}$ a second or additional language under instructional or other social conditions that differ from those in which first language (L1) acquisition takes place.

Focusing on the social conditions that influence language learning, the idea that learners learn to communicate by communicating has been widely supported in the literature. From a cognitive interactionist perspective, Long $(1981,2015)$ stated that comprehension is achieved by means of interacting, paying attention to the language of those interactions, negotiating meaning with the source, being it other interlocutors or a provider of written or oral data. Additionally, Ellis (1991), pointed to the paramount role of interacting face to face with other interlocutors in naturalistic settings; and the essential nature of interaction in instructed second language (L2) environments. The pivotal role of communication in language learning is also supported from a discourse analysis perspective. Hatch (1978) claimed that a given language is learnt by means of

\footnotetext{
${ }^{2}$ For the purpose of this dissertation, the terms 'acquisition' and 'learning' will be used as synonyms. Krashen (1982) makes a distinction between these two concepts in his Monitor Model. He believes that acquiring a language is a subconscious process, much as of children learning their L1. On the other hand, the process of learning a language is characterized as being conscious since the learner pays attention to the forms they are presented.
} 
communicating, being it the L1 for children or a given L2 for adult L2 learners. Data from her analyses of speakers' language production in interaction allowed her to reach this conclusion. Several conditions are indispensable to learn an L2, including input, output, feedback, together with motivation, and awareness. These concepts will be explained in the following subsection, devoted to the theories that explain the acquisition of a second language.

\subsubsection{Theories of second language acquisition.}

A review of the cognitive theories that explain L2 language learning as a cognitive enterprise will be presented first. Then the same will be done to summarize theories of language learning from a social perspective. A brief commentary on the relationship between pragmatics and each of the theories will be included in each theory.

\subsubsection{Cognitive theories.}

Firstly, as one of the most influential theories of SLA in the last century, Krashen's (1982) Input Hypothesis theorizes about the aspects that influence the acquisition of a second language. First, he makes a distinction between acquisition and learning, an issue that has been widely criticized in the literature, as these two processes are not proven to differ much from one another. According to Krashen, learners acquire a language if they receive "comprehensible input", which is input that is just a little more difficult than the learner's level of proficiency, what he calls " $i+1$ ". This statement represented the core of his theory and received extensive criticism as well. Researchers have questioned the nature of "i" in that equation because Krashen did not conduct any study to prove this theory. In pragmatic terms, learners will be able to understand a new pragmalinguistic form due to the fact that it implies some more level of difficulty.

In line with Krashen, and in the turn of the new century, Takimoto (2006, 2009, 2012a, 2012b) claims in his Input Processing Theory that language acquisition can only 
happen when learners comprehend the input they receive by means of a series of learning strategies to process linguistic data. Structured input activities are designed for learners to draw attention to the grammar rules provided to understand the meaning of a particular linguistic item. This theory is in line with Schmidt's (1983, 1990, 1993, 1994, 1995, 2001, 2010) Noticing Hypothesis in that both focus on noticing and awareness but while the latter focuses on production, the former does on comprehension. From a pragmatic viewpoint, learning strategies can focus on pragmatic aspects, thus facilitating the comprehension and production of the input to develop learners' L2 pragmatic system.

A year after Krashen's (1982) publication, Schmidt (1983, 1990, 1993, 1994, 1995, 2001, 2010) proposed his theory for language acquisition. His Noticing Hypothesis has been a very influential theory since its origins as well. It investigates language learning development focusing on those specific aspects required to acquire an L2. The main tenet behind this theory is the crucial role of noticing among other phenomena in language learning, in opposition to Krashen's theory. Learners need to pay attention to language forms in order for them to be aware of their existence and finally learn them. In other words, only by applying a conscious focus of attention to a given input will it become intake, and subsequently acquisition will take place. Schmidt $(1995,2010)$ distinguished between attention and awareness, two circumstances that complement each other in the L2 learning process. When learners pay attention to any given pragmatics language-related issue, they become aware of it. Nevertheless, that does not imply that they will learn that aspect. Schmidt (2010) acknowledged that some L2 features are more difficult to notice than others. Therefore, some forms will require a greater deal of attention. In turn, this author made a further distinction between two L2 learning processes, namely noticing and understanding. Additionally, Schmidt (2010) 
stated that language development may also be affected by external factors unrelated to the learner, such as learning setting or instructional treatment; as well as internal factors which are triggered by the learner, such as their attitudes or motivation towards the L2. In this vein, he $(1993,2010)$ claimed that it is important to consider individual variation since different learners will notice things differently. All in all, this theory puts forward the paramount role of noticing in the development of an L2. As for pragmatic development, noticing a pragmalinguistic feature means paying attention to it consciously whereas understanding implies relating it to its sociopragmatic context. Additionally, learners being conscious and having knowledge of the sociopragmatic information that accompanies that pragmatics-related linguistic form also fosters the acquisition of that new language form.

Concurrent to Schmidt's (1983, 1990, 1993, 1994, 1995, 2001, 2010) Noticing Hypothesis, and in reaction to Krashen's statement that language is acquired solely by receiving input, Long $(1985,1990,1996,2015)$ proposed his Interaction Hypothesis, where he identified the need for interaction, in conjunction with input and other phenomena to language acquisition. Long investigated the central role of communicating in language use. It is through communication that learners acquire an L2, mastering error identification and error correction in the process. In relation to pragmatics, interaction will foster learners' L2 pragmatic system development.

Concomitantly, Swain $(1985,1995)$ presented her Output Hypothesis, as she proposed that output was also a necessary condition to acquire a language, in line with Long's claim on the importance of interaction in language acquisition. According to Swain, while in language production, students may realize that a given form being used is different in their L1 and the L2 and/or different from that employed by other speakers. This theory brings about one main implication for language teaching, which is 
also applicable to the teaching of pragmatics. That is the important role of instructors and peers, as they may enhance students or other peers to produce language, to provide them with opportunities to put into practice their language knowledge.

In the turn of the 1990s, Bialystok $(1990,1993)$ proposed the two-dimensional model of the development of L2 proficiency to explore those mechanisms that trigger the acquisition of an L2 in adult learners. According to her, there are two distinct features in language learning: analysis of knowledge and control of processing. On one hand, analysis of knowledge deals with the mental representations of the linguistic features L2 learners already know, and accounts for the transformations they undergo in the course of language development. On the other hand, control processing tackles learner's capacity to attain that knowledge. That is, learners are capable of choosing the most important linguistic features aforementioned and put them together to get their message across in the most efficient manner. Bialystok's model of language learning has its applications to pragmatics as well. Even though this model of language learning has existed for decades now, scarce research on the area of pragmatics has been conducted following this model. Hassall (1997) and Li (2014) have adopted Bialystok's $(1990,1993)$ two-dimensional model to study the speech act of request. Results from these studies provide evidence on the fact that these two linguistic abilities are counterpart; they complement each other, thus providing a more comprehensive picture of pragmatic development; and, therefore, support for this model.

\subsection{Skill acquisition theory.}

Another cognitive-oriented theory and contemporaneous to the aforementioned is Anderson's (1993) Skill Acquisition Theory, where he envisioned that the development of language learning and use is at stake. This model was based on his previous ACT (Adaptive Control of Thought) production system (Anderson, 1976), and is similar to 
Fitts's (1964) proposition of skill acquisition. According to Fitts (1964), for a skill to be acquired, three stages are required. The cognitive stage comes first. In this initial phase, the learner has enough knowledge on the topic to be able to use a skill. Nevertheless, this use is characterized by error production as well as verbal mediation. This process of skill acquisition is 'smoothed out' in the second stage, the associative stage, in which errors tend to be spotted and corrected, and the use of verbal mediation is ceased. Finally, a gradual and indefinite melioration of the performance of a given skill is seen in stage three, namely the autonomous stage. In Skill Acquisition Theory, several of the aforementioned pivotal conditions to language learning are employed, such as noticing of language items to acquire that knowledge in stage one, as well as interaction, where input and output are salient in stages two and three above.

In turn, Anderson $(1982,1993)$ proposed this model in which the L2 is learned in two stages: declarative and procedural. This distinction was core in his 1976 work. At first, there is a conscious learning of the language in the declarative stage, in which errors appear frequently, thus resembling Fitts's (1964) model. The second stage is characterized by an unconscious application of the language rules learned previously, once knowledge is internalized. This stage is identified with a smooth use of the language and lack of mistakes. Fitts's (1964) second stage is represented in Anderson's model as the transition from the first to the second stages. This process is coined as 'knowledge compilation', which is accomplished with practice (Anderson, 1982). In turn, this second stage is made up of two subcomponents: composition and proceduralization. The former implies gathering small pieces of knowledge into one bigger chunk, which "has the effect of the sequence" (Anderson, 1982, p. 383). The latter entails the retrieval into working memory of knowledge already acquired, that is, of knowledge that no longer needs assistance in the declarative stage. As of error 
making, this knowledge compilation entails the decrease of the chances of making more mistakes in future skill performances, rather than eliminating them completely. Finally, both Fitts's (1964) third stage and Anderson's (1982, 1993) second stage represent the gradual smooth out and usage acceleration of the skill performance. Anderson (1982) identifies two mechanisms that bring about and continuously improve the second stage, the procedural stage. On one hand, process of tuning implies the constant refinement of problem-solving solution-choice process. On the other hand, the generalization process implies a facilitative transfer process of knowledge of one skill to other situations in which the same skill can be applied, and which share some features with situations worked on previously.

A proposed revised version of the original (Anderson, Bothell, Byrne, Douglass, Lebiere, \& Qin, 2004), coined ACT-R (Adaptive Control of Thought-Rational), these authors identified two types of knowledge, namely declarative and procedural, which were devised as learning stages in the previous model (Anderson, 1982, 1993). Declarative knowledge deals with the knowledge about facts - the what, the things learners know- that can be accessed consciously and which can be put into words in an explicit manner. Procedural knowledge entails the how, the unconscious knowledge about how to do things. According to Anderson et al. (2004), only by extensive practice will declarative knowledge become procedural knowledge. Therefore, intensive practice is at the core in skill acquisition theories. See DeKeyser (2017) for a comprehensive synthesis of the types of knowledge and the role of practice in instructed SLA (ISLA). As DeKeyser (2007b, p. 2) puts it, "reaction time and error rate decline gradually as a function of practice with a given task." Two core concepts within this theory are practice and power law of practice. Newell and Rosenbloom (1981, p. 2) defined practice as "the subclass of learning that deals only with improving performance on a 
task that can already be successfully performed." Moreover, practice should be meaningful (DeKeyser, 2007a) to bring about language development fully. In close relation to practice is power law of practice, since the latter may be seen as predicting the former. In other words, according to DeKeyser $(2015$, p. 96), the power law of practice was coined this way "because its mathematical formalization is a power function: an equation with an exponent, which in this case represents the amount of practice." He further acknowledges that an understanding of this concept that has been largely accepted is that it represents a change from declarative to procedural knowledge. Power law of practice predicts "the logarithm of reaction time or error rate decreases linearly with the logarithm of amount of practice" (Taguchi \& Roever, 2017, p. 44).

In relation to DeKeyser's definition of the sequential nature of learning abovementioned, Anderson (1993) believed that skills are acquired after the completion of three sequential stages. In the first stage, the cognitive stage, the rules learnt by means of explanations become portions of declarative knowledge. Subsequently, the practice of these rules involves the activation and accomplishment of the so-called proceduralization process. Lastly, the autonomous stage implies skill melioration to the extent of fluency and automaticity achievement. One specific issue that should be taken into close consideration is the fact that fully developing a skill in one realm does not mean it can be applied to one other realm right away; for example, from learning some letters to writing them. The relevance of this theory in the field of pragmatics is that it helps account for the process of form-function mapping. Additionally, skill acquisition theories bring about three implications for the development of pragmatics: (1) the acquisition of pragmatic knowledge takes place gradually; (2) practice is given an essential role; (3) pragmatic competence is embodied as a skill in and of itself. Finally, skill acquisition theories also provide two implications for instructional treatment 
design: (1) instruction needs to be implemented gradually. Therefore, the transition between declarative and procedural knowledge is smooth. And (2) practice should be done by means of communicative activities fostering the use of declarative knowledge.

As with any other theory that attempts to account for language learning and development, Skill Acquisition Theory has received some criticism. Firstly, according to Taie (2014) there is a lack of agreement on a working definition for this theory, including the conceptualization of core concepts, namely practice or skill. Secondly, the efficiency of the automatization process has also been questioned, since this theory fails to examine external factors that are related to L2 development, such as learners' anxiety or motivation (Taie, 2014). Thirdly, DeKeyser (2007a) states that this theory has received scant attention in SLA research, due to the difficulty of accessing a large number of students and track their development for an extended time span. Fourthly, DeKeyser (2007b) points out to the skill non-transferability issue. In other words, the application of the knowledge of one skill developed in one L2 area will not be successful if applied in a different L2 area. Finally, Ellis (2009) believes that Skill Acquisition Theory does not include two main issues in the field of SLA, namely (1) failure to explain the sequential development of acquisition; and (2) this author plays the role of declarative knowledge down, since he asserts that L2 learners have already had previous experience with the target language (TL). Therefore, the need for a first stage is not so prominent.

Even though Skill Acquisition Theory has been criticized, it has also received some support. As encompassed by Taie (2014), Parziale and Fischer (2009) point out several positive aspects of this theory, which DeKeyser (2007a) supports. First, they favor the use of this theory in both cross-sectional and longitudinal studies, as well as accounting for linguistic, cognitive and social aspects of L2 development because this 
theory explains the process learners go through from declarative to procedural knowledge attainment. Secondly, "Skill [acquisition] theory provides a coherent and practical means of defining and identifying skills and sequences in learning activities." (p. 103). Finally, the theory accounts for the non-linear nature of development.

All in all, this particular theory of language learning was selected to support the present study. In so doing, it helps account for the processes that learners undergo in becoming aware of -capitalized in the role of declarative knowledge- and orally producing - explained by means of procedural knowledge- a given set of conventional expressions.

Finally, Firth and Wagner's (1997) study brought a major shift in the SLA research paradigm. These authors criticized the fact that SLA research was overly focused on cognitive issues to explain the acquisition of a second or foreign language, employing theories, methods, and exploring phenomena that did not fully effectively explain social spheres of language, such as interactional or sociolinguistic (p. 285). As a consequence, the language learner was identified as lacking communicative skills, struggling to improve their L2 competence in an effort to attain the ideal native-speaker counterpart. Therefore, they claimed the need for research with a focus on the use of language in context, which would enrich the SLA research panorama, thus accounting for the acquisitional development of a second or foreign language more faithfully. This study brought about a change towards a more inclusive and comprehensive study of pragmatics with language learning theories based on the premise that language is learned and acquired in interaction. From this socially oriented perspective, theories of language learning give social interaction a paramount role. Some of these theories are explained in what follows. 


\subsubsection{Social theories.}

Having provided an overview of the cognitive-oriented theories that account for language acquisition, the present subsection includes a series of theories that explain language acquisition from a social stance. First of all, Vygotsky's (1978) Sociocultural Theory is included in this subsection because he envisioned language development as a context-dependent phenomenon, where interaction is core. Even though Vygotsky did not elaborate a theory of language acquisition, his theory of cognitive development is included in the socially oriented theories. According to Taguchi and Roever (2017), Vygotsky identified three conditions that are imperative for language acquisition to take place successfully, namely input, output, and feedback. Language is considered a semiotic tool, that mediates "higher forms of mental activity" (p. 53), being language learning an example. Language is a semiotic tool as it governs both learner's behavior and the cognitive process they undergo while learning the TL. In this process, the learner and the context in which they are surrounded are intertwined. Learner's output can be recognized as being private speech -in which learners talk to themselves aloudor inner speech -in which learners talk to themselves not verbalizing their thoughts. Another key concept in Vygotsky's theory is the zone of proximal development (ZPD). It refers to the stage in language development in which learners can manage to get their message across, but with the assistance of a more proficient language user. Therefore, by means of interacting with other speakers and being language use mediated, learners will develop their knowledge and move from assistance need to self-sufficient use of the L2.

In line with Vygotsky's conception of the importance of contextualized interaction, Schieffelin and Ochs (1986) proposed a new paradigm from which to study the acquisition of a given L2: Language Socialization. According to Taguchi and 
Roever (2017), this new theory of language learning is rooted in different research fields, such as linguistic anthropology; Sociocultural Theory (Vygotsky, 1978) or semiotics (Silverstein, 1976). Language Socialization is defined as a process in which both the linguistic system and the culture of the L2 are learned jointly. Also, that middle point between language and culture is projected in the concept of indexical knowledge; by which learners assign meaning to linguistic forms they learn (Ochs, 1996).

Considering the critical nature of learning the language and culture together, learner agency is a key aspect in this particular theory of language learning. In turn, language socialization is perceived to be successful if learners interact with more proficient speakers, as is the case with Sociocultural Theory. Another key feature within this theory is the concept of contingency. In the course of interaction, learners can socialize in a positive or in a negative manner, and they may (or not) reach the TL behavior or linguistic system either intentionally or unintentionally. For example, applied to pragmatics learning, those learners who want to maintain their L1 pragmatic system instead of embracing the L2's can still socialize successfully (e.g., Ishihara \& Tarone, 2009; Siegal, 1996). Instances such as the aforementioned depict the unpredictability of language socialization, which is another factor studied in this theory. Finally, language socialization is seen as multidirectional, as socialization goes both ways. In other words, not only novice learners will learn from the experts, but also will the experts learn from the novices. All in all, it is stated in Language Socialization that an L2 learner will socialize as they use the TL.

In the early 1990s, and aligning with the importance of the relation between learner agency and language learning, Giles, Coupland and Coupland (1991) proposed the Speech Accommodation Theory. These authors claimed that learners' identities will determine the type of language they choose to use in different situations. This, in turn, 
relies heavily on both their cognitive and affective variables. In other words, these two variables will determine whether learners may adopt or resist to the TL pragmatic norms.

There are other socially-oriented theories that account for language learning development, such as Complexity Theory (Larsen-Freeman, 2011; Larsen-Freeman \& Cameron, 2008), Dynamic Systems Theory (de Bot, 2008; Ellis \& Larsen-Freeman, 2006; Larsen-Freeman \& Cameron, 2008); the Emergentism Approach (Ellis \& LarsenFreeman, 2006); and Usage-Based Approaches (Cadierno \& Eskilden, 2015). In accordance to the main foci in these theories, Taguchi (2011b) and Taguchi and Roever (2017) point out the need to focus on the dynamic and complex aspects that play a role when acquiring a L2. Scholars focusing on this area highlight the fact that individuals and context are variables to consider, and language will only develop if interaction between these interdependent variables takes place.

\subsection{Communicative Competence}

In this second section, the definition of communicative competence and the models that have been proposed over the years will be discussed in detail.

\subsubsection{Defining communicative competence.}

Most of the models that account for communicative competence were developed having language teaching and learning in mind. Exemptions are Bachman's (1990) and Bachman and Palmer's (1996, 2010), which were created from a language assessment viewpoint. An overview of ten different models of pragmatic competence will be provided in chronological order to review the role and importance pragmatic competence has gained over the past decades. 


\subsubsection{Models of communicative competence.}

Chomsky $(1957,1965)$ proposed a model of communicative competence with one single competence: linguistic competence. It explored the rules that accounted for word and sentence formation; focusing from the smallest item, namely sound systems, to the bigger items, sentences. Chomsky accounted for language development from a linguistic perspective only, leaving aside social factors that influence and also help explain the use of this specific competence in context.

As a reaction to this model of communicative competence, Hymes $(1967,1972)$ proposed a new model of communicative competence formed by two competences: linguistic competence, which targeted the same goals as Chomsky's, and sociolinguistic competence, which accounted for the rules that govern the appropriate use of language in context. Concurrently, there was a shift in the field of language teaching and learning moving away from audiolingualism and grammar-translation method into a communicative approach informed by Hymes's new model.

The first authors that created a model within communicative competence were Canale and Swain (1980). Their model has three components: (1) grammatical competence, Hymes's linguistic competence; (2) sociolinguistic competence, in line with Hymes's $(1967,1972)$ as well; and (3) strategic competence, the ability to avoid communication breakdowns. Canale and Swain's model is of much importance since these authors were the first who took pragmatics into consideration and included it in the model. However, pragmatics was included in sociolinguistic competence.

A few years later, Canale (1983) expanded Canale and Swain's (1980) model by adding the discourse competence, which explored learners' capacity of "interpret[ing] and explor[ing] language beyond the sentence level" (Celce-Murcia, 2007, p. 42), 
therefore envisioning communicative competence as more inclusive and comprehensive.

Almost a decade after, Celce-Murcia, Dörnyei, and Thurrell (1995) designed a model in which strategic, and discourse competences remained the same, and linguistic and sociolinguistic competences' names were modified. On one hand, the former grammatical competence was labeled linguistic competence because the authors willed to encompass grammar as well as morphology and syntax into the same component. On the other hand, sociolinguistic competence was labeled sociocultural competence to account for the previous knowledge needed to carry pragmatic conversations successfully. Furthermore, it bifurcated into sociolinguistic competence and actional competence, the latter referring to learners' capability of understanding and producing the most relevant speech acts. Additionally, this model conceived all components in their model to be interrelated.

In the turn of the new century, Celce-Murcia (2007) proposed a revised version of the model she and her colleagues had developed in 1995. In this renewed account of communicative competence, discourse competence was still at the core of the model, and strategic competence remained the same. One new feature was the addition of formulaic competence to sociocultural, linguistic, and interactional competences. Formulaic competence comprises those chunks of language used in everyday language, including routines, idioms, collocations, and lexical items. This competence complements the linguistic one, which encompasses phonological, syntactic, morphological and lexical issues. In turn, formulaic competence is indispensable in this model because it recognizes the fact that formulaic language is as equally used as linguistic knowledge in interactions daily, a fact that was neglected up until three seminal works were published in this research area: Pawley and Syder (1983), Pawley 
Chapter 1: Second Language Pragmatics

(1992), and Nattinger and DeCarrico (1992). All competences aforementioned were designed to be competences on their own, influencing and being influenced by each other and discourse competence at the same time. See Figure 1 for a collection of all models of communicative competence. 


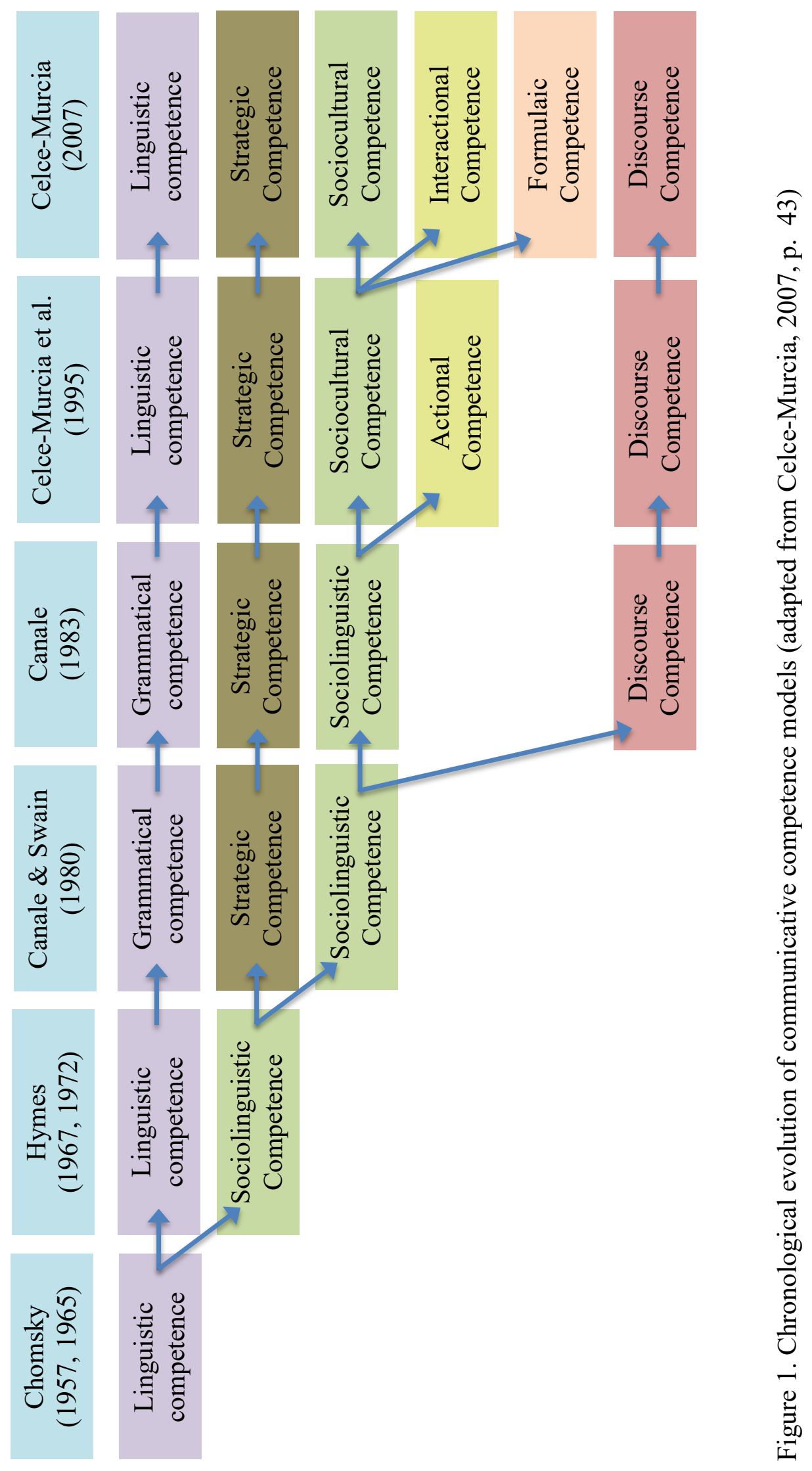


Even though Canale and Swain (1980) envisioned pragmatics within their model, they included it within sociolinguistic competence a criticism maintained by other models of communicative competence (Bachman, 1990; Bachman \& Palmer, 1996, 2010; Alcón-Soler, 2000; Martínez-Flor \& Usó-Juan, 2006; Schachter, 1990).

Bachman's (1990) model is highly significant because this author was the first who explicitly included pragmatic competence as a competence in and of itself in his model, as shown in Figure 2 below:

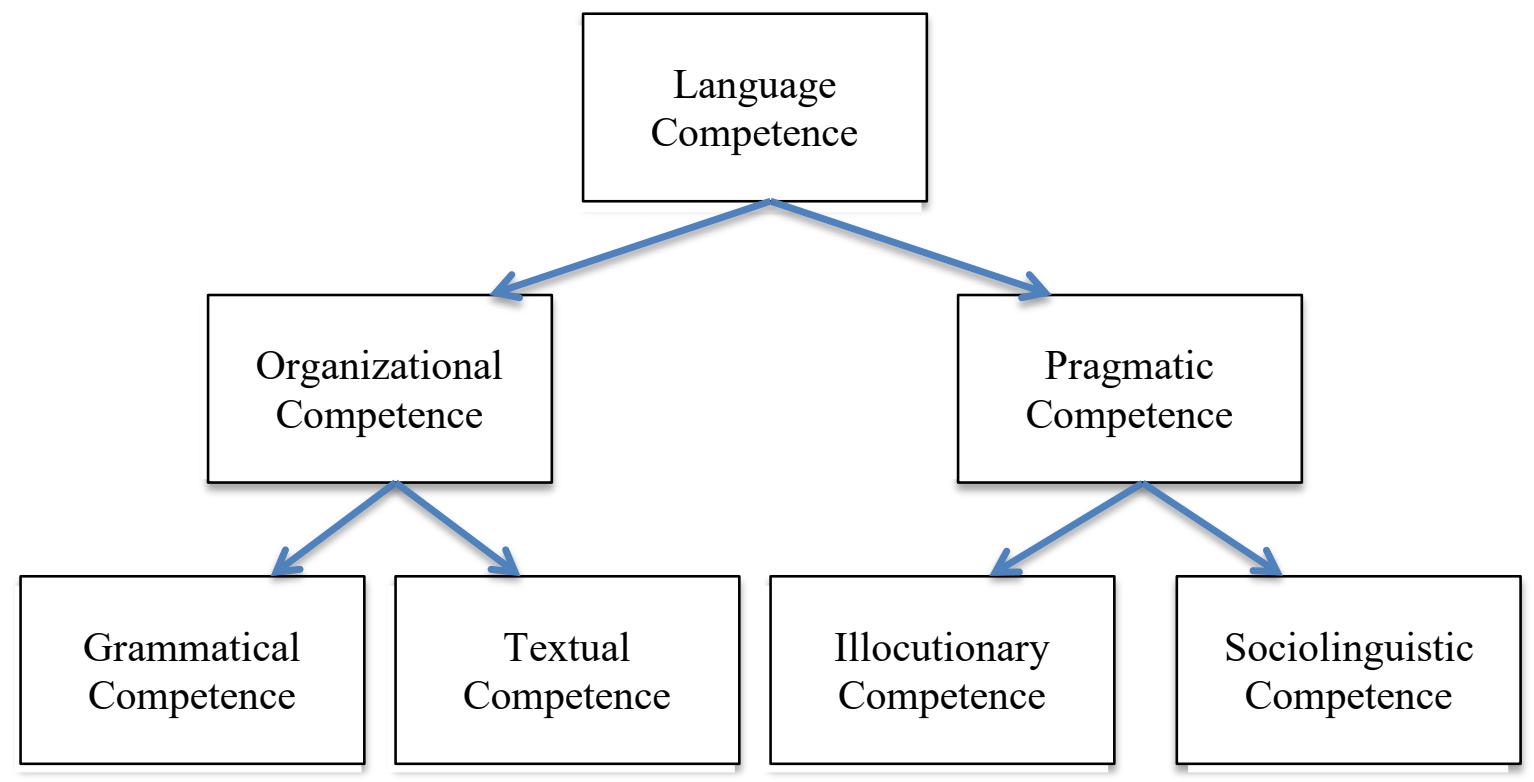

Figure 2. Bachman's model of pragmatic competence (adapted from Bachman, 1990, p. 87)

Bachman (1990) viewed language knowledge as being composed of two main competences: organizational and pragmatic. This author understood organizational competence as the knowledge to use language in social interactions. In other words, that to control language formal structures to produce and recognize sentences which are grammatically appropriate; as well as to comprehend their propositional content, and to put them together in an orderly manner to form texts. In turn, this competence is divided into grammatical and textual competences. The former draws from the one that Canale and Swain (1983) proposed and includes knowledge of vocabulary, morphology, 
syntax, phonology, and graphology. Textual competence implies having the knowledge to combine utterances to shape texts, as well as knowledge of conversational analysis. This last feature is what distinguishes this sub-competence from Canale and Swain's (1983) discourse competence.

As mentioned before, Bachman's (1990) model is an important contribution to the existing literature on models of communicative competence because he depicted pragmatic competence as one competence on its own. Pragmatic competence explores two issues. On one hand, it examines the aforementioned signs and the relation to their constituents. On the other hand, it observes the users and contexts involved in communicative acts. As seen in Figure 2 above, pragmatic competence is made up of illocutionary competence, which entails the knowledge of linguistic units to convey a message; and sociolinguistic competence, which is concerned with the contextual knowledge needed to communicate effectively. In other words, illocutionary competence embodies pragmalinguistic knowledge, whereas sociolinguistic competence represents sociopragmatic knowledge. All in all, and in line with Bachman (1990), being pragmatically competent involves the mastery of two components: illocutionary and sociolinguistic competences.

A few years later, Bachman and Palmer $(1996,2010)$ proposed a revised model for Bachman's (1990). In this revised model, all categories related to language knowledge remained the same, but they were relabeled. As can be seen in Figure 3 below, all of them are types of knowledge, instead of competences. One further change was the name of illocutionary competence, which was changed to functional knowledge. Bachman and Palmer $(1996,2010)$ included strategic competence, identified as a given series of metacognitive strategies, which allow language users to set, assess, and plan a communicative action in context. 


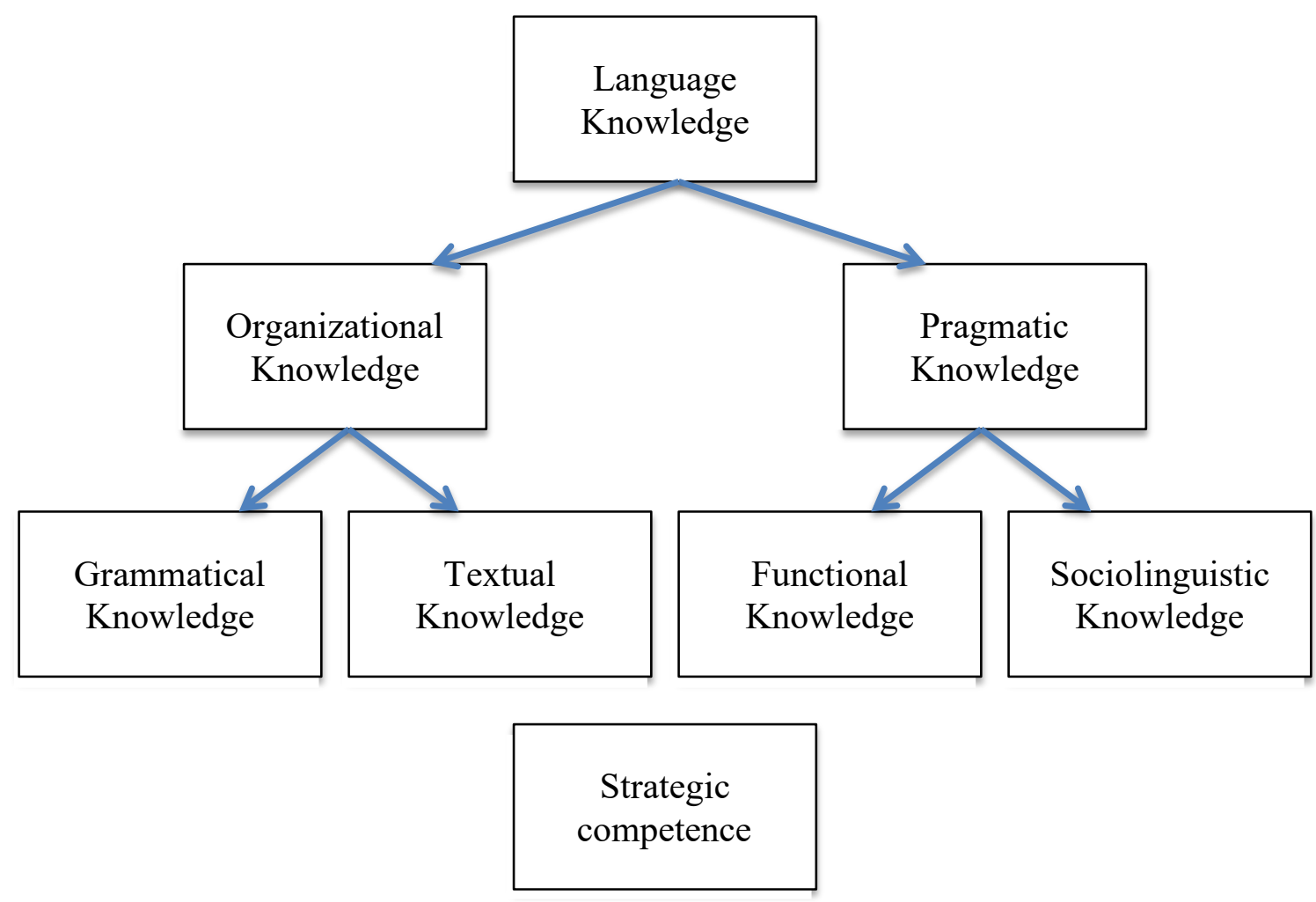

Figure 3. Bachman and Palmer's (1996, 2010) model of pragmatic competence

In the turn of the new century, to cover the need of exploring the nature of the interrelationships existing among all components within a given model of communicative competence, Alcón-Soler (2000) and Usó-Juan and Martínez-Flor (2006) proposed new models of communicative competence.

Alcón-Soler (2000) proposed her model in which discourse competence was the core. She stated that L2 learners would become communicatively competent if they acquired this specific competence, the discourse competence. 
Table 1. Alcón-Soler's (2000, p. 262) model of communicative competence

\begin{tabular}{|l|l|}
\hline Discourse competence & Linguistic competence \\
& Textual competence \\
& Pragmatic competence \\
\hline Psychomotor skills and competencies & Listening \\
& Speaking \\
& Reading \\
\hline Strategic competence & Writing \\
\hline & Communication strategies \\
\hline
\end{tabular}

As shown in Table 1 above, Alcón-Soler's (2000) model is composed of three main competences, namely discourse, psychomotor, and strategic. Discourse competence is constituted by three components: linguistic, textual, and pragmatic. Linguistic competence comprises all linguistic aspects of the language, thus resembling Celce-Murcia et al.’s (1995) linguistic competence. In turn, both textual and pragmatic competences are similar to Bachman's (1990) pragmatic competence, and both are essential in constructing and interpreting discourse. As of the second set of competences, Alcón-Soler claims that discourse competence is influenced by the four skills (i.e., listening, speaking, reading, and writing) involved in the use of language to communicate purposefully. As for the last component in her (2000) model, strategic competence encompasses a set of distinct sub-components: communication and learning strategies. 
Finally, Usó-Juan and Martínez-Flor (2006) put forward a model of communicative competence in which discourse competence was central as well, as Bachman and Palmer's (1996, 2010) and Alcón-Soler's (2000) models.

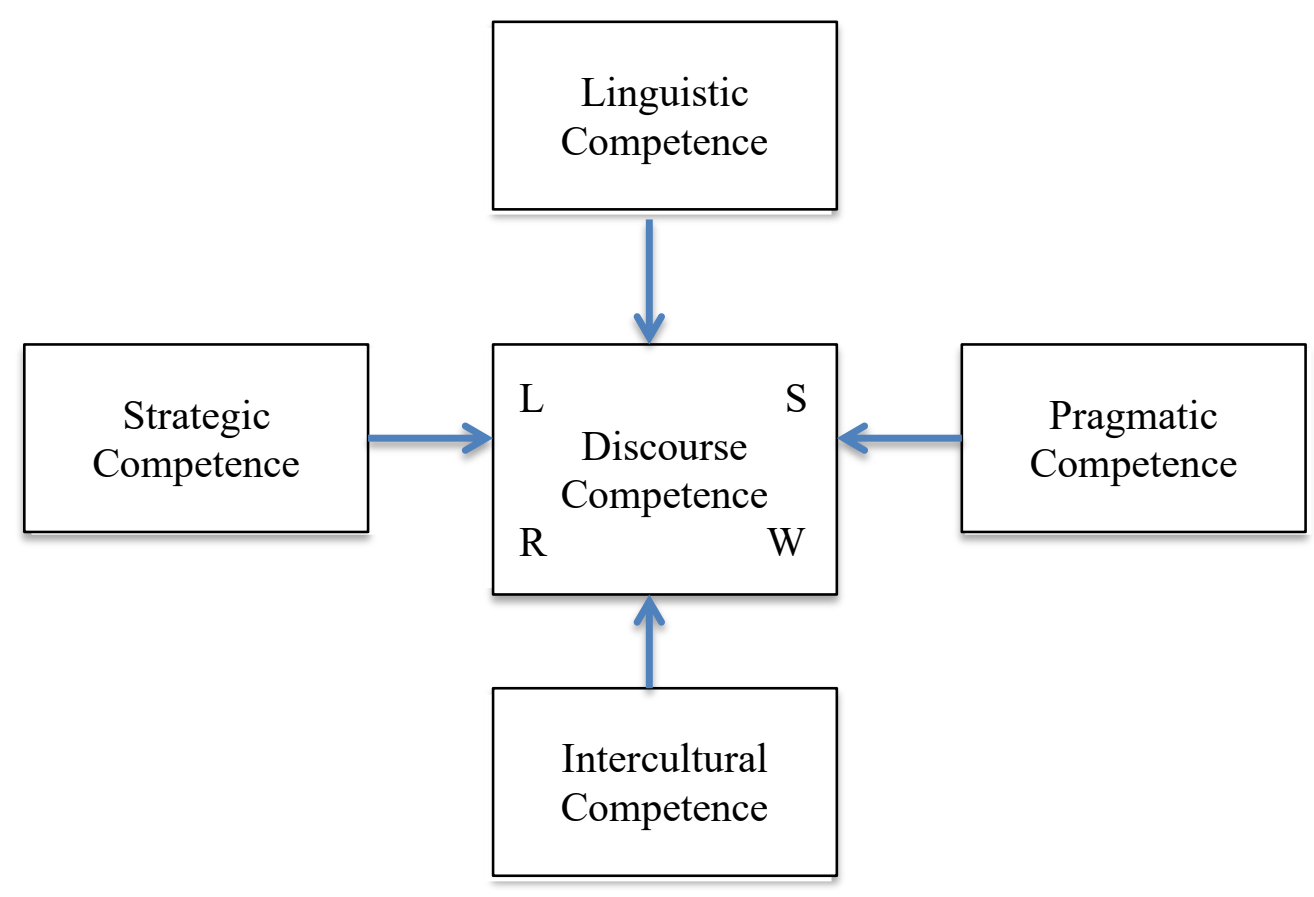

Figure 4. Usó-Juan and Martínez-Flor's (2006) model of communicative competence (adapted from Usó-Juan \& Martínez-Flor, 2006, p. 16)

As shown in Figure 4 above, discourse competence, which comprises all four skills, is at the center of this model. Knowledge on the ways to provide coherent and cohesive texts, both oral and written, is provided in this competence. In turn, linguistic competence encompasses knowledge of phonology, grammar, and vocabulary. This competence resembles Canale and Swain's (1980) and Bachman's (1990) grammatical competence and Celce-Murcia et al.'s (1995) and Alcón-Soler's (2000) linguistic competence. Accordingly, pragmatic competence involves knowledge of pragmalinguistic and sociopragmatic components, the same way Bachman's (1990) pragmatic competence did. Pragmalinguistic knowledge in this model is similar to Celce-Murcia et al.'s (1995) actional competence, whereas sociopragmatic components in this model are similar to Celce-Murcia et al.'s (1995) sociocultural competence. 
These authors drew from Celce-Murcia et al.'s (1995) sociocultural competence as well to devise their intercultural competence, which includes knowledge of cultural and nonverbal factors in communication. Finally, Usó-Juan and Martínez-Flor (2006) included strategic competence, which deals with avoiding communication breakdowns by means of acquiring communication strategies designed to obtain that goal.

The discussion of all models of communicative competence included in this section serves to reflect on the fact that to become competent in communication, not only is developing grammatical competence needed, but also other competences, such as pragmatic and discourse competences (Alcón-Soler \& Martínez-Flor, 2008). The present study is concerned with English as a foreign language (EFL) learners' development of pragmatic competence, as described by Bachman and Palmer (2010). Therefore, this study adopts Bachman and Palmer's model of communicative competence to account for learners' pragmatic trajectories.

The next section is devoted to the notion of pragmatic competence as an essential component in the learners' communicative competence.

\subsection{Pragmatic Competence}

This third and last section represents a discussion of the operationalization of pragmatics and pragmatic competence, providing detailed descriptions of such concepts, and the features that characterize them, as well as research that has been produced in the field of L2 pragmatics. 


\subsubsection{Pragmatics.}

Broadly speaking, pragmatics is the study of the use of language in context. In this first subsection, the definition of the concept will be thoroughly discussed.

The field of pragmatics originated in the decades of 1960s and 1970s to fulfill the need to study and report about language use in context. Nevertheless, it was Morris (1938) who provided the first definition of pragmatics in his work on language philosophy. He devised three main areas of research in the field of semiotics, namely syntax, semantics, and pragmatics. According to this author, syntax was seen to tackle "the formal relations of signs to one another;" semantics provided an explanation for "the relations of signs to the objects to which the signs are applicable;" and finally, pragmatics was defined as "the science of the relation of signs to the interpreters" (1938, p. 6).

After Morris, the main focus of language was structural linguists lead by Saussure (1959) and the generative-transformational grammarians lead by Chomsky (1965), as the two major schools that perceived language as an entity to study in isolation. Moving away from an entirely linguistically focused definition, Levinson (1983, p. 9) defined pragmatics as "the study of those relations between language and context (emphasis added) that are grammaticalized, or encoded in the structure of language." As it can be seen in this definition, a more central role was given to the notion of context. Following this trend Kasper and Blum-Kulka (1993, p. 3) defined pragmatics as "the study of people's comprehension and production of linguistic action in context." This particular definition has been chosen in this dissertation because it refers to the two main components that will be studied: comprehension and production of conventional expressions. In that same year, Mey (1993, p. 5) defined pragmatics as "the science of knowledge seen in relation to its users," therefore pinpointing at the relationship 
between language, learners and interaction. In this same publication, this author provided an alternative but related definition of pragmatics as "the societally necessary and consciously interactive dimension of the study of language" (Mey, 1993, p. 315). In turn, Thomas (1995, p. 22) stated that pragmatics entails "the negotiation of meaning between the speaker and hearer, the context of utterance (physical, social, and linguistic), and the meaning potential of an utterance." With this definition, the scope of pragmatics can be seen to be broadening from a mere focus on language to an integration of language, context, and interlocutors in interaction. Bachman (1990, p. 89) accounted for pragmatics as it is "concerned with the relationships between utterances and the acts or functions that speakers (or writers) intend to perform through these utterances." This author focused more on the linguistically and socially intertwined components of pragmatics. In turn, Bachman and Palmer (1996) expanded on Bachman's (1990) definition by proposing a more specific one, accounting for speakers' intentions in interaction. Thus, Bachman and Palmer claimed that, "pragmatic knowledge enables us to create or interpret discourse by relating utterances or sentences and texts to their meanings, to the intentions of language users, and to relevant characteristics of the language use setting" (p. 69).

Crystal's (1985) definition of pragmatics is also included due to its relevance and well-known status within the field of SLA. According to Crystal (1985, p. 240), "pragmatics is the study of language from the point of view of users, especially of the choices they make, the constraints they encounter in using language in social interaction and the effects their use of language has on other participants in the act of communication." The reason for including this particular definition is two-fold. On one hand, it was incorporated due to its core position within the pragmatics research field. On the other hand, in line with Crystal's (1985) definition, this dissertation tries to 
account for learners' use of conventional expressions, as well as the difficulties they may encounter in producing such expressions; and also, the effect their utterances have on other learners in the interaction process.

More recently, Alcón-Soler and Martínez-Flor (2008, p. 3) proposed a more restricted definition, as they understood pragmatics as it "deals with areas such as deixis, conversational implicature, presupposition and conversational structure." According to Archer and Grundy (2011, p. 488), pragmatics is "the study of language used in contextualized communication and the usage principles associated with it." These authors support Levinson's (1983) and Kasper and Blum-Kulka's (1993) claim that context is crucial in pragmatics as they highlight the essential role of context and the rules that guide language use. As part of the importance gained by the context, Alcón-Soler (2013, p. 179) incorporated another factor, the human factor, in her definition of pragmatics, as she stated that this field "deal(s) with language in use in particular social contexts (...), the situational factors that influence how people communicate with each other." Besides, "pragmatics takes into account the point of view of the users of a language, that is to say, both the speaker's intention and the hearer's interpretation of the utterances" (emphasis added on words in italics). Second to last in this discussion on the notion of pragmatics is Taguchi and Roever's (2017) account of pragmatics, which -in line with Bachman's (1990) definition aforementioned- defined pragmatics as it "links linguistic forms and the ways in which they are used in social context to perform a communicative act" (p.1). In a similar vein, Taguchi $(2019$, p. 1) defined pragmatics as the study of "the connection between a linguistic form and a context, where that form is used, and how this connection is perceived and realized in a social interaction." These definitions are particularly important in this dissertation since it aims to study learners' production of conventional 
expressions in specific contexts to fulfill a social act. Additionally, Taguchi and Roever (2017) stated that pragmatics observes both the linguistic production of the speaker and how hearers attend to it in the situational context of the conversation. This claim is very relevant to the present study because the other main aim is to observe leaners' awareness of conventional expressions. Therefore, by means of the instructional treatment, it was aimed to raising learners' awareness on these two issues, namely, linguistic realization of conventional expressions, and society's (other native and nonnative speakers') perceptions of those linguistic realizations; as well as the consequences - positive or negative- as regards the appropriateness of those linguistic realizations. According to Taguchi and Roever (2017), L2 Learners play two simultaneous roles when in interaction: listener and speaker. As listeners, meaning interpretation of what is explicitly and implicitly said both with words and nonlinguistic signs is essential. On the other hand, learners-as-speakers should get acquainted with the knowledge to express their ideas taking into consideration the context of interaction, that is, considering "the level of formality, politeness, and directness" (p. 1) or just saying nothing and get their message across by means of nonverbal cues. This claim is especially important for this dissertation due to the fact that participants are aimed to learn conventional expressions that are used as listeners and as speakers. I'm fine, thanks. And you? and No, thanks. I'm just looking are examples of expressions used as listeners. Thanks for having me and Sure. That sounds fun are examples of expressions used as speakers. A more detailed account of all expressions and the situations in which they appear in the present study is provided in Chapter 4 and reviewed in Chapter 6.

All in all, even when different perspectives on what pragmatics entails and accounts for exist, there are four issues that prevail in the discussion, which are 
"language, meaning, context and action" (Taguchi \& Roever, 2017, p. 2). The following subsection, 1.3.2 Pragmatic competence, presents a conscientious discussion of the term, in which the four elements aforementioned are paramount to explain the mechanisms that drive pragmatic competence.

\subsubsection{Pragmatic competence.}

Pragmatic competence entails the knowledge and ability to interpret and use a L2 in different social contexts appropriately (Celce-Murcia, 2007; Taguchi, 2012). In that line, Taguchi (2018, p. 124) claims that this ability that enables speakers to interact "draws heavily on context," thus stressing the significance of acknowledging the contextual dimension in interaction. In the following subsection, the term pragmatic competence, together with its two components, pragmalinguistics and sociopragmatics, will be discussed.

Among all the definitions that exist in the literature, there seems to be three different trends of definitions, depending on the scope of the research. These are (1) those who approach pragmalinguistic and sociopragmatic components only; (2) those who link these two components of pragmatic competence with contextual situations; and (3) those who rather focus on social aspects of pragmatic competence.

Examples of definitions falling into the first category, describing pragmatic competence by focusing on its two components only, are Kasper and Roever (2005, p. 318) who stated that any given speaker would become pragmatically competent if they undergo "the process of establishing sociopragmatic and pragmalinguistic competence and the increasing ability to understand and produce sociopragmatic meanings with pragmalinguistic conventions." In the same line, Taguchi $(2015$, p. 1) identified pragmatic competence as it "refers to one's knowledge of linguistics, norms, and social conventions, and one's ability to use these knowledge bases in a socially-bound 
interaction." Putting it more simply, "what learners can do as producers and interpreters of pragmatic meaning” Taguchi (2012, p. 7).

Before presenting the definitions of pragmatic competence in trends number two and three stated above, the concepts of pragmalinguistics and sociopragmatics are defined.

Leech (1983) and Thomas (1983) were the first authors to formulate the two subcompetences of pragmatic competence. Pragmalinguistics was defined by Leech (1983, p. 11) as "the study of the more linguistic end of pragmatics -where we consider the particular resources which a given language provides for conveying particular illocutions," while he defined sociopragmatics as "the sociological interface of pragmatics," "[t]he "more specific "local" conditions on language use" (p.10), which Thomas (1983, p. 99) borrowed and defined as "the social conditions placed on language in use."

Several definitions have been provided in the literature to operationalize these two terms more comprehensively. Kasper and Roever (2005) provide detailed definitions of these two knowledge types. Pragmalinguistics was defined as "the intersection of pragmatics and linguistic forms" (p. 317) in a broader sense. More specifically, these authors understood pragmalinguistics as "the knowledge and ability for use of conventions of means (such as the strategies for realizing speech acts) and conventions of forms (such as linguistic forms implementing speech act strategies)" (pp. 317-318). Sociopragmatics is generally concerned with the description of "the interface between pragmatics and social organization" (p. 317). More precisely, it "encompasses knowledge of the relationships between communicative action and power, social distance, and the imposition associated with future event," and also "knowledge of mutual rights and obligations, taboos, and conventional practices" (p. 317). Hassall 
(2008, p. 73) stated that pragmalinguistics entails the "knowledge about the relation between linguistic forms and pragmatic meanings they carry", whereas sociopragmatics "refers to knowledge about the social context - the weightings of factors such as status or social distance which will affect choice of linguistic form.” According to Alcón-Soler and Martínez-Flor (2008, p. 3), pragmalinguistics refers to "the linguistic resources for conveying communicative acts and interpersonal meanings", whereas sociopragmatics is concerned with "the social perceptions underlying participants' interpretation and performance of communicative acts.” A few years later, Alcón-Soler (2012, p. 512) claimed that pragmalinguistic knowledge explores "language users' knowledge of the means to weaken or strengthen the force of an utterance"; while sociopragmatic knowledge involves "their knowledge of the particular means that are likely to be most successful for a given situation.” In that same year, Taguchi (2012, pp. 2-3) asserted that "pragmalinguistics refers to the linguistic resources available for performing language functions" and "sociopragmatics refers to a language user's assessment of the context in which those linguistic resources are implemented" referring to Leech (1983) and Thomas (1983). Cohen (2013, p. 267): defined pragmalinguistics as "the linguistic structures selected for performing pragmatics," and sociopragmatics being concerned "with the focus on the crucial sociocultural factors that contribute to whether pragmatic performance is deemed appropriate." In turn, Xiao (2015, pp. 132-133) provided a more general definition of the terms. According to him, pragmalinguistics studies the "functional-linguistic aspect of pragmatic competence", whereas sociopragmatics examines the "social aspect of pragmatic competence." Finally, Taguchi and Roever (2017, p. 7) identified pragmalinguistics as the "linguistic tools for performing communicative acts in the target language," and sociopragmatics as the "knowledge of cultural rules and norms, role expectations, and appropriate conduct.” These authors 
claim the need for L2 learners to acquire and master these competences to be pragmatically competent. As they put it, "[t]hese two knowledge types must be mapped onto each other so learners can choose appropriate linguistic forms to achieve communicative goals in context" (Taguchi \& Roever, 2017, p. 7). Therefore, both components need to be taken into consideration in social interaction, as both are equally paramount to avoid pragmatic failure, that is to say, a breakdown in communication by which a given misunderstanding may lead to the termination of the conversation, as it may have caused some offence the other interlocutor. The concept of pragmatic failure will be discussed in Chapter 2.

To sum up, regarding pragmalinguistic competence, Kasper and Roever (2005), Hassall (2008), Alcón-Soler and Martínez-Flor (2008), and Alcón-Soler (2012), highlighted the fact that linguistic features are selected and used to deliver a message taking into account the effect it will have on other interactants. On the other hand, pragmalinguistics is regarded more generally as the knowledge of linguistic features in pragmatics performance (Cohen, 2013; Taguchi, 2012; Taguchi \& Roever, 2017; Xiao, 2015). As of sociopragmatics, Hassall (2008) and Alcón-Soler (2012) focused on the importance of contextual factors, and Alcón-Soler and Martínez-Flor (2008) mentioned learners' perceptions while being engaged in interaction. In turn, Taguchi (2012) focused on learner contextual assessment. And finally, Kasper and Roever (2005), Cohen (2013), Xiao (2015), and Taguchi and Roever (2017) perceived sociopragmatics as the knowledge of social context, which affects the use of pragmalinguistic knowledge. All in all, pragmalinguistics deals with language issues, whereas sociopragmatics explores social context.

The following two definitions belong to group two, since they encompass both components of pragmatic competences and relate them to contextual issues. Barron 
(2003) observed that pragmatic competence is concerned with "knowledge of the linguistic resources available in a given language for realising particular illocutions, knowledge of the sequential aspects of speech acts and knowledge of the appropriate contextual use of the particular languages linguistic resources” (p. 10). Similarly, Martínez-Flor and Usó-Juan (2006, p. 39) defined pragmatic competence as "the ability of employing target-language linguistic resources in an appropriate way for a particular context." These authors go a step forward and envisioned that pragmatic competence tackles the incorporation and further mastery of both sociopragmatic and pragmalinguistic knowledge. In line with this idea of attaining target-like mastery of rules, Taguchi (2010, p. 336) asserted that "[p]ragmatic competence involves the mastery of linguistic and non-linguistic knowledge, as well as the efficient control of both knowledge types when encoding and decoding language functions in a sociocultural context." Most recently, this author conceptualized pragmatic competence as "three-fold: (1) knowledge of linguistic forms and their functional meanings; (2) sociocultural knowledge; and (3) the ability to use these knowledge bases to create a communicative act in interaction" (Taguchi, 2018, p. 126).

Group three is composed of definitions provided by several scholars who explain pragmatic competence with a focus on social functions language use can have, such as Taguchi (2010, p. 335) who proposed pragmatic competence as "the ability to use language to perform social functions.” In a similar vein, Taguchi $(2015$, p. 1) defined it as "an ability to deal with a complex interplay of language, language users, and context of interaction." Similarly, Taguchi and Sykes $(2013$, p. 1) defined pragmatic competence as " $[\mathrm{t}]$ he ability to use language in socially and culturally appropriate ways." Additionally, these authors claimed it is essential to master this ability because "[p]ragmatic missteps often lead to miscommunications and cultural stereotyping that 
result in, best case, frustration, and worst case, long-term consequences." Taguchi (2018, p. 124) explained that for pragmatic competence to be enacted successfully and properly, context play a paramount role, because it "represents diverse language functions, communicative, and personal styles." Finally, Xiao (2015, p. 132) identified pragmatic competence as it entails "the ability to understand and use linguistic forms appropriately according to context." This author made it explicit that it will be the situational context the variable that will trigger the use of certain linguistic features over others to perform pragmatically competent.

In the present subsection, the concepts of pragmatic competence as well as its two interrelated components, namely pragmalinguistics and sociopragmatics, have been discussed. In the following subsection, a comprehensive overview is elaborated on the concept of interlanguage pragmatics, the main area where this study is located.

\subsubsection{Interlanguage pragmatics.}

Interlanguage pragmatics (ILP) aims to explore the development of learners' pragmatic competence in a given TL community (Martínez-Flor, 2005). Research in second language (L2) pragmatics diverges into three sub-fields: cross-cultural pragmatics, intercultural pragmatics, and ILP. For the purpose of the present study, only the concept of ILP will be discussed in depth because it is the main focus of the present dissertation.

\subsubsection{Defining interlanguage pragmatics.}

Selinker (1972) coined the term 'interlanguage,' which he defined as the pragmatic system that L2 learners create during the process they undergo as they learn a second or foreign language. Therefore, it neither identifies with their L1 pragmatic system, nor the TL's, but the constructs the learners learn on their way to mastering the TL. In turn, Kasper and Dahl (1991, p. 216) provided the first definition of ILP. These authors claimed that ILP studies “nonnative speakers' (NNSs') comprehension and production 
of speech acts, and how their L2-related speech act knowledge is acquired." This first definition was very narrow, only accounting for speech acts. However, it was crucial at its time, due to the fact that it accounted for acquisitional issues.

More varied accounts of ILP are found in the literature which show the wider scope of research it has to offer. Kasper and Blum-Kulka (1993, p. 3) defined ILP as "a non-native speaker's use and acquisition of linguistic action patterns in a second language." Even though these authors focused on language issues only, they understood ILP in a broader perspective. Kasper and Dahl's (1991) acquisitional aspects of pragmatics are also represented in their definition. In a similar vein, Kasper (1996, p. 145) identified ILP as “the study of nonnative speakers' use and acquisition of L2 pragmatic knowledge." Kasper provided a general definition as well, but she encompassed not only linguistic but cultural knowledge as well as she mentioned "L2 pragmatic knowledge" in general. Yule (1996, p. 131) went a step forward and includes interaction, as this author perceived ILP as " $[\mathrm{t}]$ he study of how non-native speakers communicate in a second language.” In turn, Kasper and Schmidt (1996) focused on learning strategies in their account of ILP, as they defined this term as "the study of the development and use of strategies for linguistic action by nonnative speakers" (p. 150). Kasper and Rose (2002, p. 5) provided two complementary definitions. On one hand, ILP - as investigating L2 use- inspects NNSs' comprehension and production of actions in an L2. On the other hand, ILP -as investigating L2 learning- examines L2 learners' development of their "ability to understand and perform action in a target language." This definition has been included in this review since it describes the scope of research of the present study, as it regards the comprehension and production of conventional expressions by nonnative speakers of English. Additionally, this definition is particularly important at this point because these authors shed light into the shift that 
came about from focusing just on speech acts to other issues in L2 pragmatics, such as conversational structure or conversational implicature (Alcón-Soler \& Martínez-Flor, 2008, p. 3). In this regard, Martínez-Flor, Usó-Juan, and Fernández-Guerra (2003, p. 12) supported this claim because they defined ILP as it "deals with learners' use and acquisition of pragmatic issues in the target language." Similarly, Alcón-Soler and Martínez-Flor (2008, p. 6) defined this field of study whose "main objective is to examine the developmental stages that learners go through when acquiring the pragmatic system of the target language.” Additionally, Taguchi (2010, p. 333) claimed that ILP "investigates how second language (L2) learners develop the ability to understand and perform pragmatic functions in a target language.” This particular definition has been included in this discussion since it exemplifies the essence of the present study. It investigates learners' development of recognition and production of conventional expressions. Additionally, LoCastro (2012, p. 80) accounted for ILP as "the study of pragmatic competence development of second and foreign language learners, which focuses on non-native English speakers' use of and acquisition of pragmatic competence in a second or foreign language." This author emphasized the notion of pragmatic competence, which, as far as could be established, had not been included in an ILP definition so far. Taguchi $(2012$, p. 1) went further as she stated that ILP “focuses on a second language learners' knowledge, use and development in performance of sociocultural functions in context," mentioning thus the sociocultural nature of context. Finally, Taguchi and Roever's (2017, p. 5) definition is included because it encompasses all of the above in a more general sense. These authors asserted that interlanguage pragmatics is "the field that investigates L2 learners' ability to comprehend and perform pragmatic functions in a target language and how that ability develops over time." 
Taguchi and Roever (2017, p. 16) identified a series of research areas within ILP. These are: transfer, which is a research topic that has received a great deal of attention. Language transfer refers to the implementation of one language system over another; and it can be positive or negative: positive in the case that transferring knowledge from L1 brings about positive outcomes; and negative transfer may imply the application of the rules of the L1 pragmatic system to the L2 when they are different and therefore bring about a negative outcome. Individual differences, which are varied in nature and that affect the learning and using of pragmatics, such as age, gender, motivation or anxiety. Some of these individual differences have received less attention, namely gender; and others have experienced a greater deal of attention in SLA research, such as motivation. Another research area is pragmatic comprehension. Research on this aspect will be discussed in the following subsection. ILP research has also examined routines. Chapter 4 of this dissertation is devoted to formulaic language more generally and conventional expressions more specifically, so discussion of research on this topic will be provided in the aforementioned chapter. Finally, research has explored email communication, topic that will be commented on in the following subsection.

All aforementioned definitions and research areas are included as a reflection on the evolution of the concept of ILP, firstly focusing on speech acts solely, and then taking into consideration other factors that influence the development of learner's pragmatic system, such as learning strategies, the critical role of context, the inclusion of pragmatic competence, as well as research in other pragmatic features, such as implicature. See Félix-Brasdefer $(2013,2017)$ for an updated review of ILP and the issues that characterize this research field. The features that characterize L2 pragmatics are examined in the following sub-subsection. 


\subsubsection{Features of L2 pragmatics.}

The overview of the concept of L2 pragmatics provided above allows to discuss basic elements in L2 pragmatics, which entail the core phenomena that characterize the conceptualization of L2 pragmatics and accounts for the issues of "language, meaning, context and action" that Taguchi and Roever $(2017$, p. 2) envision as essential in the conceptualization of this concept. Alcaraz (1990, pp. 116-117) and Cenoz (1999, p. 375) provide a set of characteristics that define L2 pragmatics $^{3}$. These are collected by Martínez-Flor, Usó-Juan, and Fernández-Guerra (2003, p. 9) as follows:

(1) the use of the language as a means of communication;

(2) the importance of language functions rather than language forms;

(3) the study of the processes which occur in communication;

(4) the importance of context and authentic language use;

(5) the interdisciplinary nature of pragmatics;

(6) the application of linguistic theories based on the concept of communicative competence.

According to Alcaraz (1990) and Cenoz (1999), the main issues to be highlighted in L2 pragmatics are language itself, as it allows communication to take place, as well as the importance for that communication to be authentic and influenced by the situational context. Moreover, language functions together with the cognitive processes underlying communication are core. Finally, it is imperative to explore the acquisition of pragmatic competence by means of theories of language learning, which account for communicative competence, and also by means of conducting interdisciplinary research. Some of the features aforementioned, namely (1), (2), and (5), are linked to

\footnotetext{
${ }^{3}$ This set of features was originally devised to characterize the concept of pragmatics. However, they have been used to define the concept of L2 pragmatics in this dissertation because they can also apply to this more specific context.
} 
the two intertwined components of pragmatic competence: pragmalinguistics and sociopragmatics, which were observed in the previous subsection: 1.3.2 Pragmatic competence. Finally, the two types of research strands that characterize the field of ILP research are explored in the following subsection.

\subsubsection{ILP studies: cross-sectional and longitudinal.}

ILP is regarded as a second-generation hybrid, since it grew from SLA research and pragmatics, thus being influenced by both (e.g., Taguchi, 2019). SLA research has been present in ILP in that ILP studies have acquired an acquisitional perspective in accounting for those paths in pragmatic development that learners both have and diverge from, as well as for considering learner differences, contextual, instructional, task, and input effects (Bardovi-Harlig, 2006a; Taguchi \& Roever, 2017). BardoviHarlig (2006a) stressed the important role of conducting ILP studies in SLA research since she claimed, "understanding the development of interlanguage remains crucial" (p. 69). Additionally, she stated that studying L2 development might shed some light into the extent of variables effect in that process. In turn, the field of pragmatics has also played its influence on ILP research. More specifically, it has influenced the work done on cross-cultural pragmatics, which explores the differences between NNSs' to native speakers (NSs') use of language (Bardovi-Harlig, 1999; Kasper \& Blum-Kulka, 1993; Kasper \& Rose, 2002; Kasper \& Schmidt, 1996; Taguchi, 2010, 2012). Therefore, research in ILP has two main strands: cross-sectional and longitudinal.

\subsection{Cross-sectional research.}

Cross-sectional research refers to those studies that focus on a given pragmatic feature for a short period of time ranging from weeks to months. Kasper and Rose (2002, p. 76) argued that these types of studies might have the ability to provide information on pragmatic development "by extrapolating from differences observed across various 
cross-sections." According to Kasper and Rose (2002), data can be gathered from the same sample at different times. Proficiency level and length of stay are some of the variables used to study pragmatics from a cross-sectional viewpoint (Kasper \& Rose, 2002; Taguchi, 2010, 2012). Cohen, Manion, and Morrison (2007, p. 220) identified a series of strengths and weaknesses in doing cross-sectional research:

Table 2. Cohen et al.'s (2007, p. 220) strengths and weaknesses in cross-cultural research

\begin{tabular}{|c|c|}
\hline Strengths & Weaknesses \\
\hline 1 Comparatively quick to conduct. & $\begin{array}{l}1 \text { Do not permit analysis of causal } \\
\text { relationships. }\end{array}$ \\
\hline 2 Comparatively cheap to administer. & $\begin{array}{l}2 \text { Unable to chart individual variations in } \\
\text { development or changes, and their } \\
\text { significance. }\end{array}$ \\
\hline $\begin{array}{l}3 \text { Limited control effects as subjects only } \\
\text { participate once. }\end{array}$ & $\begin{array}{l}3 \text { Sampling not entirely comparable at } \\
\text { each round of data collection as different } \\
\text { samples are used. }\end{array}$ \\
\hline $\begin{array}{l}4 \text { Stronger likelihood of participation as it } \\
\text { is for a single time. }\end{array}$ & $\begin{array}{l}4 \text { Can be time-consuming as background } \\
\text { details of each sample have to be collected } \\
\text { each time. }\end{array}$ \\
\hline 5 Charts aggregated patterns. & $\begin{array}{l}5 \text { Omission of a single variable can } \\
\text { undermine the results significantly. }\end{array}$ \\
\hline $\begin{array}{l}6 \text { Useful for charting population-wide } \\
\text { features at one or more single points in } \\
\text { time. }\end{array}$ & $\begin{array}{l}6 \text { Unable to chart changing social } \\
\text { processes over time. }\end{array}$ \\
\hline $\begin{array}{l}7 \text { Enable researchers to identify the } \\
\text { proportions of people in particular groups } \\
\text { or states. }\end{array}$ & $\begin{array}{l}7 \text { They only permit analysis of overall, net } \\
\text { change at the macro-level through } \\
\text { aggregated data. }\end{array}$ \\
\hline $\begin{array}{l}8 \text { Large samples enable inferential } \\
\text { statistics to be used, e.g. to compare } \\
\text { subgroups within the sample. }\end{array}$ & \\
\hline
\end{tabular}


Cohen et al. (2007) provided a comprehensive picture of what conducting crosssectional research entails. It may be positive because it might be easier to collect data just once than several times during a longer period of time and this is reflected in research's cost reduction. However, collecting data at only one point may bring about negative consequences, such as the incapability of tracing social developmental changes, which might translate into having to look at the data from a more general perspective only.

As of research following a cross-sectional perspective, the study of speech acts, and the speech act of requests in particular, has been a hotspot for decades now. The following studies provide some examples. Scarcella (1979a) studied learners' politeness-strategies acquisition when producing requests by means of a role-play on a group of 20 male EFL learners whose L1 was Arabic. As of learners' level of proficiency, half were beginners and the other half were advanced. Data on negative and positive politeness strategies were collected via three role plays in which they had to interact with someone superior to them, inferior to them, and of equal social status. Results show that less complex linguistic forms were acquired earlier. Additionally, pragmalinguistic knowledge was acquired before sociopragmatic knowledge. Finally, the learners in the study generally showed a limited knowledge of both pragmalinguistic and sociopragmatic competences in their L2 performance. Rose (2000) explored primary school EFL learners' acquisition of requests, apologies, and compliment responses in Hong Kong. Data was collected form three groups of learners by means of a cartoon oral production task (COPT), which they completed in their L1, Cantonese. Some patterns of development were traced. However, neither did they transfer pragmatic knowledge from their L1, nor showed awareness of pragmatic variation. Félix-Brasdefer (2007) examined the acquisition of requests in American learners of 
Spanish as a foreign language. A total of 45 students participated in this study, representing all levels of proficiency, that is, 15 participants per each group: beginner, intermediate and advanced. Data were collected by means of open role-plays that targeted formal and informal situations in which requests were used. The three types of request head acts (direct, indirect and conventional indirect) were the focus of the analysis. Results showed that beginner learners used direct requests more often, due to their lack of knowledge of pragmatic variation. Conversely, intermediate and advanced learners preferred the use of conventionally indirect forms of requests to both formal and informal scenarios. Finally, more proficient learners tended to use indirect request forms. Results showed that pragmatic development came in four different stages: Stage one being "pre-basic stage," stage two "basic stage," stage three "unpacking of formulaic use," and stage four "pragmatic expansion" (pp. 276-277). Finally, findings also highlight one of the goals of the study: the importance of pragmatic knowledge over grammatical knowledge in foreign language academic settings.

\subsection{Longitudinal research.}

Different definitions of what pragmatic development is have been provided in the literature to try to describe this language-learning phenomenon. Bardovi-Harlig (2013a) provided a general definition of L2 pragmatic development, as she perceived it as "the study of how learners come to know how-to-say-what-to-whom-when" (pp. 68-69). This author acknowledged both the accuracy of her definition as well as its scarcity detail inclusion. Taguchi $(2010,2012)$ aimed to provide those details in her accounts of L2 pragmatic development. Taguchi (2010, p. 351) focused on L2 grammar and vocabulary as she defined pragmatic development as "a process in which learners acquire pragmatic meanings of grammatical and lexical materials." Additionally, this author accounted for the importance of interaction and context as she understood this 
term as being "a long-term process because it requires abilities to manage a complex interplay of language, language users and context of interaction” (Taguchi, 2012, p. 2) Therefore, she claimed the important role of the two pragmatic components, pragmalinguistics and sociopragmatics, in the acquisition of an L2, as this author also accounted for L2 pragmatic development as it "entails acquisition of both these knowledge bases and efficient control of each of them in spontaneous communication" (Taguchi, 2012, p. 3). Even though different researchers perceive this concept differently, it has been widely acknowledged in the literature the scarce attention longitudinal research has received compared to studies conducted in cross-sectional research (Bardovi-Harlig, 1999, 2010b; Bardovi-Harlig \& Hartford, 1993a; Brandtzaeg, 2012; Chen, 2006; Kasper \& Rose, 2002; Kasper \& Schmidt, 1996; Li, 2016; Nguyen, 2011; Taguchi, 2010, 2011b; 2012; Yates \& Major, 2015).

Longitudinal research investigates the development of pragmatics learning of one same group over a prolonged period of time (Kasper \& Rose, 2002). In so doing, results could shed light into the acquisitional patterns that learners can follow in learning a TL, thus emphasizing the importance of the concept of time in SLA research (Ortega \& Iberri-Shea, 2005). However, there is a lack of consensus as to what the length of longitudinal studies should look like, ranging from months to several years, as well as to the number of data collection points to include in longitudinal studies (Ortega \& IberriShea, 2005; Taguchi, 2010, 2012). Data have mainly been collected via discourse completion tasks (DCTs), role-plays or multiple-choice questionnaires. As eliciting the same data from the same participants could result in task effects, these data elicitation methods are rather used less frequently over the course of a longitudinal study (Taguchi, 2012). In other words, researchers may decide to include fewer data collection points if 
these methods are the ones employed. Cohen et al. (2007, p. 221) identified a series of strengths and weaknesses in conducting longitudinal research:

Table 3. Cohen et al.'s (2007, p. 221) strengths and weaknesses in longitudinal research

\begin{tabular}{|l|l|}
\hline \multicolumn{1}{|c|}{ Strengths } & \multicolumn{1}{|c|}{ Weaknesses } \\
\hline $\begin{array}{l}\text { 1 Useful for establishing causal } \\
\text { relationships. }\end{array}$ & $\begin{array}{l}\text { 1 Remembered information might be } \\
\text { faulty, selective and inaccurate. }\end{array}$ \\
\hline $\begin{array}{l}\text { 2 Clear focus (e.g. how did this particular } \\
\text { end state or set of circumstances come to } \\
\text { be?). }\end{array}$ & $\begin{array}{l}\text { 2 People might forget, suppress or fail to } \\
\text { remember certain factors. }\end{array}$ \\
\hline $\begin{array}{l}\text { 3 Enables data to be assembled that are } \\
\text { not susceptible to experimental analysis. }\end{array}$ & $\begin{array}{l}\text { 3 Individuals might interpret their own } \\
\text { past behaviour in light of their subsequent } \\
\text { events, i.e. the interpretations are not } \\
\text { contemporaneous with the actual events. }\end{array}$ \\
\hline & $\begin{array}{l}4 \text { The roots and causes of the end state } \\
\text { may be multiple, diverse, complex, } \\
\text { unidentified and unstraightforward to } \\
\text { unravel. }\end{array}$ \\
\hline & $\begin{array}{l}5 \text { Simple causality is unlikely. } \\
\text { confirmable. }\end{array}$ \\
\hline & It is difficult to separate real from \\
\hline & perceived or putative causes. \\
\hline
\end{tabular}

Although these authors did not provide many positive outcomes of using longitudinal studies, Cohen et al. (2000) actually proposed some more strengths of longitudinal studies, such as “(s)eparates real trends from chance occurrence," as well as "enables change to be analyzed at the individual/micro level" (Kasper \& Rose, 2002, p. 77). On the contrary, some weaknesses also presented in Kasper and Rose (2002, p. 77) are the time-consuming nature to conduct longitudinal studies, and also "data, being 
rich at the individual level, are typically complex to analyze." In line with Cohen et al. (2000, 2007) and Kasper and Rose (2002), I believe that conducting longitudinal research favors the exploration of pragmatic development more extensively and in more detail. However, even though Kasper and Rose (2002) state that analyzing such data might be a complex task, it might be richer in detail and allow to identify tendencies which might be more difficult to trace in a cross-sectional study. On the other hand, it is undeniable the fact that exploring pragmatic features longitudinally becomes a timeconsuming task.

All the studies presented in this subsection have been selected to provide a general overview of what has been done in each of the research strands: (1) the pragmatic features under study: speech acts, mostly requests; as well as conversational implicature, and pragmatic markers among others; (2) the research contexts, that is, ESL and EFL; (3) a variety of setting: naturalistic, instructional; (4) in different countries: Japan, Spain, France, United States (US); (5) and different target languages, such as French and Japanese, but a clear predominance of English.

As for content, longitudinal studies have focused on three main research strands, namely comprehension, recognition, and production of pragmatic features. Research on pragmatics comprehension within ILP is concerned with that pragmatic meaning when expressed orally (Garcia, 2004). Research of pragmatic comprehension has tackled mainly two research areas, namely speech acts, and conversational implicature (Garcia, 2004), but also routines and implied meaning. Bouton (1992) studied the development of conversational implicature comprehension on 30 ESL learners via a written multiplechoice questionnaire in which participants would respond to conversational implicatures represented in 33 scenarios. Results showed that learners found difficult situations such as "Is the Pope catholic?" question, but attained a native-like proficiency in the rest of 
the implicatures under study. Two years later, Bouton (1994) carried out the same study with a different group of learners and for a shorter period of time: 17 months. Data analysis provided different results from previous research since learners had more difficulties in comprehending implicature, not only with the Pope question, but also with indirect criticism, irony, as well as sequence implicatures. Nearly a decade after, Taguchi undertook a series of studies in which she targeted the comprehension of indirect speech acts. Taguchi (2007) investigated the comprehension of indirect opinions and indirect refusals on a cohort of 92 first language (L1) Japanese students in an EFL setting by means of a computerized pragmatic listening test (PLT) provided twice in the course of seven weeks. Data analysis looked for learners' accuracy and response time on conventional and less conventional meaning. Results showed that positive gains were attained in both aspects. In turn, Taguchi (2008c) also explored these same pragmatic components, namely accuracy and response time, on $44 \mathrm{~L} 1$ Japanese learners of English in a second language context during the course of four months. Data was collected via the aforementioned PLT, together with a "lexical item test" and la "language contact test" (p. 33). Results showed even though no gains were demonstrated in learners' pragmatics accuracy, they did improve their comprehension, as shown in shorter response times.

Some general conclusions can be drawn from the results obtained in the aforementioned studies. Those conventional meanings that are culture-specific will be more difficult to comprehend, while conventional implicatures that are more universal, in the sense that the meaning is shared by more cultures, will be easier to understand. In turn, these results are related to accuracy and comprehension speed. The more difficult a conversational implicature is, the more response time a learner will need to process all contextual and linguistic cues related to it; and this may also affect production accuracy, 
which deals with the correctness and appropriateness of learners' responses.

Conversely, the easier an implicature is, the less time a learner will need to both understand its meaning and also provide an accurate response to it.

In turn, longitudinal studies on recognition of pragmatic features differentiate themselves form comprehension ones in that comprehension studies tackle learners' “inferential skills and recognition of speakers' intentions" (Taguchi, 2012, p. 35); and recognition studies imply the recognition of linguistic features (pragmalinguistics) and the contextual factors adhered to them (sociopragmatics) (Taguchi, 2012). Some examples of longitudinal studies tapping on learners' pragmatic recognition are Kinginger and Blatter (2008) and Matsumura (2007). Kinginger and Blattner (2008) studied the development of both French colloquial phrases and personal pronouns in a group of 17 American learners of French in a second language context for 15 weeks, although focus was directed to three case studies. Data were collected by means of an interview on language awareness. Results from data analysis show (1) positive development of sociopragmatic knowledge and variation; and (2) language use according to that knowledge gain may depend on learners' identities as well as their social interactions in the French context. Matsumura (2007) explored the effect of study abroad (SA) on a cohort of 15 L1 Japanese EFL learners' production of the speech act of advice. Data were collected three times after students came back from their stay, namely every six months in the course of one-and-a-half years, by using the same multiple-choice questionnaire in which a series of situations were provided tackling on different social status: equal, lower and higher. Results showed that L1 transfer appeared in those situations to which they had to interact with people having a higher status than theirs. On the other hand, L2 pragmatics information related to equal-status 
and lower-status situations was maintained and used, since participants in this study kept in touch with friends they made in Canada.

Finally, longitudinal studies exploring the production of pragmatic features entail the ability to produce any pragmatic feature taking into consideration both the pragmalinguistic and sociopragmatic resources needed for that linguistic production; as well as the need to have a solid knowledge of those two resource types to avoid misunderstanding, which occurs when either there is a wrong choice of linguistic features, or the contextual variables are understood inaccurately (Taguchi, 2012). Additionally, this author claims that the act of processing a pragmatic feature before producing it takes a more thorough processing effort than comprehending or recognizing it. Therefore, the importance of having an ample command of the TL pragmatics system is paramount. Three studies have been selected to exemplify these claims. Alcón-Soler (2015a, 2015b) conducted a series of studies in which she examined learners' production of lexical and syntactical request mitigators in email interaction taking into account the effects of both instruction and SA. The emails exchanged between 60 L1 Spanish EFL learners and their instructors were collected at four different points in time. Additionally, learners were instructed to keep a record on their perceptions of instruction and their stay during their time in England. Results show the positive effect of instruction, and the interaction between instruction and SA since instructional effects were perceived after the treatment was implemented only (AlcónSoler, 2015a). Nevertheless, effect of instruction was seen in further email communication, as learners preferred using "accepted patters" in this type of interaction in detriment of request mitigators (Alcón-Soler, 2015b, p. 34).

Martín-Laguna (2015) explored the acquisitional development of both textual and interpersonal pragmatic markers by learners of English in a multilingual classroom at a 
high-school institution in Spain over the course of seven months. More specifically, she aimed at accounting for the learning trajectories, together with possible positive L1 transfer on this particular pragmatic feature. Data were collected from essays written by participants in the three languages they received instruction, namely Spanish, Catalan, and English. Additionally, instructors and participants provided their perceptions of this process so as to account for changes in the learners' pragmatic system. Results showed that learners gained knowledge of textual pragmatic markers were significant in their learning trajectory, but the gained knowledge for interpersonal markers was not significant. Additionally, results provided insight into the role of individual differences, since instructional setting and learners' previous experience affected their learning as well. Moreover, this author could confirm the complex relationship between the three languages as she demonstrated the effect they have among them as regards to pragmatic markers use. With respect to transfer, Martín-Laguna found language transfer (CatalanSpanish) in textual markers, and transfer for all three languages for interpersonal markers. Finally, taking into account the relation between transfer and proficiency level, this author found that more proficient learners transferred knowledge for textual pragmatic markers, and less proficient learners did so for interpersonal pragmatic markers. All in all, this study is a valuable addition to the literature as it explores several research gaps, namely pragmatic learning from a developmental acquisitional perspective targeting high-school multilingual setting, taking into consideration reasons as well as participants' previous language experience that explain learners' learning trajectories.

All in all, whatever goals and target features these studies aim to accomplish and research, they all share one commonality: they depart from merely accounting for the use of pragmatics to address the nature of the changes taking place across time, as 
accounting for both external (contextual) and internal (learner) factors that influence language learning (Bardovi-Harlig, 1999, 2013a; Taguchi \& Roever, 2017).

Due to time and data accessibility constraints, the present dissertation can be classified as neither a cross-sectional nor as a longitudinal piece of research but as a combination of both. This study is cross-sectional in nature because data were collected during one month only, in contrast to longitudinal studies, which are characterized by taking place during a longer period of time, usually several months, such as a full academic year, or even years. Nevertheless, this limitation was compensated by the inclusion of the delayed posttest, thus bringing a longitudinal perspective to this study. Therefore, since data were not collected at just one point in time, the present dissertation gained further and richer data that allowed the observation of the start of the individual and group pragmatic development. 


\subsection{Chapter Summary}

The objective of this chapter was to provide the theoretical framework in which the present study is grounded: SLA more generally, and ILP more specifically. To do so, an overview of the cognitive and social theories that inform SLA research was presented to frame the present investigation. As for cognitive-oriented as well as for socially-driven theories, the essential conditions that drive language learning were discussed (i.e, input, output, feedback, motivation, awareness, communication, interaction), thus presenting a critical perspective on the importance these theories have within SLA but also in relation to pragmatics learning. Skill Acquisition Theory was reviewed in detail since it is the theory employed to support this dissertation. After that, the concept of communicative competence was tackled, by means of discussing the evolution of the conceptualization of communicative competence according to the models proposed in the literature. These are: Chomsky $(1957,1965)$, Hymes $(1967,1972)$, Canale and Swain (1980), Canale (1983), Celce-Muercia et al (1995), Celce Murcia (2007), Bachman (1990), Bachman and Palmer (1996, 2010), Alcón-Soler (2000), and Martínez-Flor and Usó-Juan (2006). This section preceded the third and last section that explored pragmatic competence. First of all, the definitions provided in the literature to conceptualize pragmatics were discussed to better understand this concept. After that, the concept of pragmatic competence, together with its two main components, pragmalinguistics and sociopragmatics, was thoroughly revised. Finally, this chapter ended with the discussion of the nature of ILP, including a working definition, the description of a series of features that characterize the concept of ILP, and a review of the research conducted from a cross-sectional but also from a longitudinal perspective. 



\section{Chapter 2: Teaching Pragmatics}

This second chapter investigates L2 pragmatics instruction. Section 2.1 is devoted to the identification and characterization of instructional treatments in ILP. Section 2.2 entails an in-depth discussion about the effectiveness of providing instructional treatment tackling two main issues, namely 1) instruction provision versus simple exposure; as well as 2) implicit versus explicit instruction. Then, Section 2.3 represents an overview of the research conducted on the target pragmatic features most studied in ILP contexts, with a focus on the pragmatic feature under investigation in the present dissertation: conventional expressions. Finally, the Chapter Summary encompasses the main issues raised in this chapter.

\subsection{Pragmatic Instruction}

The question whether pragmatics is teachable (e.g., Kasper, 2001; Long, 1983; Norris \& Ortega, 2000, 2001; Rose, 2005) has shaped the field of ILP as far back as the 1980s, where the pivotal role of sociolinguistic abilities was acknowledged. The research scope broadened from just investigating L2 morpho-syntactic features and started exploring phenomena related to sociolinguistic skills (Holmes \& Brown, 1987). Research has shown that pragmatics is indeed teachable (e.g., Bardovi-Harlig \& Griffin, 2005; Ellis, 2005; Rose, 2005; Rose \& Kasper, 2001; Norris \& Ortega, 2000, 2001; Taguchi, 2015a, $2015 b)$. In the early years of the study of the effects of instruction on pragmatics, this question was posted since it was uncertain whether instruction would entail major benefits for the learners compared to the lack of provision of notions of rules governing an L2. One of the main reasons that supports the statement that pragmatics is teachable is the fact that instructional treatments provide students with opportunities to realize and acknowledge the language features that are different or similar in their L1 and the L2 they are learning (Kondo, 2008; Yamashita, 2008). Furthermore, since the publication 
of the first major instructional study (i.e., Wildner-Basset, 1984), instruction in pragmatics has been of outmost importance in the field of ILP (Taguchi \& Roever, 2017). Taking into consideration the fact that ILP explores "learners' use and acquisition of L2 pragmatic ability” (Rose \& Kasper, 2001, p. 3) as it has been discussed in Chapter 1, it sets the case for the provision of instruction in L2 pragmatics to assist learners in becoming competent users of a given L2. In that process, it is essential to learn "the rules and mechanisms underlying appropriate use" of a given L2 to acquire that language (Scarcella, 1979, p. 275). In turn, instructors' role is of outmost importance in the learners' process of acquiring L2 rules of language use, due to the fact that it is critical to provide them with instances in which learners think over their selection of specific linguistic features and compare them to their L2 counterparts, to finally practice them all in an on-site classroom context (Siegal, 1996).

The core statement that teaching pragmatics is essential is yet supported and reinforced in the $21^{\text {st }}$ century (e.g., Bardovi-Harlig, 2015, 2018a), as it has been stated that it is paramount to develop pragmatic competence and therefore in the teaching of languages per se due to the fact that pragmatics is present in everyday interactions (i.e., Yamashita, 2008). For the purpose of the present investigation, Yamashita's assertion was adopted as one of the main tenets that determined the design and implementation of this study. Instructional treatment was provided to investigate whether the teaching of a set of conventional expressions allowed a group of students to improve their pragmatic development and, therefore, to become more pragmatically competent in their everyday life conversational encounters.

The concept of pragmatics instruction has been defined as the provision of target language rules either by means of direct explicit illustration of L2 rules and examples to complement such rule provision; or by directing learners to discern and think about 
those rules by themselves, thus reaching the goal implicitly (Kasper, 2001; Taguchi, 2015b). Research reveals that pragmatic pedagogical interventions are essential and effective (O'Keeffe, 2011) in the teaching of EFL and ESL. Thus, since both settings are dissimilar in nature, definitions and features of each context are provided as follows. EFL refers to the teaching of the English language where English is not an official or co-official language. Therefore, this specific context is characterized as offering fewer opportunities for learners to obtain input and also to practice their written and spoken skills. In regards to input, research shows that its authenticity, frequency and variety differ from that ESL settings offer. In other words, input in EFL settings has been revealed to be less authentic, provided less frequently, and less varied (Félix-Brasdefer, 2010). These circumstances make the case for the pivotal provision of pragmatics instruction in EFL context (O'Keeffe, 2011) by means of authentic audiovisual materials, instead of relying solely on pedagogical materials, which research has proven often pictures pragmatics stereotypically misleading (Alcón-Soler, 2005). For example, Martínez-Flor (2005) explored EFL learners' awareness and use of the speech act of suggestions, strongly recommending the employment of instructional treatment to foster learners' pragmatic competence. In contrast to EFL settings, ESL refers to those contexts where English is taught as a second language. This implies that English is either an official or co-official language. In such naturalistic contexts, the availability of input is unquestionably more frequent, authentic, and diverse. Even more, ESL contexts allow learners to use the L2 outside the instructional setting, thus using the L2 for reallife specific purposes (Martínez-Flor, 2013a). In turn, the need to teach pragmatics in ESL settings was made evident a few decades back when an early study claimed that the pragmatics system of NSs and NNSs differed (Bardovi-Harlig \& Dörnyei, 1998). They investigated the grammatical and pragmatic awareness abilities developed by a cohort 
of students in Hungary and the US compared to NSs', and concluded that ESL learners were more sensitive to pragmatic mistakes, which they regarded as more serious in contrast to EFL students, who believed grammatical mistakes were more severe. Therefore, these results showed that being aware of pragmatics is paramount, but not enough to behave pragmatically competent in a given L2. In any case, both EFL and ESL classroom settings share three characteristics that Collins and Muñoz (2016) identified. According to Collins and Muñoz, the language learning space is defined as "a physical space that serves as a learning environment and is bounded in time." Additionally, "it is managed by a facilitator who normally has expertise in the FL and FL pedagogy." Finally, "it is populated by groups of people who share the common purpose of learning/using the target L2 (although their individual learning goals may differ)" (p. 134).

Once ILP studies have been defined, the features that characterize studies in L2 pragmatics are presented. Based on results reported in the literature (Jeon \& Kaya, 2006; Kasper \& Rose, 2002; Norris \& Ortega, 2000, 2001; Plonsky \& Zhuang, 2019; Rose, 2005; Taguchi, 2015b), some commonalities are identified in ILP instructional studies. First, English predominates as the target L2 language to study pragmatics (e.g. Alcón-Soler, 2015a, 2015b; Martín-Laguna \& Alcón-Soler, 2018; Ishihara \& Chiba, 2014; Vellenga, 2011), although pragmatics has also been studied in other languages, such as Japanese (e.g. Narita, 2012), French (e.g. van Compernolle \& Henery, 2014, 2016) and Spanish (i.e. Taguchi, Gomez-Laich, \& Arrufat-Marqués, 2016; van Compernolle, Gomez-Laich, \& Weber, 2016). Taguchi (2015b) makes a strong case to conduct further investigations on the pragmatics of such underrepresented languages to deepen our understanding of pragmatics in general, but also the language-specific pragmatic issues. Many research studies also investigate students at a similar age, 
namely adult college learners (Collins \& Muñoz, 2016). A few exceptions are recent studies conducted on pragmatics learning in children (e.g. Portolés, 2015; Portolés \& Safont, 2018) and high-school learners (e.g. Lyster, 1994; Martín-Laguna, 2015). In turn, proficiency level is also a feature of participants in which an array of the research coincides. Most studies have targeted students with an intermediate level of proficiency, with a few exceptions, such as Safont and Portolés (2016) who explored the effects of instruction on children's pragmatic abilities. The instructional context where data are collected is another recurrent similarity among instructional studies in ILP. Higher-ed institutions are the most common settings with a few studies in primary schools (Portolés, 2015), high schools (Martín-Laguna, 2015), and the workplace (Pérez-Sabater \& Montero-Fleta, 2014). In regards to the pragmatic skill under investigation, production studies outnumber those that focus on comprehension of pragmatic features ${ }^{4}$ (e.g., Garcia, 2004; Safont \& Portolés, 2015; Taguchi, 2005, 2008a, 2008b). Finally, and in relation to research on production and comprehension of L2 pragmatics, research has focused mainly on speech acts, especially requests, as well as on formulaic language, implicatures, and conversational skills. A more detailed discussion on the research conducted on the most frequent target L2 pragmatic features is provided in Section 2.3 in this chapter.

Closely related to the question raised on the teachability of pragmatics is the idea that some features are more easily teachable than others. Research findings reveal that there are several variables that hinder or enhance the teaching of pragmatic realizations. Taguchi (2015b) argued that linguistic simplicity and opaqueness are two characteristics of pragmatic features that might be easier to teach. These are explored separately as follows. As for the structure of pragmatic features, research has shown that the more

\footnotetext{
${ }^{4}$ See Bardovi-Harlig (2001) and Taguchi (2015b) for a review.
} 
complex the structure is, the more difficult it might be to teach. The present investigation is an example since conventional expressions such as Do you have a pen I can borrow? posed more difficulties for students to learn than others such as Excuse me. Even though students were provided with explanations about the meaning of such conventional expressions in context, results obtained may shed light on this issue of linguistic simplicity as it relates to teaching and learning. In turn, the opaqueness of the target pragmatic rules has also been identified as challenging the teachability of pragmatic features. Some features may be more difficult to learn than others because they are less transparent in nature. Several factors may affect this outcome. For example, Kasper and Rose (2002) argued that culture-specificity might pose a greater difficulty in learning pragmatics. Bouton's $(1988,1994)$ well-known studies are an example. Bouton's (1994) students found it difficult to acquire some implicatures (those related to the L2 culture specifically) even after having lived in the US for over 4 years. Therefore, studies such as Bouton's reveal that some pragmatic features might be transferable from learners' L1 culture to their L2's thus being more transparent. However, some other target features may be more opaque since this transferability may not work. This may cause a longer or more difficult learning process. Closely related to the issue of opaqueness is the applicability to everyday language use in the real world. According to Kasper and Rose (2002), if a given pragmatic feature can be directly applicable to a real-life situation, this target pragmatic feature may be more transparent, thus being the learning process of such feature easier because it may be more meaningful. However, if a pragmatic feature is more opaque it may be more difficult to learn because the link between acquiring that knowledge and transferring it into real-life use is less direct. The present dissertation is an example. Results revealed that some students found it more difficult to learn the expression Excuse me because they had 
never used it before in the context in which it was introduced in the present investigation. Excuse me was presented to use in a supermarket situation. Students needed to employ this particular expression to ask for space to pass in an isle.

Two more features that may favor or impede pragmatic learning are length of instructional intervention and learners' proficiency level. As for the former, research has revealed mixed results regarding the definition of what constitutes short or long treatments and the effectiveness of some treatments over others (see Kasper, 2001; Jeon \& Kaya, 2006; Plonsky \& Zhuang, 2019; and Takahashi, 2010 for a review). Similarly, student's proficiency level has also been identified to constrain or enhance pragmatic learning (Taguchi, 2015b). Bardovi-Harlig (2001) stated that greater proficiency in grammatical competence might not translate into the same level of proficiency in pragmatic competence.

All in all, studies in the literature show that the teachability of pragmatics is influenced by many factors, such as context (e.g., EFL versus ESL), learner features, L2 pragmatic features, and/or instructional treatment. This last variable is explored in more depth in the following section.

\subsection{Effectiveness of Pragmatic Instruction}

Teaching L2 pragmatics is undeniably effective. Research reveals that the provision of instruction is more effective than simple exposure (Alcón-Soler, 2005; Alcón-Soler \& Martínez-Flor, 2005, 2008; Bardovi-Harlig, 2001; Cohen, 2008; Ishihara \& Cohen, 2010; Jeon \& Kaya, 2006; Kasper, 2001; Kasper \& Roever, 2005; Kasper \& Rose, 1999, 2002; Long, 1983; O’Keeffe, 2011; Plonsky \& Zhuang, 2019; Roever, 2009; Rose, 2005; Rose \& Kasper, 2001; Schmidt, 1993; Taguchi, 2011a, 2015b; Takahashi, 2010a, 2010b). The present section explores the effectiveness of teaching pragmatics as 
opposed to simple exposure, as well as the effectiveness of the two main teaching approaches used in ILP research, namely explicit and implicit.

\subsubsection{Instruction versus simple exposure.}

According to Kasper (1997, p. 2), “[i]n order to communicate successfully in a target language, pragmatic competence in L2 must be reasonably well developed." To achieve that particular pragmatically-competent state, L2 learners need to be taught pragmatics not only because exposure alone is not enough (Bardovi-Harlig, 2001; Schmidt, 1993), but also because the target pragmatic system and the contextual variables affecting this system might be inadvertent to them even after having been exposed to them for a long period of time (Bardovi-Harlig, 2001; Kasper \& Rose, 2002). Additionally, Kasper (1997) identified four criteria which instruction should target. First, she stated that NSs have been idealized; when in reality NS interaction does not reach perfection. Therefore, NNSs should not be required to obtain those inexistent perfect NS communicative skills, but the same as those skills NSs own. Second, and in line with Siegal (1996), Kasper proposed that NNSs do not generally imitate NSs, but rather create their own interlanguage in which they may tend to develop a different identity from their L1's. Third, and echoing Giles et al. (1991), Kasper proposed an optimal convergence, in contrast to a total convergence, to the TL community culture. Since a total convergence may be seen as an intrusive practice by NSs, who may identify NNSs as "outsider(s)" (p. 12), an optimal convergence allows learners to communicate in a way in which they can express their own thoughts and beliefs by means of specific pragmatic features, which might not coincide with those of NSs'. Finally, Kasper supported Peirce's (1995) claim that views L2 classroom as an environment in which students are allowed to reflect on their own L2 beliefs in relation to their L2 practice. Therefore, Kasper put forward the idea that foreign language instructional settings will 
"prepare and support learners to communicate effectively in L2" (p. 12). Additionally, L2 instruction will not only function as that, "language instruction", but also as "language education" (p. 12). Therefore, these four aims that instruction should attain according to Kasper provide a view of L2 instruction as that which focuses on an L2 learner who uses the L2 in a reflective and critical manner.

Another reason why teaching pragmatics is important refers to the challenges that pragmatics poses for adult learners. Pragmatic development is specially challenging for adult L2 learners since they have both their pragmatics systems from their alreadyacquired L1 and the L2 they are learning (Taguchi, 2015b). This occurs in contrast to L1 acquisition, where children learn their grammatical and pragmatic competences at the same time. Taguchi stated that learners should actively monitor the possible interference of the L1 pragmatic system as they learn the L2 pragmatic system, which they need to acquire "[i]n order to integrate form-function-context relations that are appropriate to L2” (p. 2). Rose and Kasper (2001) stated that learners' knowledge of their L1 pragmatic system may not imply negative consequences since there may occur a positive transfer, or simply no transfer altogether. The reason they provided for such a statement relies on the fact that students of a given L2 may be inclined to favor interpreting the literal meaning rather than making sense of the implied actual meaning, as well as not accounting for contextual factors (Carrell, 1979, 1981). Additionally, Rose and Kasper made a case for the importance of teaching L2 pragmatics when they stated that learners may not put into practice the knowledge they already have in their L1 pragmatic system. Therefore, teaching pragmatics would aim at raising awareness of learners' L1 pragmatic knowledge in order for students to apply that knowledge into L2 pragmatic settings. Bardovi-Harlig (2001) also pointed out to the benefits that L2 pragmatics instruction produces, since she claimed that it promotes L2 acquisition. 
According to Bardovi-Harlig, L2 instruction may facilitate the learning process of certain features of the L2 pragmatic system, which may take longer to acquire without instruction. Taguchi (2011a, 2015b) and Taguchi and Roever (2017), among other researchers, also call for the critical role of instruction in L2 pragmatics and the inclusion of pragmatics in teaching settings, which they reported to be frequently ignored both in the curricula and assessment. They believed the reasons behind these actions may rely on the fact that neither instructors, nor those who craft and write teaching materials and curricula may have notions of pragmatics; as well as the negative impact that not including pragmatics may bring to assessment.

All in all, research suggests that teaching pragmatics is undoubtedly possible. TL pragmatic performance of L2 learners may differ considerably upon provision of instruction. Moreover, simple exposure is considered not to provide sufficient knowledge of the L2 pragmatic system for students to learn it. Some pragmatic features have been identified as more opaque than others, being thus less easy to notice and learn. All these findings suggest that instruction in L2 pragmatics is needed for L2 learners to develop their pragmatic competence most appropriately (Kasper \& Rose, 2002; Nguyen, Pham \& Pham, 2012). More specifically, L2 pragmatics teaching in EFL contexts is essential (O'Keeffe, 2011). In EFL settings, students should be made aware of the cultural differences to avoid negative transfer, since pragmatic mistakes that L2 learners may make might be perceived as more severe than grammatical mistakes, thus affecting NSs' perceptions of L2 learners. This and other issues will be discussed in the following sub-section of the present chapter devoted to the two main methods employed to teach pragmatics in ILP, namely explicit and implicit approaches. 


\subsubsection{Explicit versus implicit instruction.}

The concept of 'instruction' was defined by Ellis, Loewen, Elder, Erlam, Philp, and Reinders $(2009$, p. 16) as it "implies an attempt to intervene in interlanguage development." In a similar vein, Martínez-Flor (2013a) pointed out that the center of attention in interventional research in ILP are pragmatic features. Additionally, she stated that the classroom is perceived as the context where instruction is focused on pragmatics acquisition, which, in turn, will foster students' pragmatics learning process. According to Martínez-Flor, it is instructional treatment that may enhance learners' comprehension of language usage, as well as the varied array of linguistic options learners can choose from based on the interlocutors and the context with whom they are interacting. There seems to be a consensus in the literature (e.g., Norris and Ortega, 2000, 2001; Ellis et al., 2009; Taguchi, 2015b) that the two most frequently used instructional treatments in ILP are explicit and implicit approaches. According to Ellis and Shintani (2014), the main difference between implicit and explicit teaching is the provision of metapragmatic information in the latter, and allowing learner to selfdiscover the L2 pragmatic feature in the former. Taguchi and Roever (2017, p. 214) stated that this distinction is in line with the studies conducted in SLA, where the distinction between explicit and implicit instruction has been investigated for decades (e.g., Rebuschat, 2015). An explicit intervention generally entails the provision of metapragmatic information as well as the provision of ample chances to practice the TL features. In turn, an implicit intervention broadly implies that learners process the TL pragmatic rules by means of practice, without paying conscious attention to such rules. Nevertheless, even though these two types of treatments have been interpreted as two separate entities, some researchers make the claim that both explicit and implicit approaches should be considered as the two ends of a same continuum (Jeon \& Kaya, 
2006; Taguchi, 2011a; Takahashi, 2010a, 2010b). In a synthesis of general SLA research, Norris and Ortega (2001, p. 173) asserted that instruction in L2 is composed of four elements, namely the "presentation of rules, provision of negative feedback, exposure to relevant input, and opportunities for practice." According to the findings in their meta-analysis, Norris and Ortega $(2000,2001)$ claimed that these specific elements could be put into practice in instructional treatments in different ways, as well as organized in different fashions in a given treatment, therefore creating distinct teaching approaches. As an example, Taguchi (2015b, p. 17) commented on the idea that the provision of metapragmatic explanation is the main difference between implicit and explicit approaches. Nevertheless, studies using an implicit instructional design could go from extremely implicit, exposing learners to input, to a somewhat explicit point in the continuum within the implicit section, which would entail the combination of input enhancement with consciousness-raising activities. Both teaching approaches, explicit and implicit, are discussed in what follows, including a definition, features, and studies conducted in each of them. The focus will be on implicit treatments first, and on explicit instructional intervention afterwards.

\section{Implicit instruction}

As mentioned before, implicit teaching in ILP does neither provide explicit information about the rules behind L2 pragmatic use, nor about the TL pragmatic features under study. Instead, implicit instruction involves learners' practice of the TL features without being aware about their actual learning process, and while being engaged in that process, they are able to detect, deduce, reflect, and ultimately learn the target pragmatic characteristic and the rules that govern such feature by themselves (DeKeyser, 1995; Ellis et al., 2009; Taguchi, 2015b; Taguchi \& Roever, 2017). 
An implicit approach is characterized by the use of particular techniques that present TL pragmatic features differently, namely input enhancement, consciousnessraising activities, and indirect feedback, such as for example in the form of recasts (Taguchi, 2015b). According to Martínez-Flor (2013a), input enhancement can be implemented in many different ways, such as the use of bold and italics, but it can also be accomplished by underscoring text, or with input flood, which entails the vast provision of a given TL item to practice and work on (Taguchi \& Roever, 2017). As for indirect feedback, Martínez-Flor (2013a) reported that recasts aim to make a given L2 element salient to learners so that they pay attention to it, but leaving aside the provision of explicit information about that element in the process. Finally, another technique used in implicit teaching is the consciousness-raising approach. According to Rose (1994, p. 7), the consciousness-raising approach strives to make learners aware of the existence of variability in language use as well as variables that affect and define such variability. Additionally, Ellis (1994) stated that students' production of L2 pragmatic features is not required while performing consciousness-raising activities. Instead, Ellis claimed that these types of activities should aim for learners' comprehension of the given L2 pragmatic feature only, thus allowing students to create some sort of mental image of the ways it is used in the TL. Rose (1994) suggested the use of video in EFL settings as an example of an activity to raise students' consciousness on L2 pragmatics, although he also acknowledged that the language used in videos is scripted and thus not totally real-life language. Nevertheless, for EFL learners, it will be the closest to reallife language use they will get. According to Rose, the goal of the consciousness-raising approach is to sensitize students about core features inherent of pragmatics, as they may be able to put such features into practice in different real-life contexts as they become more proficient. Taguchi and Roever (2017) argued that the techniques employed in 
implicit instruction can be placed in terms of a continuum. On one end, we can find techniques that aim to direct students' attention more directly to a given L2 element, such as input enhancement, i.e., the use of bolt, italics, or underscore. On the other end, we can find techniques which aim for the student to be responsible for the noticing of that L2 element, as for example with the use of feedback, i.e., recasts. Finally, the most implicit technique would imply simply the provision of input, such as in the form of input flood. Figure 5 below represents the techniques used in implicit teaching along that continuum.

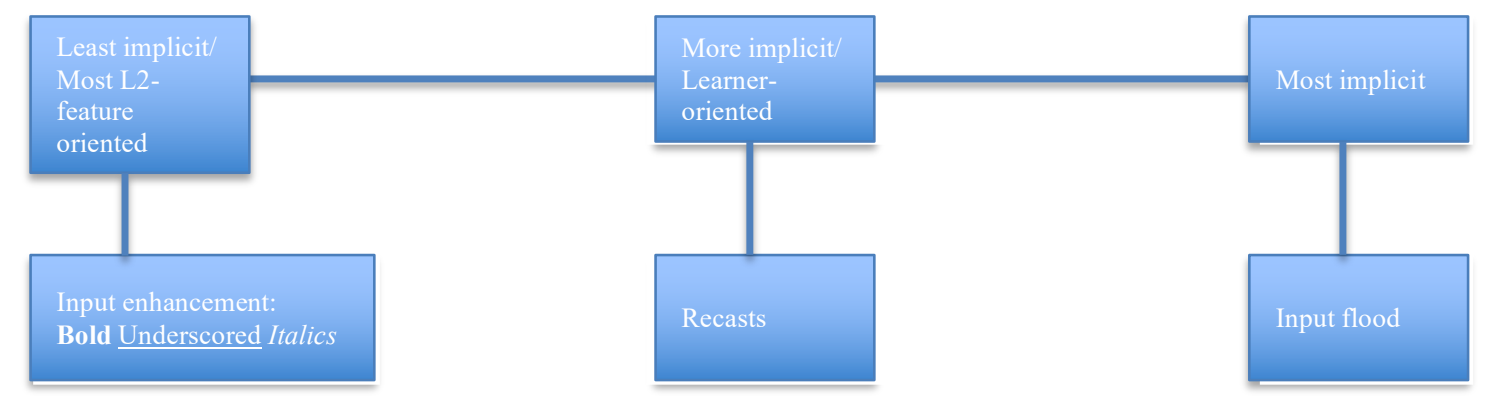

Figure 5. Implicit instruction techniques

The techniques aforementioned have been used in the literature to teach ILP in opposition to explicit instruction, which literature has shown tends to be more effective than its implicit counterpart (i.e., Jeon \& Kaya, 2006; Plonsky \& Zhuang, 2019; Takahashi, 2010). Several studies have proven the effectiveness of implementing implicit treatments over explicit ones. Some of them are illustrated as follows.

Consciousness-raising activities were used in Kubota's (1995) study. Kubota examined the learning process of conversational implicatures by a cohort of 126 Japanese EFL college learners distributed into three groups, and by means of two different treatments during 20 minutes. The first experimental group received explicit instruction via rule provision, whereas the second experimental group received implicit instruction via consciousness-raising activities. Finally, students in the third group 
received no instruction, thus conforming the control group. Results showed the effective nature of instruction over no instruction. As for treatments, the implicit group outperformed the explicit group in the pretest as well as in the first posttest. No significant results were obtained in the delayed posttest.

Regarding research on speech acts, implicit techniques such as input enhancement (Li, 2012; Martínez-Flor, 2006), consciousness-raising activities, as well as feedback, both explicit (Takimoto, 2006) and indirect (recasts) (Fukuya \& Zhang, 2002), have been used to teach a series of different speech acts (i.e., requests, and suggestions) in ILP research. Results suggest the effectiveness of implicit treatments in the teaching of ILP features.

Martínez-Flor (2006) implemented a 16-week instructional treatment to examine 81 university EFL students' production of suggestions in a pretest-posttest design. Instruction was comprised in 6 two-hour sessions. Learners were divided into three groups, two experimental and one control. The explicit treatment group worked first on the suggestion situations presented in a video featuring conversations among American NSs with varying degrees of social status and different settings. After that, learners in this group received metapragmatic information about the sociopragmatic rules and pragmalinguistic forms of suggestions. Instruction was followed by practice in the form of role-plays. On the other hand, the implicit group worked on the same video as the explicit group, although suggestions were presented to students in bold within captions for each of the situations, thus making use of the input enhancement technique. After that, students practiced such suggestions with role-plays as well and instructors provided them with recasts. Results showed that the two treatment groups performed better than those in the control group. Additionally, both treatment groups proved to be effective. As for the implicit treatment, Martínez-Flor believes that by having combined 
input enhancement and recasts learners were provided with sufficient tools for them to notice and learn the suggestions included in that particular study.

Takimoto (2006) studied the effect of providing feedback in the production of recasts by 45 Japanese EFL learners. Takimoto also designed a pretest-posttest study with three groups, two experimental and one control. As for the experimental, both received implicit instruction. One group received a structured input task, whereas the other received explicit feedback on top of that structured input task. Instruction took place twice a week during two weeks, each session lasting for 40 minutes. The control group received the same amount of instruction, although that time served to help students improve their Test of English for International Communication (TOEIC) scores. Results revealed that instruction was effective, since it fostered students' pragmatic proficiency. However, the provision of explicit negative feedback (either in the form of metalinguistic rule provision or a metalinguistic question eliciting a correct utterance) did not yield significant results, thus meaning that it was not needed for the realization of the structured input task.

Fukuya and Zhang (2002) also worked on requests, but used recasts instead. With a pretest-posttest design, Fukuya and Zhang analyzed the request oral production of 20 Chinese EFL students divided in the experimental and control groups. Both groups engaged in seven instructional sessions each lasting 50 minutes. Students were presented with the same situations in which they practiced the request conventions under study. However, the experimental group received feedback in the form of recasts and control group did not receive any type of feedback. Results from the DCT performed at the posttest session revealed that recasts were effective to teach both pragmatically appropriate as well as grammatically correct requestive elements, in addition to enhancing learners' confidence as they engage in conversation. 
Finally, Li (2012) investigated requests as well, together with requestive supportive moves, but implemented different techniques to make the input more salient to the cohort of 197 primary school Chinese EFL learners that took part in this study. Since Li had access to three intact classes, each class was given a different treatment. One received explicit instruction in the form of metapragmatic information. Another group received implicit instruction in the form of input enhancement. Finally, a third group did not receive any type of instruction but worked with the same input provided to the other two groups and was engaged in meaningful output activities. With a pretestposttest-delayed posttest design, results from the 12-scenario DCT informed that the implicit group performed better than the explicit group, whose production effects did not last as long as the implicit's group.

Results from the studies presented above are a small portion of those which attest that implicit instruction can be as effective as or more than its explicit counterpart to teach an array of pragmatic features in ILP, such as conversational implicature and speech acts. Taguchi (2015b) presents several reasons that explain these findings. First, she echoes results from Fukuya and Zhang (2002) and Narita (2012) since these studies illustrate that pragmatics can be learnt without metapragmatic information being included in a given treatment. Thus, showing the link between these outcomes and Schmidt's $(1993,2001)$ Noticing Hypothesis, which asserts that input will be noticed if attention is being paid to a given form; and this, in turn, will become intake once it is internalized. Second, Taguchi states that for receptive, offline tasks which carry a log cognitive load for the students, implicit treatment may suffice to foster their recognition of the most suitable TL forms. Third, the relationship between the TL feature complexity and learners' cognition may also play a role in such outcomes. Finally, an implicit treatment will be effective whenever it includes activities that allow students to 
focus on pragmatic forms as well as the form-function-context mappings adherent to those L2 pragmatic forms.

Now we turn our attention to explicit instruction. Definitions are provided and the mechanisms that drive this type of intervention are illustrated with some examples of studies using such treatment. Finally, some conclusions are drawn on the use of explicit teaching in ILP research.

\section{Explicit instruction}

According to DeKeyser (1995, p. 437) two conditions are needed for instructional treatment to occur: the provision of rules as well as whether "learners [are] directly asked to attend to particular forms and to try to arrive at metalinguistic generalizations of their own." In a similar vein, Ellis et al. (2009, p. 17) understood explicit instruction as a condition that fosters students to "develop metalinguistic awareness of the rule." They assert this process can be achieved in a deductive or inductive manner. The former implies the explanation of the rule in terms of grammar; whereas the latter entails instructors to provide learners with input and help them as they uncover the rules on their own. Either way, Ellis et al. envisioned explicit teaching as instruction conducted directly. Focusing on the operationalization of metapragmatic information, MartínezFlor (2013b) conceived it as the basic tenet in explicit instruction, which aims to define, categorize, and discuss the L2 pragmatic element under study. According to Taguchi (2015b) and Taguchi and Roever (2017), explicit instruction entails a researcher or instructor providing information about the target L2 sociopragmatic rules and pragmalinguistic forms to the students. Taguchi (2015b) also pointed out the fact that explicit treatment includes metapragmatic explanation in combination with practice, which she highlighted are two properties present in instructional treatments in studies which proved to be more effective. 
Explicit instruction can be operationalized in different ways. In what follows, three of those ways that characterize explicit treatments are explained: awareness raising, metapragmatic information, and variability. The rationale behind the choice of these three elements specifically relies on the fact that these were used in the pedagogical intervention implemented in the present dissertation.

First, as seen before in this chapter, awareness-raising activities have been used to study the effects of implicit instructional treatments in ILP. According to Taguchi and Roever (2017, p. 216), the awareness raising approach can be presented in many ways, by means of different activities. Regardless, the main aim of this approach is for learners to think over the pragmalinguistic forms and sociopragmatic elements that characterize an L2 pragmatic feature. A series of elements are core in this approach, namely examples of the L2 pragmatic component under investigation, and relate these features meaningfully, such as by means of contrasting them to examples of students' L1 use, as well as providing metapragmatic information of the rules. And this is what was done in the present investigation. The instructional treatment attempted at raising students' awareness by means of providing participants with examples of real-life use of conventional expressions accompanied with pictures. Some of those examples involved the infelicitous use of particular conventional expressions that involved L1 negative transfer. Metapragmatic explanations were provided for each of the conventional expressions included in the present study. As Taguchi and Roever (2017) indicated, three variables determine the design of the awareness-raising activities: the L2 pragmatic characteristic, its complexity, as well as the cohort of students participating in the study. Taguchi and Roever proposed the implementation of activities to practice and produce the pragmatic knowledge and to foster students' pragmatic competence so they will be able to use it in the future. In this dissertation, an appropriateness judgment task 
(AJT) and role-plays were designed and implemented as the practice and production activities respectively to enhance participants' pragmatic abilities as regards to conventional expressions.

Second, metapragmatic instruction is another feature by which explicit teaching can be operationalized. Metapragmatic discussion entails the provision of information about the rules that drive L2 pragmatic use and the language features employed to communicate in the L2 (Takimoto, 2012b). It is used to highlight and reinforce the target pragmatic feature (Kasper \& Rose, 2002); and also, to avoid pragmatic failure. According to Takahashi (2010a), the ultimate goal for the provision of metapragmatic information or other particular explicit treatment conditions is to help students develop their L2 pragmatic competence, since it may foster the learning of the form-functioncontext mapping process. Taguchi and Roever (2017, p. 49) echoed this idea, as they asserted that metapragmatic discussion promotes "a deeper level of cognitive processing" since students are required to evaluate and meditate upon the L2 pragmatic rules to express those thoughts verbally afterwards. Kasper (2001) conceived that metapragmatic discussion is enclosed in metapragmatic instruction, and students are expected to participate in a discussion lead by an instructor or also in small groups, about pragmalinguistic features and sociopragmatic elements, together with the links among them, reaching a common interpretation of the rules behind such links (Taguchi \& Roever, 2017). In the present dissertation, metapragmatic discussion took form of a teacher-driven activity, but student discussion was also encouraged. Metapragmatic discussion was included in the explicit instruction implemented in this study to 1) help students develop their pragmatic competence; as well as to 2) foster their critical thinking about the similarities and differences between the use of conventional 
expressions in their L1(s) and their L2; and finally 3) to avoid pragmatic failure, which is dealt with as follows.

Pragmatic failure refers to the "inability to convey or comprehend intended and/or appropriate meanings in context” (Culpeper, Mackey, \& Taguchi, 2018, p. 208). Ishihara and Cohen (2010, p. 77) identified five reasons that may trigger pragmatic failure, and categorized them according to whether the speaker is willing to diverge from the target pragmatic norms or not. On the one hand, if that divergence is involuntary, Ishihara and Cohen attributed it to four different sources. First, pragmatic failure may be due to "negative transfer of pragmatic norms," that being students' L1 or learners making an uneducated guess of other L2 speakers' production. Second, "limited grammatical ability in the L2" may also result in miscommunication, that is, communicative acts where speakers do not reach a mutual understanding. As BardoviHarlig (2001) pointed out, pragmatic competence and grammatical competence do not go hand in hand. Therefore, even if students have a good command of the TL pragmatic competence, they can still experience pragmatic failure if their grammatical competence is not as developed (Ishihara \& Cohen, 2010). Third, "overgeneralization of perceived L2 pragmatic norms" may result in the creation of stereotypes affecting the TL community, disregarding the L2 "social, geographical, and situational variation". Finally, the "effect of instruction or instructional materials" could also play a role in pragmatic failure. According to Ishihara and Cohen, the solely responsible for this unfortunate result is the instructional treatment or the instructional materials in this case, which may provide erroneous generalizations about a given target form, or even be made simple to meet students' proficiency level. On the other hand, when there is intentional divergence, the learner shows "resistance to using perceived L2 pragmatic 
norms" and this may be explained in terms of learners opposing to converge to the TL social and cultural norms, and keep their L1's instead to maintain their identity.

Finally, pragmatic variability is another feature that can characterize explicit instruction in ILP. The term 'pragmatic variability' (e.g., Beeching and Woodfield, 2015) has been selected instead of 'pragmatic variation' because it is the former concept that captures the complexity that exists in linguistic variability depending on (1) contextual features, (2) the relation between these and social interactions, as well as (3) individual and community choosing of particular linguistic forms. As Beeching and Woodfield (2015, p. 1) summed up, "the selection of particular linguistic forms in different situations is dynamic, not fixed and immutable."

According to Félix-Brasdefer and Koike (2012), variability from a sociolinguistic perspective has studied particular linguistic domains, such as phonology, morphology, and syntax for many decades now, with studies led by Labov (1972a, 1972b, 1994, 2006) or Silva-Corvalán (2001) among others. However, research on variability at the pragmatic level has received less attention. Variability in pragmatics has been discussed from a sociolinguistic viewpoint (e.g., Félix-Brasdefer \& Koike, 2012; Geeslin \& Long, 2014; Wolfram \& Schilling, 2015). Wolfram and Schilling (2015), in their work on regional variability in pragmatics, stated that the same purpose can be obtained by means of using different linguistic features, which are available "in every language variety" (p. 86), and the linguistic choice made to utter an idea will be determined by the other interlocutors and the contextual situation where the conversation takes place. Even though variability was considered from a teaching perspective in the present study, Wolfram and Schilling's statement may also apply for the operationalization of pragmatic variability in this study. Additionally, Félix-Brasdefer and Koike (2012), when comparing variability in pragmatics to that of syntax and phonology and 
morphology, stated that variability in pragmatics is more intricate because one single form may imply many different meanings. Therefore, the one-to-one correspondence may not apply in all cases for pragmatics (Taguchi, 2015b), as it may apply in other linguistic domains. Additionally, Félix-Brasdefer and Koike maintained that the ways social meaning is constructed is also a phenomenon that pragmatic variability takes into consideration. It is in this interactional activity where meaning is constructed that several features of language users come to play, such as their gender, ethnicity, age, or social class. For the present investigation, Beeching and Woodfield's (2015) perspective on variability was adopted, in the sense that it may explore target pragmatic features from a methodological perspective. The reason behind this decision relies on the fact that it is critical to include variability in pragmatics teaching. That is, providing learners with as many linguistic forms as possible that perform the same pragmatic situation is essential. Initially, the target conventional expressions forms were selected based on the categorization by Bardovi-Harlig $(2008,2009,2012 a)$ regarding the difficulty of acquisition of the form. At first, the canonical expression that fulfills that pragmatic expression was selected. Nevertheless, there exist a wide variety of expressions that fulfill the same purpose. With this in mind, while coding participants' responses, some forms were found that were not exactly the target form. However, they fulfilled the same pragmatic purpose. Therefore, they were counted as correct instances. Additionally, they were also counted as correct because participants used them in the appropriate pragmatic context, therefore showing that they have the appropriate linguistic knowledge required. It was an equivalent form correctly used with the pragmatic context they provided.

The following studies are included to provide examples of how techniques within explicit instruction are understood and employed, such as a combination of instruction 
and metapragmatic discussion or feedback (Alcón-Soler, 2005; Alcón-Soler \& GuzmánPitarch, 2010; Eslami-Rasekh, Eslami-Rasekh, \& Fatahi, 2014), the use of role-plays as a means of meaningful practice in oral mode (Eslami-Rasekh, et al., 2014; Fukuya \& Martínez-Flor, 2008), or consciousness-raising activities (Alcón-Soler, 2005; Fukuya \& Martínez-Flor, 2008). Results from these studies reveal the paramount and indisputable role of explicit treatments in the teaching of ILP.

Alcón-Soler (2005) explored the effectiveness of explicit and implicit instruction on EFL learners' use of direct, conventionally indirect, and non-conventionally indirect requests. Data were collected from 132 EFL high school learners, who were divided into an explicit instruction, implicit instruction, and control group, at pretest and posttest sessions. Instruction to both groups was provided sequentially. The explicit group viewed a series of excerpts from the TV show Stargate first, and then worked on the scripted version of such excerpts in the form of consciousness-raising activities and DCTs. Finally, students were provided with the answers as well as written metapragmatic feedback with explanation of pragmalinguistic and sociopragmatic issues related to the requests being used. The implicit group viewed the same clips as the explicit group. However, the requests appearing in the script were bold-faced. Practice entailed implicit consciousness-raising activities, and DCTs. Feedback given to students' production entailed the possible solutions for the activities, but no feedback was included. Finally, the control group worked on comprehension questions and selfcorrection after watching the same video clips. Results showed that instruction was indeed effective, and that the explicit treatment group outperformed the other two groups.

Alcón-Soler and Guzmán-Pitarch (2010) used metapragmatic instruction in the form of explaining both pragmalinguistic forms and sociopragmatic factors as they 
explored refusals in a university EFL classroom. 92 learners participated in this study that lasted for six weeks. Instruction was implemented once a week for two hours by means of a pedagogical model that was comprised of four steps, namely "identifying refusals in interaction," "Explaining the speech act set," "Noticing and understanding refusal sequences," and "Exploring learners' use of refusals" (p. 69). Results obtained from the pretest and posttest revealed that explicit instruction was beneficial, since learners were able to improve their recognition and awareness of the refusal features under study.

Eslami-Rasekh et al. (2014) examined the effects of instruction to test 66 Iranian EFL college students' comprehension of requests, apologies, and complaints in a pretest-posttest design with an experimental and control groups. Instruction lasted for twelve 30-minute sessions, and it was included within the regular teaching sessions for each class, which lasted two hours each. Explicit instruction included metapragmatic discussion of pragmalinguistic features and sociopragmatic forms first as a teacher-led approach. After that, students were distributed in groups and asked to think about specific situations in which speech act production was different in their L1 and L2. Oral practice came next in the form of role-play, in which students practiced the three speech acts under study, and the teacher provided feedback for those instances in which students' production deviated from the target features. Then, students completed a DCT. Finally, they were asked to identify a series of strategies used to request, apologize, and complain used by NSs, and to compare those with their own strategies, in a written task. On the other hand, the control group did not receive metapragmatic information, but followed the course syllabus. Results revealed the improvement in students' pragmatic competence, since explicit metapragmatic instruction enhanced learners' comprehension of the speech acts of apologies, requests, and complaints. 
Fukuya and Martínez-Flor (2008) investigated the speech act of suggestion in a cohort of Spanish EFL learners by means of implicit and explicit instruction. Fukuya and Martínez-Flor tested students' production skills by means of two different tasks, an email and a phone conversation, in which 16 situations were provided targeting different suggestion structures and including different levels in terms of power, social distance, and degree of imposition. Learners were divided into two groups, the explicit and the implicit. Both received the same amount of instruction: six two-hour sessions during 16 weeks. The explicit group received instruction on sociopragmatics and pragmalinguistic features by means of audiovisual materials, as well as a table in which the head acts and downgraders were included. Emphasis was placed on both grammatical and pragmatic accuracy. A sequential instructional treatment was applied in this group, with consciousness-raising activities first which led to oral production, namely role-plays. In turn, the implicit group received input enhancement while they viewed the same videos as the explicit group did; and recasts in role-play production. Results showed that the explicit group performed significantly better than the implicit one in the phone activity, but not in the email one, where both treatment groups performed equally.

These studies are a few examples of the vast research available in the literature that illustrates the unquestionable effect of explicit instruction (e.g., Taguchi, 2015b), mostly when metapragmatic discussion and opportunities for meaningful practice are included (e.g., Alcón-Soler \& Martínez-Flor, 2005; Jeon \& Kaya, 2006; Norris \& Ortega, 2000).

To conclude, the two main teaching approaches to pragmatics have been reviewed: on one hand, implicit treatment, which is characterized by allowing learners to discern the TL pragmatic rules on their own, helping them by means of indirect 
techniques such as input enhancement or recasts. On the other hand, explicit instruction, mainly characterized by the provision of metapragmatic discussion together with meaningful practice. Most importantly, research findings may not be generalizable since there seems to be three trends of studies in instructional ILP. On the debate about explicit and implicit approaches to teaching pragmatics, there are still many studies that assert explicit treatment to be more beneficial for students, enabling them to further develop their pragmatic competence (e.g., Alcón, 2005; Alcón-Soler \& GuzmánPitarch, 2010; Barraja-Rohan, 2011; Codina-Espurz, 2008, 2013; Cohen \& Taron, 1994; Eslami-Rasekh et al., 2004; Fordyce, 2014; Fernández-Guerra, 2008, 2013; Fukuya \& Martínez-Flor, 2008; Martínez-Flor \& Fukuya, 2005; Nguyen et al., 2012; SalazarCampillo, 2008, 2013; Wildner-Basset, 1984, 1986). However, the advantage of explicit instruction is not so clear with interventional studies in which both explicit and implicit treatments are employed. In these studies, results are not homogeneous. Some studies provide evidence that both treatments are equally effective, whereas others report implicit treatment to be more beneficial than explicit treatment (e.g., Alcón-Soler, 2005, 2007; Fukuya \& Martínez-Flor, 2008; Koike \& Pearson, 2005; Kubota, 1995; Li, 2012; Martínez-Flor, 2006; Martínez-Flor \& Alcón-Soler, 2007; Takimoto, 2006, 2007). Finally, there are other studies that have found instruction ineffective (e.g., House, 1996). On the effectiveness of explicit and implicit instruction, I agree with Taguchi (2011a) in that the two types of treatment can be understood as the two ends of a continuum rather than two different and opposing types of teaching methods. Taguchi explains that approaching one end or the other will depend on what may be more beneficial for students in particular contexts. 


\subsection{Instruction-targeted Pragmatic Features}

In the present section, a selection of the studies conducted in EFL classroom-research pragmatics is reviewed. Bardovi-Harlig and Mahan-Taylor (2003) asserted the need to teach pragmatics in the classroom together with the benefits that can be achieved from such instruction. Moreover, Bardovi-Harlig and Mahan-Taylor claimed that the learning environment, the classroom, is suitable for pragmatics teaching as it is in this context where pragmatics can be tackled and pragmatic failure avoided. As reviewed earlier in this chapter, and according to Eslami and Eslami-Rasekh (2008, p. 179), EFL settings are believed to be "impoverished L2 contexts" due to the fact that learners have restricted access to both input and chances to put into practice their knowledge about pragmatics, due to "large classes, (and) limited contact hours" compared to ESL settings, in which the target language is (one of) the official language(s) spoken in that country (Martínez-Flor, 2013a). Martínez-Flor and Usó-Juan (2006, p. 43) echoed this fact, since they believe that the restricted availability of authentic L2 pragmatic input may bring insufficient opportunities to practice the L2. Therefore, Martínez-Flor and Usó-Juan called for the inclusion of pragmatic competence in EFL contexts.

As it was introduced in section 2.1 in this chapter, ILP research shows that studies have been conducted in three particular domains, namely speech acts, conversational skills (e.g. Narita, 2012; van Compernolle, 2011), and routine formulae (e.g., Kasper \& Rose, 2002; Taguchi, 2015b; Taguchi \& Roever, 2017). The review of the selected literature in this section follows focuses on speech acts and routine formulae.

Speech acts have been the L2 pragmatic feature that has been explored the most. The speech act of requests has been investigated most frequently. Other speech acts, which have not been examined as widely as requests, are suggestions, refusals, apologies, compliments, and complaints. In the study of speech acts in general, 
Martínez-Flor and Usó-Juan (2010) claimed that three conditions are essential to learn speech acts: input, output, and feedback. Students should be presented with input they can comprehend and make use of afterwards, be given opportunities to practice the input by means of communicative activities, and lastly be provided with feedback. Literature in speech acts suggests that they are all learnable (e.g., Alcón-Soler, 2008; Martí-Arnándiz \& Salazar-Campillo, 2013; Martínez-Flor \& Usó-Juan, 2010) even though some differences may arise concerning the pace and difficulty of such learning process, as it may be related to students' proficiency level, as well as the learning context (e.g.: EFL classroom, study abroad). For example, a great command of pragmatic competence is needed to perform refusals successfully (Martí-Arnándiz \& Salazar-Campillo, 2013). In this subsection, a few studies on requests and refusals are included to attest to the major presence of studies on speech acts in the field of ILP.

As for requests, Safont (2005) explored the role of instruction and bilingualism, together with the effects of proficiency level and tasks in the identification and production of the speech act of requests. Data were collected from 160 university students aged between 19 and 22 in a public university in Eastern Spain enrolled in two different Degrees. Half of the sample studied Industrial Design Technical Engineering, and the other half did so at the Primary Teacher Education Degree. Data were collected by means of a pretest, posttest design during Spring 2000. Different data collection methods were used. First, a language proficiency test was passed to determine students' proficiency level. Likewise, a bilingualism test was administered so as to identify students' degree of bilingual competence. After that, the pretest was administered. DCT 1 and Discourse-evaluation test 1 were administered, which was followed by the instructional treatment. Finally, DCT 2 and discourse-evaluation 2 were distributed. Data collection finalized with the implementation of the posttest. Three research 
questions guided this study. All three research questions were related to instruction. However, the first two dealt with the effect of instruction towards the speech act, and research question (RQ) 3 inquired about the effect of instruction on bilingual and monolingual production. RQ1 posited whether instruction would foster learners' use of mitigating devices; and RQ2 investigated whether the use if such devices would increase as instruction advanced. RQ3 asked whether instruction would bring about a change in performance in the monolingual and bilingual groups. Results supported all three research questions in favor of the positive effect of explicit instruction.

More recently, Portolés and Safont (2018) conducted a study in which they investigated 127 children's comprehension and use of requests in a multilingual classroom. They used elicited and naturally occurring data. The former was a pragmatic comprehension test in the form of an audiovisual clip in which puppets interacted using direct and conventionally indirect requests. The latter entailed the recording of children's discourse in the classroom, which was later transcribed and analyzed. Since this study took place in a multilingual environment, the other languages children spoke were also taken into consideration, namely Spanish, Catalan, Romanian, and Arabic. Results obtained encourage further studies to include all languages students speak to obtain a more complete and comprehensive picture of the students' pragmatic competence.

As shown in articles above, the examination of requests has been tackled in students of different group ages, such as children (Portolés \& Safont, 2018) and adult learners (Safont, 2005). The positive outcomes found in Safont (2005) attest to the effectiveness of instruction, and Portolés and Safont (2018) call for the need to look closely into further languages students may know because they may also inform on students' practice competence. 
Regarding studies on refusals, Usó-Juan (2013) explored the effects of explicit instruction by means of metapragmatic explanations on refusals. A cohort of $10 \mathrm{EFL}$ students participated in a pretest-posttest study which included a three-session instructional treatment. Instruction was provided by means of the 6Rs approach (Martínez-Flor \& Usó-Juan, 2006). Each of the three sessions encompassed two of the six steps in the 6Rs approach, starting from "Researching," then moving on to "Reflecting," "Receiving," "Reasoning," "Rehearsing," to finish with "Revising." Each of the steps paralleled with either a technique or an activity. For example, the three first steps dealt with focusing on pragmatic and refusals, Spanish, and English refusals. Then steps 4 and 5 were awareness activities and oral production activities respectively. Finally, step 6 was peer feedback. She found that the instructional treatment was advantageous. Findings from the interactive written DCT in the posttest revealed that the 6Rs approach proved beneficial for students to develop their production of refusals.

Codina-Espurz (2013) observed the effect that proficiency level may have in writing refusals. Students represented 100 undergraduate EFL Spanish students majoring either in Education or English Philology at a university in Eastern Spain. Students were initially classified into four distinct groups once results were obtained from administering the Quick Placement Test (Oxford University). The original sample of 193 students was reduced to 100 so as to have an equal number of participants. Those four groups ranged from $\mathrm{Al}$ to $\mathrm{B} 2$, which refer to beginner to upper intermediate according to their proficiency level based on the CEFR. Students' pragmatic competence was measured with a Written DCT (WDCT), in which they had to write a series of refusals in response to nine different scenarios. Results from a mixed-method approach revealed that beginner learners outperformed those with higher proficiency levels as for direct strategies, but not for indirect strategies or adjuncts. Codina-Espurz 
claims this finding may be related to age and L1 transfer factors. Additionally, it was found that more proficient students preferred using indirect strategies. Results revealed that students generally tended to employ two particular strategies, namely expressing some regret because they were not able to fulfill a request, and giving an excuse for that very same reason.

Findings from these two studies provide further evidence that supports the paramount role of 1) instructional treatment in learning refusals (Usó-Juan, 2013), together with 2) the importance of considering the effect of students' proficiency level (Codina-Espurz, 2013) when studying EFL learners' pragmatic competence.

The sample of studies included above corroborate the vast literature that exists on speech acts in ILP, highlighting the importance of instruction as well as other variables, such as proficiency level or knowledge of further languages, which all influence in the development of students' pragmatic competence.

Finally, according to Taguchi (2015b) routine formulae are the second pragmatic features that have received most attention in the literature. One type of routine formulae is gambits, which are expressions that govern the interactional flow in conversation (e.g., Wilder-Bassett, 1984, 1986) are examples of research in gambits in German. Another example of routine formulae is conventional expressions, which will be discussed in depth in Chapter 4, as they are the pragmatic feature under study in the present dissertation. 


\subsection{Chapter Summary}

The objective of this chapter was to examine the research conducted in ILP based on three basic questions. First of all, the question of whether pragmatics is teachable was entertained, defining the concept of pragmatics and explaining the features that characterize ILP studies, and, together with the research reviewed, allowed confirmation that pragmatics can indeed be taught. Additionally, the issue whether some pragmatic features are more amenable to instruction was also covered, together with the debate on the length of instructional treatment as well as learners' proficiency level, which all affect and play a role in the outcome of pragmatics teaching. Once the first question was answered, yes, pragmatics is teachable, the discussion moved on to the second and related question. As for whether instruction provision is more effective than simple exposure, research has shown that exposure alone is not enough and that some sort of pragmatic instruction is needed to foster pragmatic learning. Then, the third question dealt with how pragmatics can be taught most effectively. In this subsection, the two approaches most used to teach pragmatics in ILP were discussed in depth, namely implicit and explicit instruction. Definitions, characteristics, and examples of studies were provided to illustrate both implicit and explicit instruction. Research shows inconclusive results on this third question. On the one hand, there are many studies call

for the higher effectiveness of teaching pragmatics explicitly, whereas a smaller body of research states that implicit teaching proved more effective than the explicit counterpart. Finally, some other studies stated that both types of instructional treatments were equally effective. Finally, an overview of the research conducted in EFL classroom pragmatic research was included. Studies that explored speech acts, and routine formulae were dealt with to illustrate the exploration of a wide array of pragmatic features in different EFL classroom contexts. Most importantly, this section aimed at 
Chapter 2: Teaching Pragmatics

reflecting on the importance to teach pragmatics in the EFL context, where opportunities to practice the L2 tend to be limited, and to help students develop their pragmatic competence so as to become competent users of the L2. 


\section{Chapter 3: Attitudes in Language Learning}

The present chapter explores the nature of language attitudes in relation to L2 pragmatics, since, as research shows, language attitudes constitute a central component that influence L2 language learning. To better understand the role language attitudes play in the acquisition of the L2 pragmatic system, Section 3.1 provides a general understanding of what language attitudes are. Afterwards, Section 3.2 reviews the techniques devised to measure language attitudes, and the research carried out in EFL settings similar to the one in which the present dissertation was conducted to provide the rationale for the present investigation. Finally, the main highlights in Chapter 3 are presented in the Chapter Summary.

\subsection{Language Attitudes: A Definition}

Language attitudes make an imprint in our everyday conversations, whether conscious or unconsciously. The study of language attitudes is worth being investigated for several reasons, such as: 1) Speakers of any language may not even verbalize those attitudes. However, they are present in our communicative acts daily (Garrett, 2010). 2) Additionally, language attitudes are part of learners' communicative competence (Davies, 1995). 3) As research has shown, sometimes learners' reports of their rather positive attitudes to languages do not coincide with their behaviors towards those languages (e.g., LoCastro, 2001; Maietta, 1996).

The lack of agreement in defining language attitudes (Edwards, 1994) may bring difficulties in the actual framing of defining what constitutes language attitudes. McKenzie (2010, p. 19) stated that such disagreement in social psychology is rooted in a terminology issue, since the term 'attitude' tends to overlap with a few others, such as “"belief', 'opinion', 'value', 'habit', 'trait', 'motive'i and 'ideology'.” 
Research on attitudes emerged from studies in social psychology. Scholars such as Allport emphasized their central role in humans' daily actions. According to Allport (1935, p. 810), attitudes are "a mental and neural state of readiness, organized through experience, exerting a directive and dynamic influence upon the individual's response to all objects and situations with which it is related." Attitudes in social psychology aimed to investigate the behaviors of particular groups of language users as well as the behaviors of specific individuals within such groups (Baker, 1992; Gardner \& Lambert, 1972). The study of language attitudes from the social-psychological stance received criticisms mainly from poststructuralist researchers, who claimed that investigating attitudes should consider the social sphere and the active and changing nature of learning and using L2s. According to Pavlenko (2002, p. 282), research on language attitudes should "attempt to investigate and to theorise the role of language in construction and reproduction of social relations, and the role of social dynamics in the process of additional language learning and use." Years later, language attitudes became the center of study in sociolinguistics research. In the present investigation, attitudes are explored from an EFL perspective. Generally speaking, in EFL contexts, language attitudes are targeted towards the English language, which may be positive or negative, favorable or unfavorable. According to Holmes (1992), the language attitudes that speakers may unravel provide an impression they hold towards the speakers of a given L2 as well as towards the environments and purposes related to that specific L2.

As mentioned before, attitudes have been defined differently. For example, Baker (1992, p. 10) identified attitudes as "hypothetical construct(s) used to explain the direction and persistence of human behaviour" and attitudes towards languages as "something an individual has which defines or promotes certain behaviours" (1988, p. 112). Henerson, Morris and Fitz-Gibbon (1987, p. 13) employed the term attitudes 
"broadly to describe all the objects we want to measure that have to do with affect, feelings, values and beliefs." Choi (2003) operationalized attitudes as a "reflection of psychological attitudes about languages that convey the social, cultural and sentimental values of the speakers." Other scholars focused on human beings in their definition of attitudes, identifying a rather active role of people regarding their attitudes. For instance, Giles and Billings (2006, p. 188) perceived language attitudes "as a process of person perception." More elaborately, Bem (1968) stated that speakers of any language undergo an active process of distinguishing their own attitudes to a particular language and therefore make a judgment about whether those attitudes are positive or negative. Hence, it is in that process of self-reflection that speakers build their own attitudes to a given language. Other authors turned their focus of attention to the reactions, the responses that speakers would have towards a given object. Sarnoff (1970, p. 279) proposed that attitudes are "disposition(s) to react favourably or unfavourably to a class of objects.” In line with Sarnoff (1970), Garrett, Coupland, and Williams (2003) took Sarnoff's definition (see above) as the "starting point" to provide their own. They conceptualized attitudes as "evaluative orientation(s) to a social object of some sort, but that, being a 'disposition', an attitude is at least potentially an evaluative stance that is sufficiently stable to allow it to be identified and in some sense measured" (p. 3). Additionally, they pointed out that "'language attitudes' can themselves be stereotyped responses to community-bound ways of speaking, to discourse styles as well as to dialect varieties in the conventional sense" (p. 5). As for the "social object" that they referred to in their definition, Garrett (2010, p. 20) exemplified that the object can be a language or governmental language policies. Similarly, Ajzen (1988, p. 4) provided more details on the nature of such objects, and understands attitudes as "a disposition to respond favourably or unfavourably to an object, person, institution, or event." In a 
similar vein, Cenoz (2004, p. 204) operationalized attitudes as "evaluative reactions towards an object and in the case of language learning they are evaluative reactions towards the activity of learning languages." Cenoz (2009, p. 178) refined her previous definition, referring to that of Ajzen's (1988), as she pointed out that an object could be "a specific language group," and "the activity of learning languages" an event. Finally, Oppenheim (1982) operationalized attitudes as:

a construct, an abstraction which cannot be directly apprehended. It is an inner component of mental life which expresses itself, directly or indirectly, though much more obvious processes as stereotypes, beliefs, verbal statements or reactions, ideas and opinions, selective recall, anger or satisfaction or some other emotion in various other aspects of behaviour ( $\mathrm{p}$. 39).

For the purpose of the present study, three particular definitions have been selected: Sarnoff's (1970), Garrett et al.'s (2003), and Oppenheim's (1982) because it is the combination of the ideas and understanding of the concept of attitudes, that represent the viewpoint of the conceptualization of what attitudes are to the present dissertation. More generally, attitudes are what Sarnoff (1970) said, a tendency to behave positively or negatively towards a series of 'objects,' which, according to Garrett et al. (2003) are social in nature, and which can be identified and measured to a certain extent, despite their dynamic and constantly changing nature. Finally, and more specifically, Oppenheim (1982) identified some of the many facets that attitudes to languages can take, expressed directly or indirectly, verbally or by means of nonlinguistic artifacts. These three conceptualizations mirror the results of the data obtained in the present dissertation. Therefore, and based on the three definitions aforementioned, attitudes are considered in this study as tendencies to respond 
positively or negatively to social linguistic stimuli by means of language, such as verbalizing opinions, and/or the use of gestures and other non-linguistic resources to express such conceptions about the L2 and the L2 users. Since the focus in this study is the cognitive component of attitudes, the tendencies that are referred to above tackle the reactions participants will have towards the English language according to their thoughts and beliefs about this language and its users.

As seen above, language attitudes have been defined in different ways. See Coronel-Molina (2009) for an extensive review of the term 'attitudes'. Nevertheless, research on attitudes has undoubtedly identified their three main components: cognitive, affective, and behavioral.

First, when "beliefs about the world" (Garrett, 2010, p. 23) are projected on an object, attitudes are understood to be cognitive. For example, in the present dissertation, participants' thoughts or beliefs about the English language fall into the cognitive component of language attitudes (i.e., participants thinking that learning more about a given set of conventional expressions will allow them to understand the English language better). Garrett et al. (2003) elaborated that the cognitive side of attitudes may have one main source: "stereotyping in intergroup relations" (p. 3), which in turn triggers two different functions, the 'individual' and the 'collective.' It is those individual and collective levels that tailor the cognitive underpinnings of attitudes to languages. As for the 'individual level', stereotyping brings order into "the complex social world" (p. 3), thus allowing for predictability and practicality. As these authors proposed, society is presented as more 'coherent' if stereotypes are put to work; for example, identifying similar and different traits within and among different language dialects and the people who speak such dialects. In terms of the 'intergroup level,' stereotypes have been shown to perform a crucial role in communicative acts between 
groups (Hewstone \& Giles, 1997). Additionally, stereotypes have two main functions, namely social-explanatory and social-differentiation. On one hand, the 'socialexplanatory function' deals with “the creation and maintenance of group ideologies that explain and defend relations between groups." On the other hand, the 'socialdifferentiation function' tackles "the creation, preservation and enhancement of favourable differentiations between the ingroup and relevant outgroups" (p. 3).

The following article represents an example of the exploration of language attitudes from a cognitive perspective. Santos, Cenoz, and Gorter (2018) investigated the language attitudes towards using the English language in an English-medium instruction (EMI $)^{5}$ context and the anxiety that this context may bring to students. Participants $(N=360)$ represented two groups of undergraduate students enrolled in the Business $(n=180)$ and Education $(n=180)$ degrees at the University of the Basque Country. Data were collected by means of three questionnaires: Background questionnaire, Attitudes questionnaire, and Anxiety questionnaire. As for the Attitudes questionnaire, researchers used Gardner's (2004) Attitudes and Motivation Test Battery and selected 19 items which needed to be rated according to a 7-point Likert scale from 'strongly agree' to 'strongly disagree.' Regarding the Anxiety questionnaire, researchers adapted Horwitz, Horwitz, and Cope (1986) Foreign Language Classroom Anxiety Scale and included 13 items that also measured anxiety on a 7-point Likert scale from 'strongly agree' to 'strongly disagree.' Results revealed that students in the Education Degree experienced less positive attitudes towards English than students in the Business Degree. As for students in the latter group, female participants displayed more favorable attitudes, but also higher levels of anxiety, than men.

${ }^{5}$ Other studies that look into attitudes to these three languages from different frameworks, such as Content and Language Integrated Learning (CLIL), EFL, and Multilingualism include Lasagabaster (2003, 2005b, 2008, 2009, 2017) and Lasagabaster and Sierra (2009). 
As mentioned before, the cognitive component of attitudes is the one examined in the present dissertation. In this study, the aim of contributing to the existing literature on attitudes is two-fold. On one hand, and more generally, the present investigation attempts to provide further insight into the relationship between attitudes and pragmatics. As explained later on in this chapter, very few studies have observed attitudes in relation to pragmatics. Therefore, the present investigation, set within the frameworks of ILP and EFL, tries to shed some light into the results in the existing literature that claim for the need to emphasize and stress the essential role of language attitudes in pragmatics learning (e.g., Portolés, 2011). On the other hand, and more specifically, the present dissertation aims at contributing to the existing literature in the line of research that investigates the cognitive component of language attitudes. Since this study is motivated to find out the cognitive attitudes of a group of EFL students, attention will be paid to quantitative and qualitative data that may help explain the rationale behind those attitudes, unveil and analyze students' thoughts and beliefs about the English language by means of exploring their recognition and production of a given set of conventional expressions. This study aims to contribute to the existing literature by looking closely at language attitudes in ILP, at the cognitive component in relation to a particular pragmatic feature: conventional expressions. To the best of our knowledge, this is a novelty, since no study to date attempted to investigate language attitudes in relation to the recognition and production of conventional expressions.

Second, the affective nature of attitudes is identified in the feelings projected towards those that a given object brings about. For example, participants in the present dissertation may express their positive or negative feelings towards English, as they agree or disagree with an item such as "I like speaking English." Garrett et al. (2003) laid out the opposite perspectives in the literature that tackle the relationship between 
the affective and the cognitive component in relation to determining an attitude towards an object or person. On one hand, some authors propose that these two components are separate and bare no relation between them (e.g., Mackie \& Hamilton, 1993). On the other hand, some other authors defend the idea that an attitude exists because there are affective and cognitive motives behind it (e.g., Cargile, Giles, Ryand, \& Bradac, 1994; Perloff, 1993).

The following piece of research serves as an example of the effect of the affective component on language attitudes. Lasagabaster (2005a) investigates the effects of individual and sociolinguistic variables on the attitudes towards Spanish, Basque, and English of a cohort of 1087 undergraduate students in the Basque Country. As this author claims, for L2 learning to be fruitful, students' motivation needs to be supported by an affective component that "seems to be the function of attitudes" (p. 4). Sample selection was guided by data accessibility: those students who were taking English language courses. Students were enrolled in various degrees: from English Studies, to Law, to Audiovisual Communication, and Engineering. Students' attitudes towards the three languages were measured by means of a questionnaire based on Baker's (1992) and modified for research purposes. Results suggest that the degree of competence together with the sociolinguistic context are the two variables that exert a greater influence on the students attitudes towards Spanish, Basque, and English in the Basque Country.

Lastly, attitudes are behavioral as they reflect the natural tendency to behave in a specific manner (Garrett, 2010). For instance, those students who tend to listen to music in English more often than in Spanish show more positive attitudes to English than those who prefer listening to music in Spanish or Catalan. As a component of language attitudes, behavior, the natural tendency aforementioned entails the actions speakers 
undertake towards languages (Baker, 1992). Garrett et al. (2003) reported on the controversy between attitudes and behavior. As they informed, there are a few generalizations that understand the relationship between attitudes and behavior as linear. As these authors explained, this linear relation leads to beliefs such as: if someone's attitudes change, their behavior will change as well; if someone behaves in a specific way, that may help identify their attitudes; and that if "we can get someone to behave in a certain way, their attitudes will 'look after themselves"' (p. 8). However, research on language attitudes suggests that that nature of such connection is not straightforward (e.g., Ajzen \& Fishbein, 1980; Baker, 1988; Hanson, 1980; Wicker, 1969).

An example of the effect of the behavioral component of language attitudes towards languages is the Nightingale (2016), which is reported in detail in the following subsection.

Baker (1992) observed the dynamic, fluctuating, changing relationship between the cognitive and the affective components of attitudes. Similarly, Baker proposed that the relationship between the behavioral component of attitudes and attitudes themselves was complex and affected by other factors ${ }^{6}$. Such relationships between attitudes and their components are illustrated in Figure 6 below.

\footnotetext{
${ }^{6}$ The lack of agreement in the operationalization of the relationships between attitudes and their components is acknowledge in this dissertation. For example, Garrett (2010, p. 24) pointed out that "[a]lthough attitude is often viewed in terms of cognition, affect and behaviour, there is some difficulty in determining the interconnectedness of these, and the extent to which we should anyway expect them to be in agreement all the time. This is an important issue in the attitudes field."
} 


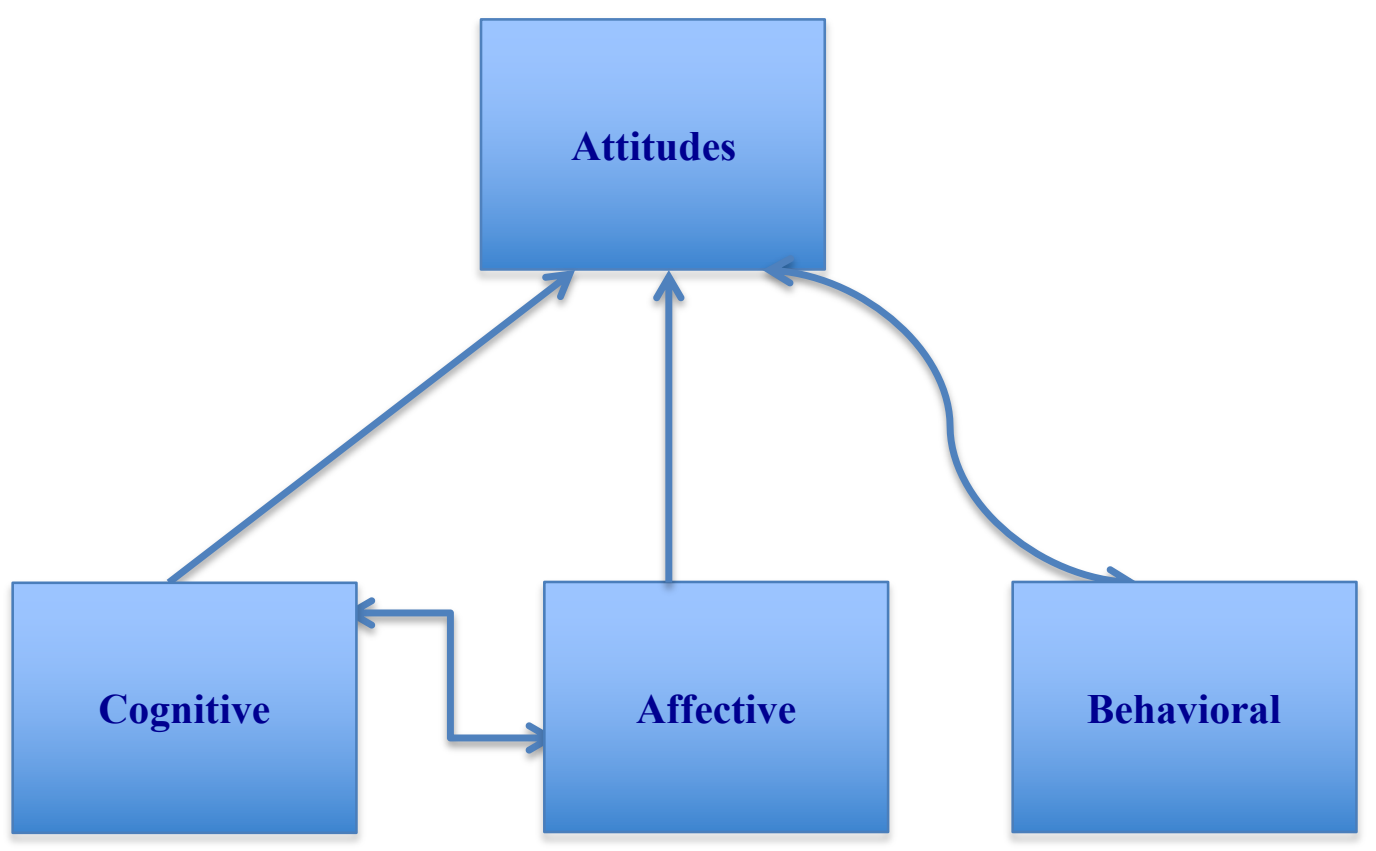

Figure 6. Relationship between attitudes and their components (adapted from Baker, 1992, p. 13)

Once attitudes have been defined and their components identified and explained, the features that characterize attitudes are presented. First, there are two types of attitudes: integrative and instrumental. As Gardner and Lambert (1972, p. 14) pointed out, integrative attitudes refer to those behaviors that seek "a desire to be like representative members of the other language community." For example, EFL learners may be eager to learn English to fit, resemble native speakers from UK or the US. On the contrary, Gardner and Lambert (1972, p. 14) defined instrumental attitudes as "a desire to gain social recognition or economic advantages through knowledge of the foreign language.” For instance, the willingness to get a well-paid job overseas. Different viewpoints exist regarding the identification of whether instrumental or integrative attitudes exert a greater influence on language learning. Some scholars (e.g., Dörnyei, 2001; Dörnyei \& Ushioda, 2011) believe that it is integrative attitudes that 
play a more significant role in language learning. Other authors (e.g., Lukmani, 1972) believe that it is instrumental attitudes the type of attitudes that may have an increased affect in the process of acquiring a new language. Finally, some other scholars (e.g., Zhou, 1999) assert that both types of attitudes play the same role in learners' language learning. Nevertheless, there is little doubt that the process of learning a given language may be more effective if students possess positive attitudes towards such language (Baker, 1992; Gardner, 1985a; Lasagabaster, 2003; Portolés, 2011; Safont, 2007). Second, attitudes are regarded as being both input and output (e.g., Baker, 1992; Garrett, 2010; Garrett et al., 2003). On one hand, attitudes may be considered input when they represent -for example- a wish to learn English because a speaker thinks this language is beautiful or useful. On the other hand, attitudes are considered as output as they are the product of something. For example, learners' attitudes towards a given language may turn to be positive due to instruction. Putting the present dissertation as an example, participants' attitudes towards English may be(come) more positive because they may have perceived the instructional treatment received as useful, thus perceiving the language more positively. This distinction of attitudes as input or output is important in the present dissertation because the results from data analysis may reveal change in language attitudes as output, in other words, as a result of the instruction provided on conventional expressions and the importance of learning and using them to communicate effectively in real life interactions.

Finally, Baker (1988, p. 114-115) described attitudes as having the following four criteria. 1) Attitudes are not inherited; but 2) learnt. 3) Some attitudes may be more resistant to change, and experience may play a significant role if a change is to occur. Finally, 4) the nature of attitudes tends to be affected by the appreciation to a given object or person. Therefore, attitudes may be favorable, unfavorable or neutral. 
Additionally, since the present investigation may be considered longitudinal, the possible attitude change from pretest to delayed posttest will be closely examined. Therefore, this study is interested in the features of stability and durability (Garret, 2010). Previous studies on language attitudes have paid attention to the features of stability and durability (Garrett, 2010, p. 29). This line of research has brought about a discussion on this topic, since there are scholars who believe that attitudes are likely to remain stable, whereas others defend the variable and alterable nature of attitudes. For example, Sherif (1967) claimed that speakers forge their attitudes as they learn to be part of a given community. Therefore, their reactions to any given object or issue will always be the same. In a middle ground, Sears (1983), asserted that attitudes may vary, but it might be unlikely for this to occur for those attitudes that are created in the early years of a speaker's existence. On the other hand, other scholars assert that attitudes can experience variation over time, such as Sears and Kosterman (1994), who put forward the idea that attitudes may change. Sears and Kosterman identified two types of attitudes. The first are even labeled as "non-attitudes," since they refer to attitudes that may change in a very short period of time, as when a speaker replies quickly and without giving it much thought. On the contrary, there are other attitudes that may take longer to change, since speakers may take more time to meditate on their response.

The present section has addressed the concept of 'attitudes' by first discussing the similarities and differences among a series of definitions, followed by the description of the attitude components, and a detailed account of the features that characterize language attitudes. The following section concentrates on the research conducted on language attitudes, preceded by the explication of the three types of instruments employed to measure attitudes. 


\subsection{Research on Language Attitudes}

As seen in the previous section, research on attitudes has been carried out since the early decades of the 1900s. Baker (1992, p. 29) considered 'language attitudes' as an "umbrella term" because different and more specific types of attitudes have been looked into within (the broader term of) language attitudes. Baker listed a series of such specific attitudes tackled in the literature up to 1992, which are still being studied: attitudes "to language variation, dialect and speech style," "to learning a new language," "to a specific minority language" (such as Catalan in the context where the present dissertation took place), "to language groups, communities and minorities," "to language lessons" (for example, the instructional treatment passed to participants in the present study), "to the uses of specific languages," "of parents to language learning," and "to language preference" (p. 29). Also, language attitudes have been studied in many different countries all over the world, attempting to portray speakers' behaviors towards many different languages, such as Welsh (Baker, 1992; Sharp et al., 1973), French (Gardner, 1979, 1982, 1985a, 1985b; Gardner \& Lambert, 1959), English (Cenoz \& Jessner, 2000; Nightingale, 2012, 2016; Portolés, 2011, 2015; Safont, 2007, 2015), Catalan (Huguet, 2007; Safont, 2007; Portolés, 2011, 2015), Spanish (Safont, 2007; Portolés, 2011, 2015), Basque (Cenoz, 1997; Lasagabaster, 2007) or Galician (Loredo, Fernández, Suárez, \& Casares, 2007). For the purpose of the present investigation only research conducted in EFL studies will be reviewed, more precisely the studies carried out in Spain, since it is the setting where the present dissertation was undertaken. Prior to discussing the research conducted on language attitudes in the Spanish context, the different methods employed to measure language attitudes are presented. 


\subsubsection{Measuring language attitudes.}

Different approaches have been created to investigate and report on attitudes in the most objective manner (see Garrett et al., 2003; Holmes, 2013; McKenzie, 2010; Oppenheim, 1992; or Ryan, Giles, \& Hewstone, 1988 for a review). One needs to consider that the method chosen to measure attitudes will bring about different insights on the data collected. Hence, a cautious choice of data measurement approach should be considered depending on the focus of the study. Moreover, Labov's (1972) 'Observer's paradox' should also be taken into consideration. This refers to the possibility that participants' responses to the questions posited by the researcher may be influenced by both the researcher's and respondents' characteristics/traits. Garrett et al. (2003) encompassed such measuring approaches to attitudes in their work Investigating language attitudes: Social meanings of dialect, ethnicity and performance. There are three different approaches, namely direct, indirect, and societal treatment.

First, Garrett et al. pointed to the fact that direct measurements are more intrusive compared to indirect and societal treatment approaches because direct methods imply asking participants questions directly, and participants report about their attitudes in a rather straightforward manner. The direct methods used most frequently and vastly in the literature are questionnaires and/or interviews. A well-known example of a questionnaire was that developed by Baker (1992) in his seminal work on young learners' language attitudes towards Welsh. Baker's longitudinal investigation examined the language attitudes to Welsh of 797 teenagers from three different schools based in Northern and Central regions in Wales. The main different between the three educational institutions was the language used in instruction. One school used $100 \%$ the minority language, namely Welsh; then another school was bilingual in that English and Welsh were employed equally; and finally, the third school implemented instruction by 
means of English only. Attitudes towards these two languages were measured by means of a questionnaire in which the following variables were included: language background, youth culture, and type of school and language ability. Results showed that only youth culture played a statistically significant role on students' language attitudes. Students who had been involved with cultural artifacts, such as playing records, experienced more positive attitudes towards Welsh. Baker's study is an example of why research on language attitudes is worth conducting because inconsistency can be found in behavior depending on the context. Therefore, the present study aims to discover whether participants' attitudes towards English resemble those of previous studies. Moreover, Baker's (1992) study became of outmost importance in the study of language attitudes because he addressed five main drawbacks identified in previous literature in language attitudes. One of them tackled the measurement of language attitudes. According to Baker, previous studies employed methods to collect data that lacked reliability as well as multidimensionality. Baker addressed this gap by creating a robust questionnaire that proved to be reliable since it included items tackling several issues, such as attitudes towards Welsh as a language per se, but also towards the Welsh speakers, for example. As Baker (1992, p. 11) asserted, "the specification of objects, persons, institutions or events is important and valuable in constructing measurement scales." The questionnaire Baker created has been used extensively to test and analyze language attitudes in the literature. A few examples are the body of research encompassed in Lasabagaster and Huguet (2007), Portolés (2011, 2015), Nightingale (2016), and the present dissertation among others. For the purpose of the present study, the original version of the questionnaire, developed by Lasagabaster and Huguet (2007), was adapted so that it would capture the reality of the specific EFL setting in which this dissertation took place more faithfully. 
Second, and as reported by Garrett et al., indirect approaches are less obtrusive than their direct counterparts because indirect methods collect attitudes towards languages by means of methods that do not elicit questions directly. For example, different types of observational techniques can be implemented to achieve this goal, such as observing participants who are not aware that their attitudes are being monitored. ${ }^{7}$ Another type of observation employed is that which the researcher measures participants' attitudes that they may not be able to control. Finally, Garrett et al. indicated that participants can be deceived by passing them an activity in which they believe they are accomplishing a specific goal, but in reality their attitudes are being looked at closely. The most well-known indirect approach is the matched-guise technique (MGT), developed by Lambert, Hodgson, Gardner, and Fillenbaum (1960) to conduct research to track and understand speakers' attitudes to French and English in Canada. The MGT aims at observing speakers' language attitudes towards languagevariety differences. It differs from the direct measurements in that the questions asked do not tap into participants responding overtly and directly about their attitudes, but rather express their attitudes by means of an attitude-rating scale. This scale is usually comprised by a statement and then a Likert scale which asks participants to rate their attitudes towards the given statement from agreeing completely to disagreeing completely, for example. In a MGT, participants are instructed that they are going to listen to a tape in which they will listen to different people reading the same text and that they are expected to rate the varieties according to their attitudes. However, what is not revealed to participants is the fact that there is only one person reading the three different texts, and that it is their attitudes towards the different language varieties or

\footnotetext{
${ }^{7}$ I acknowledge that this practice may not be perceived quite ethical in certain environments, such as universities in the US, where it is illegal to carry out such practices.
} 
accents what is being studied. Despite being the most frequently used indirect approach, the MGT has received some criticism too regarding two specific features. First, it is argued that it presents language in a decontextualized fashion, therefore leaving out essential components that may help explaining language attitude display. The second drawback refers to the fact that data are collected only by means of an attitude-rating scale, which may be perceived as being an 'over-reliance' on using only one type of data collection method.

Finally, societal treatment approaches conduct "a content analysis of the 'treatment' given to languages and language varieties, and to their speakers within society" to investigate the status and stereotypes that may be associated to particular language varieties (Garrett et al., 2003, p. 15), by means of observing speakers, conducting ethnographic research or analyzing public sources of language attitudes such as the media or literary works. According to Garrett (2010), studies using a societal treatment approach explore people's expression of their attitudes, even though these have not been explicitly or implicitly asked about. Garrett et al. (2003) indicated that much of the research conducted using societal treatment methods are qualitative in nature, outnumbering quantitative studies. Even though societal treatment approaches have not received as much attention as the previous two types of measures, and have been mainly criticized as being considered informal by social psychology researchers, these specific types of measures are of particular importance in the fields of discourse analysis and text analysis.

All in all, it could be argued that the choice of a specific method to measure language attitudes will reflect the rationale behind the study, and will provide more indepth insights of the data gathered. The direct, indirect, and societal treatment measures have been proven to be reliable data collection methods. For the present dissertation, 
direct measures were the ones selected to study participants' attitudes. On one hand, an adapted version of Lasagabaster and Huguet's (2007) questionnaire was employed because literature suggests that it is a reliable instrument to collect data but most importantly because it allowed looking closely into the cognitive component of attitudes towards English. Please see Chapter 6 and Appendix 11 for an extended account of the adaptation of this questionnaire. Additionally, attitudes towards instruction was also measured by means of a questionnaire that was created since it was found the need to explore the effects that the particular instruction delivered may exert on students' attitudes towards English but also towards such instruction. As far as could be established, no study to date may have included an instruction questionnaire that targeted students' attitudes towards the instructional treatment received and the potential benefits that the participants may identify the treatment may bring to their future pragmatic learning and development.

The next subsection is devoted to reviewing the research conducted on language attitudes in EFL contexts, most specifically the research conducted in Spain, thus reflecting on the previous research done in the same context where the present investigation was carried out.

\subsubsection{Research on language attitudes in instructed classrooms.}

In the early years, most of the research on language attitudes was conducted on attitudes towards one language only (Baker, 1992). The need to expand research foci directed scholars to drive their attention to the interplay of language attitudes towards more than one language, often being one of those a minority language. This is the case, for example, of research conducted in Spain, where studies have looked into language attitudes towards English as well as Basque, Catalan or Galician, in addition to the official language of the country, Spanish. The following studies reflect the situation 
aforementioned of language attitudes regarding multiple languages, these being official, co-official, and foreign. The research tradition on language attitudes in Spain is robust and well documented, with language attitudes being studied for more than two decades. However, most of such research was undertaken from a multilingual perspective, identified as a paramount area to explore (Cenoz, Gorter, \& May, 2017) in reaction to the vast amount of studies conducted so far, which took monolingual speakers, instruction, language usage, and learning as the norm. Therefore, a few studies reporting on attitudes in EFL settings will be presented first. Then, examples from the vast bulk of research on attitudes in multilingual settings will be discussed. Finally, a few studies conducted on attitudes in ILP will be summarized, to present the research gap that the present dissertation aims to tackle as of language attitudes: exploring language attitudes in relation to instruction in ILP. After that, the research niche that the present investigation attempts to cover is explained in detail.

Language attitudes in EFL settings have received less attention compared to multilingual environments. One piece of research has been selected to provide an example of the importance of language attitudes in EFL environments. Valencia and Cenoz (1992) investigated the linguistic and behavioral performances of a group of 321 pupils at a high school level in the Basque Autonomous Community (BAC), who were enrolled at two different educational programs, namely A and B. Students in A program received instruction in Spanish, whereas participants in B program were taught in Basque. Students were tested in their English performance according to the four skills (i.e., writing, reading, listening, and speaking), together with two tests, one for grammatical and other for vocabulary knowledge. On the other hand, students were asked about their attitudes towards a series of bilingualism dimensions, namely early bilingualism, competence in Basque language, family bilingualism and linguistic model. 
Additionally, participants' social motivation since they had to report about their attitudes towards: 1) learning English, 2) the effort they put into such endeavor, 3) living in countries where English is the official language, and 4) receiving instructional treatments as regards English language besides school time. Results showed that bilingualism played a statistically significant (positive) influence towards English achievement. Furthermore, Valencia and Cenoz employed a Structural Equations Program to investigate the possible interrelation among the selected variables. Results obtained demonstrated that there is an indirect union between bilingualism and the acquisition of an L3 (third language, English in this case), and that social motivation was the bridge mediating between them.

As mentioned before, language attitudes inspected from a multilingual stance represents a robust body of research in and of itself ${ }^{8}$. The following studies attest to such reality, as pieces of research from Galicia (Loredo et al., 2007), the BAC (Lasagabaster, 2007), Catalonia (Huguet, 2007), and the Valencian Community (Nightingale, 2012, 2016; Portolés, 2011, 2015; and Safont, 2007, 2015) are detailed in what follows.

In Galicia, Loredo et al. (2007) looked into 207 participants' (aged 18 to 35) use of and attitudes towards Spanish, Galician, and English, whom were freshmen year students majoring in Teacher Training and Pedagogy. The majority of the participants (37.7\%, a little over one third of the sample) had Galician as their L1, in contrast to a minority of L1 Spanish participants, represented by the $26.5 \%$ of the cohort. Interestingly, the rest of the group (33.8\%) was bilingual speakers of Spanish and Galician. Data were collected over the course of two months during Fall 2004 by means

\footnotetext{
${ }^{8}$ In the present section, only empirical studies are reported. For a theoretical review of multilingualism and related phenomena please refer to publications such as Cenoz (2009, 2013a, 2013b, 2013c), Cenoz and Gorter (2011a, 2014, 2015), Cenoz, Gorter, and May (2017), Coulmas (2018), Liang (2015), O'Rourke (2011), and Todeva and Cenoz (2009) among others.
} 
of the questionnaire that Lasagabaster and Huguet (2007) adapted from Baker (1992), and which was used by all studies comprised in Lasagabaster and Huguet's (2007) volume. Participants were given the opportunity to fill out the questionnaire either in Spanish or in Galician. Results showed that participants felt their linguistic competence to be better in Spanish than Galician, and these two better than in English. Interestingly, we should recall that most of the students marked Galician as their L1. Nevertheless, the superior use of Spanish in all social spheres may help understand the results obtained. Regarding linguistic attitudes, students reported higher positive attitudes towards Galician than Spanish and English, in that order. More specifically, women who are bilingual, lived in small towns, towns where Galician is the predominant language, or who were taught in Galician at school are the participants who show more positive attitudes towards the minority language. To conclude, participants who reported positive attitudes towards the foreign language were those who had experienced sojourns abroad or positive attitudes towards such language from the beginning.

The study of language attitudes in the BAC also represents an extensive body of research. An example of such considerable sample is looked into as follows.

Lasagabaster (2007) observed the use and attitudes towards Spanish, Basque, and English on a group of 222 Freshmen-year students of different Teacher Training Degrees, namely Nursery Education (31.1\% of the group), Primary Education $(28.4 \%$ of the cohort), and Physical Education (40.5\% of the sample), who were aged between 17 and 46. This particular population was selected due to the fact that these students would become teachers in the near future, thus being able to be a strong influence in their future pupils. Available research on teachers' influence on their students' attitudes is well attested (i.e., Portolés, 2015). Data were collected with the questionnaire that Lasagabaster and Huguet adapted from Baker (1992), and which all studies in their 
volume employed (see Loredo et al., 2007 above; Huguet, 2007; and Safont, 2007 below). Data were collected in Fall 2004 as well, but in this case in the time span of just one month (September). Similarly to Loredo et al. (2007), participants reported a higher competence in Spanish, followed by Basque, and English. It is noteworthy the fact that the vast majority of the sample perceived their linguistic competence in English to be very poor, which previous research had already identified (see Cenoz, 1991, and Lasagabaster, 1998). As of attitudes towards the languages, participants seemed to agree on the instrumental motive to speak Basque. In other words, results indicated that Basque was useful because it enabled participants to reside in the BAC as well as to bring up children. On the other hand, results indicated that participants used Basque more frequently among friends, and Spanish more with their families. These results may hold a positive stance towards the minority language in the future. In line with Loredo et al., students who came from smaller towns where the minority language is the norm had more positive attitudes towards such language. Likewise, students who lived in cities where Spanish was the dominant language, more positive attitudes were found towards that language. All in all, Lasagabaster pointed out to the importance of conducting more research on teacher training students because of their plausible prominent influence on pupils, as stated above, as well as the need to raise students' positive attitudes towards different languages, making them aware of the importance of such languages in the current global environment.

Turning the attention to studies conducted in Catalonia, Huguet (2007) examined the use and attitudes towards Spanish, Catalan, and English on a sample of 309 students with average age of 20.2 years. Participants were enrolled in different degrees, namely Psychology (20\% of the population), Social Education (29\%), and the rest in different specializations within Teacher Training Degrees: Nursery Education (26\%), Primary 
Education (12.5\%), Special Education (7\%), and Musical Education (5.5\%). Data were collected with Lasagabaster and Huguet's (2007) adapted version of Baker's (1992) in the time span of one month (September) in Fall 2004. Results revealed an almost entire sample agreeing on their advanced command of both the official and the co-offical languages, Spanish and Catalan respectively. Nevertheless, the picture is totally different as of the foreign language is concerned, only one third of the population reporting a good command in such language. Furthermore, Huguet stated that due to the results obtained, language policy makers should make sure that learners should be instrumentally motivated to learn a language not only in the first school environments, but all throughout their education process. A further result reflects the uneven use of Spanish and Catalan in Catalonia, but which reflects the results obtained in previous studies in the same volume. It was found that Catalan was used in familial environments, whereas Spanish was more often employed in social and public spheres, such as for example in the media. Regardless of this uneven usage of Catalan and Spanish, positive attitudes towards Catalan were reflected by the $80 \%$ of the sample. Finally, two more results were obtained. On one hand, and contrary to previous literature, the age factor was not statistically significant in this study. On the other hand, and in line with existing research, participants' L1 was statistically decisive on positive attitudes towards such language, Catalan in this case.

Focusing on research undertaken in the Valencian Community, all of the studies included in the review below were carried out from a multilingual perspective and explored language attitudes towards three specific languages (i.e., Catalan, Spanish, and English) and population samples were younger learners: adolescents (Nightingale, 2012, 2016) and children (Portolés, 2011, 2014, 2015; Safont, 2007). Results from these studies suggest that it is essential to look into language attitudes from a multilingual 
perspective to understand language development in a more comprehensive manner, taking into consideration external and internal factors that affect such learning process and the development of the attitudes linked to that language development.

Nightingale (2012) looked closely at the attitudes towards English as the main FL studied in Spain, and to the extrinsic and intrinsic factors which exert an influence in language attitudes in an attempt to shed light on the intertwined nature between sociocultural factors and language learning setting. Data were collected from a group of 29 young EFL learners, aged between 12 and 16, who attended different high schools in the cities of Castelló and Almassora in Spain, during Spring 2010. Similar to previous studies, the majority and minority languages (Spanish and Catalan in this case) are the predominant languages in the area, whereas English is the least visible. Students received instruction in all three languages at school, mostly on Spanish; the amount of instruction in Catalan may depend on the language program of their choice. As of English proficiency level, students were placed between A1 to B1 levels according to the CEFR. Data were collected by means of a questionnaire adapted from Lasagabaster (2003) to measure favorable, unfavorable or neutral attitudes to English. Participants were allowed 25 minutes to complete it. Results showed that taking a look at the three languages together, positive attitudes are predominant. When examining languages separately, Catalan is the one that receives most positive attitudes, thus adding to the existing literature on favorable attitudes to the minority language. As for Spanish, this language received the least favorable attitudes, which Nightingale attributes to the friction that appears to be between these two specific languages given the social context in which they co-exist. Attitudes regarding English resemble those of Catalan, since participants reported more positive attitudes towards the foreign language in comparison to the majority language but not as many as to the minority one. Finally, 
regarding the effect of sociocultural variables, results revealed participants allocate a positive sociocultural status to English, as well as to stay abroad. However, the 'out of school' factor was proven partially. Even though results showed students' positive attitudes to English also when it is being taught outside of the school time, results were not robust enough, thus they could not be generalized.

Nightingale (2016), looked into the development of young learners of English from a multilingual perspective as well; this time from a "dynamics system theory perspective (e.g., Larsen-Freeman \& Cameron, 2008), the Dynamic Model of Multilingualism (Herdina \& Jessner, 2002), and the Focus on Multilingualism approach (Cenoz \& Gorter, 2011a, 2011b, Gorter \& Cenoz, 2011; Cenoz, 201399)” (p. 1). He examined students' language attitudes towards the three languages (Spanish, Catalan, and English) together with other not language-related multilingual practices, such as students' involvement with different media sources broadcasted or published in those three different languages. Data were collected from 152 students aged between 12 and 17 enrolled in two high schools at four sessions in Spring 2014. Data were gathered by means of one questionnaire as well as oral interviews that conformed the mixed-method approach implemented in that study. The questionnaire included nine items that tapped on students' use of all three languages in relation to familiar and academic contexts, as well as to "traditional media" such as television, and to "new media," including Facebook and Google. A total of 15 to 20 minutes were allocated to fill out this questionnaire. As for the interviews, it was designed as a semi-structured interview comprised by eight questions, in which participants were asked about their language use, for example: "Which languages do you use in the internet?" or "Do you mix languages in social network sites?" (p. 197). Results showed that looking at the

\footnotetext{
${ }^{9}$ This article is cited and referenced in this dissertation as Cenoz (2013a).
} 
language attitudes holistically, English was reported the most positive attitudes, followed by Spanish, and Catalan. All in all, when looking at languages as a whole the existing differences between those three languages look less than when examining them separately. Hypothesis one looked into the positive effect of out-of-school may have on attitudes. This was confirmed because results showed that students who had contact with English and Catalan outside the academic environment. Hypothesis two predicted an intertwined relationship between languages, attitudes and media. It was confirmed, since results showed statistically significant between languages and contact with different media and the very notorious variability seen among languages. Hypothesis three predicted that participants' language would change due to contact with external phenomena. This hypothesis was also confirmed. Finally, hypothesis four predicted that the analysis of the qualitative data gathered from the interviews would show the complex nature between multilingual, multimodal, and social practices. This hypothesis was also confirmed.

Portolés (2011) inspected the effect of external and internal factors on language attitudes and beliefs towards Spanish, Catalan, and English on a group of 75 students aged 18 to 40, enrolled in Teacher training degrees at two universities in the Valencian Community. The selection of this particular population was purposeful (see Lasagabaster, 2007 above). Data were collected using an adapted version of Baker's (1992), which was also translated to Catalan for the purpose of the study, and the Quick Placement Test, a language proficiency test. Results from the six hypotheses are summarized as follows. Hypothesis one predicted that language attitudes would me more favorable to Spanish (majority language), followed by Catalan (the minority language), and English (the foreign language) would receive the least positive attitudes. However, this hypothesis was not confirmed because results showed that participants 
had the most positive attitudes towards English. Hypothesis two predicted that the sociolinguistic context would have an impact on the majority and minority languages but not towards the foreign one. However, this hypothesis was not confirmed either because results showed that this specific context had an influence on the majority and foreign languages but not towards the minority one. Hypothesis three predicted that the linguistic model would play a significant role on language attitudes. This was confirmed. Hypothesis four predicted that students' L1 would exert statistically significant differences in language attitudes towards the three languages, and results allowed to confirm this prediction. Hypothesis five predicted that study abroad would have an effect on the formation of attitudes towards English. This hypothesis was confirmed but results showed that a sojourn abroad might influence more languages other than just English. Finally, hypothesis six predicted that proficiency level would affect language attitudes towards English, and results confirmed that higher proficiency levels implied more positive attitudes towards English. Similar results were reported on Portolés (2014), who examined prospective teachers' attitudes towards these three languages taking into consideration two variables: the sociolinguistic context and students' L1.

Safont (2007) explored the use and attitudes towards Spanish, Catalan and English on a sample of 200 students aged between 19 and 33 enrolled in the Degrees of teacher Training and Psychology with the specialization in Education at a public university in Eastern Spain during the month of October in the Fall 2004. Data were collected by means of the adapted version of Baker's (1992) questionnaire that Lasagabaster and Huguet (2007) devised for the studies included in their volume. Results were distributed as regards three principal aspects: first, the participants' proficiency level in relation to the three languages aforementioned; second, students' 
global attitude in relation to Spanish, Catalan, and English; and third the variables that affected their attitudes the most. Regarding the first aspect, and in line with previous studies in this volume, students reported a better command of Spanish than of the two other languages. However, students also reported a high linguistic competence of Catalan, which reflects the important role of Catalan in the community. In line with this, students' attitudes towards Spanish were the most positive ones, followed by Catalan, which received the least favorable ones, and attitudes towards English were reported as neutral. Finally, the variables that influenced students' attitudes the most were the students' degree course, the specialization in which they had enrolled, and the linguistic model in which they had received instruction in previous academic environments. Surprisingly, gender and socioprofessional status did not play a significant in their language attitudes, unlike previous studies.

Finally, the last sample of research encompassed in the present subsection aims at reviewing studies that focused on attitudes and included a pragmatic component in their investigations. This combination of variables has received scant attention. The findings from one study are reported: Portolés (2015). She examined early consecutive multilingual students, more specifically their pragmatic awareness in relation to language attitudes towards Spanish, Catalan, and English in a multilingual environment. Data were collected from 402 students aged between 4 and 9, who were divided into two groups: preschool students (aged 4 to 5) and primary students (aged 8 to 9). Participants were enrolled in either of the two schools, one public (Catalan-based institution) and one private (Spanish-based institution), where the study took place. Data were gathered during a 60-minute session. Data on pragmatic awareness were collected by means of a discourse evaluation task, which tapped into students' awareness of direct and conventionally indirect request forms. Data on language 
attitudes towards the three languages were gathered by means of interviews and a matched-guise technique. These activities were encompassed in a booklet the researcher created for the study. Two booklets were crafted, depending on the students' age. The first part of the booklet entailed the matched-guise technique, and the second part of the booklet tackled the discourse-evaluation task. Results were reported on the basis of the four research questions devised in the study. RQ1 explored the students' pragmatic awareness. It was confirmed, since students showed higher degrees of pragmatic awareness, which increased as they grew older, and were able to differentiate the pragmatic systems of the three different languages. RQ2 looked into their language attitudes. It was confirmed, since students reported more positive attitudes towards Spanish first, then Catalan and finally English. Age was also found relevant because younger learners had more positive attitudes towards the minority language. RQ3 examined the possible relationship between students' pragmatic awareness and language attitudes. This RQ was confirmed, because students enrolled in a Catalanbased school performed better at the pragmatic awareness task than their Spanish-based school counterparts, who also showed more positive language attitudes in comparison to students attending the Spanish-based school. Finally, RQ4 observed the influence that other factors may present in the participants' multilingual development. Students' performance differed, depending on the type of language-based school that they attended.

The body of research explained above show that language attitudes have been mostly investigated in autonomous communities that have three languages: a minority, a majority and a foreign language. As regards participants, samples represent students at different points in their learning trajectories (i.e., primary school, high school and university levels). Generally speaking, students tend to show positive attitudes towards 
the minority languages, and rather negative ones towards the foreign language (English). In what follows, the research gap that is attempted to cover in the present dissertation is thoroughly explained, which tries to shed light on issues raised in the previous literature.

To the best of my knowledge, scant attention has been paid to research on language attitudes in ILP. Previous research has investigated the influence of a series of variables over attitudes, such as language proficiency, stay abroad, sociolinguistic context, linguistic model, L1, or other individual differences such as motivation or anxiety, and the attitudes arisen from language contact in multilingual settings (Bokhorst-Heng \& Caleon, 2009; Huguet, 2006, 2007; Lasagabaster, 2001, 2003, 2007; Lasagabaster \& Safont, 2008; Portolés, 2011; Safont, 2007; Santos et al., 2017; Yihong, Yuan, Ying, \& Yan, 2007). Hence, the present study is important because we try to bring a new perspective into the study of language attitudes. We look at students' attitudes towards English in an EFL higher-ed environment in relation to the possible effects that pragmatics instruction may exert on such attitudes. Previous research on attitudes has explored children's abilities to make requests in multilingual settings (e.g. Portolés, 2015).

As far as could be established, there is no study yet that has included the variables of instruction and attitudes in one same study in ILP, also being conventional expression the dependent variable. Therefore, this research gap is investigated in the present dissertation. Although language attitudes are explored in an EFL setting, the influence that attitudes towards other languages may exert on students' attitudes towards English is acknowledged. For the present dissertation, data on language attitudes were collected on English but also on participants' L1(s) (i.e., Spanish, Catalan 
and/or Romanian). However, for the purpose of the present dissertation, only results on language attitudes towards English are reported.

Cenoz and Perales (2000) acknowledge the complex nature that acquiring a second language is, and indicate that a number of variables - both related to the individual as well as to the context in which learning takes place- influence in such language learning process. Additionally, Cenoz and Perales indicate that such variables may exert some influence among them. For the present investigation, language attitudes are understood as an individual variable, and pragmatic instruction as a contextual variable. This viewpoint is reflected in Cenoz's (2004) and Dewaele's (2005) definitions of language attitudes, as they identify language attitudes as affecting the process of learning a language. According to Cenoz (2004, p. 203), “(1)anguage attitudes are generally considered as one of the factors that influence language acquisition." Likewise, Dewaele $(2005$, p. 118) pointed out that "attitudes are one of the central variables of language learning." Therefore, the exploration of language attitudes in the present investigation is two-fold. First, the claim made by previous research (e.g.: Baker, 1992; Cenoz, 2009; Huguet, 2007; Lasagabaster, 2007; Nightingale, 2016; Portolés, 2011; Safont, 2007) is investigated, which recognizes the important role of language attitudes in language learning. Secondly, this study tries to determine what factors (such as contextual or personal or the role of instruction) or motives (e.g., integrative or instrumental) may influence participants' attitudes towards English in the particular learning environment in which the present dissertation was undertaken. More specifically, this study attempts to define whether the role of instruction influences the participants' attitudes towards the English language. To explore those reasons aforementioned, two surveys were employed. On one hand, an adapted version of Lasagabaster and Huguet's (2007) questionnaire was passed to students at pretest, 
posttest, and delayed posttest. On the other hand, a questionnaire was created to tackle participants' perceptions towards the instruction they were provided with in this study. This questionnaire was created to tap on students' attitudes both towards the instructional treatment received as well as on their attitudes towards English after the instruction was provided. To the best of our knowledge, no study to date has attempted to carry out such endeavor. Lasagabster and Huguet's (2007) questionnaire was adapted from Baker's (1992), in his seminal work on language attitudes towards Welsh. Baker (1992) created that particular questionnaire aiming to cover the research flows and gaps he found in previous research, such as exploring the possible effects of language attitudes not only to one but also to more than one object. Baker's (1992) rationale to measure language attitudes with such a survey well fits into the present dissertation's. According to Baker (1992, p. 10), "a survey may aid understanding of social processes. Consideration of how attitudes relate to their causes and effects may provide insights into human functioning." Baker's questionnaire has been widely used in subsequent studies in language attitudes (e.g., Lasagabaster \& Huguet, 2007; Nightingale, 2016; Portolés, 2011), thus attesting their reliability and validity as researchable constructs. As regards the instruction questionnaire, it was created to look into the possible effects of instruction on language attitudes, and was pilot tested to ensure its validity and reliability. More information on both questionnaires is provided in Chapter 6.

All in all, the present study aims at investigating students' attitudes towards English, understood as participants' tendencies to respond positively or negatively to social linguistic stimuli by means of language, such as verbalizing opinions, and/or the use of gestures and other non-linguistic resources to express such understanding about the L2 and the L2 users. Since the focus in this study is the cognitive component of attitudes, the tendencies mentioned above refer to the reactions that participants will 
Chapter 3: Attitudes in Language Learning

have towards the English language according to their thoughts and beliefs about this language and their users. 


\subsection{Chapter Summary}

The scope of Chapter 3 aimed at providing a comprehensive understanding of what language attitudes are and the research conducted on these language-related phenomena in Spain, where the present investigation was undertaken.

In the first section of the chapter, the term attitudes was defined, reflecting on the different theoretical perspectives that exist in the literature, from social psychology to sociolinguistics, to SLA. After that, the three main components were identified and explained, namely cognitive, affective, and behavioral. A series of features that characterize and help operationalize the concept of language attitudes were presented. First of all, the difference between the two types of attitudes, instrumental or integrative are stated and examples given. After that, the characterization of attitudes as input as well as output is tackled. Attitudes are regarded as input as a reflection of the integrative or instrumental motives a speaker may possess. Language attitudes as output are the product of for example having a positive instructional experience, which fosters students' positive attitudes towards a language or towards a pragmatic feature as in the present dissertation. Finally, the four characteristics proposed by Baker (1988) were provided, namely attitudes are not inherited but learned, that some of the attitudes may be more resistant to change, but experience being a key factor that may enhance or perpetuate particular attitudes, and the favorable, unfavorable or neutral nature that attitudes may be permeated by language learners.

The second section of the chapter entailed a description of the 3 approaches employed to measure language attitudes. These are direct (questionnaires/surveys), indirect (matched-guise technique mainly), and societal treatment (exploring language attitudes by analyzing other sources such as the media, or literature). After that, some of the most prominent research on language attitudes in Spain was presented to provide a 
Chapter 3: Attitudes in Language Learning

basis for the present dissertation but also to explain the research gap that aims to be covered in the present dissertation, namely the study of language attitudes in relation to pragmatic instruction in the field of ILP. 



\section{Chapter 4: Conventional Expressions}

This chapter discusses conventional expressions in relation to L2 pragmatics, since, as research shows, conventional expressions are facilitators of communicative acts. As to better comprehend the role that conventional expressions play in L2 pragmatic learning, Section 4.1 entails a detailed description of the definition and features that characterize conventional expressions. After that, Section 4.2 reviews the instruments employed to measure conventional expressions, as well as the research carried out in ILP as regards recognition and production of conventional expressions. Section 4.3 discusses the target conventional expressions included in this dissertation in depth. Finally, the main takeaways of Chapter 4 are encompassed in Section 4.4, the Chapter Summary.

\subsection{Conventional Expressions and Formulaic Language}

Conventional expressions are a type of formulaic sequence, "a sequence, continuous or discontinuous, of words or other meaning elements, which is, or appears to be, prefabricated: that is, stored and retrieved whole from memory at the time of use, rather than being subject to generation or analysis by the language grammar" (Wray \& Perkins, 2000, p. 1). Wray and Perkins (2000) understood formulaic sequences with some degree of variability, a feature that is also highlighted by Hinkel (2018), Schmitt (2004) or Yamashita (2008) among others. In line with Wray and Perkins (2000), CelceMurcia (2007, p. 47) defined formulaic sequences as "fixed and prefabricated chunks of language that speakers use heavily in everyday interactions." In turn, formulaic language $(\mathrm{FcL})$ encompasses all formulaic sequences in general. In this vein, Wood $(2015$, p. 2) stated that the term 'formulaic sequence' refers to "one such item," in comparison to ' $\mathrm{FcL}$ '10, which refers to formulaic sequences "as a collective" (see also Wray, 2006). Put simply, FcL can be understood as those chunks of language that

\footnotetext{
${ }^{10}$ For a review about the formulaic nature of pragmatics see Bardovi-Harlig (2016).
} 
language users and language learners employ in communication daily. Evidence shows that FcL is an essential constituent in the use of daily language (e.g., Schmitt, 2004; Wood, 2015; Wray, 2012) in proper and effective ways (Gyllstad \& Schmitt, 2019). According to Hinkel (2018, p. 5), citing Pawley and Syder (1983) and Wray (2000, 2002), stated that social spoken communication is generally "highly conventionalized and extremely formulaic". Additionally, and citing his previous work (Hinkel, 2014, 2015), she claimed that "[c]onversational interactions and speaking routines are recurrent in an extraordinary range of situational and pragmatic purposes" (p. 5). In so doing, speakers aim to "achieve specific interactional goals" as well as "to sustain the interaction"11 (Wray, 1999, p. 227). Formulaic sequences may even serve as "survival phrases to achieve basic socio-economic interactional functions" for low-proficiency students (Wray \& Perkins, 2000, p. 23). All in all, it could be agreed that the main aim behind FcL is to facilitate conversation and communication (e.g., Coulmas, 1981; Bolander, 1989; Kasper \& Schmidt, 1996; Yamashita, 2008).

\subsubsection{Operationalization of conventional expressions.}

A wide range of terms have been used to refer to formulaic sequences in the field of ILP, such as formulas, routines, conventional expressions, gambits, lexical items or situation-bound utterances ${ }^{12}$ (examples and extensive lists of such terms can be found in e.g., Bardovi-Harlig, 2019b; Martinez \& Schmitt, 2012; Simpson-Vlach \& Ellis, 2010; Weinert, 1995; Wood, 2015; Wray, 2002; and Wray \& Perkins, 2000). Attempting to define these concepts might seem daunting, because the same term may be used to refer to two different formulaic sequences, depending on the research area. Since the present dissertation focuses on conventional expressions, the term 'formulaic sequences' will be

\footnotetext{
${ }^{11}$ Wray attests to the fact that this function of FcL may not be found as frequent in adult L2 learners in instructed settings.

${ }^{12}$ Kecskes (2002).
} 
used to refer to the target expressions included in the present investigation. The term 'pragmatic routines' appears as well employed as an umbrella term to explain theoretical concepts, such as definitions, features, and studies, which also apply to conventional expressions. To provide a definition of conventional expressions, the detailed discussion of related terminology provided by Bardovi-Harlig (2006b, 2009, 2012a, 2013b) will be presented first and will be complemented with definitions provided by other scholars, such as Coulmas (1981) or Roever (2005). The most important and more recurrent work on conventional expressions can be found in Bardovi-Harlig's studies (e.g., 2006b, 2009, 2012a, 2013b). Additionally, she is the author that provides extensive discussion on the differences between all the concepts related to conventional expressions. These are the reasons why her investigations are referenced to define the existing terms in an attempt to draw differences among them.

Bardovi-Harlig (2013b) considers pragmatic routines as an umbrella term that covers a variety of perspectives on how to approach formulaic language. Those perspectives are divided into two groups, based on whether pragmatic routines are considered as psycholinguistic phenomena or social phenomena. It is in those social phenomena where conventional expressions can be identified. As stated by this author (2013b), two distinctions can be made within the psycholinguistic aspect of pragmatic routines. On one hand, the terms 'formula' and 'chunk' can be employed to refer to the same string of words, but the term 'chunk' adds the connotation of retrieving and storing the string of words as if they were one single element. On the other hand, the terms 'formula' and 'routine' can also be used interchangeably, yet a string of words will be called 'routine' if it is employed in reference to the second language learning process. Bardovi-Harlig (2006b) differentiates three types of formulas: developmental, target, and semantics. According to her, 'developmental formulas' refer to those 
sequences which are learnt as a whole, as if they were a single word, not being analyzed, thus showing no possible errors in the acquisitional process. 'Target formulas' focus on the social aspect of formulas and their role in communication. Bardovi-Harlig, using Coulmas (1981) definitions, defines 'routine formulae' as "highly conventionalized prepatterned expressions whose occurrence is tied to more or less standardized communication situations" (pp. 2-3). Moreover, Coulmas (1981) envisions 'conversational routines' as "tacit agreements which the members of a community presume to be shared by every reasonable co-member. In embodying social knowledge they are essential in the handling of day-to-day transactions" (p. 4). Roever (2005), also following Coulmas (1981), distinguishes between 'situational routines' and 'functional routines.' 'Situational routines' are 'limited in their appropriate appearance to a specific" social communicative situation (p. 15). For example, What brings you here? is a routine used typically by a doctor as they greet a patient; or Do you have anything to declare? is what a Customs Service Officer asks a person when entering a country. 'Functional routines,' on the other hand, allow for more variable forms because they can be applied to multiple different contexts and conditions. Examples of functional routines are: I was wondering if...? or Do you mind if...?

Finally, Bardovi-Harlig (2006b, p. 4) understands 'semantic formulas' as "components of a speech acts." For example, a semantic formula can be part of an apology, such as "offer(ing) of repair" or "statement of responsibility".

Bardovi-Harlig (2009) provides different terms to refer to 'developmental' and 'target' formulas, mainly drawing on the process in which a formula is acquired in the process of second language learning. She identifies two types of formulas: acquisitional and social. An 'acquisitional formula' is acquired at early stages in the course of learning an L2. These formulas stand out since learners produce them with such fluency 
and proper syntactic manner, which contrasts with their low(er) proficiency level. Besides, acquisitional formulas are not examined by the learner's interlanguage. This lends support to the assumption that these sequences are "stored and retrieved as a whole" (Bardovi-Harlig 2009, p. 757). In a 'social formula,' the language users in a speech a community, who use a given routine in a particular situation in written or spoken mode, are the focus of attention. Besides, they can be used in SLA research as input and/or also as target pragmatic features. Additionally, evidence suggests that only learners with high proficiency level can learn and employ social formulas appropriately (Bardovi-Harlig, 2009, p. 757).

A further distinction is seen between the terms 'formula' and 'conventional expression.' Bardovi-Harlig (2013b) observes that they can be used as synonyms in the social characterization of routines. However, the concept of conventional expression emphasizes the social value of the given string of words when being used by a particular speech community, in that communities of speakers may not choose the same string. Moreover, the term 'conventional expression' does not include "the psycholinguistic claim regarding storage and retrieval" (Bardovi-Harlig, 2009, p. 757) ${ }^{13}$. Furthermore, only learners with a high level of proficiency will use conventional expressions more frequently. Since conventional expressions are complex in nature, only learners who have a more advanced interlanguage grammar will be able to use conventional expressions. These series of distinctions suggest that the term formula is employed both in the psycholinguistic and social characterization of pragmatic routines. So, other more specific terms related to each perspective, namely 'chunk' and 'routine' -for the

\footnotetext{
${ }^{13}$ Edmonds (2014) represents an exception, since she studied the processing of conventional expressions of English speakers learning French as a L2.
} 
psycholinguistic aspect- and 'conventional expression' -for the social one- add those particular connotations needed in each case.

Bardovi-Harlig (2009, p. 757) identifies 'pragmatic routines' as “those sequences that are frequently used by speakers in certain prescribed situations, (leaving aside) presuppositions about the eventual mental representation of these sequences for either native speakers or learners". Additionally, Bardovi-Harlig and Vellenga (2012, p. 77) assert that pragmatic routines are seen as "crucial to social communication." Narrowing the scope, House's (1996) definition of pragmatic routines in pragmatics teaching is essential to better understand the purpose of my study. House states that pragmatic routines could be learnt "at any learning stage," as it is in those formulas where the essence of a community dwells. Furthermore, conventional expressions are "essential in the verbal handling of everyday life" (pp. 227-228).

In line with Bardovi-Harlig (2013b), Wood (2006), and Wray (2013b) also report formulaic sequences to be invariable multi-word units which can be used in a wide range of communicative situations, having different functions and being used differently, depending on the context of a particular situation. Moreover, these authors also coincide in that speakers of a given language store and retrieve formulaic sequences as whole in the mind, and that by making use of such prefabricated language their speaking fluency improves. Besides, Bardovi-Harlig $(2009,2012 b)$ and CelceMurcia et al. (1995) asserted that a speaker is fluent in a language because they equally employ linguistic and formulaic expressions in their day-to-day communication. In turn, Wray (2002a) identified formulaic sequences as those strings of words that have a meaning or function that differs from those of the parts that compose the string of words, the sequence. Hence, this may allow hypothesizing that such strings of words are processed as a whole. 
As mentioned before, the pragmatic features under investigation are conventional expressions. Bardovi-Harlig (2009) coined this term in an attempt to distinguish it from the term 'formula' (see above). According to her, 'conventional expressions' are sequences that "emphasize the social aspect of use -namely, a speech community's preference for a particular string", that "are used frequently by speakers in certain prescribed social situations" (p. 757), and leave aside the psycholinguistic studies dealing with issues related to processing (Bardovi-Harlig, 2019a, p. 100). Taking into consideration the extensive discussion on the terms presented above, and bearing in mind that the term 'pragmatic routine' may be used as an umbrella term in this dissertation, I consider Bardovi-Harlig's (2006b, 2009, 2013b, 2019a) definitions of the terms 'target formula' (2006b) and 'social formula' (2009), as well as Coulmas' (1981) definition of 'routine formulae' and 'conversational routine' to be in line with the characterization of 'conventional expression' (Bardovi-Harlig, 2009, 2019a).

Table 4. Terms used to provide my definition of conventional expressions for the present study

\begin{tabular}{|l|l|l|}
\hline Term & Definition & Source \\
\hline Target formula & $\begin{array}{l}\text { focus on the social aspect of formulas and the role } \\
\text { they have in communicative interactions. }\end{array}$ & $\begin{array}{l}\text { Bardovi-Harlig } \\
(2006 \mathrm{~b})\end{array}$ \\
\hline Social formula & $\begin{array}{l}\text { the focus is drawn on the language users in a speech } \\
\text { community using a given routine in a specific } \\
\text { situation, either written or spoken. } \\
\text { can be used in SLA research as input and/or also as } \\
\text { target pragmatic features. } \\
\text { evidence suggests that only learners with high } \\
\text { proficiency level can learn and employ social } \\
\text { formulas appropriately }\end{array}$ & $\begin{array}{l}\text { (2009) } \\
\text { Routine } \\
\text { formulae }\end{array}$ \\
$\begin{array}{l}\text { "highly conventionalized prepatterned expressions } \\
\text { whose occurrence is tied to more or less } \\
\text { standardized communication situations" }\end{array}$ & $\begin{array}{l}\text { Coulmas } \\
\text { (1981, pp. 2-3) }\end{array}$ \\
\hline
\end{tabular}




\begin{tabular}{|c|c|c|}
\hline $\begin{array}{l}\text { Conversational } \\
\text { routine }\end{array}$ & $\begin{array}{l}\text { "tacit agreements which the members of a } \\
\text { community presume to be shared by every } \\
\text { reasonable co-member. In embodying social } \\
\text { knowledge they are essential in the handling of day- } \\
\text { to-day transactions" }\end{array}$ & $\begin{array}{l}\text { Coulmas } \\
(1981, \text { p. } 4)\end{array}$ \\
\hline \multirow[t]{2}{*}{$\begin{array}{l}\text { Pragmatic } \\
\text { routine }\end{array}$} & $\begin{array}{l}\text { "those sequences that are frequently used by } \\
\text { speakers in certain prescribed situations, (leaving } \\
\text { aside) presuppositions about the eventual mental } \\
\text { representation of these sequences for either native } \\
\text { speakers or learners". }\end{array}$ & $\begin{array}{l}\text { Bardovi-Harlig } \\
(2009, \text { p. } 757)\end{array}$ \\
\hline & "crucial to social communication." & $\begin{array}{l}\text { Bardovi-Harlig } \\
\text { and Vellenga } \\
(2012, \text { p. } 77)\end{array}$ \\
\hline \multirow[t]{2}{*}{$\begin{array}{l}\text { Conventional } \\
\text { expression }\end{array}$} & $\begin{array}{l}\text { "emphasize the social aspect of use -namely, a } \\
\text { speech community's preference for a particular } \\
\text { string" } \\
\text { "are used frequently by speakers in certain } \\
\text { prescribed social situations" } \\
\text { and leave aside the psycholinguistic studies dealing } \\
\text { with issues related to processing }\end{array}$ & $\begin{array}{l}\text { Bardovi-Harlig } \\
(2009, \text { p. } 757)\end{array}$ \\
\hline & "essential in the verbal handling of everyday life" & $\begin{array}{l}\text { House (1996, } \\
\text { pp. } 227-228)\end{array}$ \\
\hline
\end{tabular}

Based on all these definitions, my understanding of conventional expressions for the present dissertation is: a sequence, a string of words used in everyday specific communicative situations, by the members of a given community of speech, which is not necessarily limited to NSs only, and that allow some degree of variability. Most importantly, it is the social aspects of conventional expressions used in interaction what distinguishes this concept from the rest. 


\subsubsection{Features}

Evidence exists about different categorizations of FcL. These categorizations can also be applied to conventional expressions. Therefore, the term conventional expressions will be used henceforth. For example, Nattinger and DeCarrico (1992), Aijmer (1996), Schmitt and Carter (2004), and Bardovi-Harlig (2006b) ${ }^{14}$ proposed different classifications of conventional expressions according to the functions that these can carry out. Nattinger and DeCarrico (1992, pp. 60-66) classified conventional expressions according to three main interactional functions: 1) 'social interactions,' including 'conversational maintenance' and 'conversational purpose;' 2) 'necessary topics' from which language users are asked about frequently, such as their names or about the weather; and 3) 'discourse devices' which encompass 'temporal connectors,' 'exemplifiers,' and 'summarizers.' Aijmer (1996) classified conventional expressions according to its functions in relation to four specific speech acts: thanking, apologies, requests, and offers. Schmitt and Carter (2004, p. 10) also identified three main functions of conventional expressions: 1) to keep a conversation going; 2) to organize their discourses, both oral and written; and 3) to carry on a conversation "in a precise and efficient manner" to avoid confusion or miscommunication situations. BardoviHarlig (2006b) reported two different strategies: communicative strategies and productive strategies. Using a conventional expression as a communicative strategy provides learners with four specific benefits. First, they allow "learners early entry into communication when there is general lack of competence in target language rules" (p. 2). Second, they elicit more input that can be acquired later. Third, they foster learners' confidence because using them properly implies that the hearer will understand the

\footnotetext{
${ }^{14}$ For further information on issues related to the analysis of conventional expressions in L2 pragmatics see Bardovi-Harlig (2013c).
} 
message they transmitted. Finally, they will make the learner resemble a NS. Using a conventional expression as a production strategy 1) helps learners produce language more fluently as well as process faster; and 2) "saves the speaker planning time that can be used where it is needed more" (p.2).

Regarding the use of conventional expressions, Wray (1999) proposed a classification according to four different groups of speakers: adult NSs, L1 learners, child as well as adult L2 learners, and also aphasic. Wray reviews the most relevant issues per group. For example, in relation to adult L2 learners, she focuses on the following aspects, which she supports with studies that serve as examples: naturalistic and classroom settings, and the role of conventional expressions as communication, and processing and acquisition assistance devices.

For the purpose of the present dissertation, a series of features have been selected that help understand the nature of conventional expressions related to their form and function. The classification proposed by Wray (1999) was included because it differentiates between L1 and L2 speakers, considering the differences that are present in the acquisition of formulaic sequences by L1 and L2 speakers, especially on adult L2 speakers, who may find the classroom context the only resource of input to learn this pragmatic features that facilitate communication.

Myles, Hooper, and Mitchel's (1998, p. 325) classification is also relevant since they propose five features to categorize pragmatic routines in the study of second language development. As mentioned above, the term 'pragmatic routines' is used in this study as an umbrella term, thus encompassing the term 'conventional expressions' in it. Therefore, the features Myles et al. propose for pragmatic routines can also be applied to conventional expressions. According to Myles et al., pragmatic routines are "at least two morphemes in length;" "phonologically coherent, that is, fluently 
articulated, nonhesitant;" "used repeatedly and always in the same form;" "situationally dependent;" and "community-wide in use." As reported in the literature, it may be easier to identify a pragmatic routine that meets the first four features, but more complicated to do so with the last one. See Wood (2015). Bardovi-Harlig (2013b) explains that this complication may be originated by the fact that variability exists in the usage of pragmatic expressions. Bardovi-Harlig provides two more clues to identify these chunks of language. These can be found either in speech and writing; and can be expressed differently, depending on the geographical area the community resides in. Additionally, speakers' age also conditions the use of such sequences, since older native speakers may use an expression different from the one that younger native speakers of the same language may employ to refer to the same concept or issue.

This set of features has been selected because they best describe conventional expressions. It is true that the second feature suggested by Myles et al. (1998, p. 325): "used repeatedly and always in the same form" may prove problematic once variability is taken into consideration. In other words, some of the expressions vary; they are not always used in the same form. For example, Do you have a pen I can borrow? is very frequently used in this way (although other forms are possible), whereas some others are frequently employed in a variety of forms yet the meaning remains unchanged, such as Hi. How are you? and Hello. How are you?

The present section has laid the ground for understanding what conventional expressions are and the features that characterize them. The instruments used in previous studies to measure recognition and production knowledge of conventional expressions, and the research conducted on this pragmatic feature are tackled in the following section. 


\subsection{Research on Conventional Expressions}

It was in the 1970s when the area of FcL saw an increase in research production. Some of the most well-know early studies in FcL include: Wong-Filmore (1976) and Raupach (1984) that observed children's acquisition; Scarcella (1979b), which is considered the first study conducted on pragmatic routines, as seen in Chapter 1; Yorio (1980), who explored the written production of routines in adult L2 learners of English; or Schmidt's (1983) renowned investigation of the pragmatic development of Wes, an EFL learner who arrived in Hawai'i with a very low level of proficiency in English and after a 3year study, this learner experienced an exponential development of his pragmatic competence, in conjunction with his desire to participate in social events, despite his limited grammatical competence.

A renewed interest in pragmatic routines has arisen since the early $21^{\text {st }}$ century (e.g., Schmitt, 2004; Wood, 2010; Wray, 2002, 2012). Nevertheless, literature on FcL dates as back as the 1920s and 1930s, with works on epic poems (e.g., Parry, 1928, 1930, 1932) and anthropology (e.g., Malinowski, 1935). Other fields of research also showed interest for FcL, such as folklore (e.g., Opie \& Opie, 1959), psychology (e.g., Goldman-Eisler, 1968), and grammar (Fraser, 1970). In the field of linguistics, Hymes (1962) was one of the first researchers that looked into these pragmatic features. See Wood (2015) for further details. Wray (2013a) $)^{15}$ discusses six main areas for study that have investigated FcL: 'theory,' that looks into issues of processing, lexis, and grammar; 'clinical, observing language disorders; 'development' of L1 acquisition issues; 'learning and teaching' SLA; “culture," exploring "oral traditions, social roles and cultural [variability]" (p. 318); and 'text,' which examines studies using corpora.

\footnotetext{
${ }^{15}$ For a summarized revision of the concept of 'formulaic sequences' see Wray (2013b).
} 
All in all, the field of FcL has undertaken many different foci of research since it first emerged in the nineteenth century with medical studies on aphasia, until the twenty-first century with either a more psychological perspective focusing on the processing of multiword strings or a social perspective that learning FcL implies and brings to the learner's interlanguage (Wray, 2013a).

Conventional expressions (or pragmatic routines more generally) have been mainly explored in English (e.g., Barron, 2003; Edmonds, 2014; Ghobadi \& Fahim, 2009; Roever, 2005) and Chinese (e.g., Qi \& Ding, 2011; Taguchi, Li, \& Xiao, 2013; Taguchi, Xiao, \& Li, 2016). Other less-researched languages are: French (e.g., Myles et al., 1998; Raupach, 1984), Spanish (e.g., Sánchez-Hernández \& Alonso-Marks, 2018), and Japanese (e.g., Ohta, 1999; Tateyama, Kasper, Mui, Tay, \& Thananart, 1997). As for instruments to measure recognition and production knowledge of conventional expressions, a review of the most frequently employed, such as discourse completion task (DCT) or vocabulary knowledge scale (VKS), can be found on Chapter 6, where those employed in the present dissertation are explained.

The study and teaching of conventional expressions in L2 pragmatics is important due to their undeniable presence in a wide variety of social communicative contexts (e.g., Gyllstad \& Schmitt, 2019; Hinkel, 2014, 2015, 2018). According to Hinkel (2018, p. 6), “[o]ne of the main advantages of teaching conversational prefabs and routinized expressions is that they can encourage learners to participate and thus help develop their speaking skills.” Besides, Hinkel (2018, p. 6) stated that "[m]any studies have demonstrated that recurrent patterned expressions are extremely common and fundamental to language learning and use.” Similarly, Alali and Schmitt (2012) also stated that formulaic sequences are paramount in the processes of learning and using a language and claim that their inclusion in explicit instructional treatments is needed. For 
example, results from Taguchi (2013), Barron (2003) or Bardovi-Harlig (2009) reveal that even higher-proficient students may struggle with these pragmatic features.

Furthermore, Kasper and Blum-Kulka (1993, p. 9) claimed conventional expressions are "one area where insufficient control of pragmalinguistic knowledge is particularly obvious." Therefore, even though these three studies were not based in EFL settings, in light of this evidence, the inclusion of instructional treatments in the classroom setting should be emphasized more in the literature. For example, Bardovi-Harlig, Mossman, and Vellenga (2015b), as Bardovi-Harlig, Mossman, and Vellenga (2015a), analyzed the conventional expressions used in the speech acts of agreement, disagreement and clarification (self-, and other-), in the same context, English for Academic Purposes (EAP). In turn, by devising, testing and then implementing activities created from data in a spoken corpus, in which real-world pragmatics is used, they demonstrate that teaching authentic pragmatics in the classroom is possible. Besides, Bardovi-Harlig et al. (2015b) provided a series of ideas on how to compensate poor representation of pragmatics instruction on textbooks. They did so by means of the use of those corpusdriven materials when teaching both sociopragmatic and pragmalinguistic features of conventional expressions. Thus, Bardovi-Harlig et al. (2015b) proved to be beneficial both for learners (since they learnt the target speech acts) and beneficial for the instructional pragmatic field, since it provided needed and authentic materials to teach pragmatics. For a further application of this technique to teach pragmatic routines, see Bardovi-Harlig, Mossman, and Su (2017).

Learners should be made aware of the fact that some expressions allow variability, such as the response to Hi. How are you? that can be I'm/I am fine, thanks. And you?, I'm/I am good, thanks. And you? or Good. And you? Variability exists within the same expression ('I'm' or 'I am;' 'fine' or 'good') or the whole expression ('I'm 
good. And you?'). Bardovi-Harlig (2012b) observes that "studying [variability] in the use of conventional expressions shows that some speech acts and contexts promote greater use of conventional expressions" and adds that "some conventions are used by more speaker in a community than others" (p. 141) and warns that identifying the rationale behind those decisions merits further research. Moreover, Bardovi-Harlig states that the contexts in which variability in the use of conventional expressions occur should be clearly identified to better understand the operationalization of the conventional expressions occurring in such contexts.

The present investigation contributes to the research on teaching conventional expressions ${ }^{16}$. It includes an explicit instructional treatment so as to teach learners conventional expressions based on real-life experiences and interactions. This will help them learn these expressions more effectively and be able to use them in future real-life situations. As Taguchi (2015b) states, this is the ultimate goal that should be met in the teaching of any pragmatic feature. Furthermore, the implications of including variability in the teaching of conventional expressions can be related to both the use and acquisition of such pragmatic features. See Barron (2012) for examples. The benefits of using conventional expressions have been discussed above. As for the acquisition of conventional expressions, learners can benefit from instruction because the instructional treatment may foster what Pawley and Syder (1983) coined 'nativelike selection'. This refers to NSs' ability to identify and use conventional expression from a variety of sentences that are grammatically correct but may not be conventional ${ }^{17}$. Learners also have this ability, and the role it plays in their L2 language and pragmatic development is

\footnotetext{
${ }^{16}$ For a review of experimental and interventional studies on FcL, see Boers and Lindstromberg (2012).

${ }^{17}$ The issue of defining conventionality of conventional expressions in the present study is dealt with in detail in section 4.3 Target Conventional Expressions.
} 
essential. Hence, the more nativelike selection learners apply to conventional expressions, the more pragmatically competent they should be (e.g. Ortaçtepe, 2013).

In the following two subsections the studies more relevant to the recognition and production studies of conventional expressions are included. The studies set in an EFL context will be tackled first, followed by studies carried out by Bardovi-Harlig. Finally, research conducted in other contexts, such as SA, or other aspects, such as speech fluency, will be discussed.

\subsubsection{Research on recognition and production of conventional expressions.}

The present section reviews some of the existing literature of recognition and production research on conventional expressions in L2 pragmatics. Special emphasis is given to studies conducted in EFL settings, since the present dissertation is set in an EFL context. Additional information is provided about other relevant studies in the literature of pragmatic routines more generally which are based in other contexts, such as ESL or SA. The studies conducted by Bardovi-Harlig (e.g., 2008, 2009, 2010, 2011a), and further studies by this author, such as Bardovi-Harlig, Bastos, Burghardt, Chappetto, Nickels, and Rose (2010), and Bardovi-Harlig and Vellenga (2012), are included in the discussion below because the present dissertation was based in some of them (e.g., Bardovi-Harlig, 2008, 2009, 2011), even though all those studies are based on either ESL context. The studies included in the present section are divided into three groups: recognition studies, production studies, and recognition and production studies.

First, recognition studies are reviewed. Only three were found in the literature: Bardovi-Harlig $(2010,2011,2014)$. Even though these studies are based in an ESL setting, as mentioned before, results from these studies show different patterns related to proficiency. Bardovi-Harlig (2010) found that proficiency did influence the recognition of conventional expressions. However, Bardovi-Harlig (2014) found that even students 
with love proficiency level were able to identify the target conventional expression. These mixed results call for the need for more studies on recognition of conventional expression in ESL, but also in other contexts such as EFL. Evidence from BardoviHarlig (2011) relates to several issues students face in recognizing conventional expressions, such as challenges in distinguishing lexical and grammatical modifications, as well as two-particles conventional expressions.

Bardovi-Harlig (2010) features a further refinement of tasks and change in the mode of presentation of the formulas she employed in Bardovi-Harlig (2008). Please refer to subsection 4.2.2.3 Recognition and production studies below. In this latter study, she provided 123 English learners and 49 NSs with a computerized aural recognition task to test learners' ability to differentiate "authentic, conventional expressions (...) from the modified, nonconventional ones” (Bardovi-Harlig, 2010, p. 141). Results showed that learners were able to make that distinction, but proficiency level played an important role. Additionally, there were some modified expressions participants reported having heard of frequently, which native speakers never did.

Bardovi-Harlig (2011) employs the same refined computer-delivered aural recognition task as in Bardovi-Harlig (2010) above. This task consists of 60 expressions, out of which 35 are original conventional expressions (i.e., not modified), and the 25 remaining expressions have been modified so that they are grammatically correct but are nonconventional. Four main findings are reported: (1) participants made correct reports for those expressions they marked as unknown to them; (2) participants reported that they heard equally often full and reduced form of the same expressions, such as Your are welcome and You're welcome; (3) they faced difficulties with conventional expressions that consist of a verb and a particle, such as Watch out!; and (4) students found it more difficult to differentiate nonconventional grammatically 
modified expressions from the lexically modified ones, in comparison to conventional expressions, which are not modified.

Bardovi-Harlig (2014) analyzed 113 ESL learners' awareness of a set of conventional expressions by means of a computerized Vocabulary Knowledge Scale (VKS) (also employed in Bardovi-Harlig, 2008, see below). Learners were asked to provide definitions and meanings of particular conventional expressions and their responses were compared to the native speakers' participating in the study. Results showed that learners' ability to define and provide examples does not go hand in hand exclusively with higher levels of proficiency since low-intermediate participants could do so as well. Additionally, being aware of what expressions mean may affect learner's use, so some expressions are used in detriment of others. Finally, form-meaning mapping seem not to develop at the same time and are learned gradually, being the form acquired first, and the meaning afterwards, thus "confident use" coming at the end of that process (Bardovi-Harlig, 2014, p. 55).

Second, production studies are reported. Five studies are included: one undertaken in an EFL setting (Rafieyan, Sharafi-Nejad, \& Eng, 2014b), and four in an ESL setting (Bardovi-Harlig, Rose, \& Nickels, 2008; Bardovi-Harlig, Bastos, Burghardt, Chappetto, Nickels, \& Rose, 2010; Bardovi-Harlig \& Vellenga, 2012; Bardovi-Harlig, Mossman, \& Vellenga, 2015a). Evidence from these studies reveals that a series of factors can affect production of conventional expressions, such as instruction, the type of scenarios that target specific conventional expressions, proficiency level, and difficulty of the expressions among others.

Rafieyan, Sharafi-Nejad, and Eng (2014b) explored 45 university learners' oral production of conventional expressions in Iran. Students were randomly divided into three groups: control, experimental (Focus on Form) and experimental (Focus on 
Forms). The former experimental group received instruction by means on watching videos and receiving input flood via written texts where there abounded conventional expressions. The Focus on Forms experimental group received explicit instruction by means of metapragmatic information which was followed by oral practice in the form of role plays. Students in the control group were provided with instruction on grammatical forms of the English language. Each instructional session lasted 1 hour and the instructional treatment lasted for 8 session in total (two sessions twice a week). To test the benefits of instruction, students performed an aural DCT (Bardovi-Harlig, 2009). Results showed that instruction was beneficial for the Focus on Form group, and that no statistically significant difference was found between the two experimental groups.

Bardovi-Harlig et al. (2008) studied the use of conventional expressions with a group of ESL students who were L1 speakers of Chinese, Korean, Arabic and Japanese to test if learners' L1 or proficiency level leveraged production. Results from the computed-delivered aural task and ODCT were compared to those of native speakers'. Results revealed that learners' native-like production was influenced by the nature of the scenario as well as by their proficiency level (Rose, 2000; Tada, 2005), and exposure to the target language culture (Blum-Kulka \& Olshtain, 1986).

Bardovi-Harlig et al. (2010), as part of a larger study including Bardovi-Harlig (2010), tested learners' use of conventional expressions with the same computermediated aural task she used in her study that same year. Several findings were reported. Firstly, scenarios would determine the learners' oral production of these formulas. Secondly, it is suggested that learners acquire conventional expressions starting off with a word and then building on grammar. Finally, and unlike previous research, this author found that there were no significant differences between the number of words and the target forms between learners and native speakers. 
Bardovi-Harlig and Vellenga (2012) examined oral production of conventional expressions only with a pretest-posttest intervention treatment using the same instrument as Bardovi-Harlig (2009) and Bardovi-Harlig and Bastos (2011). Results obtained from an aural recognition task and an ODCT showed that learners' use of conventional expressions is not only subject to instruction but to other factors as well, such as the complexity of the expression and the learner's level of proficiency.

Bardovi-Harlig, Mossman, and Vellenga's (2015a) study focused on the effects of instruction on a given set of conventional expressions. Participants were distributed in an experimental group and a control group. With a pretest-posttest treatment, data were collected by means of a computerized ODCT. This task consisted of 30 items, which tested learners' ability to simulate conversations that required the use of expressions featuring three specific speech acts namely, agreement, disagreement and clarification in academic discussion settings. Findings reveal that instruction was effective, since the experimental group outperformed the control group.

Finally, studies that focus on both recognition and production are reviewed. A total of five studies are discussed: one in EFL (Rafieyan, Sharafi-Nejad, \& Eng, 2014a), one in Chinese as a Foreign Language (CFL) (e.g., Taguchi, Li, \& Tang, 2017) and three in ESL context (Bardovi-Harlig, 2008, 2009; and Bardovi-Harlig \& Bastos, 2011). The studies in EFL contexts are explained first, followed by those undertaken in ESL settings. Evidence from these studies show that learners find it easier to recognize a given conventional expression, and that production may be a harder task to fulfill. Furthermore, other variables may affect this process, such as the delivery mode of the test (e.g., Taguchi et al., 2017). Bardovi-Harlig and Bastos (2011) is an exception in this group, since this study was carried out in a SA context. Nevertheless, results from this 
study suggest that proficiency level together with intensity of interaction were decisive in the recognition and production of conventional expressions.

Rafieyan et al. (2014a) explored the effect of raising students' pragmatic awareness in relation to their abilities to perform recognition and production tasks more native-like in a group of 60 EFL university learners in Iran. Pragmatic awareness was measured by means of an appropriateness judgment task; recognition with a multiplechoice pragmatic pragmatic listening comprehension task, and production via an oral discourse completion task (ODCT). Evidence suggests that the pragmatic awareness task may foster students' pragmatic recognition and production. The authors highlighted the importance of including awareness-raising activities in the syllabus to help students become more pragmatically competence.

Taguchi et al. (2017) carried out an innovative piece of research, since they created a web-based game that consisted of 10 videos that represented 10 different tasks of interactions targeting a total of 28 formulaic expressions, which students had to play with game-based characters. 30 participants enrolled in Chinese courses at a private northeast university in the US participated in this study. Pretest, posttest and delayed posttest possible gains were measured by means of a comprehension test and a production test. The former involved a 28 multiple-choice-item questionnaire, representing 28 different scenarios from those in the game, from which participants had to select one out of four options. As for the computer-delivered production test, students were given seven scenarios written in English language and seven scenarios written in Chinese. There were gaps in the scenarios which students had to fill out by providing formulaic expressions in Chinese. Furthermore, 24 students from this cohort were selected for a one-on-one interview in which they were asked to share their thoughts about the web-based game. Results revealed a knowledge gain that was maintained in 
the posttest. Regarding the interviews, mixed results were found, since some students reported positive opinions about the game, whereas some others identified some aspects that could be improved in the future.

Bardovi-Harlig's (2008) study focused on ESL learners' pragmalinguistic ability only to test both their recognition and production of conversational formulas. This ability was tested by means of a recognition task, a context identification task, a written DCT, and a modified version of Wesche \& Paribakht's (1996) Vocabulary Knowledge Scale. Results showed that learners performed better at recognizing than producing a specific set of formulas.

Bardovi-Harlig (2009) also studied the recognition and production of conventional expressions, now considering proficiency level as well. Additionally, the type of tasks was modified and aural/oral substituted former ones, presented in written mode. Results, however, showed that learners were able to recognize conventional expressions more easily than to produce them, thus mirroring the results of BardoviHarlig (2008). Interestingly, this author found out four patterns that explained the less frequent use of conventional expressions. See below.

Bardovi-Harlig and Bastos (2011) used Bardovi-Harlig (2009) computer-mediated aural and oral tasks to test whether proficiency and two features of study abroad (intensity of interaction and length of stay) influenced the learners' recognition and production of conventional expressions. As regards recognition, the authors found that intensity of interaction influenced greatly on the learners' improvement of recognition of conventional expressions. Learners' use of conventional expressions improved significantly determined by their level of proficiency as well as the intensity of interaction they had with NSs and NNSs. However, length of stay turned out not to be essential on the learners' positive development. 
To sum up, Bardovi-Harlig $(2008,2009)$ reveals that learners' use of conventional expressions is less frequent than their recognition of the same formulas. The author stated that a plausible explanation could be the limited pragmalinguistic resources learners have, which was also found on Bardovi-Harlig and Vellenga (2012). Therefore, learners tend to use more words to express the same idea than they could with a conventional expression. Additionally, in her latter study (Bardovi-Harlig, 2009), the author found four patterns that could also explain these findings: learners reported to be familiar with particular expressions, which they included in their every-day conversation. Some other expressions were not so familiar to learners and, as a consequence, they did not get included in the learners' repertoire. Regarding some other expressions, the more proficient the learners became, the more those routines were produced. And finally, a striking pattern was found, due to the fact that learners reported to be able to recognize some expressions, but they did not actually use them. BardoviHarlig et al. (2008) and Bardovi-Harlig (2010a) also found out that the learners' use of these particular formulas is constrained by the type of scenario. Additionally, BardoviHarlig (2010a) suggested that learners' acquisition of conventional expressions starts off with a word and then builds on grammar. Finally, proficiency level was found to play a role on the oral production of conventional expressions (Bardovi-Harlig et al., 2008; Bardovi-Harlig \& Bastos, 2011; Bardovi-Harlig \& Vellenga, 2012).

Bardovi-Harlig $(2008,2009)$ also reveals that learners were able to recognize conventional expressions more easily than to produce them, or even recognize the high frequency of some expressions, which native speakers have less frequently heard of (Bardovi-Harlig, 2010a). Bardovi-Harlig (2010a) and Bardovi-Harlig and Bastos (2011) also found out that proficiency is also a factor that plays a role in the awareness of conventional expressions. Moreover, Bardovi-Harlig and Bastos (2011) shows intensity 
of interaction as a factor that also affects recognition of these formulas. Finally, Bardovi-Harlig (2014) mirrors those of Bardovi-Harlig (2010a) in that the acquisition of conventional expressions is first lexical and then expanded to grammatical.

All in all, learners have benefitted from instruction in all of Bardovi-Harlig's studies mentioned above as well as in Bardovi-Harlig, Mossman, and Vellenga (2015a, 2015b). Taking all these studies into consideration, and as research suggests that learners benefit from the use of instruction on the use of conventional expressions. I believe that there may be a positive correlation between the explicit instructional treatment I designed for this study and the learners' recognition and oral production of conventional expressions.

As mentioned at the beginning of this section, other studies have research conventional expressions or pragmatic routines in other contexts which have shed light on the existing literature, helping understand the processes that affect the learning and acquisition of these pragmatic features as well as the development of pragmatic competence. Examples of such studies are: in SA (e.g., Alcón-Soler \& SánchezHernández, 2017; DeBoer, 2015; Roever, 2012; Sánchez-Hernández, 2017, 2018; Taguchi, 2013; Taguchi, Li, \& Xiao, 2013; Taguchi, Xiao, \& Li, 2016; Yang, 2016); in multilingual settings (e.g., Safont \& Portolés, 2016; Spöttl \& McCarthy, 2003); studies on written production of formulaic language (e.g., AlHassan \& Wood, 2015; Durrant \& Mathews-Aydinli, 2011; Pérez-Llantada, 2014; Peters \& Pauwels, 2015); and on fluency (e.g., Tsou \& Huang, 2012; Rafieyan, 2018).

This dissertation explores the recognition and production of conventional expressions by a group of undergraduate EFL learners exposed to an instructional treatment. As an innovation, this study also considers students' attitudes towards the English language and the instructional treatment received. This study aims to contribute 
to the existing literature in four ways. First, both recognition and production of conventional expressions are examined, in comparison to those studies which only explored recognition (Bardovi-Harlig, 2010, 2014), as well as to those which only investigated production (Rafieyan et al., 2014b, in EFL context; Bardovi-Harlig, Rose, \& Nickels, 2008; Bardovi-Harlig et al., 2010; Bardovi-Harlig \& Vellenga, 2012; Bardovi-Harlig et al., 2015a, in ESL context). Regarding existing literature on recognition and production, most of the studies have been carried out in an ESL setting (Bardovi-Harlig, 2008, 2009; and Bardovi-Harlig \& Bastos, 2011), and in CFL (Taguchi, Li, \& Tang, 2017). Only one study has investigated these two skills in an EFL context (Rafieyan et al., 2014a). Therefore, The first contribution deals with the inclusion of both skills in one same study. The second contribution is related to the research setting. Extensive literature can be found on ESL and SA. However, fewer studies can be found in EFL, which is the context where this dissertation was conducted. The third contribution deals with the goals aimed to achieve with the provision of explicit instruction. Explicit instruction was provided to foster a) students' learning of conventional expressions, and b) students' future application of the target conventional expressions in real-life situations. Finally, a fourth contribution is related to the inclusion of attitudes and the effects it may have on both the English language, as well as the particular instruction implemented, which, as mentioned before, no other study has explored to date.

\subsection{Target Conventional Expressions}

A total of 23 conventional expressions were selected for the purpose of this study. They were divided into target conventional expressions used in the vocabulary knowledge scale (VKS) and the computer-delivered ODCT $(n=18)$, and those used as distractors in the instructional treatment $(n=5)$. Before going into detail on each of the 
expressions, a few issues are worth discussing: 1) difficulty of the expressions; 2) number of items included in the tests; 3 ) operationalization of validity of the conventional expressions.

As for difficulty, easier and more difficult expressions were included in this study in line with Taguchi and Roever's (2017) discussion about (the importance of) teaching conventional expressions, to which they refer as "routine formulae" (p. 229), to less proficient students. Taguchi and Roever pointed out to the existence of the majority of the research on routine formulae being carried out on intermediate students, and that "there is no reason why low-proficiency learners could not be taught simple, useful routine formulae" (p. 25) considering they can be stored as whole. Additionally, evidence suggests (e.g., Bardovi-Harlig, 2009; Roever, 2012) that difficulty in routine formulae may reside in their grammatical complexity (opacity) together with the frequency in the input (p. 25). Therefore, teaching less proficient students easier routine formulae such as Hi. How are you? should not posit higher cognitive demands and should help them boost their pragmatic competence. Besides, Taguchi and Roever argued that providing more proficient learners with instruction on how to use conventional expressions in real-life situations is also paramount, and as research shows, 1) this issue has received scant attention and 2) even more proficient students may be in need of pragmatics instruction despite their well-developed linguistic competence. On this last note, Taguchi and Roever claimed that further research is needed on the provision of instruction on routine formulae, since it may be an advantage to learners of all levels of proficiency, not only as for the pragmalinguistic resources per se, but also the sociopragmatic issues concerned with those routine formulae. Instructing learners on the contextual and cultural phenomena linked to routine formulae in communicative situations will allow students to identify context-related 
issues that may not be attended to without instruction, and which may cause communication breakdown due to for example cultural differences.

Concerning the number of items included, 17 were included in the VKS and 15 in the computer-delivered oral discourse completion test (computer-delivered ODCT). These are numbers agreed on in the literature which make a task neither too short nor too long. For example, Fukuya and Martínez-Flor (2008) included 16 items in their study on the effect of explicit and implicit instruction on the speech act of suggestions by means of DCTs; and as reported by Félix-Brasdefer (2010), a standard written DCT (WDCT) normally comprehends from 12 to 18 items $^{18}$.

Finally, conventionality ${ }^{19}$ was operationalized in the present study in line with Bardovi-Harlig $(2008,2009)$ and Bardovi-Harlig et al. (2010), where they set a 50\% cut-off as a measure to include or exclude a given conventional expression. A small group of NSs were contacted and sent a table via email, which included the target conventional expressions and the scenarios in which they would be used. Those NSs in particular were contacted because they were born and raised in different states in the US, although they all lived in Pittsburgh (PA) by the time they were reached. By including NSs from different areas of the country, it was aimed at checking for the validation of variable forms that some target expressions allowed. Thus, it was tried to ensure as much as possible the "community-wide in use" feature proposed by Myles et al. (1998). See Chapter 4. The NSs agreed on $100 \%$ of the expressions and situations. Furthermore, they provided feedback to improve the intelligibility of the scenarios. For example, they suggested vocabulary changes in a few number of situations to avoid ambiguity.

\footnotetext{
${ }^{18}$ For further information about rationale for item inclusion, see subsection 6.4.3 Computerdelivered Oral Discourse Completion Test.

${ }^{19}$ For a recent discussion on how conventionality is operationalized in L2 pragmatics see Bardovi-Harlig (2019a).
} 
Considering the issues mentioned before, two tables are presented as follows. The first (Table 5) includes the target conventional expressions used in the vocabulary knowledge scale (VKS) and the computer-delivered ODCT in the pretest, posttest and delayed posttest of this study. From these target conventional expressions, 17 were included in the VKS, and 15 in the computer-delivered ODCT. The expressions Good. How are you? and I'd love to were not explicitly given a scenario in the computerdelivered ODCT because they were elicited in the supermarket situation the first, and the dancing with the friend situation the latter. The second table (Table 6) includes the five conventional expressions used as distractors in the instructional treatment Session 1. The information in each table is presented as follows: the first column represents the scenario eliciting a given conventional expression. Then, the second column includes the target conventional expressions. The third column shows possible different forms of variation; and the fourth and last column reflects the source from where the conventional expression was selected. 


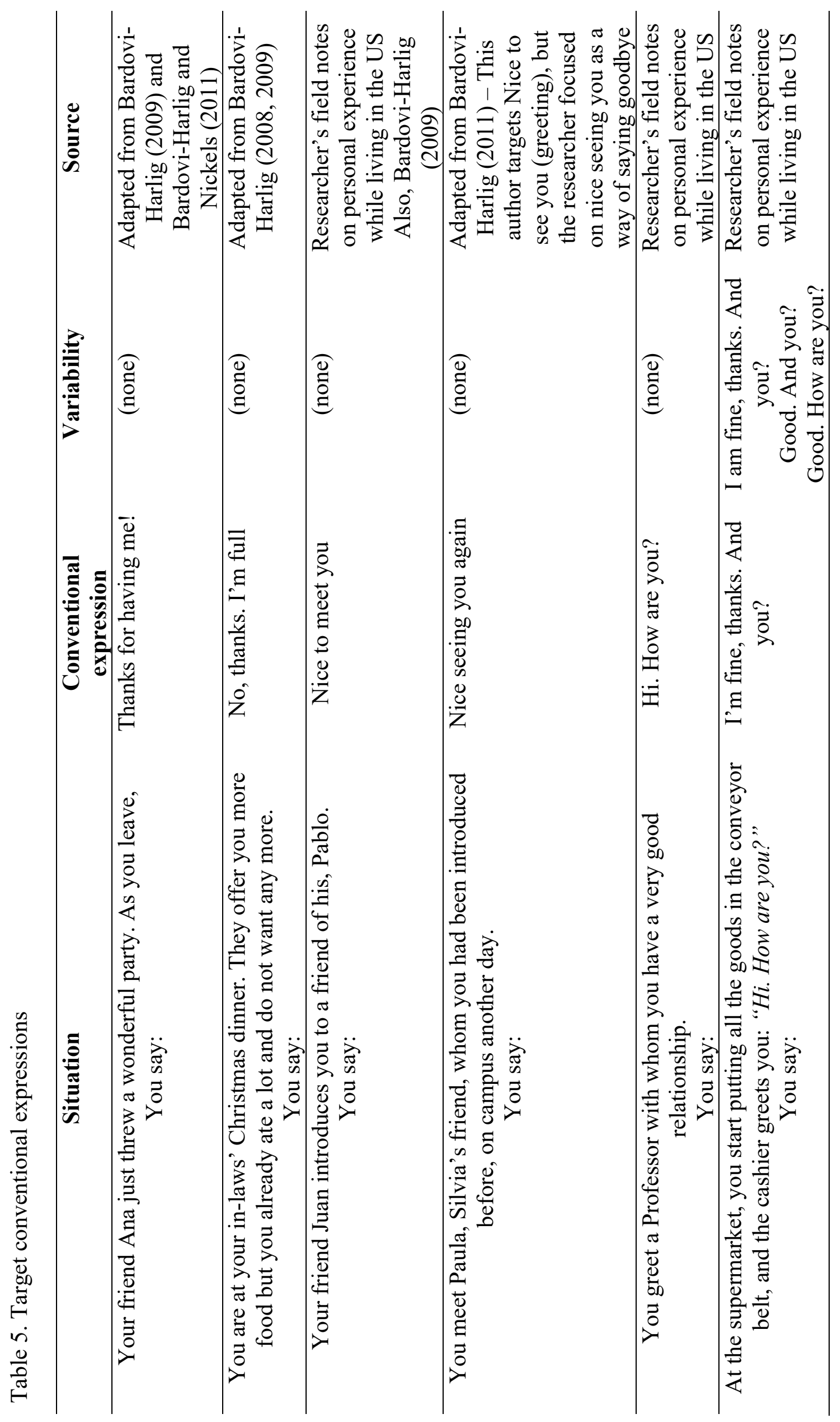




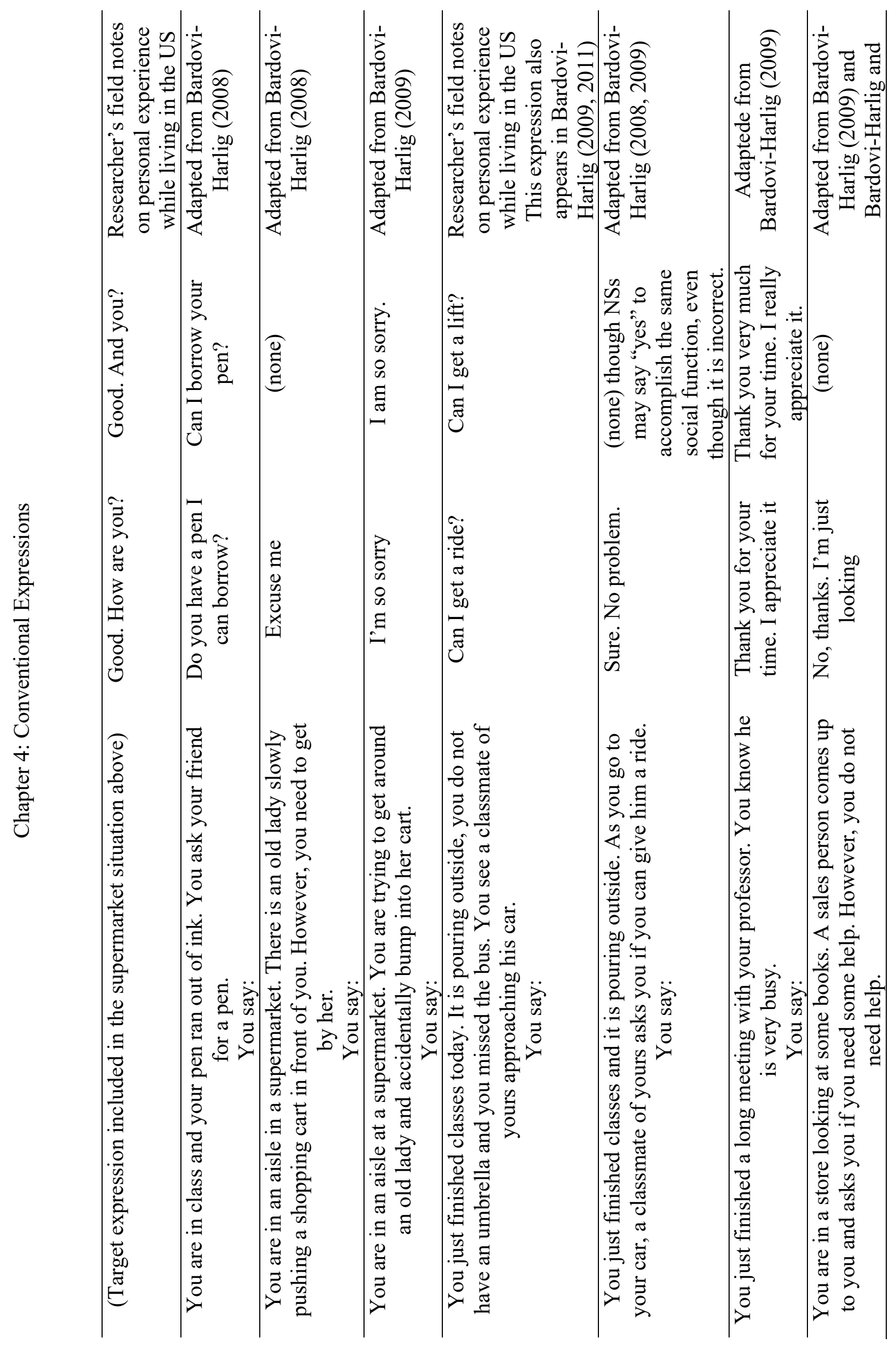




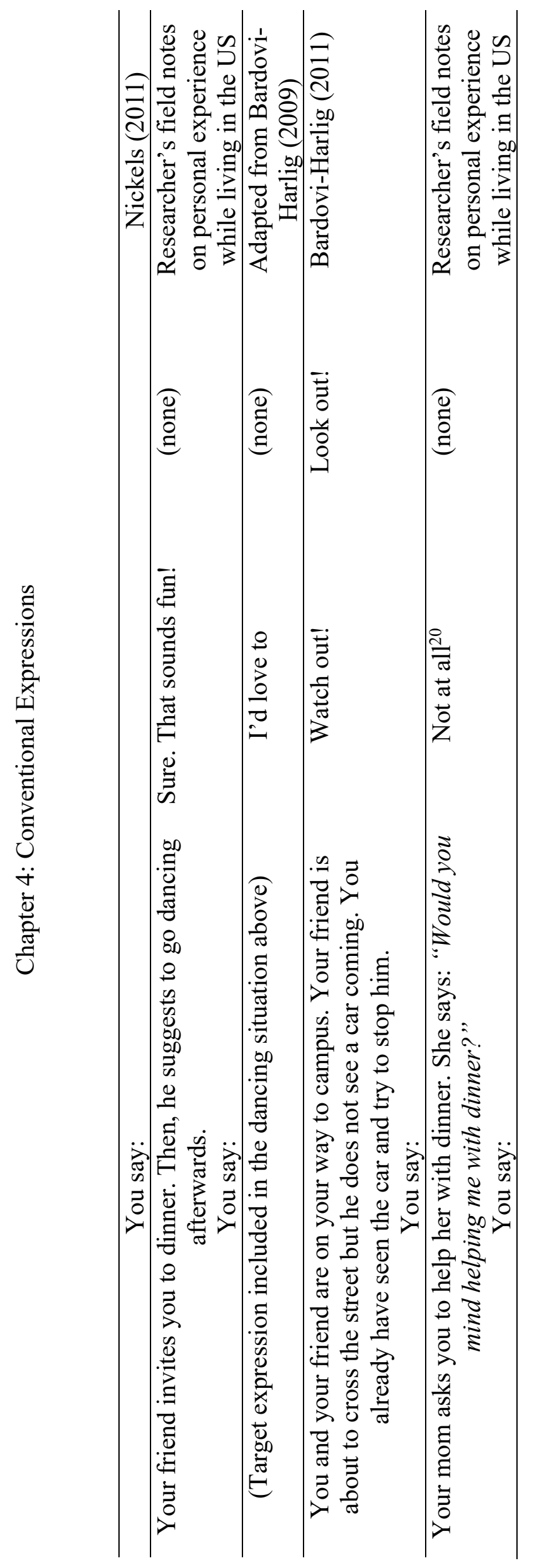




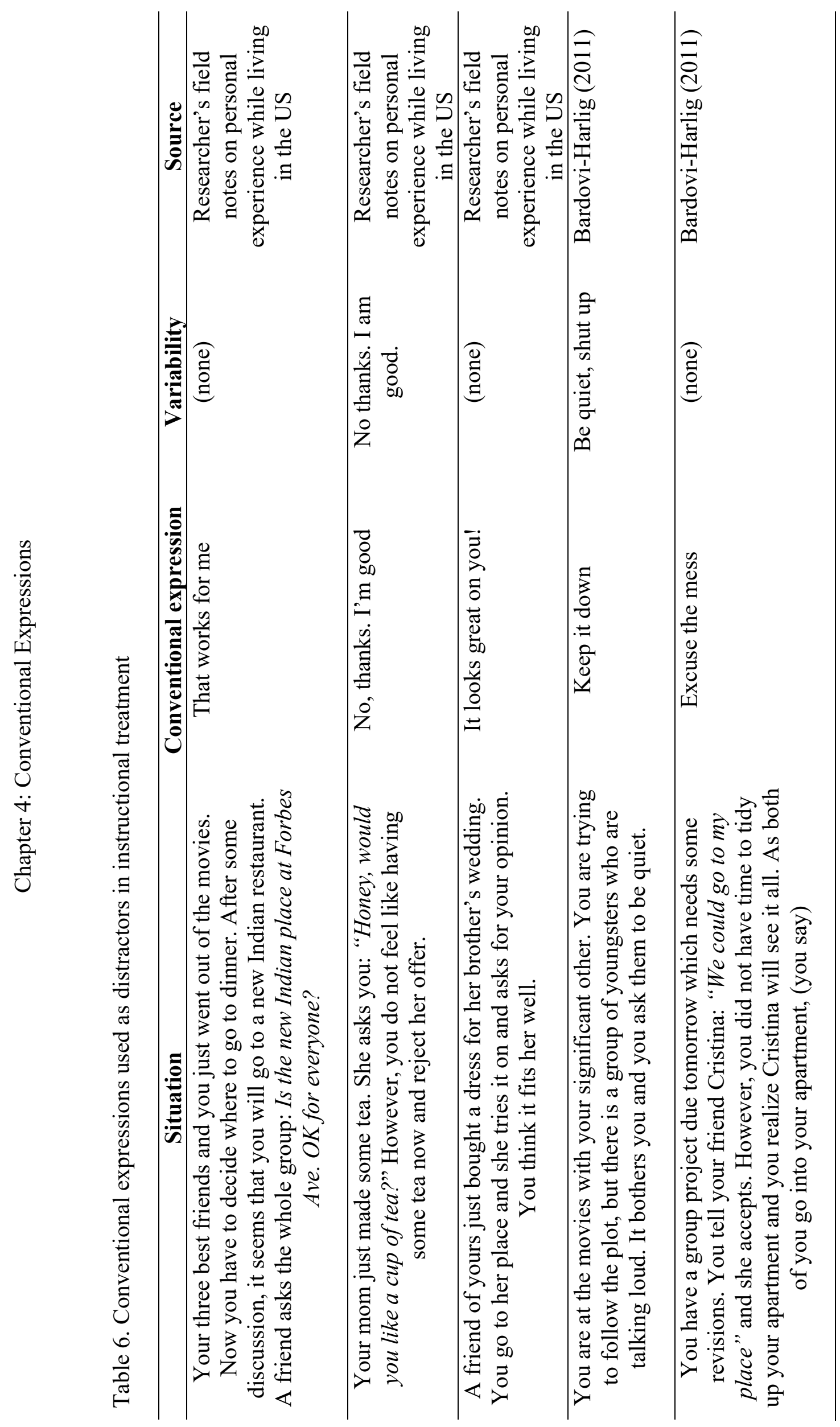




\subsection{Chapter Summary}

Chapter 4 provides a comprehensive overview of the concept of conventional expressions, and pragmatic routines as an umbrella term, and the research undertaken on this pragmatic feature in EFL settings mainly, where the present dissertation was carried out.

In the first section of the chapter, the concept of conventional expressions was explained in detail, ruling it out from other related concepts such as formula, or chunk. After that, the features that characterize this pragmatic phenomena were explained as well as the different classifications of pragmatic routines, mainly related to their social functions, which is the issue that differentiates conventional expressions from the rest of formulaic expressions (e.g., Nattinger \& DeCarrico, 1992; Aijmer, 1996; Schmitt \& Carter, 2004; and Bardovi-Harlig, 2006b).

The second section of the chapter included the characterization and description of the research conducted on conventional expressions in ILP and the identification and rationale to include the target conventional expressions used in this study. First of all, the scope of research carried out on conventional expressions was discussed. Two other features were also tackled: teaching conventional expressions, and the fundamental role it may play in EFL settings, as well as the issue of variability in the use of conventional expressions and the importance of including it in the teaching of these pragmatic resources. Finally, the chapter concludes with a review of some of the studies carried out on conventional expressions in EFL settings, but also most of Bardovi-Harlig studies, because, as mentioned above, the present dissertation was inspired by BardoviHarlig's studies $(2008,2009)$. The review of such studies was divided into three main groups: recognition studies, production studies, and recognition and production studies. A final paragraph included some of the most important pieces of research on pragmatic 
Chapter 4: Conventional Expressions

routines conducted in other research areas, such as SA or multilingual settings. This final paragraph was included to acknowledge the extensive work undertaken on formulaic expressions in different settings other than EFL. Finally, the 23 conventional expressions used in this study were identified, and commented on, including the rationale (e.g., difficulty and social situation) why they were selected. 
PART II: THE STUDY 



\section{Chapter 5: Motivation for The Study}

The present chapter explains the reasons that motivated the present investigation in

Section 5.1, as well as the research questions and hypotheses, formulated in Section 5.2. Finally, the Chapter Summary is presented in Section 5.3

\subsection{Purpose}

Two personal life events motivated me to carry out the present dissertation: a personal experience in Alfred (NY), and my MELACOM (Masters for the Teaching of English in Multilingual Contexts, Universitat Jaume I, Castellón, Spain) Masters thesis.

In regards to my personal experience, it dates back to Fall 2011, when I travelled to Alfred (NY) to do a four-month stay abroad as a requirement to graduate in my undergraduate studies in English Philology. When I arrived to this small town in upstate New York and started interacting with American NSs, they told me that I spoke 'bookish English'. That stroke me so much that I decided to pay closer attention to social interactions between people, both in and outside the classroom setting, older and younger, all members of the wider community -the country/region- and smaller communities -such as college friends or family. I especially enjoyed and learned from the social informal situations that took place outside the academic environment. That is why most of the situations included in the present dissertation take place in nonacademic settings. I started going to the local café and listen to people talk. I took notes about their and my interactions with the baristas among other people. In so doing, I realized that certain expressions were recurrent and specific to certain interactional events, such as the greeting a cashier will use at the supermarket or interacting with a sales assistant while going shopping. Most importantly, I found myself in all of those situations, and to some of whose I did not know what to say. I had never encountered such expressions in my textbooks, and when I had, it was all related to what I found to 
be stereotypes, or other things that did not really seem to make sense to me now that I was immersed in the context. All of these experiences and issues and situations made me think about how NSs really use the language, the cultural and the social sides of the language.

From everything I observed, I was fascinated by those short conversations that often do not add much information, but which bring a much social and cultural character and help to maintain and enhance social communication; and these are conventional expressions. Therefore, I took the opportunity while being abroad to learn from NSs, ask them whenever I had doubts, and try to learn those expressions to improve my pragmatic competence. By the end of my stay, I had learnt quite a few, and that made me more confident about my English, which in turn made me like the English language even more.

When I came back home to Spain, I graduated and enrolled in the MELACOM Masters Program. As a graduating requirement, I had to design and implement a research study and I saw that opportunity to investigate conventional expressions in an EFL setting. In my study, entitled The effect of instruction on production and recognition of pragmatic routines: a case study under the supervision of Dr. AlcónSoler, I taught a series of conventional expressions to children aged five to seven in an EFL context. Results evidenced that: (1) participants' oral production of pragmatic routines was better than their recognition, which may have been due to instructional effects. (2) Including pictures that aimed to reinforce the routine-picture association was essential to foster participants' acquisitional process. And, (3) emotions had an affect on both language learning and use.

All in all, seeing that the young students had learnt pragmatic routines to a certain extent by means of the games, instructional treatment, and tasks created, inspired me to 
further study these expressions in adult language learners. In what follows, I present the six aims of this dissertation as well as its contributions to the existing literature.

Recognition and production of conventional expressions

- AIM 1: Investigate the effect of an explicit instructional treatment on both the recognition and production of conventional expressions.

As explained in Chapter 4, research on conventional expressions has focused mostly on recognition (Bardovi-Harlig, 2010a, 2011, 2014), on production (Rafieyan, SharafiNejad, \& Eng, 2014b; Bardovi-Harlig, Rose, \& Nickels, 2008; Bardovi-Harlig, Bastos, Burghardt, Chappetto, Nickels, \& Rose, 2010; Bardovi-Harlig \& Vellenga, 2012; Bardovi-Harlig, Mossman, \& Vellenga, 2015a), with some studies including both recognition and production (Bardovi-Harlig, 2008, 2009; and Bardovi-Harlig \& Bastos, 2011; Taguchi, Li, \& Tang, 2017). As for these studies, examining both recognition and production, the majority has been conducted in an ESL context. Therefore, the present study aims to contribute to the research that explores both recognition and production of such sequences in an EFL environment, which -to the best of our knowledge- only one study has investigated: Rafieyan, Sharafi-Nejad, and Eng (2014a). In so doing, this dissertation provides a more comprehensive perspective on the learning of conventional expressions.

Research on conventional expressions in EFL setting

- AIM 2: Explore the effect of instruction on such pragmatic features in an EFL setting.

As seen in Aim 1 above, most of the studies conducted on the recognition and production of conventional expressions have been conducted in ESL settings (BardoviHarlig, 2008, 2009), CFL (Taguchi, Li, \& Tang, 2017), SA (Alcón-Soler \& SánchezHernández, 2017; Bardovi-Harlig \& Bastos, 2011; DeBoer, 2015; Roever, 2012; 
Sánchez-Hernández, 2017, 2018; Taguchi, 2013; Taguchi, Li, \& Xiao, 2013; Taguchi, Xiao, \& Li, 2016; Yang, 2016). In contrast, the present investigation contributes to the examination of recognition and production of conventional expressions in an EFL context.

Instruction

- AIM 3: Examine whether the explicit teaching employed proves effective for the learning of conventional expressions.

Evidence of the effect of instruction in pragmatics in general reveals four different trends: explicit treatment is more effective than implicit treatment, including metapragmatic instruction/awareness and production (e.g., Alcón-Soler \& MartínezFlor, 2005; Jeon \& Kaya, 2006; Norris \& Ortega, 2000; Taguchi, 2015b; Taguchi \& Roever, 2017); implicit treatment is more effective than explicit treatment (e.g., AlcónSoler, 2005; Fukuya \& Martínez-Flor, 2008); both treatments are equally effective (Fukuya \& Zhang, 2002; Narita, 2012), and explicit instruction is not effective (e.g., House, 1996). The present study aims to shed some light on the inconclusive results in the literature about the effectiveness of explicit versus implicit instruction (Chapter 2).

Most evidence of instructional effects on recognition of conventional expressions comes from research in ESL settings (Bardovi-Harlig \& Vellenga, 2012; Bardovi-Harlig et al., 2015a). Regarding instructional effects on recognition and production, Rafieyan et al. (2014a) was conducted in an EFL setting. As for explicit versus implicit instruction, most studies on conventional expressions used explicit instruction. This type of instruction entails metapragmatic information, instruction, and practice activities either written (Bardovi-Harlig \& Vellenga, 2012) or oral (Bardovi-Harlig et al., 2015a). Therefore, the present study contributes to the literature because it includes instruction by means of explicit metapragmatic instruction and discussion as well as written 
practice (appropriateness judgment task, AJT) and oral practice (role-plays). This pedagogical intervention is employed to raise students' awareness of both the pragmalinguistic features under study as well as the sociopragmatic contextual features inherent to each situation. Additionally, the explicit instructional treatment includes conventional expressions based on real-life experiences and interactions. In so doing, it aims to foster 1) students' learning of conventional expressions, and 2) students' future application of the target conventional expressions in real-life situations.

The instructional treatment in this dissertation also differs from the existing ones in that there is variability. In other words, a wide array of options is presented in the PowerPoint Presentation in Session 1, while in previous studies only the canonical most appropriate expression was used. For those expressions that allowed variability of some sort, other possible expressions were included and participants knew that all could be used. Explanations about the sociopragmatic features of each context were also provided to students in order for them to better understand the target conventional expressions as well as their use in each of the situations. Such metapragmatic instruction was used to raise students' awareness, which studies in both EFL and ESL studies have regarded as essential in the provision of instruction in teaching pragmatics.

\section{Language attitudes}

- AIM 4: Observe participants' attitudes towards the interventional treatment provided.

- AIM 5: Study participants' attitudes towards English.

Research abounds on the effect of attitudes towards languages in multilingual settings (e.g., Huguet, 2007; Lasagabaster, 2007; Loredo, Fernández, Suárez, \& Casares, 2007; Nightingale, 2012, 2016; Portolés, 2011, 2014, 2015; and Safont, 2007, 2015) and with different populations: adolescents (e.g., Nightingale, 2016), children (e.g., Portolés, 2015) 
and university students (e.g., Safont, 2007). From within these studies, just one explores the relation between attitudes and pragmatics (e.g., Portolés, 2015). Therefore, the present study aims to contribute to the literature on the effects of language attitudes towards languages in three ways. First, and more generally, this study investigates language attitudes and ILP in an EFL context. Second, and more specifically, the present study explores the cognitive component of attitudes towards English based on the students' recognition and production of conventional expressions, which, as far as could be established, has not been explored. Particularly, I attempt to identify the extent to which favorable attitudes may play a role in the production and recognition of conventional expressions. Finally, the present study also contributes to the literature by studying participants' attitudes towards English, based on their attitudes towards the instructional treatment they received. Portolés (2011) stresses the importance of conducting research on language attitudes and pragmatics to identify such attitudes and track the possible effects they can have in the development of students' pragmatic competence. This study presents several novelties, since, to the best of my knowledge, no study to date has included the connection between attitudes and conventional expressions in EFL.

\section{Research design improvement}

- AIM 6: Explore the possible effect of instruction over time

As explained in Chapter 4, from some of the studies on conventional expressions, only three included instructional treatment as a variable to affect recognition and/ or production of conventional expressions: Bardovi-Harlig and Vellenga (2012), Bardovi-Harlig et al. (2015a), and Rafieyan et al. (2014b). The research design of all of these studies included a pretest and a posttest but not a delayed posttest. Therefore, the present study contributes to this existing literature by including a delayed posttest to explore whether the effects of instruction are maintained over a longer period of time. 


\section{Improvement of production task}

- AIM 7: Improve the computer-delivered ODCT to create a more robust and reliable data collection instrument

Many studies that have looked into the oral production of conventional expressions have used ODCTs (e.g., Bardovi-Harlig, 2009; Bardovi-Harlig et al., 2010; Bardovi-Harlig \& Bastos, 2011; Bardovi-Harlig et al., 2008; Bardovi-Harlig \& Vellenga, 2012; BardoviHarlig et al., 2015a; and Rafieyan et al., 2014a). All of these studies used the same ODCT: the one designed by Bardovi-Harlig (2009). Since ODCTs have received so much criticism (see Chapter 6), a series of features were introduced to improve the computerdelivered ODCT created specifically for the present dissertation. First, audiovisual material was included in the form of pictures and a video that depicted real-life situations. Additionally, a retrospective verbal protocol (RVP) was added to this instrument to gain qualitative insights into the quantitative data obtained from the computer-delivered ODCT.

To sum up, the present investigation contributes to the literature in six ways:

- Includes the study of both recognition and production of conventional expressions,

- Explores an EFL setting.

- Examines the effects of instruction.

- Examines attitudes:

○ towards English and

o towards the instruction received.

- Includes a delayed posttest, in order to track the possible effects of instruction for a longer period of time.

From these research aims, two research questions and their subsequent hypotheses have been formulated, which are presented in the following section. 


\subsection{Research Questions}

Research question 1 (RQ1): To what extent does explicit instruction affect the development of conventional expressions?

Research has shown that learners find it easier to recognize conventional expressions rather than to produce them. Besides, evidence shows that instruction is essential in order to foster learners' pragmatic competence. Based on previous studies, three hypotheses are formulated regarding this research question.

Hypothesis 1 (H1): Participants' awareness of conventional expressions will improve after receiving instruction (posttest), and will mostly be lost after a longer period of time (delayed posttest), as measured by the scores in the VKS.

Hypothesis 2 (H2): Participants' production of conventional expressions will improve after receiving instruction (posttest), and will mostly be lost after a longer period of time (delayed posttest), as measured by the scores in the computer-delivered ODCT.

Hypothesis 3 (H3): Participants' responses to the retrospective verbal protocols will reflect the effect of instruction on their recognition and further production of conventional expressions.

The second part of this dissertation focuses on students' attitudes. Research question 2 (RQ2) answers this question.

Research question 2 (RQ2): How do participants' attitudes influence towards the recognition and use of conventional expressions?

Previous studies that investigated the effect of attitudes towards languages have shown that attitudes play a decisive role in the language learning process.

Hypothesis 4 (H4): Students with more positive attitudes towards the instructional treatment will perform better after instruction. 
Chapter 5: Motivation for The Study

Hypothesis 5 (H5): Participants will change their attitudes in the attitudes questionnaire across times. 
Chapter 5: Motivation for The Study

\subsection{Chapter Summary}

The present chapter examined first the reasons that drove the design of the present study as well as the aims and contributions that this dissertation brings to the existing literature on ILP, teaching pragmatics, conventional expressions, language attitudes, and research in the field of EFL. Finally, the research questions and hypotheses drawn from the research gaps are explained. 


\section{Chapter 6: Method}

The present study aims to examine the effects of technology-enhanced instruction and language attitudes on the developmental process of recognition and production of a given set of conventional expressions by Spanish learners of English in an EFL context. As the theoretical underpinnings that support the study were articulated in the first four chapters and the rationale and research questions by which this study was driven were explained in Chapter 5, Chapter 6 accounts for the method designed to conduct the present dissertation. The following subsections are explored in detail: the setting and participants in Section 6.1, a revision of the target conventional expressions in Section 6.2, the instructional treatment in Section 6.3, the instruments for data collection in Section 6.4, the data collection procedure in Section 6.5, the data analysis for both quantitative and qualitative instruments in Section 6.6, and the Chapter Summary to conclude in Section 6.7.

\subsection{Setting and Participants}

Data were collected at Universitat Jaume I, in Castellón de La Plana, Spain. This is a public institution composed of four main schools, namely the College of Humanities and Social Sciences, the School of Technology and Experimental Sciences, the School of Law and Economics, and the School of Medicine. This university is multilingual in nature, since both Spanish and Catalan languages are co-official. English for Specific Purposes (ESP) courses in the freshmen year are a requirement in all major programs throughout campus. Data for the present study was collected at the College of Humanities and Social Sciences for one main reason: data accessibility. Therefore, this study was conducted in an English as a Foreign Language (EFL) context, that is, one in which English is not the (co)official language. As previously explained in Chapter 2, since English is not used in the community, learners have a rather limited access to the 
language. The academic environment tends to be the only, or main, setting where students may have access to and put into practice their knowledge of English. Therefore, pragmatics instruction is essential, since learners will find scarce opportunities to practice the TL outside the instructional setting. In other words, in such educational environments, classroom instruction may be the only opportunity learners have to receive input and have interactional situations to practice their L2 (Nguyen et al, 2012; Eslami \& Liu, 2013).

Other sources that allow EFL students to be in contact with English in this particular context are the media and exchange student programs, to which they can enroll later in their Junior and Senior years. Additionally, students may also have the opportunity to be in contact with other exchange students that come to Universitat Jaume I from different (non-) English-speaking countries to do their stay abroad semester program. In addition, Universitat Jaume I hosts a series of events throughout the semester in which local students can sign up to meet the incoming exchange students from Europe, US, and Asia. Such events bring about opportunities for local and exchange students to meet new people, get to know and understand other cultures, and be more open to the world. For example, cooking events, where exchange students prepare special dishes from their countries of origin, are excellent opportunities for local and exchange students to interact. These encounters help students develop their interpersonal skills, which is essential in the globalized world we live in nowadays.

Participants in this study were 48 undergraduate junior year students enrolled at the English Studies Degree in the aforementioned university. Data from two participants from the control group were not included in the final sample because one participant was a NS from the US and the other participant looked for information about the target pragmatic features online, thus having access to some of the information provided to 
participants in the experimental group. The final sample consisted of 46 participants. Male participants' $(n=14)$ age ranged from 20 to $45($ Mean $=24.21)$. Female participants' $(n=32)$ age ranged from 20 to 55 (Mean $=23.21)$. All 46 participants were enrolled in the course EA0930: English Sociolinguistics. From the 46 students, 21 made up the experimental group, who were enrolled in the course E0936: Linguistics and English Language Teaching Methodology. The rationale behind dividing the participants into the control group and the experimental group was based on the courses that they were enrolled in. These were the two courses to which access was granted to collect data for this dissertation. As mentioned above, all participants took a language attitude questionnaire, which included some questions eliciting background knowledge from the students. In regards to participants' L1s, the majority of the students indicated that their L1 was Spanish $(n=21)$ or both Catalan and Spanish $(n=15)$. A more reduced group acknowledged Catalan as their L1 $(n=5)$. Finally, a minority stated that Italian $(n=1)$ or Rumanian $(n=4)$ was their L1.

All 46 participants were junior year students enrolled in the English Studies Degree. In this degree, all the instruction is provided in English, except for very few optional courses that are offered in other languages, such as Spanish. Regarding participants' proficiency level, it ranged from $\mathrm{A} 2$ to $\mathrm{C} 1$, that is, from upper beginner to advanced, according to the Common European Framework of Reference (CEFR). The Quick Placement Test (Oxford University Press) was administered to determine the participants' English proficiency level according to the CEFR. The scores obtained by the students are shown in Table 7 grouped according to their proficiency level. 
Table 7. Number of students per level of proficiency in English

\begin{tabular}{|l|l|}
\hline Level of proficiency & Students $(N=46)$ \\
\hline A2 & 1 \\
\hline B1 & 11 \\
\hline B2 & 25 \\
\hline C1 & 9 \\
\hline
\end{tabular}

The CEFR conceives language proficiency in terms of six different levels. A1 and A2 levels correspond to a low proficiency level. Moving up the scale, the levels B1 and B2 correspond to the intermediate proficiency level. Finally, C1 and C2 levels correspond to an advanced proficiency level. As shown in Table 7 above, the majority of the students were placed in an intermediate level of proficiency $(n=36)$. A further distinction within this particular proficiency level refers to whether these are preintermediate, namely B1 level $(n=11)$, or upper-intermediate, namely B2 level ( $n=$ 25). Only one participant was reported to have an A2 level, which is the upper-beginner level. Lastly, nine participants were placed in the $\mathrm{C} 1$ level, which translates into the first of the two levels within the advanced level of proficiency aforementioned.

In regards to the media mentioned above, participants were asked about their use of newspapers, TV, and music in the Attitudes Questionnaire. They were asked to mark the language they prefer to 1) watch TV or online shows; 2) read the press; 3) listen to music; and 4) listen to the radio on a likert scale from one to seven, one being "Always in L1" and seven being "Always en English." This likert scale also accounted for an L2, which to most of the participants in the present study was not English, but either Spanish or Catalan mainly. Data from the Attitudes Questionnaire showed that the majority of the participants watched TV or online shows often in English (54\%), while $19 \%$ of the participants reported watching TV/Online shows always in English, 15\% reported doing this activity fore often in their L2 than in their L1, and only about a $6 \%$ 
watched TV/Online shows in their L1. Interestingly, 32\% of the participants reported reading the press in their L1 (mostly Spanish) and the same percentage of students doing so exclusively in English. As regards to music, $63 \%$ of the participants stated that they listen to it in their L2 more often than in English, and nearly 24\% reported doing so always in English. On the contrary, when it comes to listening to the radio, nearly $37 \%$ of the participants reported doing so always in their L1, whereas only $2 \%$ listen to the radio always in English. About $19 \%$ of the participants prefer listening to the radio always in their L2, that being Spanish, whereas $13 \%$ of the participants do so more in the L2 than in their L1, and another 13\% always in English. All in all, this cohort represents a multilingual group of learners who generally prefers to use the English language to Watch TV/online shows and to listen to music. On the other hand, when it comes to listening to the radio, most prefer to do so in their L1, some do so equally in their L1 and L2, and fewer participants do so often in English. This picture is somewhat similar regarding the press, since students prefer to do so always in their L1 and only a minority reading the press often in English.

Data for the pretest, posttest, and delayed posttest were collected at three different locations: 1) a classroom, 2) the researcher's office, and 3) another departmental facility, due to institutional constraints. Data collection from the instructional sessions took place at a different classroom in the same university building. In terms of technological appliances available, both classrooms in the building were equipped with a multimedia table, which consists of one PC with two screens, and an overhead projector. As regards to the researcher's office and the aforementioned departmental facility, the researcher's personal laptop was the only instrument needed to collect data with. 
Chapter 6: Method

\subsection{Target Conventional Expressions}

A total of 23 conventional expressions were selected for the purpose of this study, as explained in Chapter 4. Table 8, a summarized version of Table 5 (see Chapter 4), is included in this section to facilitate recalling the expressions used in the VKS and computer-delivered ODCT tasks. 


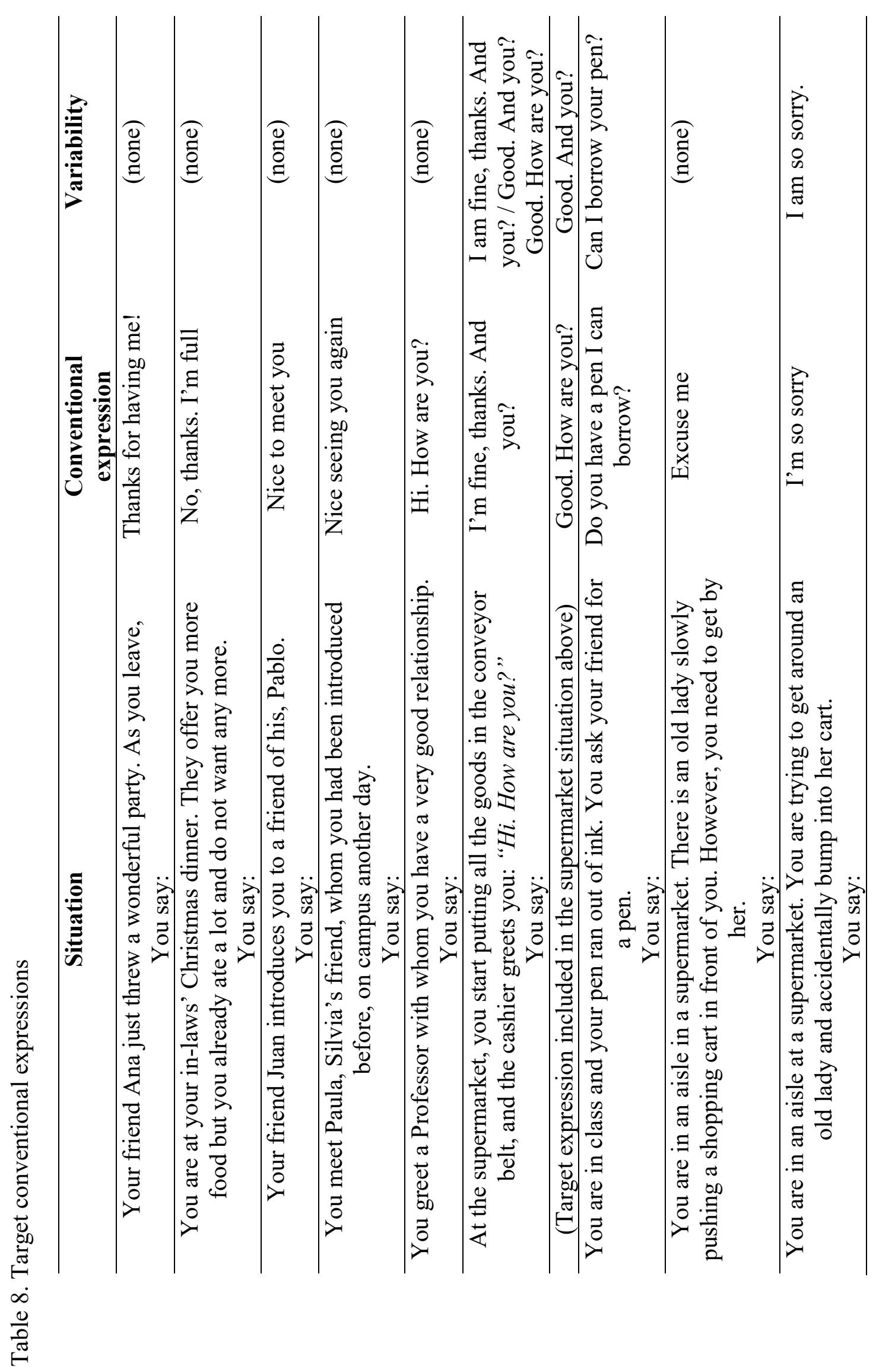




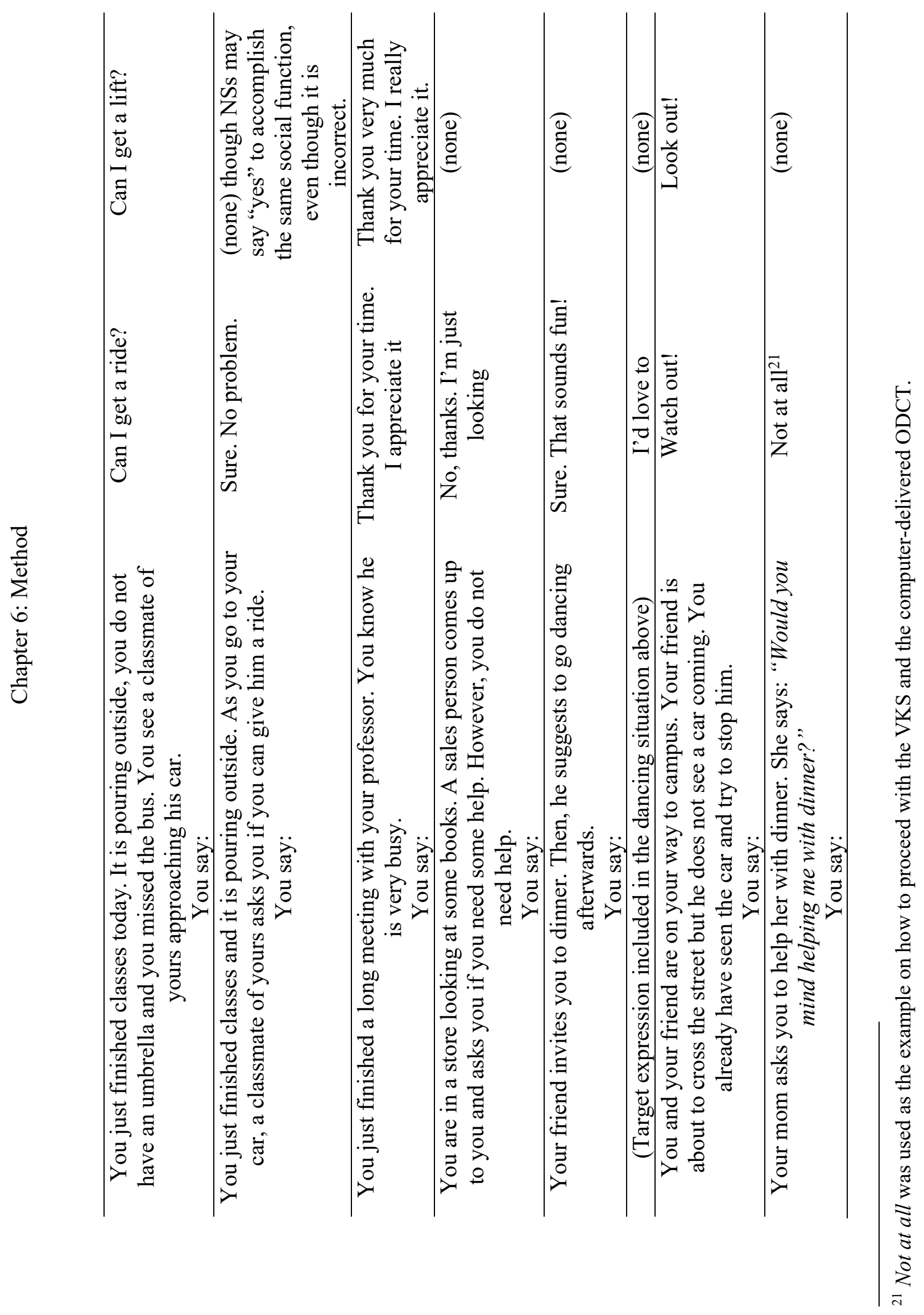




\subsection{Instructional Treatment}

The instructional treatment was provided during the second week of February 2017, and it was divided into two sessions, two days apart. As mentioned in the previous subsection, 21 participants received the instructional treatment, those who were enrolled in the course E0936: Linguistics and English Language Teaching Methodology. Both sessions lasted for 90 minutes, which is the official time duration for each class of this course.

Session 1: This session was devised to provide explicit instruction via a PowerPoint (PPT) explanation of conventional expressions with metapragmatic information. This first session was structured in two main blocks. Instruction was introduced first, followed by an awareness-raising activity on the instruction in the form of an Appropriateness Judgment Task (AJT). The PPT presentation started with a revision of Celce-Murcia's (2007) revised model of communicative competence to trace the origins of the inclusion of conventional expressions in such model. This was followed by a definition of the concept of conventional expressions and a provision of their main features in order for students to recognize them more easily. The final part of the PPT presentation entailed an introduction and discussion of 19 real-life contextualized situations in which different conventional expressions were presented and explained to students, focusing on the differences between cultures, and the pragmatic misunderstandings that may be caused from L1 transfer, and other variables that may influence L2 learning. Students were encouraged to actively discuss these issues by asking questions or making comments. Please refer to Appendix 1 for a copy of this PPT presentation. After that, students were distributed a paper-and-pen AJT, in which they were given a handout with the 19 situations provided before. Participants had to judge whether the response provided for each of the contexts was appropriate or 
inappropriate and also explain why. The purpose of doing this activity was for students to reflect on the information received from the PPT presentation, and to put it into practice, reasoning on the consequences of using particular conventional expressions in specific situations (in)appropriately. Students worked individually and then their responses -to each of the situations- were discussed by the whole class, allowing them to share their thoughts and knowledge. Unfortunately, this last part had to be shortened due to time constraints. The researcher asked whether each of the responses provided for each of the situations were appropriate or inappropriate, then the students gave their answers, and finally the researcher accounted for the reasons why it was one or the other. Students' comments and questions were addressed to clarify doubts. Please refer to Appendix 2 for a copy of this AJT activity.

Session 2: This second session was devised to 1) enable students to reflect on the theoretical concepts presented in Session 1, and to 2) practice orally the conventional expressions they were introduced in the previous session as well. Session 2 was designed to have three main activities. The first one entailed a short revision of the most important concepts presented in the PPT presentation in Session 1 in a PPT format as well. The researcher asked some questions to the participants to check whether they remembered the key issues they worked on in the previous session. This activity was conceived and administered to foster participants' active involvement in class discussion, and sharing of ideas with their peers and the researcher to develop their critical thinking skills on the oral performance of conventional expressions and their social meaning. Please refer to Appendix 3 for a copy of this PPT presentation.

After that, students were randomly assigned a partner with whom they would perform some closed role-plays. They were randomly assigned three different situations with a role to play. Students were given three minutes to read and prepare the situations. 
Then they volunteered to come in front of the class to role-play those situations. Each dyad performed the three different situations assigned to them. This activity was videorecorded to transcribe the data. Please refer to Appendix 4 for a copy of the role-play scenarios.

Finally, participants were distributed the Post-instruction Questionnaire, which was designed specifically for the purpose for the present investigation. In this questionnaire, students had to evaluate the instructional materials provided to them, namely both PPT Presentations, the AJT, and the role-play activities, as well as the visual materials included in the PPT presentations, namely pictures and video. Such questionnaire also included a section in which participants were encouraged to share other thoughts or comments they had about the instructional treatment in general or about the researcher's provision of such treatment, in the form of open-ended questions for each of the parts aforementioned and a final section devoted exclusively for this purpose. In turn, the second part of the questionnaire included a table with all of the conventional expressions included in the pedagogical intervention. Students had to choose whether those had been difficult or easy to learn and then explain why. See Appendix 5 for a copy of the Post-instruction Questionnaire. 


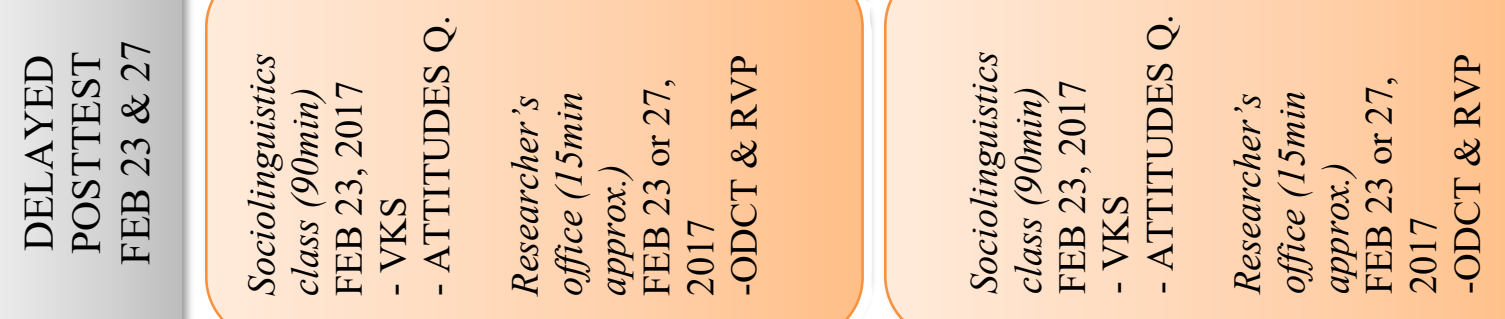

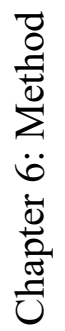

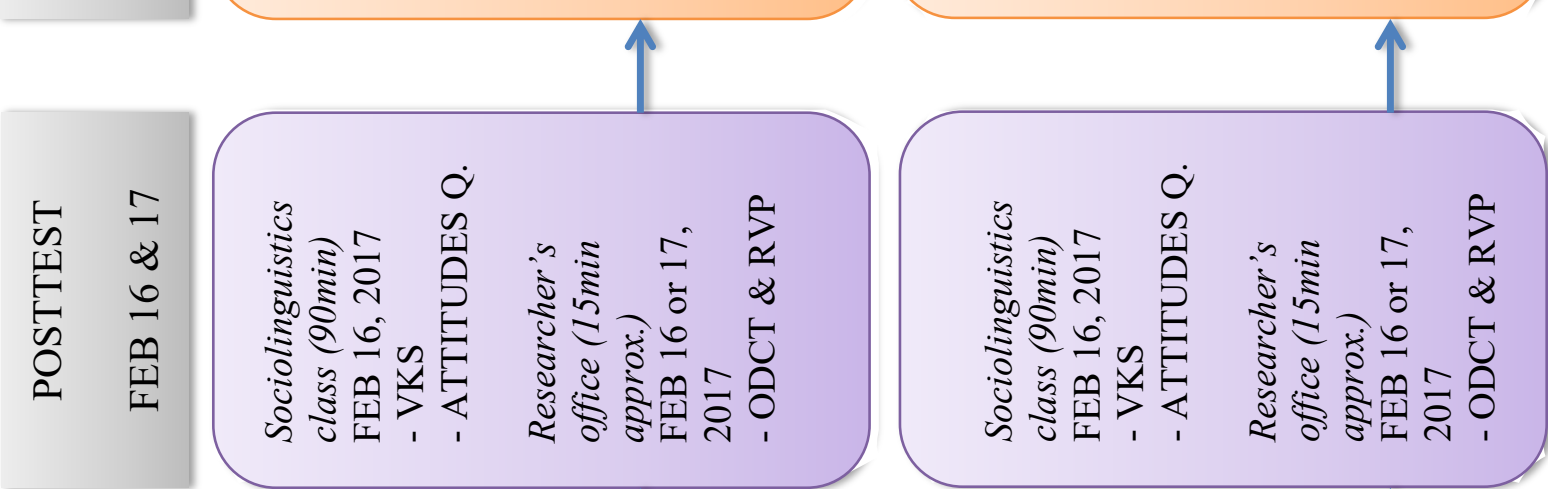

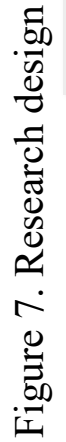

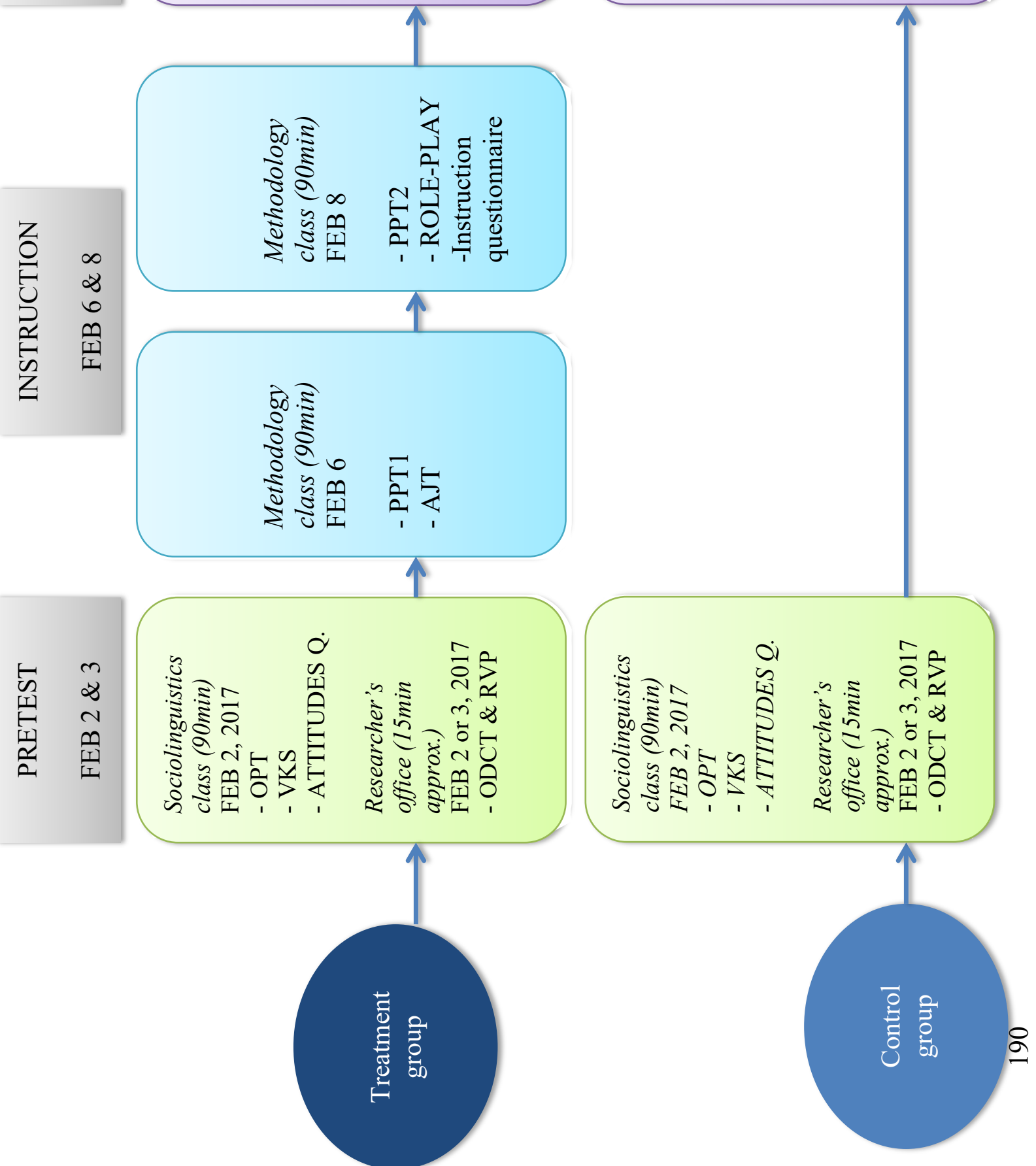


Figure 7 above displays the timeline outlined to collect data for each day and the materials used in each of those sessions. Not included in the research design above is the pilot study, which was conducted in Fall 2016 at Universitat Jaume I as well. Participants were seven $(n=7)$ students enrolled in the course EA0950 English Discourse and Pragmatics, an elective course in the senior year in the English Studies Degree.

\subsection{Instruments for Data Collection}

A multi-method approach (e.g., Brown, 2014) was used to collect data in the present study. This entails the collection of both quantitative and qualitative data, thus providing a more comprehensive and rich understanding perspective on the data analysis and the interpretation of the results obtained. The instruments to collect data in this study are explained in a continuum, from the more quantitative, to the more qualitative.

\subsubsection{Vocabulary knowledge scale.}

The vocabulary knowledge scale (Wesche \& Paribakht, 1996) was used in this study to explore participants' awareness of conventional expressions and their use in social interactions (Wesche \& Paribakht, 1994). According to these authors, the VKS is a multiple-choice test that understands the acquisitional process of specific vocabulary as repetitive, entailing cognition of various types and levels. Furthermore, this instrument was created to recognize and classify the knowledge of specific words (conventional expressions in the present study) by learners' own observed and evidenced performance on such test (Wesche \& Paribakht, 1996). This instrument was created by Paribakht and Wesche (1993a, 1997), and further employed in Paribakht and Wesche (1993b), and Wesche and Paribakht (1994) to explore adult university ESL learners' acquisition of vocabulary while performing a reading task. The original instrument presented the 
vocabulary items in isolation and then offered five multiple-choice options from which students would need to choose the one that best suited their knowledge for each of the items. Table 9 below exemplifies the five multiple-choice options configured in the original study.

Table 9. Wesche and Paribakht's (1994, p. 23) five multiple-choice options outline

\begin{tabular}{|c|c|}
\hline \multicolumn{2}{|c|}{ VKS Elicitation Scale Self-Report Categories } \\
\hline I & I don't remember having seen this word before. \\
\hline II & $\begin{array}{l}\text { I have seen this word before, but I don't know what it } \\
\text { means. }\end{array}$ \\
\hline III & $\begin{array}{l}\text { I have seen this word before, and I think it means } \\
\text { (synonym or translation) }\end{array}$ \\
\hline IV & $\begin{array}{l}\text { I know this word. It means } \\
\text { (synonym or translation) }\end{array}$ \\
\hline $\mathrm{V}$ & $\begin{array}{l}\text { I can use this word in a sentence: } \\
\text { (If you do this section, please also do Section IV). }\end{array}$ \\
\hline
\end{tabular}

Other studies have employed modified versions of the VKS in ILP research (e.g., Bardovi-Harlig, 2014; Bardovi-Harlig \& Bastos, 2011; Kecskes, 2000; SánchezHernández, 2017; Roever, 2005). Nevertheless, the version of the VKS in this dissertation was based on Bardovi-Harlig's (2008), who employed a refined version based on the original version shown above. Bardovi-Harlig also used a five multiplechoice option selection for participants to choose from. Nevertheless, she modified the wording of each of the items for the purpose of her study. Figure 8 below shows an example of such modification. 
(6) Excuse me

(a) I don't remember having heard this expression before.

(b) I have heard this expression before, but I don't know what it means.

(c) I have heard this expression before, and I think it means

(d) I know this expression. It means

(e) I can use this expression in a conversation:

Figure 8. Bardovi-Harlig's (2008, p. 222) modification of VKS

For the present study, the selection of the conventional expressions was based on previous studies that also employed VKS for the same research purposes (i.e., BardoviHarlig, 2008), collecting information about participants' awareness of conventional expressions and instances of their use in specific social interactional situations, as well as using conventional expressions that have already been explored in prior investigations. Additionally, the decision to modify the original VKS was motivated to provide students with fewer options to choose from, thus attempting at narrowing down students' criteria for item selection to provide the most faithful representation of their knowledge of the conventional expressions included in the test, as well as to reduce the statistical analysis. To design the final version of the VKS used in the present study, several steps were followed: (a) review of the existing literature, (b) selection and listing of target conventional expressions, (c) instrument design (item construction), (d) piloting with NSs, (e) modification of the instrument, (f) piloting with NNSs, (g) further revision, (h) implementation. ${ }^{22}$

As for the structure of this instrument, the VKS used in this dissertation provided instructions on top of the page. Then, an example was included for students to visually comprehend what the task entailed, followed by the target 17 conventional expressions

\footnotetext{
${ }^{22}$ Sánchez-Hernández (2017) is another example where these series of steps were followed to design her version of the VKS.
} 
selected for this particular instrument. Figure 9 below includes an example of an item that exemplifies the modifications applied in the version of the VKS in the present study. Moreover, item randomization was applied for each of the tests to avoid task repetition effect. See Appendix 6, Appendix 7 and Appendix 8 for copies of the VKS used in the pretest, posttest and delayed posttest respectively.

\section{Watch out!}

(a) I do not know this expression at all.

(b) It sounds just a little familiar.

(c) I know this expression.

If you have chosen $\mathrm{C}$, please give an example of this expression in a conversation:

Figure 9. Example of item included in the VKS version used in this dissertation.

\subsubsection{Attitudes questionnaire.}

The Attitudes Questionnaire was employed in the present study to explore EFL learners' attitudes towards the English language in a public tertiary education institution in Eastern Spain, a multilingual setting where Catalan and Spanish are the main languages spoken. In multilingual environments, such as the one where this dissertation was carried out, students learn attitudes from various sources, such as from their teachers, family, language community, etcetera. The societal and family spheres are also crucial in EFL learners' configuration of their attitudes towards the languages themselves, the speakers of such languages, and the process of learning those languages (Lasagabaster \& Huguet, 2007). The use of this particular questionnaire was based on the existing literature on language attitudes in multilingual contexts (Lasagabaster \& Huguet, 2007; Portolés, 2011, 2015; Safont, 2007), as well as on the research niche on the interplay of language attitudes, instruction, and conventional expressions in ILP.

For the purpose of the present investigation, the questionnaire developed by Lasagabaster and Huguet (2007) on their work on language attitudes in multilingual 
contexts was adapted. All studies included in Lasagabaster and Huguet (2007) administered the same instrument, namely the attitudes questionnaire these authors developed based on Baker's (1992) study on language attitudes. In so doing, Lasagabaster and Huguet (2007) ensured the comparability of the results among the studies, and therefore draw more robust conclusions about students' language attitudes towards their L1, L2, and L3 in different European countries.

The original questionnaire by Lasagabaster and Huguet (2007) is composed of three main sections. Section 1 includes personal questions, such as age, sex, and identification of students' L1. Questionnaire items in Section 2 focus on the two official languages spoken in the region the study took place, the Valencian Community in our case. This part of the questionnaire asked participants to identify the language(s) they use when (1) speaking with their closest relatives such as family and friends, but also their neighbors; as well as (2) using the media, namely reading newspapers, watching TV or listening to the radio to name a few. Further items in this second section prompted participants to identify and rate the importance of the minority language they speak, English in our case, in relation to everyday activities such as getting a job, reading, or going shopping. Finally, Section 3 displays three tables, one per each of the target languages. Each table includes the same 10 items, which students were asked to rate using a 5-point likert scale about their L1, L2, and L3. See Appendix 9 for a copy of Lasagabaster and Huguet (2007) version of the attitudes questionnaire. Please refer to Appendix 10 for a copy of the Attitudes Questionnaire used in the present investigation; and Appendix 11 for a detailed explanation of all modifications to the original and the rationale behind those changes. 


\subsubsection{Computer-delivered oral discourse completion task.}

The implementation of this particular version of DCTs, namely the computer-delivered ODCT, in the present study is three-fold. On one hand, despite the large body of research in the literature that criticizes the employment of DCTs to collect production data in ILP (e.g., Golato, 2003), this particular instrument was distributed as it elicits short responses which imply just one-turn interactions in real life language use, which Taguchi and Roever (2017) identify as one of the few advantages of using DCTs for this specific purpose. On the other hand, the computer-delivered ODCT created for the present investigation aims at collecting data from participants' pragmalinguistic knowledge of conventional expressions, which is also another positive aspect Taguchi and Roever (2017) highlight about the use of DCTs in ILP research. Additionally, the decision to design oral DCTs in the present study was based on studies in the literature that inform that eliciting formulaic sequences (i.e., conventional expressions) in spoken mode is crucial (Culpeper, Mackey, \& Taguchi, 2018). Conventional expressions were defined in Chapter 4, where it was reported that Wray (2002b) was one of the first authors who identified these formulaic sequences as fixed or semi-fixed strings of words which learners store in their minds as one whole unit, and which are also linked to a particular social situation (Bardovi-Harlig, 2012). In line with these assertions, Culpeper et al., (2018) maintain that participants who retrieve and produce these expressions not hesitating, but fluently, show features of having formulaic competence in a given L2. Therefore, these authors assert that oral DCTs may be a useful instrument in that they may assist in the identification of L2 users' easy retrieval and fluent production of conventional expressions.

DCTs have been widely employed for several decades in ILP research to collect production data on several target pragmatic features, especially on speech acts 
(Bardovi-Harlig, 2010b; Cohen, 2013; Cohen \& Olshtain, 1981; Culpeper et al., 2018; García-Mayo \& Alcón-Soler, 2016; Kasper, 1999, 2008; Kasper \& Rose, 2002; FélixBrasdefer, 2010; Schauer, 2009; Taguchi, 2015b; Taguchi \& Roever, 2017), politeness research (Taguchi \& Roever, 2017), on other pragmatic features or sociopragmatic competence using ODCTs (e.g. Li \& Taguchi, 2014, Roever, Wang, \& Brohpy, 2014; Taguchi, Xiao, \& Li, 2016), and to a less extent on pragmatic formulas or conventional expressions using computer-mediated ODCTs (e.g., Bardovi-Harlig, 2009; BardoviHarlig et al., 2010; Bardovi-Harlig \& Bastos, 2011; Taguchi, Li, \& Xiao, 2013). This instrument has been used in the present study to investigate EFL participants' oral production of a given set of conventional expressions. Additionally, this particular test was designed and distributed to gauge the pragmatic benefit participants may gain from instruction provision, which García-Mayo and Alcón-Soler (2016) identify as one of the main objectives to use DCTs in EFL contexts. In turn, these particular authors defined DCTs as tasks whose main focus is a given pragmatic feature and which are employed to prompt L2 re-created and "socially differentiated" (Blum-Kulka, House, \& Kasper, 1989, p. 14) interactional situations (García-Mayo \& Alcón-Soler, 2016).

The DCT was originally designed by Blum-Kulka (1982), and it became more acknowledgeable in the literature seven years later when Blum-Kulka, et al. (1989) used it in their seminal work on speech act production, the CCSARP. DCTs have a particular defining structure. First, the description of a given situation is provided, in which information about the participants, the setting, and the relationship between the participants is provided (Blum-Kulka, et al., 1989; Félix-Brasdefer, 2010, Martínez-Flor \& Usó-Juan, 2011). These factors are reported to play a decisive role on participants' linguistic choice (García-Mayo \& Alcón-Soler, 2016). After that, a blank is introduced for participants to provide a response, a reply they think they would give as they 
imagine themselves taking part in such imagined, simulated situation (Félix-Brasdefer, 2010).

Traditionally, participants' responses were featured in the written mode. It is for this reason that DCTs have also been coined written DCTs (WDCTs). Therefore, and as Félix-Brasdefer (2010) identified, this data collection instrument taps on learners' knowledge instead of on the actual ways students' usage of their interactional competence skills. This learners' knowledge of pragmalinguistic or sociopragmatic issues is measured offline (emphasis added), meaning that there is no interactional features in the DCT test taking process. Taguchi and Roever (2017) asserted and support the extensive criticism this feature has received in recent years. Additionally, these authors identified several other issues that question the usefulness of employing DCTs to collect production data. These are (1) the absence of pressure as regards to response provision time; and (2) the lack of interactivity in the instrument itself. Thus, DCTs are unable to provide opportunities for longer interactional situations to occur. Subsequently, thus, this issue does not allow researchers to draw conclusions on the skills participants may have and use to participate in such situations (p. 85). Related to this second drawback, Taguchi and Roever (2017) further ascertained that DCTs do not resemble real-life interactions since participants' production in DCTs are just a prompt, whereas social interactions entail meaning 'co-construction' between speakers, a feature that DCTs are unable to provide. Félix-Brasdefer (2010) also drew attention to this issue, as this author ascertained that since DCTs normally include just one turn, it enables to discern the lacking features of oral discourse this instrument has. Culpeper et al., (2018) more recently acknowledged this drawback as the most critical of all. These authors also recognized several other disadvantages in the use of DCTs in L2 production research. Firstly, they identified the problem raised by the "authenticity of 
the situational prompts" (p. 59), namely the resemblance of the situations described in the prompts to real-world situations, as they argue that participants' production -and thus the gathered DCT data generally- may be hindered by their lack of knowledge or awareness with the situation itself or details included in the situation described.

Secondly, and related to the previous caveat, Culpeper et al. (2018) maintained that the linguistic features used to respond to DCT prompts might not be as authentic as those used in real-life situations, because the former may lack conversational characteristics, such as repetitions, and response length. Finally, Félix-Brasdefer (2010) also identified another crucial disadvantage discussed in the literature that refers to the concern of how much information should be included in the prompt to contextualize the situation description sufficiently. According to Culpeper, et al. (2018), the amount of information included in the situation description will likely determine participants' production. Shorter descriptions may impede learners to imagine the situation in which they are required to play a role and produce a given pragmatic target feature.

Nevertheless, and despite all these disadvantages, the computer-delivered ODCT created specifically for the purpose of this study was employed because the target pragmatic feature under study are conventional expressions, which are themselves oneturn interactional features in real-life spoken situations. Therefore, the use of ODCTs to collect this type of data may not hinder on the issue on the authentic nature of the language employed to provide oral responses. Additionally, this dissertation aims to explore the participants' pragmalinguistic knowledge of a given set of conventional expressions. Hence, the rationale to employ DCTs to collect production data in ILP focusing on these two particular goals has been supported in the literature (e.g., FélixBrasdefer, 2010; Taguchi \& Roever, 2017). 
Further advantages for the use of DCTs are outlined as follows. Firstly, DCTs favor the collection of vast amounts of data in a rather short time span, and from many participants all at once (Nguyen, 2019; Usó-Juan \& Martínez-Flor, 2014; Taguchi \& Roever, 2017). Secondly, another favoring circumstance to use DCTs in any of its forms, namely ODCT, reverse DCT, or interactive DCT among others, is the researcher's ability to control the social variables of power, social distance, and ranking of imposition in terms of Brown and Levinson's (1987) Politeness Theory (FélixBrasdefer, 2010). In so doing, different situations are presented with socially distinguishable features (Blum-Kulka et al., 1989), which as they tap into participants' sociopragmatic knowledge, this in turn will show in their pragmalinguistic strategies they will use to provide a response. In other words, participants' understanding of the situation and the sociopragmatic knowledge they already acquired will allow them to provide a more or less direct and formal response; adjusting their pragmalinguistic strategies to provide the most appropriate response according to these two features: formality and directness (Taguchi \& Roever, 2017). Thirdly, and closely related to the previous advantage, relies the fact that the "cross-cultural variations" (Culpeper et al., 2018 , p. 59) that the manipulation of these variables allow may enable researches to identify instances of L1 transfer of strategies into the L2 system. Fourthly, and also related the second advantage, Félix-Brasdefer (2010) argued that providing as much information as possible in the prompt may imply that not only the instrument will be more robust, but also the concern about participants' language use authenticity will be addressed. The more informed participants are about the situation being described, the more accurate response they may be likely to provide, a response that may resemble real-life interactions more faithfully. This, in turn, may allow L2 users to use pragmalinguistic resources they may be knowledgeable about that they may have been 
unable to use if the situational description may have contained less information. Fifthly, and also related to the connection between the pragmalinguistic and sociopragmatic competences, Culpeper et al. (2018, p. 59) asserted that this connection between these two competences, the link between the form and the context of a given situation can be looked into by "(t)he systematic approach used to develop a situational scenario.” Finally, these same authors asserted that since DCTs have a consistent structure, replicating studies that employ this instrument might become a secure task in the future.

After having discussed extensively the advantages and disadvantages of the use of DCTs in the collection of production data in ILP, a review of the different versions of DCTs existing in the literature is provided as follows. Since WDCTs have been extensively reviewed and criticized, improved versions of the original format have been created in the past decades (see Bardovi-Harlig \& Hartford, 1993b; Félix-Brasdefer, 2010; Culpeper et al., 2018; Nguyen, 2019; Taguchi \& Roever, 2017; Youn \& Bogorevich, 2019 for a review) to further its application for research purposes and in so doing being more truthful to real-life language use. Barron (2003) created the free discourse completion task (FDCT), which, even though it elicits written responses, differs from the WDCT in that FDCT asks students to write a short interaction between two speakers. FDCTs have also been named dialogue production tasks (DPT) in studies focusing on pragmatic variation (e.g. Schneider, 2008). Similarly to Barron's (2003) FDCT is Martínez-Flor's (2013b) interactive DCT (IDCT), in which participants were prompted to create a written dialogue according to the information presented in the situational description. A further refined model of DCTs is the content-enriched DCT (Billmyer \& Varghese, 2000), in which the prompt is further defined, including more information about the spatial and temporal features of the situation being described. 
A different type of DCT is the cartoon oral production task (COPT) (FloresSalgado, 2009), in which participants are asked to produce oral responses to visual stimuli. As an adaptation from Rose (2000), this author employed the COPT where the provision of visual materials to describe the situation is one of the main advantages of this instrument. Two other types of refined DCTs are (1) reverse DCT, and (2) collaborative DCT. (1) Reverse DCTs are different from all the other versions in that participants are given the responses to a given scenario, which they have to create (e.g. McLean, 2005). In turn, (2) Collaborative DCTs distinguish themselves as these DCTs are carried out in pairs. As traditional DCTs, students are provided with a situation description but instead of providing the response right away, learners jointly discuss and create the dialogue they will later provide as a response to the prompt provided (e.g. Taguchi \& Kim, 2016). With the further development of technology, versions of DCT using different technological tools were produced. Two examples are Schauer's (2007) multimedia elicitation task (MET), and Halenko's (2013) computer-animated production task (CAPT), both targeting speech acts.

Finally, Culpeper et al. (2018) included the review of the type of DCT used in the present study, namely DCT with verbal report (e.g. Beltrán-Palanques, 2013, 2016 23). The employment of this particular version of the DCT is two-fold. On one hand, the implementation of RVPs in the DCTs provides researchers with rich detailed qualitative data is used to better understand participants' oral production. In turn, this action addresses one of the main disadvantages discussed in the literature, namely the reliability of this data collection instrument (Félix-Brasdefer, 2010).

\footnotetext{
${ }^{23}$ This last study was not included in Culpeper et al.'s (2018) review, but it does provide an extensive review of those studies in which RVPs were used in combination with WDCTs.
} 
The objective of the present discussion was to provide an overview of the different versions of DCT available in the literature to exemplify how the computerdelivered ODCT and RVP designed for the present study was developed. The main concern aimed at addressing was ensuring the validity of the computer-delivered ODCT, which was approached in three different ways: firstly by implementing the RVP within the ODCT; secondly by including audiovisual materials in the computerdelivered ODCT, which provided a more reliable and real-word approach to situation description and response prompting; and thirdly by test piloting it with NNSs.

As introduced earlier, items in this computer-delivered ODCT were designed to elicit different conventional expressions in oral mode. Additionally, the three social dimensions that characterize and define politeness encounters, namely power, social distance and ranking of imposition (Brown \& Levinson, 1987) between speakers were also modified in the situations included in this instrument so that participants would need to reflect on their language production according to the imaginary speaker they would interact with. Even though this exercise of imagining a possible situation has been identified as one of the main caveats in the literature on DCTs in ILP research (see discussion above), this feature is handled rather as an advantage -when comparing ODCTs to traditional WDCTs-, in line with Cohen (2014), who stated that the former entail an interactional oral simulation situation instead of the production of written text as if it were elicited orally.

The computer-delivered ODCT was created based as the same fashion as those already designed and implemented in the literature (i.e., Bardovi-Harlig, 2009; BardoviHarlig et al., 2010; Bardovi-Harlig \& Bastos, 2011). Items included in the computerdelivered ODCT in this dissertation were (1) extracted from the studies 
aforementioned ${ }^{24}$, and also (2) taken from the field notes the researcher collected when she lived in the US, based on first-person experience prior to the start of the present investigation. As of the number of items, 16 were included (i.e., an example and 15 situations), also based on previous studies (e.g. Schauer, 2007) and after reviewing the literature available on DCTs. For example, Félix-Brasdefer (2010, p. 52) stated that the regular WDCT typically includes from 12 to 18 situations. Another reason why 16 items were included was the difficulty of the conventional expressions included, as examples of both easier expressions such as 'Hi. How are you?' and more difficult ones, namely 'Do you have a pen I can borrow?' were selected. Thus, this was done trying to address the concern about designing a version of a DCT that is neither too short nor too long. Therefore, task construction was designed in an attempt to move away from decisions based on intuition. Instead, many of the situations were adapted from the researcher's own experience in the years that she lived in the US. In sum, the same steps to create the ODCT and the VKS described above were used, but with a different approach, since the researcher's personal experience also weighted in in the design of the present instrument. All in all, the actions taken to develop the computerdelivered ODCT and RVP are outlined as follows: (a) revision of the existing literature, (b) selection and listing of target conventional expressions, (c) instrument design (item construction), (d) piloting with NSs, (e) modification of the instrument, (f) piloting with NNSs, (g) further revision, (h) implementation.

Concerning the refinements that were aimed at introducing in this particular version of the ODCT, this instrument was mainly devised as being computer-delivered because the fostering and enhancement of understanding the situations and the conventional expressions were core, as well as students' application of this knowledge

\footnotetext{
${ }^{24}$ See Section 4.3 Target Conventional Expressions.
} 
in everyday real-life situations in the future. Therefore, the provision of audiovisual materials was at stake to meet this goal. Previous research that introduced a technological component as an improvement of the original DCT (i.e. Bardovi-Harlig \& Bastos, 2011) was also taken into consideration. Additionally, visual materials were provided in the form of a short video for the example and one picture per situation, to help participants understand the situation more clearly and in a more detailed fashion in order for them to provide the closest real-world oral performance they could of the target conventional expressions. The real-world pictures, taken by the researcher herself a colleague captured true social real-life interactions. A few pictures were selected from media outlets that permitted the use of pictures for non-commercial purposes. Item randomization was applied for each of the versions of this computer-delivered ODCT and RVP to avoid task repetition effect. Figure 10 below illustrates one of the items included in this instrument. 


\section{Scenario 3}

Scenario: Your friend Juan introduces you to a friend of his, Pablo.

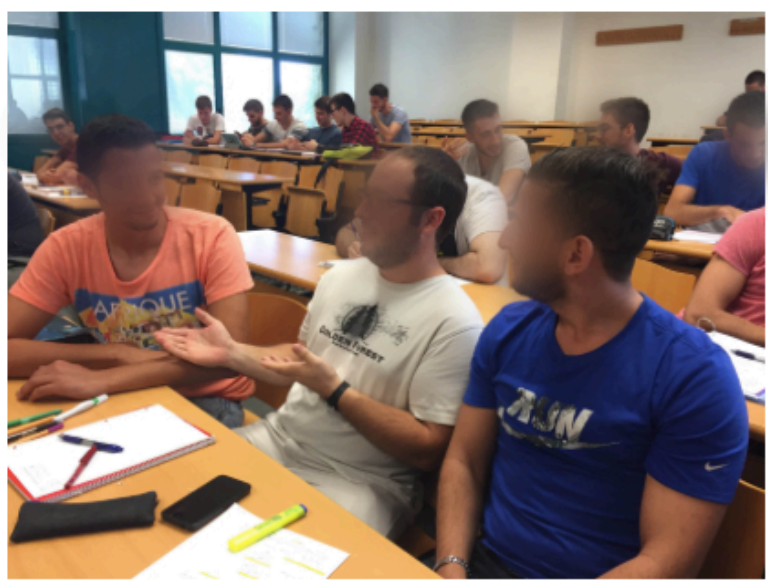

You say: ...

Why have you used that expression?

\section{Next}

Figure 10. Item illustration in computer-delivered ODCT and RVP

Further refinement of the present instrument came to being after it was revised by NSs and NNSs before collecting data for this study. NSs' feedback focused on the issues of situation descriptions as well as variability in conventional expressions targeted in some of the situations. First, the wording for some situations was modified so that the presentation of the information would be clearer. Also, NSs pointed out the fact that some situations allowed for the use of different conventional expressions that shared the same pragmatic meaning. For example, for the situation: "At the supermarket, you start putting all the goods in the conveyor belt and the cashier greets you: "Hi. How are you?" the target conventional expression assigned to it was Good. How are you? However, NSs claimed that other variants were also possible, such as I'm fine, thanks. And you? Even though the researcher was already aware of these variants, 
she was not sure whether and how to include these conventional expressions in the present study, and feedback from NSs helped her in discerning the best way to address this issue. Secondly, and to further validate the instrument, it was piloted with seven EFL students in the Fall 2016 Semester at the same university and under the same conditions data were collected from the participants during the data collection period explained earlier in this chapter. NNSs' feedback confirmed the modifications made after NSs' comments. In other words, NNSs confirmed that both the example and the situations, together with the instructions at the beginning of the task were clear and that the task could be performed successfully.

\subsubsection{Semi-structured interview.}

A semi-structured interview was included at the end of the computer-delivered ODCT, after participants had provided a prompt for the last situation in the computer-delivered ODCT and RVP. This semi-structured interview included seven questions that elicited participants' perceptions on the instrument itself, the real-life nature of the situations included in it, the intelligibility of the wording in each situation, and whether the inclusion of audiovisual materials was helpful in the test taking process:

1) is there anything you would like to comment on this activity?

2) was the example clear?

3) were the instructions that you read afterwards clear?

4) is there anything you would change?

5) is there anything that was particularly helpful to you to do this activity?

6) do you think the situations in this activity represent real-life situations?

7) do you have any other comments?

This semi-structured interview was piloted with the NNSs aforementioned to validate the instrument, to ensure the clarity and usefulness of the questions. 
Information gathered from this semi-structured interview was not included in the data analysis in the present study. See Appendix 12, Appendix 13, and Appendix 14 for copies of the three versions used of the computer-delivered OCDT and RVP in this study in the pretest, posttest, and delayed posttest respectively.

\subsubsection{Post-instruction questionnaire.}

The Post-instruction Questionnaire used in this dissertation was designed specifically for the purpose of this study. This questionnaire was distributed to gain insights into participants' experiences with the instructional treatment more generally. More specifically, this questionnaire featured items targeting the particular materials and instruments used and the conventional expressions targeted in the instructional treatment. As far as could be established, no experimental study had included an instructional questionnaire similar to this one. Therefore, this Post-instruction Questionnaire was designed taking into consideration previous research on instruction in L2 pragmatics that included interviews regarding the instructional treatment.

As regards to the structure of the Post-instruction Questionnaire, it consists of two parts. Part 1 features a series of multiple-choice questions targeting the instruments used in the instructional treatment, namely the PPT, the AJT, and the role-play, together with a series of open-ended questions that allowed participants to provide more detailed information about the issues targeted in the multiple-choice questions they had just answered. In turn, Part 2 illustrates a table in which all the target conventional expressions included in the study are featured and students are asked to describe the easiness as regards to their learning process of such expressions, as well as to account for the reasons why such process was easy or difficult for them.

This questionnaire was designed bearing in mind the drawbacks that running interviews entail, such as the time-consuming nature of transcribing the data once it has 
been collected. Hence, all questions were provided in written form and in paper-andpencil format to gather both quantitative and qualitative data at the same time, thus making the data collection process faster and more efficient, comparing it to collecting data orally and then transcribing it. The multiple-choice questions were designed as a three-option questionnaire instead of the typical five-point likert scale to reduce the statistical analysis and thus obtain more detailed results. The downfall of providing three options instead of two, which would have provided even more precise data, was also taken into consideration. Nevertheless, as the two open-ended questions were listed afterwards, students were given the opportunity to explain in more detail the option they chose.

In sum, the aim behind the design and implementation of the Post-instruction Questionnaire was two-fold: (1) to collect further information from the participants regarding their perception of the instructional treatment as they actively participated in it; and (2) to enhance the validity of the computer-delivered ODCT and RVP instrument. Data collected from the Post-instruction Questionnaire was analyzed to explain the qualitative data collected from the computer-delivered ODCT and RVP. Therefore, students' responses to this particular questionnaire may support the data analyzed from the final tests, namely the computer-delivered ODCT and RVP, fostering the validity of such instrument in so doing. Please refer to Appendix 5 for a copy of the Post-instruction Questionnaire.

\subsubsection{Retrospective verbal protocol.}

The use of retrospective verbal protocols (RVPs) in the present study was three-fold. Firstly, they were employed to collect participants' oral insights about the rationale that lead them to provide such pragmatically focused oral responses. According to Gass and Mackey (2016), the use of verbal reports is practical for this purpose because the mental 
processes the learners go through in pragmatic oriented task completion cannot be observed on the spot. Therefore, asking participants to retrieve those insights is helpful in identifying such cognitive processes. Secondly, RVPs were used to ensure the validation of the computer-delivered ODCT, as mentioned before in subsection 6.4.3 Computer-delivered ODCT, and as advised in the literature (Félix-Brasdefer, 2010; Culpeper et al., 2018). Thirdly, RVPs are a source of data that can be analyzed qualitatively, thus providing rich information on the more quantitative and numerical data obtained from quantitative methods, such as the computer-delivered ODCT. Additionally, qualitative data is an essential component in the multi-method approach devised for the present study.

RVPs were collected in the present investigation to elicit participants' thoughts about their decision-making on selecting one expression over others depending on the situation given. The controversy raised about the employment of such instrument in SLA research is also acknowledge in this study. See Bowles (2010) for a review. Nevertheless, Cohen (2013) acknowledged the validity of this instrument and supported its use in ILP research because verbal reporting triggers the perceptions of learners, even though they may be used as a complementary instrument to improve and reinforce the analysis of the main data gathered from the primary instruments. In the present study, data collected from RVPs allow to better understand and interpret more precisely the data collected from the computer-delivered ODCT (Culpeper et al., 2018).

RVPs have been defined as "immediately consecutive realizations" (Kasper, 1999, p. 95). Kasper's (1999) definition of RVPs is adopted because it represents the conceptualization of RVPs in the present study: eliciting participants' thoughts immediately after their pragmatic-focused production. There are two types of verbal protocols: concurrent and retrospective. Concurrent verbal protocols ask participants to 
verbally express their thoughts at the same time they provide a response to a given prompt, for example doing a role-play (Félix-Brasdefer, 2010). On the other hand, RVPs are asked (right) after students' production (Woodfield, 2010), since a great portion of the information provided is still allocated in the short-term memory (STM) (Ericsson \& Simon, 1993, as cited in Taguchi \& Roever, 2017; Félix-Brasdefer, 2010). RVPs might be asked immediately after the production of the target pragmatic feature, such is the case in the present study, or days after of test taking (i.e. Taguchi et al., 2016).

When designing the RVP, two issues raised in the literature were taken into consideration, namely (1) the training of students; and (2) the language used to perform the RVP. To address the issue of training students prior to administer an RVP to improve the test and its results (Culpeper et al., 2018), participants were trained as they were given instructions on how to proceed with this particular instrument in the instructions screen. They were also presented with an example given at the beginning of the computer-delivered ODCT. Therefore, participants became familiar with this instrument, which, in turn, is essential to provide the most tailored answer possible (Culpeper et al., 2018). As previously seen in Figure 10, which illustrates an example of a situation included in the computer-delivered ODCT and RVP, the second question corresponds to the RVP. Second, a concern existed regarding the limited information some participants may provide depending on the language they are required or allowed to use for such task (Culpeper et al., 2018). To address this limitation, students were instructed to use whatever language they felt most comfortable with to express their thoughts. Most of the students preferred English, although a handful of participants performed the RVPs in Spanish and/or Catalan $(n=3)$. For those instances in which 
participants' L1(s) were used, those responses were translated into English to code the information provided by the participants.

\subsection{Data Collection Procedure}

As mentioned in Section 6.3 Instructional Treatment above, data were collected in the month of February 2017. The same procedure was applied in the pretest, posttest, and delayed posttest data collection sessions, as with one exception in the pretest, where the Quick Placement Test was distributed first.

Prestest: Four tests were distributed to the students in this session prior to the provision of the pedagogical intervention in subsequent sessions. No specific times were allocated for participants to perform the tasks. Nevertheless, they were encouraged to finish each of them in less than thirty minutes, which was the estimated test-taking time. The first test they were required to take was the Quick Placement Test (UCLES, 2001). This is a paper-and-pen proficiency level test composed of a total of 60 questions, which are grouped into the two main sections the test is divided into. Part 1 includes questions 1 to 40, and Part 2 comprises questions 41 to 60. Each question is valued one point, being zero the lowest score and 60 the highest; therefore, the higher the score, the higher the test taker's proficiency level. See Figure 11 below for a visualization of CEFR's proficiency levels as distributed in the Quick Placement Test. This test was employed following the literature on L2 pragmatics in EFL contexts (e.g., Codina-Espurz, 2013; Martínez-Flor, 2013b; Martín-Laguna, 2015; Usó-Juan \& Martínez-Flor, 2015). These studies have used this proficiency test to determine participants' level of proficiency in institutions where the TOEFL exam or other official examination proof of proficiency level is not a requirement. However, the validity of this instrument has been questioned, since it is claimed that this test may reflect proficiency level partially, because the pragmatic component is not taken into 
consideration to evaluate proficiency in such test (Taguchi \& Roever, 2017). Please refer to Appendix 15 for a copy of the Quick Placement Test used in the present study.

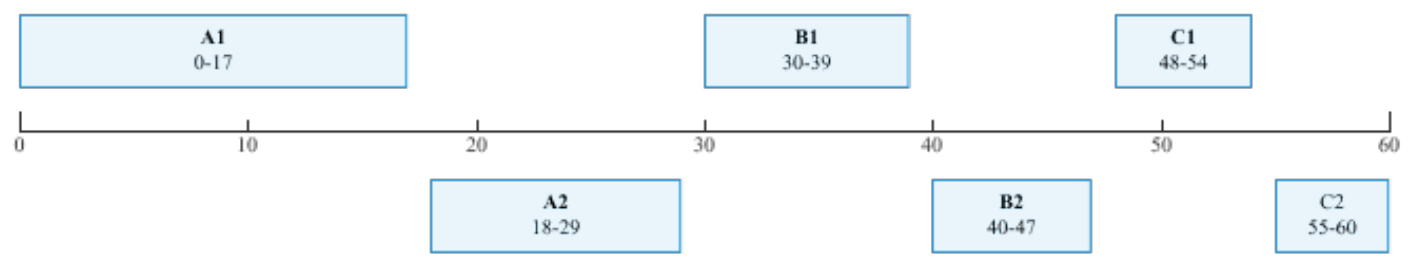

Figure 11. CEFR proficiency levels as delimited in Quick Placement Test

As participants finished the Quick Placement Test, the VKS was provided. This second test was adapted from Bardovi-Harlig (2008), and distributed to gather data on the participants' awareness of the conventional expressions at stake. The test was also provided in a paper-and-pen format. Participants were required to take this test individually. The test included an example for participants to get acquainted with the test taking procedure. After that, students found 17 questions, each targeting a different conventional expression. For each of the questions, a conventional expression was provided in italics first, with no contextual information, followed by three statements, which asked participants to rate the extent to which they were familiar with the expressions, from not knowing the expression, to being acquainted with it and so being able to provide a written example of a situation where they would use such expression. 
Figure 12 below represents an example of one of the expressions included in the pretest version of the VKS.

8 Do you have a pen I can borrow?

(a) I do not know this expression at all.

(b) It sounds just a little familiar.

(c) I know this expression.

If you have chosen $\mathrm{C}$, please give an example of this expression in a conversation:

Figure 12. Data elicitation design in VKS

The third and last test was the Attitudes Questionnaire, which was adapted from Lasagabaster and Huguet (2007), as mentioned earlier in this chapter. This questionnaire was also provided in paper-and-pen format. The first page included questions that elicited background information from the students, such as the identification of their L1, L2, and additional languages they may speak, number of years they had been studying English, and at what type of educational institutions, namely primary and secondary schools, tertiary education centers, and/or private language academies. The rest of the pages featured tables in which participants had to provide information about what languages they use to do several social activities, such as speaking with their parents (mother and father separately) and instructors; watching TV; and to rate the importance the English language has for them to achieve specific social, personal, and professional goals, such as making friends, reading the press or listening to music or obtaining a job. Lastly, as soon as participants finished completing this questionnaire, they chose a time to take the last test, the computer-delivered ODCT and RVP, either that same day or the day after. 
As regards to the computer-delivered ODCT and RVP, two days were allocated for participants to take this test due to time constraints. This particular test was designed for the purpose of the present investigation and in a computer-delivered format to elicit oral data from the students and provide them with opportunities to practice their oral production knowledge of such expressions, hence nearly experiencing an everyday conversation where conventional expressions are used. Data were collected at the researcher's office or another departmental facility. In turn, data were audio or video recorded, depending on how students felt most comfortable with taking this test. Since the computer-delivered ODCT and RVP were administered individually, the researcher asked every single participant whether they preferred their performance to be video or audio recorded at the beginning of this short session, before starting the test. The structure of this test was devised and designed to be easy, clear, and quick for participants. It was designed to last no more than 20 minutes. In the pretest, some students took longer to complete it, and that time decreased to 15 minutes or less in the posttest and delayed posttest sessions. Using the researcher's personal laptop, this test was administered as follows. Once students gave their consent on what type of recording they preferred, the test was administered. The first screen participants were shown was the example. Participants read the situational description first, then they played the video, and then they had a look at the questions. After that, once they were ready to move on, they clicked on the button "NEXT" and a second screen appeared, which included the instructions on how to take the test. As soon as the students had read and understood them, they clicked the "NEXT" button and they found a series of 15 different screens, targeting 15 different conventional expressions. Each of the situations had the same structure as in the example: first the situation description was found at the top of the page, then students were provided with a picture and then they were required 
to answer the two questions: (1) "What do you say?" and (2) "Why did you say that?" This second question was the RVP. These two data collection methods were combined to save time, but most importantly to help students in the recalling process to provide the rationale behind their use of a particular conventional expression. Figure 13 bellow illustrates one of the situations included in the computer-delivered ODCT test.

\section{Situation 6}

Scenario: You greet a Professor with whom you have a very good relationship.

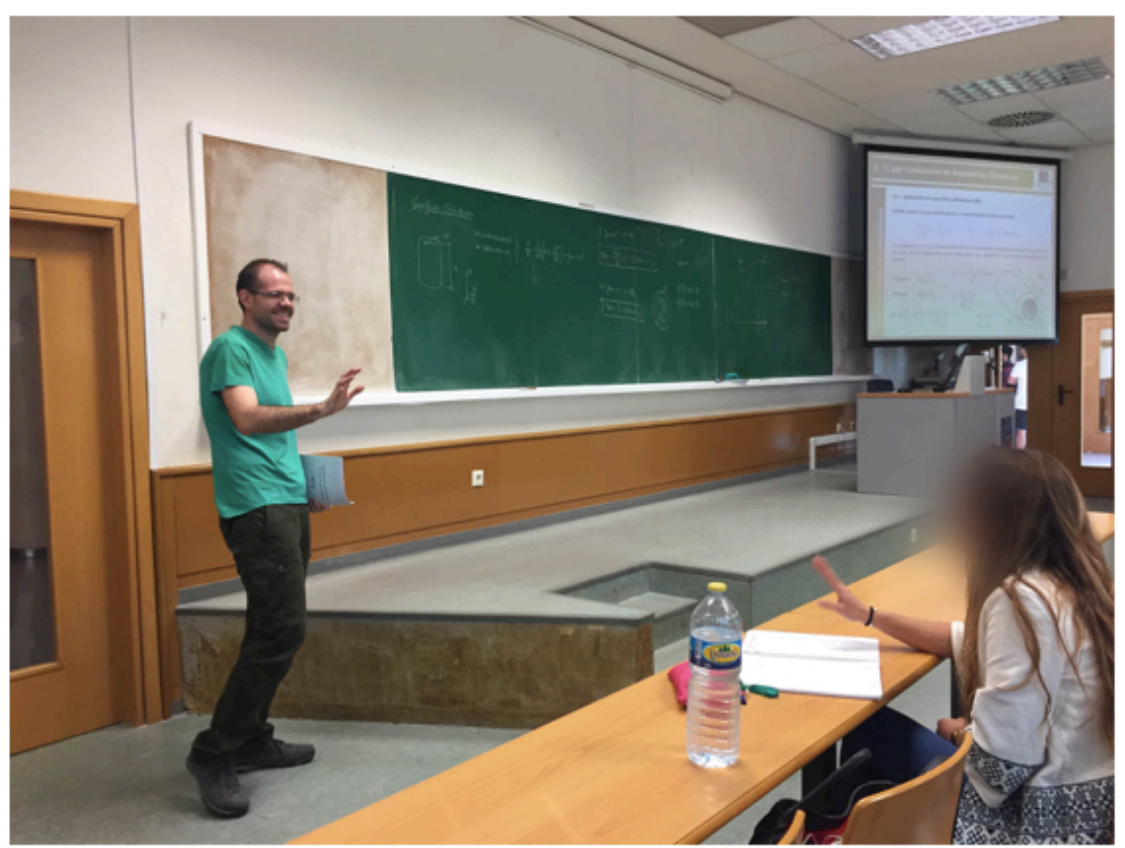

You say:

Why have you used that expression?:

Figure 13. Data elicitation design in computer-delivered OCDT

Posttest: Three tests were distributed to the students in this second data collection time point: VKS, Attitudes Questionnaire, and computer-delivered ODCT and RVP. The same procedures were applied to collect data for the aforementioned tests in the posttest that were applied in the pretest session. The posttest was administered 14 days after the pretest.

Delayed posttest: Same procedures were applied to collect data for the aforementioned three tests in the delayed posttest that were applied in the pretest and 
posttest data collection time points. The delayed posttest was administered 7 days after the posttest. Table 10 below summarizes the data collection procedure for the pretest, posttest, and delayed posttest.

Table 10. Summary of data collection procedure

\begin{tabular}{|l|l|l|}
\hline PRETEST & POSTTEST & DELAYED POSTTEST \\
Feb 2nd \& 3rd, 2017 & Feb 16th \& 17th, 2017 & Feb 23rd \& 27th, 2017 \\
Feb 2. Sociolinguistics & Feb 16. Sociolinguistics & Feb 27. Sociolinguistics \\
1) Quick Placement Test & 1) VKS & class (90min) \\
2) VKS & 2) Attitudes Questionnaire & 2) Attitudes Questionnaire \\
3) Attitudes Questionnaire & 1) VKS \\
Feb 2. \& Feb 3 & Feb 16. \& Feb 17 & Feb 23. \& Feb 27 \\
Researcher's office (15min & Researcher's office (15min & Researcher's office (15min \\
aprox) & aprox) & 3) ODCT \& RVP \\
4) ODCT \& RVP & 3) ODCT \& RVP
\end{tabular}

\subsection{Data Analysis}

Details on how data were analyzed for each of the instruments are provided in the present subsection. Table 11 below summarizes the hypothesis formulated, the data collection methods used in different data collection time points, and the different data analysis employed for each hypothesis. As explained in subsection 6.3 Instructional Treatment, AJT, and role-plays were also employed. However, data gathered from these instruments were not included in this dissertation because the effect of instruction across times and students' attitude development were given more prominence. This 
subsection presents the data analysis procedures for quantitative methods first, and the procedures followed to analyze qualitative data after that.

\subsubsection{Quantitative data analysis.}

The instruments designed to collect data quantitatively were the VKS, the computerdelivered ODCT, and the attitudes questionnaire, which are tackled as follows in terms of the type of data elicited with each type.

\subsubsection{Recognition data.}

Data collected from the VKS was analyzed numerically. A score of three points were devised for each of the target expression included in this instrument. Option A, which implied students not knowing the given expression a score of 0 was given. In turn, Option B, which entailed participants being familiar with the conventional expression at hand, a score of one point was provided. Finally, Option C stated that participants knew that expression and further asked them to provide an example of a short conversation in which they would use the target conventional expression. The scoring of this option was two points whenever the example students provided was correct, and one point if the example was not correct, thus resembling Option B above. After that, all scores were added, thus being the total score in a minimum of zero and a maximum of 34 points per test. Once the oral responses were scored, they were shared with one NS of English who rated each of the responses according to whether they believed were target expressions NSs use in daily life or not. For this task, a total of $100 \%$ agreement was reached for each of the items at the pretest, posttest, and delayed posttest.

Additionally, some specific data from the Post-instruction Questionnaire were used. In this questionnaire, there were two open-ended questions that asked students to discuss what they liked best and least about the AJTs. These data were employed to 
interpret and discuss the results obtained from the quantitative analysis of the recognition data.

\subsubsection{Production data.}

Data collected from the computer-delivered ODCT was analyzed in a binary fashion. In other words, for those target expressions that participants produced correctly, one point was given. On the other hand, if the target conventional expression was not uttered, zero points were provided. Therefore, for this instrument, participants would have a minimum of zero points and a maximum of 15 . Finally, all points each participant had in each of the data collection points, namely pretest, posttest, and delayed posttest, were added to monitor their progression in the production of conventional expressions. Once the oral responses were transcribed and scored, they were shared with two American NSs who rated each of the responses according to whether they believed were target expressions NSs use in daily life or not. The total percentage of agreement among the two raters and the researcher was calculated by adding all the items in which they agreed on per time of task and then adding the three totals, one per time of task, and then dividing it per the total number of responses obtained: 2070. They agreed on a total of 444 items at the pretest, a total of 525 items at the posttest, and a total items of 516 at the delayed posttest, which adds up to 1485 , and divided by 2070 , results in 71.739 . Therefore, the overall agreement between the two raters and the researcher was of $71.739 \%$.

Similarly to using data from the AJTs open-ended questions in the Postinstruction Questionnaire for the recognition task as explained above, the role-plays open-ended questions in the Post-instruction Questionnaire were used. These questions asked students to discuss what they liked best and least about the role-plays they 
performed as oral practice. These data were employed to interpret and discuss the results obtained from the quantitative analysis of the production data.

\subsubsection{Attitudes data.}

Attitudes were measured in a binary manner. As explained in the previous subsection, participants were asked to check whether they agreed or disagreed on a set of ten items. For those items that they checked the "Agree" box, one point was given. On the contrary, zero points were given for those items that students checked as "Disagree." Therefore, once all points were added, participants would end up having a score of minimum zero points and a maximum of ten points.

\subsubsection{Statistical analyses.}

SPSS version 25 was used to run statistical analyses for the four instruments explained above, namely the VKS, the computer-delivered ODCT, the Attitudes Questionnaire, and the Post-instruction Questionnaire. Paired t-tests and independent t-tests were run for each of the data collection instruments. Paired t-tests were used to compare intragroup scores to explore differences from pretest to delayed posttest within each group. Independent t-tests were employed to compare scores between the two groups (control and experimental) from pretest to delayed posttest. Since there are three time points, one-way ANOVAs and mixed ANOVAs were performed to confirm and support the results obtained by the independent and paired samples t-tests.

One-way ANOVAs were performed to ensure the results from the independentsamples t-tests. Whenever there are only two groups, which is the case of the present study, results form these two statistical tests must be mathematically the same. This study was no exception, and results from the one-way ANOVA corroborated the results obtained from the independent-samples t-test. However, this test was not chosen because it did not help explain within-group differences. 
Mixed ANOVAs were also performed to ensure that the between group and within group comparisons were statistically significant in the same way that they prove to be by the independent and dependent samples t-tests. Mixed ANOVAs could be run because there are two independent variables in this study: time (i.e., pretest, posttest, and delayed posttest) and group (i.e., experimental and control), and one dependent variable (task scores: pragmatic recognition and production tasks). The mixed ANOVAs yielded similar results to those obtained by both types of t-tests. The between-group and within-group significant differences were also identified. However, this statistical test was not finally selected to explain the results in this dissertation because data did not meet all the assumptions that need to be met in order for mixed ANOVAs to be valid (e.g., Larson-Hall, 2016). For example, as will be explained later on in this chapter, outliers were found at different time points in all tasks (pragmatic recognition, pragmatic production) and Attitudes Questionnaire, and the consideration of removing them from the pool of participants was rejected because that would risk the ecology of the study, that is, since intact classes were used, it was important for pedagogic reasons to consider all students. Another example of data assumption violation is related to Levene's test that assumes that all variances are equal. Since this was not the case for all tasks across the three points in time, transforming the data did not seem a desirable thing to do. It would not make sense to transform the data for a time where the variances were actually equal.

Parametric statistics were selected in opposition to nonparametric tests for several reasons (Minitab Blog Editor, 2015). First, parametric tests are known to provide results with larger statistical power. Therefore, independent and paired-samples t-tests were employed because findings obtained from performing these tests would yield more robust results. Second, nonparametric analyses do not expect data to show normal 
distribution and skewness. However, other assumptions need to be met to perform nonparametric tests. As explained above, data in the present dissertation did not meet all of those assumptions. Hence, parametric tests were employed to explore possible significant differences between and within the control group and the experimental group. Third, since the sample in this study was small $(n=46)$, parametric tests were selected because nonparametric tests may not contribute to help provide the most faithful representation of the findings.

All in all, t-tests allowed identifying the significant differences between groups and within groups, being aware of the fact that the error $\%$ would increase. In other words, each time that a t-test (independent or paired) is run, there is a $5 \%$ error percentage. Therefore, the more t-tests performed, the more the error percentage increases. Nevertheless, t-tests seemed to be the most reliable method with which to analyze quantitative data in this dissertation. The independent samples t-test was performed to compare both samples, both groups, independently from each other each time. In so doing, the evolution of each of the groups was analyzed separately. Finally, paired samples t-tests were calculated to track group development across times.

\subsubsection{Qualitative data analysis.}

Qualitative data analyzed in the present study was gathered from the RVPs and the Post-instruction Questionnaire. For both instruments, a topic analysis was carried out. This entailed first a close reading of all the participants' responses to find out recurrent issues. Once these were identified, they were grouped by topic. Topic analysis was performed to identify and track possible recurrent topics that would arise before and after instruction, as well as to explore whether the effects of instruction were also reflected on students' reports. As for RVPs, there were 15 RVPs per each of the participants $(N=46)$, this made a total of 690 RVPs per each time of task: pretest, 
Chapter 6: Method

posttest, and delayed posttest with a total of 2070 RVPs. Additionally, once all topics were classified, the tokens per topic were re-counted and MANOVAs were performed to explore possible significant differences among topics per time of task and between groups. 


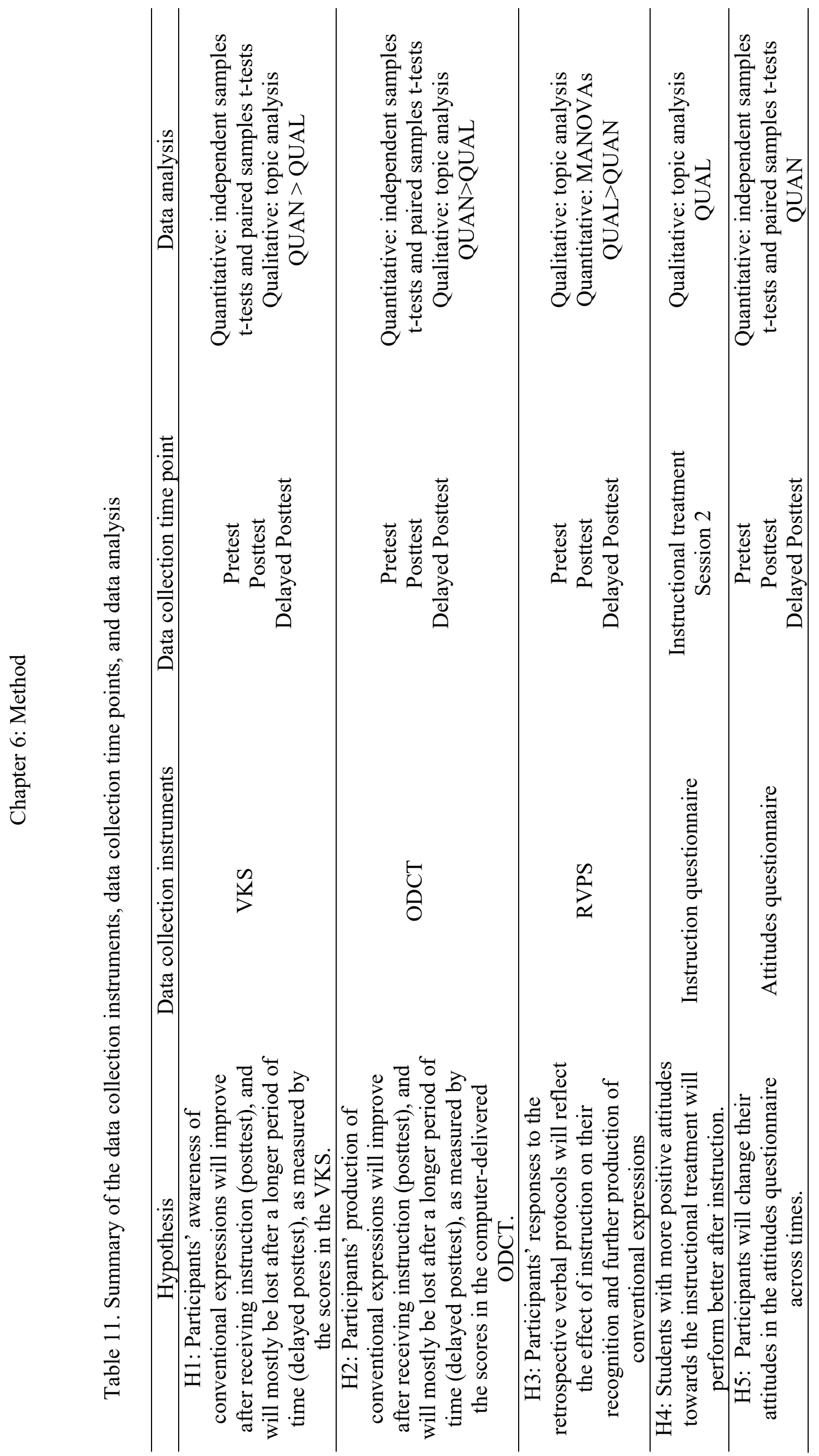




\subsection{Chapter Summary}

The present chapter presented a detailed account of the method designed and implemented in the present dissertation. The setting and the participants were identified first. Then, the target conventional expressions used in the tests were reviewed to help the reader remember them to better comprehend the instructional treatment. It was explained afterwards, commenting on the steps followed in each of the two sessions designed to teach the selected conventional expressions: the use of PowerPoint with visual materials and metapragmatic explanations followed by awareness-raising activities (AJT) and practice (role-play) as well as the distribution of the instruction questionnaire at the end of the instructional treatment. Then, a detailed account of the data collection instruments was provided, including the advantages and disadvantages of each of them as well as the rationale and details of the instruments used in this dissertation, whether they were designed specifically for this study, or were adapted, for example. This was followed by the operationalization of the data collection procedure, were detailed accounts about the research design were illustrated. Finally, the analysis procedures carried out both on the quantitative and the qualitative instruments were explained. Quantitative analysis for the VKS, computer-delivered ODCT and attitudes questionnaire were performed by means of paired t-tests and independent t-test to investigate the evolution of each of the two groups in and of themselves as well as comparing both groups across times respectively. Qualitative data was analyzed from data gathered with the RVPs and the instruction questionnaire, and topic analysis were carried out to identify recurrent issues raised by the students as regards to the English language and the instructional treatment they received. 



\section{Chapter 7: Results and Discussion}

This chapter encompasses the outcomes of the two research questions and five hypotheses formulated in Section 5.2. The first three sections include the analysis and discussion of the results for the three first hypotheses under RQ1: Effect of instruction. Section 7.1 refers to the effect of instruction on recognition (H1), Section 7.2 to the effect of instruction on production (H2), and Section 7.3 to participants' perceptions about their knowledge of conventional expressions (H3). Similarly, the next two sections encompass the analysis and discussion of the results for the two last hypotheses, which are included under RQ2: Students' attitudes. Section 7.4 relates to the effect of instruction on learners' attitudes (H4) and Section 7.5 to the effect of attitudes towards English (H5). Finally, Section 7.6 presents the Chapter Summary.

\subsection{Results and Discussion Related to Hypothesis 1}

Hypothesis 1 (H1) states that participants' recognition of conventional expressions will improve after receiving instruction (posttest), and will mostly be lost after a longer period of time (delayed posttest), as measured by the scores in the vocabulary knowledge scale (VKS). Independent samples t-test and paired-samples t-tests were performed to identify and monitor possible statistically significant differences between groups and also within each of the two groups. Results are reported in terms of three different data collection time points: pretest (i.e., Time 1, T1), posttest (i.e., Time 2, T2), and delayed posttest (i.e., Time 3, T3). Results from the data analysis allow confirming this first hypothesis partially. Results confirm the improvement in the posttest and the score decrease in the delayed posttest. However, they cannot be entirely attributed to the effect of instruction. Results from the independent samples t-tests at Time 2 corroborate the improvement by the posttest $(t=-4.999$, Sig. $(2$-tailed $)=<.001)$ and the decrease in scores at Time $3(t=-4.944$, Sig. $(2$-tailed $)=<.001)$. These results 
are further elaborated in this section Therefore, it could be said that instruction was partially effective. However, the extent of its effectiveness might be blurred because of the existence of ceiling effect due to task repetition, as observed from the results obtained in the task performance by the control group across times. Nevertheless, such effectiveness of the pedagogical intervention can be understood as strong, according to Cohen (1977), if attention is paid to the effect sizes from both the dependent samples ttest and independent samples t-tests comparing Mean scores within groups and between groups across times respectively as explained below. These results are explained from a Skill Acquisition Theory viewpoint.

Figure 14 below illustrates a summary of the general findings obtained by both groups in the VKS. Group performance is explained separately in what follows, preceded by a summarized report of the descriptive statistics per group.

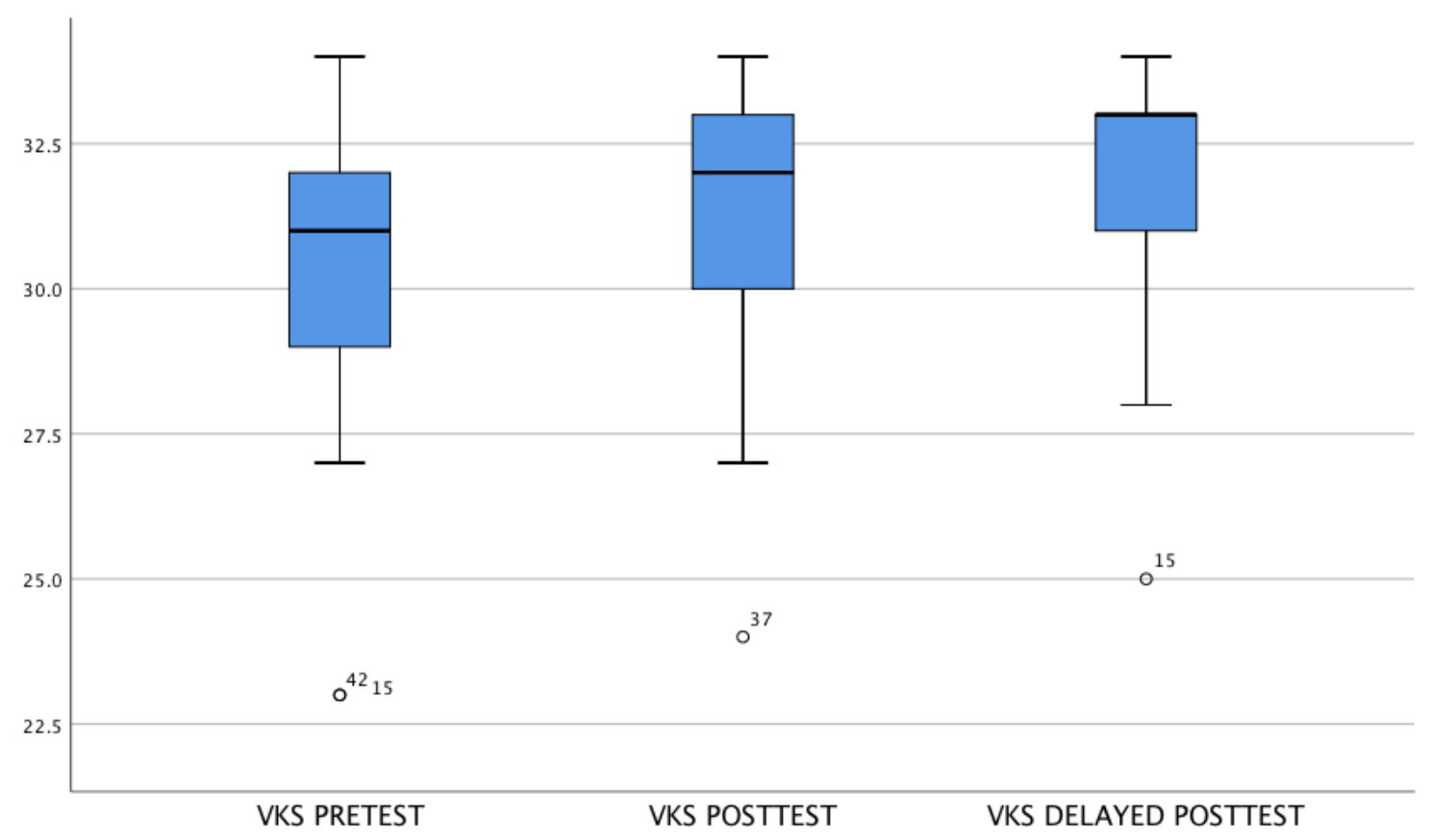

Figure 14. Boxplot for control and experimental groups performance of VKS 
A summary of the descriptive statistics is provided per group to identify the sample and highlight changes in performance from Time 1 (T1) to Time 3 (T3). The descriptive statistics for the control group are reported first and those for the experimental group afterward. Please refer to Appendix 16 for a more detailed account of the descriptive statistics per time of task for both groups in the VKS.

Table 12. Descriptive statistics for experimental group across times in VKS

\begin{tabular}{|c|c|c|c|c|c|c|}
\hline \multirow{4}{*}{$\begin{array}{c}\text { Experimental } \\
\text { group } \\
\text { [Group 1] } \\
n=21\end{array}$} & Time & Mean & $S D$ & Range & Skewness & Kurtosis \\
\hline & $\begin{array}{c}\text { Pretest } \\
\text { [Time 1] }\end{array}$ & 31.00 & 1.643 & $\begin{array}{c}6 \\
{[28-34]}\end{array}$ & $\begin{array}{c}-.075 \\
\text { (sd error } \\
.501)\end{array}$ & $\begin{array}{c}-.896 \\
\text { (sd error } \\
.972)\end{array}$ \\
\hline & $\begin{array}{l}\text { Posttest } \\
\text { [Time 2] }\end{array}$ & 32.81 & .928 & $\begin{array}{c}4 \\
{[30-34]}\end{array}$ & $\begin{array}{c}-1.243 \\
(\mathrm{sd} \text { error } \\
.501)\end{array}$ & $\begin{array}{c}3.083 \\
\text { (sd error } \\
.972)\end{array}$ \\
\hline & $\begin{array}{c}\text { Delayed } \\
\text { posttest } \\
\text { [Time 3] }\end{array}$ & 33.19 & .873 & $\begin{array}{c}3 \\
{[31-34]}\end{array}$ & $\begin{array}{c}-1.400 \\
\text { (sd error } \\
.501)\end{array}$ & $\begin{array}{c}2.250 \\
\text { (sd error } \\
.972)\end{array}$ \\
\hline
\end{tabular}

Table 12 illustrates the summary of the descriptive statistics for the experimental group in the VKS across times. The experimental group was conformed by 21 participants $(n=21)$. Participants in this group also scored rather high on the test $(\mathrm{M}=$ $31.00, \mathrm{SD}=1.643$ ), remembering that the minimum score in the VKS was 0 and the highest was 34 . Scores improved in the posttest $(\mathrm{M}=32.81, \mathrm{SD}=.928)$, and in the delayed posttest as well $(\mathrm{M}=33.19, \mathrm{SD}=.873)$, administered 11 days after the posttest. As seen in Table 13, the mean incremented from T1 to T3, which means that this group improved their performance from pretest to posttest. This is supported by the decrease of SD across times that also reflects this performance improvement at $\mathrm{T} 2$ and $\mathrm{T} 3$. As per the range of scores, it decreased from 6 in T1, to 4 in T2, and finally 3 in T3. The minimum scores also incremented across times, being the lowest 28 at T1 and 31 the highest at T3. In turn, the highest score obtained across times was 34, which was the maximum score participants could obtain in this test. Findings in skewness and Kurtosis 
inform that scores are normally distributed, and therefore there is no significant departure from the Mean score across times.

These results might be explained in terms of task repetition effect as well as the effect of instruction. If the control group experimented an increase in task performance, the same could be expected for the improvement in the scores in the experimental group. However, looking closely at the SDs across times for the experimental group, the lower number helps us identify that the scores became higher and more homogeneous, which can be seen in the histograms above. On the contrary, even though the scores also improved in the control group, the differences in the SDs across times indicate that even though the performance was higher, the scores were also less homogeneous, with larger ranges, as shown in the histograms above.

Table 13. Descriptive statistics for control group across times in VKS

\begin{tabular}{|c|c|c|c|c|c|c|}
\hline \multirow{4}{*}{$\begin{array}{l}\text { Control } \\
\text { group } \\
\text { [Group 0] } \\
n=25\end{array}$} & Time & Mean & $S D$ & Range & Skewness & Kurtosis \\
\hline & $\begin{array}{c}\text { Pretest } \\
\text { [Time 1] }\end{array}$ & 29.72 & 2.716 & $\begin{array}{c}11 \\
{[23-34]}\end{array}$ & $\begin{array}{c}-1.035 \\
\text { (sd error } \\
.464)\end{array}$ & $\begin{array}{c}1.345 \\
\text { (sd error } \\
.902) \\
\end{array}$ \\
\hline & $\begin{array}{l}\text { Posttest } \\
\text { [Time 2] }\end{array}$ & 30.44 & 2.142 & $\begin{array}{c}10 \\
{[24-34]}\end{array}$ & $\begin{array}{c}-1.126 \\
\text { (sd error } \\
.464)\end{array}$ & $\begin{array}{c}2.094 \\
\text { (sd error } \\
.902)\end{array}$ \\
\hline & $\begin{array}{l}\text { Delayed } \\
\text { posttest } \\
\text { [Time 3] }\end{array}$ & 31.00 & 2.000 & $\begin{array}{c}8 \\
{[25-33]}\end{array}$ & $\begin{array}{c}-1.326 \\
\text { (sd error } \\
.464)\end{array}$ & $\begin{array}{c}1.763 \\
\text { (sd error } \\
.902)\end{array}$ \\
\hline
\end{tabular}

Table 13 synthesizes the descriptive statistics for the control group in the VKS from T1 to T3. The control group was conformed by 25 participants $(n=25)$. This group scored high on the test $(\mathrm{M}=29.72, \mathrm{SD}=2.716)$ taking into consideration that the minimum score for the VKS was 0 and the highest was 34 . Scores improved in the posttest $(M=30.44, S D=2.142)$, and in the delayed posttest as well $(M=31.00, S D=$ 2.000), which was administered 11 days after the posttest. This is illustrated with the Mean. As seen in Table 12, it increased across times, which reflects the score 
improvement by students in the control group. This is supported by the decrease in the SD, which explains that the improvement became more homogeneous at Time 2 (T2) and $\mathrm{T} 3$ compared to the preceding times. The decrease in score range also reflected that score melioration. The minimum score obtained at T1 was 23, 24 at T2, and 25 at T3. The highest score was obtained at $\mathrm{T} 1$ and $\mathrm{T} 2$, but decreased to 33 at $\mathrm{T} 3$. The values for skewness and Kurtosis reveal normally distributed scores, which means that there was not significant departure form the Mean score across times. These results might be explained in terms of task repetition effect. When this test was handed in at Time 2 and Time 3, some students mentioned that they remembered the situations, which may explain the increase in scores across times.

The results from the independent samples t-tests and the paired samples t-tests are presented as follows. Findings obtained from these statistical analyses are discussed afterward considering the existing literature.

The independent samples t-tests were performed to identify and track possible significant differences between the control group and the experimental group. Three independent samples t-tests were run to compare the Mean scores of the groups per time of task.

Table 14. Descriptive statistics for group Mean comparison in the VKS at Time 1

\begin{tabular}{ccccc}
\hline Group & $N$ & Mean & $S D$ & $\begin{array}{c}\text { SD Error } \\
\text { Mean }\end{array}$ \\
\hline $\begin{array}{c}\text { Control } \\
\text { Group 0] }\end{array}$ & 25 & 29.72 & 2.716 & .543 \\
\hline $\begin{array}{c}\text { Experimental } \\
\text { [Group 1] }\end{array}$ & 21 & 31.00 & 1.643 & .359 \\
\hline
\end{tabular}

Table 14 provides the descriptive statistics from the comparison of the Mean difference between both groups at Time 1. The Mean for the control group was 29.72, whereas it was 31.00 for the experimental group. As for the SD, the control group 
obtained a SD of 2.716, and the experimental group 1.643. The SD Error Mean for the control group was .543 , and .359 for the experimental group.

Table 15. Independent samples t-test both groups in VKS at Time 1

\begin{tabular}{|c|c|c|c|c|c|c|}
\hline \multicolumn{7}{|c|}{ t-test for Equality of Means } \\
\hline \multirow[t]{3}{*}{$\mathrm{t}$} & \multirow[t]{3}{*}{ df } & \multirow{3}{*}{$\begin{array}{l}\text { Sig. (2- } \\
\text { tailed) }\end{array}$} & \multirow{3}{*}{$\begin{array}{c}\text { Mean } \\
\text { Difference }\end{array}$} & \multirow{3}{*}{$\begin{array}{l}\text { Std. Error } \\
\text { Difference }\end{array}$} & \multirow{2}{*}{\multicolumn{2}{|c|}{$\begin{array}{l}95 \% \text { Confidence } \\
\text { Interval of the } \\
\text { Difference }\end{array}$}} \\
\hline & & & & & & \\
\hline & & & & & Lower & Upper \\
\hline-1.887 & 44 & 0.66 & -1.280 & .678 & -2.647 & .087 \\
\hline
\end{tabular}

Table 15 illustrates the results from the independent samples t-test to compare the Mean difference of the control group and experimental group in the VKS at Time 1.

Data at this first time period showed departure from non-normality, since two outliers were found for the control group. Nevertheless, distributions seemed to be symmetric. Variances were equal, since the Levene test provided a no significant difference $(F=$ 2.779, Sig. $=.103$ ) between the variances of each group. An independent samples t-test found no evidence of a difference between the Means on the VKS at Time 1 for the control group $(n=25$, Mean $=29.72, \mathrm{SD}=2.716)$ and for the experimental group $(n=$ 21$, Mean $=31.00, \mathrm{SD}=1.643)$. See box plot Figure 15 below. Since the $95 \% \mathrm{CI}$ contains zero $[-2.647, .087]$, it can be concluded that there is no statistical difference between the groups. The narrow CI, less than 3 points on a test where the maximum score was 17 points, illustrates that the estimate of how different the groups are is uncertain, but not likely to be far from zero. The effect size for this comparison was calculated following Cohen's $\mathrm{d}^{25}$, which resulted in a Cohen's $\mathrm{d}=0.57$. According to Cohen's guidelines for effect sizes can be considered a medium effect size.

\footnotetext{
${ }^{25}$ For the present dissertation, effect sizes were calculated following Cohen's (1977) guidelines. Nevertheless, the field of SLA currently employs Plonsky and Oswald's (2014) guidelines to interpret effect sizes.
} 


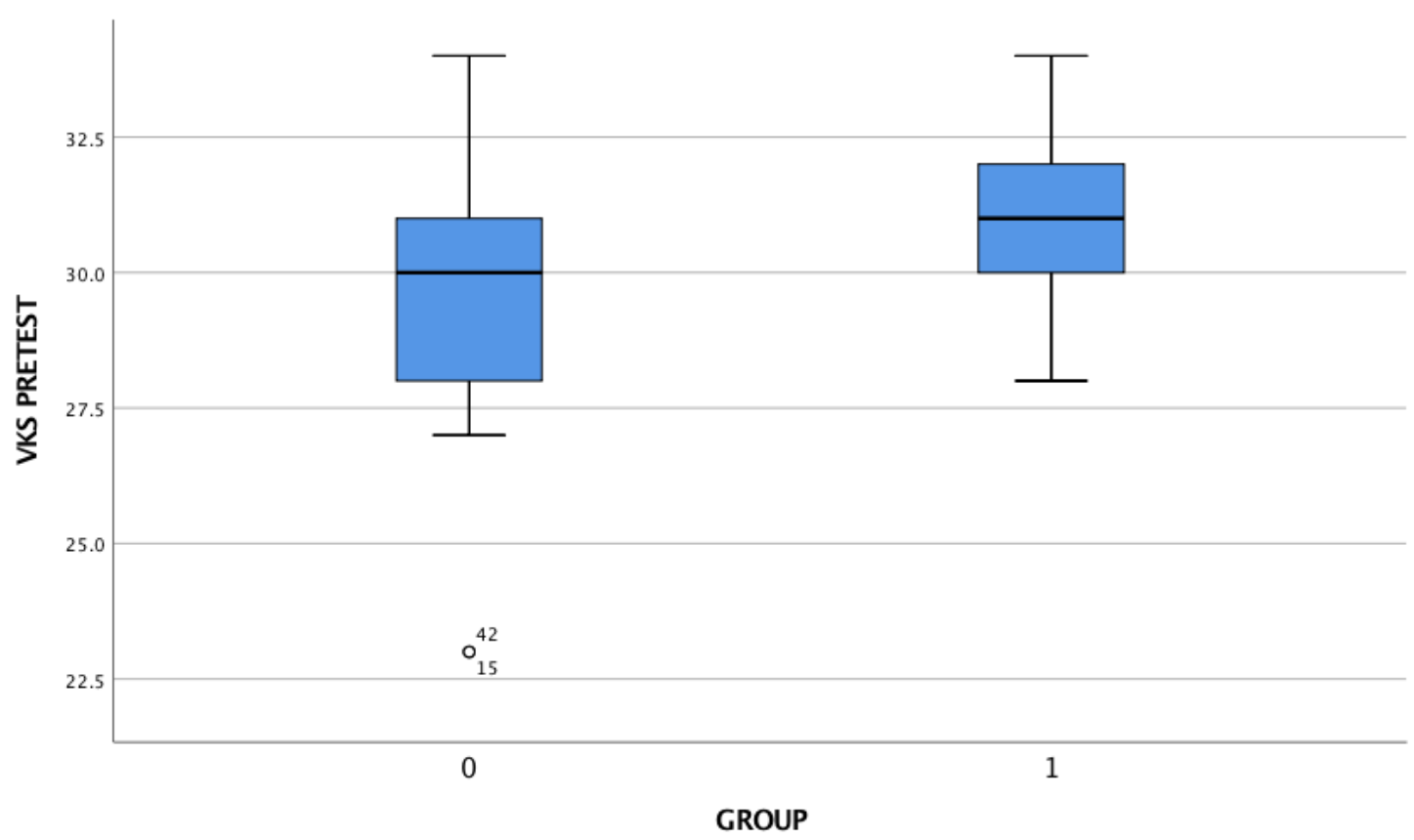

Figure 15. Box plot for Mean difference between control group and experimental group in VKS at Time 1

As shown in the descriptive statistics, there was already a difference in performance between the control group and the experimental group at T1, which the independent samples t-test revealed not to be significant, and with a medium effect size. These performances were already high taking into consideration that the highest score is 34 for the VKS. Results from the independent samples t-tests performed for T2 and T3 help understand score performance development and the possible reasons behind such changes and between-group differences.

Table 16. Descriptive statistics for group Mean comparison in the VKS at Time 2

\begin{tabular}{ccccc}
\hline Group & $N$ & Mean & $S D$ & $\begin{array}{c}\text { SD Error } \\
\text { Mean }\end{array}$ \\
\hline $\begin{array}{c}\text { Control } \\
\text { [Group 0] }\end{array}$ & 25 & 30.44 & 2.142 & .428 \\
\hline $\begin{array}{c}\text { Experimental } \\
\text { [Group 1] }\end{array}$ & 21 & 32.81 & .928 & .203 \\
\hline
\end{tabular}

Table 16 provides the descriptive statistics from the comparison of the Means of both groups at Time 2. The Mean for both groups was higher than 30 this time, as so 
were each of the Means in comparison to those at Time 1 respectively. At Time 2, there was a Mean of 30.44, with a SD of 2.142 and a SD error mean of .428 for the control group; and a mean of 32.81 , with a SD of .928 and a SD error mean of .203 for the experimental group.

Table 17. Independent samples t-test both groups in VKS at Time 2

\begin{tabular}{|c|c|c|c|c|c|c|}
\hline \multicolumn{7}{|c|}{ t-test for Equality of Means } \\
\hline \multirow[t]{2}{*}{$\mathrm{t}$} & \multirow[t]{2}{*}{$\mathrm{df}$} & \multirow[t]{2}{*}{$\begin{array}{l}\text { Sig. (2- } \\
\text { tailed) }\end{array}$} & \multirow[t]{2}{*}{$\begin{array}{c}\text { Mean } \\
\text { Difference }\end{array}$} & \multirow[t]{2}{*}{$\begin{array}{l}\text { Std. Error } \\
\text { Difference }\end{array}$} & \multicolumn{2}{|c|}{$\begin{array}{l}95 \% \text { Confidence } \\
\text { Interval of the } \\
\text { Difference }\end{array}$} \\
\hline & & & & & Lower & Upper \\
\hline-4.999 & 33.897 & $p<.001$ & -2.370 & .474 & -3.333 & -1.406 \\
\hline
\end{tabular}

Table 17 illustrates the results from the independent samples t-test to compare the means of the control group and experimental group in the VKS at Time 2. Data at this second time period showed departure from non-normality, since two outliers can be found: one per each group. Also, variances were found to be not equal, as obtained from the Levene test $(F=10.550$; Sig. $=.002)$. An independent samples t-test found evidence of a difference between the means on the VKS at Time 2 for the control group $(n=25$, Mean $=30.44, \mathrm{SD}=2.142)$ and for the experimental group $(n=21$, Mean $=32.81, \mathrm{SD}=$ .928). See box plot Figure 16 below. Since the 95\% CI does not contain zero [-3.333, 1.406], it can be concluded that there is a statistical difference between the groups. The narrow CI, less than 2 points on a test where the maximum score was 17 points, illustrates that the estimate of how different the groups are is uncertain, but not likely to be far from zero. The effect size for this comparison was calculated following Cohen's $\mathrm{d}$, which resulted in a Cohen's $\mathrm{d}=1.436$. According to Cohen's guidelines for effect sizes can be considered a large effect size. 


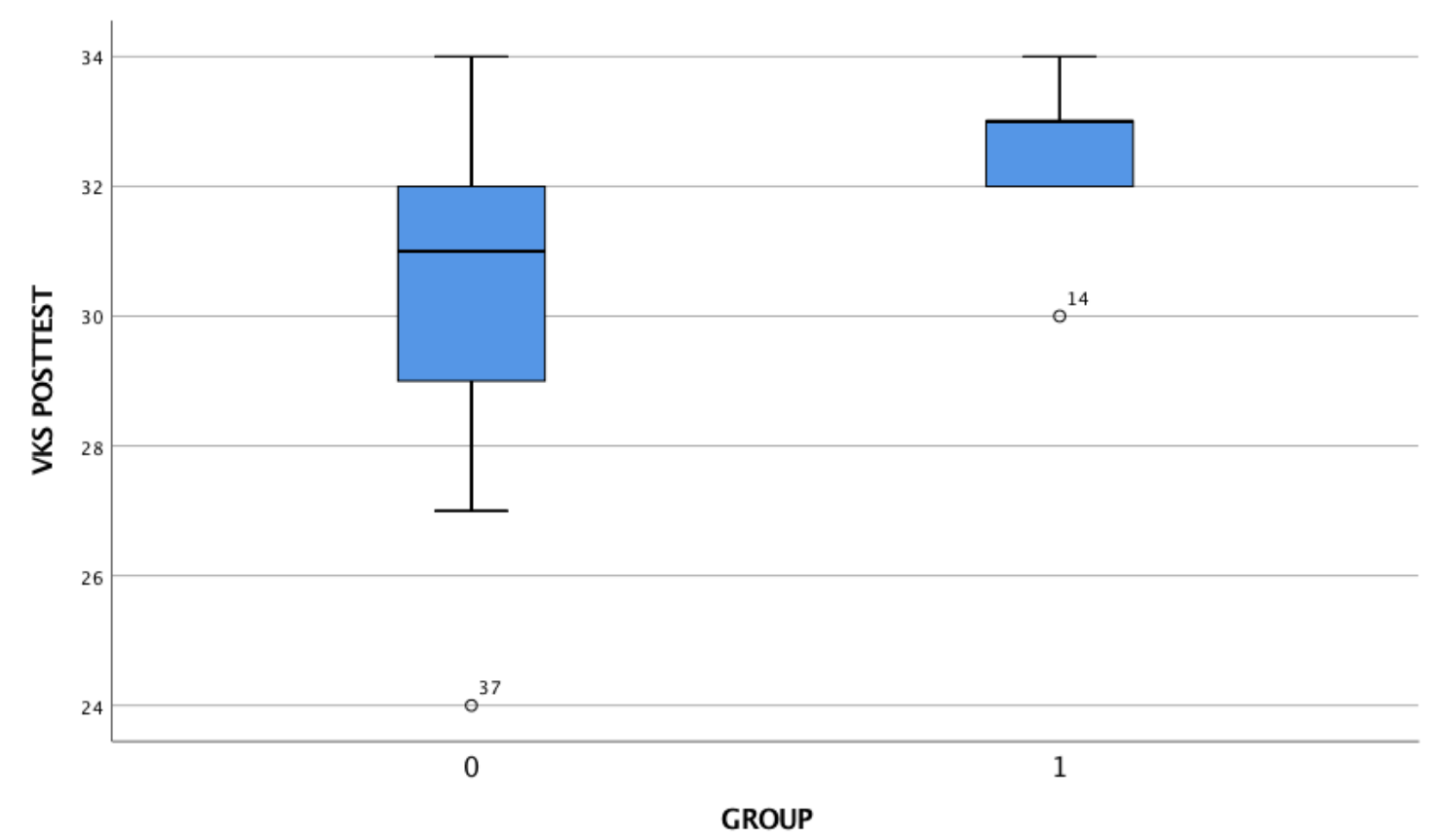

Figure 16. Box plot for Mean difference between control group and experimental group in VKS at Time 2

The descriptive statistics for Mean comparison at $\mathrm{T} 2$ also revealed a difference in performance between these two groups. The independent samples t-test revealed that this difference was statistically significant, and Cohen's $d=1.436$ informed that this statistical difference was large. This could be explained in terms of both task repetition effect as well as the effect of instruction. As for the former, it could help explain the score improvement by the control group. At the same time, the same could be applied to the experimental group. Nevertheless, since the control group received instruction, this variable could also be the source of this significant difference between control group and experimental group. 
Now that the scores, distribution of the scores, and Mean comparison of both groups for Time 2 have been reported, the same will be done for Time 3 .

Table 18. Descriptive statistics for group Mean comparison in the VKS at Time 3

\begin{tabular}{ccccc}
\hline Group & $N$ & Mean & $S D$ & $\begin{array}{c}\text { SD Error } \\
\text { Mean }\end{array}$ \\
\hline $\begin{array}{c}\text { Control } \\
\text { [Group 0] }\end{array}$ & 25 & 31.00 & 2.000 & .400 \\
\hline $\begin{array}{c}\text { Experimental } \\
{[\text { Group 1] }}\end{array}$ & 21 & 33.19 & .873 & .190 \\
\hline
\end{tabular}

Table 18 provides the descriptive statistics from the comparison of the score performance by both groups at Time 3. The Mean for both groups was higher than 30 this time, and higher than the previous two Means. There was a Mean of 31.00, with a $\mathrm{SD}$ of 2.000 and a SD error mean of .400 for the control group; and a mean of 33.19 , with a SD of .873 and a SD error mean of .190 for the experimental group.

Table 19. Independent samples t-test both groups in VKS at Time 3

\begin{tabular}{|c|c|c|c|c|c|c|}
\hline \multicolumn{7}{|c|}{ t-test for Equality of Means } \\
\hline \multirow[t]{3}{*}{$\mathrm{t}$} & \multirow[t]{3}{*}{ df } & \multirow{3}{*}{$\begin{array}{l}\text { Sig. }(2- \\
\text { tailed) }\end{array}$} & \multirow{3}{*}{$\begin{array}{c}\text { Mean } \\
\text { Difference }\end{array}$} & \multirow{3}{*}{$\begin{array}{l}\text { Std. Error } \\
\text { Difference }\end{array}$} & \multirow{2}{*}{\multicolumn{2}{|c|}{$\begin{array}{l}95 \% \text { Confidence } \\
\text { Interval of the } \\
\text { Difference }\end{array}$}} \\
\hline & & & & & & \\
\hline & & & & & Lower & Upper \\
\hline-4.944 & 34.019 & $\mathrm{p}<.001$ & -2.190 & .443 & -3.091 & -1.290 \\
\hline
\end{tabular}

Table 19 illustrates the results from the independent samples t-test that compared the Means of the control group and experimental group in the VKS at Time 3. Data at this third time period showed departure from non-normality, since two outliers were found for the experimental group. Additionally, variances were found to be not equal, resulted from the Levene test $(F=12.369$, Sig. $=.001)$. An independent samples t-test found evidence of a difference between the means on the VKS at Time 3 for the control group $(n=25$, mean $=31.00, \mathrm{SD}=2.000)$ and for the experimental group $(n=21$, Mean $=33.19, \mathrm{SD}=.873$ ). See box plot Figure 17 below. Since the $95 \% \mathrm{CI}$ does not 
contain zero $[-3.091,-1.290]$, it can be concluded that there is a statistical difference between the groups. The narrow CI, less than 2 points on a test where the maximum score was 17 points, illustrates that the estimate of how different the groups are is uncertain, but not likely to be far from zero. The effect size for this comparison was calculated following Cohen's d, which resulted in a Cohen's d $=1.419$. According to Cohen's guidelines for effect sizes can be considered a large effect size.

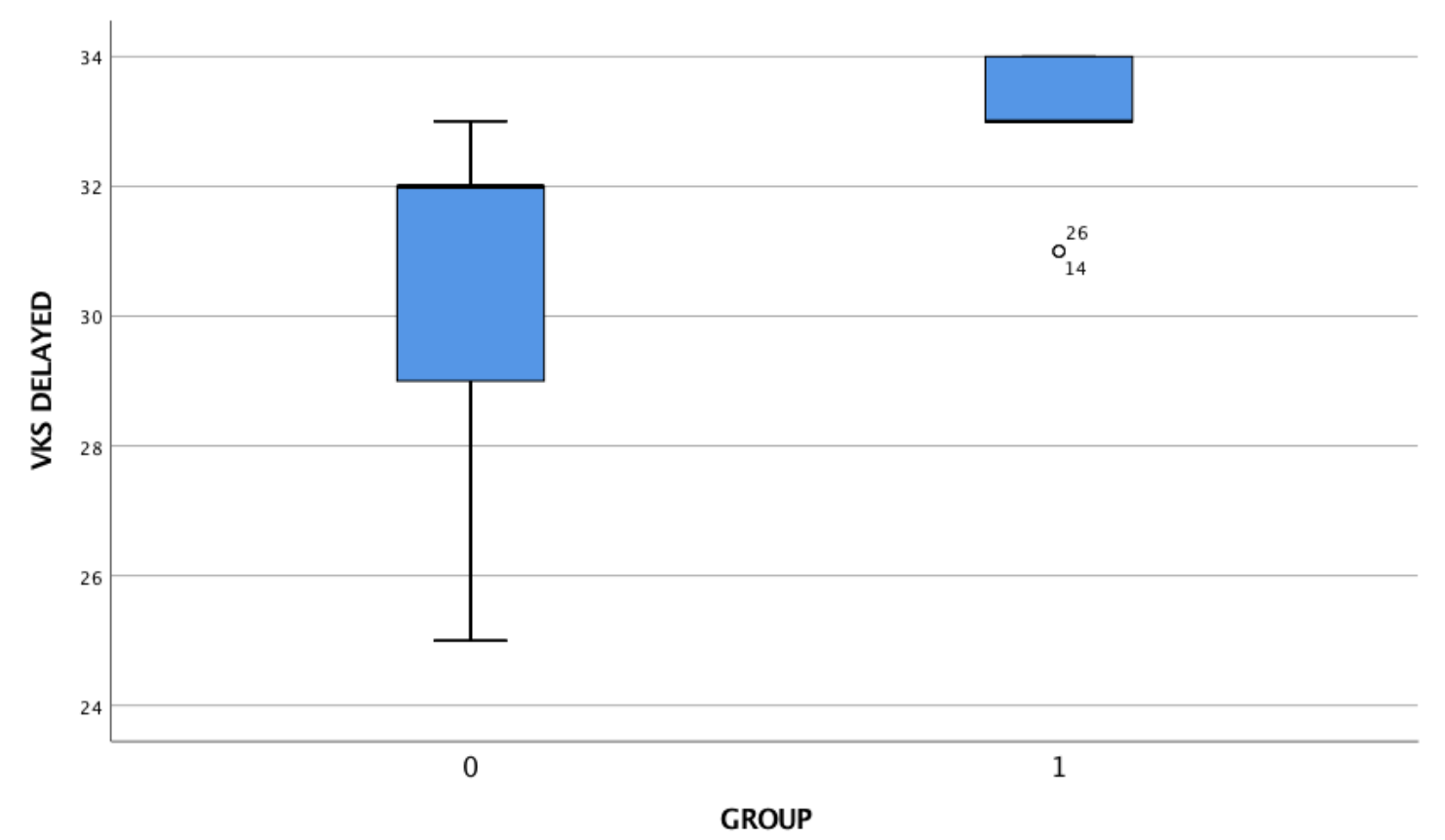

Figure 17. Box plot for Mean difference between control group and experimental group in VKS at Time 3

Finally, the descriptive statistics for Mean comparison at T3 also revealed a difference in performance between the control and the experimental groups. The independent samples t-test revealed that this difference was statistically significant, with an effect size of Cohen's d=1.419. Even though the effect size was slightly smaller than at T2, it was still large. Similar to the findings obtained in the mean comparison at T2, the findings obtained in the independent samples t-test run at T3 could be explained in terms of both task repetition effect as well as the effect of instruction. Since the performance of the control group still improved at T3, it could be argued that task 
repetition effect was not only present in this group, but also in the experimental group. Nevertheless, the score improvement experienced by the experimental group could also be explained in terms of effect of instruction.

In sum, results from the independent samples t-test showed that there were two outliers in the control group, which means that two participants scored lower than the group's mean. Moreover, and most importantly, this test found a difference that was not significant between these two groups at $\mathrm{T} 1$, which had a medium effect size $(\mathrm{d}=0.57)$. As for the independent samples t-test that compared the Mean differences between groups at Time 2, different results were obtained. On the one hand, the number of outliers remained the same. However, one outlier per group was found at the posttest. Most importantly, a statistically significant difference was found at T2 between these two groups, with a large effect size $(d=1.436)$, which could be attributed to the effect of instruction in the greater part. Finally, the independent samples t-test performed to observe mean differences between control and experimental group at T3 revealed different as well as similar results compared to these tests at T1 and T2. Different from results obtained so far, two outliers were found as well. However, this time both participants belonged to the experimental group. Most importantly, and in line with results obtained at $\mathrm{T} 2$, there was a statistically significant difference between the control and the experimental group at this third and last data collection point, with a large effect size $(d=1.419)$, which was a bit smaller than at $T 2$. Nevertheless, this evidence indicates that the effect of instruction may have also exerted a large effect at the delayed posttest. However, and as mentioned before, since the increment in scores for the control group can be explained in terms of task repetition effect, the effect of instruction should be taken cautiously. These findings are now discussed in relation to those present in the existing literature. 
Once the between group differences were analyzed and findings discussed, a series of paired samples t-tests were performed to investigate whether there were statistically significant differences between the Means within each of the groups across times. Results related to the control group's performance are explained first and those obtained by the experimental group afterwards.

Table 21 illustrates the paired samples t-test performed to compare Mean difference for the control group between $\mathrm{T} 1(n=25, \mathrm{M}=29.72, \mathrm{SD}=2.716)$ and $\mathrm{T} 2(n=$ $25, \mathrm{M}=30.44, \mathrm{SD}=2.142$ ) in the VKS. See descriptive statistics in Table 20 below. This test found no significant difference for the control group between these two times, since the $95 \%$ CI $[-1.728, .288]$ ran through zero. The size of the interval shows that the actual Mean could be as small as less than 1 point, or as large as nearly 2 points. A Cohen's d effect size was performed for this comparison, and resulted in $\mathrm{d}=0.295$, which means that the difference between the pretest and the posttest was small.

Table 20. Paired samples t-test descriptive statistics for VKS control group from Time 1 to Time 2

\begin{tabular}{|c|c|c|c|c|c|}
\hline & & $\mathrm{N}$ & Mean & SD & $\begin{array}{l}\text { SD Error } \\
\text { Mean }\end{array}$ \\
\hline \multirow{2}{*}{$\begin{array}{l}\text { Control } \\
\text { Group } \\
\text { [Group 0] }\end{array}$} & $\begin{array}{l}\text { VKS Pretest } \\
\text { [Time 1] }\end{array}$ & 25 & 29.72 & 2.716 & .543 \\
\hline & $\begin{array}{l}\text { VKS Posttest } \\
\text { [Time 2] }\end{array}$ & 25 & 30.44 & 2.142 & .428 \\
\hline
\end{tabular}

Table 21. Paired samples t-test for VKS control group from Time 1 to Time 2

\begin{tabular}{cccccccc}
\hline \multicolumn{7}{c}{ Paired Differences } \\
\hline Group & Mean & $S D$ & $S D$ & $95 \% C I$ & $t$ & $d f$ & Sig $p$. \\
\multicolumn{7}{c}{ Error } \\
& \multicolumn{7}{c}{ mean } \\
\hline Control & -.720 & 2.441 & .488 & {$[-1.728$,} & -1.475 & 24 & .153 \\
{$[$ Group 0] } & & & & $.288]$ & & & \\
\hline
\end{tabular}


Table 23 shows the paired samples t-test performed to compare Mean difference for the control group between $\mathrm{T} 2(n=25, \mathrm{M}=30.44, \mathrm{SD}=2.142)$ and $\mathrm{T} 3(n=25, \mathrm{M}=$ $31.00, \mathrm{SD}=2.000$ ) in the VKS. See descriptive statistics in Table 22 below. This test found no significant difference for the control group between these two times, since the $95 \%$ CI $[-1.452, .332]$ ran through zero. The size of the interval shows that the actual mean could be as small as less than 1 point, or as large as nearly 1.5 points. A Cohen's $\mathrm{d}$ effect size was performed for this comparison, and resulted in $\mathrm{d}=0.259$, which means that the difference between the pretest and the posttest was small.

Table 22. Paired samples t-test descriptive statistics for VKS control group from Time 2 to Time 3

\begin{tabular}{cccccc}
\hline & $\mathrm{N}$ & Mean & SD & $\begin{array}{c}\text { SD Error } \\
\text { Mean }\end{array}$ \\
\hline $\begin{array}{c}\text { Control } \\
\text { Group } \\
\text { [Group 0] }]\end{array}$ & $\begin{array}{c}\text { VKS Posttest } \\
{[\text { Time 2] }}\end{array}$ & 25 & 30.44 & 2.142 & .428 \\
\cline { 2 - 6 } & $\begin{array}{c}\text { VKS Delayed } \\
\text { Posttest } \\
{[\text { Time 3] }}\end{array}$ & 25 & 31.00 & 2.000 & .400 \\
\hline
\end{tabular}

Table 23. Paired samples t-test for VKS control group from Time 2 to Time 3

\begin{tabular}{cccccccc}
\hline \multicolumn{7}{c}{ Paired Differences } \\
\hline Group & Mean & $S D$ & $\begin{array}{c}\text { SD } \\
\text { Error } \\
\text { mean }\end{array}$ & $95 \% C I$ & $t$ & $d f$ & Sig $p$ \\
\hline Control & -.560 & 2.162 & .432 & {$[-1.452$,} & -1.295 & 24 & .208 \\
[Group 0] & & & $.332]$ & & & \\
\hline
\end{tabular}


Table 25 provides the paired samples t-test performed to compare Mean difference for the control group between $\mathrm{T} 1(n=25, \mathrm{M}=29.72, \mathrm{SD}=2.716)$ and $\mathrm{T} 3(n=$ $25, \mathrm{M}=31.00, \mathrm{SD}=2.000)$ in the VKS. See descriptive statistics in Table 24 below. This test found a significant difference for the control group between these two times, since the $95 \%$ CI $[2.093,-.467]$ did not run through zero. The size of the interval shows that the actual mean could be as small as less than 0.5 point, or as large as over 2 points. A Cohen's d effect size was performed for this comparison, and resulted in $\mathrm{d}=0.65$, which means that the difference between the pretest and the posttest was medium. Table 24. Paired samples t-test descriptive statistics for VKS control group from Time 1 to Time 3

\begin{tabular}{cccccc}
\hline & N & Mean & SD & $\begin{array}{c}\text { SD Error } \\
\text { Mean }\end{array}$ \\
\hline $\begin{array}{c}\text { Control } \\
\text { Group } \\
\text { [Group 0] }\end{array}$ & $\begin{array}{c}\text { VKS Pretest } \\
{[\text { Time 1] }}\end{array}$ & 25 & 29.72 & 2.716 & .543 \\
\cline { 2 - 6 } & $\begin{array}{c}\text { VKS Delayed } \\
\text { Posttest } \\
{[\text { Time 3] }}\end{array}$ & 25 & 31.00 & 2.000 & .400 \\
\hline
\end{tabular}

Table 25. Paired samples t-test for VKS control group from Time 1 to Time 3

\begin{tabular}{cccccccc}
\hline \multicolumn{7}{c}{ Paired Differences } \\
\hline Group & Mean & $S D$ & $\begin{array}{c}\text { SD } \\
\text { Error } \\
\text { mean }\end{array}$ & $95 \% C I$ & $t$ & $d f$ & Sig $p$ \\
\hline Control & -1.280 & 1.969 & .394 & {$[-2.093$,} & -3.251 & 24 & .003 \\
{$[$ Group 0] } & & & & $-.467]$ & & & \\
\hline
\end{tabular}


Results from the paired samples t-test help identify whether those score increases are significant or not. The first paired samples t-test, which compared the Mean difference between $\mathrm{T} 1$ and $\mathrm{T} 2$, was not significant and the effect size was small $(\mathrm{d}=$ 0.295) which suggest that participants' performance did not improve significantly from pretest to posttest, maybe due to the lack of provision of pedagogical intervention. The paired samples t-test between $\mathrm{T} 2$ and $\mathrm{T} 3$ revealed a no significant difference between the Means at these two points in time, with a small effect size $(d=0.259)$, which was a bit smaller than that of the first comparison above. This suggests that participants' recognition of conventional expressions did not improve that much either from the posttest to the delayed posttest. Similar to the previous comparison, not receiving instruction may explain this performance. Finally, the last paired samples t-test confirmed a significant difference between the Means at T1 and T3 with a medium effect size $(\mathrm{d}=0.65)$ for the control group in the VKS. These results imply that even though scores increased overall, that rise was only statistically significant from Time 1 to Time 3. These results may be explained by the fact that this group did not receive instruction and that all performance improvement across times may be attributed to the task repetition effect. One of the constraints of this study was the limited access to the students, which affected the research design of the present investigation. Had there been more time between pretest, posttest, and delayed posttest, that may have translated in the absence or less presence of task repetition effect.

The paired samples t-tests performed in the Mean score performance by the experimental group are explained and discussed as follows. 
Table 27 illustrates the paired samples t-test performed to compare Mean difference for the experimental group between T1 $(n=21, \mathrm{M}=31.00, \mathrm{SD}=1.643)$ and $\mathrm{T} 2(n=21, \mathrm{M}=32.81, \mathrm{SD}=.928)$ in the VKS. See descriptive statistics in Table 26 below. This test found a significant difference for the experimental group between these two times, since the $95 \%$ CI $[-2.479,-1.140]$ did not run through zero. The size of the interval shows that the actual Mean could be as small as over 1 point, or as large as over 2 points. A Cohen's $d$ effect size was performed for this comparison, and resulted in $\mathrm{d}=$ 1.23, which means that the difference between the pretest and the posttest was large. This could mean that the effect of instruction was very effective.

Table 26. Paired samples t-test descriptive statistics for VKS experimental group from Time 1 to Time 2

\begin{tabular}{cccccc}
\hline & $\mathrm{N}$ & Mean & SD & $\begin{array}{c}\text { SD Error } \\
\text { Mean }\end{array}$ \\
\hline $\begin{array}{c}\text { Experimental } \\
\text { Group } \\
\text { [Group 1] }\end{array}$ & $\begin{array}{c}\text { VKS Pretest } \\
\text { [Time 1] }\end{array}$ & 21 & 31.00 & 1.643 & .359 \\
\cline { 2 - 6 } & $\begin{array}{c}\text { VKS Posttest } \\
\text { [Time 2] }\end{array}$ & 21 & 32.81 & .928 & .203 \\
\hline
\end{tabular}

Table 27. Paired samples t-test for VKS experimental group from Time 1 to Time 2

\begin{tabular}{cccccccc}
\hline \multicolumn{7}{c}{ Paired Differences } \\
\hline Group & Mean & SD & SD & $95 \% C I$ & $t$ & $d f$ & Sig $p$. \\
& \multicolumn{7}{c}{$\begin{array}{c}\text { Error } \\
\text { mean }\end{array}$} \\
\hline Experimental & -1.810 & 1.470 & .321 & {$[-2.479$,} & -5.640 & 20 & $\mathrm{p}<.001$ \\
[Group 1] & & & & $-1.140]$ & & & \\
\hline
\end{tabular}


Table 29 provides the paired samples t-test performed to compare Mean difference for the experimental group between $\mathrm{T} 2(n=21, \mathrm{M}=32.81, \mathrm{SD}=.928)$ and $\mathrm{T} 3$ $(n=21, \mathrm{M}=33.19, \mathrm{SD}=.873)$ in the VKS. See descriptive statistics in Table 28 below. This test found no significant difference for the experimental group between these two times, since the $95 \%$ CI $[-.718,-.044]$ ran through zero. The size of the interval shows that the actual Mean could be as small as less than 1 point, or as large as nearly 1 point. A Cohen's d effect size was performed for this comparison, and resulted in $\mathrm{d}=0.515$, which means that the difference between the pretest and the posttest was medium. This means that the effect of instruction was less effective.

Table 28. Paired samples t-test descriptive statistics for VKS experimental group from Time 2 to Time 3

\begin{tabular}{cccccc}
\hline & $\mathrm{N}$ & Mean & SD & $\begin{array}{c}\text { SD Error } \\
\text { Mean }\end{array}$ \\
\hline $\begin{array}{c}\text { Experimental } \\
\text { Group } \\
\text { [Group 1] }\end{array}$ & $\begin{array}{c}\text { VKS Posttest } \\
\text { [Time 2] }\end{array}$ & 21 & 32.81 & .928 & .203 \\
\cline { 2 - 6 } & $\begin{array}{c}\text { VKS Delayed } \\
\text { Posttest } \\
\text { [Time 3] }\end{array}$ & 21 & 33.19 & .873 & .190 \\
\hline
\end{tabular}

Table 29. Paired samples t-test for VKS experimental group from Time 2 to Time 3

\begin{tabular}{cccccccc}
\hline \multicolumn{7}{c}{ Paired Differences } \\
\hline Group & Mean & $S D$ & $\begin{array}{c}S D \\
\text { Error } \\
\text { mean }\end{array}$ & $95 \% C I$ & $t$ & $d f$ & Sig $p$. \\
\hline Experimental & -.381 & .740 & .161 & {$[-.718$,} & -2.359 & 20 & .029 \\
[Group 1] & & & & $-.044]$ & & & \\
\hline
\end{tabular}


Table 31 shows the paired samples t-test performed to compare Mean difference for the experimental group between $\mathrm{T} 1(n=21, \mathrm{M}=31.00, \mathrm{SD}=1.643)$ and $\mathrm{T} 3(n=21$, $\mathrm{M}=33.19, \mathrm{SD}=.873)$ in the VKS. See descriptive statistics in Table 30 below. This test found a significant difference for the control group between these two times, since the $95 \%$ CI $[-2.860,-1.521]$ did not run through zero. The size of the interval shows that the actual Mean could be as small as over than 1.5 points, or as large as nearly 3 points. A Cohen's d effect size was performed for this comparison, and resulted in $\mathrm{d}=1.49$, which means that the difference between the pretest and the posttest was large. This means that the effect of instruction may have been very effective.

Table 30. Paired samples t-test descriptive statistics for VKS experimental group from Time 1 to Time 3

\begin{tabular}{cccccc}
\hline & $\mathrm{N}$ & Mean & SD & $\begin{array}{c}\text { SD Error } \\
\text { Mean }\end{array}$ \\
\hline $\begin{array}{c}\text { Experimental } \\
\text { Group } \\
\text { [Group 1] }\end{array}$ & $\begin{array}{c}\text { VKS Pretest } \\
\text { [Time 1] }\end{array}$ & 21 & 31.00 & 1.643 & .359 \\
\cline { 2 - 6 } & $\begin{array}{c}\text { VKS Delayed } \\
\text { Posttest } \\
\text { [Time 3] }\end{array}$ & 21 & 33.19 & .873 & .190 \\
\hline
\end{tabular}

Table 31. Paired samples t-test for VKS experimental group from Time 1 to Time 3

\begin{tabular}{cccccccc}
\hline \multicolumn{7}{c}{ Paired Differences } \\
\hline Group & Mean & $S D$ & $\begin{array}{c}S D \\
\text { Error } \\
\text { mean }\end{array}$ & $95 \% C I$ & $t$ & $d f$ & Sig $p$. \\
\hline Experimental & -2.190 & 1.470 & .321 & {$[-2.860$,} & -6.827 & 20 & $\mathrm{p}<.001$ \\
[Group 1] & & & & $-1.521]$ & & & \\
\hline
\end{tabular}

The results obtained from the paired samples t-test help understand whether the increase in scores are significant or not. For the experimental group, the first paired samples t-test, which compared the Mean difference between T1 and T2, was significant and the effect size was large $(d=1.23)$, quite an opposite result comparing it to the control group at this same time. The paired samples t-test between T2 and T3 
revealed a no significant difference between the Means at these two points in time, with a medium effect size $(\mathrm{d}=0.515)$, which was half the time smaller than that of the first comparison above. This may be translated in the fact that the effect of instruction did not last until T3 as equally effective than at T2, which was the expected outcome. Finally, the last paired samples t-test confirmed a significant difference between the Means at T1 and T3 with a large effect size $(\mathrm{d}=1.49)$ for the experimental group in the VKS. These results reveal that scores increased overall, and that rise was not significant from $\mathrm{T} 2$ to $\mathrm{T} 3$, but it was indeed statistically significant from $\mathrm{T} 1$ to $\mathrm{T} 2$, and from $\mathrm{T} 1$ to T3. These results may be explained by the fact that this group did receive instruction and that performance improvement across times may be attributed to both the task repetition effect, but also to effect of pedagogical intervention.

Results from the data analysis allow to partially confirm this first hypothesis. Results confirm the improvement in the posttest and the score decrease in the delayed posttest. However, they cannot be entirely attributed to the effect of instruction. Therefore, it could be said that instruction was partially effective. However, the extent of its effectiveness might be blurred due to the existence of ceiling effect due to task repetition, as observed from the results obtained in the task performance by the control group across times. Nevertheless, such effectiveness of the pedagogical intervention can be understood as strong if attention is paid to the effect sizes from both the dependent samples t-test and independent samples t-tests comparing Mean scores within groups and between groups across times respectively as reported above. These results can also be explained from a Skill Acquisition Theory viewpoint.

In line with previous research, which focused on the recognition of conventional expressions, studies that include instructional intervention are very few. Nevertheless, they found that the effect of the instruction was maintained in the posttest (e.g., Taguchi 
et al., 2017). In the case of Taguchi et al. (2017) results could be explained based on participants' scores as well as their motivation to be involved and learn by means of a technology-mediated data collection method that resembled real-life interactions, as shown in the interview reports. In this dissertation, the pragmatic gains were also found in the posttest and, as expected, they did not last in the delayed posttest.

A large number of studies have explored the recognition of conventional expressions without intervention. Particularly interesting to my investigation are Bardovi-Harlig $(2011,2014)$. Bardovi-Harlig reported that participants made correct reports for those expressions they marked as unknown to them, which was also the case in this dissertation. Participants chose option “A: I don’t know this expression” for those conventional expressions they had never heard of. Additionally, participants in Bardovi-Harlig (2011) found conventional expressions that consist of a verb and a particle, such as Watch out!, challenging. Results from the present dissertation corroborate this finding, because this particular expression was found to be difficult to learn for students. Similar to results from Bardovi-Harlig (2011) students in the present study also misinterpreted the meaning of this expression. For example, P7Pret ${ }^{26}$ used the following example to demonstrate that they knew this expression: "Watch out! They are kissing!” In a similar vein, P29Pret ${ }^{27}$ wrote: “(A) Watch out! There’s a dog dancing! (B) Are you kidding me?" These students understood this expression literally, as they meant to look through the window.

Bardovi-Harlig (2014) found out that recognition skills of conventional expressions are not determined by the participants' proficiency level. In her study, even less proficient learners were able to define and provide examples of conventional

\footnotetext{
${ }^{26}$ Participant 7 at the pretest.

${ }^{27}$ Participant 29 at the pretest.
} 
expressions. This was the case in the present dissertation as well, in which even students with an A2 and B1 proficiency levels according to the CEFR were able to carry out this task equally successful as their more proficient classmates. This research finding goes in line with fact that pragmatic performance does not go hand in hand with grammatical proficiency (e.g. Bardovi-Harlig, 2001; Taguchi, 2015b). In other words, a higher proficiency level does not imply a higher pragmatic knowledge, and vice versa. Those students who have a lower proficiency level do not necessarily have to have a low command of pragmatic knowledge.

Another interesting finding in the present study was the better performance at the pragmatic recognition task than at the pragmatic production task. This result goes in line with previous research, in which students find it easier to recognize conventional expressions than to produce them both in ESL and EFL contexts (e.g., Bardovi-Harlig, 2008, 2009; Rafieyan, Sharafi-Nejad \& Eng, 2014a) a plausible source for this finding lies on the fact that providing students with pragmatic awareness activities may foster the recognition process of such expressions. In the present dissertation, evidence that supports this finding comes also from the Post-instruction Questionnaire. More specifically from the two open-ended questions that asked students to identify the things they liked most and least about the AJT. The AJT aimed at promoting students' awareness of the issues related to the recognition and production of conventional expressions (i.e., pragmalinguistic resources together with sociopragmatic contextual issues), and the responses obtained from participants about this task in the Postinstruction Questionnaire show that students thought about such issues in their learning process. For example, P25, P5, P12 and P9 coincided in the fact that this task provided them with the opportunity to think about the expression that needed to be used in relation to the context where it had to be expressed. 
"You have to think about the expression in a specific situation and that is an important factor [sic]" (P25).

"I liked the moment we have to explain why was appropriate or not because we had to provide feedback [sic]" (P12), meaning reasons to explain why they had used a specific expression over others.

"the discussion part in which we explained whether we considered the sentences appropriate or not, because it was the most practical one [sic]" (P9).

A few other students highlighted the use of the expressions, which is inherent to their nature. In other words, conventional expressions refer to expressions with a focus on their social role in everyday interactions. For example, three students explained that what they liked best about the AJT was:

"the emphasis on pragmatic elements in common every-day speech, which is usually ignored by teachers, as well as your explanations. :) [sic]" (P2).

Similarly, "for me, the best point of the test was that it dealt with many everydaylife situations in which we need the use of certain conventional expressions according to culture [sic]" (P.27).

More succinctly, the situations presented "were based on real situations [sic]" (P6).

P2 above also mentioned a key aspect, which reports on the inexistent or scant attention to pragmatics and pragmatic features such as conventional expressions in other courses taught in this degree. It is true that there is a course that focuses solely on pragmatics, but which has never included conventional expressions, and mainly focused on speech acts, and the learning, teaching, and assessing processes related to them. Additionally, this course of pragmatics has also focused on different speech acts together with issues regarding politeness and impoliteness, and the introduction of 
cross-cultural and intercultural pragmatics. This course represents an attempt to work on and help students develop their pragmatic competence in EFL settings, which research shows to be essential for the learning of L2 pragmatics (e.g., Martínez-Flor \& Usó-Juan, 2006) by raising their awareness on pragmatics (e.g. Alcón-Soler \& Safont, 2008).

Finally, two students pointed out to the importance of having received feedback, and valued it the most of the entire activity.

"the feedback provided at the end of the activity. I think it is necessary to provide it so as to enhance our knowledge on that [sic]" (P41).

In line with his classmate, "that now we know how to use the expressions correctly, since we have received feedback [sic]" (P48).

All in all, all these examples highlight the importance of providing students with metapragmatic information together with metapragmatic discussion to foster their pragmatic development more generally (e.g., Alcón-Soler, 2005; Badjadi, 2016) and their recognition skills of conventional expressions more specifically in this study. Additionally, the triangulation of data is also essential in validating the results obtained from the quantitative analysis, and also giving the results a more robust character. On perception and judgment, Bardovi-Harlig (2001, p. 20) states that studies that include a perception component, such as including a recognition task as well as an AJT in the present dissertation, aim to explore "differences that are no less real, but are somewhat less obvious to an observer. This set of studies is smaller and less cohesive than the production studies; however, it shows that learner judgments and comprehension are often different from those of NSs." This statement lends support to the robustness and strength that triangulation of data provides to the understanding of results obtained from analysis of both quantitative and qualitative data that tackle the same phenomena, that being pragmatic recognition task in the present study. 
In line with existing findings in the literature on the effect of instruction, results from the present study attest to the effect of instruction from pretest to posttest, which does not last through the delayed posttest (e.g., Taguchi, 2015b). The present investigation was no exception. Previous research on conventional expressions only included a pretest and a posttest without instruction (i.e., Bardovi-Harlig, 2008, 2009, 2019, 2014; Rafieyan et al., 2014b) and with instruction (e.g., Taguchi et al., 2017). Nevertheless, they all side with this well-known and amply supported research finding. Additionally, the present investigation shed light into this phenomenon, providing data from a group of EFL students whose pragmatic performance increased across times, but with a slight decrease from Time 2 to Time 3 . Moreover, this study represents an example in which the role of instruction was important in pragmatics learning, which research has proven to be more effective than simple exposure (e.g., Bardovi-Harlig, 2001; Kasper \& Rose, 2002). Even though the effect of instruction was masked by the task repetition effect, it could be argued that there is little doubt that the pedagogical intervention was effective in the pragmatic recognition of conventional expressions.

Results obtained in H1 can also be explained in terms of Skill Acquisition Theory (Anderson, 1993; DeKeyser, 1997, 1998, 2001, 2003, 2007a). Recalling the main tenets of this theory, which was discussed in Chapter 1, Skill Acquisition Theory perceives the development of language learning and use at stake. Learning a skill takes place gradually, and skill can take the form of a whole language or a particular part of it, such as pragmatic competence. Anderson identified three learning stages: 1) cognitive stage, where the new rules become procedural knowledge; 2) proceduralization process, which is activated by means of meaningful practice of such rules; and 3) autonomous stage, where the knowledge of such rules becomes automatic and fluent, and is characterized be the less frequent appearance of mistakes. These learning stages can also be translated 
to the learning of L2 pragmatics, which help understand the process of form-function mapping. Taking into consideration the learning of recognizing conventional expressions, the autonomous stage took place gradually, since students were able to work on the recognition of conventional expressions at three points in time.

Additionally, since practice is essential in this theory of language learning, activities to practice recognition skills were provided (i.e., VKS and AJT together with metapragmatic discussion). Finally, pragmatic competence is perceived as a skill in and of itself, recognizing conventional expressions in this case. Evidence from data on $\mathrm{H} 1$ exist to support that participants successfully achieved the first and second learning stage, and stayed somewhere in the third and last phase, the autonomous stage. This autonomous stage was accomplished for some of the learners on some of the easier conventional expressions but not for other learners or for more complex conventional expressions. These results provide food for thought about the research design. Had there been more time, students would have been given more opportunities to practice their recognition skill, working on more metapragmatic discussion, for example. Comments from the AJT lend support to employ such activity to foster students' pragmatic awareness, and therefore their recognition skills and subsequent development of their pragmatic competence. In this regard, Badjadi (2016) points out to the correlation that exists between metapragamtic discussion and the improvement in scores for structured production activities, such as the VKS. Skill Acquisition Theory also has some implications for the design of the pedagogical intervention. This theory puts forward the idea that instruction should be implemented gradually, so that the transition from the declarative to the procedural knowledge is smooth. This was the case in the present investigation, where instruction took place in two stages, first presenting the theoretical constructs essential to understand conventional expressions, and then the presentation, 
discussion, and practice of the target conventional expressions. Finally, further practice was included to provide students with meaningful research-based situations that included real world interactions that students may potentially face when visiting an English-speaking country. However, it could be argued that more practice could have enhanced a more fully and positive pragmatic development in recognizing conventional expressions.

All in all, even though the effect of instruction was very present in the pragmatic development of the experimental group, as seen from the statistical results from the ttests and the effect sizes of such results, a task repetition effect could potentially be attributed the high scores from the control group in the VKS across times. Hence, H1 can only be partially confirmed. Even though results could be obscured by the task repetition effect, this study presents a potential opportunity to understand the cognitive processes that affect the recognition of conventional expressions in an EFL setting, where interventional studies such as this dissertation are less present.

\subsection{Results and Discussion Related to Hypothesis 2}

Hypothesis $2(\mathrm{H} 2)$ predicts that participants' production of conventional expressions will improve after receiving instruction (posttest), and will mostly be lost after a longer period of time (delayed posttest), as measured by the scores in the computer-delivered ODCT. Following the same procedure as for the recognition task above in H1, independent samples t-test and paired-samples t-tests were performed to identify and monitor possible intergroup and intragroup statistically significant differences. The analyses have also been conducted across three times: pretest (i.e., Time 1, T1), posttest (i.e., Time 2, T2), and delayed posttest (i.e., Time 3, T3). Results from the data analysis of the pragmatic production task allow confirming this second hypothesis, since there was a gradual pragmatic production gain, and it was not maintained at the delayed 
posttest for the experimental group. Results from the independent samples t-tests at Time 2 corroborate the improvement by the posttest $(t=-10.949$, Sig. $(2$-tailed $)=$ $<.001)$ and the decrease in scores at Time $3(t=-7.579$, Sig. $(2$-tailed $)=<.001)$. These results are further elaborated in this section. In general terms, it could be agreed on the partial effectiveness of the pedagogical intervention, as backed up by the research on instructional effects on pragmatics (e.g., Taguchi, 2015b; Taguchi \& Roever, 2017). However, the extent of its effectiveness might be masked by the task repetition effect observed from the results obtained in the task performance by the control group across times. Nevertheless, the effectiveness of the instructional treatment could be interpreted as strong if attention is paid to the effect sizes from both the dependent samples t-test and independent samples t-tests comparing Mean scores within groups and between groups across times respectively as explained below. These results are discussed from a Skill Acquisition Theory stance.

Figure 18 below represents a summary of the general findings obtained by both groups in the computer-delivered ODCT. Performance per group is explained separately as follows, preceded by a summarized revision of the descriptive statistics per group.

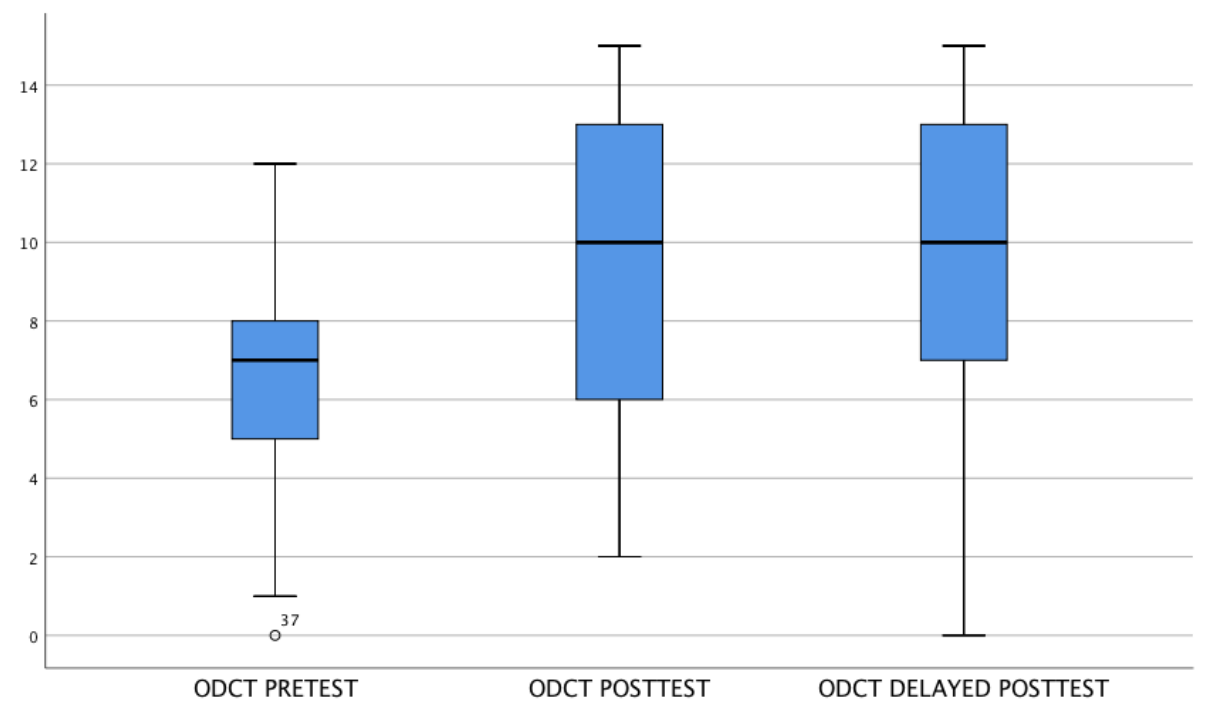

Figure 18. Boxplot for control and experimental groups performance of computerdelivered ODCT 
Similarly to $\mathrm{H} 1$ above, a summary of the descriptive statistics is provided per group to identify the sample and highlight performance development across times. The descriptive statistics for the control group are reported first and those for the experimental group afterwards. Please refer to Appendix 17 for a more detailed account of the descriptive statistics per time of task for both groups in the computer-delivered ODCT.

Table 32. Descriptive statistics for control group across times in computer-delivered ODCT

\begin{tabular}{ccccccc}
\hline & Time & Mean & SD & Range & Skewness & Kurtosis \\
\cline { 2 - 7 } $\begin{array}{c}\text { Control } \\
\text { group }\end{array}$ & Pretest & 5.72 & 2.509 & $\begin{array}{c}10 \\
{[0-10]}\end{array}$ & $\begin{array}{c}-.532(\mathrm{sd} \\
\text { error } .464)\end{array}$ & $\begin{array}{c}-.034(\mathrm{sd} \\
\text { error } .902)\end{array}$ \\
\cline { 2 - 7 }$n=25$ & Posttest & 6.40 & 2.693 & $\begin{array}{c}10 \\
{[2-12]}\end{array}$ & $\begin{array}{c}.259(\mathrm{sd} \\
\text { error } .464)\end{array}$ & $\begin{array}{c}-.580(\mathrm{sd} \\
\text { error } .902)\end{array}$ \\
\cline { 2 - 7 } & $\begin{array}{c}\text { Delayed } \\
\text { posttest }\end{array}$ & 6.88 & 3.087 & $\begin{array}{c}12 \\
{[0-12]}\end{array}$ & $\begin{array}{c}-.451(\mathrm{sd} \\
\text { error } .464)\end{array}$ & $\begin{array}{c}-.133(\mathrm{sd} \\
\text { error } .902)\end{array}$ \\
\hline
\end{tabular}

Table 32 synthesizes the descriptive statistics for the control group in the computer-delivered ODCT from T1 to T3. The control group $(n=25)$ generally scored high on this task. In the pretest, the 25 participants scored rather high $(\mathrm{M}=5.72, \mathrm{SD}=$ 2.509) taking into consideration that the minimum score for the computer-delivered ODCT was 0 and the highest was 15 . Scores improved in the posttest $(\mathrm{M}=6.40, \mathrm{SD}=$ 2.693), as well as in the delayed posttest $(\mathrm{M}=6.88, \mathrm{SD}=3.087)$, administered 11 days after the posttest, as reported in the Mean. As shown in Table X below, the mean increased from T1 to T3, which translates into participants in the control group improving their scores across times. However, the continuous increase of the SD reflects the less homogeneous score improvement from T1 to T3. In other words, even though task performance improved, this task melioration was less homogeneous across times. This is reflected in score range. The minimum score at T1 and T3 was 0 , but it was 2 at T2. Regarding the maximum score obtained by the control group, it was 10 at $\mathrm{T} 1$ and increased to 12 in T2, which was maintained at T3. The values for skewness and 
Kurtosis reveal a normal distribution of the scores. There was no significant departure form the Mean score across times. Task repetition effect might explain the increase in pragmatic performance in the control group. Some of the participants in the control group, as well as in the experimental group, commented on the fact that they remembered some of the situations from previous task performance.

Table 33. Descriptive statistics for experimental group across times in computerdelivered ODCT

\begin{tabular}{ccccccc}
\hline & Time & Mean & SD & Range & Skewness & Kurtosis \\
\cline { 2 - 7 } $\begin{array}{c}\text { Experimental } \\
\text { group } \\
n=21\end{array}$ & Pretest & 7.24 & 2.644 & $\begin{array}{c}11 \\
{[1-12]}\end{array}$ & $\begin{array}{c}-.374(\mathrm{sd} \\
\text { error }\end{array}$ & $\begin{array}{c}.185(\mathrm{sd} \\
\text { error } \\
\end{array}$ \\
\cline { 2 - 7 } & & & & & $.501)$ & $.972)$ \\
\hline & Posttest & 13.38 & 1.564 & 5 & $\begin{array}{c}-.968(\mathrm{sd} \\
\text { error }\end{array}$ & $\begin{array}{c}.315(\mathrm{sd} \\
\text { error }\end{array}$ \\
& & & & {$[10-15]$} & $\begin{array}{c}.501) \\
.972)\end{array}$ \\
\cline { 2 - 7 } & Delayed & 12.76 & 1.921 & 7 & $-.935(\mathrm{sd}$ & $.218(\mathrm{sd}$ \\
& posttest & & & {$[8-15]$} & error & error \\
& & & & & $.501)$ & $.972)$ \\
\hline
\end{tabular}

Table 33 synthesizes the descriptive statistics for the experimental group in the computer-delivered ODCT from T1 to T3. The control group $(n=21)$ scored a rather medium score $(\mathrm{M}=7.24, \mathrm{SD}=2.644)$ in the pretest, considering that the minimum score in the computer-delivered ODCT was 0 and the highest was 15 . Scores improved noticeable in the posttest $(M=13.38, \mathrm{SD}=1.564)$, but decreased in the delayed posttest $(\mathrm{M}=12.76, \mathrm{SD}=1.921)$, which was administered 11 days after the posttest. This task improvement is reflected in the Mean and supported by the SD. The Mean increased over 5 points from $\mathrm{T} 1$ to $\mathrm{T} 3$, which reflects the score improvement. In turn, the SD reveals the less homogeneous nature of such score improvement. Even though it decreased from $\mathrm{T} 1$ to $\mathrm{T} 2$, which translates into a more homogeneous range of scores, it increased from T2 to T3 again, meaning a larger range of scores in the final time point. The minimum range score varied dramatically from being 1 at $\mathrm{T} 1$ to 10 at $\mathrm{T} 2$, then it decreased to 8 at T3. As for the maximum score, it was 12 at T1 and increased to 15 at 
T2, which was maintained at T3. This was the highest score that could be obtained in this task. Findings in skewness and Kurtosis inform that scores are normally distributed. Therefore, there is no significant departure from the Mean score across times.

These results might be explained in terms of task repetition effect as well as the effect of instruction. If the control group experimented an increase in task performance, the same could be expected for the improvement in the scores in the experimental group. However, looking closely at the Means and SDs across times for the experimental group in Table 33, the Mean increases exponentially at Time 2, which may be attributed to a greater extent to the effect of the instructional treatment. However, scores decreased at Time 3, and were also less homogeneous, as seen in an increase in the SD from Time 2 to Time 3.

The results from the independent samples t-tests and the paired samples t-tests are presented below. Findings obtained from these statistical analyses are discussed afterwards taking into consideration the existing literature.

The independent samples t-tests were performed to identify and inspect possible significant differences between the control group and the experimental group. Three independent samples t-tests were run to compare the Mean scores of the groups per each time of task. 
Table 34. Descriptive statistics for group Mean comparison in the computer-delivered ODCT at Time 1

\begin{tabular}{ccccc}
\hline Group & $N$ & Mean & $S D$ & $\begin{array}{c}\text { SD Error } \\
\text { Mean }\end{array}$ \\
\hline $\begin{array}{c}\text { Control } \\
\text { Group 0] }\end{array}$ & 25 & 5.72 & 2.509 & .502 \\
\hline $\begin{array}{c}\text { Experimental } \\
{[\text { Group 1] }}\end{array}$ & 21 & 7.24 & 2.644 & .577 \\
\hline
\end{tabular}

Table 34 provides the descriptive statistics from the comparison of the Mean difference between both groups at Time 1. The Mean for the control group was 5.72, whereas it as 7.24 for the experimental group. As for the SD, the control group obtained a SD of 2.509, and an SD of 2.644 the experimental group. The SD Error Mean for the control group was .502 , and .577 for the experimental group.

Table 35. Independent samples t-test both groups in computer-delivered ODCT at Time 1

\begin{tabular}{|c|c|c|c|c|c|c|}
\hline \multicolumn{7}{|c|}{ t-test for Equality of Means } \\
\hline \multirow[t]{2}{*}{$\mathrm{t}$} & \multirow[t]{2}{*}{ df } & \multirow[t]{2}{*}{$\begin{array}{l}\text { Sig. }(2- \\
\text { tailed) }\end{array}$} & \multirow[t]{2}{*}{$\begin{array}{c}\text { Mean } \\
\text { Difference }\end{array}$} & \multirow[t]{2}{*}{$\begin{array}{l}\text { Std. Error } \\
\text { Difference }\end{array}$} & \multicolumn{2}{|c|}{$\begin{array}{l}95 \% \text { Confidence } \\
\text { Interval of the } \\
\text { Difference }\end{array}$} \\
\hline & & & & & Lower & Upper \\
\hline-1.995 & 44 & .052 & -1.518 & .761 & -3.052 & .016 \\
\hline
\end{tabular}

Table 35 illustrates the results from the independent samples t-test to compare the Means of the control group and experimental group in the computer-delivered ODCT at Time 1. Data at this first time period did not show departure from non-normality, distributions were symmetric and variances were equal, as reported by the Levene test $(F=.021 ;$ sig. $=.886)$. An independent samples t-test found no evidence of a difference between the Means on the computer-delivered ODCT at T1 for the control group $(n=$ 25$, Mean $=5.72, \mathrm{SD}=2.509)$ and for the experimental group $(n=21$, Mean $=7.24, \mathrm{SD}=$ 2.644). See box plot Figure 19 below. Since the 95\% CI contains zero [-3.052, .016], it can be concluded that there is no statistical difference between the groups. The narrow 
CI, less than 3 points on a test where the maximum score was 15 points, illustrates that the estimate of how different the groups are is uncertain, but not likely to be far from zero. The effect size for this comparison was calculated following Cohen's d, which resulted in a Cohen's $d=0.59$. According to Cohen's guidelines for effect sizes can be considered a medium effect size.

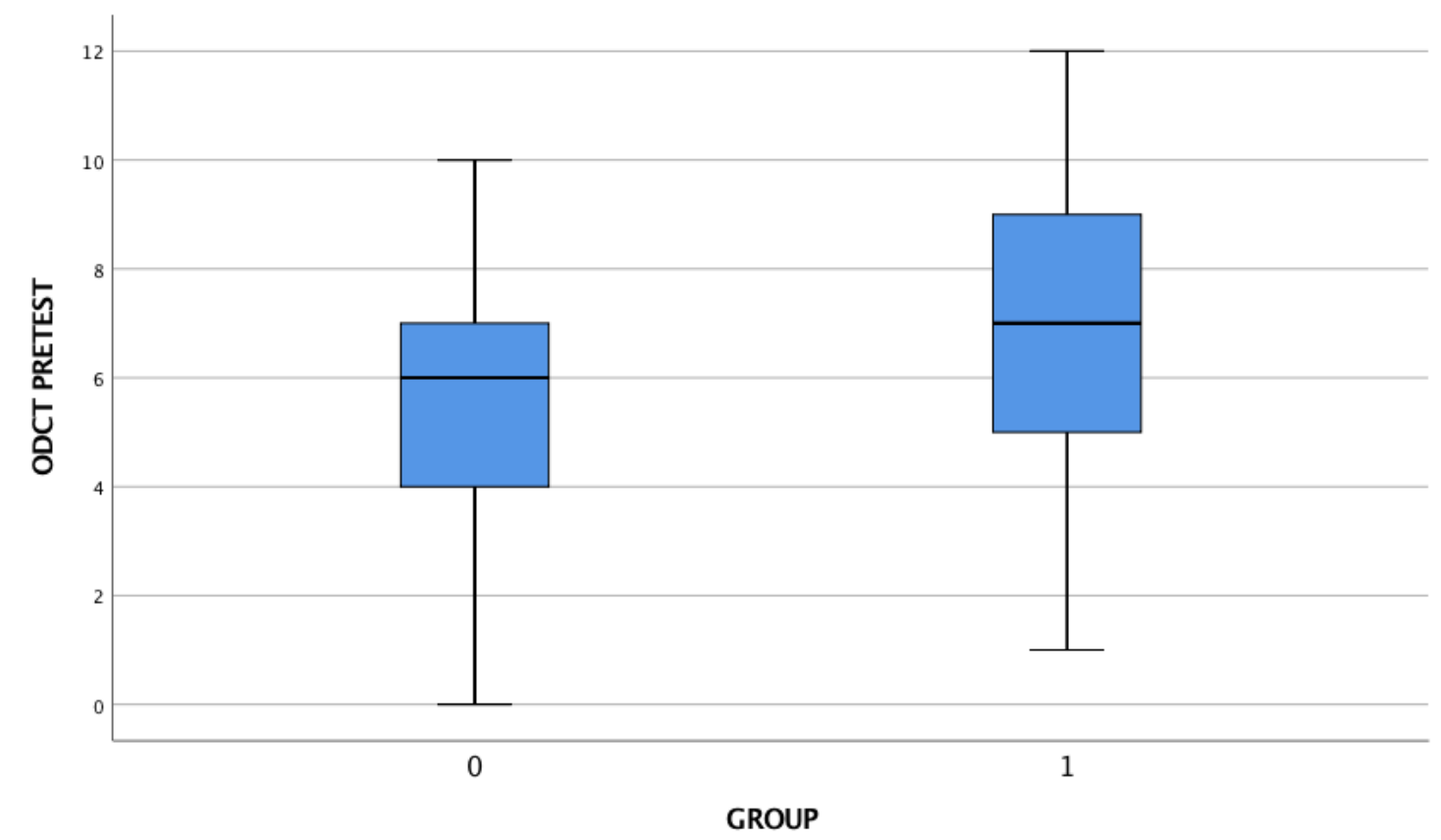

Figure 19. Box plot for Mean difference between control group and experimental group in computer-delivered ODCT at Time 1

As shown in the descriptive statistics, a difference in performance already existed between these two groups at $\mathrm{T} 1$. The independent samples t-test revealed it not to be significant and with a medium effect size. These performances were between low for the control group and medium for the experimental group taking into consideration that the highest score is 15 for the computer-delivered ODCT. Results from the independent samples t-tests performed for T2 and T3 will help understand the development of score performance and the possible reasons behind such changes and differences between the control group and the experimental group. 
Table 36. Descriptive statistics for group Mean comparison in the computer-delivered ODCT at Time 2

\begin{tabular}{ccccc}
\hline Group & $N$ & Mean & $S D$ & $\begin{array}{c}\text { SD Error } \\
\text { Mean }\end{array}$ \\
\hline $\begin{array}{c}\text { Control } \\
\text { Group 0] }\end{array}$ & 25 & 6.40 & 2.693 & .539 \\
\hline $\begin{array}{c}\text { Experimental } \\
{[\text { Group 1] }}\end{array}$ & 21 & 13.38 & 1.564 & .341 \\
\hline
\end{tabular}

Table 36 provides the descriptive statistics from the comparison of the Mean between both groups at Time 2. The Mean for the control group was 6.40, whereas it was 13.38 for the experimental group. As for the SD, the control group obtained a SD of 2.693, and 1.564 the experimental group. The SD Error Mean for the control group was .539 , and .341 for the experimental group.

Table 37. Independent samples t-test both groups in computer-delivered ODCT at Time 2

\begin{tabular}{|c|c|c|c|c|c|c|}
\hline \multicolumn{7}{|c|}{ t-test for Equality of Means } \\
\hline \multirow[t]{2}{*}{$\mathrm{t}$} & \multirow[t]{2}{*}{$\mathrm{df}$} & \multirow[t]{2}{*}{$\begin{array}{l}\text { Sig. }(2- \\
\text { tailed) }\end{array}$} & \multirow[t]{2}{*}{$\begin{array}{c}\text { Mean } \\
\text { Difference }\end{array}$} & \multirow[t]{2}{*}{$\begin{array}{l}\text { Std. Error } \\
\text { Difference }\end{array}$} & \multicolumn{2}{|c|}{$\begin{array}{l}95 \% \text { Confidence } \\
\text { Interval of the } \\
\text { Difference }\end{array}$} \\
\hline & & & & & Lower & Upper \\
\hline-10.949 & 39.510 & $p<.001$ & -6.981 & .638 & -8.270 & -5.692 \\
\hline
\end{tabular}

Table 37 illustrates the results from the independent samples t-test to compare the Means of the control group and experimental group in the computer-delivered ODCT at Time 2. Data at this second time period did not show departure from non-normality, distributions were symmetric, but variances were fount to be not equal, as revealed by the Levene test $(F=7.022$, Sig. $=.011)$. An independent samples t-test found evidence of a difference between the Means on the computer-delivered ODCT at Time 2 for the control group $(n=25$, mean $=6.40, \mathrm{SD}=2.693)$ and for the experimental group $(n=21$, Mean $=13.38, \mathrm{SD}=1.564)$. See box plot Figure 20 below. Since the $95 \%$ CI does not contain zero $[-8.270,-5.692]$, it can be concluded that there is a statistical difference 
between the groups. The narrow CI, less than 3 points on a test where the maximum score was 15 points, illustrates that the estimate of how different the groups are is uncertain, but likely to be farther from zero. The effect size for this comparison was calculated following Cohen's d, which resulted in a Cohen's $d=3.17$. According to Cohen's guidelines for effect sizes can be considered a large effect size.

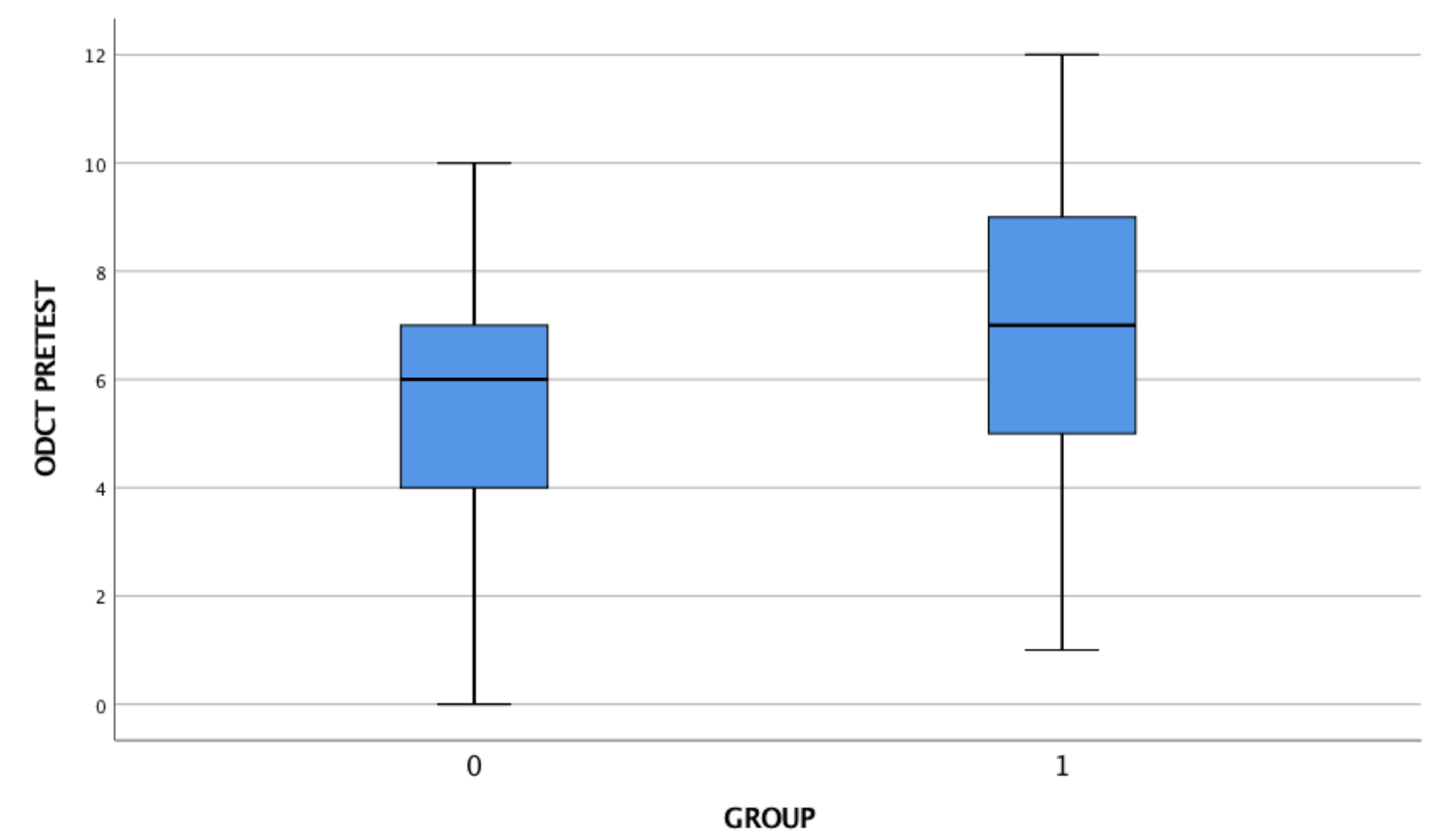

Figure 20. Box plot for Mean difference between control group and experimental group in computer-delivered ODCT at Time 2

The descriptive statistics run to compare the Means at T2 revealed a difference in performance between the control and the experimental groups. The independent samples t-test allowed assuring that this difference was statistically significant. The Cohen's d=3.17 informed that this difference in Mean scores was large. These results could also be explained in terms of task repetition effect and the instructional effect. Task repetition effect could account for the score improvement experienced by the control group. Therefore, the same could be expected from the experimental group. However, the effect of the pedagogical treatment provided could also explain the Mean increase experienced by the experimental group. In other words, participants in the 
experimental group may have improved their scores as a result of the positive effect that the instructional treatment had on their production of conventional expressions.

Now that the scores, distribution of the scores, and Mean comparison of both groups for Time 2 have been reported, the same will be done for Time 3.

Table 38. Descriptive statistics for group score comparison in the computer-delivered ODCT at Time 3

\begin{tabular}{ccccc}
\hline Group & $N$ & Mean & $S D$ & $\begin{array}{c}\text { SD Error } \\
\text { Mean }\end{array}$ \\
\hline $\begin{array}{c}\text { Control } \\
\text { [Group 0] }\end{array}$ & 25 & 6.88 & 3.087 & .617 \\
\hline $\begin{array}{c}\text { Experimental } \\
\text { [Group 1] }\end{array}$ & 21 & 12.76 & 1.921 & .419 \\
\hline
\end{tabular}

Table 38 provides the descriptive statistics from the comparison of the Means between the two groups at Time 3. The Mean for the control group was 6.88 , whereas it as 12.76 for the experimental group. As for the SD, the control group obtained a SD of 3.087, and 1.921 the experimental group. The SD Error Mean for the control group was .617 , and .419 for the experimental group.

Table 39. Independent samples t-test both groups in computer-delivered ODCT at Time 3

\begin{tabular}{|c|c|c|c|c|c|c|}
\hline \multicolumn{7}{|c|}{ t-test for Equality of Means } \\
\hline \multirow[t]{2}{*}{$\mathrm{t}$} & \multirow[t]{2}{*}{ df } & \multirow[t]{2}{*}{$\begin{array}{l}\text { Sig. (2- } \\
\text { tailed) }\end{array}$} & \multirow[t]{2}{*}{$\begin{array}{c}\text { Mean } \\
\text { Difference }\end{array}$} & \multirow[t]{2}{*}{$\begin{array}{l}\text { Std. Error } \\
\text { Difference }\end{array}$} & \multicolumn{2}{|c|}{$\begin{array}{l}95 \% \text { Confidence } \\
\text { Interval of the } \\
\text { Difference }\end{array}$} \\
\hline & & & & & Lower & Upper \\
\hline-7.579 & 44 & $p<.001$ & -5.882 & .776 & -7.446 & -4.318 \\
\hline
\end{tabular}

Table 39 illustrates the results from the independent samples t-test for Mean comparison between the control group and experimental group in the computerdelivered ODCT at Time 3. Data at this third time period revealed a departure from non-normality, since two outliers can be found in the control group. Nevertheless, distributions were symmetric and variances were equal, as obtained in the Levene test 
$(F=3.042, \mathrm{Sig} .=.088)$. An independent samples t-test found no evidence of a difference between the means on the computer-delivered ODCT at Time 3 for the control group $(n=25$, Mean $=6.88, \mathrm{SD}=3.087)$ and for the experimental group $(n=21$, Mean $=12.76, \mathrm{SD}=1.921$ ). See box plot Figure 21 below. Since the 95\% CI does not contain zero $[-7.446,-4.318]$, it can be concluded that there is a statistical difference between the groups. The narrow CI, a little over than 3 points on a test where the maximum score was 15 points, illustrates that the estimate of how different the groups are is uncertain, but less likely to be far from zero. The effect size for this comparison was calculated following Cohen's d, which resulted in a Cohen's $d=2.287$. According to Cohen's guidelines for effect sizes can be considered a large effect size.

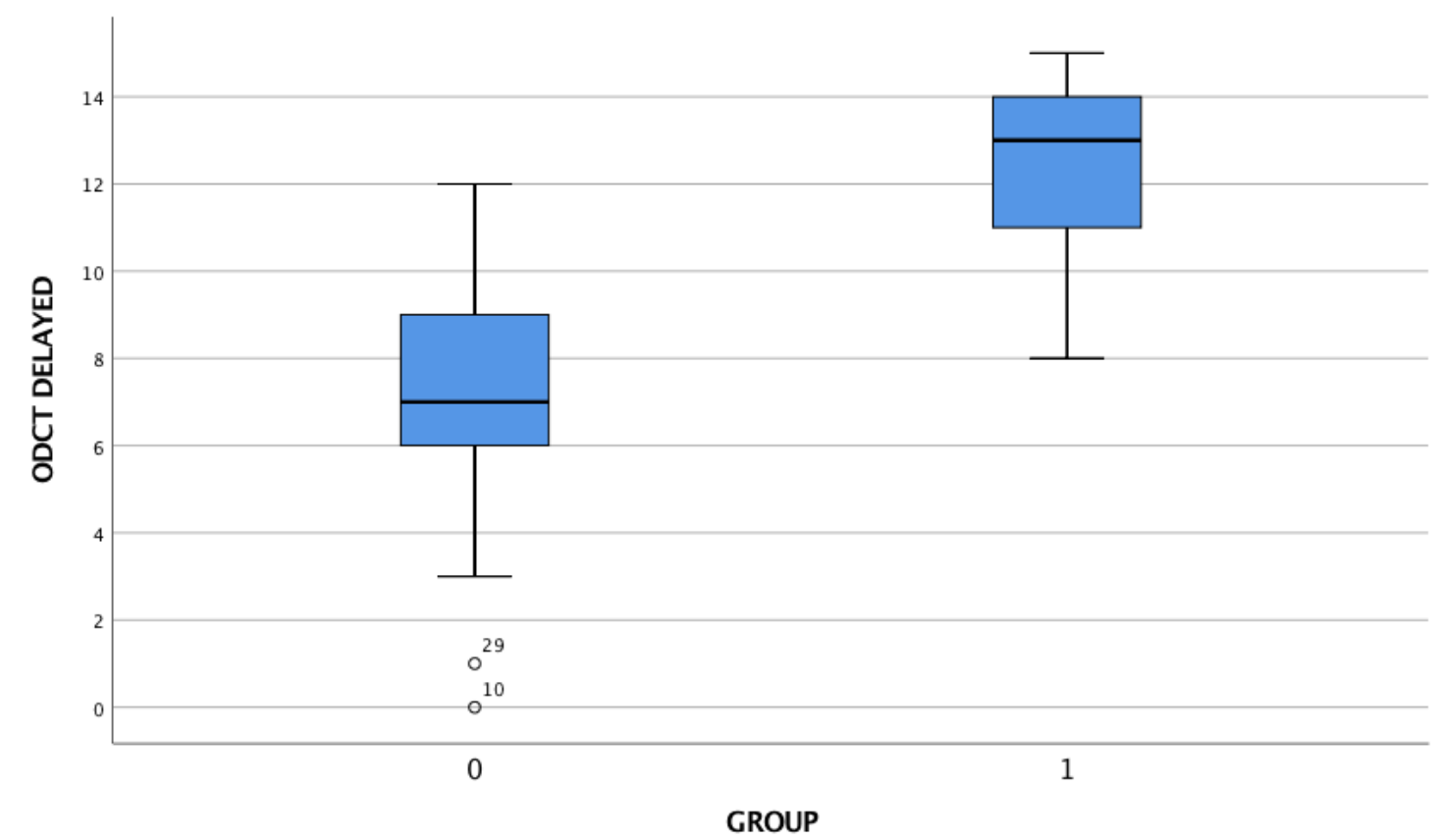

Figure 21. Box plot for Mean difference between control group and experimental group in computer-delivered ODCT at Time 3

The descriptive statistics for Mean comparison at T3 also illustrated a different performance pattern for the control and the experimental group. The independent samples t-test revealed that this difference was statistically significant, with a large 
effect size: Cohen's d=2.287. Similarly to the results obtained in H1 above, the effect size for the production of conventional expressions in $\mathrm{H} 2$ increased from $\mathrm{T} 1$ to $\mathrm{T} 2$, but decreased from T2 to T3. Likewise, results obtained from the independent samples t-test at $\mathrm{T} 3$ could be explained in terms of task repetition effect and instructional effect, as in T2 above. The small increase in scores by the control group could mainly be explained with the existence of a task repetition effect. Therefore, if the control group experienced it, the experimental group could be expected to as well. As for the experimental group, even though the mean score decreased at T3, it was still larger than the control group's. This finding could be explained in terms of instructional effects, which would support the larger mean score by this group in comparison to the control group's.

All in all, results from the independent samples t-test revealed that there was no significant difference between these two groups at Time 1, which had a medium effect size $(d=0.59)$. Regarding the independent samples t-test that compared the Mean differences between groups at Time 2, very different results were obtained. One the one hand, a statistically significant difference was found, which had a large effect size $(\mathrm{d}=$ 3.17). This radical change could be mostly attributed to the effect of instruction, since performance from the experimental group was significantly better than the control group's. Finally, the independent samples t-test performed to observe Mean differences between control and experimental groups at Time 3 revealed different as well as similar results compared to these tests at Time 1 and Time 2 . On one hand, and different from results obtained so far, two outliers were found in the control group. On the other hand, and in line with results obtained at Time 2 , there was a statistically significant difference between the control and the experimental groups at this third and last data collection point, with a large effect size $(\mathrm{d}=2.287)$, which was a bit smaller than at Time 2. Nevertheless, this evidence indicates that the effect of instruction may have also 
exerted a large effect at the delayed posttest, although less effective than at Time 2.

However, and as mentioned before, since the increase in score performance by the control group could be explained in terms of task repetition effect, the effect of instruction should be taken cautiously. These findings are discussed in relation to those present in the existing literature after the presentation and discussion of findings obtained from performing paired samples t-tests below.

Finally, a series of paired samples t-tests were performed to investigate whether there were statistically significant differences within each of the groups across times. Table 40. Paired samples t-test descriptive statistics for computer-delivered ODCT control group from Time 1 to Time 2

\begin{tabular}{cccccc}
\hline & $\mathrm{N}$ & Mean & SD & $\begin{array}{c}\text { SD Error } \\
\text { Mean }\end{array}$ \\
\hline $\begin{array}{c}\text { Control } \\
\text { [Group 0] }\end{array}$ & $\begin{array}{c}\text { Computer-delivered } \\
\text { ODCT Pretest } \\
{[\text { Time 1] }}\end{array}$ & 25 & 5.72 & 2.509 & .502 \\
& $\begin{array}{c}\text { Computer-delivered } \\
\text { ODCT Posttest } \\
{[\text { Time 2] }}\end{array}$ & 25 & 6.40 & 2.693 & .539 \\
\hline
\end{tabular}

Table 41. Paired samples t-test for computer-delivered ODCT control group from Time 1 to Time 2

\begin{tabular}{cccccccc}
\hline \multicolumn{7}{c}{ Paired Differences } \\
\hline Group & Mean & SD & SD & $95 \% C I$ & $t$ & $d f$ & Sig $p$. \\
Error \\
mean
\end{tabular}

Table 41 shows the paired samples t-test performed to compare Mean difference for the control group between $\mathrm{T} 1(n=25, \mathrm{M}=5.72, \mathrm{SD}=2.509)$ and $\mathrm{T} 2(n=25, \mathrm{M}=$ $6.40, \mathrm{SD}=2.693$ ) for the computer-delivered ODCT. See descriptive statistics in Table 40 below. This test found no significant difference for the control group between these two times, since the $95 \%$ CI $[-1.737, .377]$ ran through zero. The size of the interval 
shows that the actual mean could be as small as less than 1 point, or as large as nearly 2 points. A Cohen's d effect size was performed for this comparison, and resulted in $\mathrm{d}=$ 0.265 , which means that the difference between the pretest and the posttest was small.

Table 43 illustrates the paired samples t-test performed to compare Mean difference for the control group between T2 $(n=25, \mathrm{M}=6.40, \mathrm{SD}=2.693)$ and $\mathrm{T} 3(n=$ $25, \mathrm{M}=6.88, \mathrm{SD}=3.087$ ) for the computer-delivered ODCT. See descriptive statistics in Table 42 below. This test found no significant difference for the control group between these two times, since the $95 \%$ CI $[-1.434, .474]$ ran through zero. The size of the interval shows that the actual mean could be as small as less than 1 point, or as large as nearly 1.5 points. A Cohen's d effect size was performed for this comparison, and resulted in $\mathrm{d}=0.208$, which means that the difference between the pretest and the posttest was small.

Table 42. Paired samples t-test descriptive statistics for computer-delivered ODCT control group from Time 2 to Time 3

\begin{tabular}{cccccc}
\hline & N & Mean & SD & $\begin{array}{c}\text { SD Error } \\
\text { Mean }\end{array}$ \\
\hline $\begin{array}{c}\text { Control } \\
\text { [Group 0] }\end{array}$ & $\begin{array}{c}\text { Computer-delivered } \\
\text { ODCT Posttest } \\
{[\text { Time 2] }}\end{array}$ & 25 & 6.40 & 2.693 & .539 \\
\cline { 2 - 5 } & $\begin{array}{c}\text { Computer-delivered } \\
\text { ODCT Delayed } \\
\text { Posttest } \\
\text { [Time 3] }\end{array}$ & 25 & 6.88 & 3.087 & .617 \\
\hline
\end{tabular}

Table 43. Paired samples t-test for computer-delivered ODCT control group from Time 2 to Time 3

\begin{tabular}{cccccccc}
\hline \multicolumn{7}{c}{ Paired Differences } \\
\hline Group & Mean & $S D$ & $\begin{array}{c}S D \\
\text { Error } \\
\text { mean }\end{array}$ & $95 \% C I$ & $t$ & $d f$ & Sig $p$. \\
\hline Control & -.480 & 2.312 & .462 & {$[-1.434$,} & -1.038 & 24 & .309 \\
{$[$ Group 0] } & & & & $.474]$ \\
\hline
\end{tabular}


Table 45 provides the paired samples t-test performed to compare Mean difference for the control group between $\mathrm{T} 1(n=25, \mathrm{M}=5.72, \mathrm{SD}=2.509)$ and $\mathrm{T} 3(n=$ $25, \mathrm{M}=6.88, \mathrm{SD}=3.087$ ) for the computer-delivered ODCT. See descriptive statistics in Table 44 below. This test found no significant difference for the control group between these two times, since the $95 \%$ CI $[-2.402, .082]$ ran through zero. The size of the interval shows that the actual mean could be as small as less than 1 point, or as large as nearly 2.5 points. A Cohen's d effect size was performed for this comparison, and resulted in $\mathrm{d}=0.385$, which means that the difference between the pretest and the posttest was small.

Table 44. Paired samples t-test descriptive statistics for computer-delivered ODCT control group from Time 1 to Time 3

\begin{tabular}{cccccc}
\hline & $\mathrm{N}$ & Mean & SD & $\begin{array}{c}\text { SD Error } \\
\text { Mean }\end{array}$ \\
\hline $\begin{array}{c}\text { Control } \\
\text { [Group 0] }\end{array}$ & $\begin{array}{c}\text { Computer-delivered } \\
\text { ODCT Pretest } \\
{[\text { Time 1] }}\end{array}$ & 25 & 5.72 & 2.509 & .502 \\
\cline { 2 - 5 } & $\begin{array}{c}\text { Computer-delivered } \\
\text { ODCT Delayed } \\
\text { Posttest } \\
\text { [Time 3] }\end{array}$ & & 6.88 & 3.087 & .617 \\
& & & & \\
\hline
\end{tabular}

Table 45. Paired samples t-test for computer-delivered ODCT control group from Time 1 to Time 3

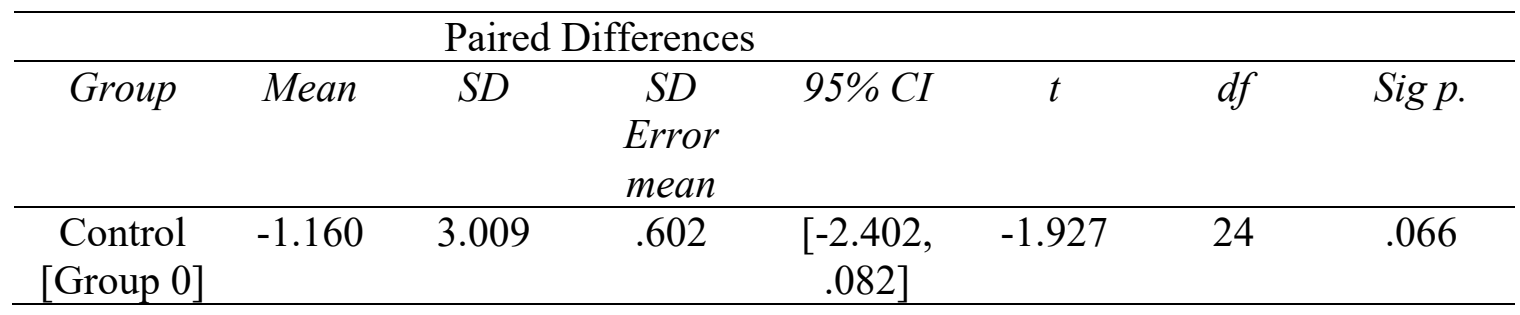


Results from the paired samples t-test help identify whether those score increases are significant or not. The first paired samples t-test compared the Mean difference between Time 1 and Time 2. This first test was not significant and the effect size was small $(d=0.265)$. The paired samples performed $t$-test between Time 2 and Time 3 revealed a no significant difference between the Means at these two points in time, with a small effect size $(d=0.208)$, which was a bit smaller than that of the first comparison above. Finally, the third and last paired samples t-test provided a no significant difference between the Means from Time 1 to Time 3 with a small effect size $(d=$ 0.385) for the control group in the computer-delivered ODCT. These results imply that even though scores increased overall, that rise was not statistically significant in between or across any of the three time points. In line with the finding for the control group in $\mathrm{H} 1$ above, these results may be explained by the fact that this group did not receive instruction treatment, and that any performance improvement across times may be attributed to task repetition effect. Similarly to the results obtained in the pragmatic recognition task in $\mathrm{H} 1$, one of the main limitations in the present dissertation was the limited access to the students, which affected the research design of the present investigation. Task repetition effect may have been avoided whether more time had been assigned between data collection time points. 
Table 47 illustrates the paired samples t-test performed to compare Mean difference for the experimental group between $\mathrm{T} 1(n=21, \mathrm{M}=7.24, \mathrm{SD}=2.644)$ and $\mathrm{T} 2$ $(n=21, \mathrm{M}=13.38, \mathrm{SD}=1.564)$ in the computer-delivered ODCT. See descriptive statistics in Table 46 below. This test found a significant difference for the experimental group between these two times, since the 95\% CI [-7.634, -4.652] did not run through zero. The size of the interval shows that the actual mean could be as small as over 4.5 points, or as large as over 7.5 points. A Cohen's d effect size was performed for this comparison, and resulted in $\mathrm{d}=1.875$, which means that the difference between the pretest and the posttest was large. This could mean that the effect of instruction was very significant.

Table 46. Paired samples t-test descriptive statistics for computer-delivered ODCT experimental group from Time 1 to Time 2

\begin{tabular}{cccccc}
\hline & $\mathrm{N}$ & Mean & SD & $\begin{array}{c}\text { SD Error } \\
\text { Mean }\end{array}$ \\
\hline $\begin{array}{c}\text { Experimental } \\
\text { [Group 1] }\end{array}$ & $\begin{array}{c}\text { Computer-delivered } \\
\text { ODCT Pretest } \\
\text { [Time 1] }\end{array}$ & 21 & 7.24 & 2.644 & .577 \\
\cline { 2 - 5 } & $\begin{array}{c}\text { Computer-delivered } \\
\text { ODCT Posttest } \\
\text { [Time 2] }\end{array}$ & 21 & 13.38 & 1.564 & .341 \\
\hline
\end{tabular}

Table 47. Paired samples t-test for computer-delivered ODCT experimental group from Time 1 to Time 2

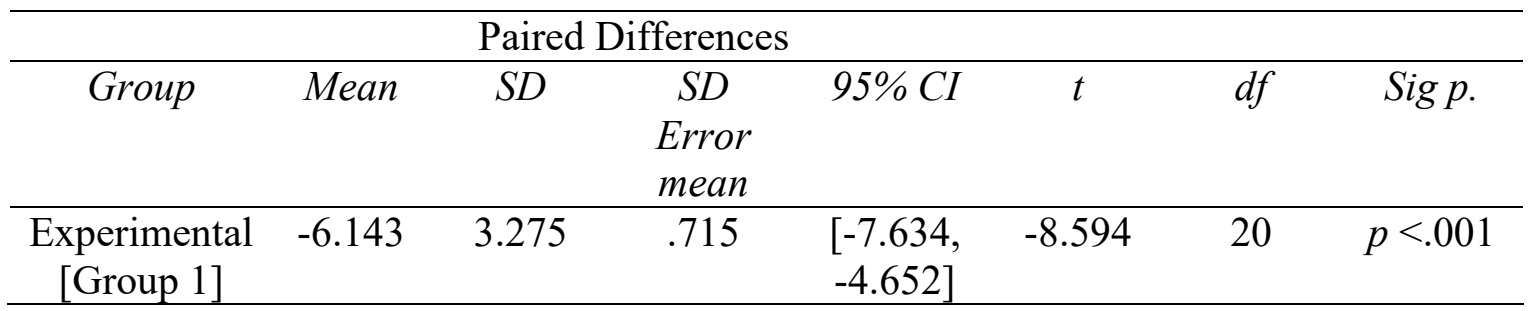


Table 49 provides the paired samples t-test performed to compare Mean difference for the experimental group between T2 $(n=21, \mathrm{M}=13.38, \mathrm{SD}=1.564)$ and $\mathrm{T} 3(n=21, \mathrm{M}=12.76, \mathrm{SD}=1.921)$ in the computer-delivered ODCT. See descriptive statistics in Table 48 below. This test found no significant difference for the experimental group between these two times, since the 95\% CI [-.285, 1.523] ran through zero. The size of the interval shows that the actual mean could be as small as over 1.5 points, or as large as nearly 0 points. A Cohen's d effect size was performed for this comparison, and resulted in $\mathrm{d}=0.311$, which means that the difference between the pretest and the posttest was small. This means that the instructional treatment was less effective.

Table 48. Paired samples t-test descriptive statistics for computer-delivered ODCT experimental group from Time 2 to Time 3

\begin{tabular}{cccccc}
\hline & $\mathrm{N}$ & Mean & SD & $\begin{array}{c}\text { SD Error } \\
\text { Mean }\end{array}$ \\
\hline $\begin{array}{c}\text { Experimental } \\
\text { [Group 1] }\end{array}$ & $\begin{array}{c}\text { Computer-delivered } \\
\text { ODCT Posttest } \\
{[\text { Time 2] }}\end{array}$ & 21 & 13.38 & 1.564 & .341 \\
& $\begin{array}{c}\text { Computer-delivered } \\
\text { ODCT Delayed } \\
\text { Posttest } \\
\text { [Time 3] }\end{array}$ & 21 & 12.76 & 1.921 & .419 \\
& & & & \\
\hline
\end{tabular}

Table 49. Paired samples t-test for computer-delivered ODCT experimental group from Time 2 to Time 3

\begin{tabular}{|c|c|c|c|c|c|c|c|}
\hline \multicolumn{8}{|c|}{ Paired Differences } \\
\hline Group & Mean & $S D$ & $\begin{array}{c}S D \\
\text { Error } \\
\text { mean }\end{array}$ & $95 \% C I$ & $t$ & $d f$ & $\operatorname{Sig} p$. \\
\hline $\begin{array}{c}\text { Experimental } \\
\text { [Group 1] }\end{array}$ & .619 & 1.987 & .434 & $\begin{array}{l}-.285, \\
1.523]\end{array}$ & 1.428 & 20 & .169 \\
\hline
\end{tabular}


Table 51 illustrates the paired samples t-test performed to compare Mean difference for the experimental group between $\mathrm{T} 1(n=21, \mathrm{M}=7.24, \mathrm{SD}=2.644)$ and $\mathrm{T} 3$ $(n=21, \mathrm{M}=12.76, \mathrm{SD}=1.921)$ in the computer-delivered ODCT. See descriptive statistics in Table 50 below. This test found a significant difference for the experimental group between these two times, since the 95\% CI [-7.118, -3.930] did not run through zero. The size of the interval shows that the actual mean could be as small as nearly 4 points, or as large as over 7 points. A Cohen's d effect size was performed for this comparison, and resulted in $\mathrm{d}=1.577$, which means that the difference between the pretest and the posttest was large. This could imply that the pedagogical intervention was very effective.

Table 50. Paired samples t-test descriptive statistics for computer-delivered ODCT experimental group from Time 1 to Time 3

\begin{tabular}{cccccc}
\hline & $\mathrm{N}$ & Mean & SD & $\begin{array}{c}\text { SD Error } \\
\text { Mean }\end{array}$ \\
\hline $\begin{array}{c}\text { Experimental } \\
\text { Group } \\
\text { [Group 1] }\end{array}$ & $\begin{array}{c}\text { Computer-delivered } \\
\text { ODCT Pretest } \\
\text { [Time 1] }\end{array}$ & 21 & 7.24 & 2.644 & .577 \\
\cline { 2 - 5 } & $\begin{array}{c}\text { Computer-delivered } \\
\text { ODCT Delayed } \\
\text { Posttest } \\
\text { [Time 3] }\end{array}$ & 21 & 12.76 & 1.921 & .419 \\
& & & & \\
\hline
\end{tabular}

Table 51. Paired samples t-test for computer-delivered ODCT experimental group from Time 1 to Time 3

\begin{tabular}{cccccccc}
\hline \multicolumn{7}{c}{ Paired Differences } \\
\hline Group & Mean & SD & SD & $95 \% C I$ & $t$ & $d f$ & Sig $p$. \\
Error \\
mean
\end{tabular}


The results obtained from the paired samples t-test help understand whether those increases in scores are significant or not. For the experimental group, the first paired samples t-test, which compared the Mean difference between Time 1 and Time 2, was significant and with a large effect size $(d=1.875)$, quite the opposite result comparing it to the control group at this same time. The paired samples t-test between Time 2 and Time 3 revealed a no significant difference between the Means between these two points in time, with a small effect size $(d=0.311)$. This extreme change may be translated in the fact that the effect of instruction did not last as equally effective at Time 3 as at Time 2. Finally, the last paired samples t-test confirmed a significant difference between the Means from Time 1 to Time 3 with a large effect size $(d=$ 1.577) for the experimental group in the computer-delivered ODCT. These results illustrate that scores increased overall, and that rise was not significant from Time 2 to Time 3, but it was indeed statistically significant from Time 1 to Time 2, and from Time 1 to Time 3. These results may be explained in terms of instructional effect and that performance improvement across times may be attributed to both task repetition effect resulted as well as to effect of pedagogical intervention.

The findings obtained in $\mathrm{H} 2$ are now discussed considering previous literature on this research topic. Research that examines the production of conventional expressions is more extensive than that of recognition of such pragmatic features. First of all, results from the present dissertation will be compared to studies that also included an instructional treatment. After that, the same procedure will be applied but with studies that did not include instruction.

In an EFL context, Rafieyan et al. (2014a) found that instruction proved to be more beneficial for the Focus on Form group (which received implicit instruction) over the Focus of Forms group (who received explicit instruction). Both groups 
outperformed the control group in the production of conventional expressions. Similarly to that study, the experimental group in this dissertation outperformed the control group in performing oral production of a given set of these expressions. However, and in contrast to this study and previous research on the effectiveness of implicit treatments, results from the present dissertation revealed that participants in the experimental group, who received explicit instruction, performed significantly better than the control group, which is a research finding amply supported by the literature on pragmatics instruction (e.g., Alcón-Soler, 2005; Alcón-Soler \& Martínez-Flor, 2008; Jeon \& Kaya, 2006; Kasper \& Rose, 2002; Norris \& Ortega, 2000, 2001; Plonsky \& Huang, 2019; Rose \& Kasper, 2001; Taguchi, 2015a, 2015b; Taguchi \& Roever, 2017).

As for research in ESL settings, Bardovi-Harlig and Vellenga (2012) and Bardovi-Harlig et al. (2015a) examined the production of conventional expressions in a pretest-posttest design and also included an instructional treatment. Results obtained from Bardovi-Harlig and Vellenga (2012) showed that learners' use of conventional expressions was subject to 1) instruction, 2) the complexity of the expression, and 3) the learner's proficiency level. The results obtained in this study mirror those obtained by Bardovi-Harlig and Vellenga. First of all, results from the statistical analysis above support the positive effect of instruction in the development of the oral production skill in pragmatic performance. Instructional effects were also positively found in BardoviHarlig et al. (2015a), who found that the control group outperformed the control group in specific semantic formulas (i.e., agreement, disagreement and clarification) in academic contexts. Even though the conventional expressions in this study were targeted in different contexts from those of the present investigation (i.e., academic setting versus mostly social situations outside the academic environment), BardoviHarlig et al. (2015a) is another example that supports the vital role of instruction in 
pragmatics, and on conventional expressions particularly. Continuing with the results obtained from Bardovi-Harlig and Vellenga (2012), secondly, the results are also explained in terms of the complexity of the conventional expressions. Research shows (e.g., Taguchi, 2015b) that opaqueness and complexity of the target pragmatic feature may hinder or foster learning and its consequent recognition or production. Regarding opaqueness, less transparent (e.g., more culture-specific) expressions seem to be more difficult to learn. Similarly, the more complex a pragmatic feature is in terms of its structure, the more difficult it may be to learn it. This was the case for the expression Do you have a pen I can borrow?, which students found challenging due to opaqueness and complexity. Participant found this expression opaque in the sense that their L1 pragmatic knowledge may not easily be transferred. Therefore, their cognitive processes to learn and further produce this expression were greater. A similar level of difficulty was reported by students in relation to the complexity of this expression. Compared to other and easier expressions, such as Hi. How are you?, participants found it more intellectually demanding to process and learn this expression due to two main reasons: 1) the syntactic structure was more complex, and 2) their knowledge of this expression in their preexisting L1 pragmatic system was different from that in their L2 pragmatic system. Therefore, making it a more complex task to learn this expression.

Finally, and as already explained in the discussion of results for $\mathrm{H} 1$, the level of proficiency of the learners may have influenced their pragmatic performance, not only negatively but also positively. It is true that learners who have a well-developed grammatical knowledge may lack pragmatic skills, and vice versa. However, and as seen above in the pragmatic recognition task, even students with the lowest proficiency levels could carry out these two tasks successfully. 
These studies are examples that support the undeniable fact that pragmatics is teachable (Bardovi-Harlig, 2015, 2018; Kasper, 2001; Long, 1983; O’Keeffe, 2011; Norris \& Ortega, 2000, 2001; Rose, 2005; Rose \& Kasper, 2001; Norris \& Ortega, 2001; Plonsky \& Huang, 2019; Taguchi, 2015a, 2015b). Additionally, they also shed light into the research that claims that the provision of instruction is more effective than simple exposure to the target pragmatic feature even after longer periods of exposure (Alcón-Soler, 2005; Alcón-Soler \& Martínez-Flor, 2008; Bardovi-Harlig, 2001, 2015, 2018; Cohen, 2008; Ishihara \& Cohen, 2010; Jeon \& Kaya, 2006; Kasper, 2001; Kasper \& Roever, 2005; Kasper \& Rose, 1999, 2002; Long, 1983; Martínez-Flor \& AlcónSoler, 2005; O’Keeffe, 2011; Roever, 2009; Rose, 2005; Rose \& Kasper, 2001; Schmidt, 1993; Taguchi, 2011a, 2015b; Takahashi, 2010a, 2010b), as it has proven to be essential in the development of pragmatic competence and therefore a more proficient and appropriate pragmatic performance in everyday interactions. Moreover, Bardovi-Harlig and Mahan-Taylor (2003) claim that teaching pragmatics in the classroom context is very important and that it is beneficial, and that it is in this context where can be tackled and pragmatic failure avoided.

The instructional treatment designed for the present dissertation included explicit instruction with the provision of metapragmatic information and discussion, and ample opportunities to practice the target conventional expressions, both in recognition and production activities. Additionally, students were also provided with (1) feedback (both positive and negative) as well as (2) relevant input, which in conjunction with rule provision and opportunities to practice the target pragmatic feature, are the four main pillars that conform L2 pragmatic instruction (Norris \& Ortega, 2001).

The following studies are examples of different ways to approach and put into practice instruction, such as a combination of instruction and metapragmatic discussion 
or feedback (Alcón-Soler, 2005; Alcón-Soler \& Guzmán-Pitarch, 2010; Eslami-Rasekh, Eslami-Rasekh \& Fatahi, 2004), the use of role-plays as a means of meaningful practice in oral mode (Eslami-Rasekh et al., 2014; Fukuya \& Martínez-Flor, 2008), or consciousness-raising activities (Alcón-Soler, 2005; Fukuya \& Martínez-Flor, 2008). Results from these studies reveal the paramount and indisputable role of explicit treatments in the teaching of ILP.

This dissertation found that students' lack of knowledge of certain conventional expressions, such as Excuse me, prevented them from performing appropriately in this task which is in line with studies that have explored the production of conventional expressions without the inclusion of instructional treatments. Usó-Juan and MartínezFlor (2015) found out that EFL students had a limited repertoire of pragmalinguistic sequences (i.e., explicit complaints, and expression of apology, and provision of an explanation) that proved rudimentary and less effective than having had a more comprehensive knowledge of pragmalinguistic features to accomplish the same pragmatic actions. Interestingly, similar results were obtained in the present investigation.

In this dissertation, results from the production task as well as participants' comments on the interventional treatment provided highlighted the essential role of pragmatic awareness to foster their knowledge and acquisition of conventional expressions. Similarly, Rafieyan et al. (2014b) also explored the production of conventional expressions in EFL settings. They found that raising students' pragmatic awareness fostered their production of these pragmatic features. Similarly, the present investigation included metapragmatic information and discussion to fulfill that goal. Research shows that an effective intervention entails the combination of explicit instruction with metapragmatic information and discussion. This exemplifies the 
indisputable role of explicit treatments in the teaching of ILP (e.g., Alcón-Soler, 2005; Alcón-Soler \& Guzmán-Pitarch, 2010; Eslami-Rasekh et al., 2004; Fukuya \& MartínezFlor, 2008).

In ESL contexts, Bardovi-Harlig et al. (2008) found that learners' native-like production was influenced by the nature of the scenario - which was also found in Bardovi-Harlig et al. (2010)- as well as by their level of proficiency (Rose, 2000; Tada, 2005), and exposure to the target language culture (Blum-Kulka \& Olshtain, 1986). Results from the present investigation found out that participants perceived some scenarios easier than others. For example, and as explained earlier in this manuscript, the supermarket scenario that targeted the conventional expression Excuse me was more difficult for students because they lacked the pragmalinguistic resources to complete this dialogue successfully. Additionally, the role that culture plays in learning and producing conventional expressions is undeniable. Students found it very easy to produce expressions they had already been involved in at some point, such as greeting someone they knew with Hi. How are you? but found it difficult to respond to this question with I'm fine, thanks. And you? when asked by someone they did not know, such as a cashier in a supermarket. In the present dissertation, cultural aspects of such scenarios and the conventional expressions employed in each of them were presented to and discussed with students in an attempt to include these critical issues in pragmatics instruction (Ishihara \& Cohen, 2010), which are essential in creating useful and comprehensive materials to teach pragmatics. Possible solutions to help students overcome these cultural differences and hence help them develop their pragmatic skills successfully may entail the inclusion of pragmatics in other courses, as well as the creation of workshops that are solely focused on pragmatics and teaching pragmatics from a research-based perspective that relies on real-life goal-oriented situations. 
However, this may be a daunting or challenging task in settings where the curriculum of a given Degree is planned out and established by the government, such as the EFL context where this dissertation took place. Creating courses and offering them to students may not be a successful task, since this may imply a time-consuming endeavor for professors and educators who already have a full schedule of teaching and research duties. Additionally, if these courses were finally to be created, they would have to be offered outside of the academic schedule. This may be translated into a low student enrollment, since students may already have other personal or academic chores or jobs outside the academic schedule. All in all, it could be argued pragmatics-focused course or workshop creation might not be the most appropriate option in EFL settings where the course provision in a Degree is not prompt to change. Other solutions could include the inclusion of pragmatics in course that tackle pragmatics to a greater or lesser extent. Anyhow, research has shown that EFL tend to be impoverished settings (Eslami \& Eslami-Rasekh, 2008) in which opportunities to teaching and learning of pragmatics should be more present in the curricula to foster and hasten adult EFL learning and acquisition of pragmatic compentence.

The results obtained in $\mathrm{H} 2$ can also be explained in terms of Skill Acquisition Theory (Anderson, 1993; DeKeyser, 1997, 1998, 2001, 2003, 2007a). A theoretical summary of the main features of this theory was reported in Section 7.2 above. Nevertheless, the application of such theoretical tenets into pragmatics and the implications of this theory in L2 pragmatics instruction are discussed in relation to the results obtained in $\mathrm{H} 2$ above.

Skill Acquisition theory understand learning as a gradual process. The present study was designed to facilitate pragmatic development of recognition of conventional expressions gradually as a step to achieve the ultimate goal to use this pragmatic 
knowledge in the future (Taguchi, 2015b; Taguchi \& Roever, 2017). First the computerdelivered ODCT was provided as a means of meaningful, communicative practice. This was later reinforced by the provision of pedagogical intervention that was designed as a student-centered practice-oriented treatment. The inclusion of metapragmatic instruction also aimed at providing information to expand learners' pragmatic knowledge of conventional expressions. This knowledge could be put into practice critically by means of metapragmatic discussion lead by the instructor and which students were expected to engage in actively in an individual or collective manner (Kasper, 2001). This entailed a cognitive processing into a deeper level (Taguchi \& Roever, 2017). As seen from the comments above, the further oral practice provided by means of role-plays was generally perceive as useful and meaningful practice, which students undertook as a way to reinforce their knowledge of conventional expressions.

The second tenet in Skill Acquisition Theory applied to pragmatics learning states that practice is fundamental. The present dissertation attempted to address this need, which was partially met, as seen in different pragmatic performance by different learners. In so doing, it was essential to put into practice the claim made by Taguchi (2015b, p. 34) as she stated that, "[a]dding to the previous discussion on effective treatment conditions, repetitive practice in a meaningful context has emerged as a new, promising treatment feature for developing pragmatic abilities.” Additionally, Badjadi (2016, p. 241) stated that, "interventions which actively engaged learners in metapragmatic discussion (...) produced larger effects.” Results from the paired samples ttests performed on the experimental group together with the results from the independent samples t-tests reported above support this statement. In this regard, and supporting Skill Acquisition Theory, Taguchi (2015b) stated that sustained practice is required in order for declarative knowledge to become procedural knowledge. 
These results are also supported by participants' responses to two open-ended questions in the Post-instruction Questionnaire that targeted the use of role-play as an opportunity to further practice their knowledge of conventional expressions. Role-plays were included in the instructional treatment as a means of meaningful practice in oral mode (Eslami-Rasekh et al., 2004; Fukuya \& Martínez-Flor, 2008), however, not all students perceived them as meaningful practice. For example, P5 explained that, "well, to be honest I didn't like it because if I am not in a real situation I cannot do it natural because I guess that we did it because the recordings were needed for the research so it was just OK [sic].” Nevertheless, there were many other students who took this activity as extra practice and an opportunity to learn more about these expressions. For example, P27 stated that, "I think the best of this activity has been that it is very dynamic as well as funny. Besides, it has been very useful to put into practice the use of conventional expressions studied [sic]." Similarly, P24 added that, "It was funny and visual, because of representing them [sic]." P19 perceived this activity as a preparation for future social interactions, as they explained that, "The role-play introduces you in real-life situations [sic]." This idea was shared by P25, who indicated that what they liked best about roleplays was "having fun with classmates and proving yourself in real situations [sic]." P7 also shared this viewpoint, since this participant thought that, "I like that these were real situations that can happen everyday [sic]." Additionally, some other students liked this activity because they learnt from it. For example, P6 reported that, "we could learn the correct (appropriate) answers to some situations [sic]" and P45 added that, "the thing I like most was to reinforce the expressions. Because they are not learnt in one day [sic]." In sum, participants liked the role-play as they generally perceived this opportunity to further practice their recently gained knowledge of conventional expressions; and they 
perceived this task as useful, fun while reinforcing their knowledge of what they would say in real-life situations.

The results from the quantitative data are supported by these results from qualitative data. The significant differences between the control and experimental group as well as the statistically significant differences within each of the groups are complemented and supported by students' comments, mainly those in the experimental group, about the instructional treatment. Participants explained what issues or specific things were helpful for them to understand and learn conventional expressions.

All in all, based on the quantitative and qualitative results obtained in $\mathrm{H} 2$, it could be concluded that $\mathrm{H} 2$ was confirmed. Participants' production of conventional expressions will improve after receiving instruction (posttest), and will mostly be lost after a longer period of time (delayed posttest), as measured by the scores in the computer-delivered ODCT. This result supports previous research findings on the effectiveness of instruction at the posttest that does not last through the delayed posttest (e.g., Taguchi, 2015b). Additionally, the significant differences found across times in the experimental group, the lack of those in the control group, and the very large effect sizes, according to Cohen (1977), in the statistically significant differences in the independent samples t-tests at Time 2 and Time 3 also lend support to these findings.

Pragmatic production poses a greater difficulty for students, in comparison to pragmatic recognition, since the former entails a greater processing load (Taguchi, $2015 b$ ) and that may help account for the gradual pragmatic development by the control group as well as the experimental group, but the non-sustained gain in the delayed posttest by the latter group. Nevertheless, the significant differences between the two groups and the large effect sizes of such differences shed some light into the effectiveness of the explicit treatment provided. The present dissertation aimed at 
contributing to the existing literature on routine formulae, and on conventional expressions more specifically by looking at the adult EFL students' production of a set of conventional expressions, which has received less attention. Additionally, by means of combining the teaching of pragmalinguistic resources together with their sociopragmatic norms in the metapragmatic instruction and discussion, and further recognition and production practice, it attempts to contribute to the literature on the effectiveness of explicit instruction in teaching pragmatics in an EFL setting.

\subsection{Results and Discussion Related to Hypothesis 3}

Hypothesis 3 (H3) predicts that participants' responses to the RVPs will reflect the effect of instruction on their production of conventional expressions. A combination of qualitative analysis (i.e., topic analysis) and quantitative analysis (i.e., MANOVAs) was carried out. Data were also collected at three time points: pretest, posttest, and delayed posttest. To analyze the data, qualitative analysis in the form of topic analysis was performed first to identify, classify, and code the data obtained from the retrospective verbal protocols (RVPs). After that, MANOVAs were performed to explore possible significant differences in participants' topic use. Based on the results obtained from the triangulation of data in $\mathrm{H} 3$, it could be concluded that $\mathrm{H} 3$ was confirmed. Findings from the topic analysis of the RVPs together with the MANOVAs revealed a significant difference in the use of IIRs (Instruction Induced Reasons) in detriment of LR, POL, and SitD topics, as reflected in the MANOVAs indexes from pretest to posttest (Mean difference $=2.05, p<.001,95 \%$ CI $[-2.92,-1.17])$ and delayed posttest (Mean difference $=1.07, p<.001,95 \% \mathrm{CI}[-1.61,-.53])$. These results are further elaborated in the following two subsections. 


\subsubsection{Qualitative results.}

As explained in Chapter 6, RVPs were collected to elicit participants' thoughts about the rationale behind their selection of one expression over another for each of the situations in the computer-delivered ODCT. In so doing, the computer-delivered ODCT was intended to be a more robust data collection instrument. Most importantly, the reasons that led participants to provide such pragmatically focused oral responses were explored, thus triangulating the quantitative data collected from the computer-delivered ODCT with the qualitative data provided by the RVPs.

The topic analysis (also called 'thematic analysis', e.g., Braun \& Clarke, 2006; Greg, 2012; Richards, 2003) was conducted by means of exploring the content of the RVPs provided by the participants. There were 15 RVPs per each of the participants $(n$ $=46$ ), this made a total of 690 RVPs per each time of task: pretest, posttest, and delayed posttest with a total of 2070 RVPs. Once all the RVPs were put together in a document, a total of 15 recurrent topics were identified all throughout the total number of responses. These topics and what they mean are explained in Table 64 below.

Table 52. Topics and their meanings in RVPs classification

\begin{tabular}{|l|l|}
\hline Topic & Meaning \\
\hline Logical reasoning (LR) & $\begin{array}{l}\text { Participants provide a logical response so as to justify their } \\
\text { answer. See Taguchi (2002). } \\
\text { For example, Participant 46 responded, "I don't want my } \\
\text { friend to die" to the "Watch out" situation in the posttest. }\end{array}$ \\
\hline Instruction-induced & $\begin{array}{l}\text { Participants use the information provided to them during } \\
\text { instruction sessions 1 and 2. That information can refer to } \\
\text { specific words used during the instruction, the same idea the } \\
\text { researcher gave students but rephrased with their words, or } \\
\text { parts of what the researcher said verbatim combined with } \\
\text { their own words. } \\
\text { For example, Participant 20 said, 'you are meeting this }\end{array}$ \\
\hline
\end{tabular}




\begin{tabular}{|c|c|}
\hline & $\begin{array}{l}\text { person for the first time and it's something that you say } \\
\text { always when you meet someone for the first time' in relation } \\
\text { to the "Nice to meet you" situation in the delayed posttest. }\end{array}$ \\
\hline $\begin{array}{l}\text { Knowledge from test } \\
\text { (KFT) }\end{array}$ & $\begin{array}{l}\text { Knowledge participants gained from taking the VKS or the } \\
\text { computer-delivered ODCT. Participants remembered that a } \\
\text { given expression was included in either or both of those } \\
\text { instruments. }\end{array}$ \\
\hline $\begin{array}{l}\text { General life knowledge } \\
\text { (GLK) }\end{array}$ & $\begin{array}{l}\text { Participants provided examples of (1) life experiences and } \\
\text { (2) global knowledge, and also ( } 3 \text { ) statements in which } \\
\text { students said, "I know X". See Taguchi (2002). }\end{array}$ \\
\hline I don't know (IDK) & $\begin{array}{l}\text { Participant said explicitly "I don't know" as a reason why } \\
\text { they had used a particular expression in a given situation. }\end{array}$ \\
\hline $\begin{array}{l}\text { Previous experience } \\
\text { (PE) }\end{array}$ & $\begin{array}{l}\text { Participants provided reasons that were based on previous } \\
\text { experiences depending on three specific contexts: (1) SA: } \\
\text { while living or traveling abroad, (2) taught X at school or } \\
\text { high school, and (3) social, such as greeting a person you } \\
\text { have previously met. }\end{array}$ \\
\hline $\begin{array}{l}\text { L1-specific knowledge } \\
\text { (L1SK) }\end{array}$ & $\begin{array}{l}\text { Participants provided literal translations from Spanish or } \\
\text { Catalan, such as "go" instead of "let's go". "Go" in Spanish } \\
\text { means "vamos", and so students experience L1 transfer. }\end{array}$ \\
\hline Politeness (POL) & $\begin{array}{l}\text { Participants said they wanted to be polite, and sometimes } \\
\text { they provided information related to close-distant/formal- } \\
\text { informal relations, social factors, and face-threatening issues } \\
\text { or also the lack of politeness. }\end{array}$ \\
\hline $\begin{array}{l}\text { Concept definition } \\
\text { (CD) }\end{array}$ & $\begin{array}{l}\text { Participants provides a definition or description of a concept } \\
\text { or conventional expression, whether it was correct or } \\
\text { incorrect }\end{array}$ \\
\hline $\begin{array}{l}\text { Situation description } \\
\text { (SD) }\end{array}$ & $\begin{array}{l}\text { Participants elaborated a description of the situation in which } \\
\text { they used a given conventional expression, which was } \\
\text { different to the situation description provided for them in } \\
\text { each of the situations. }\end{array}$ \\
\hline $\begin{array}{l}\text { Participant's beliefs } \\
\text { (PB) }\end{array}$ & $\begin{array}{l}\text { Participants said something they were not completely sure } \\
\text { about introducing the idea with "I think" or "maybe." }\end{array}$ \\
\hline
\end{tabular}




\begin{tabular}{|l|l|}
\hline $\begin{array}{l}\text { Something established } \\
\text { (SE) }\end{array}$ & $\begin{array}{l}\text { Participants refer to pragmatic or linguistic rules used in } \\
\text { specific situations, using phrases such as "it is something } \\
\text { established", "because it is the common sentence". }\end{array}$ \\
\hline Difficult (DIF) & $\begin{array}{l}\text { Participants say that the situation is difficult for them for } \\
\text { whatever reason the provide, whether it is cultural } \\
\text { differences or language-related, linguistic or pragmatic } \\
\text { issues }\end{array}$ \\
\hline Awkward (AWK) & $\begin{array}{l}\text { Participants say that the situation is awkward for them for } \\
\text { whatever reason the provide, whether it is cultural } \\
\text { differences or language-related/linguistic issues }\end{array}$ \\
\hline Not applicable (NA) & $\begin{array}{l}\text { Participants provided a reason that was unintelligible to } \\
\text { transcribe }\end{array}$ \\
\hline
\end{tabular}

Some examples from each of the categories are presented to illustrate the descriptions provided in Table 52 above.

Logical reasoning (LR): for example, P3 (PRT-P3-Sit2) ${ }^{28}$ provided the following reason to explain why they would refuse some salesperson's help at a store: “because I already eat a lot so I don't want more food because I'm already satisfied [sic]'. Another example is P4's (PRT-P4-Sit4) ${ }^{29}$ reasoning on why they would ask a friend or someone they know how they are doing when greeting that person: "because if I don't have seen her on a while, I think that I would like to know how is she doing [sic]".

Instruction-induced reason (IIR): Providing an explanation why they would refuse a clerk's help at a store, P5 (DLY-P5-Sit10) $)^{30}$ said, "you have to deny first and then explain a little bit why you don't need his help [sic]". In a similar vein, P11 (DLY-P11Sit14) $)^{31}$ drew on the instructions provided by the researcher during the pedagogical

\footnotetext{
${ }^{28}$ PRT-P3-Sit2: Participant 3 in Situation 2 at Pretest.

${ }^{29}$ PRT-P4-Sit4: Participant 4 in Situation 4 at Pretest.

${ }^{30}$ DLY-P5-Sit10: Participant 5 in Situation 10 at Delayed Posttest.

${ }^{31}$ DLY-P11-Sit14: Participant 11 in Situation 14 at Delayed Posttest.
} 
intervention to explain why they would thank a host for being invited to a party:

"because you have to be polite to say that it's been a good party and you thank for being invited [sic]"'.

Knowledge from test (KFT). P35 (PRT-P35-Sit13) ${ }^{32}$ reported that "I remember this special item was in our test. 'I'm just looking.' 'No, thanks you. I'm just looking.' And I would say 'no, thank you' because I know that this person is doing his or her job. And that's their job that they have to come and ask me something. And I would say 'no, thank you' because I'm grateful for offering me his help. But I don't need it so, I would say 'thank you' because I really don't need it. Thank you for offering [sic]”. This participant first mentioned that they recalled finding this particular situation in the VKS and then provided a response to explain their pragmatic oral performance.

General life knowledge (GLK). P2 (PRT-P2-Sit7) ${ }^{33}$ drew on their pragmalinguistic and sociopragmatic knowledge in Spanish to provide a reason why they would ask for a classmate's pen in such a particular way in English compared to what they would say in Spanish: "and why? Because that's something I heard before. Maybe in Spanish I would say 'I take you the pen' and that's it, but in English you just need to be a little bit more polite and use indirect questions can I borrow your pen? $[$ sic]".

I don't know (IDK). Examples falling into this category reflect students' lack of knowledge why certain pragmalinguistic forms are used in particular sociopragmatic contexts. For example, P23 (PRT-P23-Sit6) ${ }^{34}$ kept repeating this sentence, "I don't really know. Because I don't really know and I don't know what I would say to her. Just

\footnotetext{
${ }^{32}$ PRT-P35-Sit13: Participant 35 in Situation 12 at Pretest.

${ }^{33}$ PRT-P2-Sit7: Participant 2 in Situation 7 at Pretest.

${ }^{34}$ PRT-P23-Sit6: Participant 23 in Situation 6 at Pretest.
} 
what people say. [sic]”. Similarly, P11 (PRT-P11-Sit12) 35 stated: “I don't know. It's a way of saying goodbye. I don't know [sic]" as they tried to provide a reason why they would say Thanks for your time. I appreciate it to a Professor as they left the Professor's office.

Previous experience (PE). P21 (PRT-P21-Sit2) ${ }^{36}$ reflected on their previous experience when living in the UK to explain how they would refuse the offer of more food by a host. They said, "some English people talked to me and said that I have to say 'yes, but only a small amount, please' because I'm full. Yeah because it's quite rude to say 'no, thank you. I'm full.' Yes, so I prefer to say yes but only a small amount please. I'm full but I want to taste it or just trying to be nice [sic]". The researcher took the opportunity to ask this participant where they were taught that and they replied "in Manchester [sic]." This participant further elaborated their response afterwards: "it's like someone is presenting you broccoli or something like you're not really or to small children or something like it it's just polite to say only just a small amount because if you don't like something but you say that you don't want more, and then someone offers you like a cake or something and you're oh yes!! And so you were full and now? Yes [sic]".

L1-specific knowledge (L1SK). P10 (DLY-P10-Sit4) ${ }^{37}$ applied a pragmalinguistic strategy used in their L1 to fulfill a social interaction in English: "well because a short answer, I don't know. 'Okay, go.' I'm going to make up and then go [sic]', as they meant to accept a friend's invitation to go dancing. The researcher further asked this participant if they thought providing this particular response (i.e., "okay, go") was a good idea, to what the participant responded: “yes. He is my friend and is a good idea to

\footnotetext{
${ }^{35}$ PRT-P11-Sit12: Participant 11 in Situation 12 at Pretest.

${ }^{36}$ PRT-P21-Sit2: Participant 21 in Situation 2 at Pretest.

${ }^{37}$ DLY-P10-Sit4: Participant 10 in Situation 4 at Delayed Pretest.
} 
go dancing with my friend and have fun, and I don't know, is short and clear, the answer. It's direct: 'go,' why not? [sic]'.

Politeness (POL). P2 (PST-P2-Sit5) ${ }^{38}$ referred explicitly to the fact of being polite when thanking a Professor for their time: "because I am the one who has to study, has to do the things on my own, and he is losing time. Although he is working, he's trying to help me understand things and I have to appreciate his effort. I wanna make sure he knows that. Politeness [sic]".

Concept definition (CD). P31 (PST-P31-Sit13) ${ }^{39}$ provided the following definition to refer to the expression No problem: "it's an expression or an answer that you can tell your friend in order to say that yeah he or she can go with me [sic]".

Situation description (SD). P13 (DLY-P13-Sit13) ${ }^{40}$ described how they would ask a friend for a pen and why: "I would call him or her in his proper name and I would say for example, 'Maria, can you borrow me a pen?' Because it's an informal situation and if you are asking for something and that's all [sic]".

Participant's beliefs (PB). P19 (PRT-P19-Sit12) ${ }^{41}$ made reference to this topic as they explained why they had said Thank you very much. I really appreciate it: "because I consider that teaching deserve a lot of consideration, because it's a great effort that teachers do, and well I am a teacher as well, and I understand the role and if any pupil of mine would say 'thank you very much,' I am very pleased and I feel good [sic]”.

Something established (SE). P5 (PRT-P5-Sit3) ${ }^{42}$ elaborated the following response as they explained why they used the expression nice to meet you: "because I

\footnotetext{
${ }^{38}$ PST-P2-Sit5: Participant 2 in Situation 5 at Posttest.

${ }^{39}$ PST-P31-Sit13: Participant 31 in Situation 15 at Posttest.

${ }^{40}$ DLY-P13-Sit13: Participant 13 in Situation 13 at Delayed Posttest.

${ }^{41}$ PRT-P19-Sit12: Participant 19 in Situation 12 at Pretest.

${ }^{42}$ PRT-P5-Sit3: Participant 5 in Situation 3 at Pretest.
} 
don't know it's everyday conversation and it's the common sentence you say when you meet someone [sic]".

Difficult (DIF). P6 (DLY-P6-Sit13) ${ }^{43}$ uttered: "I have to ask for permission.

Sometimes it's difficult to explain why [sic]" as they tried to explain why they used the expression Do you have a pen I can borrow?

Awkward (AWK). P37 (PRT-P37-Sit6) ${ }^{44}$ reported feeling uncomfortable in the situation in which a cashier greets you and asks you how you are. In their own words, P37 explained that “ah, that's very uncomfortable. And I don't know, probably I will just look. I will try to be busy with something else because I don't like talking to people I don't know. I don't feel comfortable. I know some people at work they try to be like very friendly and so you feel like in a (high) when you go to buy, yeah or something, but it depends. If I've been to the place many many many times, maybe I feel okay. But still, I'm like I will just say 'hi,' something like short, and 'I'm good. Hi' and just start putting things in a bag or looking for money so I can just [sic]”.

Not applicable (NA). Examples falling into this category would imply that participants would provide no rationale to explain their pragmatic production or would provide an explanation which was unintelligible when being transcribed. For example, P23 (PST-P23-Sit13) ${ }^{45}$ provided an unintelligible response, which was transcribed as follows: "Because (xxxx) [sic]".

Once RVPs were classified according to the topics explained above, they were transformed into numerical values. Each token was given one point, and all tokens were given the same number of points because all topics were considered equally important. If one sentence included more than one token, each token was given one point and

\footnotetext{
${ }^{43}$ DLY-P6-Sit13: Participant 6 in Situation 13 at Delayed Posttest.

${ }^{44}$ PRT-P37-Sit6: Participant 37 in Situation 6 at Pretest.

${ }^{45}$ PST-P23-Sit13: Participant 23 in Situation 13 at Posttest.
} 
assigned to the corresponding topic. These numeric values were used for the quantitative analysis of these data. This procedure is explained in more detail in the following subsection.

\subsubsection{Quantitative results.}

The number of tokens per topic and per time of task yielded a total of 690 tokens per time of task, as mentioned at the beginning of this subsection. MANOVAs were performed to examine possible significant differences among the same topic across times, and among all the topics across time. Descriptive statistics for all the topics are provided first and then the significant differences between and within topics are reported to shed light on the possible effect of instruction on participants' perception of the effect of instruction on their use of conventional expressions as explained in their RVPs.

Appendix 18 illustrates the between-subjects effects that exist among the different topics. Significant differences are found for the LR, IIR, POL, and SitD. More specifically, those differences are found in LR DLY ${ }^{46}$, IIR PST ${ }^{47}$ and IIR DLY ${ }^{48}$, POL $\mathrm{PST}^{49}$ and POL DLY ${ }^{50}$, and SitD $\mathrm{PST}^{51}$. To determine the nature of such differences, MANOVAs were performed for each of the topics. The results for these specific four topics are reported here and the tables illustrating the within-subjects differences, between-subjects differences, and pairwise comparisons can be found in Appendix 18 . Results from the within-group analyses show where these differences are significant. The Greenhouse-Geisser correction is used to report the statistical differences because it

\footnotetext{
${ }^{46}$ Logical Reasoning at Delayed Posttest.

${ }^{47}$ Instruction-Induced Reason at Posttest.

${ }^{48}$ Instruction-Induced Reason at Delayed Posttest.

${ }^{49}$ Politeness at Posttest.

${ }^{50}$ Politeness at Delayed Posttest.

${ }^{51}$ Situation Description at Posttest.
} 
is shown to be more conservative than other measures in the table, such as Huynh-Feldt (Larson-Hall, 2016).

Concerning LR, results from the test of within-subjects effects found statistically significant differences in both time and in the interaction between time and group. Regarding Time, it was statistical using the Greenhouse-Geisser correction $(F(1.48)=$ $32.43, p=<.001$, partial $\eta^{2}=.42$ ). As for Time and Group, this correlation was statistical using the Greenhouse-Geisser correction $\left(F(1.48,1.48)=, p=.004\right.$, partial $\eta^{2}$ $=.14)$. The test of Between-Subjects effects performed for this topic in particular reveals that there was not statistical effect for group $\left(p=.625\right.$, partial $\left.\eta^{2}=.005\right)$. Nevertheless, the pairwise comparisons found that there ware statistically significant differences (a) between Time 1 and Time 2 (Mean difference $=1.932, p<.001,95 \%$ CI $[1.042,2.822]$ ), and (b) Time 1 and Time 3 (Mean difference $=2.33, p<.001,95 \%$ CI $[1.47,3.19])$. As can be seen from both of the CIs, these numbers are wide. Thus, we may not be so confident about the actual amount of difference. Due to those large numbers, the amount of difference could be small.

Regarding IIR, results from the test of within-subjects effects reveal statistically significant differences in both time and in the interaction between time and group. Regarding time, it was statistical using the Greenhouse-Geisser correction $(F(1.58)=$ 52.17, $p=<.001$, partial $\left.\eta^{2}=.54\right)$. As for Time and Group, this correlation was statistical using the Greenhouse-Geisser correction $(F(1.58,1.58)=, p=<.001$, partial $\left.\eta^{2}=.54\right)$. The pairwise comparisons found that there were statistically significant differences across the three times: between Time 1 and Time 2 (Mean difference $=2.05$, $p<.001,95 \%$ CI $[-2.92,-1.17])$, between Time 2 and Time 3 (Mean difference $=1.07$, $p<.001,95 \%$ CI $[-1.61,-.53])$, and between Time 1 and Time 3 (Mean difference $=$ 
$3.12, p<.001,95 \%$ CI $[-3.97,-2.26])$. The amount of difference may be small, as seen in rather large difference in the CIs across times.

As for POL, results from the test of within-subjects effects reveal statistically significant differences in both time and in the interaction between time and group. Regarding Time, it was statistical using the Greenhouse-Geisser correction $(F(1.94)=$ $5.73, p=.005$, partial $\left.\eta^{2}=.115\right)$. As for Time and Group, this correlation was statistical using the Greenhouse-Geisser correction $\left(F(1.94,1.94)=4.55, p=.014\right.$, partial $\eta^{2}=$ .94). The pairwise comparisons found that there was a statistically significant difference between Time 1 and Time 3 (Mean difference $=1.32, p=.011,95 \%$ CI $[.248,2.396]$ ). The amount of difference may be small, as seen in rather large difference in the CIs across times.

Finally, in regards to SitD, results from the test of within-subjects effects reveal a statistically significant difference in time. It was statistical using the GreenhouseGeisser correction $\left(F(1.97)=5.63, p=.005\right.$, partial $\left.\eta^{2}=.113\right)$. The between-subjects effect found a significant effect of group $\left(p=.045\right.$, partial $\left.\eta^{2}=.088\right)$. The pairwise comparisons found that there were statistically significant differences between (a) Time 1 and Time 2 (Mean difference $=.694, p=.013,95 \%$ CI [-1.266, -.122]), and (b) between Time 1 and Time 3 (Mean difference $=.546, p=.054,95 \%$ CI [-1.08, -.009]). The amount of difference may be small, as seen in rather large difference in the CIs across times.

As seen above, a total of 2070 tokens were obtained from the RVPs collected in the computer-delivered ODCT from all participants. These tokens were analyzed to trace recurrent topics into which they could be classified. A total of 15 topics were identified. After that, the tokens were classified according to topic and given a numeric value of 1 . MANOVAs were used with the 2070 tokens to locate possible significant 
differences between and within topics that could the change between topics across times due to the effect of instruction. Results reveal a significant decrease in use of LR, POL, and SitD reasons at Time 3, where the use of IIR reasons were significantly more frequently used to explain participants' use of a particular conventional expression. See Appendix 18. Students' RVPs helped understand that change and the significance that the effect of instruction had in relation to their pragmatic production.

The differences found from the evidence above are now summarized in terms of the participants' changes in the use of one specific topic (i.e., IIR) in detriment of others, such as POL and SitD as mentioned above.

Table 53. Participants' use of IIR in RVPs

\begin{tabular}{|l|l|l|}
\hline Participant & Posttest & Delayed posttest \\
\hline P1 & $8 / 15$ & $5 / 15$ \\
\hline P2 & $4 / 15$ & $6 / 15$ \\
\hline P5 & $5 / 15$ & $7 / 15$ \\
\hline P6 & $1 / 15$ & $4 / 15$ \\
\hline P7 & $1 / 15$ & $4 / 15$ \\
\hline P9 & $1 / 15$ & $4 / 15$ \\
\hline P11 & $10 / 15$ & $11 / 15$ \\
\hline P12 & $2 / 15$ & $2 / 15$ \\
\hline P14 & $0 / 15$ & $4 / 15$ \\
\hline P19 & $1 / 15$ & $4 / 15$ \\
\hline P20 & $5 / 15$ & $9 / 15$ \\
\hline P22 & $1 / 15$ & $6 / 15$ \\
\hline P24 & $5 / 15$ & $8 / 15$ \\
\hline P25 & $9 / 15$ & $15 / 15$ \\
\hline P27 & $0 / 15$ & $3 / 15$ \\
\hline P29 & $9 / 15$ & $12 / 15$ \\
\hline P36 & $2 / 15$ & $3 / 15$ \\
\hline P41 & $11 / 15$ & $8 / 15$ \\
\hline P45 & $3 / 15$ & $5 / 15$ \\
\hline P46 & $1 / 15$ & $3 / 15$ \\
\hline P48 & $6 / 15$ & $9 / 15$ \\
\hline & & \\
\hline
\end{tabular}

Table 53 illustrates different trends in the use of IIR motives to explain pragmalinguistic use. Instruction seems to have been most effective for some participants in some various degrees (i.e., P2, P5, P6, P7, P9, P11, P14, P19, P20, P22, 
P24, P25, P27, P29, P3, P45, P46, and P48), less effective for others (i.e., P1, P41), and barely effective across times for other participants (i.e., P12). These findings imply some food for thought regarding the pedagogical intervention and the different effects it may have had in different students, as RVPs illustrate. Therefore, further research would entail the improvement of the instructional treatment by for example including more varied audiovisual materials (i.e., more videos), more conventional expressions (i.e., include other expressions which also vary in the degree of difficulty), and further opportunities to practice both the recognition and production skills of conventional expressions.

Previous studies on the use of RVPs in combination with DCTs have focused mainly on the combination of retrospective RVPs and written versions of DCTs, such as WDCTs and interactive DCTs (see Beltrán-Palanques, 2016 for a review). However, to date, there seems to be no study that has employed the combination designed in this dissertation (i.e., ODCTs and concurrent RVPs) to study the production of conventional expressions. Hence, results from the present investigation allow assuring two general remarks. Results from data analysis in $\mathrm{H} 3$ bring two main contributions to the existing literature: (1) the use of RVPs as a qualitative tool to support quantitative data to reflect the effect of pedagogical interventions; and (2) the importance of triangulation of data to confirm or reject one hypothesis. In this case, it was the use of MANOVAs, the transformation of the same data into numbers, what helped support the findings from the results of the analysis of the qualitative data. 


\subsection{Results and Discussion Related to Hypothesis 4}

$\mathrm{H} 4$ predicts that students with more positive attitudes towards the instructional treatment will perform better after instruction. Results from the qualitative analysis allow confirming this hypothesis. A total of 14 topics were identified, which encompassed all participants' responses to two open-ended questionnaires in the Postinstruction Questionnaire. The reasons that participants provided reflect the effectiveness of pedagogical treatments and thus support the main tenet behind the effect of explicit instruction. These results are further explored as follows.

As previously explained in Chapter 6, the Post-instruction Questionnaire was distributed to students in the experimental group to obtain insightful information about their opinions on several aspects of the instructional treatment they had received. One of those aspects focuses on their attitudes towards instruction, which was elicited by means of two open-ended questions in page one of the questionnaire. See Appendix 5. These two questions read: What did you like best about the presentation of the information on conventional expressions? Why? And What did you like least about the presentation of the information on conventional expressions? Why? The same procedure was applied to the data gathered from the two questions. The first step in this analysis was to extract these comments from the individual questionnaires and transcribe them into a Word processor, since this was a paper-and-pencil questionnaire. After that, all the reasons provided by participants were carefully examined and topics were identified from this data exploration. Finally, participants' responses were classified according to such topics.

Concerning the first question, "What did you like best about the presentation of the information on conventional expressions? Why? ", the 21 participants provided a total of 23 examples regarding different reasons in reference to what they liked best and 
why. All students provided one reason, except for three students, who provided two reasons each. Those six reasons were counted as six different instances instead of three and were classified accordingly. Six topics emerged from the analysis of the first question: real life, useful, target pragmatic feature, instruction, activities, and instructor.

First, the most frequent comments found in the data were related to the topic of instruction. Eight participants out of $21(38,095 \%$ of the total sample in the experimental group) expressed that what they liked best about the instructional treatment was the instruction itself, and for various reasons. For example, P2 reported more generally that what they liked was "the quality of the explanation, the examples, etc." Similarly, P12 reported that, "I think it is very useful to understand the expressions". More specifically, P1 elaborated that "the presentation was very useful and the thing that I enjoyed the most about it was the way in which conventional expressions were used in examples.” In a similar vein, P29 thought that, "firstly, the thing I like most about the presentation is that you understand the context of these expressions." Likewise, P45 elaborated that, "the aspect I like the most is the way in which they are presented, they are easy to understand." This could be summarized with the P24's contribution, as they liked instruction due to "the way the professor presented them" meaning the conventional expressions. Focusing on the presentation of both the theoretical concepts and the examples, P48 believed that "it was easy to understand since the explanations were clear and the pictures helped us to know the context." Finally, P27 provided a very comprehensive response, which highlights one goal of the pedagogical treatment. P27 said, "in my opinion, the best aspects of the presentation were that it is was clear and concise and that it included a lot of examples, providing in this way students with some important knowledge about the use of conventional expressions." 
Second, the second most recurrent topic referred to the usefulness of knowing conventional expressions in relation to social communication, with comments from seven students out of 21 (around 34\% of the total sample in the experimental group). More generally, P14 argued that conventional expressions "are very useful”. Providing a little more detail, P11 reported that, "what I liked the most was that they are very useful in our daily routines". Similarly, P45 pointed out that, "besides, they are very useful in everyday and they are highly frequent, therefore they are important to use them fluently". In a similar vein, P7 expressed that, "I like the knowledge of these expressions is useful to communicate properly in English”. Likewise, P29 stated that, "secondly, the information included is really useful for us to increase our knowledge about everyday language". On a different note, but still related to the idea of conventional expressions being useful for social communication, P46 explained that, "what I like the most that the conventional expressions faced are very useful and will help me in the future". Adding another layer of detail, P41 referred to conventional expressions, as "I definitely liked them since I think they are very useful in everyday life and they are not dealt with in other subjects".

Third, the topic of situations depicting real life interactions was identified, with examples from three students out of the total pool of 21 in the experimental group (14.28\%). These participants provided a reason related to the fact that conventional expressions are related to real life interactions. For example, P6 said that what they liked best was "the fact that real examples situations were used". Similarly, P25 reported that the conventional expressions "were explained using real life situations and that is really helpful". Finally, P5 pointed out that "I liked it [the instructional treatment] because the expressions that we've seen are used in everyday conversation and it is good 
to know it". The second most frequently topic that students talked about was related to the usefulness of knowing conventional expressions.

Fourth, the next topic refers to comments made by three students $(14.28 \%$ of the total population in the experimental group sample) about the conventional expressions themselves. This topic is identified as target pragmatic feature. Generally, P22 referred to this topic as, "what I liked the most are some of the examples because they were funny". The two other students referred to the fact that conventional expressions are not studied in any other course in the degree in which they are enrolled. For example, P41 mentioned "the examples. I definitely liked them since I think they are very useful in everyday life and they are not dealt with in other subjects." Similarly, P20 explained that what they felt liked best was "the conventional expressions themselves, since I think that these kinds of expressions are not taught when dealing with grammar or whatever, and they are so important".

Fifth, only one student out of 21 referred to the data collection methods ${ }^{52}$ used in the instructional treatment as the preferred aspect in the pedagogical intervention. More specifically, P9 explained that what he liked best was "the part in which we had to participate in role plays because it was the most practical one".

Finally, one student out of 21 mentioned the instructor, which is the last topic identified in this data set. P19 mentioned that, "the teacher is willing to explain everything in detail”.

Now that all six topics have been identified and examples provided, the discussion of such results will be dealt with in detail in the following subsection. However, the

\footnotetext{
${ }^{52}$ It is acknowledged that this student did not refer to role-plays as a type of data collection methods, but as a pedagogical activity. However, for the purpose of topic identification, it was labeled as "data collection methods".
} 
results from the analysis of participants' comments for the second question are presented as follows.

In regards to the second question about the instructional treatment, "What did you like least?", the 21 participants provided a total of 21 examples regarding different reasons in reference to what they liked less and why. All students provided one reason, except for one student, who provided two reasons. Those reasons were counted as different instances and were classified separately. Eight topics emerged from the analysis of the second question: previous knowledge, theoretical explanation, explanation of expressions, number of expressions (few target expressions were included - wished for more), audiovisual materials, nothing, taking notes, and time constraint.

First, seven students out of 21 that conform the experimental group reported that the least they liked about the instructional treatment was the theoretical explanation. As tackled in detail in Chapter 5, the theoretical explanation that the students refer to entailed (1) the presentation of Celce-Murcia's (2007) model of communicative competence to introduce (2) the concept of conventional expressions together with features that characterize them, and the importance of learning conventional expressions for social communication. For example, and even though this pedagogical intervention was student-oriented designed, P9 mentioned that what they liked least was "the theoretical part because even it was important it was the less dynamic". Some of the students expressed they felt this theoretical explanation boring, such as P14, who stated that "it as a bit boring". P22 elaborated on this idea and said that, "what I liked least is the historical explanation because even knowing that I need to know it, I still don't really like it because it seems a bit boring to me". In contrast to these two participants, P27 would have preferred a more in-depth discussion of the concept of communicative 
competence. As they said, "maybe, the aspect I liked the least was the fact that the presentation should include more theory about the communicative construct". On another note, P20 preferred the practical part, where students were provided with opportunities to practice their knowledge of conventional expressions, over the theoretical part. In their words, they expressed that, "if I have to say something, I would say the theory, but it was totally fine. It is only that I have enjoy more the questionnaires and the role plays". Finally, two students had an overall positive perception about the theoretical presentation. However, they still mentioned this part as the one they disliked most. For example, P1 stated "maybe the theoretical part because you have to pay a lot of attention to understand it; however, it was fine". Finally, P46 pointed out that "maybe the theoretical part, but it was well structured and clean, so I don't know."All in all, the theoretical presentation of the instructional treatment was perceived as boring (i.e., P14 and P22) or short, since other students would have preferred a further explanation regarding the concept of communicative competence (i.e., P27). It was also felt as less dynamic (P9), and the practice that followed it was more desired (P20). Finally, one student mentioned the cognitive load required to be actively engaged with the theoretical concepts (P1), and another student just mentioned this section as their least favorite, even though they reported it had a clear structure (P46).

Second, four students (around 19\% of the total experimental sample) mentioned that there was nothing they liked least. For example, P12 said that "I liked everything", P29 belied that, "in my opinion, everything was fine", and P19 wrote that, "it was everything all righ". In turn, P41 provided a more elaborated response: “I think I liked everything. It was worth mentioning the theory first and then the examples and the practice. From my point of view, it was very good". 
A third group of students (three out of 21, around 14\%) expressed their concerns regarding their previous knowledge about the target conventional expressions. For example, P25 said that, "we already know very well the most basic ones". In a similar vein, P48 reported that, "maybe the fact that I knew some of them already, however, it was OK." Finally, P7 referred to all the conventional expressions, as they mentioned that, "I think that the conventional expressions were too easy according to our level of English.”

Fourth, two students identified the explanation of the expressions as their least preferred issue in the treatment. P11 said that, "what I liked least was that the explanation of each of the situations was too long", whereas P24 claimed that, "some concepts seemed to be the same".

Finally, four different students referred to four different topics. For example, $f e w$ expressions was the topic identified in P5's comment. According to this participant, "I think we have focused a lot in 15 expressions and maybe we could have learnt more instead of just practicing a few". In turn, P2 referred to the audiovisual materials employed in the treatment: "I liked everything. But maybe I missed more audiovisual examples, extracted from movies or TV shows, maybe" (emphasis added by the student in the word 'more'). Changing the subject, P6 referred to the fact that I advised students to pay attention instead of trying to copy everything the information in the slides, and ask questions whenever they needed. P6 mentioned that, "we couldn't write during the explanation and maybe it would be more useful to take notes to do the summary at home." From P6's comment, it could be guessed that participants needed to write a report about the instruction for other purposes related to the course where data could be collected for this dissertation. P6's comment was categorized as taking notes. Finally, time constraints were also reflected on students' perceptions of the instruction, as for 
example P45, who was concerned about the fact that "trying to learn all the expressions in a few time. It makes me feel nervous". In the following subsection, these data are summarized and discussed in depth.

As can be seen from this analysis, for the first question that reads "What did you like best?" about the instruction, the most recurrent topic was 'instruction' with comments from eight students, followed closely by 'useful' with comments from seven students. Then, 'real life' and 'target pragmatic feature' both have the same number of examples: three each. Finally, and also with the same number of examples, but the least frequently mentioned topics are 'activities' and 'instructor' with only one student commenting on each of the topics. These results can be explained in terms of the following aspects:

First, an instrumental motivation component was identified, since some of the students reported that knowing these conventional expressions would be helpful for them in the future. Second, some other students mentioned the fact that this pragmatic feature is not tackled in any other course in the degree. This may be so because there is only one course in this specific degree that deals with pragmatics and conventional expressions is not part of the syllabus.

Third, another recurrent topic was that of situations reflecting real-life interactions. This was the main goal to achieve when the target conventional expressions were selected. Moreover, conventional expressions are those expressions in which a focus is given to their social role in interaction. Additionally, and based on research findings (e.g., Taguchi, 2015b), it was essential to provide students with reallife situations if they ever go abroad and find themselves in these situations. The instructional treatment in this dissertation aimed at preparing students for those social 
exchanges outside the academic environment, so that they could learn something that they could really apply in their lives outside of the classroom environment.

Fourth, and related to the topic above, some other students reported that what they did like best was the fact that the target conventional expressions were useful to social communication. As stated in the definition of conventional expressions, there is a focus on the social role that these expressions play in interaction (Bardovi-Harlig, 2009). Additionally, conventional expressions have been identified as being recurrent in everyday communicative situations (House, 1996).

Fifth, and also related to the topic above, most students referred to the instruction itself about the aspect that they liked best about the instructional treatment. In particular, students mentioned the quality (i.e., clarity and concision) of the explanation and the use of examples and audiovisual materials to facilitate learning and the way in which the researcher presented all the situations and explained both the pragmalinguistic features and sociopragmatic rules specific to each situation. One student explicitly referred to my teaching as the aspect that they liked best about the instructional treatment. This reflects on the importance of the instructor as a facilitator of knowledge, fostering students' autonomy, and their motivation to learn more, as for example by means of inclusion of real-life situations, for example, as done in this study.

Finally, the topic of practice was also a recurrent one in those issues most valued by students as regards the pedagogical intervention. Research evidence reveals the importance of including ample opportunities to practice (e.g., DeKeyser, 2007b; Taguchi, 2015b). This is critical in the EFL classroom because it is only in the classroom where students may have more opportunities to use the language meaningfully, since English is not an official language and therefore may not be found as frequently and easily outside of the classroom than in ESL contexts. Research has 
shown that (meaningful recurrent) practice (e.g., Kasper, 2001; Taguchi, 2015b; Taguchi \& Roever, 2007) is one key aspect in pragmatics learning as well as in successful explicit intervention. It is essential for students to develop their pragmatic skills, and therefore their pragmatic competence. Most importantly, by means of providing students with opportunities to practice, they become active agents of their learning process.

Despite the wide range of issues that students regarded as key to foster their pragmatic learning, some students also commented on those tools or aspects that they liked least. Responses to this second question yielded a total of 21 responses from the 21 students. The most commonly found topic was the theoretical explanation with six counts, then nothing with four counts, previous experience with three counts, and explanation of expressions and boring with two counts each. Then, a series of topics received one count each: number of expressions, audiovisual materials, taking notes, and time constraint. Students referred to knowing some of the conventional expressions as one aspect that they found negative about the instructional treatment, which is related to the topic of number of expressions. Some students referred to the fact that they would have liked to learn and practice more expressions since they found 15 insufficient. From these topics, the topic about time constraints was found the most critical. There was one student who believed that there was not sufficient time for them to learn the target conventional expressions, and that affected their learning process, since it made them feel nervous. This constructive feedback is as equally helpful, since it helped me reevaluate the instructional treatment to improve it for the future.

All in all, findings from qualitative analysis allowed confirming $\mathrm{H} 4$, which support the main tenet that explicit instruction fosters pragmatic acquisition. According to Taguchi and Roever (2017, p. 412) citing Ellis and Shintani (2014) as well as 
Schmidt (2001), “[e]xplicit teaching is designed for intentional language learning” as well as "directs learners' attention to the instructional target to promote learning with awareness of what is being learned, often involving understanding of metapragmatic rules." Results from this study contribute to the literature on pragmatics instruction, particularly on explicit instruction, as well as on studies on the effect of instruction on the recognition and production of conventional expressions. More specifically, the present study aims at enhancing and fostering students' learning and use of conventional expressions by means of an explicit instruction with metapragmatic explanations supported with audiovisual materials, as well as metapragmatic discussion and opportunities to practice both recognition and production skills. Analysis of qualitative data allows asserting that the combination of these tools enhanced students' successful learning of conventional expressions and subsequent development of pragmatic competence.

\subsection{Results and Discussion Related to Hypothesis 5}

Hypothesis 5 (H5) predicts that participants will change their attitudes across times, as reflected in the Attitudes Questionnaire. Data were also collected at three points in time: pretest (i.e., Time 1, T1), posttest (i.e., Time 2, T2), and delayed posttest (i.e., Time 3, T3). Results from the independent samples t-test help support that this hypothesis cannot be confirmed, as shown in the pretest $(t=0.39$, Sig. $(2$-tailed $)=.969)$ and delayed posttest $(t=-1.150$, Sig. $(2$-tailed $)=.256)$. Contrary to the expected results, participants' attitudes did not affect their performance on the Attitudes Questionnaire. Results from both the independent samples t-test and the dependent samples t-test reveal no significant differences either between groups or within groups. These results are unprecedented, since all of the studies reviewed on the effect of attitudes towards 
languages illustrated a significant correlation between language attitudes and task performance.

Figure 22 below illustrates a summary of the general findings obtained by both groups in the Attitudes Questionnaire. Group performance is explained separately in what follows, preceded by a summarized report of the descriptive statistics per group.

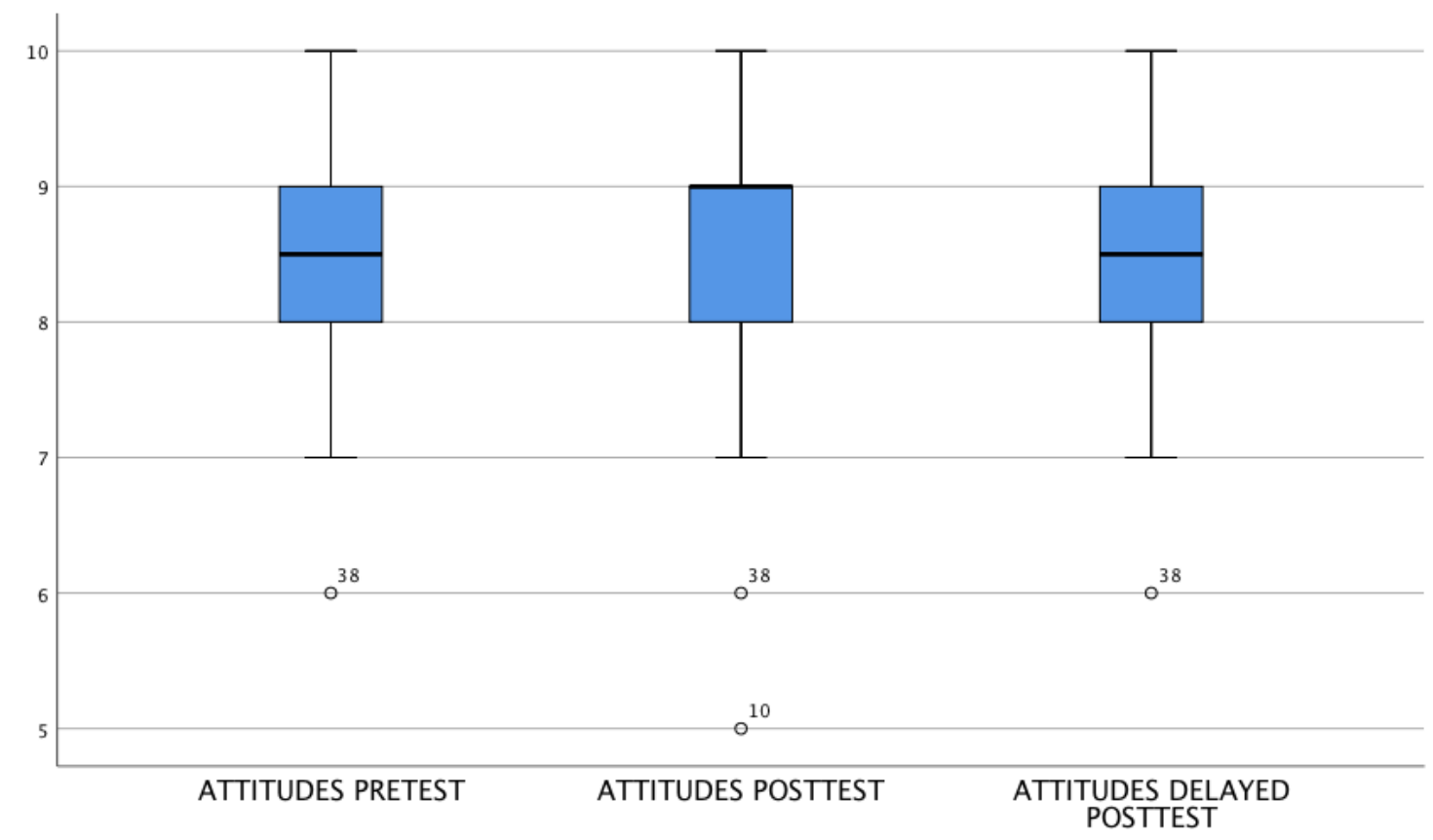

Figure 22. Boxplot for control and experimental groups performance of Attitudes Questionnaire

A summary of the descriptive statistics is provided per group to identify the sample and highlight changes in performance from Time 1 (T1) to Time 3 (T3). The descriptive statistics for the experimental group are reported first and those for the control group afterwards. Please refer to Appendix 19 for a more detailed account of the descriptive statistics per time of task for both groups in the Attitudes Questionnaire. 
Table 54. Descriptive statistics for experimental group across times in VKS

\begin{tabular}{ccccccc}
\hline & Time & Mean & SD & Range & Skewness & Kurtosis \\
\cline { 2 - 7 } $\begin{array}{c}\text { Experimental } \\
\text { group } \\
n=21\end{array}$ & Pretest & 8.43 & .870 & 3 & $\begin{array}{c}-.010(\mathrm{sd} \\
\text { error }\end{array}$ & $\begin{array}{c}-.467(\mathrm{sd} \\
\text { error } \\
\end{array}$ \\
\cline { 2 - 7 } & & & & {$[7-10]$} & $\begin{array}{c}.501) \\
.972)\end{array}$ \\
\cline { 2 - 7 } & Posttest & 8.62 & .865 & 3 & $\begin{array}{c}-.150(\mathrm{sd} \\
\text { error }\end{array}$ & $\begin{array}{c}-.150(\mathrm{sd} \\
\text { error }\end{array}$ \\
& & & & {$[7-10]$} & $.501)$ & $.501)$ \\
\cline { 2 - 7 } & Delayed & 8.57 & .870 & 3 & $.010(\mathrm{sd}$ & $-.467(\mathrm{sd}$ \\
& posttest & & & {$[7-10]$} & error & error \\
& & & & & $.501)$ & $.972)$ \\
\hline
\end{tabular}

Table 54 illustrates the summary of the descriptive statistics for the experimental group in the Attitudes Questionnaire across times. The experimental group was conformed by 21 participants $(n=21)$. They scored rather high $(\mathrm{M}=8.43, \mathrm{SD}=0.870)$ in the pretest, taking into consideration that the minimum score in the Attitudes Questionnaire was 0 and the highest was 10 . Scores slightly improved in the posttest (M $=8.62, \mathrm{SD}=.865)$, but slightly decreased in the delayed posttest $(\mathrm{M}=8.57, \mathrm{SD}=.870)$, which was administered 11 days after the posttest. As illustrated in Table 54, the Mean increased from $\mathrm{T} 1$ to $\mathrm{T} 2$, but decreased from $\mathrm{T} 2$ to $\mathrm{T} 3$, which could be translated in the unnoticeable change in scores in this task This performance pattern is supported by the slight change in the SD. As per range and scores, they remain the same across times: a range of three and scores with a minimum of 7 and a maximum of 10 , which is the highest score that can be obtained in the Attitudes Questionnaire. Findings in skewness and Kurtosis inform that scores are normally distributed, and therefore there is no significant departure from the Mean score across times. These results might be explained in terms of the pragmatic nature of the recognition and production tasks, which did not include an attitude component. 
Table 55. Descriptive statistics for control group across times in Attitudes Questionnaire

\begin{tabular}{|c|c|c|c|c|c|c|}
\hline \multirow{4}{*}{$\begin{array}{l}\text { Control } \\
\text { group } \\
n=25\end{array}$} & Time & Mean & $S D$ & Range & Skewness & Kurtosis \\
\hline & Pretest & 8.44 & 1.083 & $\begin{array}{c}4 \\
{[6-10]}\end{array}$ & $\begin{array}{c}-.367(\mathrm{sd} \\
\text { error } \\
.464) \\
\end{array}$ & $\begin{array}{c}-.403(\mathrm{sd} \\
\text { error } \\
.902)\end{array}$ \\
\hline & Posttest & 8.28 & 1.173 & $\begin{array}{c}5 \\
{[5-10]}\end{array}$ & $\begin{array}{c}-1.102(\mathrm{sd} \\
\text { error } \\
.464) \\
\end{array}$ & $\begin{array}{c}1.423(\mathrm{sd} \\
\text { error } \\
.902)\end{array}$ \\
\hline & $\begin{array}{l}\text { Delayed } \\
\text { posttest }\end{array}$ & 8.24 & 1.052 & $\begin{array}{c}4 \\
{[6-10]}\end{array}$ & $\begin{array}{c}-.291(\mathrm{sd} \\
\text { error } \\
.464)\end{array}$ & $\begin{array}{c}-.709(\mathrm{sd} \\
\text { error } \\
.902)\end{array}$ \\
\hline
\end{tabular}

Table 55 synthesizes the descriptive statistics for the control group in the Attitudes Questionnaire from T1 to T3. The control group was conformed by 25 participants $(n=25)$. These students scored rather high in the pretest $(\mathrm{M}=8.44, \mathrm{SD}=$ 1.083 ) as well taking into consideration that the minimum score for the Attitudes Questionnaire was 0 and the highest was 10 . However, scores did not improve either in the posttest $(M=8.28, S D=1.173)$, or in the delayed posttest $(M=8.24, S D=1.052)$, administered 11 days after the posttest. This is illustrated with the Mean. As seen in Table 55, it decreased across times. However, the SD shows that such decrease was not homogeneous. Score performance at T1 and at T3 was the same, with a range of 4 points with a minimum of 5 and a maximum of 10 . However, score performance varied at T2, with a lower range, namely 5, and a minimum score of 5 and a maximum of 10 . The values for skewness and Kurtosis reveal normally distributed scores, which means that there was not significant departure form the Mean score across times. Similarly to score performance experienced by the experimental group, results from the control group might also be explained in terms of the pragmatic nature of the recognition and production tasks, which did not include an attitude component. 
The results from the independent samples t-tests and the paired samples t-tests are presented as follows. Findings obtained from these statistical analyses are discussed afterward considering the existing literature.

The independent samples t-tests were performed to identify and track possible significant differences between the control group and the experimental group. Three independent samples t-tests were run to compare the Mean scores of the groups per time of task.

Table 56. Descriptive statistics for group Mean comparison in the computer-delivered ODCT at Time 1

\begin{tabular}{ccccc}
\hline Group & $N$ & Mean & SD & $\begin{array}{c}\text { SD Error } \\
\text { Mean }\end{array}$ \\
\hline $\begin{array}{c}\text { Control } \\
\text { [Group 0] }\end{array}$ & 25 & 8.44 & 1.083 & .217 \\
\hline $\begin{array}{c}\text { Experimental } \\
{[\text { Group 1] }}\end{array}$ & 21 & 8.43 & .870 & .190 \\
\hline
\end{tabular}

Table 56 provides the descriptive statistics from the Mean comparison between both groups at Time 1. The Mean for the control group was 8.44 , whereas it as 8.43 for the experimental group. As for the SD, the control group obtained a SD of 1.083, and .870 the experimental group. The SD Error Mean for the control group was .217, and .190 for the experimental group. 
Table 57. Independent samples t-test both groups in the Attitudes Questionnaire at Time 1

\begin{tabular}{|c|c|c|c|c|c|c|}
\hline \multicolumn{7}{|c|}{ t-test for Equality of Means } \\
\hline \multirow[t]{2}{*}{$\mathrm{t}$} & \multirow[t]{2}{*}{$\mathrm{df}$} & \multirow[t]{2}{*}{$\begin{array}{l}\text { Sig. (2- } \\
\text { tailed) }\end{array}$} & \multirow[t]{2}{*}{$\begin{array}{c}\text { Mean } \\
\text { Difference }\end{array}$} & \multirow[t]{2}{*}{$\begin{array}{l}\text { Std. Error } \\
\text { Difference }\end{array}$} & \multicolumn{2}{|c|}{$\begin{array}{l}95 \% \text { Confidence } \\
\text { Interval of the } \\
\text { Difference }\end{array}$} \\
\hline & & & & & Lower & Upper \\
\hline .039 & 44 & .969 & .011 & .294 & -.580 & .603 \\
\hline
\end{tabular}

Table 57 illustrates the results from the independent samples t-test performed to compare the Means of the control group and experimental group in the Attitudes Questionnaire at Time 1. Data at this first time period did not show abnormalities, distributions were symmetric and variances were equal, as shown in the Levene test $(F$ $=1.217$; Sig. $=.276)$. An independent samples t-test found no evidence of a difference between the means on the Attitudes Questionnaire at Time 1 for the control group $(n=$ 25 , mean $=8.44, \mathrm{SD}=1.083)$ and for the experimental group $(n=21$, Mean $=8.43, \mathrm{SD}=$ .870). See box plot Figure 23 below. Since the 95\% CI contains zero [-.580, .603], it can be concluded that there is no statistical difference between the groups. The narrow CI, less than 2 points on a test where the maximum score was 10 points, illustrates that the estimate of how different the groups are is uncertain, but not likely to be far from zero. The effect size for this comparison was calculated following Cohen's d, which resulted in Cohen's $d=0.01$. According to Cohen's guidelines for effect sizes may be considered a very small effect size because the small effect size is 0.2 . 


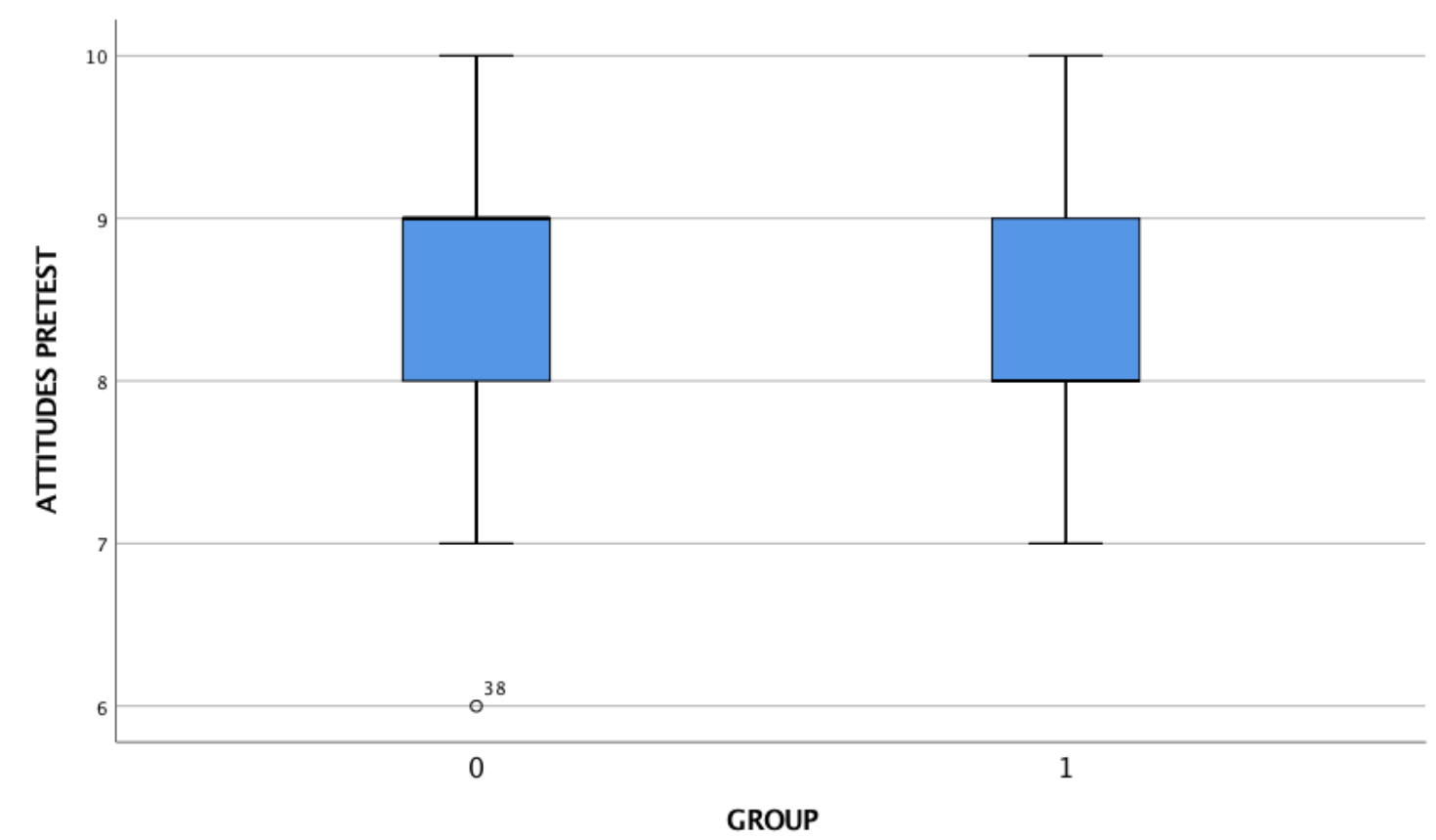

Figure 23. Box plot for Mean difference between control group and experimental group in Attitude Questionnaire at Time 1

As shown in the descriptive statistics, there was already a slight difference in performance between the experimental group and the control group at $\mathrm{T} 1$, which the independent samples t-test revealed not to be significant, and with a very small effect size. These performances were already high taking into consideration that the highest score is 10 for the Attitudes Questionnaire. Results from the independent samples t-tests performed for T2 and T3 help understand score performance development and the possible reasons behind such changes and between-group differences. 
Table 58. Descriptive statistics for group Mean comparison in the computer-delivered ODCT at Time 2

\begin{tabular}{ccccc}
\hline Group & $N$ & Mean & $S D$ & $\begin{array}{c}\text { SD Error } \\
\text { Mean }\end{array}$ \\
\hline $\begin{array}{c}\text { Control } \\
\text { Group 0] }\end{array}$ & 25 & 8.28 & 1.173 & .235 \\
\hline $\begin{array}{c}\text { Experimental } \\
{[\text { Group 1] }}\end{array}$ & 21 & 8.62 & .865 & .189 \\
\hline
\end{tabular}

Table 58 provides the descriptive statistics from the comparison of the Means by both groups at Time 2. The Mean for the control group was 8.28 , whereas it was 8.62 for the experimental group. As for the SD, the control group obtained a SD of 1.173, and .865 the experimental group. The SD Error Mean for the control group was .235, and .189 for the experimental group.

Table 59. Independent samples t-test both groups in the Attitudes Questionnaire at Time 2.

\begin{tabular}{|c|c|c|c|c|c|c|}
\hline \multicolumn{7}{|c|}{ t-test for Equality of Means } \\
\hline \multirow[t]{2}{*}{$\mathrm{t}$} & \multirow[t]{2}{*}{$\mathrm{df}$} & \multirow[t]{2}{*}{$\begin{array}{l}\text { Sig. (2- } \\
\text { tailed) }\end{array}$} & \multirow[t]{2}{*}{$\begin{array}{c}\text { Mean } \\
\text { Difference }\end{array}$} & \multirow[t]{2}{*}{$\begin{array}{l}\text { Std. Error } \\
\text { Difference }\end{array}$} & \multicolumn{2}{|c|}{$\begin{array}{l}95 \% \text { Confidence } \\
\text { Interval of the } \\
\text { Difference }\end{array}$} \\
\hline & & & & & Lower & Upper \\
\hline-1.097 & 44 & .279 & -.339 & 309 & -.962 & .284 \\
\hline
\end{tabular}

Table 59 illustrates the results from the independent samples t-test performed to compare the means of the control group and experimental group in the Attitudes Questionnaire at Time 2. Data at this second time period showed departure from nonnormality, since two outliers can be found in the control group. Nevertheless, distributions were symmetric and variances were equal, as revealed in the Levene test $(F=1.077 ;$ Sig. $=.305)$. An independent samples t-test found no evidence of a difference between the means on the Attitudes Questionnaire at Time 2 for the control group $(n=25$, mean $=8.28, \mathrm{SD}=1.173)$ and for the experimental group $(n=21$, Mean $=$ $8.62, \mathrm{SD}=.865)$. See box plot Figure 24 below. Since the $95 \%$ CI contains zero [-.962, 
$.284]$, it can be concluded that there is no statistical difference between the groups. The narrow CI, less than 2 points on a test where the maximum score was 10 points, illustrates that the estimate of how different the groups are is uncertain, but not likely to be far from zero. The effect size for this comparison was calculated following Cohen's d and resulted in an effect size of Cohen's $d=0.33$. According to Cohen's guidelines for effect sizes can be considered a small effect size.

The independent samples t-test revealed that the Means of the two groups are not significantly different from each other, as seen in the boxplot Figure 37 below that shows the distribution of means by time of task and group.

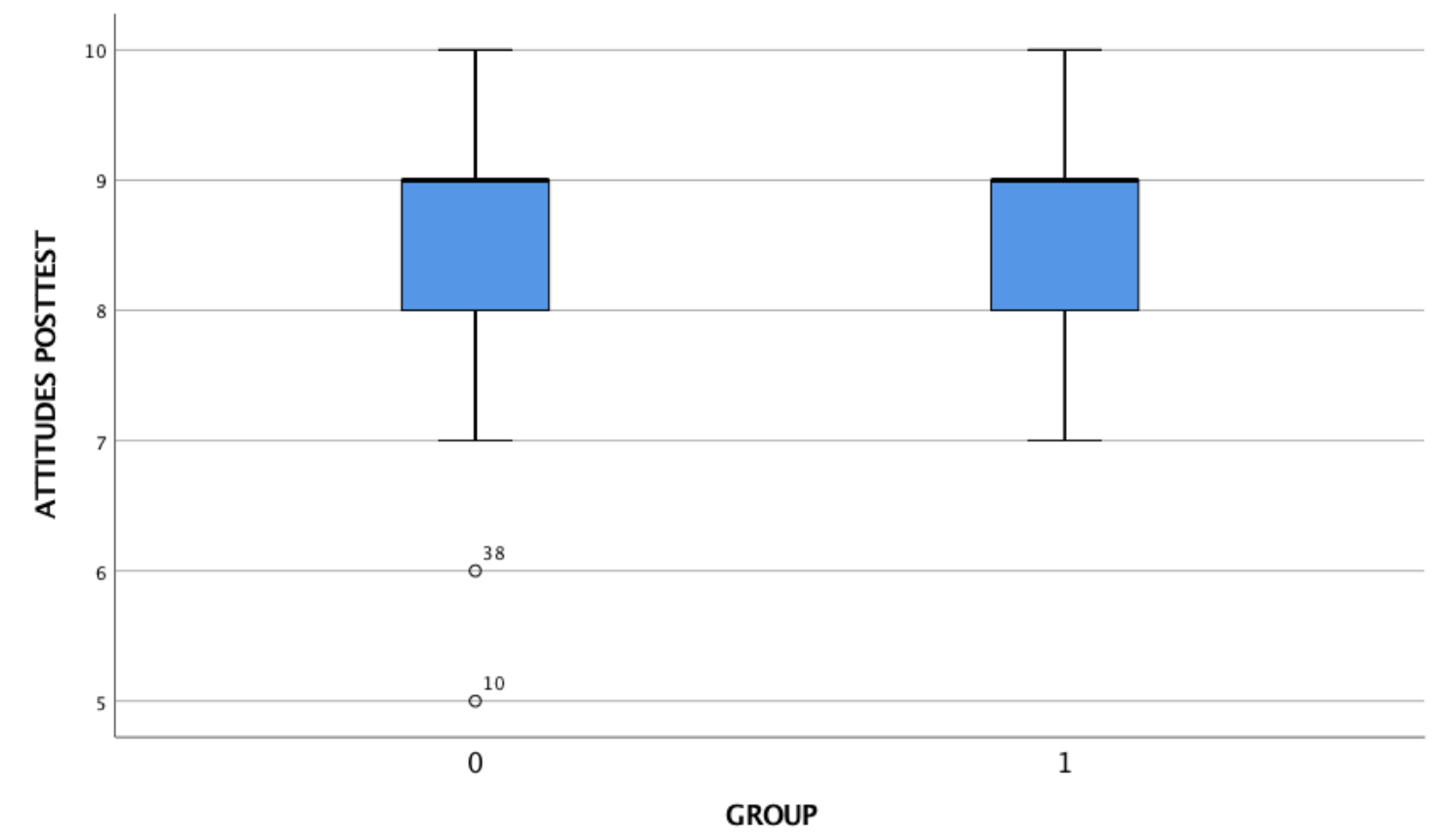

Figure 24. Box plot for Mean difference between control group and experimental group in Attitude Questionnaire at Time 2

The descriptive statistics for Mean comparison at T2 revealed another subtle difference in performance between these two groups. The independent samples t-test revealed that this difference was not statistically significant, and Cohen's $d=0.33$ informed that this statistical difference was small. This could be explained in terms of the fact that the tasks at stake were pragmatic-focused tasks. In other words, the core of 
the tasks was the pragmalinguistic features and sociopragmatic conventions attached to conventional expressions and attitudes were not tackled in either the VKS or the computer-delivered ODCT.

So far, the score performance for the experimental group and control groups has been discussed, and the Mean comparison of the two groups at Time 2 provided. Now, the same will be done for Time 3 .

Table 60. Descriptive statistics for group score comparison in the computer-delivered ODCT at Time 3

\begin{tabular}{ccccc}
\hline Group & $N$ & Mean & SD & $\begin{array}{c}\text { SD Error } \\
\text { Mean }\end{array}$ \\
\hline $\begin{array}{c}\text { Control } \\
\text { [Group 0] }\end{array}$ & 25 & 8.24 & 1.052 & .210 \\
\hline $\begin{array}{c}\text { Experimental } \\
{[\text { Group 1] }}\end{array}$ & 21 & 8.57 & .870 & .190 \\
\hline
\end{tabular}

Table 60 provides the descriptive statistics from the Mean comparison between both groups at Time 3. The Mean for the control group was 8.24, whereas it as 8.57 for the experimental group. As for the SD, the control group obtained a SD of 1.052, and .870 the experimental group. The SD Error Mean for the control group was .210, and .190 for the experimental group. 
Table 61. Independent samples t-test both groups in the Attitudes Questionnaire at Time 3

\begin{tabular}{|c|c|c|c|c|c|c|}
\hline \multicolumn{7}{|c|}{ t-test for Equality of Means } \\
\hline \multirow[t]{2}{*}{$\mathrm{t}$} & \multirow[t]{2}{*}{$\mathrm{df}$} & \multirow[t]{2}{*}{$\begin{array}{l}\text { Sig. (2- } \\
\text { tailed) }\end{array}$} & \multirow[t]{2}{*}{$\begin{array}{c}\text { Mean } \\
\text { Difference }\end{array}$} & \multirow[t]{2}{*}{$\begin{array}{l}\text { Std. Error } \\
\text { Difference }\end{array}$} & \multicolumn{2}{|c|}{$\begin{array}{l}95 \% \text { Confidence } \\
\text { Interval of the } \\
\text { Difference }\end{array}$} \\
\hline & & & & & Lower & Upper \\
\hline-1.150 & 44 & .256 & -.331 & .288 & -.912 & .249 \\
\hline
\end{tabular}

Table 61 illustrates the results from the independent samples t-test performed to compare the Means of the control group and experimental group in the Attitudes Questionnaire at Time 3. Data at this third time period did not show departure from non-normality, distributions were symmetric and variances were equal, as reported in the Levene test $(F=1.139$; Sig. $=.292)$. An independent samples t-test found no evidence of a difference between the means on the Attitudes Questionnaire at Time 3 for the control group $(n=25$, mean $=8.24, \mathrm{SD}=1.052)$ and for the experimental group $(n=21$, Mean $=8.57, \mathrm{SD}=.870)$. See box plot Figure 25 below. Since the $95 \% \mathrm{CI}$ contains zero $[-.912, .249]$, it can be concluded that there is no statistical difference between the groups. The narrow CI, less than 2 points on a test where the maximum score was 10 points, illustrates that the estimate of how different the groups are is uncertain, but not likely to be far from zero. The effect size for this comparison was calculated following Cohen's $d$ that resulted in a Cohen's $d=0.342$. According to Cohen's guidelines for effect sizes can be considered a small effect size. 


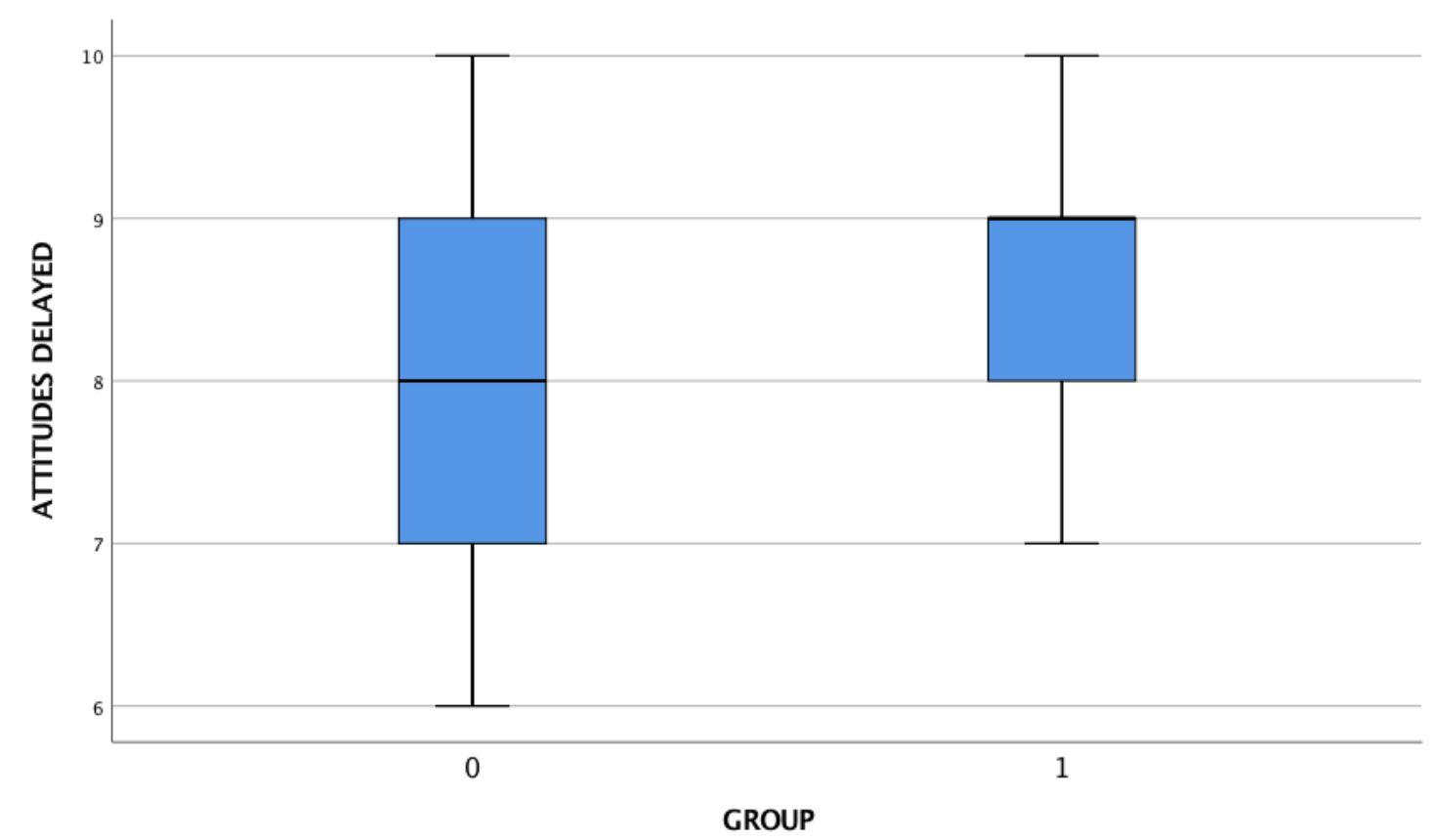

Figure 25. Box plot for Mean difference between control group and experimental group in Attitude Questionnaire at Time 3

Finally, the descriptive statistics for Mean comparison at T3 also revealed a small difference in performance between the experimental group and the control group. The independent samples t-test revealed that this difference was not statistically significant, with an effect size of Cohen's $d=0.342$. Even though the effect size was slightly larger than at T2, it was still small. Similarly to the findings obtained in the mean comparison at $\mathrm{T} 2$, the findings obtained in the independent samples t-test performed at $\mathrm{T} 3$ could be explained in terms of the focus on the VKS and the computer-delivered ODCT: conventional expressions. Since these two main tasks were pragmatic-focused, participants' attitudes were not explored.

All in all, results from the independent samples t-test revealed that there was no significant difference between these two groups at Time 1, which had a very small effect size $(d=0.01)$. Regarding the independent samples t-test that compared the Mean differences between groups at Time 2, different results were obtained. One the one hand, two outliers were found in the control group. On the other hand, and in line with 
results at Time 1, there was no statistically significant difference between these two groups in the posttest. This difference had a small effect size $(d=0.33)$. Finally, the independent samples t-test performed to observe Mean differences between control and experimental groups at Time 3 revealed a similar result compared to these tests at time 1 and Time 2 . There was a no statistically significant difference between the control and the experimental groups at this third and last data collection point, with a small effect size $(\mathrm{d}=0.342)$, which was a bit larger than at Time 2 , and larger than at Time 1 .

Finally, a paired samples t-test was performed to investigate whether there were statistically significant differences within each of the groups across times.

Once the differences between the experimental group and control group were analyzed and findings discussed, a series of paired samples t-tests were performed to investigate whether there were statistically significant differences between the Means within each of the groups across times. Results related to the performance of the experimental group performance are explained first and those obtained by the control group afterwards. 
Table 63 reports the paired samples t-test performed to compare Mean difference for the control group between Time $1(n=25, \mathrm{M}=8.44, \mathrm{SD}=1.083)$ and Time $2(n=$ $25, \mathrm{M}=8.28, \mathrm{SD}=1.173$ ) for the Attitudes Questionnaire. See descriptive statistics in Table 62 below. This test found no significant difference for the control group at these two times, since the $95 \%$ CI $[-.444, .764]$ ran through zero. The size of the interval shows that the actual mean could be as small as less than 1 point, or as large as nearly 0.5 points to zero. A Cohen's d effect size was performed for this comparison, and resulted in $d=0.109$, which means that the difference between the pretest and the posttest was small.

Table 62. Paired samples t-test descriptive statistics for Attitudes Questionnaire control group from Time 1 to Time 2

\begin{tabular}{cccccc}
\hline & N & Mean & SD & $\begin{array}{c}\text { SD Error } \\
\text { Mean }\end{array}$ \\
\hline $\begin{array}{c}\text { Control } \\
\text { [Group 0] }\end{array}$ & $\begin{array}{c}\text { Attitudes } \\
\text { Questionnaire Pretest } \\
{[\text { Time 1] }}\end{array}$ & 25 & 8.44 & 1.083 & .217 \\
& $\begin{array}{c}\text { Attitudes } \\
\text { Questionnaire } \\
\text { Posttest } \\
\text { [Time 2] }\end{array}$ & 25 & 8.28 & 1.173 & .235 \\
& & & & \\
& & & & \\
\hline
\end{tabular}

Table 63. Paired samples t-test for Attitudes Questionnaire control group from Time 1 to Time 2

\begin{tabular}{cccccccc}
\hline \multicolumn{7}{c}{ Paired Differences } \\
\hline Group & Mean & $S D$ & $\begin{array}{c}\text { SD } \\
\text { Error } \\
\text { mean }\end{array}$ & $95 \% C I$ & $t$ & $d f$ & Sig $p$ \\
Control & .160 & 1.463 & .293 & {$[-.444$,} & .547 & 24 & .590 \\
{$[$ Group 0] } & & & $.764]$ & & & \\
\hline
\end{tabular}


Table 65 illustrates the paired samples t-test performed to compare Mean difference for the control group between Time $2(n=25, \mathrm{M}=8.28, \mathrm{SD}=1.173)$ and Time $3(n=25, \mathrm{M}=8.24, \mathrm{SD}=1.052)$ for the Attitudes Questionnaire. See descriptive statistics in Table 64 below. This test found no significant difference for the control group at these two times, since the $95 \%$ CI $[-.286, .366]$ ran through zero. The size of the interval shows that the actual mean could be as small as a little over 0 points positive, or as large as little over 0 points negative. A Cohen's d effect size was performed for this comparison, and resulted in $\mathrm{d}=0.051$, which means that the difference between the pretest and the posttest was small.

Table 64. Paired samples t-test descriptive statistics for Attitudes Questionnaire control group from Time 2 to Time 3

\begin{tabular}{cccccc}
\hline & N & Mean & SD & $\begin{array}{c}\text { SD Error } \\
\text { Mean }\end{array}$ \\
\hline $\begin{array}{c}\text { Control } \\
\text { [Group 0] }\end{array}$ & $\begin{array}{c}\text { Attitudes } \\
\text { Questionnaire Posttest } \\
\text { [Time 2] }\end{array}$ & 25 & 8.28 & 1.173 & .235 \\
\cline { 2 - 5 } & $\begin{array}{c}\text { Attitudes } \\
\text { Questionnaire } \\
\text { Delayed Posttest } \\
\text { [Time 3] }\end{array}$ & 25 & 8.24 & 1.052 & .210 \\
& & & & \\
\hline
\end{tabular}

Table 65. Paired samples t-test for Attitudes Questionnaire control group from Time 2 to Time 3

\begin{tabular}{|c|c|c|c|c|c|c|c|}
\hline \multicolumn{7}{|c|}{ Paired Differences } & \multirow[b]{2}{*}{ Sig $p$. } \\
\hline Group & Mean & $S D$ & $\begin{array}{c}S D \\
\text { Error } \\
\text { mean }\end{array}$ & $95 \% C I$ & $t$ & $d f$ & \\
\hline $\begin{array}{c}\text { Control } \\
\text { [Group 0] }\end{array}$ & .040 & .790 & .158 & $\begin{array}{c}{[-.286,} \\
.366]\end{array}$ & .253 & 24 & .802 \\
\hline
\end{tabular}


Table 67 provides the paired samples t-test performed to compare Mean difference for the control group between Time $1(n=25, \mathrm{M}=8.44, \mathrm{SD}=1.083)$ and Time $3(n=25, \mathrm{M}=8.24, \mathrm{SD}=1.052)$ for the Attitudes Questionnaire. See descriptive statistics in Table 66 below. This test found no significant difference for the control group at these two times, since the $95 \%$ CI $[-.306, .706]$ ran through zero. The size of the interval shows that the actual mean could be as small as nearly 1 point, or as large as close to 0 points. A Cohen's d effect size was performed for this comparison, and resulted in $d=0.163$, which means that the difference between the pretest and the posttest was small (also small by Plonsky \& Oswald, 2014).

Table 66. Paired samples t-test descriptive statistics for Attitudes Questionnaire control group from Time 1 to Time 3

\begin{tabular}{cccccc}
\hline & N & Mean & SD & $\begin{array}{c}\text { SD Error } \\
\text { Mean }\end{array}$ \\
\hline $\begin{array}{c}\text { Control } \\
\text { [Group 0] }\end{array}$ & $\begin{array}{c}\text { Attitudes } \\
\text { Questionnaire Pretest } \\
{[\text { Time 1] }}\end{array}$ & 25 & 8.44 & 1.083 & .217 \\
\cline { 2 - 5 } & $\begin{array}{c}\text { Attitudes } \\
\text { Questionnaire } \\
\text { Delayed Posttest } \\
\text { [Time 3] }\end{array}$ & 25 & 8.24 & 1.052 & .210 \\
& & & & \\
\hline
\end{tabular}

Table 67. Paired samples t-test for Attitudes Questionnaire control group from Time 1 to Time 3

\begin{tabular}{|c|c|c|c|c|c|c|c|}
\hline \multicolumn{7}{|c|}{ Paired Differences } & \multirow[b]{2}{*}{ Sig $p$. } \\
\hline Group & Mean & $S D$ & $\begin{array}{c}S D \\
\text { Error } \\
\text { mean }\end{array}$ & $95 \% C I$ & $t$ & $d f$ & \\
\hline $\begin{array}{c}\text { Control } \\
\text { [Group 0] }\end{array}$ & .200 & 1.225 & .245 & $\begin{array}{c}{[-.306,} \\
.706]\end{array}$ & .816 & 24 & .422 \\
\hline
\end{tabular}


Results from the paired samples t-test show the possible existence of significant differences within a given group. As for the control group, the first paired samples t-test compared the Mean difference between Time 1 and Time 2 that there was no significant difference and the effect size was very small $(d=0.109)$. The paired samples performed t-test between Time 2 and Time 3 revealed another no significant difference between the Means at these two points in time, with an even smaller effect size $(d=0.051)$. Finally, the third and last paired samples t-test provided a further no significant difference between the Means from Time 1 to Time 3 with a small effect size $(d=$ 0.163) for the control group in the Attitudes Questionnaire. These results imply that even though scores increased overall, that decrease was not statistically significant across any of the three time points. These results may be explained by the fact that tasks focused on pragmatic performance instead of on participants' attitudes.

The paired samples t-tests performed on the Mean score performance by the experimental group are explained and discussed as follows. 
Table 69 illustrates the paired samples t-test performed to compare Mean difference for the experimental group between $\mathrm{T} 1(n=21, \mathrm{M}=8.43, \mathrm{SD}=.870)$ and $\mathrm{T} 2$ ( $n=21, \mathrm{M}=8.62, \mathrm{SD}=.865)$ for the Attitudes Questionnaire. See descriptive statistics in Table 68 below. This test found no significant difference for the experimental group at these two times, since the $95 \%$ CI $[-.464, .083]$ ran through zero. The size of the interval shows that the actual mean could be as small as nearly 1 point, or as large as nearly 0.5 points to zero. A Cohen's d effect size was performed for this comparison, and resulted in $\mathrm{d}=0.316$, which means that the difference between the pretest and the posttest was small. This means that the effect of instruction was less effective.

Table 68. Paired samples t-test descriptive statistics for Attitudes Questionnaire experimental group from Time 1 to Time 2

\begin{tabular}{cccccc}
\hline & $\mathrm{N}$ & Mean & SD & $\begin{array}{c}\text { SD Error } \\
\text { Mean }\end{array}$ \\
\hline $\begin{array}{c}\text { Experimental } \\
\text { [Group 1] }\end{array}$ & $\begin{array}{c}\text { Attitudes } \\
\text { Questionnaire } \\
\text { Pretest } \\
\text { [Time 1] }\end{array}$ & 21 & 8.43 & .870 & .190 \\
\cline { 2 - 5 } & $\begin{array}{c}\text { Attitudes } \\
\text { Questionnaire } \\
\text { Posttest } \\
\text { [Time 2] }\end{array}$ & 21 & 8.62 & .865 & .189 \\
\hline
\end{tabular}

Table 69. Paired samples t-test for Attitudes Questionnaire experimental group from Time 1 to Time 2

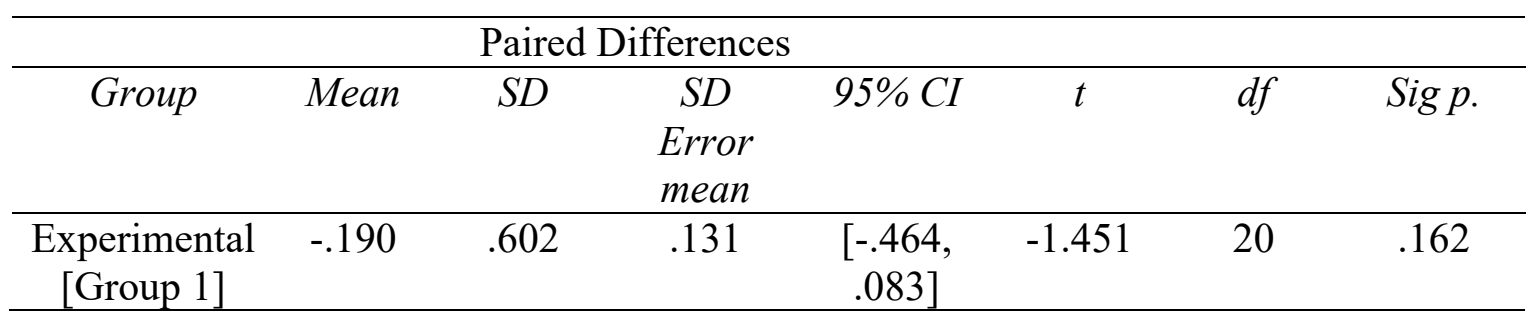


Table 71 provides the paired samples t-test performed to compare Mean difference for the experimental group between $\mathrm{T} 2(n=21, \mathrm{M}=8.62, \mathrm{SD}=.865)$ and $\mathrm{T} 3$ $(n=21, \mathrm{M}=8.57, \mathrm{SD}=.870)$ for the Attitudes Questionnaire. See descriptive statistics in Table 70 below. This test found no significant difference for the experimental group at these two times, since the $95 \%$ CI $[-.179, .274]$ ran through zero. The size of the interval shows that the actual mean could be as small as a little over 0 points, or as large as less than 0 points. A Cohen's d effect size was performed for this comparison, and resulted in $\mathrm{d}=0.096$, which means that the difference between the pretest and the posttest was very small. This means that the effect of instruction was less effective. Table 70. Paired samples t-test descriptive statistics for Attitudes Questionnaire experimental group from Time 2 to Time 3

\begin{tabular}{cccccc}
\hline & N & Mean & SD & $\begin{array}{c}\text { SD Error } \\
\text { Mean }\end{array}$ \\
\hline $\begin{array}{c}\text { Experimental } \\
\text { [Group 1] }\end{array}$ & $\begin{array}{c}\text { Attitudes } \\
\text { Questionnaire Posttest } \\
\text { [Time 2] }\end{array}$ & 21 & 8.62 & .865 & .189 \\
\cline { 2 - 5 } & $\begin{array}{c}\text { Attitudes } \\
\text { Questionnaire Delayed } \\
\text { Posttest } \\
\text { [Time 3] }\end{array}$ & 21 & 8.57 & .870 & .190 \\
& & & & \\
\hline
\end{tabular}

Table 71. Paired samples t-test for Attitudes Questionnaire experimental group from Time 2 to Time 3

\begin{tabular}{|c|c|c|c|c|c|c|c|}
\hline \multicolumn{8}{|c|}{ Paired Differences } \\
\hline Group & Mean & $S D$ & $\begin{array}{c}S D \\
\text { Error } \\
\text { mean }\end{array}$ & $95 \% C I$ & $t$ & $d f$ & Sig $p$. \\
\hline $\begin{array}{c}\text { Experimental } \\
\text { [Group 1] }\end{array}$ & .048 & .498 & .109 & $\begin{array}{c}{[-.179,} \\
.274]\end{array}$ & .439 & 20 & .666 \\
\hline
\end{tabular}


Table 73 shows the paired samples t-test performed to compare Mean difference for the experimental group between $\mathrm{T} 1(n=21, \mathrm{M}=8.43, \mathrm{SD}=.870)$ and $\mathrm{T} 3(n=21$, $\mathrm{M}=8.57, \mathrm{SD}=.870)$ for the Attitudes Questionnaire. See descriptive statistics in Table 72 below. This test found no significant difference for the experimental group at these two times, since the $95 \%$ CI $[-.504, .218]$ ran through zero. The size of the interval shows that the actual mean could be as small as a little over 0 points, or as large as a little over 0.5 points. A Cohen's d effect size was performed for this comparison, and resulted in $\mathrm{d}=0.18$, which means that the difference between the pretest and the posttest was very small, considering that the Cohen's d small effect size is around 0.2 . This means that the effect of instruction was less effective.

Table 72. Paired samples t-test descriptive statistics for Attitudes Questionnaire experimental group from Time 1 to Time 3

\begin{tabular}{cccccc}
\hline & N & Mean & SD & $\begin{array}{c}\text { SD Error } \\
\text { Mean }\end{array}$ \\
\hline $\begin{array}{c}\text { Experimental } \\
\text { [Group 1] }\end{array}$ & $\begin{array}{c}\text { Attitudes } \\
\text { Questionnaire Pretest } \\
{[\text { Time 1] }}\end{array}$ & 21 & 8.43 & .870 & .190 \\
\cline { 2 - 5 } & $\begin{array}{c}\text { Attitudes } \\
\text { Questionnaire Delayed } \\
\text { Posttest } \\
\text { [Time 3] }\end{array}$ & 21 & 8.57 & .870 & .190 \\
& & & & \\
\hline
\end{tabular}

Table 73. Paired samples t-test for Attitudes Questionnaire experimental group from Time 1 to Time 3

\begin{tabular}{cccccccc}
\hline \multicolumn{7}{c}{ Paired Differences } \\
\hline Group & Mean & SD & $\begin{array}{c}S D \\
\text { Error } \\
\text { mean }\end{array}$ & $95 \% C I$ & $t$ & $d f$ & Sig $p$ \\
Experimental & -.143 & .793 & .173 & $\begin{array}{c}{[-.504,} \\
.218]\end{array}$ & -.826 & 20 & .419 \\
[Group 1] & & & & & \\
\hline
\end{tabular}


The results obtained from the paired samples t-test help identify whether those increases in scores are significant or not. For the experimental group, the first paired samples t-test, which compared the Mean difference between Time 1 and Time 2, was not statistically significant and with a small effect size $(d=0.316)$, a bit larger than the effect size in the control group at this same time. The paired samples t-test between Time 2 and Time 3 revealed another no significant difference between the Means between these two points in time, with an even smaller effect size $(d=0.096)$. This noticeable change may not be fully explained, since there is no qualitative data that can help account for this drop in effect size. Finally, the last paired samples t-test confirmed a significant difference between the Means from Time 1 to Time 3 with a larger effect size $(d=0.18)$ than at Time 2 but smaller than at Time 1 for the experimental group in the Attitudes Questionnaire. These results illustrate that scores increased from Time 1 to Time 2, but decreased from Time 2 to Time 3. Even though none of the differences were significant, they were still a little bit higher than those by the control group.

Statistical analysis of data from the Attitudes Questionnaire allowed rejecting H5. Two reasons may help account for such results. On one hand, the two tasks were pragmatic-focused. That is, they were related to the pragmalinguistic and sociopragmatic aspects of language use. Both in the VKS and the computer-delivered ODCT, the focus was on producing the appropriate conventional expression depending on the social context provided. Therefore, the focus was on the pragmalinguistic features students needed to learn, together with the sociopragmatic norms they had to understand to perform pragmatically appropriate. Therefore, participants' attitudes are less affected. In other words, students relied on their pragmatic knowledge and not on their attitudes towards English to fulfill both pragmatic recognition and pragmatic production tasks. 
On the other hand, the research method employed may have negatively influenced on the results. The Attitudes Questionnaire is precisely that, a questionnaire, and one of the main disadvantages of using questionnaires is the fact that they provide numerical data. There were no open-ended questions where students could provide their thoughts and beliefs, their attitudes towards English. Although the numbers obtained from the questionnaire are informative, they may not help us that much into explaining whether a given difference is really significant or not. For example, if a given student scores a total of 6 points, that does not really mean that they have a less favorable attitudes towards English, due to the fact that each of the ten items in the questionnaire referred to different aspects of language attitudes.

All in all, even though the differences were not significant, we need to remember that Means were overall high for both the experimental and the control group, which implies that their attitudes were rather favorable across times. The present study did contribute to the existing literature, not with the expected results, but actually with the obtained results. In other words, even though it was expected to obtain results that resembled those already existing in studies that were carried out in the same context as this dissertation, the results obtained from this group of students reveal that the opposite can take place as well, that attitudes may not affect language performance. Either way, results from this dissertation should be understood as reflection for further investigations, where the same context can be approached differently, namely EFL instead of multilingual setting. 
Chapter 7: Results and Discussion

\subsection{Chapter Summary}

Table 74 includes a summary of the hypotheses formulated in this study, the data collection methods, data collection time points, data analysis, and finally the hypothesis confirmation. 


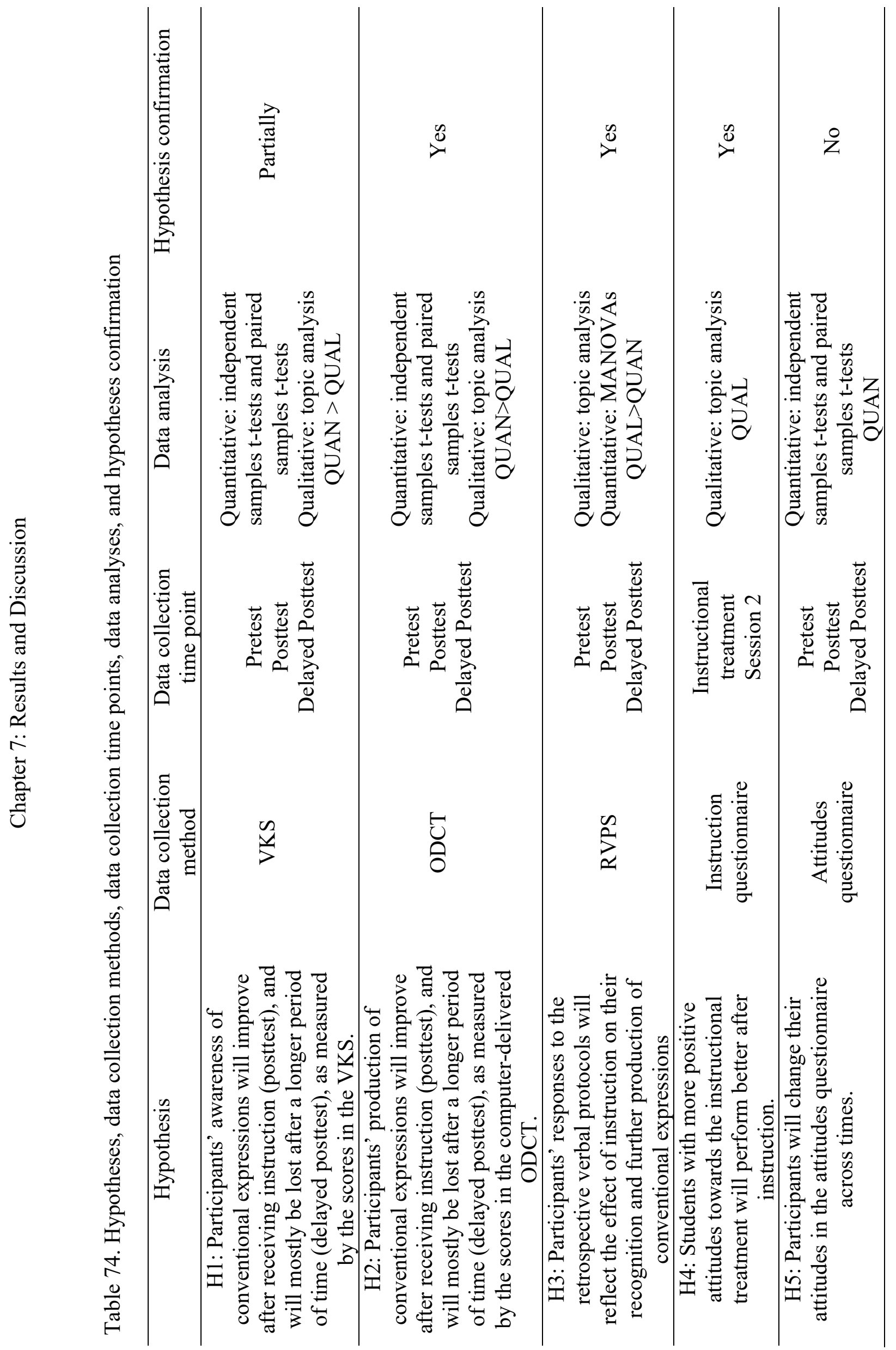




\section{Chapter 8: Conclusions}

In this final chapter, the summary of the main findings and contributions of this investigation are discussed in Section 8.1. The limitations of the study and directions for further research are presented in Section 8.2. Finally, and drawing on the results and limitations, some pedagogical implications are proposed in Section 8.3.

\subsection{Originality of The Study and Summary of Main Findings}

In this first section, the main findings obtained from the five hypotheses proposed are summarized and their contributions to the literature discussed afterwards. Nevertheless, and for the purpose of facilitating the reader remembering, the main goals of the study are stated. These were: (1) to explore the development of the recognition and production of conventional expressions; (2) to investigate the effect of instruction; and (3) to observe participants' language attitudes from pretest to delayed posttest.

RQ1 explored the effect of instruction in production and recognition of conventional expressions, as well as its effectiveness in the use of RVPs, as summarized above. The originality of this study implies a series of contributions regarding this first RQ. First of all, this study shed light into the existing literature that explored the recognition together with the production of conventional expressions in one same study, since there is scant research on the combination of these two skills in pone same piece of research. Second, this study contributed to the even more scant attention that the exploration of this pragmatic feature has received in EFL settings, with only a few studies conforming the body of existing literature on this matter. The greater bulk of research studies on this pragmatic feature can be found in ESL and SA contexts. See Chapter 4. The third contribution relates to the inclusion of an explicit instructional treatment to the two conditions above-mentioned. This treatment was designed based on research findings claiming for the combination of instruction, metapragmatic 
discussion, and practice to provide larger effects on pragmatic performance. Hence, in this study, the explicit treatment included audiovisual materials, which accompanied the metapragmatic instruction. Afterwards, students were provided with opportunities to practice both their (a) recognition skills with AJT, metapragamtic discussion, and feedback; and (b) production skills with role-play and feedback. The originality in this treatment was also the use of real-life and research-based situations, as well as audiovisual materials (i.e., pictures and videos) retrieved from the researcher's personal archives or from real-life contexts from which the researcher asked a colleague to take pictures. Additionally, a control group was included to ensure that if there are pragmatic gains, they could be attributed to a possible effect of the explicit intervention (Taguchi, 2015b). However, in this study, a task repetition effect was found in the control group recognition and production skills. Hence, the pragmatic improvement of the experimental group cannot be attributed solely to the role of instruction.

In regards to $\mathrm{H} 1$, results from the quantitative analysis of the participants' responses to the VKS confirmed the expected outcomes: the effect of instruction was present in the posttest, but did not last through the delayed posttest. More specifically, the control group increased their performance across time, with lower scores than the experimental group. There were no significant differences from Time 1 to Time 2, and from Time 2 to Time 3, even though evidence showed a statistically significant Mean difference from Time 1 to Time 3. The experimental group increased their task performance from T1 to T3, with higher scores than the control group. Statistically significant differences were found from Time 1 to Time 2 and from T1 to T3. Results from the independent samples t-test revealed the appearance of a few outliers in each of the groups at different times. No statistical significant difference was found between groups at Time 1 with medium effect size $(d=0.57)$. However, statistically significant 
differences were identified between groups at Time 2 and Time 3, with large effect sizes (i.e., $\mathrm{d}=1.436$ (Time 2), $\mathrm{d}=1.419$ (Time 3 )). These data were supported by students' reports on the use of AJTs and metapragmatic discussion to foster and enhance their pragmatic knowledge. However, evidence of task repetition effect was found in the control group's performance because participants in this group already scored quite high in the pretest, scores that were higher and then lower through the delayed posttest but still higher than at the pretest. Therefore, it could be assumed that the experimental group could have also experienced this effect. Participants in this group also scored rather high in the pretest. However, the statistically significant differences at posttest and delayed posttest together with participants' comments in the open-ended questions for the AJT could also explain their pragmatic gain in terms of instructional effects. Hence, $\mathrm{H} 1$ can only be partially confirmed because even though the evidence obtained is in line with previous research, the appearance of task repetition effect may not allow attributing task improvement solely to the role of instruction.

As for $\mathrm{H} 2$, results from the quantitative analysis of the participants' responses to the computer-delivered ODCT confirmed the expected outcomes. The effect of instruction was present in the posttest, but did not last through the delayed posttest. More specifically, the control group increased their performance across times. Moreover, no significant differences across times, with small effect sizes across times. The experimental group increased their performance from Time 1 to Time 2 that slightly decreased at Time 3. Nevertheless scores were higher than the control group's. Interestingly, there was evidence of statistically significant differences from Time 1 to Time $2(\mathrm{~d}=1.875)$ and from Time 1 to Time $3(\mathrm{~d}=1.577)$, but no significant difference from Time 2 to Time $3(\mathrm{~d}=0.311)$. Results from the independent samples t-tests revealed the existence of two outliers in the control group at Time 3, the absence of 
statistical significant difference at Time 1 , with medium effect size $(d=0.59)$, and the existence of statistically significant differences between groups at Time $2(\mathrm{~d}=3.17)$, and Time $3(\mathrm{~d}=2.287)$ with very large effect sizes at each of these two data collection points. These data were supported by students' reports on the use of role-plays and feedback to foster and enhance their pragmatic knowledge and production of conventional expressions. These qualitative findings, the significant differences within and between groups across times, and very large effect sizes support the effect of instruction in the students' performance in the pragmatic production task. Reflecting on this triangulation of data, it seems safe to state that this particular instructional treatment was effective due to several reasons, which explain the quantitative and qualitative findings: (1) including pictures both in this task as well as in the PPT presentation at session 1, (2) emphasizing the importance of appropriate use of conventional expressions to achieve successful communicative events, and providing participants with opportunities (3) to practice them orally with the role plays, and (4) to express their own opinion about this specific pedagogical intervention. Hence, these findings allow confirming $\mathrm{H} 2$.

Regarding H3, results from the qualitative analysis of the participants' responses to the RVPs confirmed the expected outcomes. The effect of instruction was present in most of the participants' use of specific RVPs in order to explain their choice of pragmalinguistic resources to respond to the situations included in the computerdelivered ODCT. These data were supported by the transformation of these qualitative data into quantitative ones and their further analysis by means of MANOVAs. Results from these analyses highlighted the significant differences within and between topics, with the use of IIR reasons in the posttest and delayed posttest in detriment of LR, POL, and SitD more specifically. The combination of the results from both qualitative and 
quantitative explorations made a strong case on the effect of instruction on participants' use of RVPs. Particularly, this was achieved by the wide use of IIR reasons that participants provided to explain their pragmalinguistic choices to match specific sociopragmatic conditions to be pragmatically competent, which they were taught during the first instructional session and further reinforced and practiced during the second instructional session. Hence, results from data analyses and data triangulation allowed and supported the confirmation of H3.

To sum up, research has shown that learners find it easier to recognize conventional expressions (e.g., Bardovi-Harlig, 2008, 2009, 2010, 2011, 2014; BardoviHarlig \& Bastos, 2011; Bardovi-Harlig \& Vellenga, 2012) rather than producing them (e.g., Bardovi-Harlig, 2008, 2009; Bardovi-Harlig \& Bastos, 2011; Bardovi-Harlig et al., 2010; Bardovi-Harlig et al., 2008; Bardovi-Harlig \& Vellenga, 2012; BardoviHarlig et al., 2015a; Martínez-Flor \& Usó-Juan, 2015; Rafieyan, Sharafi-Nejad, \& Eng, 2014a, 2014b; Taguchi et al., 2017; and Usó-Juan \& Martínez-Flor, 2015). Besides, evidence shows that instruction is essential in order to foster learners' pragmatic competence (e.g., Alcón-Soler, 2005; Alcón-Soler \& Martínez-Flor, 2008; BardoviHarlig \& Mahan-Taylor, 2003; Taguchi, 2015b; Taguchi \& Roever, 2017).

RQ2 explored participants' attitudes in relation to the effect of instruction and in and of themselves from Time 1 to Time 3, as seen above in $\mathrm{H} 4$ and $\mathrm{H} 5$ respectively. The originality of this study implies a series of contributions regarding this first RQ. First of all, the connection between participants' attitudes in relation to attitudes as observed in the Post instruction Questionnaire. To the best of my knowledge, no study to date distributed a questionnaire such as the one designed for this dissertation, which compiled not only quantitative but also qualitative data from a series of aspects that characterized the pedagogical intervention in this study. Second of all, and most 
importantly, the present dissertation was the first study to date that explored instruction as well as language attitudes under one same investigation, and most importantly, in regards to conventional expressions. Therefore, the contribution to the existing literature is three-fold: on the literature on (1) conventional expressions, (2) instruction and the effect of explicit interventions as summarized above, and (3) language attitudes. Third, the unexpected research findings in H5 provide shed light into the development of language attitudes and pragmatic development.

In regards to $\mathrm{H} 4$, results from the qualitative analysis of participants' responses to a particular section of the Post-instruction Questionnaire (i.e., issues that students liked best and least about the instructional treatment) confirmed the expected outcomes: students with more positive attitudes towards the instructional treatment would perform better after instruction. The performance of exhaustive topic analysis of students' comments provides some evidence concerning participants' performance in both of the pragmatic tasks. This could help explain the higher score performance of participants in the experimental group (both in recognition and in production tasks) to the lower score performance of participants in the control group could be originated. This, in turn, support the positive effect that this particular instruction had on the experimental group. Hence, the evidence obtained from the qualitative exploration of these particular data allows confirming H4.

Finally, results from the quantitative analysis of students' scores in the Attitudes Questionnaire did not confirm the expected outcomes in H5. Contrary to previous research on language attitudes, students' attitudes did not change across times. Their scores in the Attitudes Questionnaire did not differ significantly either between groups or within each of the groups. This outcome could be explained in terms of the tasks as well as the Attitudes Questionnaire itself. First, both the recognition and the production 
tasks pragmatics focused. Attitudes seem to have been less affected because these two tasks focused on students' pragmalinguistic resources to meet specific sociopragmatic contextual factors. Second, attitudes were numerically measured in the Attitudes Questionnaire. Had there been open-ended questions or other type of items that allowed students to express their attitudes in a more qualitative fashion, this may have triggered different outcomes. Hence, the evidence obtained from the quantitative exploration of data from the Attitudes Questionnaire allows rejecting H5.

In the present dissertation, a multi-method ${ }^{53}$ approach was followed. Results from quantitative data were triangulated with results from qualitative data gathered from the RVPs as well as the open-ended questions from the Post instruction Questionnaire in order to better understand participants' pragmalinguistic choices more specifically, as well as to gain deeper knowledge into their pragmatic development from pretest to delayed posttest in terms of recognition skills (open-ended questions from AJT) as well as production skills (open-ended questions from role-plays). These results put forth the importance of data triangulation to ensure, reject, and/or provide further insights into the data analysis and comprehension of the results obtained.

\subsection{Limitations of The Study and Directions for Further Research}

The first limitation was that all instruments were piloted just once, at a pretest, with a group of EFL students with similar characteristics as the ones that conformed the sample in this dissertation. Additionally, the VKS and computer-delivered ODCT \& RVP were also piloted with two American NSs. Due to limited access to students and time constraints, only the ODCT \& RVP were piloted at a posttest. Acknowledging that this situation is not ideal, and that even though the rest of the instruments could not be

\footnotetext{
${ }^{53}$ Please refer to Brown (2014) and Ross and Hong (2019) for an explanation of the differences between 'mixed-method' and 'multi-method' approaches and an updated review of the research conducted in L2 pragmatics using mixed-method approaches.
} 
piloted at a posttest and neither of them at a delayed posttest, the detailed and sometimes extensive feedback obtained from both the NSs and the NNSs was used to improve these instruments. These comments helped make these instruments robust enough to collect data for this dissertation.

The second limitation dealt with the format in which most of the instruments were finally distributed to the participants. As illustrated and discussed in the literature review section, the majority of the studies exploring recognition and production of conventional expressions administered computerized versions of recognition and production tasks. In the present investigation, this was one of the original goals. However, since the language media laboratory in the Humanities and Social Sciences hall proved to be inefficient and unreliable, the researcher could not risk losing data, mainly due to my limited access to the participants. Therefore, and to ensure complete data collection, the pragmatic recognition task (i.e., VKS) and the other tests (i.e., OPT and Attitudes Questionnaire) were administered in paper-and-pencil format. This decision implied one main disadvantage: doing paper-and-pencil tasks seems more cognitive demanding and tiresome for the participants. This may not be a limitation per se, but it may have affected students' performance. If technology had been used to create and take these tasks, it may have been less time-consuming and cognitive demanding for the students in the test-taking process. Both the recognition task and the Attitudes Questionnaire were paper and pencil based, which required participants to be more focused in comparison to reading and clicking on a button on a computer screen. Thus, this may have affected their pragmatic performance. Some of the students commented on the fact that the recognition task was very long and that the researcher identified a few students struggling to keep focused while doing this task. 
The third drawback found to carry out this $\mathrm{PhD}$ dissertation implied limited access to students. A total of 48 students participated. However, only 46 formed the final simple since two participants had to be left out. One was a native speaker of American English, and the other participant looked for the answers to some of the items on the tests on the Internet. The main limitation that derives from having a small pool of participants implies the difficulty of generalizing the results obtained in this dissertation to a larger population of EFL students. In this sample, only a few outliers were identified, which could have been less having had a larger sample. These two limitations could be addressed recruiting more students. Therefore, further research would entail conducting this study with a larger cohort in order to ensure the generalizability of the results obtained in the present investigation.

The fourth limitation deals with data analysis. Data for the pragmatic recognition task (i.e., VKS), the pragmatic production task (i.e., computer-delivered ODCT \& RVP), and the Attitudes Questionnaire for both between group and within-group differences were analyzed considering each group as a whole. Further research would entail the division of the data of each group in more detail. For example, scores of each group for both of the pragmatics tasks could be divided into low, medium, and high performance. Therefore, this would provide a more detailed understanding of pragmatic development within each of the groups, and would provide richer results for the between group analysis. Regarding data from the Attitudes Questionnaire, data from the ten items selected (see Chapter 6) were also computed globally. A detailed account of attitude development for both groups could shed light into the results obtained in this study. Had there been open-ended questions or other qualitative measures within this questionnaire could help understand participants' attitudes. Further research could entail the analysis of results per each of the ten items explored to (1) identify and track 
possible item development over time, as well as (2) compare these more specific results to the recognition and production of conventional expressions to investigate the possible effects of specific attitudes towards pragmatic behavior. Furthermore, future analysis could investigate the effect of attitudes on pragmatic development. The effect of attitudes towards recognition and towards production of conventional expressions could be explored. Regarding data obtained from the RVPs, future analysis could examine RVPs produced by control group and experimental group by means of case studies. In so doing, changes per topics across times could be traced more precisely.

The fifth limitation relates to the variables included in the data analysis. In this study, only two variables were taken into consideration regarding pragmatic development: time of task (i.e., pretest, posttest, and delayed posttest) and group (i.e., control and experimental). Even though the analysis of the results yielded some interesting findings, the inclusion of other variables (provided a larger group of participants) could also help understand the pragmatic performance of this group of students. For example, other studies that examined conventional expressions reported on the effects that proficiency level exerts over the recognition and production of conventional expressions (e.g., Bardovi-Harlig, 2010, 2011, 2014; Bardovi-Harlig et al., 2008; Bardovi-Harlig \& Vellenga, 2012). Further exploration of the data gathered in the present dissertation could observe the possible correlation between pragmatic performance (both in recognition and production tasks) and proficiency level. Another variable that, to the best of my knowledge, has received scant attention in the literature on conventional expressions is gender. Future directions could also include the observation whether female or male participants diverge in their recognition and production of conventional expressions. 
The sixth and final limitation deals with administering the delayed posttest only 11 days after the posttest. Due to time constraints and limited access to students explained above, the delayed posttest needed to be administered in those specific days and times (See research design in Chapter 6). Had this final data collection time point been administered later on in the semester, different results could have yielded different findings, especially those related to the effects of instruction. In order to address this limitation, further research could entail the administration of the delayed posttest months after.

\subsection{Pedagogical Implications}

The evidence obtained from the quantitative and qualitative analysis of the data gathered at the pretest, posttest, and delayed posttest, as well as the data gathered from the Post instruction Questionnaire call for the creation and improvement of existing data collection methods to test in the classroom setting.

First, teaching conventional expressions at any proficiency level should be given more prominence in language and content courses. Designing activities that foster recognition and pragmatic skills is at stake, specially since research has shown the inappropriate representation of pragmatic features and issues in textbooks and the need to include culture (e.g., Ishihara \& Cohen, 2010), and real-life situations in pragmatics teaching and research and materials for pragmatics teaching (e.g., Bardovi-Harlig, 2017; Bardovi-Harlig \& Mahan-Taylor, 2003; Houck \& Tatsuki, 2011; Tatsuki, 2019; Tatsuki \& Houck, 2010). Research reported in this dissertation supports and encourages the teaching of pragmatics in general, and of conventional expressions more specifically, not only to intermediate and advanced, but also to more novice learners. Since the effect of the pedagogical treatment did not last through the delayed posttest, some actions could be taken, such as (1) reinforcing metapragmatic awareness by means of more 
detailed explanations fostering metapragmatic discussion could; and (2) providing students with more varied oral tasks to promote pragmatic learning.

Second, the need to include more audiovisual components in instructional treatments and data collection methods is essential. As done in this dissertation, if activities are distributed in a paper-and-pencil manner, pictures should be included to enhance understanding of the pragmatic situation and its contextual factors as well as foster pragmatic learning ${ }^{54}$. The Post-instruction Questionnaire, which contained a section devoted to participants' opinions on the use of audiovisual materials in the teaching intervention, showed that students welcomed these audiovisual materials very enthusiastically and happily. The majority of the comments moved along the lines of the accurate representation of the situations. For example, P25 said that "[t]hey represent the situations in a real clear image [sic]"; the fact that they were an important aid in their understanding of the conventional expressions. For example, P46 reported that "[b]ecause by looking at the pictures you can understand the situation even though you don't get the written explanation [sic]." Therefore, the use of audiovisual cues in the design and implementation of pragmatic tasks is of utterly importance.

Third, raising pragmatic awareness is essential to enhance and foster students' pragmatic knowledge of particular pragmatic realizations and of their pragmatic competence in general. For example, this can be achieved from different perspectives, such as assigning students the role of ethnographers (e.g., Dantas-Whitney, 2011), or by focusing on semantic formulas more specifically (e.g., Taguchi, 2011b) to comprehend communicative actions and master them.

\footnotetext{
${ }^{54}$ This statement originated from the results that the main researcher obtained in her MA thesis, which corroborated that pictures and drawings fostered and hastened children's recognition and production of pragmatic routines.
} 
Fourth, since these tasks were designed and developed having in mind the application of the knowledge gained in this study to future real-life situations, these tasks involved social communicative situations that are encountered very frequently in daily interactions. Therefore, the tasks together with the instructional treatment were designed with that future application to real-life situation in mind. Even though results show that students' knowledge did not last through the delayed posttest, they did report in the interview after the computer-delivered ODCT that they did enjoy doing these tasks and that they helped them remember at least some of the expressions. According to Taguchi and Roever (2017, p. 240): “[u]nderstanding how pragmatics testing relates to real-world performance and how this relationship can be strengthened should be at the heart of future research on testing L2 pragmatics."

Finally, I would like to conclude this section by providing some reflections on what future research could look like in order to address all the aspects mentioned above and the fourth one in particular. According to Taguchi (2015b, p. 42) in her seminal paper on instruction and pragmatics, and supported more recently by Tang (2019), Taguchi claimed that "[t]he studies that have used technology platforms for instruction have shown a promising approach to connecting learning with authentic language use (Wishnoff, 2000; Belz \& Vyatkina, 2005; Kakegawa, 2009; Sykes 2009, 2013; Sardegna \& Molle, 2010; Cunningham \& Vyatkina, 2012).” Additionally, she stated that "[s]ome of the key instructional features endorsed in the multiuser virtual world input, interaction, simulation, and multimedia environment - are indeed key conditions for learning pragmatics that are concerned with language use for achieving social functions." Therefore, future studies on conventional expressions could adopt a technology-enhanced or technology-mediated design in order to foster pragmatic learning and development more meaningfully. 
All in all, the recommendation would be to include some pragmatic instruction in the EFL classroom because its benefits promote pragmatic learning. Even though we, instructors and researchers, may not know what specific type of task or instructional treatment is more effective, it is certainly acknowledged and accepted that pragmatics instruction helps and that, regardless the length of the intervention, it is still more effective than just simple exposure or none at all. Pragmatics instruction will help students to at least be aware of the fact that being accurate does not only imply grammatically but also pragmatically; in other words, being aware of the appropriate use of language in context. Students may benefit from this knowledge in the future because, even if they forget grammatical structures, their communicative interactions will be appropriate and they will be polite. 


\section{REFERENCES}

Aijmer, K. (1996). Conversational routines in English. London: Longman.

Ajzen, I. (1988). Attitudes, personality and behaviour. Milton Keynes: Open University Press.

Ajzen, I., \& Fishbein, M. (1980). Understanding attitudes and predicting social behaviour. Englewood Cliffs, NJ: Prentice-Hall.

Alali, F. A., \& Schmitt, N. (2012). Teaching formulaic sequences: The same or different from teaching single words? TESOL Journal, 3(2), 153-180.

Alcaraz, E. (1990). Tres paradigmas de investigación científica. Alcoy: Marfil.

Alcón-Soler, E. (2000). Desarrollo de la competencia discursiva oral en el aula de lenguas extranjeras: Perspectivas metodológicas y de la investigación. In C. Muñoz (Ed.), Segundas lenguas: Adquisición en el aula (pp. 259-276). Barcelona: Ariel Lingüística.

Alcón-Soler, E. (2005). Does instruction work for learning pragmatics in the EFL context? System, 33(3), 417-435.

Alcón-Soler, E. (2007). Fostering EFL learners' awareness of requesting through explicit and implicit consciousness-raising tasks. In M. P. García-Mayo (Ed.), Investigating tasks in informal language learning (pp. 221-241). Clevedon: Multilingual Matters.

Alcón-Soler, E. (2008). Investigating pragmatic language learning in foreign language classrooms. International Review of Applied Linguistics, 46(3), 173-195.

Alcón-Soler, E. (2012). Teachability and bilingualism effects on third language learning pragmatic knowledge. Intercultural Pragmatics, 9(4), 511-541.

Alcón-Soler, E. (2013). Discourse and Pragmatics in SLA. In P. Robinson (Ed.), The Routledge encyclopedia of second language acquisition (pp. 178-186). New York, NY: Routledge.

Alcón-Soler, E. (2015a). Pragmatic learning and study abroad: Effects of interaction and length of stay. System, 48, 62-74.

Alcón-Soler, E. (2015b). Instruction and pragmatic change during study abroad email communication. Innovation in Language Learning and Teaching, 9(1), 34-54.

Alcón-Soler, E., \& Guzmán-Pitarch, R. (2010). The effect of instruction on learners' pragmatic awareness: A focus on refusals. International Journal of English Studies, 10(1), 65-80.

Alcón-Soler, E., \& Martínez-Flor, A. (2005). Special Issue: Pragmatics in instructed language learning. System, 33(3), 381-546.

Alcón-Soler, E., \& Martínez-Flor, A. (2008). Investigating pragmatics in foreign language learning, teaching and testing. Bristol, Buffalo, Toronto: Multilingual Matters.

Alcón-Soler, E., \& Safont, M. P. (2008). Pragmatic awareness in second language acquisition. In J. Cenoz, \& H. Hornberger (Eds.), Encyclopedia of language and education (Vol. 6, pp. 193-204). Berlin: Springer.

Alcón-Soler, E., \& Sánchez-Hernández, A. (2017). Learning pragmatic routines during study abroad: A focus on proficiency and type of routines. ATLANTIS. Journal of the Spanish Association of Anglo-American Studies, 39(2), 191-210.

AlHassan, L., \& Wood, D. (2015). The effectiveness of focused instruction of formulaic sequences in augmenting L2 learners' academic writing skills: A quantitative research study. Journal of English for Academic Purposes, 17, 51-62.

Allport, G. W. (1935). Attitudes. In C. Murchison (Ed.), A handbook of social psychology (pp. 798-844). Worcester, MA: Clark University Press.

Anderson, J. R. (1976). Language, memory, and thought. Hillsdale, NJ: Erlbaum.

Anderson, J. R. (1982). Acquisition of cognitive skills. Psychological Review, 89(4), 369406. 
Anderson, J. R. (1993). Rules of the mind. Hillsdale, NJ: Erlbaum.

Anderson, J. R., Bothell, D., Byrne, M. D., Douglass, S., Lebiere, C., \& Qin, Y. (2004). An integrated theory of mind. Psychological Review, 111, 1036-1060.

Archer, D., \& Grundy, P. (2011). The pragmatics reader. New York, NY: Routledge.

Bachman, L. F. (1990). Fundamental considerations in language testing. Oxford, UK: Oxford University Press.

Bachman, L. F., \& Palmer, A. S. (1996). Language assessment in practice: Designing and developing useful language tests. Oxford, UK: Oxford University Press.

Bachman, L. F., \& Palmer, A. S. (2010). Language assessment in practice. Oxford, UK: Oxford University Press.

Badjadi, N. E. I. (2016). A meta-analysis of the effects of instructional tasks on L2 pragmatics comprehension and production. In S. F. Tang, \& L. Logonnathan (Eds.), Assessment for learning within and beyond the classroom (pp. 241-268). Singapore: Springer.

Baker, C. (1988). Key issues in bilingualism and bilingual education. Clevedon: Multilingual Matters.

Baker, C. (1992). Attitudes and language. Bristol, PA: Multilingual Matters.

Bardovi-Harlig, K. (1999). Exploring the interlanguage of interlanguage pragmatics: A research agenda for acquisitional pragmatics. Language Learning, 49(4), 677-713.

Bardovi-Harlig, K. (2001). Evaluating the empirical evidence: Grounds for instruction in pragmatics? In K. R. Rose, \& G. Kasper (Eds.), Pragmatics in language teaching (pp. 13-32). Cambridge, UK: Cambridge University Press.

Bardovi-Harlig, K. (2006a). Interlanguage development: Main routes and individual paths. AILA Review, 19, 69-82.

Bardovi-Harlig, K. (2006b). On the role of formulas in the acquisition of L2 pragmatics. In K. Bardovi-Harlig, J. C., Félix-Brasdefer, \& A. S. Omar (Eds.), Pragmatics and language learning (Vol. 11, pp. 1-28). Honolulu, HI: University of Hawai'i, National Foreign Language Resource Center.

Bardovi-Harlig, K. (2008). Recognition and production of formulas in L2 pragmatics. In ZH. Han (Ed.), Understanding second language process (pp. 205-222). Clevedon: Multilingual Matters.

Bardovi-Harlig, K. (2009). Conventional expressions as a pragmalinguistic resource: Recognition and production of conventional expressions in L2 pragmatics. Language Learning, 59(4), 755-795.

Bardovi-Harlig, K. (2010a). Recognition of conventional expressions in L2 pragmatics. In G. Kasper, H. T. Nguyen, D. R. Yoshimi, \& J. K. Yoshioka (Eds.), Pragmatics and language learning (Vol. 12, pp. 141-162). Honolulu, HI: University of Hawai'i, National Foreign Language Resource Center.

Bardovi-Harlig, K. (2010b). Exploring the pragmatics of interlanguage pragmatics: Definition by design. In A. Trosborg (Ed.), Pragmatics across languages and cultures (pp. 219-259). Berlin, New York: De Gruyter Mouton.

Bardovi-Harlig, K. (2011). Assessing familiarity with pragmatic formulas: Planning oral/aural assessment. In N. R. Houck, \& D. H. Tatsuki (Eds.), Pragmatics: Teaching natural conversation (pp. 7-22). Alexandria, VA: TESOL.

Bardovi-Harlig, K. (2012a). Formulas, routines, and conventional expressions in pragmatics research. Annual Review of Applied Linguistics, 32, 206-227.

Bardovi-Harlig, K. (2012b). Variation in the pragmatic use of conventional expressions. In J. C. Félix-Brasdefer, \& D. Koike (Eds.), Pragmatic variation in first and second language contexts: Methodological issues (pp. 141-173). Amsterdam: John Benjamins.

Bardovi-Harlig, K. (2013a). Developing L2 pragmatics. Language Learning, 63(1), 68-86. 
Bardovi-Harlig, K. (2013b). Pragmatic routines. In C. A. Chapelle (Ed.), The encyclopedia of applied linguistics. Oxford: Wiley-Blackwell.

Bardovi-Harlig, K. (2013c). On saying the same thing: Issues in the analysis of conventional expressions in L2 pragmatics. In T. Greer, D. H. Tatsuki, \& C. Roever (Eds.), Pragmatics and language learning (Vol. 13, pp. 191-211). Honolulu, HI: University of Hawai'i, National Foreign Language Resource Center.

Bardovi-Harlig, K. (2014). Awareness of meaning or conventional expressions in secondlanguage pragmatics. Language Awareness, 23(1-2), 41-56.

Bardovi-Harlig, K. (2015). Operationalizing conversation in studies of instructional effect in L2 pragmatics. System, 48, 21-34.

Bardovi-Harlig, K. (2016). How formulaic is pragmatics? In K. Bardovi-Harlig, J. C. FélixBrasdefer, \& D. Koike (Eds.), Pragmatics and language learning (Vol. 14, pp. 325340). Honolulu, HI: Univeristy of Hawai'i, National Foreign Language Resource Center.

Bardovi-Harlig, K. (2017). Acquisition of L2 pragmatics. In S. Loewen, \& M. Sato (Eds.), The Routledge handbook of instructed second language acquisition (pp. 224-245). New York / London: Routledge.

Bardovi-Harlig, K. (2018). Formulaic language in second language pragmatics research. In A. Siyanova-Chanturia, \& A. Pellicer-Sánchez (Eds.), Understanding formulaic language: A second language acquisition perspective (pp. 97-114). New York: Routledge.

Bardovi-Harlig, K. (2019a). Formulaic language in second language pragmatics research. In A. Siyanova-Chanturia, \& A. Pellicer-Sánchez (Eds.), Understanding formulaic language: A second language acquisition perspective (pp. 97-114). New York / London: Routledge.

Bardovi-Harlig, K. (2019b). Routines in L2 pragmatics research. In N. Taguchi (Ed.), The Routledge handbook of second language acquisition and pragmatics (pp. 47-62). New York / London: Routledge.

Bardovi-Harlig, K., \& Bastos, M.-T. (2011). Proficiency, length of stay, and intensity of interaction, and the acquisition of conventional expressions in L2 pragmatics. Intercultural Pragmatics, 8(3), 347-384.

Bardovi-Harlig, K., \& Dörnyei, Z. (1998). Do language learners recognize pragmatic violations? Pragmatic versus grammatical awareness in instructed L2 learning. TESOL Quarterly, 32(2), 233-259.

Bardovi-Harlig, K., \& Griffin, R. (2005). L2 pragmatic awareness: Evidence from the ESL classroom. System, 33(3), 401-415.

Bardovi-Harlig, K., \& Hartford, B. S. (1993a). Learning the rules of academic talk: A longitudinal study of pragmatic development. Studies in Second Language Acquisition, 15, 279-304.

Bardovi-Harlig, K., \& Hartford, B. S. (1993b). Refining the DCT: Comparing open questionnaires and dialogue completion tasks. In L. F. Bouton, \& Y. Kachru (Eds.), Pragmatics and language learning (Vol. 4, pp.143-165). Urbana-Champaign, IL: Division of English as an International Language, University of Illinois at UrbanaChampaign.

Bardovi-Harlig, K., \& Mahan-Taylor, R. (2003). Teaching pragmatics. Washington, DC: United States Department of State. Retrieved from https://americanenglish.state.gov/resources/teaching-pragmatics

Bardovi-Harlig, K., \& Nickels, E. L. (2011). No, Thanks. I'm full! Raising awareness of expressions of gratitude and conventional expressions. In N. R. Houck, \& D. H. Tatsuki 
(Eds.), Pragmatics: Teaching natural conversation (pp. 23-40). Alexandria, VA: TESOL.

Bardovi-Harlig, K., \& Vellenga, H. E. (2012). The effect of instruction on conventional expressions in L2 pragmatics. System, 40(1), 77-89.

Bardovi-Harlig, K., Bastos, M.-T., Burghardt, B., Chapetto, E., Nickels, E. L., \& Rose, M. (2010). The use of conventional expressions and utterance length in L2 pragmatics. In G. Kasper, H. T. Nguyen, D. R. Yoshimi, \& J. K. Yoshioka (Eds.), Pragmatics and language learning (Vol. 12, pp. 163-186). Honolulu, HI: University of Hawai'i, National Foreign Language Resource Center.

Bardovi-Harlig, K., Mossman, S., \& Su, Y. (2017). The effect of corpus-based instruction on pragmatic routines. Language Learning \& Technology, 21(3), 76-103.

Bardovi-Harlig, K., Mossman, S., \& Vellenga, H. E. (2015a). The effect of instruction on pragmatic routines in academic discussion. Language Teaching Research, 19(3), 324350 .

Bardovi-Harlig, K., Mossman, S., \& Vellenga, H.E. (2015b). Developing corpus-based materials to teach pragmatic routines. TESOL Journal, 6(3), 499-526.

Bardovi-Harlig, K., Rose, M., \& Nickels, E. L. (2008). The use of conventional expressions of thanking, apologizing, and refusing. In M. Bowles, R. Foote, S. Perpiñán, \& R. Bhatt (Eds), Selected proceedings of the 2007 Second language Research Forum (pp. 113130). Somerville, MA: Cascadilla Proceedings.

Barraja-Rohan, A. M. (2011). Using conversation analysis in the second language classroom to teach interactional competence. Language Teaching Research, 15(4), 479-507.

Barron, A. (2003). Acquisition in interlanguage pragmatics: Learning how to do things with words in a study abroad context. Amsterdam: John Benjamins.

Barron, A. (2005). Variational pragmatics in the foreign language classroom. System, 33, 519-536.

Barron, A. (2012). Interlanguage pragmatics: From use to acquisition to second language pedagogy. Language Teaching, 45(1), 44-63.

Beeching, K., \& Woodfield, H. (2015). Researching sociopragmatic variability: Perspectives from variational, interlanguage and contrastive pragmatics. Hampshire, New York: Palgrave Macmillan.

Beltrán-Palanques, V. (2013). Exploring research methods in interlanguage pragmatics: A study based on apologies. Saarbrücken: LAP Lambert.

Beltrán-Palanques, V. (2016). Assessing pragmatics: DCTs and retrospective verbal reports. In A. Pareja-Lora, C. Calle-Martínez, \& P. Rodríguez-Arancón (Eds.), New perspectives on teaching and working with languages in the digital era (pp. 303-312). Dublin: Research-publishing.net.

Belz, J. A., \& Vyatkina, N. (2005). Learner corpus analysis and the development of the L2 pragmatic competence in the networked intercultural language study: The case of German modal particles. The Canadian Modern Language Review, 62, 17-48.

Bem, D. J. (1968). Attitudes as self-descriptions: Another look at the attitude-behaviour link. In A. G. Greenwald, T. C. Brock, \& T. M. Ostrom (Eds.), Psychological foundations of attitudes. New York, NY: Academic Press.

Bialystok, E. (1990). The competence of processing: Classifying theories of second language acquisition. TESOL Quartely, 24, 635-668.

Bialystok, E. (1993). Symbolic representation and attentional control in pragmatic competence. In G. Kasper, \& S. Blum-Kulka (Eds.), Interlanguage pragmatics (pp. 4364). New York, NY: Oxford University Press.

Billmyer, K., \& Varghese, M. (2000). Investigating instrument-based pragmatic variability: Effects of enhancing discourse completion tests. Applied Linguistics, 21(4), 517-552. 
Blum-Kulka, S. (1982). Learning to say what you mean in a second language: A study of the speech act performance of learners of Hebrew as a second language. Applied Linguistic, 3(1), 29-59.

Blum-Kulka, S., \& Olshtain, E. (1986). Too many words: Length of utterance and pragmatic failure. Studies in Second Language Acquisition, 8(2), 165-179.

Blum-Kulka, S., House, J., \& Kasper, G. (1989). Cross-cultural pragmatics: Requests and apologies. Norwood, NJ: Ablex.

Boers, F., \& Lindstromberg, S. (2012). Experimental and interventional studies on formulaic sequences in a second language. Annual Review of Applied Linguistics, 32, 83-110.

Bokhorst-Heng, W., \& Caleon, I. S. (2009). The language attitudes of bilingual youth in multilingual Singapore. Journal of Multilingual and Multicultural Development, 30(3), 235-251.

Bolander, M. (1989). Prefabs, patterns and rules in interaction? Formulaic speech in adult learners' L2 Swedish. In K. Hyltenstam, \& L. K. Obler (Eds.), Bilingualism across the lifespan: Aspects of acquisition, maturity, and loss (pp. 73-86). Cambridge: Cambridge University Press.

Bouton, L. (1992). The interpretation of implicature in English by NNS: Does it come automatically without being explicitly taught? Pragmatics and Language Learning Monograph Series, 3, 64-77.

Bouton, L. F. (1994). Can NNS skill in interpreting implicature in American English be improved through explicit instruction? A pilot study. Pragmatics and Language Learning Monograph Series, 5, 88-108.

Bouton, L. F. (1988). A cross-cultural study of ability to interpret implicatures in English. World Englishes, 17(2), 183-196.

Bowles, M. A. (2010). The think-aloud controversy in second language research. New York / London: Routledge.

Brandtzaeg, P. B. (2012). Social networking sites: Their users and social implications: A longitudinal study. Journal of Computer-Mediated Communication, 17(4), 467-488.

Braun, V., \& Clarke, V. (2008). Using thematic analysis in psychology. Qualitative Research in Psychology, 3(2), 77-101.

Brown, J. D. (2014). Mixed methods research for TESOL. Edinburgh: Edinburgh University Press.

Brown, P., \& Levinson, S. D. (1987). Politeness: some universals in language usage. Cambridge: Cambridge University Press.

Cadierno, T., \& Eskilden, S. W. (2015). Usage-based perspectives on second language learning. Berlin: de Gruyter Mouton.

Canale, M. (1983). From communicative competence to communicative language pedagogy. In J. Richards, \& R. Schmidt (Eds.), Language and communication (pp. 227). London, UK: Longman.

Canale, M., \& Swain, M. (1980). Theoretical bases of communicative approaches to second language teaching and testing. Applied Linguistics, 1(1), 1-48.

Cargile, A., Giles, H., Ryan, E. B., \& Bradac, J. (1994). Language attitudes as a social process: A conceptual model and new directions. Language and Communication, 14(3), 211-236.

Carrell, P. (1979). Indirect speech acts in ESL: Indirect answers. In C. Yorio, K. Perkins, \& J. Schachter (Eds.), On TESOL '79: The learner in focus (pp. 297-307). Washington, DC: TESOL.

Carrell, P. (1981). Relative difficulty of request forms in L1/L2 comprehension. In M. Hines, \& W. Rutherford (Eds.), On TESOL '81 (pp. 141-152). Washington, DC: TESOL. 
Celce-Murcia, M. (2007). Rethinking the role of communicative competence in language teaching. In E. Alcón-Soler, \& M. P. Safont (Eds.), Intercultural language use and language learning (pp. 41-57). Dordrecht, The Netherlands: Springer.

Celce-Murcia, M., Dörnyei, Z., \& Thurrell, S. (1995). A pedagogical framework for communicative competence: A pedagogically motivated model with content specifications. Issues in Applied Linguistics, 6(2), 5-35.

Cenoz, J. (1991). Enseñanza-aprendizaje del inglés como L2 o L3. San Sebastián-Donostia: Universidad del País Vasco - Euskal Herriko Unibertsitatea.

Cenoz, J. (1997). The influence of bilingualism on multilingual acquisition: Some data from the Basque Country. Actas do I Simposio Internacional Sobre o Bilinguismo (pp. 278287). Universidade de Vigo, 21-25. Vigo: University of Vigo.

Cenoz, J. (1999). La adquisición de la competencia pragmática: Implicaciones para la enseñanza de lenguas extranjeras. In S. Salaberri (Ed.), Lingüística aplicada a la enseñanza delLenguas extranjeras. Almería: Servicio de Publicaciones de la Universidad de Almería.

Cenoz, J. (2004). Teaching English as a third language: The effect of attitudes and motivation. In C. Hoffmann, \& J. Ytsma (Eds.), Trilingualism in family, school and community, (pp. 202-218). Clevedon, Buffalo, Toronto, Sydney: Multilingual Matters.

Cenoz, J. (2009). Towards multilingual education: Basque educational research from an interactional perspective. Bristol, Buffalo, Toronto: Multilingual Matters.

Cenoz, J. (2013a). The influence of bilingualism on third language acquisition: Focus on multilingualism. Language Teaching, 46(1), 71-86.

Cenoz, J. (2013b). Bilingual and multilingual education: Overview. In C.A. Chapelle (Ed.), The Encyclopedia of Applied Linguistics. Oxford, UK: Wiley-Blackwell.

Cenoz, J. (2013c). Defining multilingualism. Annual Review of Applied Linguistics, 33, 318.

Cenoz, J., \& Gorter, D. (2011a). A holistic approach in multilingual education: Introduction. Special issue: Toward a multilingual approach in the study of multilingualism in school contexts. The Modern Language Journal, 95(3), 339-343.

Cenoz, J., \& Gorter, D. (2011b). Focus on multilingualism: A study of trilingual writing. The Modern Language Journal, 95(3), 356-369.

Cenoz, J., \& Gorter, D. (2014). Focus on multilingualism as an approach in educational contexts. In A. Blackledge, \& A. Creese (Eds.), Heteroglossia as practice and pedagogy (pp. 239-254). Dordrecht: Springer.

Cenoz, J., \& Gorter, D. (2015). Towards a holistic approach in the study of multilingual education. In J. Cenoz, \& D. Gorter (Eds.), Multilingual education: Between language learning and translanguaging (pp. 1-15). Cambridge: Cambridge University Press.

Cenoz, J., \& Jessner, U. (2000). English in Europe: The acquisition of a third language. Clevedon: Multilingual Matters.

Cenoz, J., \& Perales, J. (2000). Las variables contextuales y el efecto de la instrucción en la adquisición de segundas lenguas. In C. Muñoz (Ed.), Segundas lenguas: Adquisición en el aula (pp. 109-125). Barcelona: Ariel.

Cenoz, J., Gorter. D., \& May, S. (2017). Language awareness and multilingualism. Switzerland: Springer.

Chen, C.-F. E. (2006). The development of e-mail literacy: From writing to peers to writing to authority figures. Language Learning \& Technology, 10(2), 35-55.

Choi, J. (2003). Language attitudes and the future of bilingualism: The case of Paraguay. International Journal of Bilingual Education and Bilingualism, 6(2), 81-94.

Chomsky, N. (1957). Syntactic structures. The Hague: Mouton.

Chomsky, N. (1965). Aspects of the theory of syntax. Cambridge, MA: MIT Press. 
Codina-Espurz, V. (2008). The immediate vs. delayed effect of instruction on mitigators in relation to the learner's language proficiency in English. In E. Alcón-Soler (Ed.), Learning how to request in an instructed language learning context (pp. 227-256). Bern, Switzerland: International Academic Publishers.

Codina-Espurz, V. (2013). The role of proficiency in the production of refusals in English in an instructed context. In O. Martí-Arnándiz, \& P. Salazar-Campillo (Eds.), Refusals in instructional contexts and beyond (pp. 121-146). Amsterdam / New York, NY: Rodopi.

Cohen, A. D. (2008). Teaching and assessing L2 pragmatics: What can we expect from learners? Language Teaching, 41(2), 213-235.

Cohen, A. D. (2013). Commentary on technology in interlanguage pragmatics research and teaching. In N. Taguchi, \& J. M. Sykes (Eds.), Technology in interlanguage pragmatics research and teaching. Philadelphia, PA: John Benjamins.

Cohen, A. D., \& Tarone, E. (1994). The effects of training on written speech act behavior: Stating and changing an opinion. MinneTESOL Journal, 12, 39-62.

Cohen, A. D., \& Olshtain, E. (1981). Developing a measure of sociocultural competence: The case of apology. Language Learning, 31(1), 113-134.

Cohen, A.D. (2013). Verbal report. In C. Chapelle, (Ed.), The encyclopedia of applied linguistics. Oxford, UK: Wiley-Blackwell.

Cohen, A.D. (2014). Strategies in learning and using a second language. New York, NY: Harlow.

Cohen, J. (1977). Statistical power analysis for the behavioral sciencies. Routledge.

Cohen, L., Manion, L., \& Morrison, K. (2000). Research methods in education. London, UK: Routledge/Falmer.

Cohen, L., Manion, L., \& Morrison, K. (2007). Research methods in education. London / New York: Routledge.

Collins, L., \& Muñoz, C. (2016). The foreign language classroom: Current perspectives and future considerations. The Modern Language Journal, 100, 133-147.

Coronel-Molina, S. M. (2009) Definitions and critical literature review of language attitude, language choice and language shift: Samples of language attitude surveys. Bloomington, IN: IU Scholar Works.

Coulmas, F. (1981). Conversational routine: Explorations in standardized communication situations and prepatterned speech. The Hague: Mouton.

Coulmas, F. (2018). An introduction to multilingualism: Language in a changing world. Oxford: Oxford University Press.

Crystal, D. (1985). A dictionary of linguistics and phonetics. Oxford, UK: Blackwell.

Culpeper, J., Mackey, A., \& Taguchi, N. (2018). Second language pragmatics: From theory to research. New York, NY: Routledge.

Cunningham, J., \& Vyatkina, N. (2012). Telecollaboration for the professional purposes: Towards developing a formal register in the foreign language classroom. The Canadian Modern Language Review, 68, 422-450.

Dantas-Whitney, M. (2011). Developing students' language awareness. In N. R. Houck, \& D. H. Tatsuki (Eds.), Pragmatics: Teaching natural conversation (pp. 193-205). Alexandria, VA: TESOL.

Davies, W. (1995). Linguistic variation and language attitudes in Mannheim-Neckarau. Stuttgart: Franz Steiner Verlag.

de Bot, K. (2008). Introduction: Second language development as a dynamic process. Modern Language Journal, 92, 166-178.

DeBoer, A. J. (2015). Second language learners' recognition and production of conventional expressions: The role of proficiency, length of stay, and intensity of 
interaction. Culminating Projects in English. Minnesota, MI: St. Cloud State University. The Repository at St. Cloud State.

DeKeyser, R. (1995). Learning second language grammar rules: An experiment with a miniature linguistic system. Studies in Second Language Acquisition, 17(3), 379-410.

DeKeyser, R. M. (1997). Beyond explicit rule learning: Automatizing second language morphosyntax. Studies in Second Language Acquisition, 19(2), 195-221.

DeKeyser, R. M. (1998). Beyond focus on form: Cognitive perspectives on learning and practicing second language grammar. In C. Doughty, \& J. Williams (Eds.), Focus on form in classroom second language acquisition (pp. 42-63). New York, NY: Cambridge University Press.

DeKeyser, R. M. (2001). Automaticity and automatization. In P. Robinson (Ed.), Cognition and second language instruction (pp. 125-151). New York, NY: Cambridge University Press.

DeKeyser, R. M. (2003). Implicit and explicit learning. In C. Doughty, \& M. Long (Eds.), Handbook of second language acquisition (pp. 313-348). Malden, MA: Blackwell.

DeKeyser, R. M. (2007a). Skill acquisition theory. In B. VanPatten, \& J. Williams (Eds.), Theories in second language acquisition: An introduction (pp. 97-113). New Jersey, NJ: Lawrence Erlbaum Associates, Inc.

DeKeyser, R. M. (2007b). Practice in a second language: Perspectives from applied linguistics and cognitive psychology. Cambridge, UK: Cambridge University Press.

DeKeyser, R. (2015). Skill acquisition theory. In B. VanPatten, \& J. Williams (Eds.), Theories in second language acquisition: An introduction (pp. 94-112). New York, NY: Routledge.

DeKeyser, R. (2017). Knowledge and skill in ISLA. In S. Loewen, \& M. Sato (Eds.), The Routledge handbook of instructed second language acquisition (pp. 15-32). New York, London: Routledge.

Dewaele, J.M. (2005). Sociodemographic, psychological and politicocultural correlates in Flemish students' attitudes towards French and English. Journal of Multilingual and Multicultural Development, 26(2), 118-137.

Dörnyei, Z. (2001). Teaching and researching motivation. Harlow, UK: Longman.

Dörnyei, Z., \& Ottó, I. (1998). Motivation in action: A process model of L2 motivation. Working Papers in Applied Linguistics, 4, 43-69.

Dörnyei, Z., \& Ushioda, E. (2011). Teaching and researching motivation. Harlow, UK: Longman.

Durrant, P., \& Mathews-Aydinli, J. (2011). A function-first approach to identifying formulaic language in academic writing. English for Specific Purposes, 30(1), 58-72.

Edmonds, A. (2014). Conventional expressions: Investigating pragmatics and processing. Studies in Second Language Acquisition, 36(1), 69-99.

Edwards, J. (1994). Multilingualism. London, UK: Penguin Books.

Ellis, N., \& Larsen-Freeman, D. (2006). Language emergence: Implications for applied linguistics - Introduction to the special issue. Applied Linguistics, 27, 558-589.

Ellis, R. (1991). The interaction hypothesis: A critical evaluation, presented at the Regional Language Center Seminar, Singapore, 1991, USA.

Ellis, R. (1994). The study of second language acquisition. Oxford: Oxford University Press.

Ellis, R. (2005). Principles of instructed language learning. System, 33(2), 209-224.

Ellis, R. (2009). Implicit and explicit learning, knowledge and instruction. In R. Ellis, S. Loewen, C. Elder, R. Erlam, J. Philip, \& H. Reinders (Eds.), Implicit and explicit knowledge in second language learning, testing, and teaching (pp. 3-26). Bristol: Multilingual Matters. 
Ellis, R., Loewen, S., Elder, C., Erlam, R., Philip, J., \& Reinders, H. (2009). Implicit and explicit knowledge in second language learning, testing, and teaching. Bristol, UK: Multilingual Matters.

Ellis, R., \& Shintani, N. (2014). Exploring language pedagogy through second language acquisition research. London: Routledge.

Ericsson, K., \& Simon, H. (1993). Protocol analysis: Verbal reports as data. Boston, MA: MIT Press.

Eslami-Rasekh, Z., Eslami-Rasekh, A., \& Fatahi, A. (2004). The effect of explicit metapragmatic instruction on the speech act awareness of advanced EFL students. TESL-EJ, 8(2), 1-10.

Eslami, Z. R., \& Eslami-Rasekh, A. (2008). Enhancing the pragmatic competence of nonnative English-speaking teacher candidates (NNESTCs) in an EFL context. In E. AlcónSoler, \& A. Martínez-Flor (Eds.), Investigating pragmatics in foreign language learning, teaching and testing (pp. 178-197). Bristol, UK: Multilingual Matters.

Eslami, Z. R., \& Liu, C. N. (2013). Learning pragmatics through computer-mediated communication in Taiwan. Iranian Journal of Society, Culture \& Language, 1(1): 5273.

Félix-Brasdefer, J. C. (2007). Pragmatic development in the Spanish as a FL classroom: A cross-sectional study of learner requests. Intercultural Pragmatics, 4(2), 253-286.

Félix-Brasdefer, J. C. (2010). Data collection methods in speech act performance: DCTs, role plays, and verbal reports. In A. Martínez-Flor, \& E. Usó-Juan (Eds.), Speech act performance: Theoretical, empirical and methodological issues (pp. 41-56). Amsterdam/ Philadelphia, PA: John Benjamins.

Félix-Brasdefer, J.C. (2013). Interlanguage pragmatics. In C. A. Chapelle (Ed.), The encyclopedia of applied linguistics. Oxford, UK: Wiley-Blackwell.

Félix-Brasdefer, J.C. (2017). Interlanguage pragmatics. In Y. Huang (Ed.), The Oxford handbook of pragmatics (pp. 416-434). Oxford, UK: Oxford University Press.

Félix-Brasdefer, J. C., \& Koike, D. A. (2012). Pragmatic variation in first and second language contexts: Methodological issues. Impact: Studies in Language and Society 31. Amsterdam: John Benjamins.

Fernández-Guerra, A. B. (2008). Requests in TV series and in naturally occurring discourse: A comparison. In E. Alcón-Soler (Ed.), Learning how to request in an instructed language learning context (pp. 111-126). Bern, Switzerland: International Academic Publishers.

Fernández-Guerra, A. B. (2013). Using TV series as input source of refusals in the classroom. In O. Martí-Arnándiz, \& P. Salazar-Campillo (Eds.), Refusals in instructional contexts and beyond (pp. 5-22). Amsterdam / New York, NY: Rodopi.

Firth, A., \& Wagner, J. (1997). On discourse, communication, and (some) fundamental concepts in SLA research. Modern Language Journal, 81, 285-300.

Fitts, P. M. (1964). Perceptual-motor skill learning. In A.W. Melton (Ed.), Categories of human learning (pp. 243-285). New York, NY: Academic Press.

Flores-Salgado, E. (2009). A pragmatic study of developmental patterns in Mexican students making English requests and apologies. ( $\mathrm{PhD}$ dissertation). Macquarie University, Australia.

Fordyce, K. (2014). The differential effects of explicit and implicit instruction on EFL learners' use of epistemic stance. Applied Linguistics, 35(1), 6-28.

Fraser, B. (1970). Idioms within a transformational grammar. Foundations of Language, $6(1), 22-42$.

Fukuya, Y. J., \& Martínez-Flor, A. (2008). The interactive effects of pragmatic-eliciting tasks and pragmatic instruction. Foreign Language Annals, 41(3), 478-500. 
Fukuya, Y. J., \& Zhang, Y. (2002). Effects of recasts on EFL learners' acquisition of pragmalinguistic conventions of request. Second language Studies, 21(1), 1-47.

García-Mayo, M.P., \& Alcón-Soler, E. (2016). Eliciting oral interaction data in EFL settings. In A. Mackey, \& E. Marsden (Eds.), Advancing methodology and mractice: The IRIS repository of instruments for research into second languages. (pp. 132-148). New York / London: Routledge

Garcia, P. (2004). Pragmatic comprehension of high and low level language learners. TESLEJ, 8(2).

Gardner, R.C. (1979). Social psychological aspects of second language acquisition. In H. Giles, \& R. St. Clair (Eds.), Language and social psychology. Oxford, UK: Blackwell.

Gardner, R.C. (1982). Language attitudes and language learning. In E. B Ryan, \& H. Giles (Eds.), Attitudes towards language variation. London: Edward Arnold.

Gardner, R.C. (1985a). Social psychology and second language learning: The role of attitudes and motivation. London: Edward Arnold.

Gardner, R.C (1985b). The attitude/motivation test battery: Technical report. Ontario: University of Western Ontario.

Gardner, R. C. (2004). Attitude/motivation test battery: International AMBT research project. London: The University of Western Ontario.

Gardner, R. C., \& Lambert, W. E. (1959). Motivational variables in second-language acquisition. Canadian Journal of Psychology, 13(4), 266-272.

Gardner, R. C., \& Lambert, W. E. (1972). Attitudes and motivation in second-language learning. Rowley, MA: Newbury House.

Garrett, P. (2010). Attitudes to language. London, New York: Cambridge University Press.

Garrett, P., Coupland, N., \& Williams, A. (2003). Investigating language attitudes: Social meanings of dialect, ethnicity and performance. Cardiff: University of Wales Press.

Gass, S., \& Mackey, A. (2016). Stimulated recall methodology in applied linguistics and L2 research. New York, NY: Routledge.

Geeslin, K. L., \& Long, A. Y. (2014). Sociolinguistics and second language acquisition: Learning to use language in context. New York, NY: Routledge.

Ghobadi, A., \& Fahim, M. (2009). The effect of explicit teaching of English "thanking formulas" on Iranian EFL intermediate level students at English language institutes. System, 37(3), 526-537.

Giles, H., \& Billings, A. C. (2006). Assessing language attitudes: Speaker evaluation studies. In A. Davies \& C. Elder (Eds.), The handbook of applied linguistics (pp. 187-209). Oxford, UK: Blackwell Publishing.

Gilles, H., Coupland, N, \& Coupland, J. (1991). Accommodation theory: Communication, context and consequence. In H. Giles, N. Coupland, \& J. Coupland (Eds.), Contexts of accommodation: Developments in applied sociolinguistics (pp. 1-68). Cambridge, UK: Cambridge University Press.

Golato, A. (2003). Studying compliment responses: A comparison of DCTs and recordings of naturally-occurring data. Applied Linguistics, 24(1), 90-121.

Goldman-Eisler, F. (1968). Psycholinguistics: Experiments in spontaneous speech. London / New York: Academic Press.

Gorter, D., \& Cenoz, J. (2011). A multilingual approach: Conclusions and further perspective: Afterword. The Modern Language Journal, 95(3), 442-445.

Greg, G. (2012). Applied thematic analysis. Thousand Oaks, CA: Sage.

Gyllstad, H., \& Schmitt, N. (2019). Testing formulaic language. In A. Siyanova-Chanturia, \& A. Pellicer-Sánchez, (Eds.), Understanding formulaic language: A second language acquisition perspective (pp. 174-191). London/ New York, NY: Routledge. 
Halenko, N. (2013). Using computer animation to assess and improve spoken language skills. In ICT for language learning conference proceedings (6th ed., pp. 286-290). Florence: Libreriauniversitaria.

Hanson, D. (1980). Relationship between methods and findings in attitude-behaviour research. Psychology, 17, 11-13.

Hassall, T. (1997). Requests by Australian learners of Indonesian (Unpublished doctoral dissertation). Australian National University, Canberra, ACT.

Hassall, T. (2008). Pragmatic performance: What are learners thinking? In E. Alcón-Soler, \& A. Martínez-Flor (Eds.), Investigating pragmatics in foreign language learning, teaching and testing (pp. 72-93). Bristol, Buffalo, Toronto: Multilingual Matters.

Hatch, E. (1978). Discourse analysis and second language acquisition. In E. Hatch (Ed.), Second language acquisition: A book of readings (pp. 402-435). Rowley, MA: Newbury House.

Henerson, M. E., Morris, L. L., \& Fitz-Gibbon, C. T. (1987). How to measure attitudes. Newbury Park: Sage.

Herdina, P., \& Jessner, U. (2002). A dynamic model of multilingualism: Perspectives of change in psycholinguistics. Clevedon: Multilingual Matters.

Hewstone, M., \& Giles, H. (1997). Social groups and social stereotypes. In N. Coupland, \& A. Jaworski (Eds.), Sociolinguistics: A reader and coursebook. Basingstoke, UK: Macmillan.

Hinkel, E. (2014). Culture and pragmatics in second language teaching and learning. In M. Celce-Murcia, D. Brinton, \& M. Snow (Eds.), Teaching English as a second or foreign language (pp. 394-408). Boston, MA: National Geographic Learning.

Hinkel, E. (2015). Effective curriculum for teaching L2 writing: Principles and techniques. New York, NY: Routledge.

Hinkel, E. (2018). Teaching and learning formulaic sequences and prefabs. In J. I. Liontas (Ed.), The TESOL encyclopedia of English language teaching. Wiley.

Holmes, J. (1992). An Introduction to Sociolinguistics. London: Longman.

Holmes, J. (2013). An Introduction to Sociolinguistics. London, New York: Routledge.

Holmes, J., \& Brown, D. F. (1987). Teachers and students learning about compliments. TESOL Quarterly, 21(3), 523-546.

Horwitz, E. K., Horwitz, M. B., \& Cope, J. (1986). Foreign language classroom anxiety. The Modern Language Journal, 70(2), 125-132.

Houck, N. R., \& Tatsuki, D. H. (2011). Pragmatics: Teaching natural conversation. Alexandria, VA: TESOL.

House, J. (1996). Developing pragmatic fluency in English as a foreign language: Routines and metapragmatic awareness. Studies in Second Language Acquisition, 18(2), 225-252.

Huguet, A. (2006). Attitudes and motivation versus language achievement in cross-linguistic settings: What is cause and what is effect? Journal of Multilingual and Multicultural Development, 27(5), 413-429.

Huguet, A. (2007). Language use and language attitudes in Catalonia. In D. Lasagabaster, \& A. Huguet (Eds.), Multilingualism in European bilingual contexts: Language use and attitudes (pp. 17-39). Clevedon: Multilingual Matters.

Hymes, D. (1962). The ethnography of speaking. In T. Gladwin, \& W. C. Sturtevant (Eds.), Anthropology and human behavior (pp. 13-53). Washington, DC: Anthropological Society of Washington.

Hymes, D. (1967). Models of the interaction of language and social setting. Journal of Social Issues, 23(2), 8-38.

Hymes, D. (1972). On communicative competence. In J. B. Pride, \& J. Holmes (Eds.), Sociolinguistics: Selected readings (pp. 269-293). Harmondsworth: Penguin. 
Ishihara, N., \& Chiba, A. (2014). Teacher-based or interactional?: Exploring assessments for children's pragmatic development. Iranian Journal of Language Testing, 4(1), 84112.

Ishihara, N., \& Cohen, A. D. (2010). Teaching pragmatics: Where language and culture meet. Harlow, UK: Pearson Longman.

Ishihara, N., \& Tarone, E. (2009). Subjectivity and pragmatic choice in L2 Japanese: Emulating and resisting pragmatic norms. In N. Taguchi (Ed.), Pragmatic competence (pp. 101-128). Berlin, New York: Mouton de Gruyter.

Jeon, E. H., \& Kaya, T. (2006). Effects of L2 instruction on interlanguage pragmatic development: A meta-analysis. In J. M. Norris, \& L. Ortega (Eds.), Synthesizing research on language learning and teaching (pp. 165-211). Amsterdam / Philadelphia: John Benjamins.

Kakegawa, T. (2009) Development of the use of Japanese sentence-final particles through email correspondence. In N. Taguchi (Ed.), Pragmatic competence (pp. 301-333). Berlin: Mouton De Gruyter.

Kasper, G. (1996). Introduction: Interlanguage pragmatics in SLA. Studies in Second Language Acquisition, 18, 145-148.

Kasper, G. (1997). Can pragmatic competence be taught? Honolulu, HI: University of Hawai'i at Mānoa, Second Language Teaching \& Curriculum Center.

Kasper, G. (1999). Data collection in pragmatics research. University of Hawai'i Working Papers in ESL, 18(1), 71-107.

Kasper, G. (2001). Classroom research on interlanguage pragmatics. In K. R. Rose, \& G. Kasper (Eds.), Pragmatics in language teaching (pp. 33-60). Cambridge, UK: Cambridge university press.

Kasper, G. (2008). Data collection in pragmatics research. In H. Spencer-Oatey (Ed.), Culturally speaking: Culture, communication and politeness theory (pp. 279-302). London / New York: Continuum

Kasper, G., \& Blum-Kulka, S. (1993). Interlanguage pragmatics. New York, NY: Oxford University Press.

Kasper, G., \& Dahl, M. (1991). Research methods in interlanguage pragmatics. Studies in Second Language Acquisition, 13, 215-247.

Kasper, G., \& Roever, C. (2005). Pragmatics in second language learning. In E. Hinkel (Ed.), Handbook of research in second language teaching and learning (pp. 317-334). Mahwah, NJ: Lawrence Erlbaum Associates.

Kasper, G., \& Rose, K. R. (1999). Pragmatics and SLA. Annual Review of Applied Linguistics, 19, 81-104.

Kasper, G., \& Rose, K. R. (2002). Pragmatic development in a second language. Oxford, UK: Blackwell.

Kasper, G., \& Schmidt, R. (1996). Developmental issues in interlanguage pragmatics. Studies in Second Language Acquisition, 18, 149-169.

Kecskes, I. (2000). Conceptual fluency and the use of situation-bound utterances in L2. Links \& Letters, 7, 145-161.

Kecskes, I. (2002). Situation-bound utterances in L1 and L2. Berlin: Mouton de Gruyter.

Kinginger, C., \& Blattner, G. (2008). Development of sociolinguistic awareness in study abroad. In L. Ortega, \& H. Byrnes (Eds.), Longitudinal studies and advanced L2 capacities (pp. 223-246). New York, NY: Routledge.

Koike, D. A., \& Pearson, L. (2005). The effect of instruction and feedback in the development of pragmatic competence. System, 33(3), 481-501.

Kondo, S. (2008). Effects of pragmatic development through awareness-raising instruction: Refusals by Japanese EFL learners. In E. Alcón-Soler, \& A. Martínez-Flor (Eds.), 
Investigating pragmatics in foreign language learning, teaching and testing (pp. 153177). Bristol, Buffalo, Toronto: Multilingual Matters.

Krashen, S. (1982). Principles and practice in second language acquisition. Pergamon Press Inc.

Kubota, M. (1995). Teachability of conversational implicatures to Japanese EFL learners. IRLT Bulletin, 9, 35-67.

Labov, W. (1972a). Sociolinguistic patterns. Philadelphia, PA: University of Pennsylvania Press.

Labov, W. (1972b). Language in the inner city. Philadelphia, PA: University of Pennsylvania Press.

Labov, W. (1994). Principles of linguistic change. Oxford: Blackwell.

Labov, W. (2006). The atlas of North American English: Phonetics, phonology, and sound change. Berlin: de Gruyter Mouton.

Lambert, W. E., Hodgson, R. C., Gardner, R. C., \& Fillenbaum, S. (1960). Evaluational reactions to spoken languages. Journal of Abnormal and Social Psychology, 60(1), 4451.

Larsen-Freeman, D. (2011). A complexity theory approach to second language development/acquisition. In D. Atkinson (Ed.), Alternative approaches to second language acquisition (pp. 48-72). London, New York: Routledge.

Larsen-Freeman, D., \& Cameron, L. (2008). Complex systems and applied linguistics. Oxford, UK: Oxford University Press.

Larson-Hall, J. (2016). A guide to doing statistics in second language research using SPSS and $R$. New York, London: Routledge.

Lasagabaster, D. (1998). Creatividad y conciencia metalingüistica: Incidencia en el aprendizaje del inglés como L3. Bilbao-Bilbo: Universidad del País Vasco - Euskal Herriko Unibertsitatea.

Lasagabaster, D. (2001). University students' attitudes towards English as an L3. In J. Cenoz, B. Hufeisen, \& U. Jessner, (Eds.), Looking beyond second language acquisition: Studies in tri- and multilingualism (pp. 43-50). Tübingen: Stauffenburg Verlag.

Lasagabaster, D. (2003). Attitudes towards English in the Basque Autonomous Community. World Englishes, 22(4), 585-597.

Lasagabaster, D. (2005a). Attitudes towards Basque, Spanish and English: An analysis of the most influential variables. Journal of Multilingual and Multicultural Development, 26(4), 1-21.

Lasagabaster, D. (2005b). Bearing multilingual parameters in mind when designing a questionnaire on attitudes: Does this affect the results? International Journal of Multilingualism, 2(1), 26-51.

Lasagabaster, D. (2007). Language use and language attitudes in the Basque Country. In D. Lasagabaster, \& A. Huguet (Eds.), Multilingualism in European bilingual contexts: Language use and attitudes (pp. 65-89). Clevedon: Multilingual Matters

Lasagabaster, D. (2008). Multilingualism and language attitudes: Local versus immigrant students' perceptions. Language Awareness, 17(4), 326-341.

Lasagabaster, D. (2009). The implementation of CLIL and attitudes towards trilingualism. International Journal of Applied Linguistics, 157, 23-43.

Lasagabaster, D. (2017). Language learning motivation and language attitudes in multilingual Spain from and international perspective. The Modern Language Journal, 101(3), 583-596.

Lasagabaster, D., \& Huguet, A. (2007). Multilingualism in European bilingual contexts: Language use and attitudes. Clevedon: Multilingual Matters 
Lasagabaster, D., \& Safont, M. P. (2008). Un análisis de las actitudes lingüísticas en dos comunidades bilingües. XXVI Congreso AESLA.

Lasagabaster, D., \& Sierra, J. M. (2009). Language attitudes in CLIL and traditional EFL classes. International CLIL Research Journal, 1(2), 4-17.

Leech, G. (1983). Principles of pragmatics. London: Longman.

Levinson, S. C. (1983). Pragmatics. Cambridge, UK: Cambridge University Press.

Li, Q. (2016). Variations in developmental patterns across pragmatic features. Studies in Second Language Acquisition, 6(4), 587-617.

Li, S. (2012). The effects of input-based practice on pragmatic development of requests in L2 Chinese. Language Learning, 62(2), 403-438.

Li, S. (2014). The effects of different levels of linguistic proficiency on the development of L2 Chinese request production during study abroad. System, 45, 103-116.

Li, S., \& Taguchi, N. (2014). The effects of practice modality on the development of pragmatic performance in L2 Chinese. The Modern Language Journal, 98(3), 794-812.

Liang, S. (2015). Language attitudes and identities in multilingual China: A linguistic ethnography. Dordrecht: Springer.

LoCastro, V. (2001). Individual differences in second language acquisition: Attitudes, learner subjectivity and L2 pragmatic forms. System, 29(1), 69-89.

LoCastro, V. (2012). Pragmatics for language educators: A sociolinguistic perspective. London, UK: Routledge.

Long, M. H. (1981). Input, interaction and second language acquisition. In W. Winitz (Ed.), Annals of the New York Academy of Sciences: Vol. 379. Native language and foreign language acquisition (pp. 259-278). New York, NY: New York Academy of Sciences.

Long, M. H. (1983). Does second language instruction make a difference? A review of research. TESOL Quarterly, 17(3), 359-382.

Long, M. H. (1985). Input and second language acquisition theory. In S. Gass, \& C. Madden (Eds.), Input and second language acquisition (pp. 377-393). Rowley, MA: Newbury House.

Long, M. H. (1990). The least a second language acquisition theory needs to explain. TESOL Quarterly, 24, 649-666.

Long, M. H. (1996). The role of the linguistic environment in second language acquisition. In W. C. Ritchie, \& T. H. Bahtia (Eds.), Handbook of second language acquisition (pp. 413-468). New York, NY: Academic Press. Reprinted in L. Ortega (Ed.), Second language acquisition: Critical concepts in linguistics. London, UK: Routledge.

Long, M. H. (2015). Second language acquisition and task-based language teaching. Malden, MA: Wiley-Blackwell.

Loredo, X., Fernández, A., Suárez, I., \& Casares, H. (2007). Language use and language attitudes in Galicia. In D. Lasagabaster, \& A. Huguet (Eds.), Multilingualism in European bilingual contexts: Language use and attitudes (pp. 40-64). Clevedon: Multilingual Matters.

Lukmani, Y. M. (1972). Motivation to learn and language proficiency. Language Learning, $22(2), 261-273$.

Lyster, R. (1994). The effect of functional-analytic teaching on aspects of French immersion students' sociolinguistic competence. Applied Linguistics, 15(3), 263-287.

Mackie, D., \& Hamilton, D. (1993). Affect, cognition, and stereotyping: Interactive processes in group perception. San Diego, CA: Academic Press.

Maietta, S. (1996). Patterns of language attitudes and language use: A study of New Mexican adolescents. University of Pittsburgh.

Malinowski, B. (1935). Coral gardens and their magic: A study of the methods of tiling the soil and of agricultural rites in the Trobriand Islands. New York, NY: Routledge. 
Martín-Laguna, S. (2015). Pragmatic learning trajectories and transfer in a multilingual classroom context: A study on pragmatic markers. (Unpublished doctoral dissertation). Universitat Jaume I, Castelló.

Martín-Laguna, S. \& Alcón-Soler, E. (2018). Development of discourse-pragmatic markers in a multilingual classroom: A mixed-method approach. System, 75, 68-80.

Martínez-Flor, A. (2005). The effect of instruction on the development of pragmatic competence in the English as a foreign language context: A study based on suggestions. (Unpublished doctoral dissertation). Universitat Jaume I, Castelló.

Martínez-Flor, A. (2006). The effectiveness of explicit and implicit treatments on EFL learners' confidence in recognizing appropriate suggestions. In K. Bardovi-Harlig, J. C. Félix-Brasdefer, \& A. S. Omar (Eds.), Pragmatics and language learning (Vol. 11, pp. 199-225). Honolulu, HI: University of Hawaii Press.

Martínez-Flor, A. (2013a). Classroom research on pragmatics. In C. A. Chapelle (Ed.), The encyclopedia of applied linguistics. Oxford: Wiley-Blackwell.

Martínez-Flor, A. (2013b). Learners' production of refusals: Interactive written DCT versus oral role-play. In O. Martí-Arnándiz, \& P. Salazar-Campillo (Eds.), Refusals in instructional contexts and beyond (pp. 175-211). Amsterdam / New York, NY: Rodopi.

Martínez-Flor, A., \& Alcón-Soler, E. (2007). Developing pragmatic awareness of suggestions in the EFL classroom: A focus on instructional effects. RCLA, 10(1), 47-76.

Martínez-Flor, A., \& Fukuya, Y. J. (2005). The effects of instruction on learners' production of appropriate and accurate suggestions. System, 33(3), 463-480.

Martínez-Flor, A., \& Usó-Juan, E. (2006). A comprehensive pedagogical framework to develop pragmatics in the foreign language classroom: The 6Rs approach. Applied Language Learning, 16(2), 39-63.

Martínez-Flor, A., \& Usó-Juan, E. (2010). Speech act performance: Theoretical, empirical and methodological issues. Amsterdam/ Philadelphia, PA: John Benjamins.

Martínez-Flor, A., \& Usó-Juan, E. (2011). Research methodologies in pragmatics: Eliciting refusal to requests. Estudios de Lingüistica Inglesa Aplicada, 11, 47-87.

Martínez-Flor, A., \& Usó-Juan, E. (2015). The role of instruction on EFL learners' use of complaining-apologising semantic formulas. Procedia - Social and Behavioral Sciences, 212, 23-28.

Martínez-Flor, A., Usó-Juan, E., \& Fernández-Guerra, A. B. (2003). Pragmatic competence and foreign language teaching. Castelló: Publicacions de la Universitat Jaume I.

Martinez, R., \& Schmitt, N. (2012). A phrasal expressions list. Applied Linguistics, 33(3), 299-320.

Matsumura, S. (2007). Exploring the aftereffects of study abroad on interlanguage pragmatic development. Intercultural Pragmatics, 4, 167-192.

McKenzie, R. M. (2010). The social psychology of English as a global language: Attitudes, awareness and identity in the Japanese context. London, New York: Springer.

McLean, T. (2005). "Why no tip?" Student-generated DCTs in the ESL classroom. In S. Tatsuki (Ed.), Pragmatics in language learning, theory, and practice (pp.150-156). Tokyo: JALT Pragmatics SIC.

Mey, J. (1993). Pragmatics: An introduction. Oxford, UK: Blackwell.

Minitab Blog Editor. (2015). Choosing between a nonparametric test and a parametric test. Retreived from https://blog.minitab.com/blog/adventures-in-statistics-2/choosingbetween-a-nonparametric-test-and-a-parametric-test

Morris, C. (1938). Foundations of the theory of signs. Chicago, IL: University of Chicago Press.

Myles, F., Hooper, J., \& Mitchel, R. (1988). Rote or rule? Exploring the role of formulaic language in classroom foreign language learning. Language Learning, 48(3), 323-363. 
Narita, R. (2012). The effects of pragmatic consciousness-raising activity on the development of pragmatic awareness and use of hearsay evidential markers for learners of Japanese as a foreign language. Journal of Pragmatics, 44, 1-29.

Nattinger, J. R., \& DeCarrico, J. S. (1992). Lexical phrases and language teaching. Oxford, UK: Oxford University Press.

Newcomb, T. M. (1950). Social psychology. New York, NY: Holt.

Newell, A., \& Rosenbloom, P. S. (1981). Mechanisms of skill acquisition and the law of practice. In J. R. Anderson (Ed.), Cognitive skills and their acquisition (pp. 1-55). New Jersey, NJ: Erlbaum.

Nguyen, H. (2011). Achieving recipient design longitudinally: Evidence from a pharmacy intern in patient consultations. In J. K. Hall, J. Hellermann, \& S. P. Doehler (Eds.), L2 interactional competence and development (pp. 173-205). Bristol, Buffalo: Multilingual Matters.

Nguyen, T. T. M. (2019). Data collection methods in L2 pragmatics research: An overview. In N. Taguchi (Ed.), The Routledge handbook of second language acquisition and pragmatics (pp. 195-211). London / New York: Routledge.

Nguyen, T. T. M., Pham, T. H., \& Pham, M. T. (2012). The relative effects of explicit and implicit form-focused instruction on the development of L2 pragmatic competence. Journal of Pragmatics, 44(4), 416-434.

Nightingale, R. (2012). Bridging the gap between the internal and the external: the effect of sociocultural factors in adolescent learners' attitudes towards English. Saarbrücken: Lambert Academic Publishing.

Nightingale, R. (2016). The effect of out-of-school media contact on language attitudes in multilingual adolescents: A complex psycho-sociolinguistic system. (Unpublished doctoral dissertation). Universitat Jaume I, Castelló.

Norris, J. M., \& Ortega, L. (2000). Effectiveness of L2 instruction: A research synthesis and quantitative meta-analysis. Language Learning, 50, 417-528.

Norris, J. M., \& Ortega, L. (2001). Does type of instruction make a difference? Substantive findings from a meta-analytic review. Language Learning, 51(1), 157-213.

Norris, J., \& Ortega, L. (2003). Defining and measuring SLA. In C. J. Doughty, \& M. H. Long (Eds.), The handbook of second language acquisition (pp. 717-761). Malden, MA: Blackwell Publishing.

O'Keeffe, A. (2011). Pragmatics and language teaching. In A. O'Keeffe, B. Clancy, \& S. Adolphs (Eds.), Introducing pragmatics in use (pp. 137-164). London, New York: Routledge.

O'Rourke, B. (2011). Galician and Irish in the European context: Attitudes towards weak and strong minority languages. Basingstoke: Palgrave Macmillan.

Ochs, E. (1996). Linguistic resources for socializing humanity. In J. J. Gumperz, \& S. C. Levinson (Eds.), Rethinking linguistic relativity (pp. 407-437). Cambridge, UK: Cambridge University Press.

Ohta, A. S. (1999). Interactional routines and the socialization of interactional style in adult learners of Japanese. Journal of Pragmatics, 31(11), 1493-1512.

Opie, I., \& Opie, P. (1959). The lore and language of schoolchildren. Oxford: Oxford University Press.

Oppenheim, A. N. (1992). Questionnaire design, interviewing and attitude measurement. London: Pinter.

Oppenheim, B. (1982). An exercise in attitude measurement. In G. M. Breakwell, H. Foot, \& R. Gilmour (Eds.), Social psychology (pp. 38-56). London, UK: Palgrave.

Ortaçtepe, D. (2013). Formulaic language and conceptual socialization: The route to becoming nativelike in L2. System, 41(3), 852-865. 
Ortega, L., \& Iberri-Shea, G. (2005). Longitudinal research in SLA: Recent trends and future directions. Annual Review of Applied Linguistics, 25, 26-45.

Oxford University Press, University of Cambridge, \& Association of Language Testers in Europe. (2001). Quick placement test: Paper and pen test. Oxford: Oxford University Press.

Paribakht, T. S., \& Wesche, M. B. (1993a). Vocabulary enhancement activities and reading for meaning in second language vocabulary acquisition. Paper presented at the AILA Congress, Amsterdam.

Paribakht, T. S., \& Wesche, M. B. (1993b). Reading comprehension and second language development in a comprehension-based ESL program. TESL Canada Journal, 11(1), 929.

Paribakht, T. S., \& Wesche, M. B. (1997). Vocabulary enhancement activities and reading for meaning in second language vocabulary development. In J. Coady, \& T. Huckin (Eds.), Second language vocabulary acquisition: A rationale for pedagogy (pp. 174200). New York, NY: Cambridge University Press.

Parry, M. (1928). L'Epithète traditionelle dans Homère. Paris: Société Editrice 'Les Belles Lettres'.

Parry, M. (1930). Studies in the epic technique of oral verse-making. I: Homer and Homeric style. Harvard Studies in Classical Philology, 41, 73-148.

Parry, M. (1932). Studies in the epic technique of oral verse-making. II: The Homeric language as the language of an oral poetry. Harvard Studies in Classical Philology, 43, $1-50$.

Parziale, J., \& Fischer, K. W. (2009). The practical use of skill theory in classrooms. In R. J. Sternberg, \& W. M. Williams (Eds.), Intelligence, instruction, and assessment: Theory into practice (pp. 95-110). New Jersey, NJ: Taylor \& Francis e-Library.

Pavlenko, A. (2002). Poststructuralist approaches to the study of social factors in second language learning and use. In V. Cook (Ed.), Portraits of the L2 user (pp. 275-302). Clevedon, UK: Multilingual Matters.

Pawley, A. (1992). Formulaic speech. In W. Bright (Ed.), International encyclopedia of linguistics, Vol 2. New York, NY: Oxford University Press.

Pawley, A., \& Syder, F. H. (1983). Two puzzles for linguistic theory: Nativelike selection and nativelike fluency. In J. C. Richards, \& R. W. Schmidt (Eds.), Language and communication (pp. 191-225). London: Longman.

Pérez-Llantada, C. (2014). Formulaic language in L1 and L2 expert academic writing: Convergent and divergent usage. Journal of English for Academic Purposes, 14, 84-94.

Pérez-Sabater, C. \& Montero-Fleta, B. (2014). Pragmatic competence in social power awareness: The case of written and spoken discourse in non-native English environments. International Journal of English Studies, 14(2), 21-38.

Perloff, R. (1993). The dynamics of persuasion. Hillsdale, NJ: Lawrence Erlbaum Associates.

Peters, E., \& Pauwels, P. (2015). Learning academic formulaic sequences. Journal of English for Specific Purposes, 20, 28-39.

Pierce, B. N. (1995). Social identity, investment, and language learning. TESOL Quarterly, 29, 9-31.

Plonsky, L., \& Oswald, F. L. (2014). How Big Is "Big"? Interpreting Effect Sizes in L2 Research: Effect Sizes in L2 Research. Language Learning, 64(4), 878-912. https://doi.org/10.1111/lang.12079

Plonsky, L., \& Zhuang, J. (2019). A meta-analysis of L2 pragmatics instruction. In N. Taguchi (Ed.), The Routledge handbook of second language acquisition and pragmatics (pp. 287-307). London / New York: Routledge. 
Portolés, L. (2011). A multilingual portrait of language attitudes in higher education: The effect of internal and external factors. Saarbrücken: VDM Verlag Dr. Müller.

Portolés, L. (2014). Analysing prospective teachers' attitudes towards three languages in two different sociolinguistic and educational settings. In A. Otwinowska, \& G. De Angelis (Eds.), Teaching and learning in multilingual contexts: Sociolinguistic and educational perspectives (pp. 50-74). Bristol: Multilingual Matters.

Portolés, L. (2015). Multilingualism and very young learners: An analysis of pragmatic awareness and language attitudes. Berlin: De Gruyter Mouton.

Portolés, L., \& Safont, M. P. (2018). Examining authentic and elicited data from a multilingual perspective. The real picture of child requestive behaviour in the L3 classroom. System, 75, 81-92.

Qi, Y., \& Ding, Y. (2011). Use of formulaic sequences in monologues of Chinese EFL learners. System, 39(2), 164-174.

Rafieyan, V. (2018). Knowledge of formulaic sequences as a predictor of language proficiency. International Journal of Applied Linguistics \& English Literature, 7(2), 6469.

Rafieyan, V., Sharafi-Nejad, M., \& Eng, L. S. (2014a). Effect of pragmatic awareness on comprehension and production of conventional expressions. Theory and Practice in Language Studies, 4(7), 1352-1358.

Rafieyan, V., Sharafi-Nejad, M., \& Eng, L. S. (2014b). Effect of form-focused pragmatic instruction on production of conventional expressions. Theory and Practice in Language Studies, 4(8), 1586-1592.

Raupach, M. (1984). Formulae in second language speech production. In H. W. Dechert, D. Möhle, \& M. Raupach (Eds.), Second language productions (pp. 114-137). Tübingen: Gunter Narr Verlag.

Rebuschat, P. (2015). Implicit and explicit learning of languages Amsterdam: John Benjamins.

Richards, K. (2003). Qualitative inquiry in TESOL. New York, NY: Palgrave Macmillan.

Roever, C. (2005). Testing ESL pragmatics. Frankfurt am Main, Germany: Peter Lang.

Roever, C. (2009). Teaching and testing pragmatics. In M. H. Long, \& C. J. Doughty (Eds.), Handbook of language teaching (pp. 560-577). Malden, MA: Wiley-Blackwell.

Roever, C. (2012). What learners get for free: Learning of routine formulae in ESL and EFL environments. English Language Teaching, 66(1), 10-21.

Roever, C., Wang, S., \& Brophy, S. (2014). Learner background factors and learning of second language pragmatics. International Review of Applied Linguistics, 52(4), 377401.

Rose, K. R. (1994). Pragmatic consciousness-raising in an EFL context. In L. Bouton, \& Y. Kachru (Eds.), Pragmatics and language learning, monograph series (Vol. 5, pp. 5263). Urbana, IL: Division of English as an International Language, University of Illinois at Urbana-Champaign.

Rose, K. R. (2000). An exploratory cross-sectional study of interlanguage pragmatic development. Studies in Second Language Acquisition, 22, 27-67.

Rose, K. R. (2005). On the effects of instruction in second language pragmatics. System, 33(3), 385-399.

Rose, K. R., \& Kasper, G. (2001). Pragmatics in language teaching. Cambridge, UK: Cambridge University Press.

Ross, S. J., \& Hong, Y. (2019). Mixed methods in L2 pragmatics research. In N. Taguchi (Ed.), The Routledge handbook of second language acquisition and pragmatics (pp. 211-225). New York, London: Routledge. 
Ryan, E. B., Giles, H., \& Hewstone, M. (1988). The measurement of language attitudes. In U. Ammon, D. Dittmar, \& K. J. Mattheier (Eds.), Sociolinguistics: An international handbook of the science of language (Vol. II, pp. 1068-1081). Berlin: de Gruyter Mouton.

Safont, M. P. (2005). Third language learners: Pragmatic production and awareness. Clevedon, UK: Multilingual Matters.

Safont, M. P. (2007). Language use and language attitudes in the Valencian Community. In D. Lasagabaster, \& A. Huguet (Eds.), Multilingualism in European bilingual contexts: Language use and attitudes (pp. 90-113). Clevedon: Multilingual Matters.

Safont, M. P. (2015). The promotion of multilingualism in a Catalan-speaking area. Familial challenges in the Valencian Community. In U. Jessner, \& C. Kramsch (Eds.), The multilingual challenge: Cross-disciplinary perspectives. Berlin: de Gruyter Mouton.

Safont, M. P., \& Portolés, L. (2015). Pragmatic awareness in early consecutive third language learners. In M. P. Safont, \& L. Portolés (Eds.), Learning and using multiple languages: Current findings from research on multilingualism (pp. 218-237). Cambridge, UK: Cambridge Scholars Publishing

Safont, M. P., \& Portolés, L. (2016). Pragmatic functions of formulaic speech in three different languages. Journal of Immersion and Content-Based Language Education, 4(2), 225-250.

Salazar-Campillo, P. (2008). Task analysis on mitigation in the speech act of requesting: Discourse completion task and role-play. In E. Alcón-Soler (Ed.), Learning how to request in an instructed language learning context (pp. 143-161). Bern, Switzerland: International Academic Publishers.

Salazar-Campillo, P. (2013). Production of refusals: Insights from stimulated recall. In O. Martí-Arnándiz, \& P. Salazar-Campillo (Eds.), Refusals in instructional contexts and beyond (pp. 235-249). Amsterdam / New York, NY: Rodopi.

Sánchez-Hernández, A. (2017). Acculturation and acquisition of pragmatic routines in the study abroad context. (Unpublished doctoral dissertation). Universitat Jaume I, Castelló.

Sánchez-Hernández, A. (2018). A mixed-methods study of the impact of sociocultural adaptation on the development of pragmatic production. System, 75, 93-105.

Sánchez-Hernández, A., \& Alonso-Marks, E. (2018). Factors affecting the acquisition of Spanish pragmatic routines during study abroad. In M. A. Moreno, \& F. J. Díaz Pérez (Eds.), Languages at The Crossroads: Training, Accreditation and Context of Use (pp. 33-50). Jaen: Universidad de Jaen.

Santos, A., Cenoz, J., \& Gorter, D. (2017). Communicative anxiety in English as a third language. International Journal of Bilingual Education and Bilingualism, 20(7), 823836.

Santos, A., Cenoz, J., \& Gorter, D. (2018). Attitudes and anxieties of business and education students towards English: Some data from the Basque Country. Language, Culture and Curriculum, 31(1), 94-110.

Sardegna, V. G., \& Molle, D. (2010). Videoconferencing with strangers: Teaching Japanese EFL students verbal backchannel signals and reactive expressions. Intercultural Pragmatics, 7-2, 279-310.

Sarnoff, I. (1970). Social attitudes and the resolution of motivational conflict. In M. Jahoda, \& N. Warren (Eds.), Attitudes (pp. 279-284). Harmondsworth: Penguin.

Saussure, F. de. (1959). Course in general linguistics. New York, NY: Philosophical Library.

Scarcella, R. (1979a). On speaking politely in a second language. In C. A. Yorio, K. Perkins, \& J. Schachter (Eds.), On TESOL '79: The learner in focus (pp. 275-287). Boston, MA: 
Selected papers from the Annual Convention of Teachers of English to Speakers of Other Languages.

Scarcella, R. C. (1979b). Watch up!: A study of verbal routines in adult second language performance. Working Papers on Bilingualism Toronto, 19, 79-90.

Schachter, J. (1990). Communicative competence revisited. In B. Harley, P. Allen, J. Cummins, \& M. Swain (Eds.), The development of second language proficiency (pp. 39-49). New York, NY: Cambridge University Press.

Schauer, G. (2007). Finding the right words in the study abroad context: The development of German learners' use of external modifiers in English. Intercultural Pragmatics, 4(2), 193-220.

Schauer, G. A. (2009). Interlanguage pragmatic development: The study abroad context. New York, NY: Continuum.

Schieffelin, B. B., \& Ochs, E. (1986). Language socialization across cultures. Cambridge, UK: Cambridge University Press.

Schmidt, R. (1983). Interaction, acculturation, and the acquisition of communicative competence: A case study of an adult. In N. Wolfson, \& E. Judd (Eds.), Sociolinguistics and second language acquisition (pp. 137-174). Rowley, MA: Newbury House.

Schmidt, R. (1990). The role of consciousness in second language learning. Applied Linguistics, 11, 17-46.

Schmidt, R. (1993). Consciousness, learning and interlanguage pragmatics. In G. Kasper, \& S. Blum-Kulka, (Eds.), Interlanguage pragmatics (pp. 43-57). New York, NY: Oxford University Press.

Schmidt, R. (1994). Implicit learning and the cognitive unconscious. In N. Ellis (Ed.), Implicit and explicit learning of languages (pp.165-209). New York, NY: Academic Press.

Schmidt, R. (1995). Consciousness and foreign language learning: A tutorial on the role of attention and awareness in learning. In R. Schmidt (Ed.), Attention and awareness in foreign language learning (pp. 1-63). Honolulu, HI: University of Hawai'i, Second Language Teaching and Curriculum Center.

Schmidt, R. (2001). Attention. In P. Robinson (Ed.), Cognition and second language instruction (pp. 3-32). Cambridge, UK: Cambridge University Press.

Schmidt, R. (2010). Attention, awareness, and individual differences in language learning. In W. M. Chan, S. Chi, K. N. Cin, J. Istanto, M. Nagami, J. W. Sew, T. Suthiwan, \& I. Walker (Eds.), Proceedings of CLaSIC 2010, Singapore, December 2-4 (pp. 721-737). Singapore: National University of Singapore, Center for Language Studies.

Schmitt, N. (2004). Formulaic sequences: Acquisition, processing and use. Amsterdam/Philadelphia: John Benjamins.

Schmitt, N., \& Carter, R. (2004). Formulaic sequences in action: An introduction. In N. Schmitt (Ed.), Formulaic sequences: Acquisition, processing and use (pp. 1-22). Amsterdam/Philadelphia: John Benjamins.

Schneider, K. (2008). Small talk in England, Ireland, and the U.S.A. In K. Schneider, \& A. Barron (Eds.), Variational pragmatics: A focus on regional varieties and pluricentric languages (pp. 97-139). Amsterdam: John Benjamins.

Sears, D. (1983). The persistence of early political predispositions: The roles of attitude object and life stage. In L. Wheeler, \& P. Shaver (Eds.), Review of personality and social psychology (vol. 4, pp. 79-116). Beverly Hills, CA: Sage.

Sears, D., \& Kosterman, R. (1994). Mass media and political persuasion. In S. Shavitt, \& T. Brock (Eds.), Persuasion: Psychological insights and perspectives. Boston, MA: Ally and Bacon.

Selinker, L. (1972). Interlanguage. IRAL, 10, 209-231. 
Sharp, D., Thomas, B., Price, E., Francis, G., \& Davies, I. (1973). Attitudes to Welsh and English in the schools of Wales. Basingstoke, Cardiff: Macmillan/ University of Wales Press.

Sherif, M. (1967). Introduction. In C. Sherif, \& M. Sherif (Eds.), Attitude, ego, involvement and change. New York, NY: Wiley.

Siegal, M. (1996). The role of learner subjectivity in second language sociolinguistic competency: Western women learning Japanese. Applied Linguistics, 17(3), 356-382.

Silva-Corvalán, C. (2001). Sociolingüistica y pragmática del español. (Sociolinguistics and pragmatics of Spanish) [Georgetown Studies in Spanish Linguistics]. Washington DC: Georgetown University Press.

Silverstein, M. (1976). Shifters, linguistic categories and cultural description. In K. H. Baso, \& H. A. Selby (Eds.), Meaning in anthropology (pp. 11-55). Albuquerque, NM: University of New Mexico Press.

Simpson-Vlach, R., \& Ellis, N. (2010). An academic formulas list: New methods in phraseology research. Applied Linguistics, 31(4), 487-512.

Spöttl, C., \& McCarthy, M. (2003). Formulaic utterances in the multilingual context. In J. Cenoz, B. Hufeisen, \& U. Jessner (Eds.), The multilingual lexicon (pp. 133-151). The Netherlands: Kluwer Academic Publishers.

Swain, M. (1985). Communicative competence: Some roles of comprehensible input and comprehensible output in its development. In S. Gass, \& C. Madden (Eds.), Input in second language acquisition (pp. 235-253). Rowley, MA: Newbury House.

Swain, M. (1995). Three functions of output in second language learning. In G. Cook, \& B. Seidlhofer (Eds.), Principle and practice in applied linguistics (pp. 245-256). Oxford, UK: Oxford University Press.

Sykes, J. (2009). Learner request in Spanish: Examining the potential of multiuser virtual environments for L2 pragmatics acquisition. In L. Lomika, \& G. Lord (Eds.), The second generation: Online collaboration and social networking in CALL (pp. 199-234). San Marcos, TX: CALICO Monograph.

Sykes, J. (2013). Multiuser virtual environments: Learner apologies in Spanish. In N. Taguhci, \& J. Sykes (Eds.), Technology in interlanguage pragmatics research and teaching (pp. 71-100). Philadelphia, PA: John Benjamins.

Tada, M. (2005). Assessment of EFL pragmatic production and perception using video prompts. (Unpublished doctoral dissertation). Temple University, Philadelphia, PA.

Taguchi, N. (2002). An application of Relevance theory to the analysis of L2 interpretation processes: The comprehension of indirect replies. International Review of Applied Linguistics, 40, 151-176.

Taguchi, N. (2005). Comprehension of implied meaning in English as a second language. Modern Language Journal, 89, 543-562.

Taguchi, N. (2007). Development of speed and accuracy in pragmatic comprehension of English as a foreign language. TESOL Quarterly, 41, 313-338.

Taguchi, N. (2008a). Pragmatic comprehension in Japanese as a foreign language. Modern Language Journal, 92, 558-576.

Taguchi, N. (2008b). The role of learning environment in the development of pragmatic comprehension: A comparison of gains between EFL and ESL Learners. Studies in Second Language Acquisition, 30, 423-452.

Taguchi, N. (2008c). Cognition, language contact, and development of pragmatic comprehension in a study-abroad context. Language Learning, 58, 33-71.

Taguchi, N. (2010). Longitudinal studies in interlanguage pragmatics. In A. Trosborg (Ed.), Pragmatics across languages and cultures (pp. 333-362). Berlin, New York: De Gruyter Mouton. 


\section{References}

Taguchi, N. (2011a). Teaching pragmatics: Trends and issues. Annual Review of Applied Linguistics, 31, 289-310.

Taguchi, N. (2011b). Pragmatic development as a dynamic, complex process: General patterns and case histories. The Modern Language Journal, 95, 605-627.

Taguchi, N. (2012). Context, individual differences and pragmatic competence. Bristol, Buffalo, Toronto: Multilingual Matters.

Taguchi, N. (2013). Production of routines in L2 English: Effect of proficiency and studyabroad experience. System, 41, 109-121.

Taguchi, N. (2015a). "Contextually" speaking: A survey of pragmatic learning abroad, in class, and online. System, 48, 3-20.

Taguchi, N. (2015b). Instructed pragmatics at a glance: Where instructional studies were, are, and should be going. Language Teaching, 48(1), 1-50.

Taguchi, N. (2018). Contexts and pragmatics learning: Problems and opportunities of the study abroad research. Language Teaching, 51(1), 124-137.

Taguchi, N. (2019). Second language acquisition and pragmatics: An overview. In N. Taguchi (Ed.), The Routledge handbook of second language acquisition and pragmatics (pp. 1-14). New York, London: Routledge.

Taguchi, N. Li, S., \& Xiao, F. (2013). Production of formulaic expressions in L2 Chinese: A developmental investigation in a study abroad context. Chinese As a Second Language Research, 2(1), 23-58.

Taguchi, N., \& Kim, Y. (2016). Collaborative dialogue in learning pragmatics: Pragmaticsrelated episodes as an opportunity for learning request-making. Applied Linguistics, $37(3), 416-437$.

Taguchi, N., \& Roever, C. (2017). Second language pragmatics. Oxford, UK: Oxford University Press.

Taguchi, N., \& Sykes, J. M. (2013). Technology in interlanguage pragmatics research and teaching. Philadelphia, PA: John Benjamins.

Taguchi, N., Gómez-Laich, M. P., \& Arrufat-Marqués, M. J. (2016). Comprehension of indirect meaning in Spanish as a foreign language. Foreign language Annals, 49, 677698.

Taguchi, N., Li, Q., \& Tang, X. (2017). Learning Chinese formulaic expressions in a scenario-based interactive environment. Foreign language Annals, 50(4), 641-660.

Taguchi, N., Xiao, F., \& Li, S. (2016). Development of pragmatic knowledge in L2 Chinese: effects of intercultural competence and social contact on speech act production in a study abroad context. The Modern Language Journal, 100(4), 775-796.

Taie, M. (2014). Skill acquisition theory and its important concepts in SLA. Theory and Practice in Language Studies, 4(9), 1971-1976.

Takahashi, S. (2010a). Assessing learnability in second language pragmatics. In A. Trosborg (Ed.), Pragmatics across languages and cultures (pp. 391-421). Berlin: De Gruyter Mouton.

Takahashi, S. (2010b). The effect of pragmatic instruction on speech act performance. In A. Martínez-Flor, \& E. Usó-Juan (Eds.), Speech act performance: Theoretical empirical and methodological issues (pp. 127-144). Amsterdam / Philadelphia, PA: John Benjamins.

Takimoto, M. (2006). The effects of explicit feedback on the development of pragmatic proficiency. Language Teaching Research, 10, 393-417.

Takimoto, M. (2007). The effects of referential oriented activity in the structured input of the development of learners' pragmatic proficiency. New Zealand Studies in Applied Linguistics, 13, 46-60. 
Takimoto, M. (2009). The effects of input-based tasks on the development of learners' pragmatic proficiency. Applied Linguistics, 30, 1-25.

Takimoto, M. (2012a). Assessing the effects of identical task repetition and task type repetition on learners' recognition and production of second language request downgraders. Intercultural Pragmatics, 9, 71-96.

Takimoto, M. (2012b). Metapragmatic discussion in interlanguage pragmatics. Journal of Pragmatics, 44, 1240-1253.

Tateyama, Y., Kasper, G., Mui, L., Tay, H., \& Thananart, O. (1997). Explicit and implicit teaching of pragmatic routines. In L. Bouton (Ed.), Pragmatics and language learning (Vol. 8, pp. 163-177). Urbana-Champaign, IL: Division of English as an International Language, University of Illinois, Urbana-Champaign.

Tatsuki, D. H. (2019). Instructional material development in L2 pragmatics. In N. Taguchi (Ed.), The Routledge handbook of second language acquisition and pragmatics (pp. 322-337). New York, London: Routledge.

Tatsuki, D. H., \& Houck, N. R. (2010). Pragmatics: Teaching speech acts. Alexandria, VA: TESOL.

Thomas, J. (1983). Cross-cultural pragmatic failure. Applied Linguistics, 4, 91-112.

Thomas, J. (1995). Meaning in interaction: an introduction to pragmatics. London, UK: Longman.

Todeva, E., \& Cenoz, J. (2014). The multiple realities of multilingualism: Personal narratives and researchers' perspectives. Berlin: de Gruyter Mouton.

Tsou, W., \& Huang, Y. (2012). The effect of explicit instruction in formulaic sequences on academic speech fluency. Taiwan International ESP Journal, 4(2), 57-80.

Usó-Juan, E. (2013). Effects of metapragmatic instruction on EFL learners' production of refusals. In O. Martí-Arnándiz, \& P. Salazar-Campillo (Eds.), Refusals in instructional contexts and beyond (pp. 65-99). Amsterdam / New York, NY: Rodopi.

Usó-Juan, E., \& Martínez-Flor, A. (2006). Current trends in the development and teaching of the four language skills. Berlin: Mouton de Gruyter.

Usó-Juan, E., \& Martínez-Flor, A. (2014). Reorienting the assessment of the conventional expressions of complaining and apologising: From single-response to interactive DCTs. Iranian Journal of Language Testing, 4(1), 113-136.

Usó-Juan, E., \& Martínez-Flor, A. (2015). Assessing EFL learners' performance of conventional expressions of complaining and apologising. Procedia - Social and Behavioral Sciences, 173, 53-60.

Valencia, J. F., \& Cenoz, J. (1992). The role of bilingualism in foreign language acquisition. Journal of Multilingual and Multicultural Development, 13(5), 433-449.

van Compernolle, R. A. (2011). Developing second language sociopragmatic knowledge through concept-based instruction: A microgenetic study. Journal of Pragmatics, 43(13), 3267-3283.

van Compernolle, R. A., \& Henery, A. (2014). Instructed concept appropriation and L2 pragmatic development in the classroom. Language Learning, 64(3), 549-578.

Van Compernolle, R. A., \& Henery, A. (2016). Evaluating L2 pragmatic appropriateness and authenticity in synchronous computer-mediated strategic interaction scenarios. In R. A. Van Compernolle, \& J. McGregor (Eds.), Authenticity, language, and interaction in second language contexts (pp. 10-34). Bristol, UK: Multilingual Matters.

van Compernolle, R. A., Gomez-Laich, M. P., \& Weber, A. (2016). Teaching L2 Spanish sociopragmatics through concepts: A classroom-based study. Modern language journal, 100(1), 341-361.

Vellenga, H. (2011). Teaching L2 pragmatics: Opportunities for continuing professional development. TESL-EJ, 15(2), 1-27. 
Vygotsky, L. S. (1978). Mind in society. Cambridge, MA: Harvard University Press.

Weinert, R. (1995). The role of formulaic language in second language acquisition: A review. Applied Linguistics, 16(2), 180-205.

Wesche, M., \& Paribakht, T. S. (1994). Enhancing vocabulary acquisition through reading: A hierarchy of text-related exercise type. Paper presented at the Annual Meeting of the American Association of Applied Linguistics. Baltimore (MD) March 5-8.

Wesche, M., \& Paribakht, T. S. (1996). Assessing second language vocabulary knowledge: Depth vs. breadth. Canadian Modern Journal Review, 53(1), 13-40.

Wicker, A. W. (1969). Attitudes versus actions: The relationship of verbal and overt behavioral responses to attitude objects. Journal of Social Issues, 25(4), 41-78.

Wildner-Bassett, M. (1984). Improving pragmatic aspects of learners' interlanguage. Tübingen: Narr.

Wildner-Bassett, M. (1986). Teaching and learning "polite noises": Improving pragmatic aspects of advanced adult learners' interlanguage. In G. Kasper (Ed.), Learning, teaching and communication in the foreign language classroom (pp. 163-178). Aarhus, Denmark: Aarhus University Press.

Wishnoff, J. R. (2000). Hedging your bets: L2 learners' acquisition of pragmatic devices in academic writing and computer-mediated discourse. Second Language Studies, 19, $127-$ 157. www.hawaii.edu/sls/sls/wp-content/uploads/2011/06/Wishnoff.pdf

Wolfram, W., \& Schilling, N. (2015). American English: Dialects and variation. Malden, MA: Wiley Blackwell.

Wong-Filmore, L. (1976). The second time around: Cognitive and social strategies in second language acquisition. (Unpublished doctoral dissertation). Stanford University, Palo Alto, CA.

Wood, D. (2006). Uses and functions of formulaic sequences in second language speech: An exploration of the foundations of fluency. The Canadian Modern Language Review/La Revue canadienne des langues vivantes, 63(1), 13-33.

Wood, D. (2015). Fundamentals of formulaic language: An introduction. London/ New York, NY: Bloomsbury.

Woodfield, H. (2010) What lied beneath?: Verbal report in interlanguage requests in English. Multilingua: Journal of Cross-Cultural and Interlanguage Communication, 29(1), 1-27.

Wray, A. (1999). Formulaic language in learners and native speakers. Language Teaching, $32(4), 213-231$.

Wray, A. (2000). Formulaic sequences in second language teaching: Principle and practice. Applied Linguistics, 21(4), 463-489.

Wray, A. (2002a). Formulaic language and the lexicon. Cambridge: Cambridge University Press.

Wray, A. (2002b). Formulaic language in computer-assisted communication: Theory meets reality. Language Awareness, 11, 114-131.

Wray, A. (2006). Formulaic language. In K. Brown (Ed.), Encyclopedia of language \& linguistics (pp. 590-597). Oxford, UK: Elsevier.

Wray, A. (2012). What do we (think we) know about formulaic language? An evaluation of the current state of play. Annual Review of Applied Linguistics, 32, 231-254.

Wray, A. (2013a). Formulaic language. Language Teaching, 46(3), 316-334.

Wray, A. (2013b). Formulaic sequences. In C. A. Chapelle (Ed.), The encyclopedia of applied linguistics (Vol. IV). Oxford: Oxford University Press.

Wray, A., \& Perkins, M. R. (2000). The functions of formulaic language: An integral model. Language \& Communication, 20, 1-28. 


\section{References}

Xiao, F. (2015). Adult second language learners' pragmatic development in the study-abroad context: A review. Frontiers: The Interdisciplinary Journal of Study Abroad, XXV, 132149.

Yamashita, S. (2008). Investigating interlanguage pragmatic ability: What are we testing? In E. Alcón-Soler, \& A. Martínez-Flor (Eds.), Investigating pragmatics in foreign language learning, teaching and testing (pp. 201-223). Bristol, Buffalo, Toronto: Multilingual Matters.

Yang, J. (2016). CFL learners' recognition and production of pragmatic routine formulae. Chinese as a Second Language, 51(1), 29-61.

Yates, L., \& Major, G. (2015). "Quick-chatting", "smart dogs", and how to "say without saying": Small talk and pragmatic learning in the community. System, 48, 141-152.

Yihong, G., Yuan, Z., Ying, C., \& Yan, Z. (2007). Relationship between English learning motivation types and self-identity changes among Chinese students. TESOL Quarterly, 41(1), 133-155.

Yorio, C. A. (1980). Conventionalized language forms and the development of communicative competence. TESOL Quarterly, 14(4), 433-442.

Youn, S. J., \& Bogorevich, V. (2019). Assessment in L2 pragmatics. In N. Taguchi (Ed.), The Routledge handbook of second language acquisition and pragmatics (pp. 308-321). London / New York: Routledge.

Yule, G. (1996). Pragmatics. Oxford: Oxford University Press.

Zhou, M. (1999). The official national language and language attitudes of three ethnic minority groups in China. Language Problems and Language Planning, 23(2), 157-174. 



\section{APPENDICES}

Appendix 1. PowerPoint Presentation Session 1 Instructional treatment

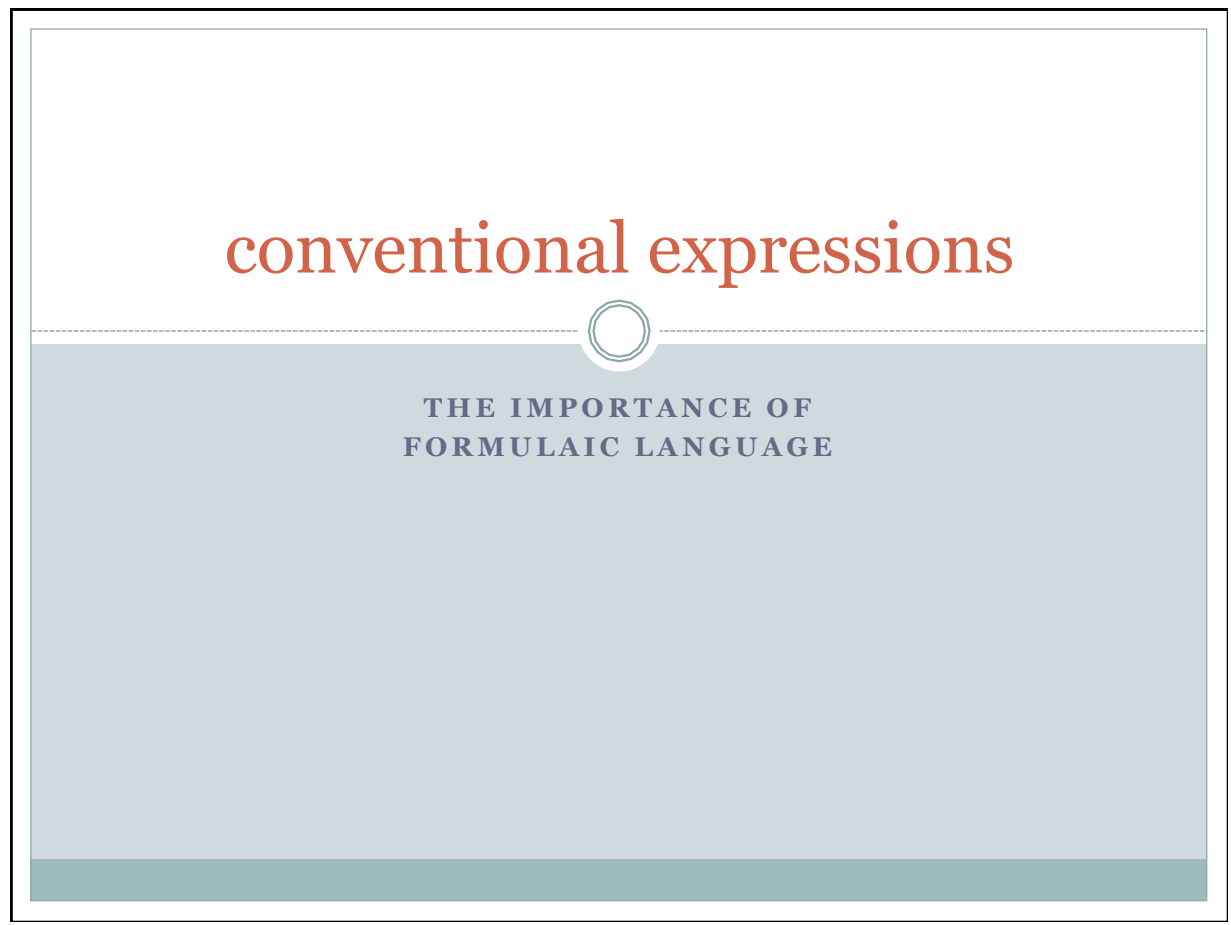

\section{Communicative Competence}

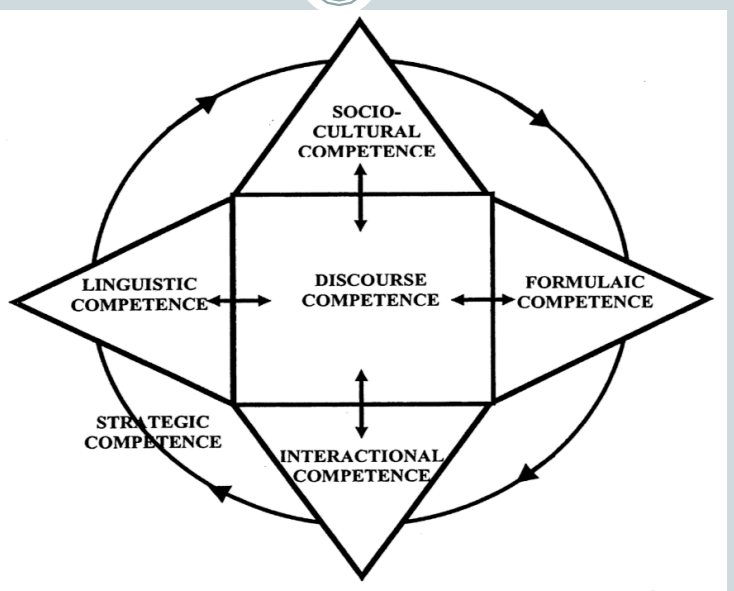

Figure 3.3 Revised schematic representation of 'communicative competence' 


\section{A definition}

(Bardovi-Harlig, 2009, 2013)

- String of words, chunks of language

- Attention on social characterization of routines

- Focus on speech communities

- Use determined by proficiency level

\section{Main features}

(Myles, Hooper and Mitchel, 1998: 325)

- "at least two morphemes in length;"

- "fluently articulated, nonhesitant;"

- "used repeatedly and always in the same form;"

- "situationally dependent;"

- "community-wide in use." 


\section{Main features}

(Bardovi-harlig, 2013)

- Pragmatic variation:

- In speech or writing

- Location of community

- Speaker's age (E.g.: “Easy peasy” \& “A piece of cake”)

\section{Why are CE important?}

- "Crucial to social communication" (Bardovi-Harlig \& Vellenga, 2012: 77).

- House (1996: 227-228): CE "essential in the verbal handling of everyday life.” 


\section{Social dimensions in interaction}

- Brown and Levinson (1987):

- Social distance

- Power

- Degree of imposition

\section{Examples}

- (1) Situation: Your mom asks you to help her with dinner. She says: "Would you mind helping me with dinner?"

https://www.youtube.com/watch?

$\mathrm{v}=9$ GouWszJhM\&feature=youtu.be

You say:

Not at all. 


\section{Examples}

- (2) Situation: Your three best friends and you just went out of the movies. Now you have to decide where to go to dinner. After some discussion, it seems that you will go to a new Indian restaurant. A friend asks the whole group: Is the new Indian place at Forbes Ave. OK for everyone?

You say:

That works for me.

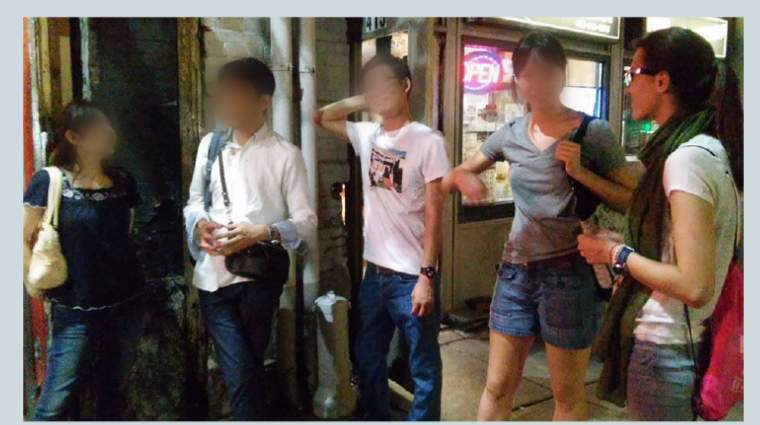

(3) Situation: Your friend Ana just threw a wonderful party. As you leave,

You say:

Thanks for having me.

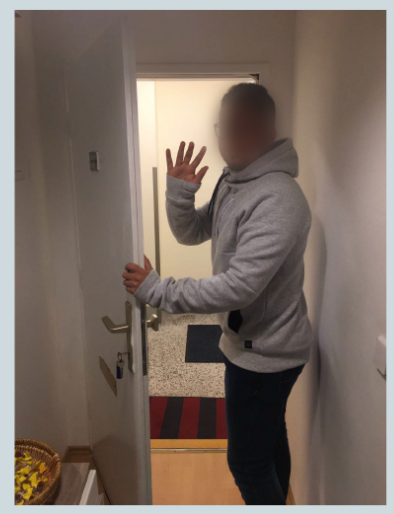




\section{Appendices}

- (4) Situation: You meet Paula, Silvia's friend, whom you had been introduced before, on campus another day.

You say:

"Nice to see you again" (or "Good to see you again") AND THEN

Nice seeing you again. (or "Good seeing you again") AT END OF CONVERSATION

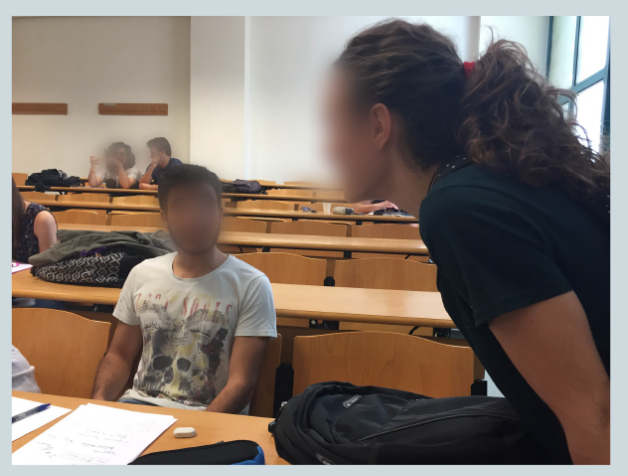

(5) Situation: You just finished classes and it is pouring. As you go to your car, a classmate of yours asks you if you can give him a ride.

You say:

Sure. No problem.

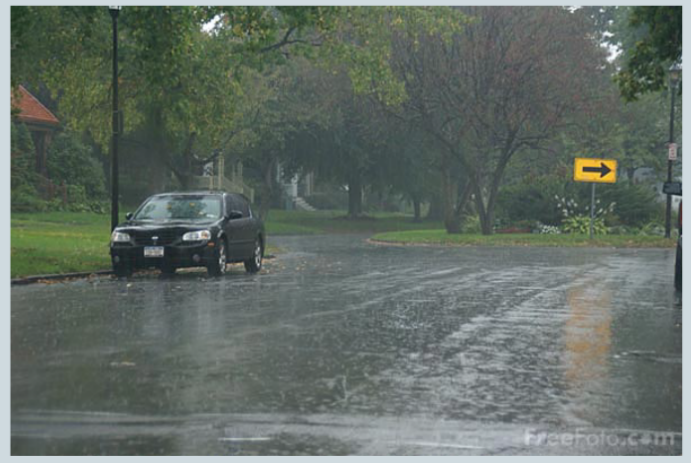

Source: http://injust10.blogspot.com.es/2011 03 01 archive.html 


\section{Examples}

- (6) Situation: Your mom just made some tea. She asks you: "Honey, would you like a cup of tea?" However, you do not feel like having some tea now and reject her offer.

You say:

No, thanks. I'm good.

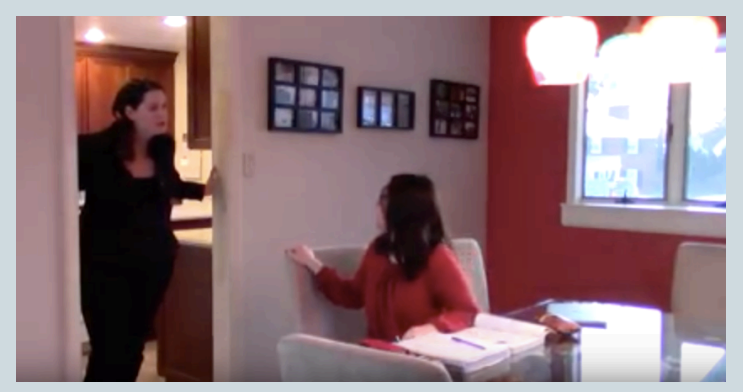

- (7) Situation: You are at your in-laws' Christmas dinner. They offer you more food but you already ate a lot and do not want any more.

You say:

No, thanks. I'm full.

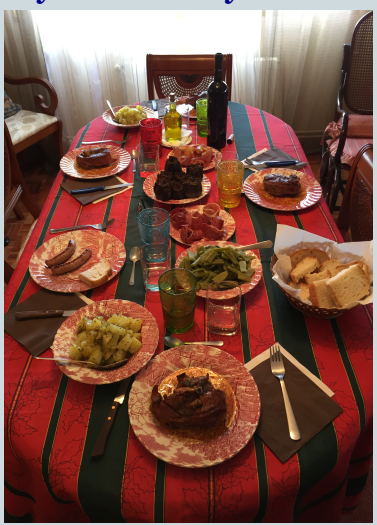




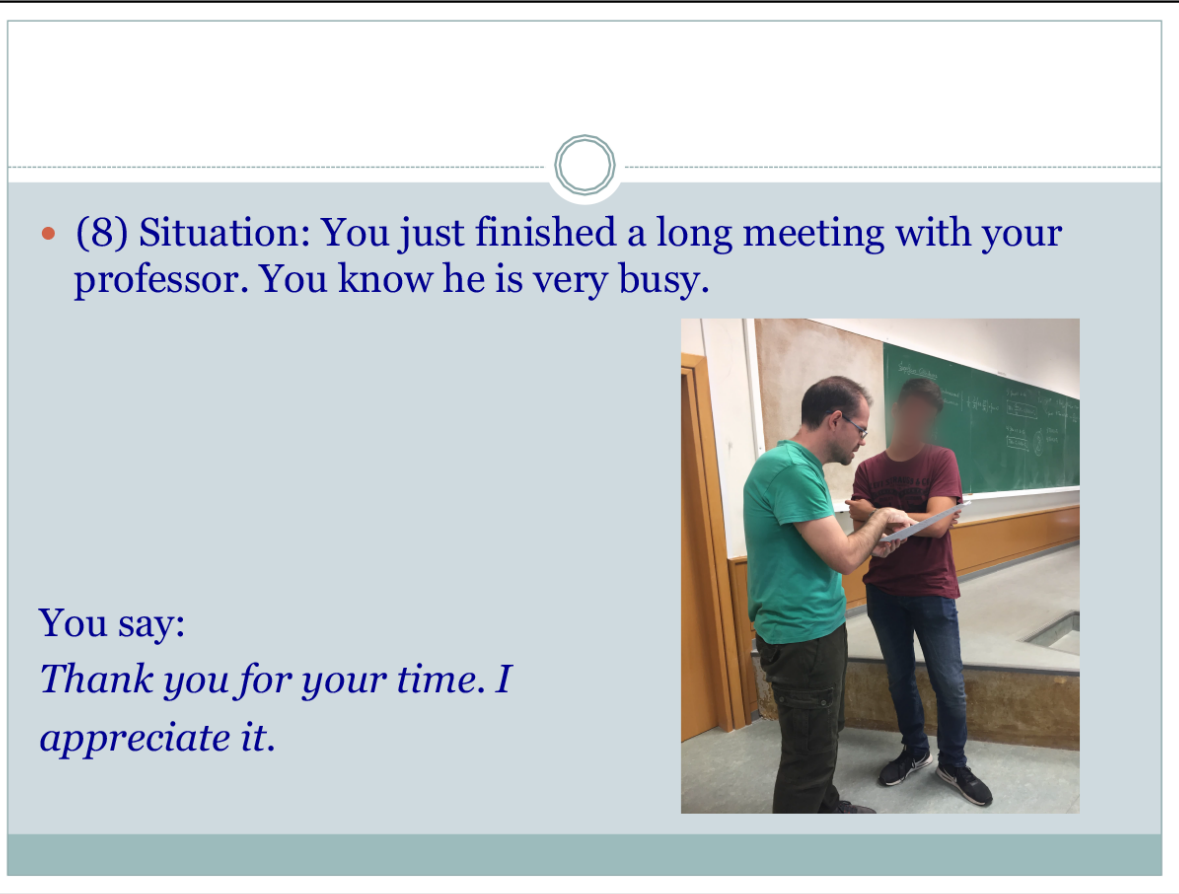

\section{Examples}

- (9) Situation: A friend of yours just bought a dress for her brother's wedding. You go to her place and she tries it on and asks for your opinion. You think it fits her well.

You say:

It looks great on you!

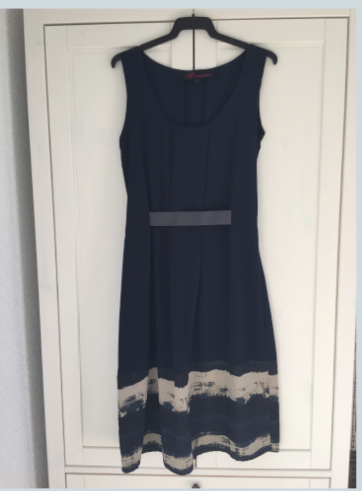




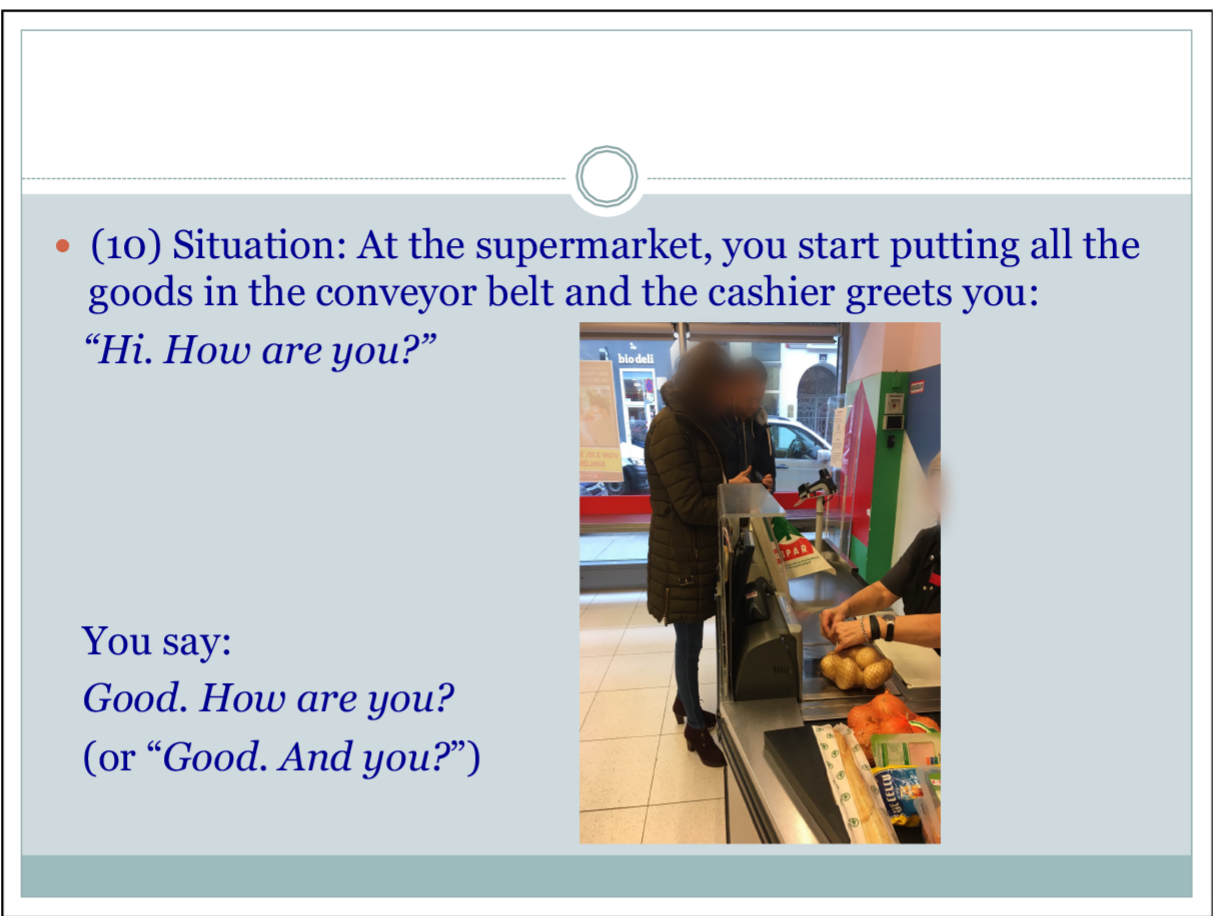

\section{Examples}

- (11) Situation: You just finished classes today. It is pouring outside, you do not have an umbrella and you missed the bus. You see a classmate of yours approaching his car.

You say:

Can I get a ride?

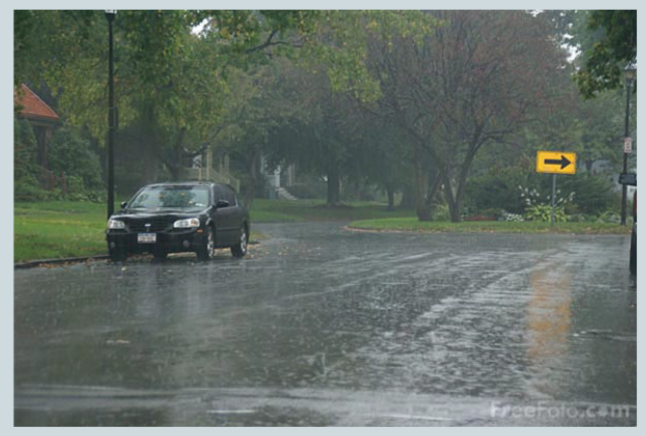

Source: http://injust1o.blogspot.com.es/2011 0301 archive.html 


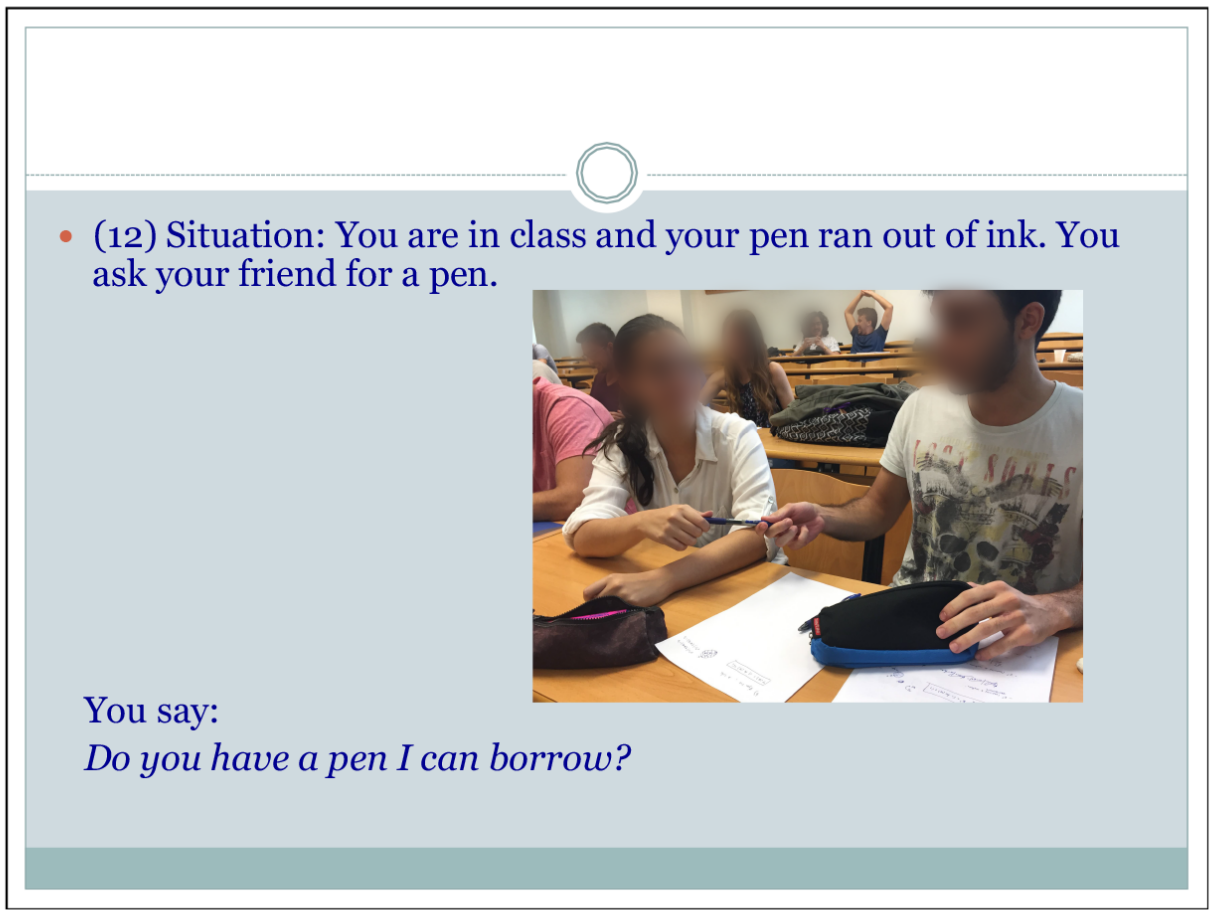

- (13) Situation: Your friend invites you to dinner. Then, he suggests to go dancing afterwards.

You say:

I'd love to.

(or "That sounds fun!")

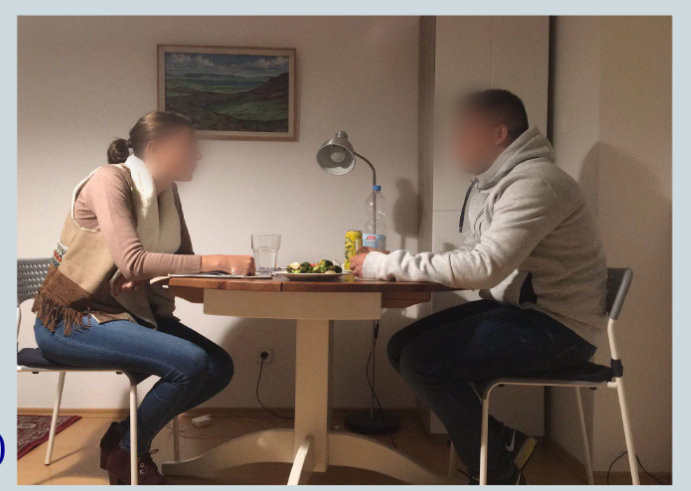




\section{Examples}

- (14) Situation: You are at the movies with your significant other. You are trying to follow the plot, but there is a group of youngsters who are talking loud. It bothers you and you ask them to be quiet.

You say:

Keep it down.

(also "Be quiet" or "Shut up")

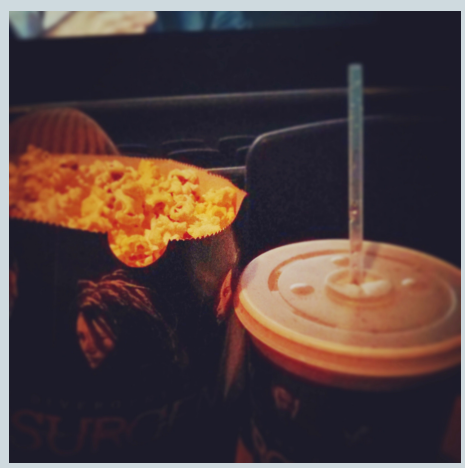

- (15) Situation: You are in an aisle in a supermarket. There is an old lady slowly pushing a shopping cart in front of you. However, you need to get by her.

You say:

Excuse me.

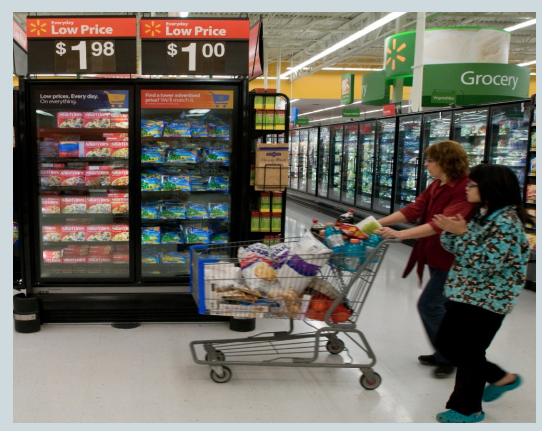

Source: https://www.flickr.com/photos/walmartcorporate/5684145463 


\section{Examples}

- (16) Situation: You are in an aisle at a supermarket. You are trying to get around an old lady and accidentally bump into her cart.

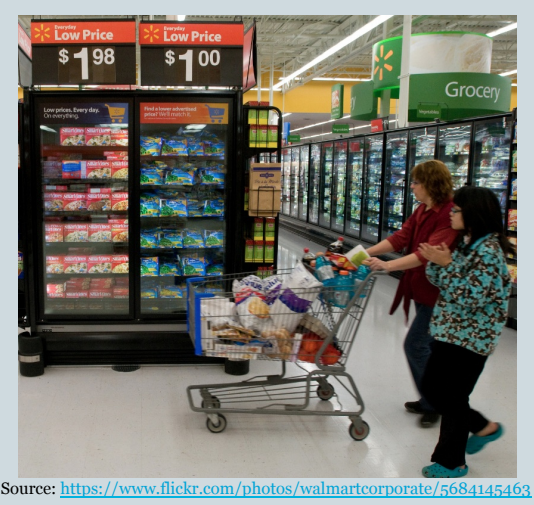

I'm/I am so sorry.

\section{Examples}

- (17) Situation: You have a group project due tomorrow which needs some revisions. You tell your friend Cristina: "We could go to my place" and she accepts. However, you did not have time to tidy up you apartment and you realize Cristina will see it all. As both of you go into your apartment,

You say:

Excuse the mess.

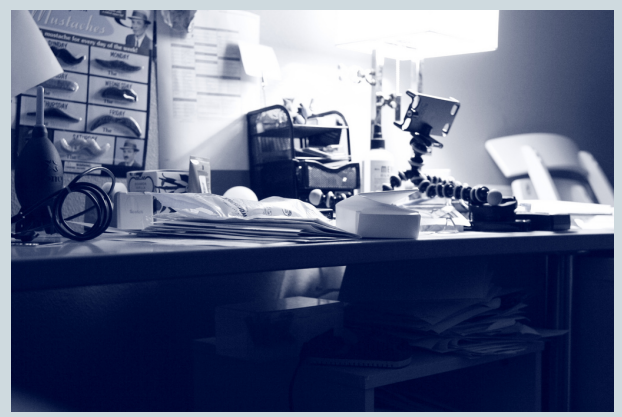

Source: https://wwww.flickr.com/photos/mccun934/84003,3056.3 
- (18) Situation: You are in a store looking at some books. A sales person comes up to you and asks you if you need some help.

However, you do not need help.

You say:

No, thanks. I'm just looking.

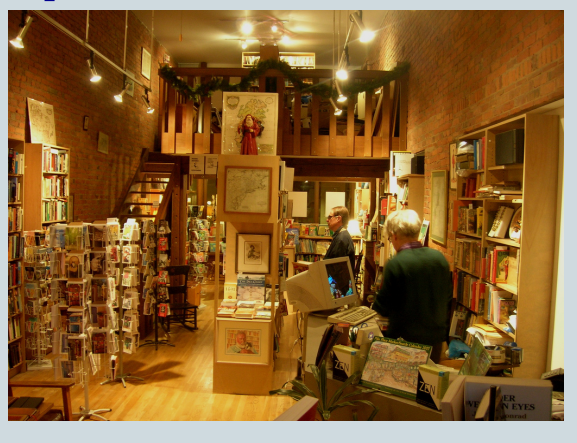

Source: https://www.flickr.com/photos/brewbooks/330665317

\section{Examples}

- (19) Situation: You and your friend are on your way to campus. Your friend is about to cross the street but he does not see a car coming. You already have seen the car and try to stop him.

You say:

Watch out!

(or "Look out!")

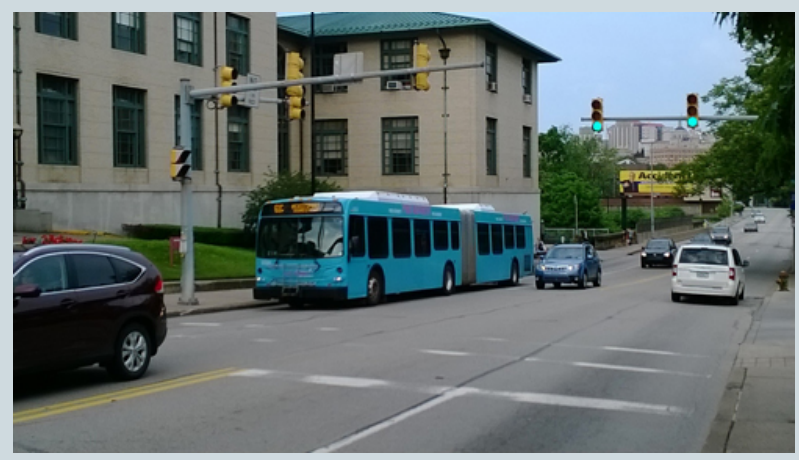


Appendices

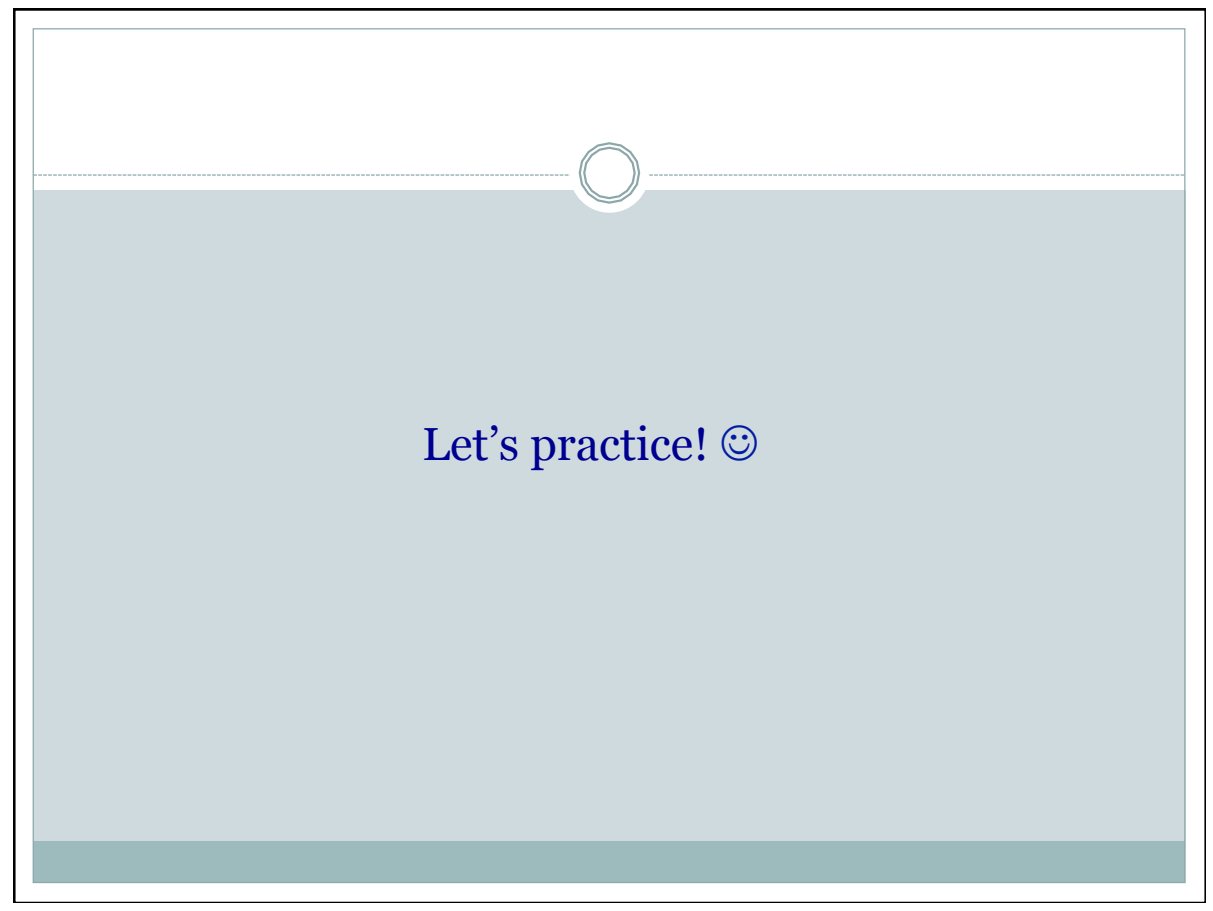


Appendix 2. Appropriateness Judgment Task Session 1 Instructional treatment

NAME:

Instructions: Please read the following situations and the responses provided for each of the situations. Rate the appropriateness of each of the expressions by circling iust one out of the two options. Then explain why you think the expression used is appropriate or not for the context in which it appears.

Rating options: 1: Appropriate OR 2: Inappropriate

\section{Situation 1:}

Scenario: Your mom asks you to help her with dinner. She says: "Would you mind helping me with dinner?"

You say: Of course not, madam. I will gladly assist you.
1: Appropriate
2: Inappropriate

Explain why the response provided is appropriate or not for this context:

\section{Situation 2:}

Scenario: Your three best friends and you just went out of the movies. Now you have to decide where to go to dinner. After some discussion, it seems that you will go to a new Indian restaurant. A friend asks the whole group: Is the new Indian place at Forbes Ave. OK for everyone?

You say: That works for me.
1: Appropriate
2: Inappropriate

Explain why the response provided is appropriate or not for this context: 
Appendices

\section{Situation 3:}

Scenario: Your friend Ana just threw a wonderful party. As you leave,

You say: Goodbye. See you around.
1: Appropriate
2: Inappropriate

Explain why the response provided is appropriate or not for this context:

\section{Situation 4:}

Scenario: You meet Paula, Silvia's friend, whom you had been introduced before, on campus another day.

You say: See you around! How are you?
1: Appropriate
2: Inappropriate

Explain why the response provided is appropriate or not for this context:

\section{Situation 5:}

Scenario: You just finished classes and it is pouring outside. As you go to your car, a classmate of yours asks you if you can give him a ride.

You say: I will joyfully drive you home, my kind fellow.
1: Appropriate
2: Inappropriate

Explain why the response provided is appropriate or not for this context: 
Appendices

\section{Situation 6:}

Scenario: Your mom just made some tea. She asks you: "Honey, would you like a cup of tea?" However, you do not feel like having some tea now and reject her offer.

You say: I am very sorry, but I am afraid I may not want to have a cup of tea right now. Thank you very much, though.
1: Appropriate
2: Inappropriate

Explain why the response provided is appropriate or not for this context:

\section{Situation 7:}

Scenario: You are at your in-laws' Christmas dinner. They offer you more food but you already ate a lot and do not want any more.

You say: Thanks. I'm full.
1: Appropriate
2: Inappropriate

Explain why the response provided is appropriate or not for this context:

\section{Situation 8:}

Scenario: You just finished a long meeting with your professor. You know he is very busy.

You say: Thanks, buddy! See ya!
1: Appropriate
2: Inappropriate

Explain why the response provided is appropriate or not for this context: 
Appendices

\section{Situation 9:}

Scenario: A friend of yours just bought a dress for her brother's wedding. You go to her place and she tries it on and asks for your opinion. You think it fits her well.

You say: It looks great on you!
1: Appropriate
2: Inappropriate

Explain why the response provided is appropriate or not for this context:

\section{Situation 10:}

Scenario: At the supermarket, you start putting all the goods in the conveyor belt and the cashier greets you: "Hi. How are you?"

You say: Fine.
1: Appropriate
2: Inappropriate

Explain why the response provided is appropriate or not for this context:

\section{Situation 11:}

Scenario: You just finished classes today. It is pouring outside, you do not have an umbrella and you missed the bus. You see a classmate of yours approaching his car.

You say: Could you get me a ride?
1: Appropriate
2: Inappropriate

Explain why the response provided is appropriate or not for this context: 
Appendices

\section{Situation 12:}

Scenario: You are in class and your pen ran out of ink. You ask your friend for a pen.

You say: Give me your pen.
1: Appropriate
2: Inappropriate

Explain why the response provided is appropriate or not for this context:

Situation 13:

Scenario: Your friend invites you to dinner. Then, he suggests to go dancing afterwards.

You say: I'd love to.
1: Appropriate
2: Inappropriate

Explain why the response provided is appropriate or not for this context:

\section{Situation 14:}

Scenario: You are at the movies with your significant other. You are trying to follow the plot, but there is a group of youngsters who are talking loud. It bothers you and you ask them to be quiet.

You say: Shut up!!!
1: Appropriate
2: Inappropriate

Explain why the response provided is appropriate or not for this context: 


\section{Appendices}

\section{Situation 15:}

Scenario: You are in an aisle in a supermarket. There is an old lady slowly pushing a shopping cart in front of you. However, you need to get by her.

You say: Do you mind?
1: Appropriate
2: Inappropriate

Explain why the response provided is appropriate or not for this context:

\section{Situation 16:}

Scenario: You are in an aisle at a supermarket. You are trying to get around an old lady and accidentally bump into her cart.

You say: $\underline{\text { Sorry. }}$
1: Appropriate
2: Inappropriate

Explain why the response provided is appropriate or not for this context:

\section{Situation 17:}

Scenario: You have a group project due tomorrow which needs some revisions. You tell your friend Cristina: "We could go to my place" and she accepts. However, you did not have time to tidy up you apartment and you realize Cristina will see it all. As both of you go into your apartment,

You say: Excuse the mess.
1: Appropriate
2: Inappropriate

Explain why the response provided is appropriate or not for this context: 


\section{Appendices}

\section{Situation 18:}

Scenario: You are in a store looking at some books. A sales person comes up to you and asks you if you need some help.

You say: Yes, thanks. I'm just looking.
1: Appropriate
2: Inappropriate

Explain why the response provided is appropriate or not for this context:

\section{Situation 19:}

Scenario: You and your friend are on your way to campus. Your friend is about to cross the street but he does not see a car coming. You already have seen the car and try to stop him.

You say: Watch out!
1: Appropriate
2: Inappropriate

Explain why the response provided is appropriate or not for this context: 
Appendices 
Appendix 3. PowerPoint Presentation Session 2 Instructional treatment

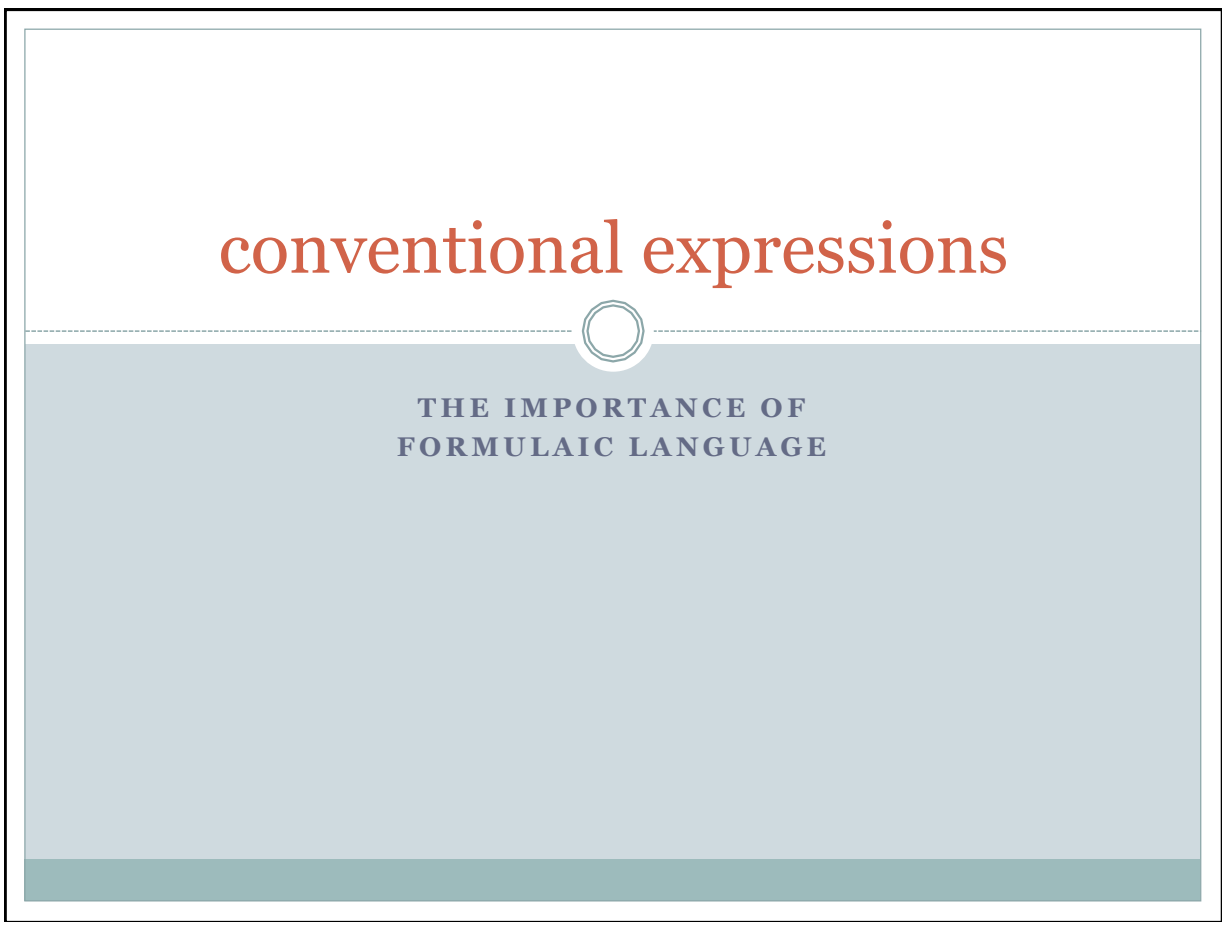

\section{Communicative Competence}

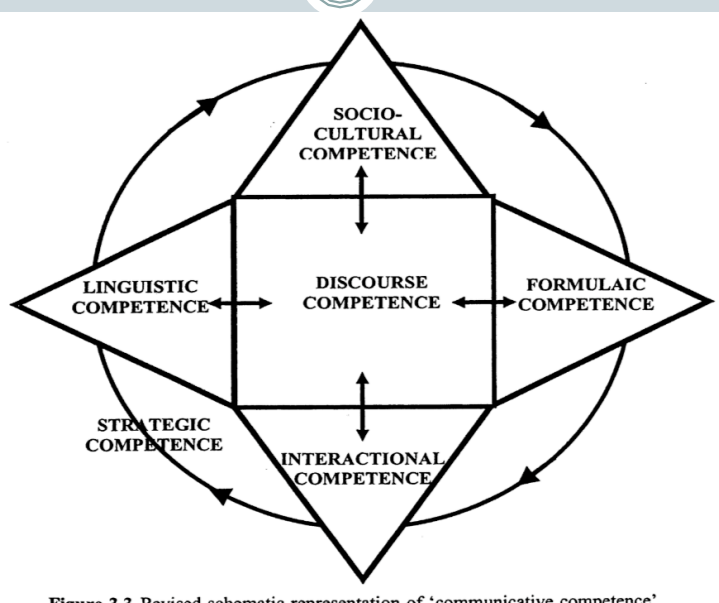

Figure 3.3 Revised schematic representation of 'communicative competence' 


\section{Introduction}

- Conventional expressions

- ESSENTIAL IN EVERYDAY INTERACTIONS

- Features (5)

- Variation (speech/writing, age, location of community)

- Brown \& Levinson's (1987) 3 social dimensions Social distance, Power, Degree of imposition

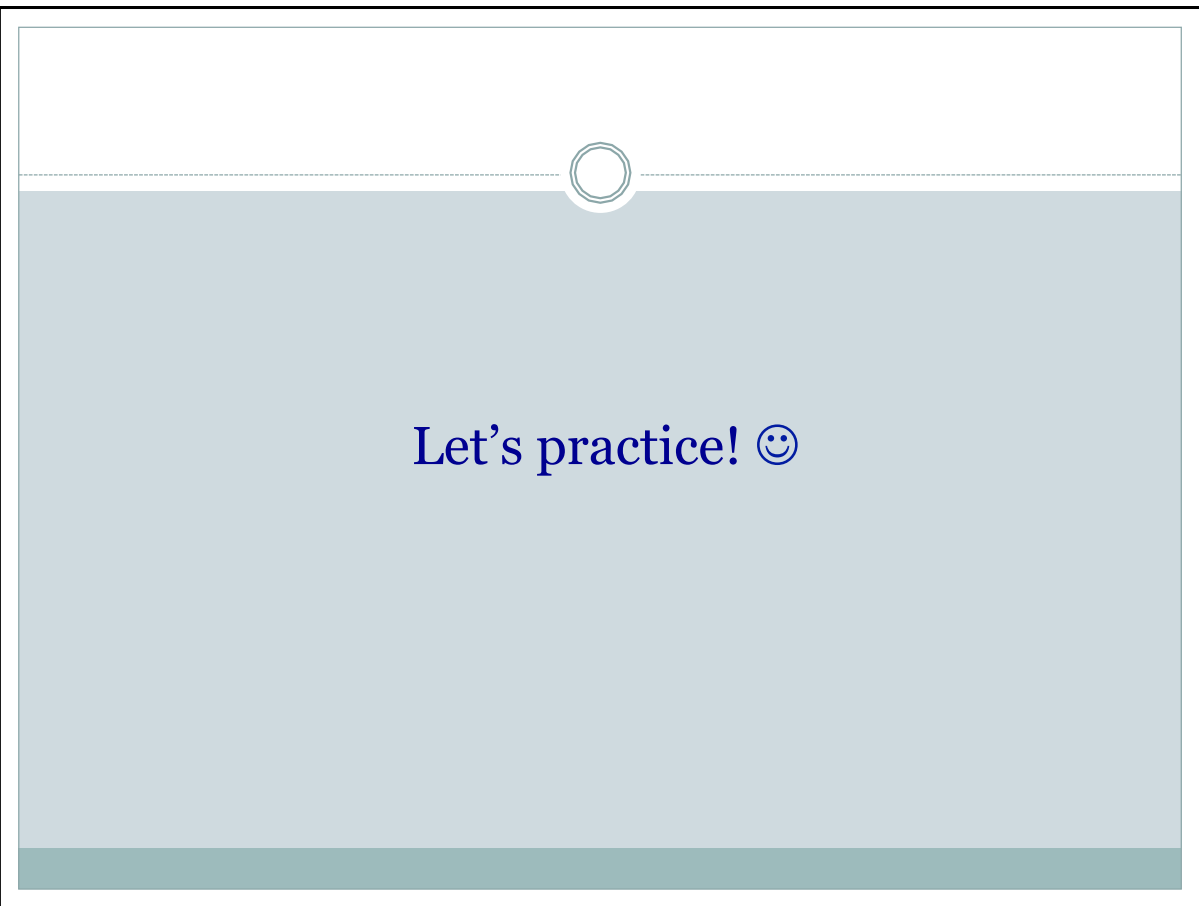


Appendices

Appendix 4. Role-play Task Session 2 Instructional treatment

SITUATION 1

PARTICIPANT A

Scenario: At home, you are a mother and you ask you daughter to help you with dinner.

\section{SITUATION 1}

\section{PARTICIPANT B}

Scenario: At home, your mom asks you to help her with dinner. You are willing to help her and tell her so.

\section{SITUATION 2}

\section{PARTICIPANT A}

Scenario: Your three best friends and you just went out of the movies. Now you have to decide where to go to dinner. After some discussion, it seems that you will go to a new Indian restaurant. A friend asks the whole group: Is the new Indian place at Forbes Ave. OK for everyone? You tell your friend you agree on going to this place.

\section{SITUATION 2}

\section{PARTICIPANT B}

Scenario: Your three best friends and you just went out of the movies. Now you have to decide where to go to dinner. After some discussion, it seems that you will go to a new Indian restaurant. You ask your friends if the new Indian place at Forbes Avenue is OK for everyone. 


\section{SITUATION 3}

\section{PARTICIPANT A}

Scenario: You are at home, in your living room with your son. You just made some tea and ask him whether he wants some.

\section{SITUATION 3}

\section{PARTICIPANT B}

Scenario: You are at home, in your living room with your mom. Your mom just made some tea and she asks you whether you would like some. However, you do not feel like having some tea now and reject her offer.

\section{SITUATION 4}

PARTICIPANT A

Scenario: A friend of yours just bought a dress for her brother's wedding. You go to her place and she tries it on and asks for your opinion. You think it fits her well.

\section{SITUATION 4}

\section{PARTICIPANT B}

Scenario: You just bought a dress for your brother's wedding. A friend of yours is coming over your place. You try it on and show it to your friend. You ask her about her opinion. 


\section{Appendices}

\section{SITUATION 5}

\section{PARTICIPANT A}

Scenario: You just finished classes today. It is pouring outside, you do not have an umbrella and you missed the bus. You see a classmate of yours approaching his car. You ask him whether he could drive you home.

\section{SITUATION 5}

\section{PARTICIPANT B}

Scenario: You just finished classes today. It is pouring outside. As you go to your car, a classmate of yours approaches you and asks you if you can drive him home. You tell him you can.

\section{SITUATION 6}

\section{PARTICIPANT A}

Scenario: You are at the movies with your significant other. You are trying to follow the plot, but there is a group of youngsters who are talking loud. It bothers you and you ask them to be quiet.

\section{SITUATION 6}

\section{PARTICIPANT B}

Scenario: You are at the movies with a group of friends. Even though the movie is already on, you keep talking loud. At some point, a young man asks you all to stop talking. You apologize and you tell him you will stop talking. 
Appendices

\section{SITUATION 7}

\section{PARTICIPANT A}

Scenario:

Part 1) You are in an aisle in a supermarket. There is an old lady slowly pushing a shopping cart in front of you. However, you need to get by her.

(Wait for your partner's response. Then continue:)

Part 2) Now, you are trying to get around the old lady and accidentally bump into her cart. You apologize.

\section{SITUATION 7}

\section{PARTICIPANT B}

Scenario:

Part 1) You are an old lady and are doing your groceries. You are in an aisle and a person behind you needs to get by you.

Part 2) Now, this person bumps into your cart all of a sudden. This person apologizes. You give him a reply.

\section{SITUATION 8}

\section{PARTICIPANT A}

Scenario: You have a group project due tomorrow which needs some revisions. You suggest your friend Cristina to go to your place and she accepts. However, you did not have time to tidy up you apartment and you realize Cristina will see it all. As both of you go into your apartment you apologize.

\section{SITUATION 8}

\section{PARTICIPANT B}

Scenario: You have a group project due tomorrow which needs some revisions. Your friend Cristina suggests you to go to her place and you accept. However, your friend did not have time to tidy up her apartment and she realizes you will see it all. As both of you go into your apartment she apologizes. Now you respond to her apology. 


\section{SITUATION 9}

\section{PARTICIPANT A}

Scenario: You and your friend are on your way to campus. Your friend is about to cross the street but he does not see a car coming. You already have seen the car and warn him.

\section{SITUATION 9}

\section{PARTICIPANT B}

Scenario: You and your friend are on your way to campus. You are about to cross the street and you don't see the car coming. Your friend warns you and saves you. You thank him.

\section{SITUATION 10}

PARTICIPANT A

Scenario: You are hosting a Christmas dinner with your family. You offer more food to your daughter-in-law.

\section{SITUATION 10}

\section{PARTICIPANT B}

Scenario: You are at your in-laws' Christmas dinner. They offer you more food but you already ate a lot and do not want any more. You decline the offer. 
SITUATION 11

PARTICIPANT A

Scenario: You are a Professor at a university and you just finished a long meeting with one of your students at your office. Reply to what they tell you as they leave.

SITUATION 11

PARTICIPANT B

Scenario: You are a student at a university. You just had a long meeting with a Professor of yours in his office. As you leave, you say:

SITUATION 12

PARTICIPANT A

Scenario: In a bookstore, you see a customer browsing some books. You offer them some help.

\section{SITUATION 12}

PARTICIPANT B

Scenario: In a bookstore, you are browsing some books when suddenly a shop assistant comes up to you and offers their help. You decline her help. 
SITUATION 13

PARTICIPANT A

Scenario: You are having dinner with a friend of yours and suggest to go dancing afterwards.

\section{SITUATION 13}

PARTICIPANT B

Scenario: You are having dinner with a friend of yours and they suggest you to go dancing afterwards. You like that plan and so you accept their suggestion.

SITUATION 14

PARTICIPANT A

Scenario: You are in class and your friend asks you for a pen. You lend it to him.

\section{SITUATION 14}

PARTICIPANT B

Scenario: You are in class and your pen ran out of ink. You ask your friend for a pen. 
SITUATION 15

PARTICIPANT A

Scenario: Your friend Ana just threw a wonderful party. As you leave, you say:

\section{SITUATION 15}

\section{PARTICIPANT B}

Scenario: You just threw a wonderful party. A friend of yours is leaving and they thank you for having invited them. You say:

\section{SITUATION 16}

\section{PARTICIPANT A}

Scenario: At the university, you bump into a friend of yours on your way to class. You have not seen them for a while. You greet your friend. And after a short conversation, you say goodbye to your friend.

\section{SITUATION 16}

\section{PARTICIPANT B}

Scenario: At the university, you are on your way to the cafeteria to get a coffee. You bump into a friend whom you have not seen for a while. They greet you. You greet them back. After a short conversation, they say goodbye to you and you say goodbye back. 
Appendix 5. Post-instruction Questionnaire

NAME:

Please circle just one number that best explains what you think about the theoretical explanation you have been presented with, the activities, and the pictures on conventional expressions you have worked on.

Information provided on conventional expressions:

1) Rate the overall information provided:

1 - Poor 2 - Just fine 3 - Good

2) The concepts included were:

1 - Not enough 2 - Enough 3 - More than enough

3) The presentation of the concepts was:

$$
1 \text { - Messy and unclear } \quad 2 \text { - Just fine } \quad 3 \text {-Structured and clear }
$$

4) The concepts included were:

$$
1 \text { - Completely not useful } \quad 2 \text { - Just useful } \quad 3 \text { - Very useful }
$$

Now, please tell us your opinion about the following aspects. Please be as truthful as you can, since your personal opinion is very important.

5) What did you like most about the presentation of the information on conventional expressions? Why?

6) What did you like least about the presentation of the information on conventional expressions? Why? 
Activities

Judgment task

1) In general, this activity was:

$$
1 \text { - Poor } 2 \text { - Just fine } 3 \text { - Good }
$$

2) The situations included were:

$$
1 \text { - Not enough } 2 \text { - Enough } 3 \text { - More than enough }
$$

3) This activity was:

$$
1 \text { - Not enough } 2 \text { - Enough } 3 \text { - More than enough }
$$

4) This activity was:

$$
1 \text { - Not useful at all } 2 \text { - Useful } 3 \text {-Very useful }
$$

5) The presentation of each of the situations was:

$$
1 \text { - Messy and unclear } \quad 2 \text {-Just fine } \quad 3 \text {-Structured and clear }
$$

6) The situations included were:

$$
1 \text { - Completely not useful } \quad 2 \text { - Just useful } 3 \text { - Very useful }
$$

7) The feedback provided by the instructor was:

$$
1 \text { - Not sufficient } 2 \text {-Somewhat sufficient } 3 \text {-Sufficient }
$$

8) The feedback provided by the instructor was:

$$
1 \text { - Messy and unclear } 2 \text { - Just fine } 3 \text { - Structured and clear }
$$

9) The feedback provided by the instructor was:

$$
1 \text { - Not useful at all } \quad 2 \text {-Just useful } \quad 3 \text { - Useful }
$$

Now, please tell us your opinion about the following aspects. Please be as truthful as you can, since your personal opinion is very important.

10) What did you like most about this activity? Why?

11) What did you like least about this activity? Why? 
Role-play

1) In general, this activity was:

1 - Poor 2 -Just fine 3 -Good

2) The situations included were:

1 - Not enough 2 - Enough 3 - More than enough

3) This activity was:

$$
1 \text { - Not enough } \quad 2 \text { - Enough } 3 \text { - More than enough }
$$

4) This activity was:

$$
1 \text { - Not useful at all } 2 \text { - Useful } 3 \text {-Very useful }
$$

5) The presentation of each of the situations was:

$$
1 \text { - Messy and unclear } \quad 2 \text { - Just fine } \quad 3 \text {-Structured and clear }
$$

6) The situations included were:

$$
\text { 1-Completely not useful } \quad 2 \text { - Just useful } \quad 3 \text {-Very useful }
$$

7) The feedback provided by the instructor was:

$$
1 \text { - Not sufficient } 2 \text {-Somewhat sufficient } 3 \text {-Sufficient }
$$

8) The feedback provided by the instructor was:

$$
1 \text { - Messy and unclear 2-Just fine } 3 \text { - Structured and clear }
$$

9) The feedback provided by the instructor was:

$$
1 \text { - Not useful at all } \quad 2 \text {-just useful } \quad 3 \text { - Useful }
$$

Now, please tell us your opinion about the following aspects. Please be as truthful as you can, since your personal opinion is very important.

10) What did you like most about this activity? Why?

11) What did you like least about this activity? Why? 
Visual material (photos included in situations)

1) Were the pictures included in the situations clear?

Yes No No

Why / Why not?

2) Did the pictures included in the situations help you understand the context better?

Yes $\quad$ No

Why / Why not?

3) Do you think the pictures represented real life situations?

Yes

No

Why / Why not?

Finally, is there anything else you would like to comment on as regards the presentation of the concepts on conventional expressions, the activities we did, the feedback received, and the pictures included? 
NAME:

In the following table, all the conventional expressions we have been using so far are included. Please, choose one of the two following options and then provide a/some reason(s) why the conventional expression was: A) easy to learn; or B) difficult to learn.

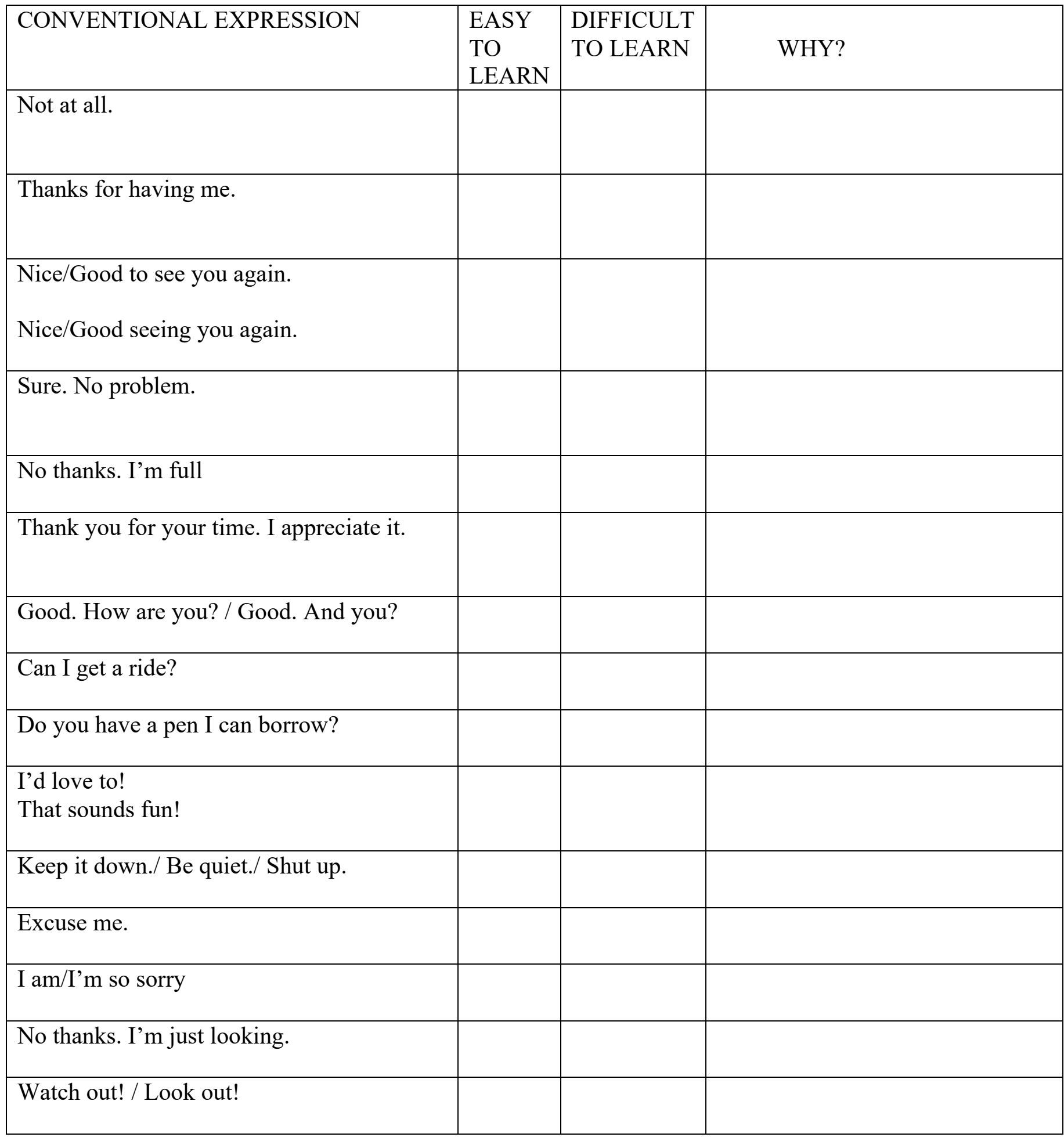


Appendices 
Appendix 6. Vocabulary Knowledge Scale Pretest Version

Name:

Please choose just ONE of the following options. Circle the letter.

Example: Not at all.

A) I do not know this expression at all.

B) It sounds just a little familiar.

C) I know this expression.

If you have chosen $\mathrm{C}$, please give an example of this expression in a conversation:

A friend of yours asks you for help. He says: Would you mind helping me with this recipe? I believe I am measuring the ingredients wrong.

And then you tell him: Not at all. Let me see the recipe.

\section{Thanks for having me!}

A) I do not know this expression at all.

B) It sounds just a little familiar.

C) I know this expression.

If you have chosen $\mathrm{C}$, please give an example of this expression in a conversation:

2 No, thanks. I'm full.

A) I do not know this expression at all.

B) It sounds just a little familiar.

C) I know this expression.

If you have chosen $C$, please give an example of this expression in a conversation:

3 Nice to meet you.

A) I do not know this expression at all.

B) It sounds just a little familiar.

C) I know this expression.

If you have chosen $C$, please give an example of this expression in a conversation: 
4 Nice seeing you again.

A) I do not know this expression at all.

B) It sounds just a little familiar.

C) I know this expression.

If you have chosen $\mathrm{C}$, please give an example of this expression in a conversation:

5 Hi. How are you?

A) I do not know this expression at all.

B) It sounds just a little familiar.

C) I know this expression.

If you have chosen $\mathrm{C}$, please give an example of this expression in a conversation:

6 I'm fine, thanks. And you?

A) I do not know this expression at all.

B) It sounds just a little familiar.

C) I know this expression.

If you have chosen $\mathrm{C}$, please give an example of this expression in a conversation:

7 Good. How are you?

A) I do not know this expression at all.

B) It sounds just a little familiar.

C) I know this expression.

If you have chosen $\mathrm{C}$, please give an example of this expression in a conversation: 


\section{Appendices}

8 Do you have a pen I can borrow?

A) I do not know this expression at all.

B) It sounds just a little familiar.

C) I know this expression.

If you have chosen $\mathrm{C}$, please give an example of this expression in a conversation:

9 Excuse me.

A) I do not know this expression at all.

B) It sounds just a little familiar.

C) I know this expression.

If you have chosen $\mathrm{C}$, please give an example of this expression in a conversation:

10 I'm so sorry.

A) I do not know this expression at all.

B) It sounds just a little familiar.

C) I know this expression.

If you have chosen $\mathrm{C}$, please give an example of this expression in a conversation:

11 Can I get a ride?

A) I do not know this expression at all.

B) It sounds just a little familiar.

C) I know this expression.

If you have chosen $\mathrm{C}$, please give an example of this expression in a conversation: 
12 Sure. No problem.

A) I do not know this expression at all.

B) It sounds just a little familiar.

C) I know this expression.

If you have chosen $\mathrm{C}$, please give an example of this expression in a conversation:

13 Thank you for your time. I appreciate it.

A) I do not know this expression at all.

B) It sounds just a little familiar.

C) I know this expression.

If you have chosen $\mathrm{C}$, please give an example of this expression in a conversation:

14 No, thanks. I'm just looking.

A) I do not know this expression at all.

B) It sounds just a little familiar.

C) I know this expression.

If you have chosen $\mathrm{C}$, please give an example of this expression in a conversation:

15 I'd love to.

A) I do not know this expression at all.

B) It sounds just a little familiar.

C) I know this expression.

If you have chosen $\mathrm{C}$, please give an example of this expression in a conversation: 


\section{Appendices}

16 Sure. That sounds fun!

A) I do not know this expression at all.

B) It sounds just a little familiar.

C) I know this expression.

If you have chosen $\mathrm{C}$, please give an example of this expression in a conversation:

17 Watch out!

A) I do not know this expression at all.

B) It sounds just a little familiar.

C) I know this expression.

If you have chosen $\mathrm{C}$, please give an example of this expression in a conversation: 
Appendices 
Appendix 7. Vocabulary Knowledge Scale Posttest Version

NAME:

Please choose just ONE of the following options. Circle the letter.

Example: Not at all
A) I do not know this expression at all.
B) It sounds just a little familiar.
C) I know this expression.

If you have chosen $\mathrm{C}$, please give an example of this expression in a conversation:

_A friend of yours asks you for help. He says: Would you mind helping me with this recipe? I believe I am measuring the ingredients wrong.

And then you tell him: Not at all. Let me see the recipe.

\section{Nice to meet you.}

A) I do not know this expression at all.

B) It sounds just a little familiar.

C) I know this expression.

If you have chosen $\mathrm{C}$, please give an example of this expression in a conversation:

2 Hi. How are you?

A) I do not know this expression at all.

B) It sounds just a little familiar.

C) I know this expression.

If you have chosen $\mathrm{C}$, please give an example of this expression in a conversation:

3 Excuse me.

A) I do not know this expression at all.

B) It sounds just a little familiar.

C) I know this expression.

If you have chosen $\mathrm{C}$, please give an example of this expression in a conversation: 
4 Good. How are you?

A) I do not know this expression at all.

B) It sounds just a little familiar.

C) I know this expression.

If you have chosen $\mathrm{C}$, please give an example of this expression in a conversation:

5 Sure. No problem.

A) I do not know this expression at all.

B) It sounds just a little familiar.

C) I know this expression.

If you have chosen $\mathrm{C}$, please give an example of this expression in a conversation:

6 Thanks for having me!

A) I do not know this expression at all.

B) It sounds just a little familiar.

C) I know this expression.

If you have chosen $\mathrm{C}$, please give an example of this expression in a conversation:

7 I'm fine, thanks. And you?

A) I do not know this expression at all.

B) It sounds just a little familiar.

C) I know this expression.

If you have chosen $\mathrm{C}$, please give an example of this expression in a conversation: 
8 I'd love to.

A) I do not know this expression at all.

B) It sounds just a little familiar.

C) I know this expression.

If you have chosen $\mathrm{C}$, please give an example of this expression in a conversation:

9 Watch out!

A) I do not know this expression at all.

B) It sounds just a little familiar.

C) I know this expression.

If you have chosen $\mathrm{C}$, please give an example of this expression in a conversation:

10 I'm so sorry.

A) I do not know this expression at all.

B) It sounds just a little familiar.

C) I know this expression.

If you have chosen $\mathrm{C}$, please give an example of this expression in a conversation:

11 No, thanks. I'm full.

A) I do not know this expression at all.

B) It sounds just a little familiar.

C) I know this expression.

If you have chosen $\mathrm{C}$, please give an example of this expression in a conversation: 
12 Nice seeing you again.

A) I do not know this expression at all.

B) It sounds just a little familiar.

C) I know this expression.

If you have chosen $\mathrm{C}$, please give an example of this expression in a conversation:

13 Thank you for your time. I appreciate it.

A) I do not know this expression at all.

B) It sounds just a little familiar.

C) I know this expression.

If you have chosen $\mathrm{C}$, please give an example of this expression in a conversation:

14 Can I get a ride?

A) I do not know this expression at all.

B) It sounds just a little familiar.

C) I know this expression.

If you have chosen $\mathrm{C}$, please give an example of this expression in a conversation:

15 Do you have a pen I can borrow?

A) I do not know this expression at all.

B) It sounds just a little familiar.

C) I know this expression.

If you have chosen $\mathrm{C}$, please give an example of this expression in a conversation: 


\section{Appendices}

16 Sure. That sounds fun!

A) I do not know this expression at all.

B) It sounds just a little familiar.

C) I know this expression.

If you have chosen $\mathrm{C}$, please give an example of this expression in a conversation:

17 No, thanks. I'm just looking.

A) I do not know this expression at all.

B) It sounds just a little familiar.

C) I know this expression.

If you have chosen $\mathrm{C}$, please give an example of this expression in a conversation: 
Appendices 
Appendix 8. Vocabulary Knowledge Scale Delayed Posttest Version

NAME:

Please choose just ONE of the following options. Circle the letter.

Example: Not at all

A) I do not know this expression at all.

B) It sounds just a little familiar.

C) I know this expression.

If you have chosen $\mathrm{C}$, please give an example of this expression in a conversation:

A friend of yours asks you for help. He says: Would you mind helping me with this recipe? I believe I am measuring the ingredients wrong.

And then you tell him: Not at all. Let me see the recipe.

\section{I'd love to.}

A) I do not know this expression at all.

B) It sounds just a little familiar.

C) I know this expression.

If you have chosen $\mathrm{C}$, please give an example of this expression in a conversation:

2 I'm fine, thanks. And you?

A) I do not know this expression at all.

B) It sounds just a little familiar.

C) I know this expression.

If you have chosen $\mathrm{C}$, please give an example of this expression in a conversation:

\section{Can I get a ride?}

A) I do not know this expression at all.

B) It sounds just a little familiar.

C) I know this expression.

If you have chosen $\mathrm{C}$, please give an example of this expression in a conversation: 
4 No, thanks. I'm just looking.

A) I do not know this expression at all.

B) It sounds just a little familiar.

C) I know this expression.

If you have chosen $\mathrm{C}$, please give an example of this expression in a conversation:

5 I'm so sorry.

A) I do not know this expression at all.

B) It sounds just a little familiar.

C) I know this expression.

If you have chosen $\mathrm{C}$, please give an example of this expression in a conversation:

6 Hi. How are you?

A) I do not know this expression at all.

B) It sounds just a little familiar.

C) I know this expression.

If you have chosen $\mathrm{C}$, please give an example of this expression in a conversation:

7 No, thanks. I'm full.

A) I do not know this expression at all.

B) It sounds just a little familiar.

C) I know this expression.

If you have chosen $\mathrm{C}$, please give an example of this expression in a conversation: 
8 Sure. No problem.

A) I do not know this expression at all.

B) It sounds just a little familiar.

C) I know this expression.

If you have chosen $\mathrm{C}$, please give an example of this expression in a conversation:

9 Sure. That sounds fun!

A) I do not know this expression at all.

B) It sounds just a little familiar.

C) I know this expression.

If you have chosen $\mathrm{C}$, please give an example of this expression in a conversation:

10 Do you have a pen I can borrow?

A) I do not know this expression at all.

B) It sounds just a little familiar.

C) I know this expression.

If you have chosen $\mathrm{C}$, please give an example of this expression in a conversation:

11 Thank you for your time. I appreciate it.

A) I do not know this expression at all.

B) It sounds just a little familiar.

C) I know this expression.

If you have chosen $\mathrm{C}$, please give an example of this expression in a conversation: 
12 Excuse me.

A) I do not know this expression at all.

B) It sounds just a little familiar.

C) I know this expression.

If you have chosen $\mathrm{C}$, please give an example of this expression in a conversation:

13 Nice to meet you.

A) I do not know this expression at all.

B) It sounds just a little familiar.

C) I know this expression.

If you have chosen $\mathrm{C}$, please give an example of this expression in a conversation:

14 Good. How are you?

A) I do not know this expression at all.

B) It sounds just a little familiar.

C) I know this expression.

If you have chosen $\mathrm{C}$, please give an example of this expression in a conversation:

15 Thanks for having me!

A) I do not know this expression at all.

B) It sounds just a little familiar.

C) I know this expression.

If you have chosen $\mathrm{C}$, please give an example of this expression in a conversation: 


\section{Appendices}

16 Watch out!

A) I do not know this expression at all.

B) It sounds just a little familiar.

C) I know this expression.

If you have chosen $\mathrm{C}$, please give an example of this expression in a conversation:

17 Nice seeing you again.

A) I do not know this expression at all.

B) It sounds just a little familiar.

C) I know this expression.

If you have chosen $\mathrm{C}$, please give an example of this expression in a conversation: 
Appendices 


\section{Appendices}

\section{Appendix 9. Lasagabaster and Huguet's (2007) Attitudes Questionnaire}

in education departments and ministries, but could also prove useful to those working and studying in a wide range of fields, such as sociology, sociolinguistics, psychology, second-language acquisition, education, bilingualism, multilingualism and even politics.

\section{References}

Baker, C. (1992) Attitudes and Language. Clevedon: Multilingual Matters.

Huguet, A. (2004) La educación bilingüe en el Estado español: situación actual y perspectivas. Cultura y Educación 16, 399-418.

Lasagabaster, D. (2003) Trilingüismo en la enseñanza. Actitudes hacia la lengua minoritaria, la mayoritaria y la extranjera. Lleida: Milenio.

Turell, M.T. (2001) Multilingualism in Spain. Clevedon: Multilingual Matters.

\section{Appendix A}

The instrument underwent some minimal changes depending on the context. L1 refers to the minority language, L2 to the majority language and L3 corresponds to the foreign language. For example, in the case of the Basque Country, the L1 would be Basque, the L2 Spanish and the L3 English, whereas in the case of Ireland, the L1 would be Irish, the L2 English and the L3 Spanish, German or French.

\section{Attitudes towards three languages in contact}

We would like to ask you to help us by answering the following questions. This is not a test so there are no 'right' or 'wrong' answers and you don't even have to write your name on it. We are interested in your personal opinion. Please give your answers sincerely as only this will guarantee the success of the investigation. Thank you very much for your help.

1. Age (in years and months):

2. Specialisation (degree to be obtained):

3. Course:

In the following please put an ' $\mathrm{X}$ ' in the right place.

4. Gender: Male _ Female _

5. Mother Tongue:__ Basque Spanish _ Basque \& Spanish 


\section{Appendices}

a/ Manager, director or owner of a business/company with more than 25 workers

b/ Bachelor's degree (lawyer, architect, chemist, engineer, doctor, lecturer, economist, etc.)

c/ Degree or HND ( ${ }^{*}$ Higher National Diploma) (school teacher, technical engineer, social worker, etc.), or middle management without a bachelor's degree (commercial head, production head, administrative head, etc.)

d/ Owner of a business or company with less than 25 staff, health worker, clerical worker, salesperson, etc.

e/ Specialised worker (mechanic, chauffeur, policeman, plumber, waiter mason, electrician, etc.), farmer or cattle breeder.

f/ Labourer, seasonal worker, watchman, etc.

g/ Housework

h/ Others (please specify)

7. In the following section we would like you to answer some questions by simply giving marks from 1 to 4 .

$1=$ None, 2 = A little, $3=$ Good, $4=$ Very good

For example, if your Chinese is 'very good', your Japanese 'good' and you can speak no Arabic ('None'), write this:

\begin{tabular}{|l|c|c|c|}
\hline & Chinese & Japanese & Arabic \\
\hline General proficiency & 4 & 3 & 1 \\
\hline
\end{tabular}

Please put one (and only one) whole number in each box and don't leave out any of them in the first three columns (L1, L2 and L3). If you know another language, please put numbers in the 'Other' columns after specifying the language concerned. 


\section{Appendices}

In your opinion, what is your language proficiency in. . ?

\begin{tabular}{|l|l|l|l|l|}
\cline { 2 - 5 } \multicolumn{1}{l|}{} & L1 & L2 & $\begin{array}{c}\text { L3 Other } \\
\text { (Specify:) }\end{array}$ & $\begin{array}{c}\text { Other } \\
\text { (Specify:) }\end{array}$ \\
\hline General proficiency & & & & \\
\hline Reading & & & & \\
\hline Writing & & & & \\
\hline Speaking & & & & \\
\hline Listening & & & & \\
\hline
\end{tabular}

8. I started learning L1 at the age of

9. I started learning L2 at the age of

10. I started learning L3 at the age of

11. Have you ever been to an L3 speaking country?: Yes _ No _

12. Hometown: a) More than 100,000 inhabitants

b) Less than 100,000 inhabitants

13. Province: _ Araba

$$
\begin{aligned}
& \text { - Bizkaia } \\
& \text { - Gipuzkoa } \\
& \text { - Nafarroa }
\end{aligned}
$$

14. My hometown is mainly a: _ L2-speaking community _ L1-speaking community

15. I studied at a: _ public school

$$
\text { — private school }
$$

16. How often do you watch TV in L3?

$$
\begin{array}{ll}
\text { - Never _ Hardly ever } & \text { - Once/twice a week } \\
\text { - } 3 \text { to } 5 \text { times a week } & \text { - Daily }
\end{array}
$$

17. What type of High School studies did you complete before entering university?
_ Technical-Scientific
_ Humanities and Social Sciences
Artistic
_ Other (specify): 


\section{Appendices}

18. In which linguistic model did you predominantly complete your preuniversity studies?

_ Model B

— Model D

Now we would like to know which language you speak to the following people. Please put an ' $X$ ' in the box which best expresses your situation. For example, if you always speak in L2 with your father, put an ' $X$ ' in the last box:

\begin{tabular}{|l|l|l|l|l|l|}
\cline { 2 - 6 } \multicolumn{1}{c|}{} & $\begin{array}{c}\text { Always } \\
\text { in L1 }\end{array}$ & $\begin{array}{c}\text { In L1 } \\
\text { more } \\
\text { often } \\
\text { than L2 }\end{array}$ & $\begin{array}{c}\text { In L1 and } \\
\text { L2 about } \\
\text { equally }\end{array}$ & $\begin{array}{c}\text { In L2 } \\
\text { more } \\
\text { often } \\
\text { than L1 }\end{array}$ & $\begin{array}{c}\text { Always } \\
\text { in L2 }\end{array}$ \\
\hline 1. Father & & & & & $x$ \\
\hline
\end{tabular}

In which language do YOU speak to the following people? Choose one of these answers:

\begin{tabular}{|l|l|l|l|l|l|}
\cline { 2 - 6 } \multicolumn{1}{c|}{} & $\begin{array}{c}\text { Always } \\
\text { in L1 }\end{array}$ & $\begin{array}{c}\text { In L1 } \\
\text { more } \\
\text { often } \\
\text { than L2 }\end{array}$ & $\begin{array}{c}\text { In L1 } \\
\text { and L2 } \\
\text { about } \\
\text { equally }\end{array}$ & $\begin{array}{c}\text { In L2 } \\
\text { more } \\
\text { often } \\
\text { than L1 }\end{array}$ & $\begin{array}{c}\text { Always } \\
\text { in L2 }\end{array}$ \\
\hline 1. Father & & & & & \\
\hline 2. Mother & & & & & \\
\hline \begin{tabular}{l} 
3. $\begin{array}{l}\text { Brothers \& } \\
\text { sisters }\end{array}$ \\
\hline $\begin{array}{l}\text { 4. Friends in the } \\
\text { classroom }\end{array}$
\end{tabular} & & & & & \\
\hline $\begin{array}{l}\text { 5. Friends } \\
\text { outside school }\end{array}$ & & & & & \\
\hline $\begin{array}{l}\text { 6. Teachers } \\
\text { (except with } \\
\text { language } \\
\text { teachers) }\end{array}$ & & & & & \\
\hline $\begin{array}{l}\text { 7. Neighbours } \\
\text { (near my } \\
\text { house) }\end{array}$ & & & & & \\
\hline
\end{tabular}




\section{Appendices}

Which language do YOU use with the following?

\begin{tabular}{|l|l|l|l|l|l|}
\cline { 2 - 6 } \multicolumn{1}{c|}{} & $\begin{array}{c}\text { Always } \\
\text { in L1 }\end{array}$ & $\begin{array}{c}\text { In L1 } \\
\text { more } \\
\text { often } \\
\text { than L2 }\end{array}$ & $\begin{array}{c}\text { In L1 } \\
\text { and L2 } \\
\text { about } \\
\text { equally }\end{array}$ & $\begin{array}{c}\text { In L2 } \\
\text { more } \\
\text { often } \\
\text { than L1 }\end{array}$ & $\begin{array}{c}\text { Always } \\
\text { in L2 }\end{array}$ \\
\hline $\begin{array}{l}\text { 1. Watching } \\
\text { TV }\end{array}$ & & & & & \\
\hline 2. The press & & & & & \\
\hline 3. Music & & & & & \\
\hline 4. Radio & & & & & \\
\hline
\end{tabular}

How important or unimportant do you think that the L1 language is for people to do the following?

There are no right or wrong answers.

\begin{tabular}{|c|c|c|c|c|}
\hline $\begin{array}{l}\text { For people } \\
\text { to: }\end{array}$ & Important & $\begin{array}{l}\text { A little } \\
\text { important }\end{array}$ & $\begin{array}{c}\text { A little } \\
\text { unimportant }\end{array}$ & Unimportant \\
\hline $\begin{array}{l}\text { 1. To make } \\
\text { friends }\end{array}$ & & & & \\
\hline 2. Read & & & & \\
\hline 3. Write & & & & \\
\hline 4. Watch TV & & & & \\
\hline 5. Get a job & & & & \\
\hline 6. Be liked & & & & \\
\hline $\begin{array}{l}\text { 7. Live in the L1 } \\
\text { country }\end{array}$ & & & & \\
\hline $\begin{array}{l}\text { 8. Bring up } \\
\text { children }\end{array}$ & & & & \\
\hline $\begin{array}{l}\text { 9. Go } \\
\text { shopping }\end{array}$ & & & & \\
\hline $\begin{array}{l}\text { 10. Make phone } \\
\text { calls }\end{array}$ & & & & \\
\hline
\end{tabular}




\section{Appendices}

\begin{tabular}{|l|l|l|l|l|}
\hline $\begin{array}{l}\text { 11. Pass } \\
\text { exams }\end{array}$ & & & & \\
\hline $\begin{array}{l}\text { 12. Be accepted } \\
\text { in the } \\
\text { community }\end{array}$ & & & & \\
\hline $\begin{array}{l}\text { 13. Talk to } \\
\text { friends at } \\
\text { university }\end{array}$ & & & & \\
\hline $\begin{array}{l}\text { 14. Talk to } \\
\text { teachers at } \\
\text { university }\end{array}$ & & & & \\
\hline $\begin{array}{l}\text { 15. Talk to } \\
\text { people } \\
\text { out of } \\
\text { university }\end{array}$ & & & & \\
\hline
\end{tabular}

Here are some statements about the L1 language. Please say whether you agree or disagree with these statements. There are no right or wrong answers. Please be as honest as possible. Answer with ONE of the following:

SA = Strongly Agree (circle SA)

A $=$ Agree (circle A)

NAND $=$ Neither Agree Nor Disagree (circle NAND)

$\mathbf{D}=$ Disagree (circle D)

$\mathrm{SD}=$ Strongly Disagree (circle SD)

1. I like hearing L1 spoken.

SA A NAND D SD

2. L1 should be taught to all pupils in the

Basque Country...

SA A NAND D SD

3. I like speaking L1.................................................... SA A NAND D SD

4. L1 is an easy language to learn.................................. SA A NAND D SD

5. There are not more useful languages to learn than L1

6. I prefer to be taught in L1.

SA A NAND D SD

7. Learning L1 enriches my cultural knowledge.......... SA A NAND D SD

8. I would not mind marrying a L1 speaker...

SA A NAND D SD

9. $\mathrm{L} 1$ is a language worth learning SA A NAND D SD

10. If I have children, I would like them to be L1 speakers regardless of other languages they may know..

SA A NAND D SD 


\section{Appendices}

Here are some statements about the L2 language. Please say whether you agree or disagree with these statements. There are no right or wrong answers. Please be as honest as possible. Answer with ONE of the following:

$\mathbf{S A}=$ Strongly Agree (circle SA)

$\mathbf{A}=$ Agree (circle A)

NAND $=$ Neither Agree Nor Disagree (circle NAND)

$\mathbf{D}=$ Disagree $($ circle $\mathbf{D})$

$\mathrm{SD}=$ Strongly Disagree (circle SD)

1. I like hearing L2 spoken SA A NAND D SD

2. L2 should be taught to all pupils in the Basque Country.. SA A NAND D SD

3. I like speaking L2 …........................................... SA A NAND D SD

4. L2 is an easy language to learn. SA A NAND D SD

5. There are not more useful languages to learn than $\mathrm{L} 2$.

6. I prefer to be taught in L2....................................... SA A NAND D SD

7. Learning L2 enriches my cultural knowledge.......... SA A NAND D SD

8. I would not mind marrying a L2 speaker................. SA A NAND D SD

9. L2 is a language worth learning................................ SA A NAND D SD

10. If I have children, I would like them to be L2 speakers regardless of other languages they may know...

SA A NAND D SD

Here are some statements about the L3 language. Please say whether you agree or disagree with these statements. There are no right or wrong answers. Please be as honest as possible. Answer with ONE of the following:

SA $=$ Strongly Agree (circle SA)

$\mathbf{A}=$ Agree (circle A)

NAND $=$ Neither Agree Nor Disagree (circle NAND)

$\mathbf{D}=$ Disagree $($ circle $\mathbf{D})$

$\mathrm{SD}=$ Strongly Disagree (circle SD)

1. I like hearing L3 spoken

SA A NAND D SD

2. L3 should be taught to all pupils in the

Basque Country.....

SA A NAND D SD

3. I like speaking L3.

SA A NAND D SD

4. L3 is an easy language to learn.

SA A NAND D SD

5. There are not more useful languages to learn than L3.

SA A NAND D SD 


\section{Appendices}

6. I prefer to be taught in L3......................................... SA A NAND D SD

7. Learning L3 enriches my cultural knowledge.......... SA A NAND D SD

8. I would not mind marrying an L3 speaker............... SA A NAND D SD

9. L3 is a language worth learning................................ SA A NAND D SD

10. If I have children, I would like them to be L3 speakers regardless of other languages they may know.

SA A NAND D SD

Thank you very much for your cooperation 
Appendix 10. Attitudes Questionnaire employed in this dissertation at Pretest, Posttest, and Delayed Posttest

NAME:

We would like to ask you to help us by answering the following questions. This is not a test, so there are no "right" or "wrong" answers. Also, all information you provide us with will be kept confidential. We are interested in your personal opinion. Please give your answers sincerely as only this will guarantee the success of the investigation. Thank you very much for your help.

1. Name and surnames:

2. Age:

3. Specialization (degree to be obtained):

4. Year in which you are enrolled in this degree:

5. Course (e.g.: Pragmatics, Sociolinguistics):

In the following please put and ' $\mathrm{X}$ ' in the right place.

6. Gender: Male

Female

7. First language:__ Catalan Spanish

Both Catalan \& Spanish

Other: Please specify:

8. Province: Castellón

Valencia

Alicante

Other. Please specify:

9. I studied at a: __ public school

__ private school charter school

10. In the following section, we would like you to answer some questions by simply giving marks from 1 to 4 .

$$
1=\text { None, } 2 \text { = A little, } 3=\text { Good, } 4=\text { Very good }
$$

For example, if your Chinese is 'very good', your Japanese 'good' and you can speak no Arabic ('None'), write this: 


\begin{tabular}{|l|c|c|c|}
\hline & Chinese & Japanese & Arabic \\
\hline General proficiency & 4 & 3 & 1 \\
\hline
\end{tabular}

Please put one (and only one) whole number in each box and don't leave out any of them in the first three columns (L1, L2 and English). If you know another language, please put the numbers in the 'Other' columns after specifying the language concerned. In your opinion, what is your language proficiency in...?

\begin{tabular}{|l|l|l|l|l|}
\hline & L1 & L2 & English & $\begin{array}{c}\text { Other } \\
\text { (Specify: }\end{array}$ \\
\hline General Proficiency & & & & \\
\hline Reading & & & & \\
\hline Writing & & & & \\
\hline Speaking & & & & \\
\hline Listening & & & & \\
\hline
\end{tabular}

11. I started learning L1 at the age of

12. I started learning L2 at the age of

13. I started learning English at the age of

14. Where did you start learning English (city/town)?:

Where did you do so?:

Public school - Name of the school:

Private school - Name of the school:

Other. Please, specify:

15. How many courses were you taught in English? Please specify number and name of subjects: (e.g.: 1: English / 2: Physics and English): 
16. Do you take any extra lessons outside the university in English during this academic year?

EOI

language school

private lessons

Other. Please, specify

None

17. Have you ever been to an English speaking country? If you have not, skip question 18.

Yes

No

18. How many times have you been to an English speaking country? Please complete the following table.

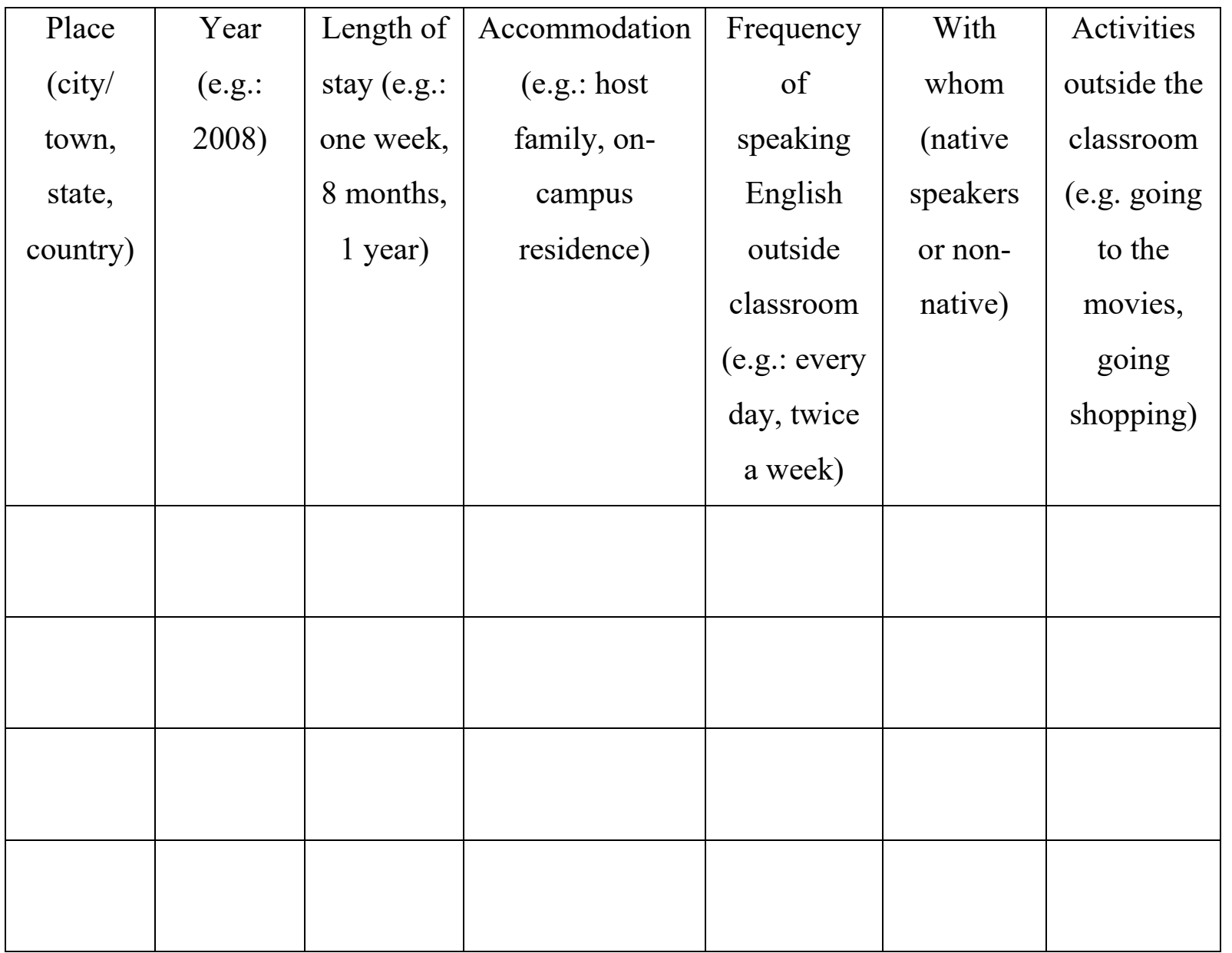




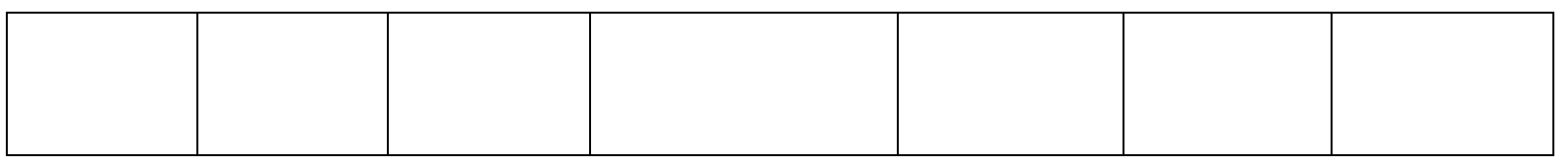

Now we would like to know which language you speak to the following people. Please put an ' $\mathrm{X}$ ' in the box which best expresses your situation. For example, if you always speak in L2 with your father, put an ' $\mathrm{X}$ ' in the third from last box.

\begin{tabular}{|l|l|l|l|l|l|l|l|}
\hline & $\begin{array}{l}\text { Always } \\
\text { in L1 }\end{array}$ & $\begin{array}{l}\text { In L1 } \\
\text { more } \\
\text { often } \\
\text { than L2 }\end{array}$ & $\begin{array}{l}\text { In L1 } \\
\text { and L2 }\end{array}$ & $\begin{array}{l}\text { In L2 } \\
\text { about } \\
\text { equally }\end{array}$ & $\begin{array}{l}\text { Always } \\
\text { often } \\
\text { than L1 }\end{array}$ & $\begin{array}{l}\text { Often in L2 } \\
\text { English }\end{array}$ & $\begin{array}{l}\text { Always } \\
\text { in } \\
\text { English }\end{array}$ \\
\hline Father & & & & & $\mathrm{X}$ & & \\
\hline
\end{tabular}

In which language do YOU speak to the following people? Choose the answers that are most appropriate to you:

\begin{tabular}{|c|c|c|c|c|c|c|c|}
\hline & $\begin{array}{l}\text { Always } \\
\text { in L1 }\end{array}$ & $\begin{array}{l}\text { In L1 } \\
\text { more } \\
\text { often } \\
\text { than L2 }\end{array}$ & $\begin{array}{l}\text { In L1 \& } \\
\text { L2 about } \\
\text { equally }\end{array}$ & $\begin{array}{l}\text { In L2 } \\
\text { more } \\
\text { often } \\
\text { than L1 }\end{array}$ & $\begin{array}{l}\text { Always } \\
\text { in L2 }\end{array}$ & $\begin{array}{l}\text { Often in } \\
\text { English }\end{array}$ & $\begin{array}{l}\text { Always } \\
\text { in } \\
\text { English }\end{array}$ \\
\hline Father & & & & & & & \\
\hline Mother & & & & & & & \\
\hline $\begin{array}{l}\text { Brothers } \\
\& \text { Sisters }\end{array}$ & & & & & & & \\
\hline $\begin{array}{l}\text { Friends in } \\
\text { the } \\
\text { classroom }\end{array}$ & & & & & & & \\
\hline $\begin{array}{l}\text { Friends } \\
\text { outside } \\
\text { school }\end{array}$ & & & & & & & \\
\hline $\begin{array}{l}\text { Teachers } \\
\text { (except } \\
\text { language } \\
\text { teachers) }\end{array}$ & & & & & & & \\
\hline
\end{tabular}


Which language do YOU use with the following?

\begin{tabular}{|l|l|l|l|l|l|l|l|}
\hline & $\begin{array}{l}\text { Always } \\
\text { in L1 }\end{array}$ & $\begin{array}{l}\text { In L1 } \\
\text { more } \\
\text { often } \\
\text { than L2 }\end{array}$ & $\begin{array}{l}\text { In L1 } \\
\text { and L2 } \\
\text { about } \\
\text { equally }\end{array}$ & $\begin{array}{l}\text { In } \\
\text { more } \\
\text { often } \\
\text { than L1 }\end{array}$ & $\begin{array}{l}\text { Always } \\
\text { in L2 }\end{array}$ & $\begin{array}{l}\text { Often in } \\
\text { English }\end{array}$ & $\begin{array}{l}\text { Always } \\
\text { in } \\
\text { English }\end{array}$ \\
\hline $\begin{array}{l}\text { Watching } \\
\text { TV/series } \\
\text { online }\end{array}$ & & & & & & & \\
\hline The press & & & & & & & \\
\hline Music & & & & & & & \\
\hline Radio & & & & & & & \\
\hline
\end{tabular}

How important or unimportant do you think that the English language is for people to do the following?

There are no right or wrong answers.

\begin{tabular}{|l|l|l|l|l|}
\hline For people to: & Important & $\begin{array}{c}\text { A little } \\
\text { important }\end{array}$ & $\begin{array}{c}\text { A little } \\
\text { unimportant }\end{array}$ & Unimportant \\
\hline Make friends & & & & \\
\hline Read & & & & \\
\hline Write & & & & \\
\hline Watch TV & & & & \\
\hline Get a job & & & & \\
\hline Be liked & & & & \\
\hline $\begin{array}{l}\text { Live in the L1 } \\
\text { country }\end{array}$ & & & & \\
\hline $\begin{array}{l}\text { Bring up } \\
\text { children }\end{array}$ & & & & \\
\hline Go shopping & & & & \\
\hline $\begin{array}{l}\text { Make phone } \\
\text { calls }\end{array}$ & & & & \\
\hline Pass exams & & & & \\
\hline $\begin{array}{l}\text { Be accepted } \\
\text { commity }\end{array}$ & & & & \\
\hline
\end{tabular}




\begin{tabular}{|l|l|l|l|l|}
\hline Talk to & & & & \\
friends at & & & & \\
\hline $\begin{array}{l}\text { Talk to } \\
\text { teachers at } \\
\text { university }\end{array}$ & & & & \\
\hline Talk to people & & & & \\
out of & & & & \\
university & & & & \\
\hline
\end{tabular}

Here are some statements about the English language. Please say whether you agree (A) or disagree (D) with the statements. There are no right or wrong answers. Please be as honest as possible. Answer with ONE of the following:

\begin{tabular}{|c|c|c|}
\hline & Agree (A) & Disagree (D) \\
\hline I like hearing English spoken & & \\
\hline $\begin{array}{l}\text { English should be taught to all pupils in the Valencian } \\
\text { Community }\end{array}$ & & \\
\hline I like speaking English & & \\
\hline English is an easy language to learn & & \\
\hline $\begin{array}{l}\text { There are not more useful languages to learn than } \\
\text { English }\end{array}$ & & \\
\hline I prefer to be taught in English & & \\
\hline Learning English enriches my cultural knowledge & & \\
\hline I would not mind marrying an English speaker & & \\
\hline English is a language worth learning & & \\
\hline $\begin{array}{l}\text { If I have children, I would like them to be English } \\
\text { speakers regardless of other languages they may know }\end{array}$ & & \\
\hline
\end{tabular}

Thank you for your collaboration! 
Appendix 11. Rationale for modifications to Lasagabaster and Huguet's (2007) Attitudes Questionnaire

Item 1 "1. Name and surnames," was added in which participants were asked to write their name and surnames. This item was included for research purposes, in order to identify who had taken what test, and also in order to check participants' change in their attitudes (if any) throughout the pretest, posttest, and delayed posttest. Participants' names have not been used. Instead, a number has been assigned to each of them so as to protect their anonymity.

Items 4 and 5, "4. Year in which you are enrolled in this degree," and "5. Course (e.g.: Pragmatics, Sociolinguistics)" were added for research purposes, so as to classify the participants into those belonging to the experimental group and those in the control group, so that this data could be accessed faster later on in data analysis.

As of item 6, "6. Gender: Male Female ," the word "gender" replaced "sex" the noun used in the original version of this questionnaire, Lasabagaster \& Huguet's (2007).

Item 7, "7. First language" was adapted. In the original version, the item read "Mother tongue," terminology that we replaced for "First language" because the former is in disuse. On the other hand, and also in the orginal version, Spanish and Basque languages were outlined. In order to fit the present investigation, Basque was replaced by Catalan. Additionally, another sub item was incorporated here, namely “ Other: Please specify: ___ _ In so doing, we accounted for other languages participants may speak.

Items 8 and 9, "8. Province," and "9. I studied at" the latter targeting the type of institution, namely private or public, were moved towards the top of this section in our version because we arranged the more personal less-language learning related 
information together at the beginning of Section 1. In turn, another sub-item was included in item 9, namely "charter school," which was not contemplated in Lasagabaster and Huguet's (2007) version.

Item 6 in the original version of this questionnaire, "6. Parental occupation" was not included in our version of the attitudes questionnaire because the information this item elicits lacked purpose and intent in the present investigation.

Item 10 in our version was slightly modified, since the column that read "L3" in the original was named "English" because we focus on language attitudes towards the English language in the present study.

Item 13 in our version underwent a similar modification as item 10 described above. In our version, this item reads "13. I started learning English at the age of___ , whereas in the original version Lasagabaster and Huguet (2007) it reads "L3."

Item 14 and item 15 in our version were added in order to gain access to more detailed information as regards the participants' English learning starting point.

Item 16 in our version was also incorporated, namely "16. Do you take extra lessons outside the university in English during this academic year? EOI Language school Private lessons Other. Please, specify None in order to include the variable of stay abroad. Data collected from this item was not included in the analysis of attitudes towards English in the present investigation.

Item 16 in the original version was eliminated because it prompted information about students' frequency of watching TV in the L3. We did not include this item because this information is already included in the table in Section 3.

Item 17 and item 18 in Lasagabaster and Huguet's (2007) version, namely “17. What type of High School studies did you complete before entering university? 


\section{Appendices}

“18. In which linguistic model did you predominantly complete your preuniversity studies?" were neither included in our version since we perceived this items asked for information unrelated to the purpose of our study.

In Section 2, just one change was made, in the first table that asks participants to identify the language they use to speak with family, friends, and classmates, we did not include sub-item "7. Neighbours (near my house)." In so doing, we aimed at keeping the focus of language attitudes towards English within the closest people or relatives that participants have.

In Section 3, three main modifications were applied to the original version. On the one hand, we reduced to one the tables included in the section. Keeping in mind that we explore learners' attitudes towards English, we excluded the two tables that referred to participants' attitudes towards their L1, and L2. On the other hand, as regards the instructions for the table that we did keep in this section, we changed "L3" for "English" since we focus on attitudes towards this specific language and no other. Finally, the third change was related to the options the students were provided to choose from on a likert-scale base. Lasagabaster and Huguet (2007) conceived five categories from strongly disagreeing with a given item to strongly agreeing with the item. In our version of this attitudes questionnaire, we reduced the options to two, namely "Agree (A)" and "Disagree (D)" in order to reduce the amount of data that would need to be analyzed statistically afterwards. Data from Section 3 was the data analyzed to be included in this dissertation. The same version of the questionnaire was distributed in the pretest, posttest, and delayed posttest sessions, since there was no risk on task repetition effect. 
Appendices 
Appendix 12. Computer-delivered ODCT and RVP Pretest Version

You are going to work on a series of situations in which there is a situation description, and a picture that shows the situation. Then you are asked two questions: what you would say in each of the situations, and why.

\section{Example}

Scenario: Your mom asks you to help her with dinner. She says: "Would you mind helping me with dinner?"

\section{https://www.youtube.com/watch?v=9 G9uWszJhM\&feature=youtu.be}

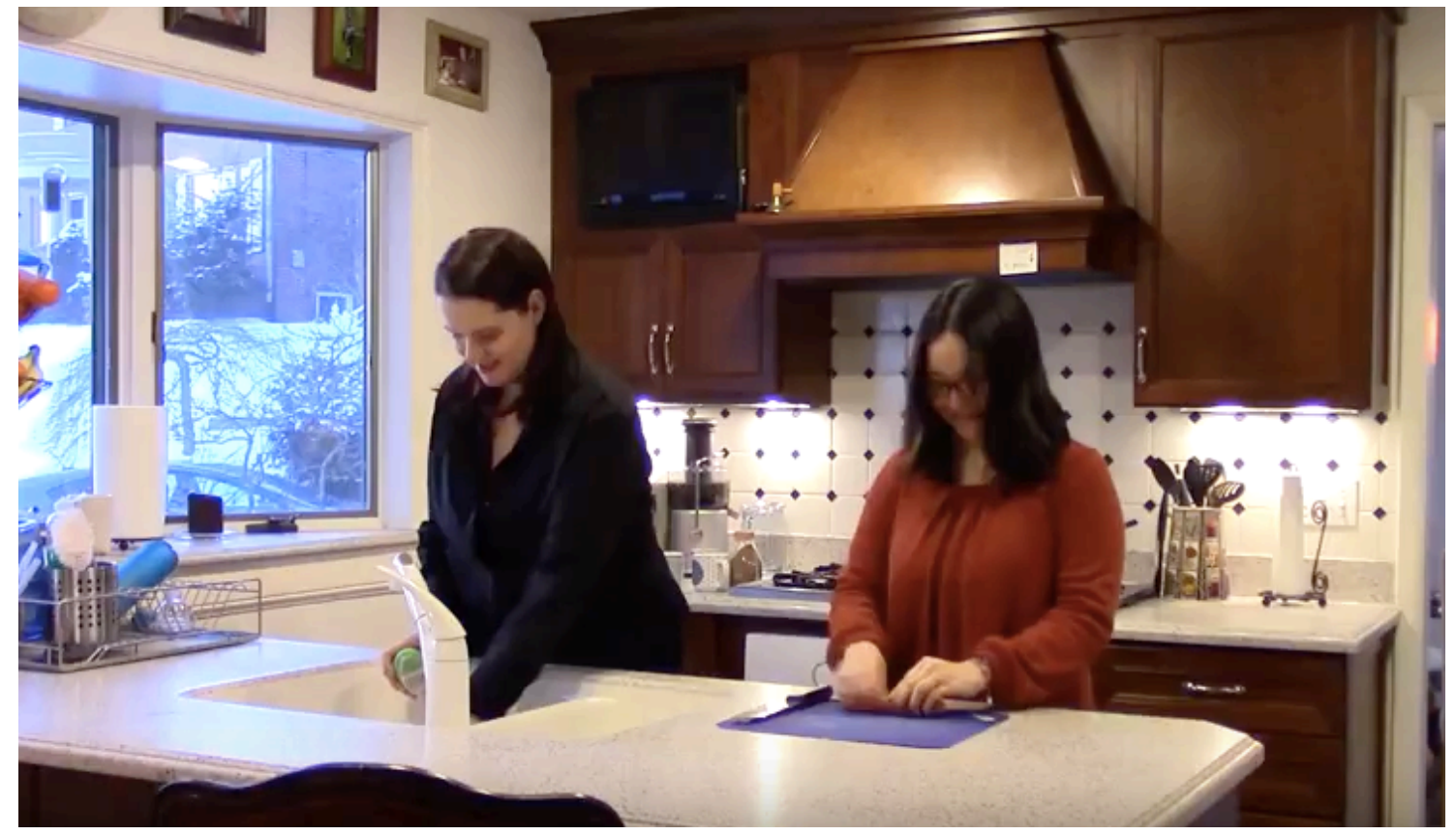

You say: Not at all.

Why have you used that expression?:

I have used that expression because it shows that I am willing to help her.

Now, please proceed to complete the following situations. 
Appendices

\section{Situation 1}

Scenario: Your friend Ana just threw a wonderful party. As you leave,

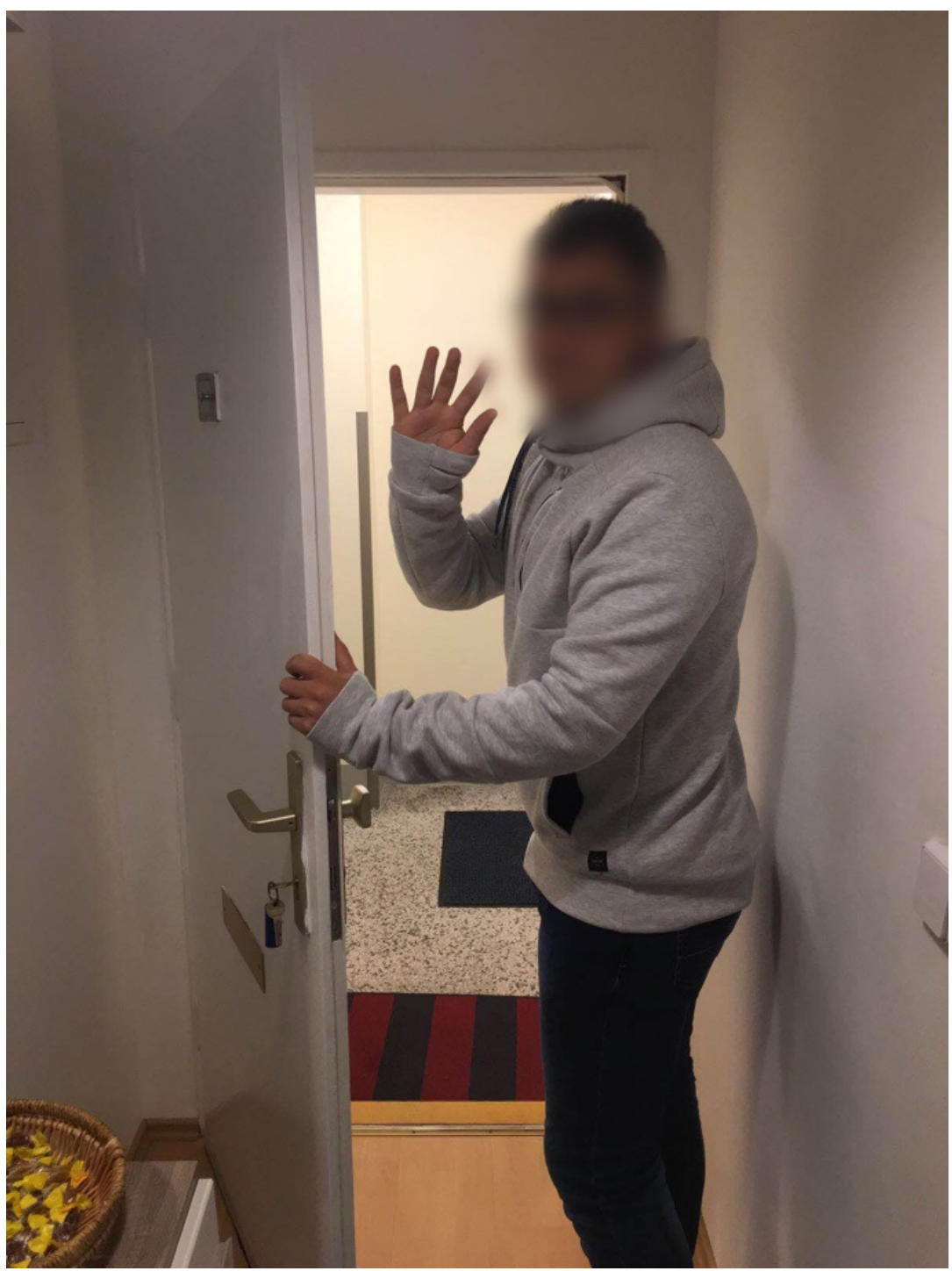

You say:

Why have you used that expression?: 
Appendices

\section{Situation 2}

Scenario: You are at your in-laws' Christmas dinner. They offer you more food but you already ate a lot and do not want any more.

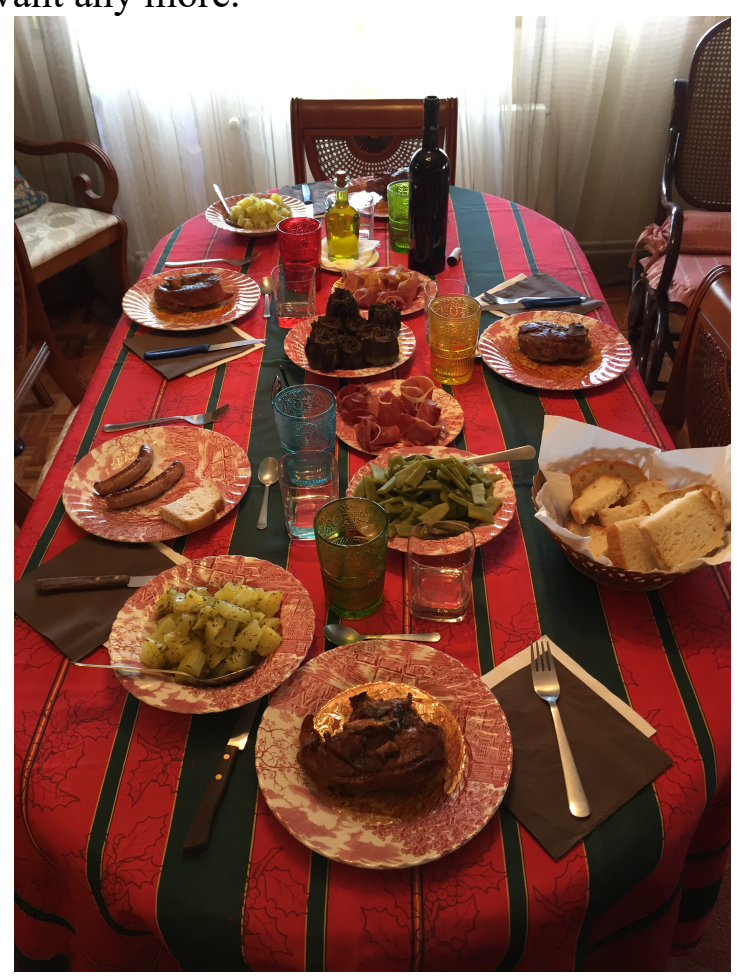

You say:

Why have you used that expression?: 


\section{Situation 3}

Scenario: Your friend Juan introduces you to a friend of his, Pablo.

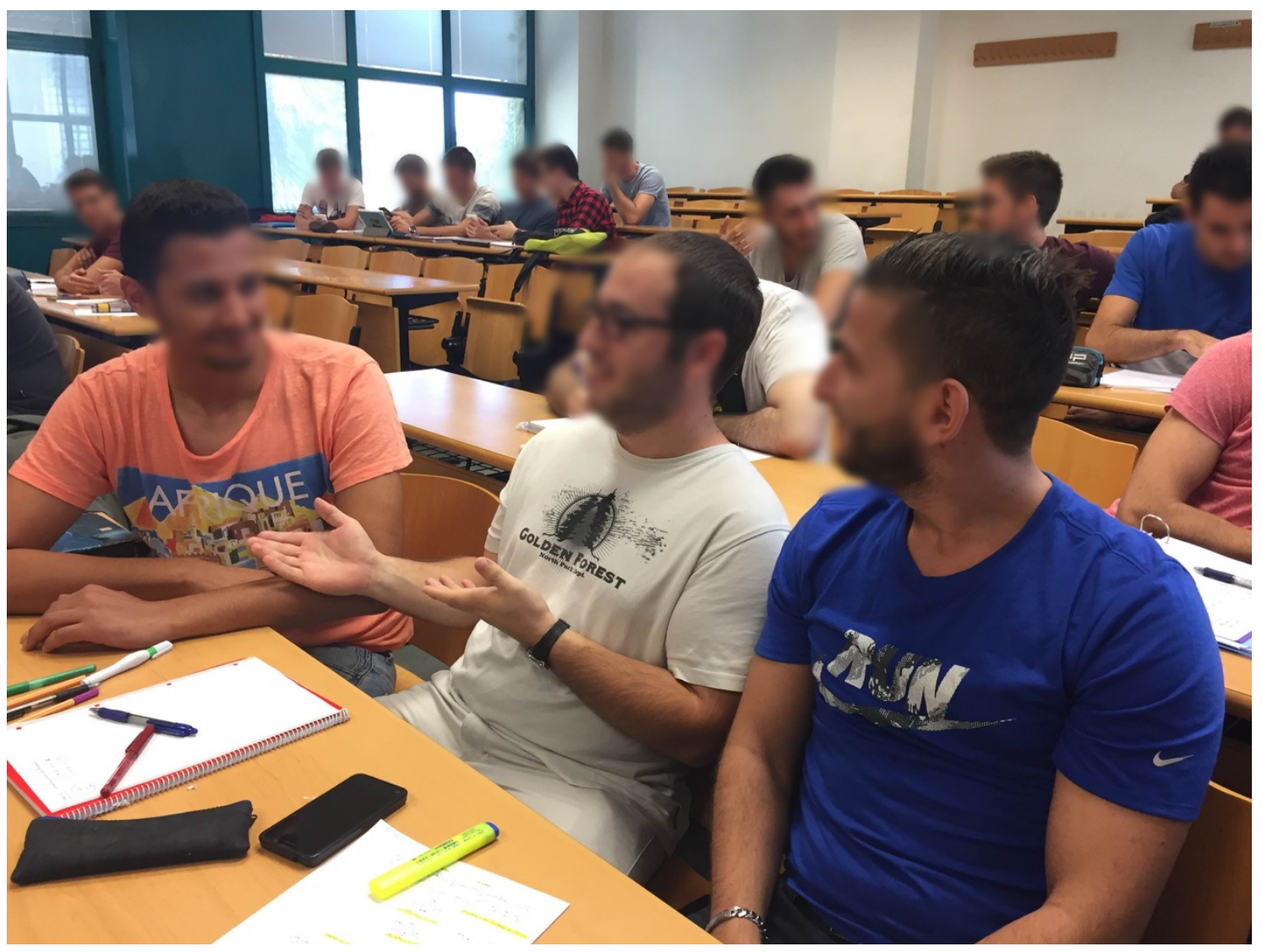

You say:

Why have you used that expression?: 
Appendices

\section{Situation 4}

Scenario: You meet Paula, Silvia's friend, whom you had been introduced before, on campus another day.

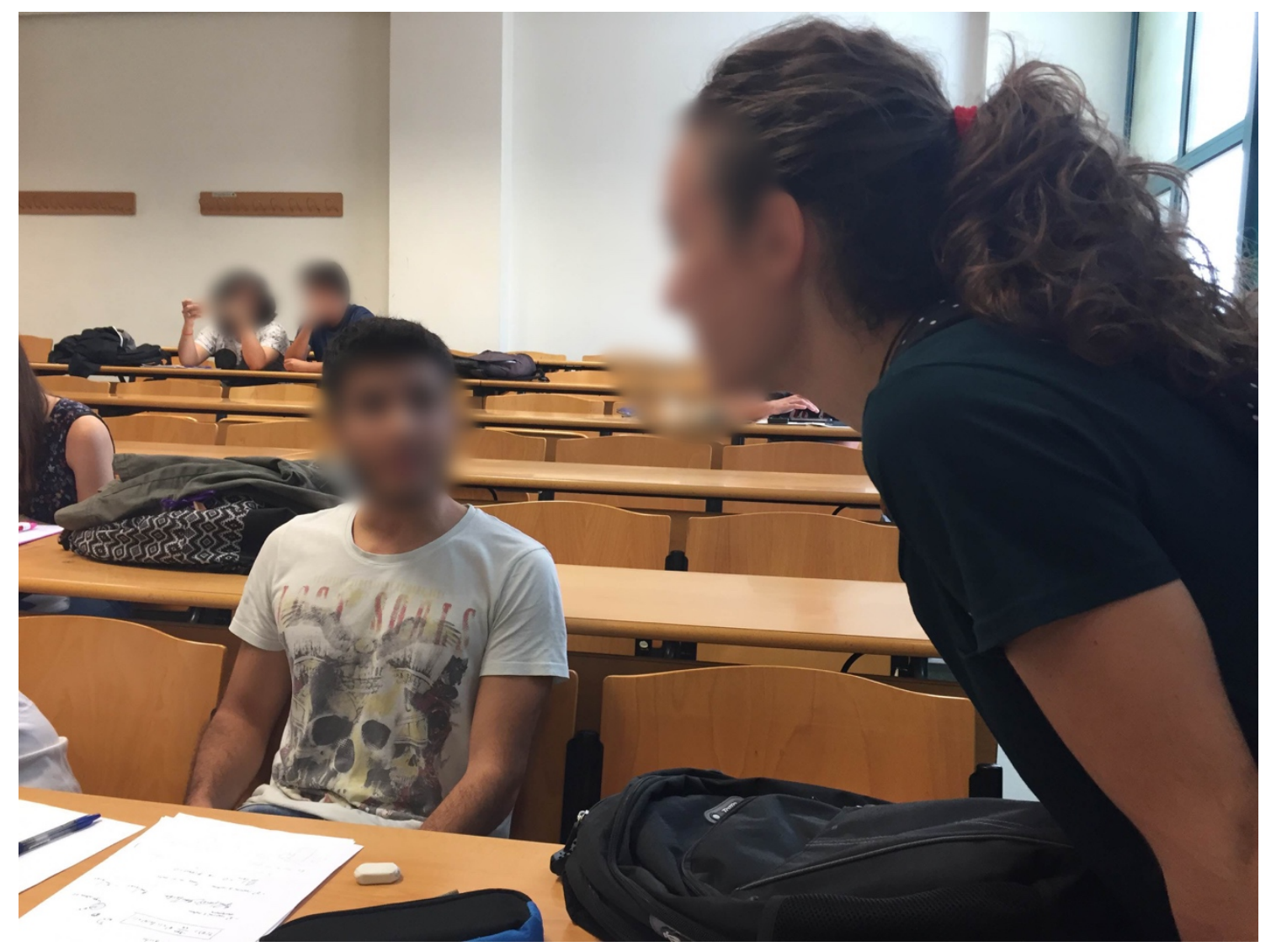

You say:

Why have you used that expression?: 
Appendices

\section{Situation 5}

Scenario: You greet a Professor with whom you have a very good relationship.

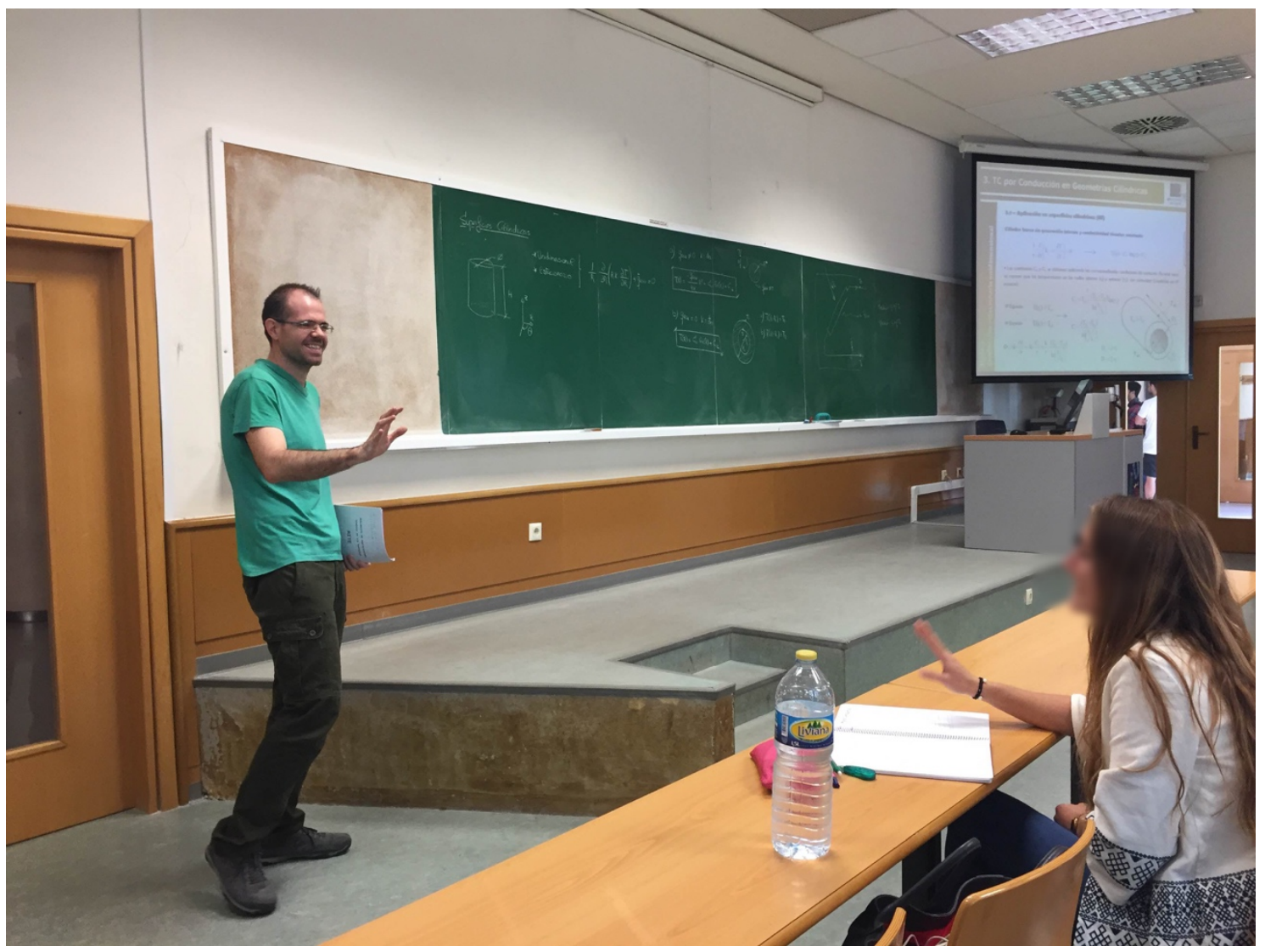

You say:

Why have you used that expression?: 


\section{Situation 6}

Scenario: At the supermarket, you start putting all the goods in the conveyor belt, and the cashier greets you: "Hi. How are you?"

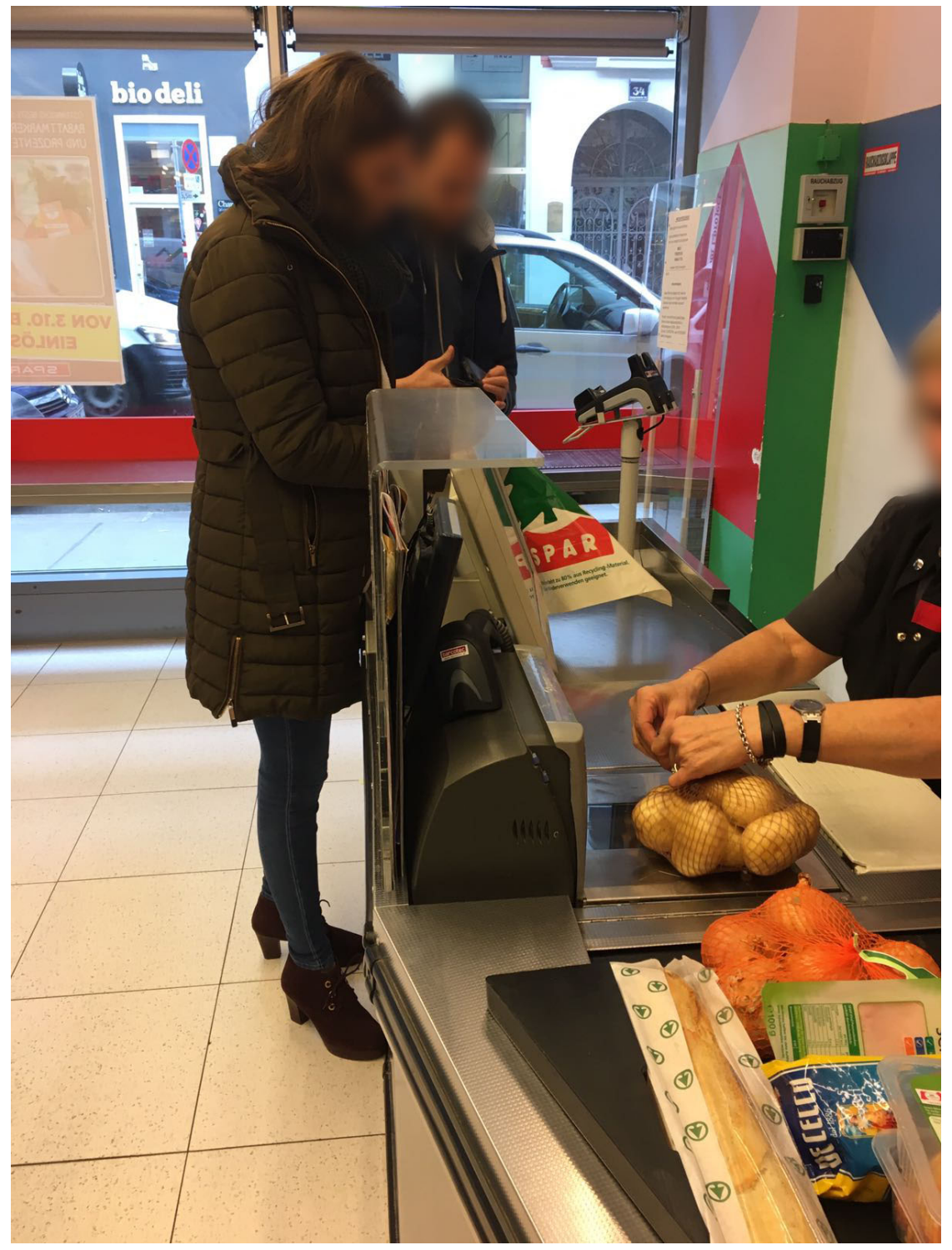

You say:

Why have you used that expression?: 


\section{Situation 7}

Scenario: You are in class and your pen ran out of ink. You ask your friend for a pen.

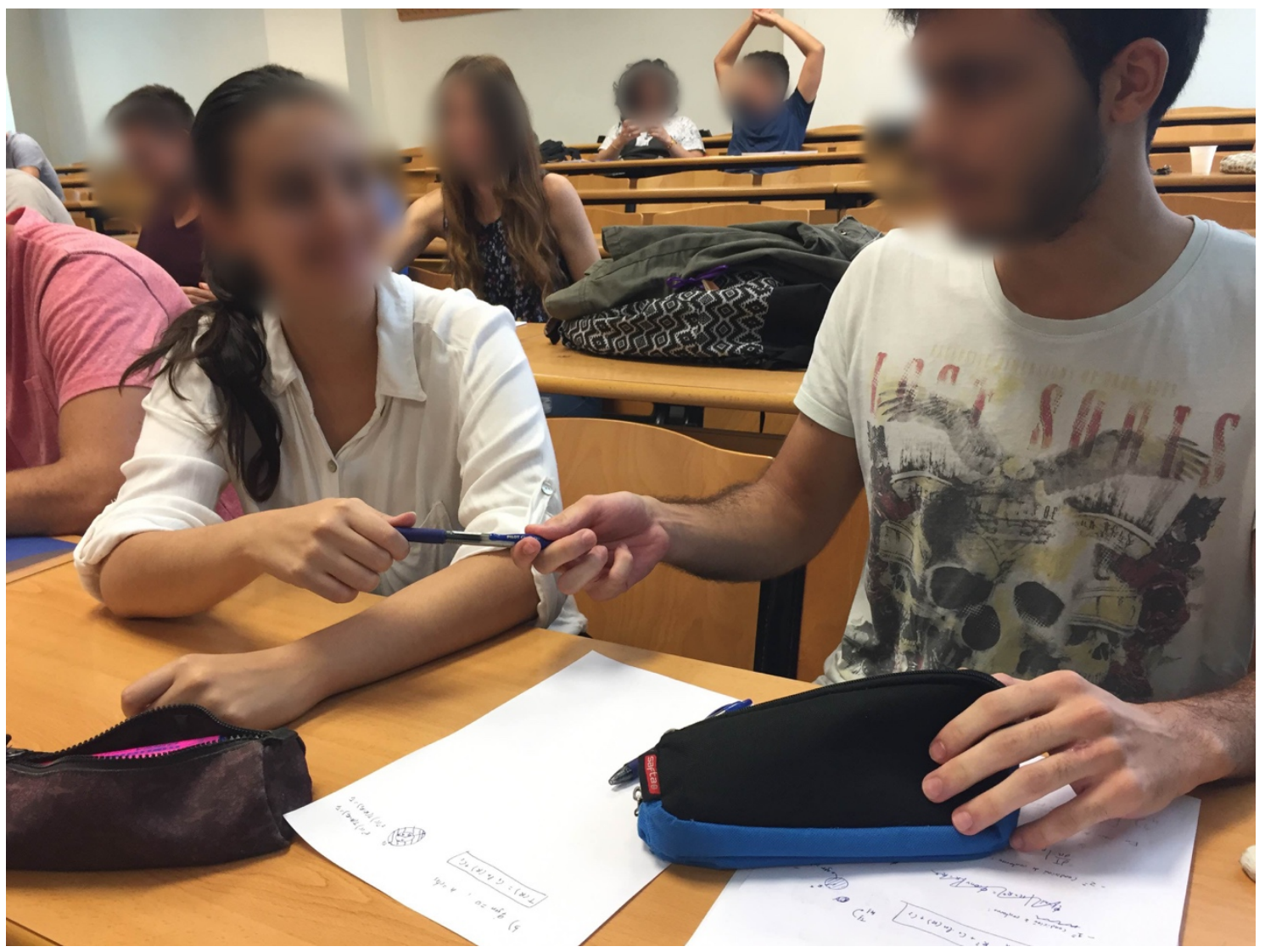

You say:

Why have you used that expression?: 


\section{Situation 8}

Scenario: You are in an aisle in a supermarket. There is an old lady slowly pushing a shopping cart in front of you. However, you need to get by her.

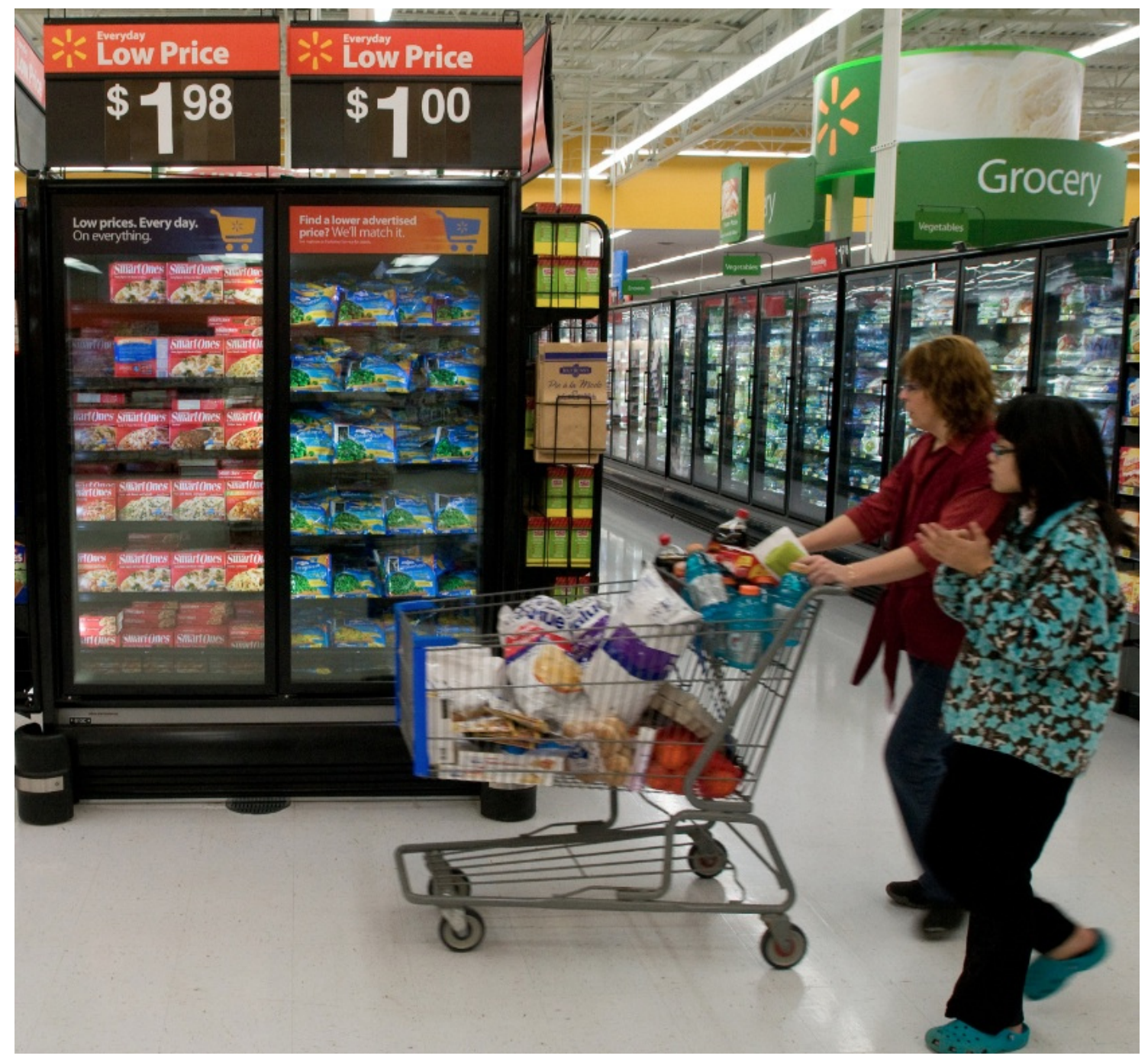

Source: https://www.flickr.com/photos/walmartcorporate/5684145463

You say:

Why have you used that expression?: 


\section{Situation 9}

Scenario: You are in an aisle at a supermarket. You are trying to get around an old lady and accidentally bump into her cart.

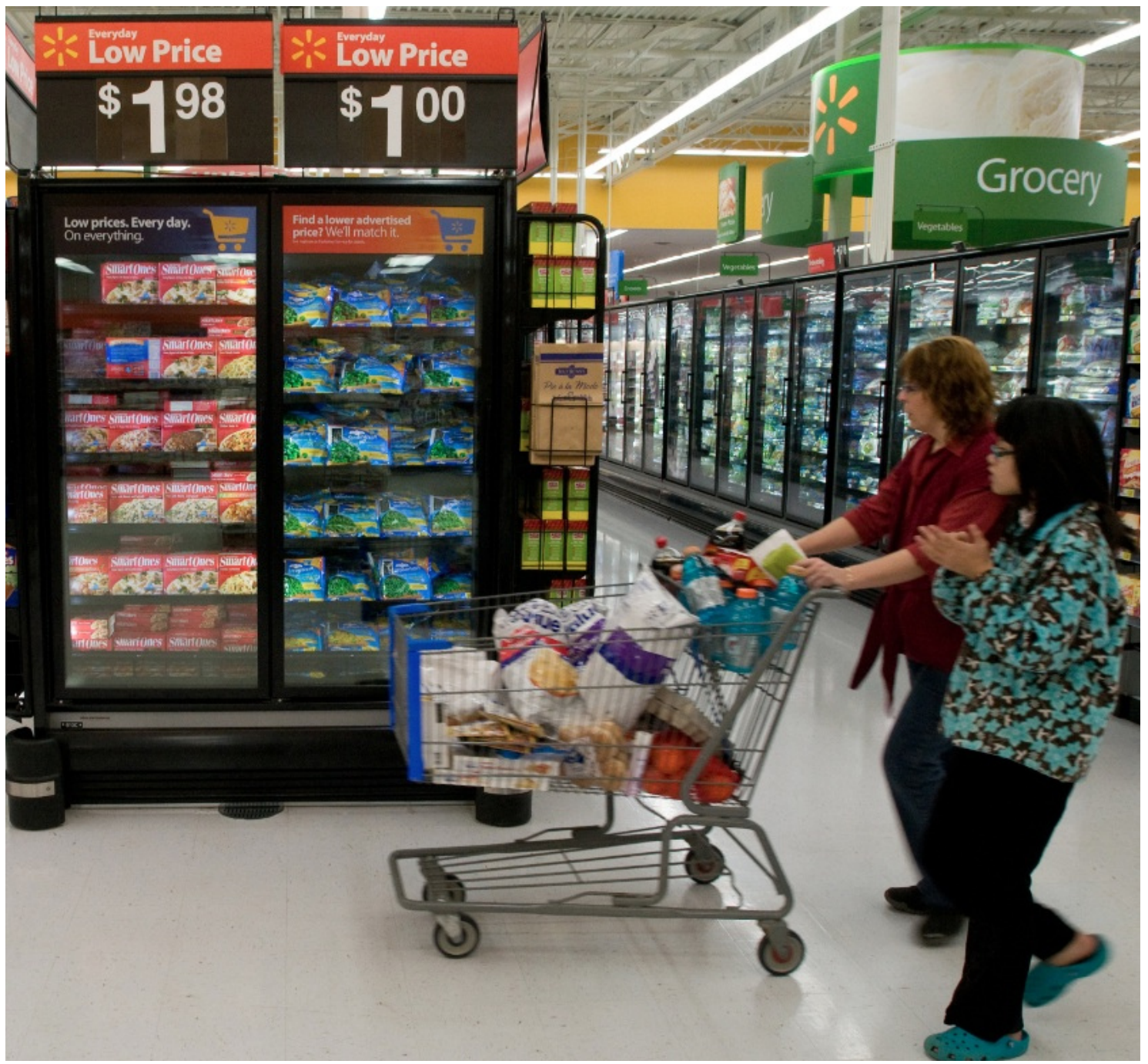

Source: https://www.flickr.com/photos/walmartcorporate/5684145463

You say:

Why have you used that expression?: 


\section{Appendices}

\section{Situation 10}

Scenario: You just finished classes today. It is pouring outside, you do not have an umbrella and you missed the bus. You see a classmate of yours approaching his car.

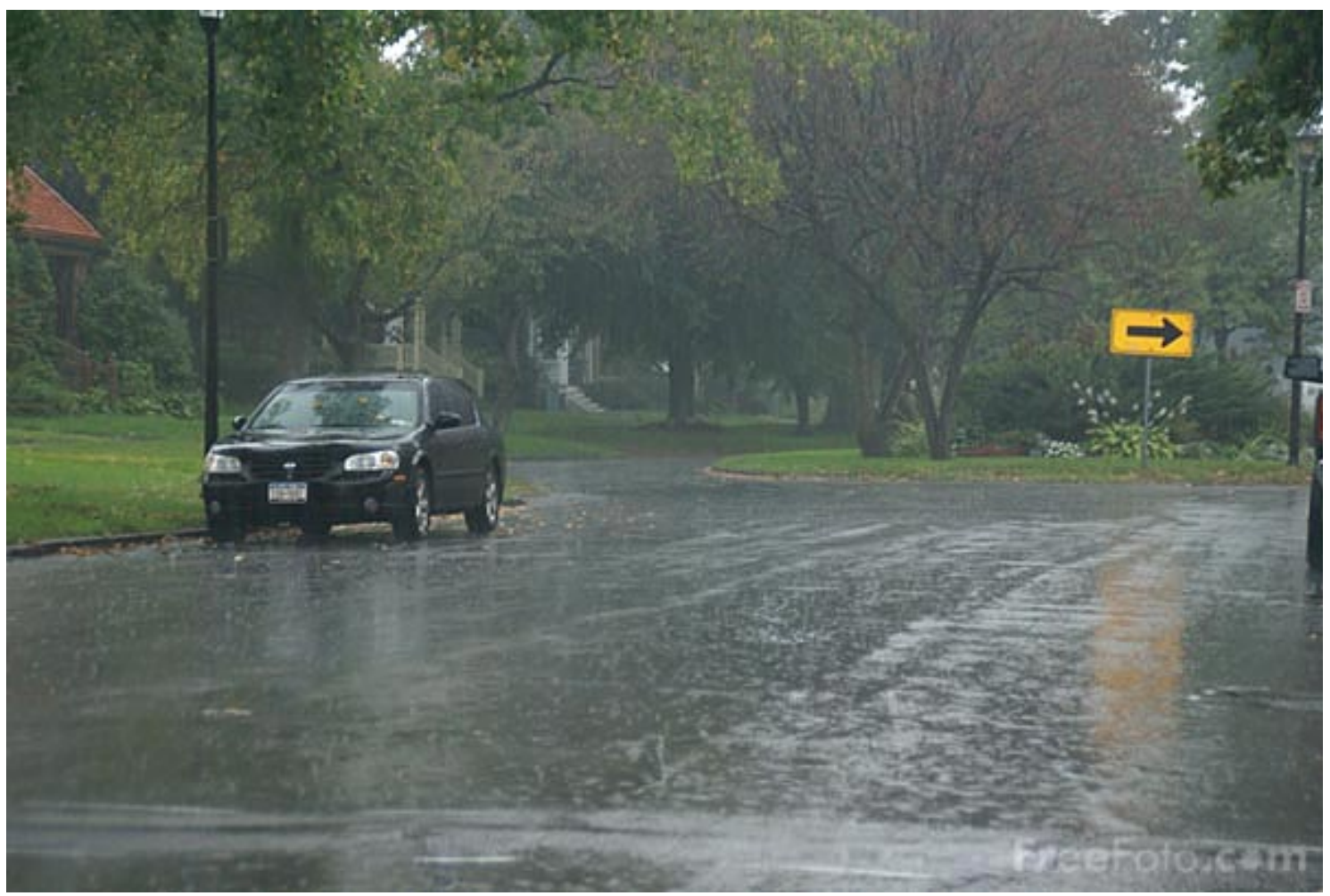

Source: http://injust10.blogspot.com.es/2011 0301 archive.html

You say:

Why have you used that expression?: 


\section{Appendices}

\section{Situation 11}

Scenario: You just finished classes and it is pouring outside. As you go to your car, a classmate of yours asks you if you can give him a ride.

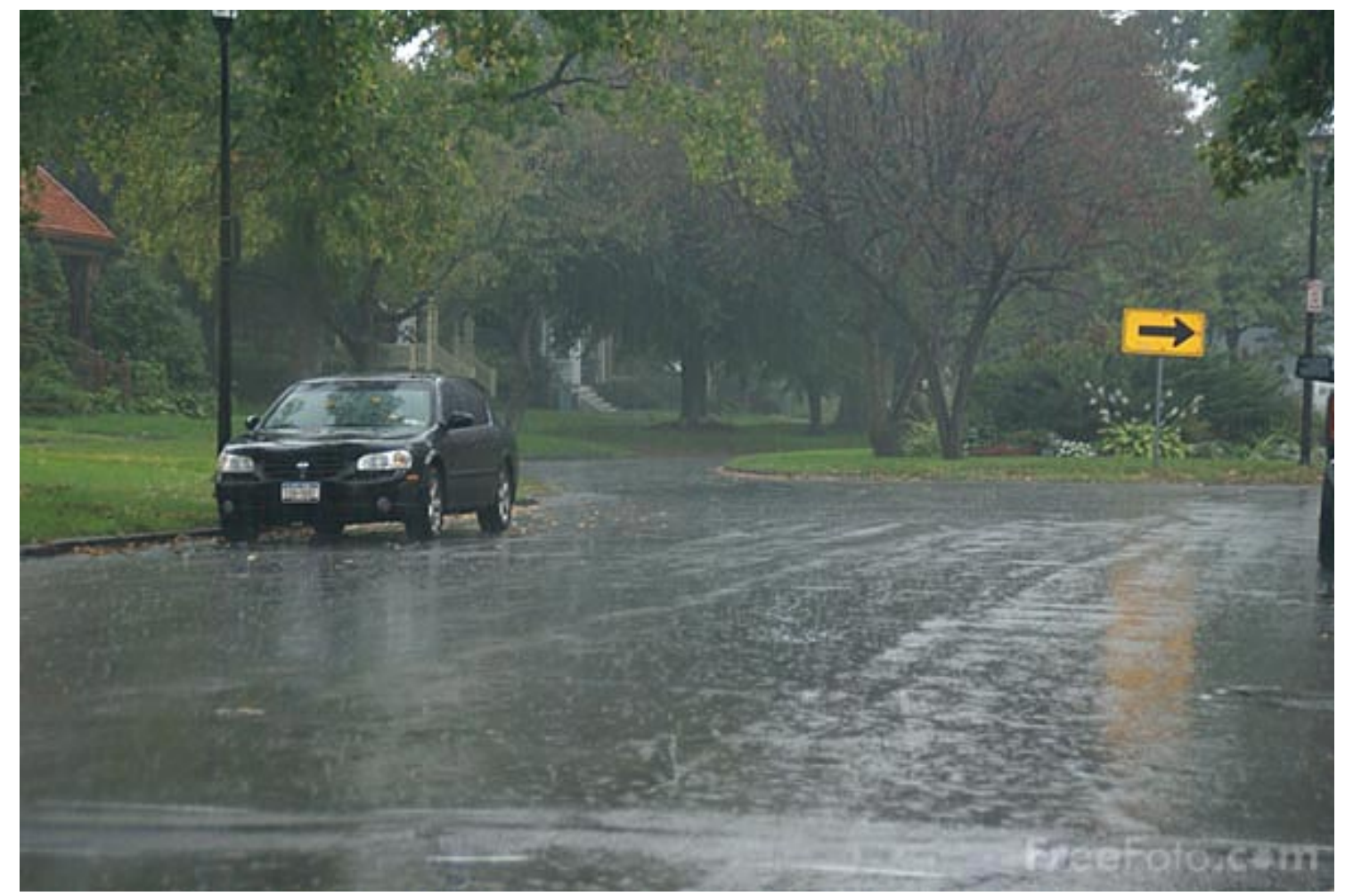

Source: http://injust10.blogspot.com.es/2011 0301 archive.html

You say:

Why have you used that expression?: 
Appendices

\section{Situation 12}

Scenario: You just finished a long meeting with your professor. You know he is very busy.

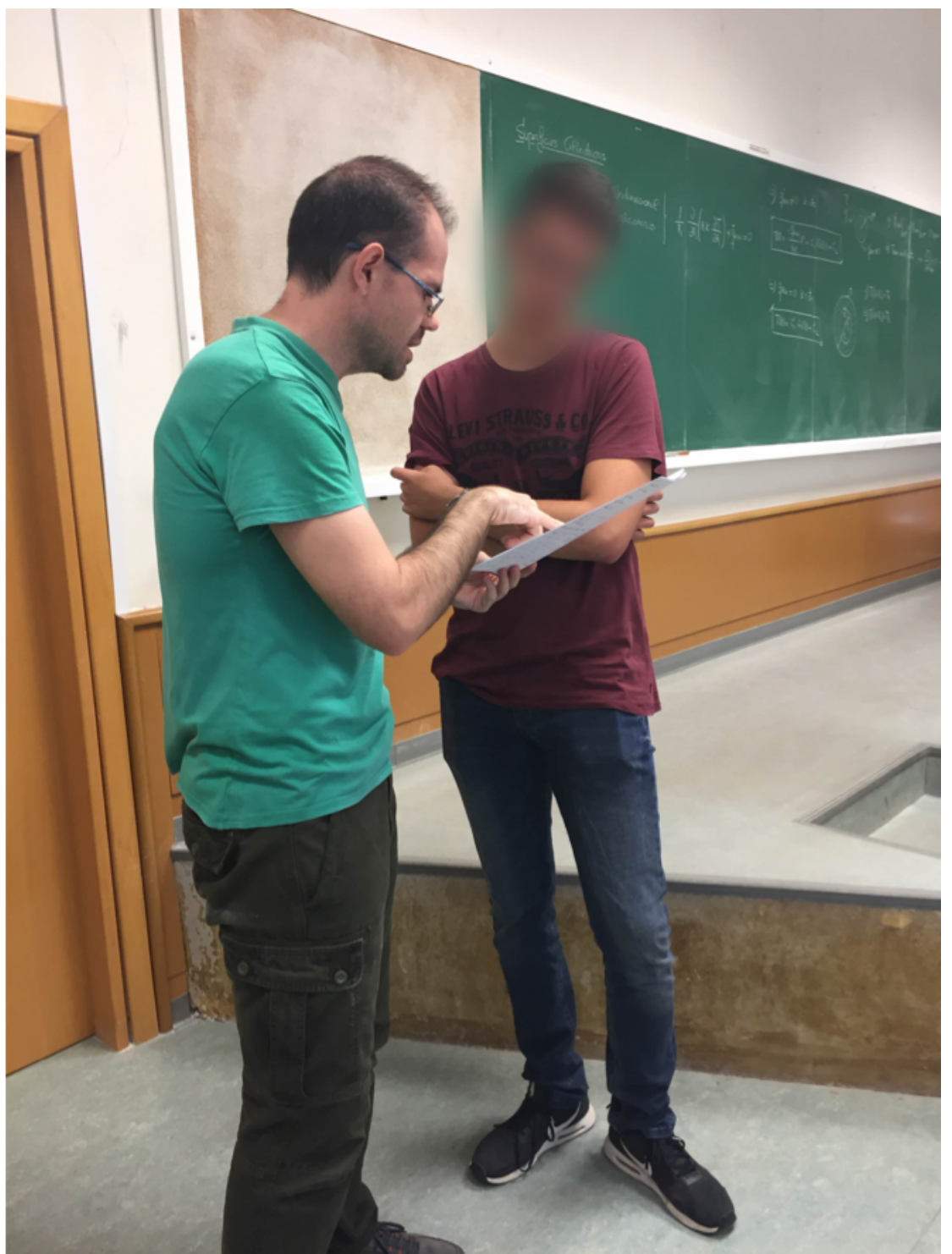

You say:

Why have you used that expression?: 
Appendices

\section{Situation 13}

Scenario: You are in a store looking at some books. A sales person comes up to you and asks you if you need some help. However, you do not need help.

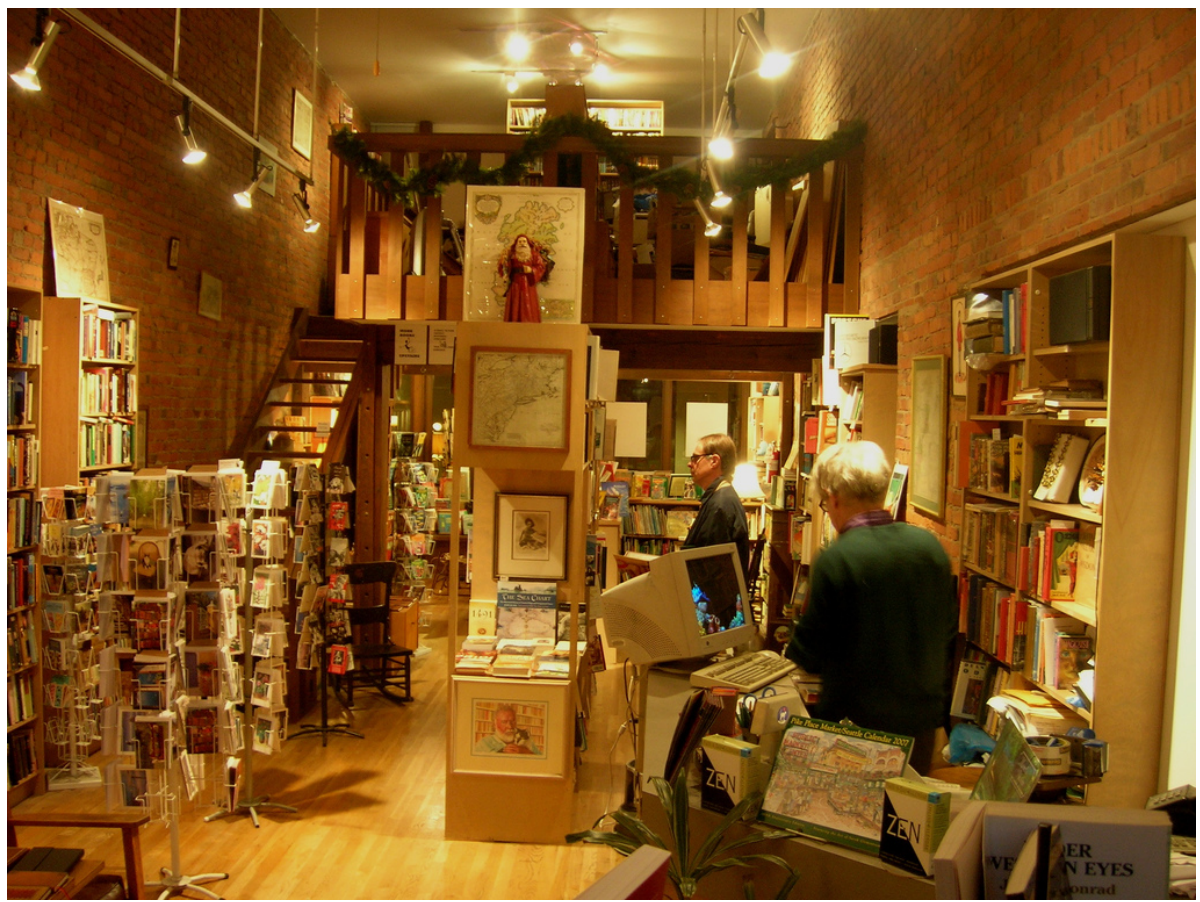

Source: https://www.flickr.com/photos/brewbooks/330665317

You say:

Why have you used that expression?: 
Appendices

\section{Situation 14}

Scenario: Your friend invites you to dinner. Then, he suggests to go dancing afterwards.

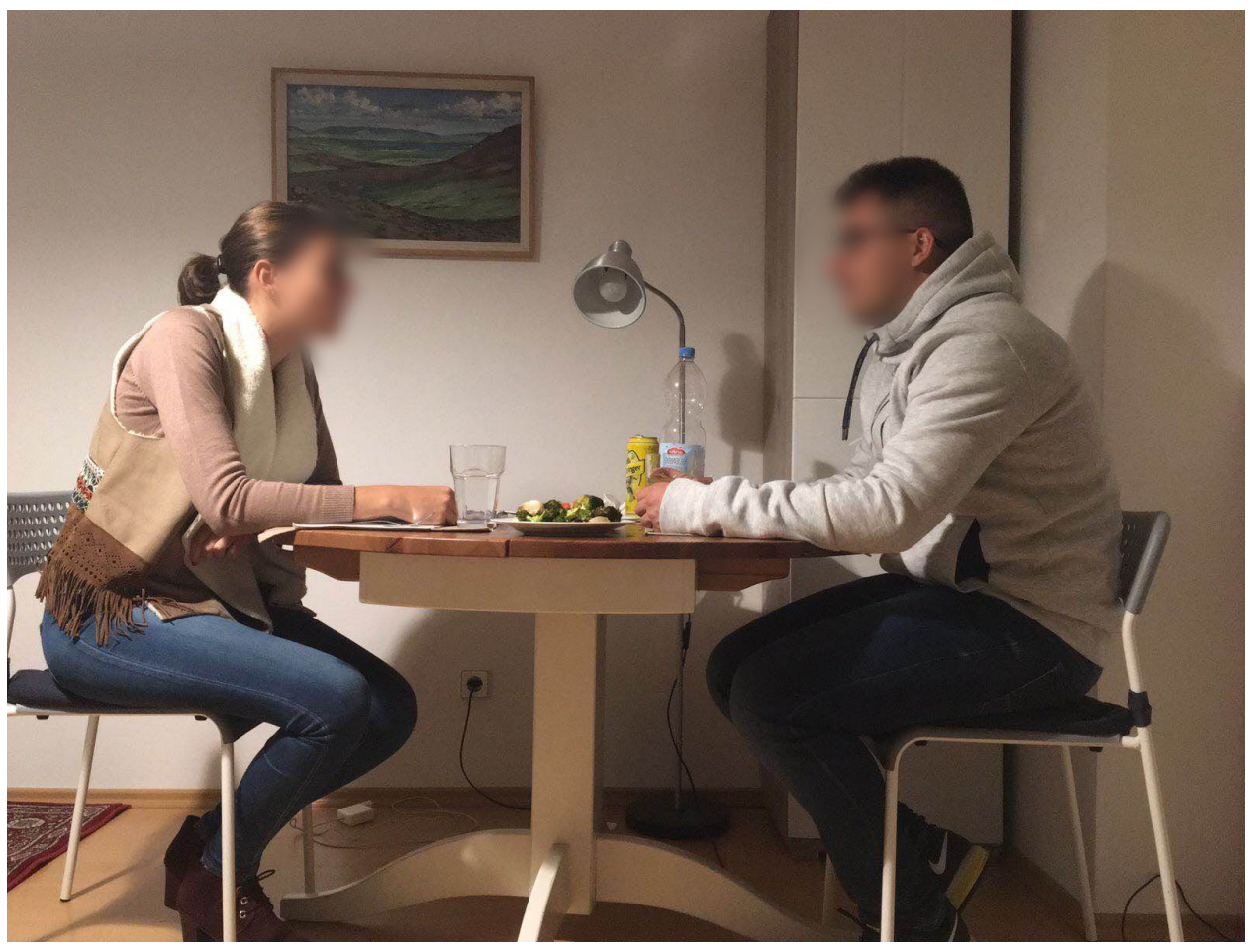

You say:

Why have you used that expression?: 
Appendices

\section{Situation 15}

Scenario: You and your friend are on your way to campus. Your friend is about to cross the street but he does not see a car coming. You already have seen the car and try to stop him.

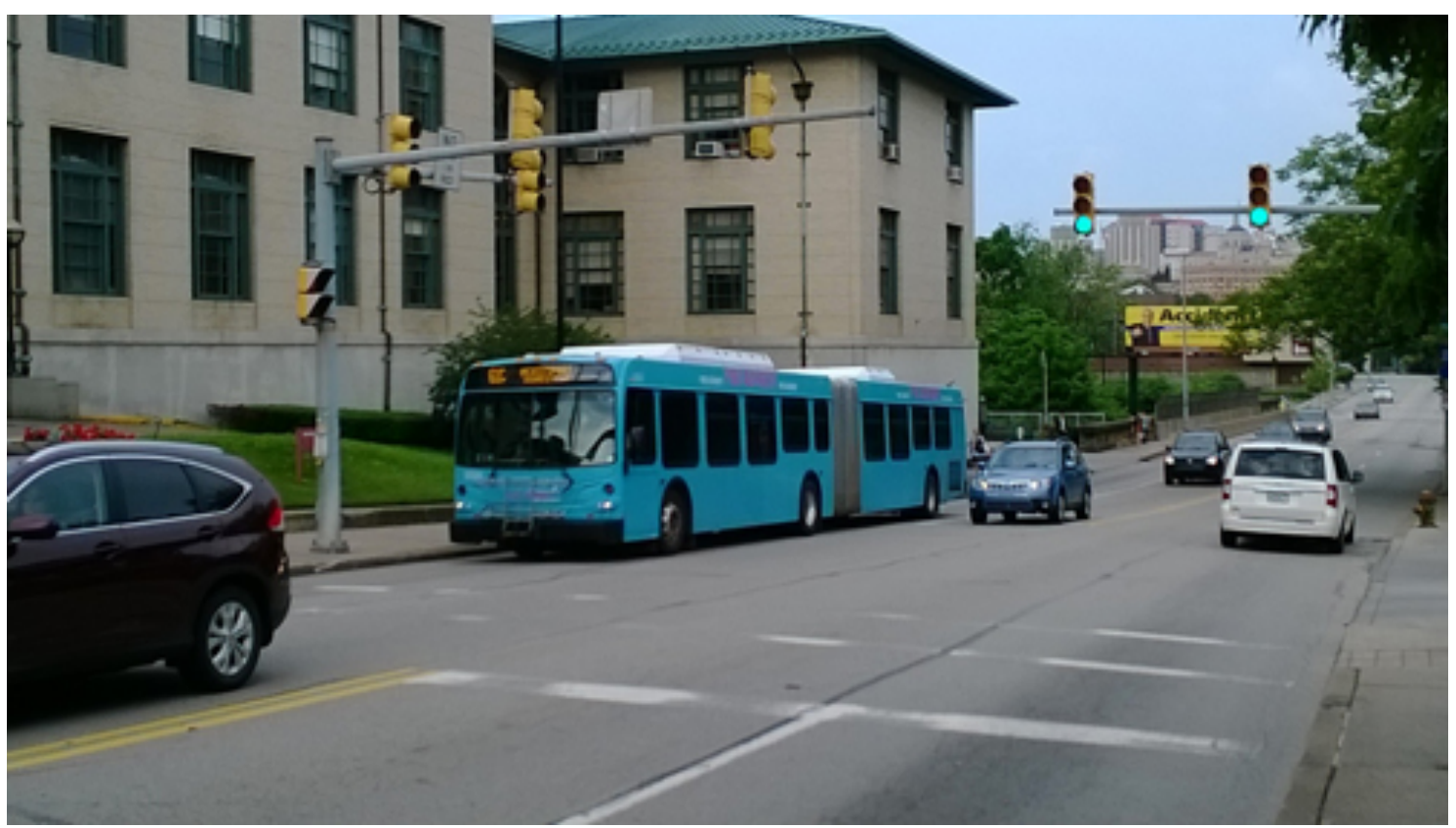

Source: http://www.cmu.edu/news/stories/archives/2014/june/images/buslinephoto_500x281.jpg

You say:

Why have you used that expression?: 
Appendix 13. Computer-delivered ODCT and RVP Posttest Version

You are going to work on a series of situations in which there is a situation description, and a picture that shows the situation. Then you are asked two questions: what you would say in each of the situations, and why.

\section{Example}

Scenario: Your mom asks you to help her with dinner. She says: "Would you mind helping me with dinner?"

\section{https://www.youtube.com/watch?v=9 G9uWszJhM\&feature=youtu.be}

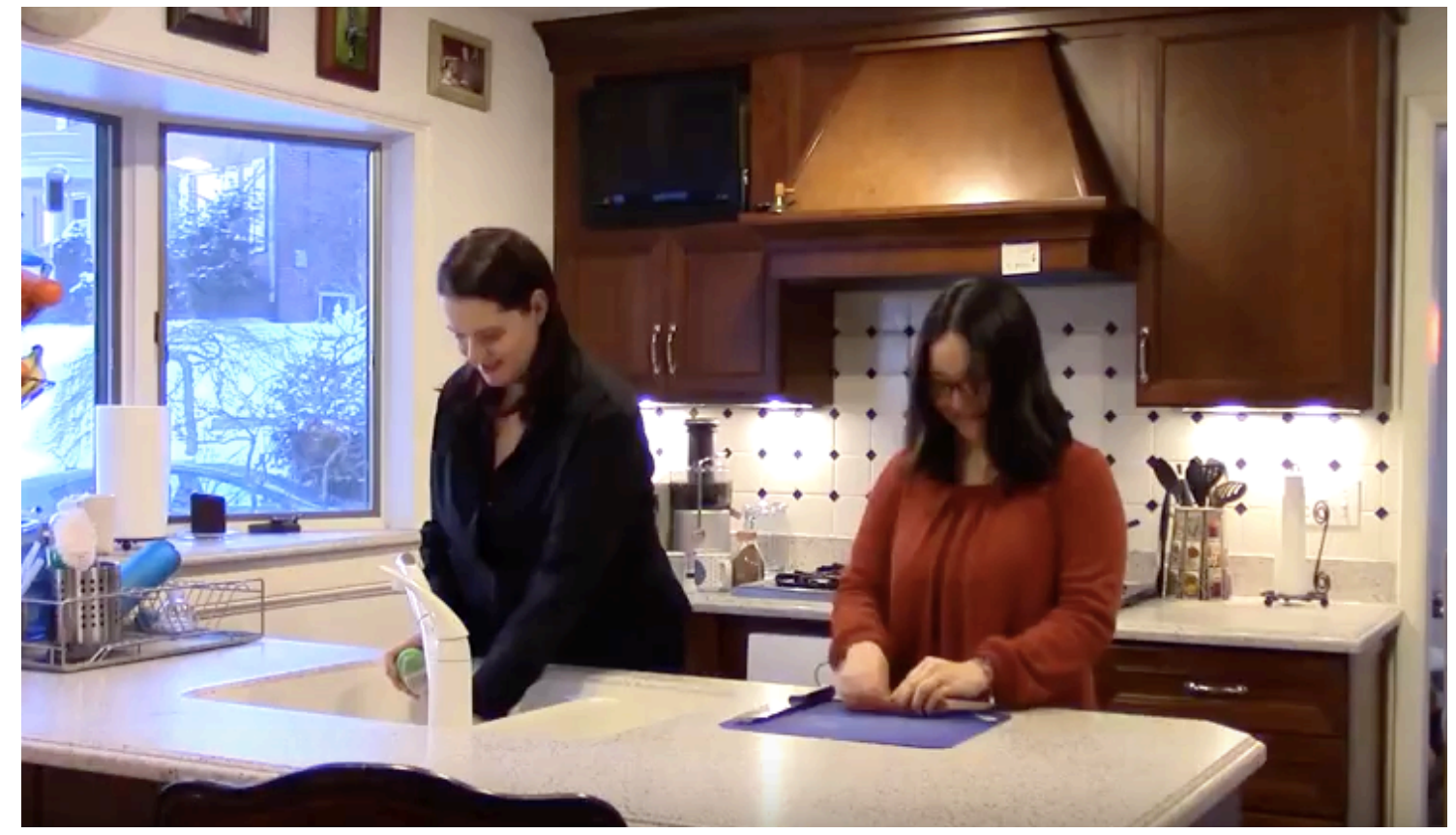

You say: Not at all.

Why have you used that expression?

I have used that expression because it shows that I am willing to help her.

Now, please proceed to complete the following situations. 


\section{Situation 1}

Scenario: Your friend Juan introduces you to a friend of his, Pablo.

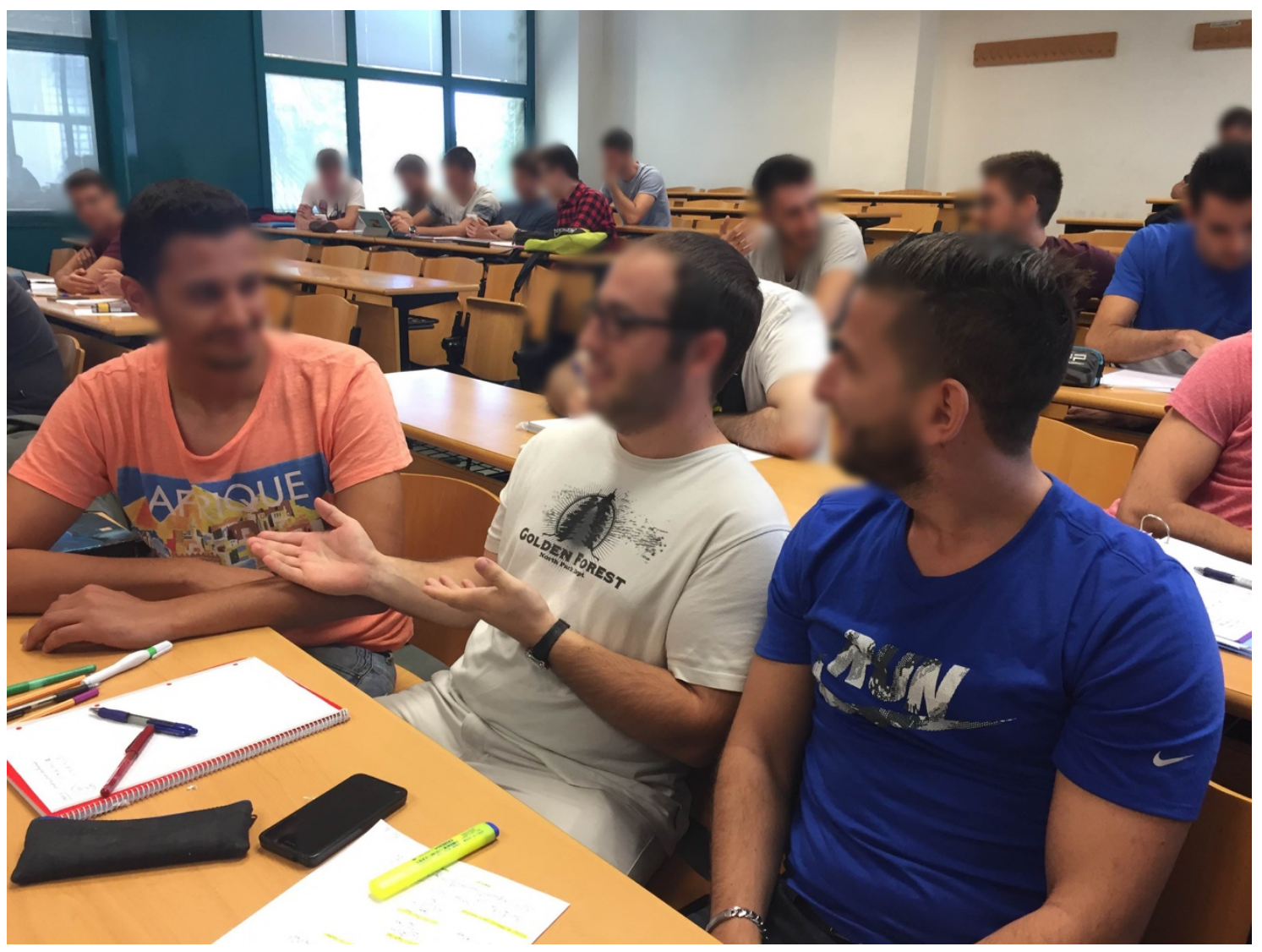

You say:

Why have you used that expression?: 
Appendices

\section{Situation 2}

Scenario: You greet a Professor with whom you have a very good relationship.

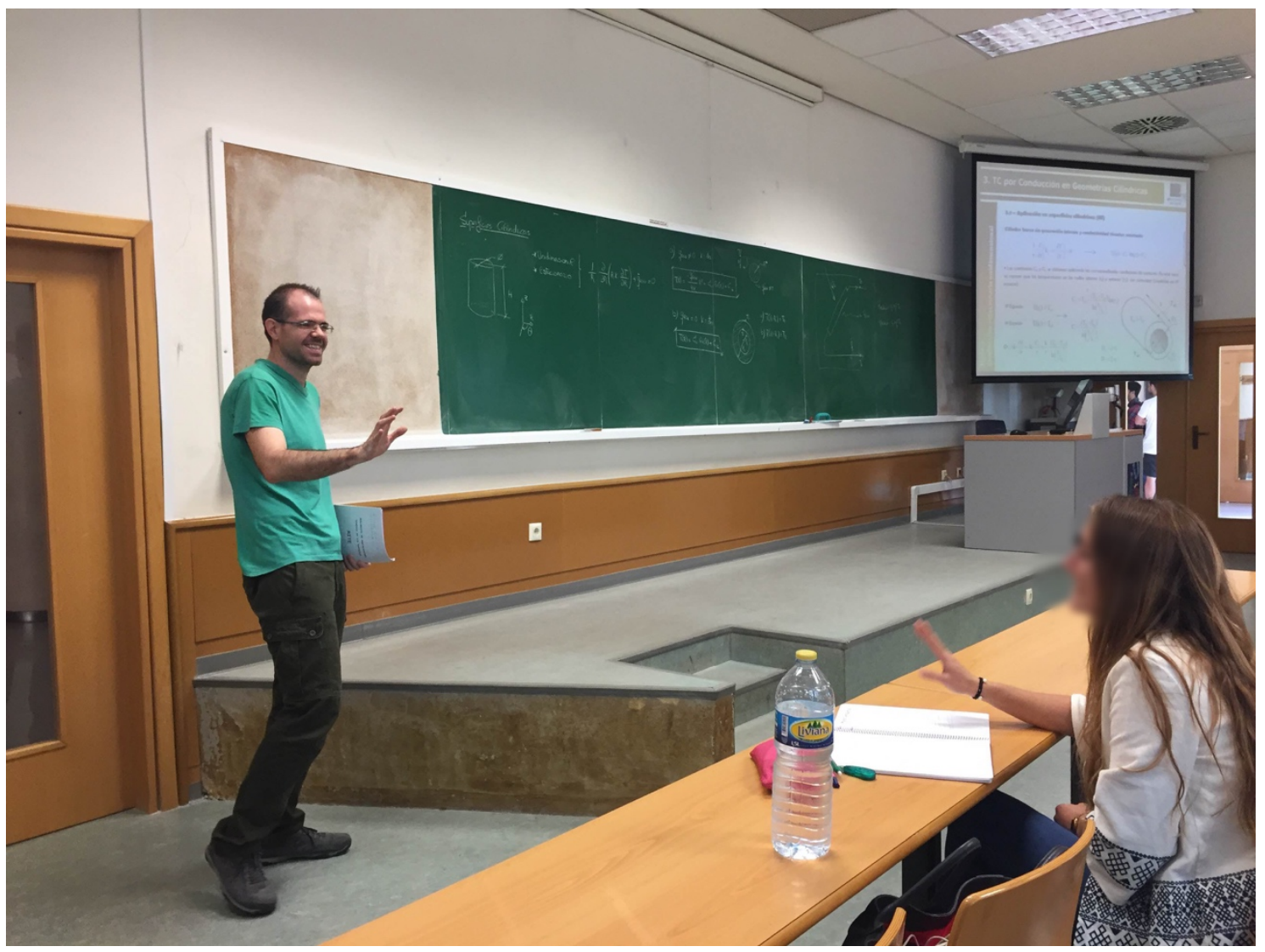

You say:

Why have you used that expression?: 


\section{Situation 3}

Scenario: You are in an aisle at a supermarket. You are trying to get around an old lady and accidentally bump into her cart.

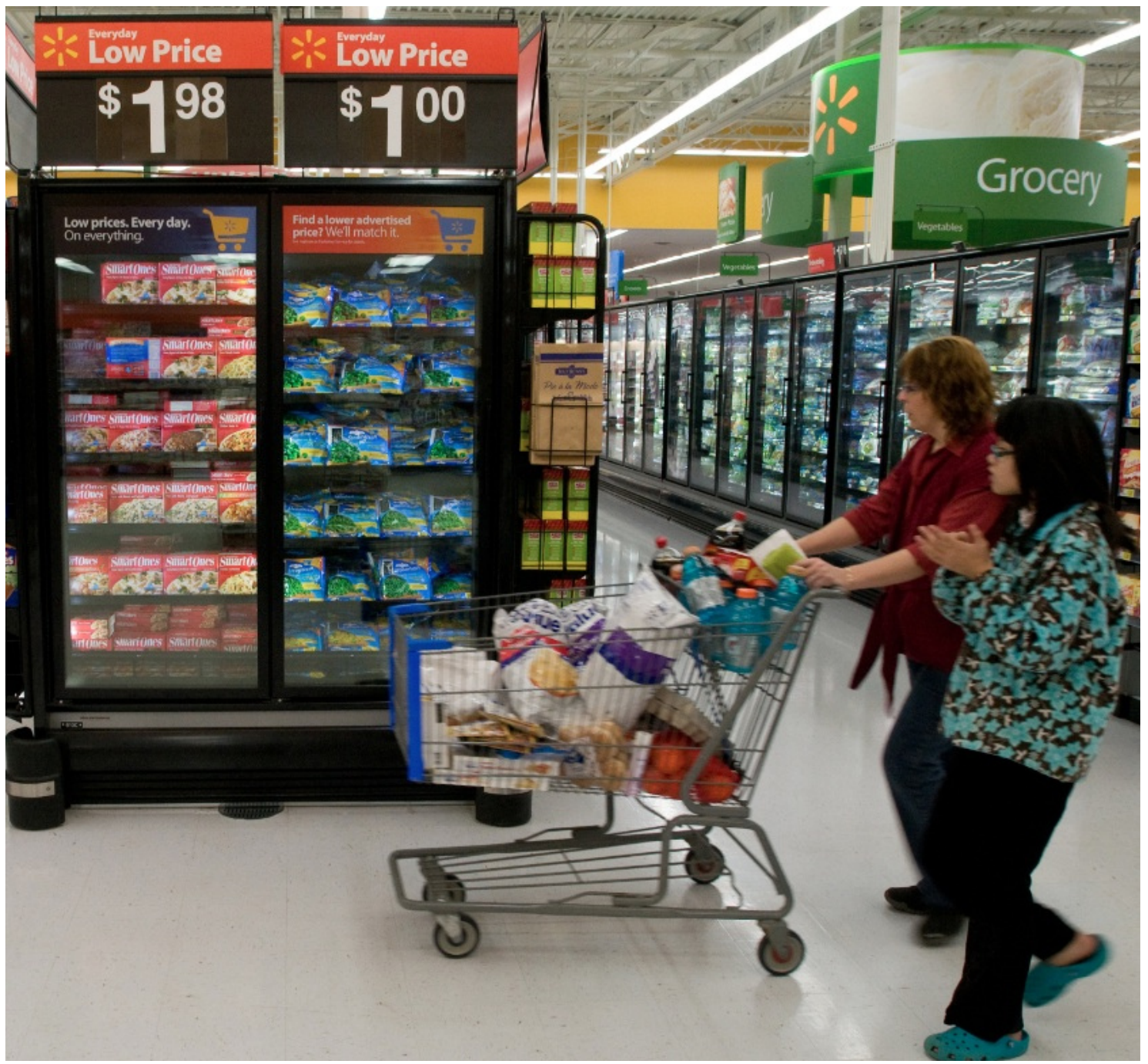

Source: https://www.flickr.com/photos/walmartcorporate/5684145463

You say:

Why have you used that expression?: 


\section{Situation 4}

Scenario: You are in class and your pen ran out of ink. You ask your friend for a pen.

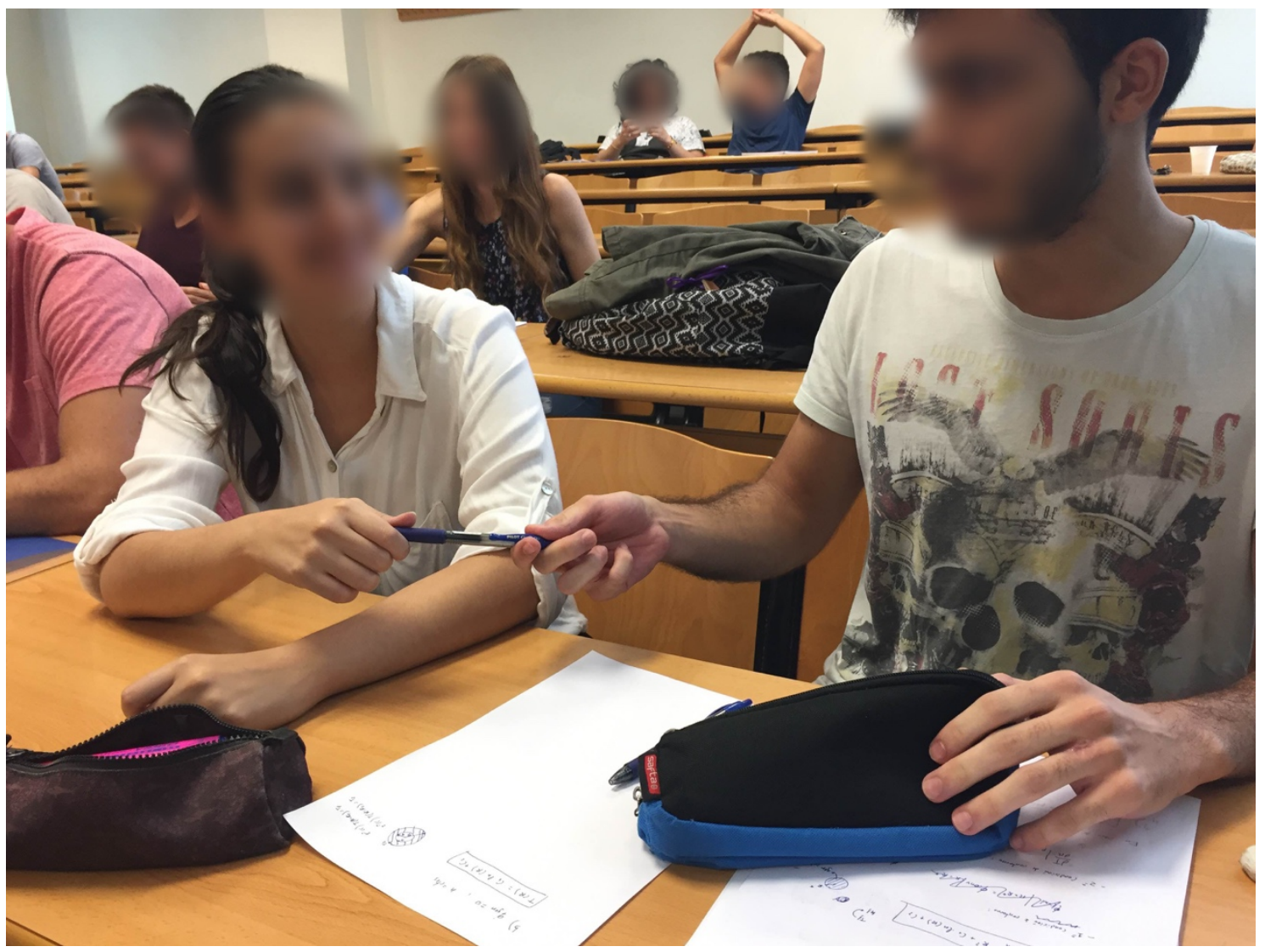

You say:

Why have you used that expression?: 
Appendices

\section{Situation 5}

Scenario: You just finished a long meeting with your professor. You know he is very busy.

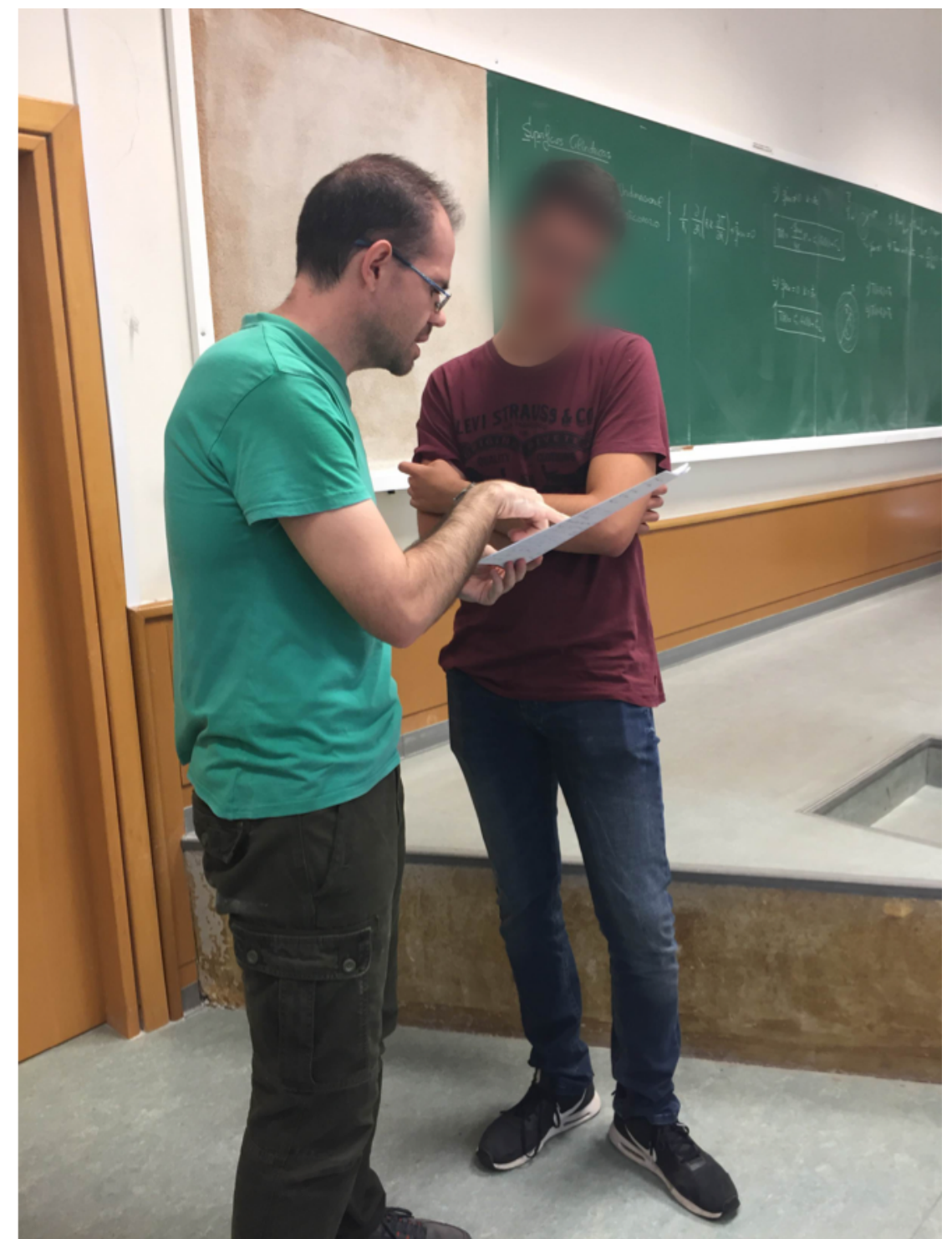

You say:

Why have you used that expression?: 
Appendices

\section{Situation 6}

Scenario: Your friend Ana just threw a wonderful party. As you leave,

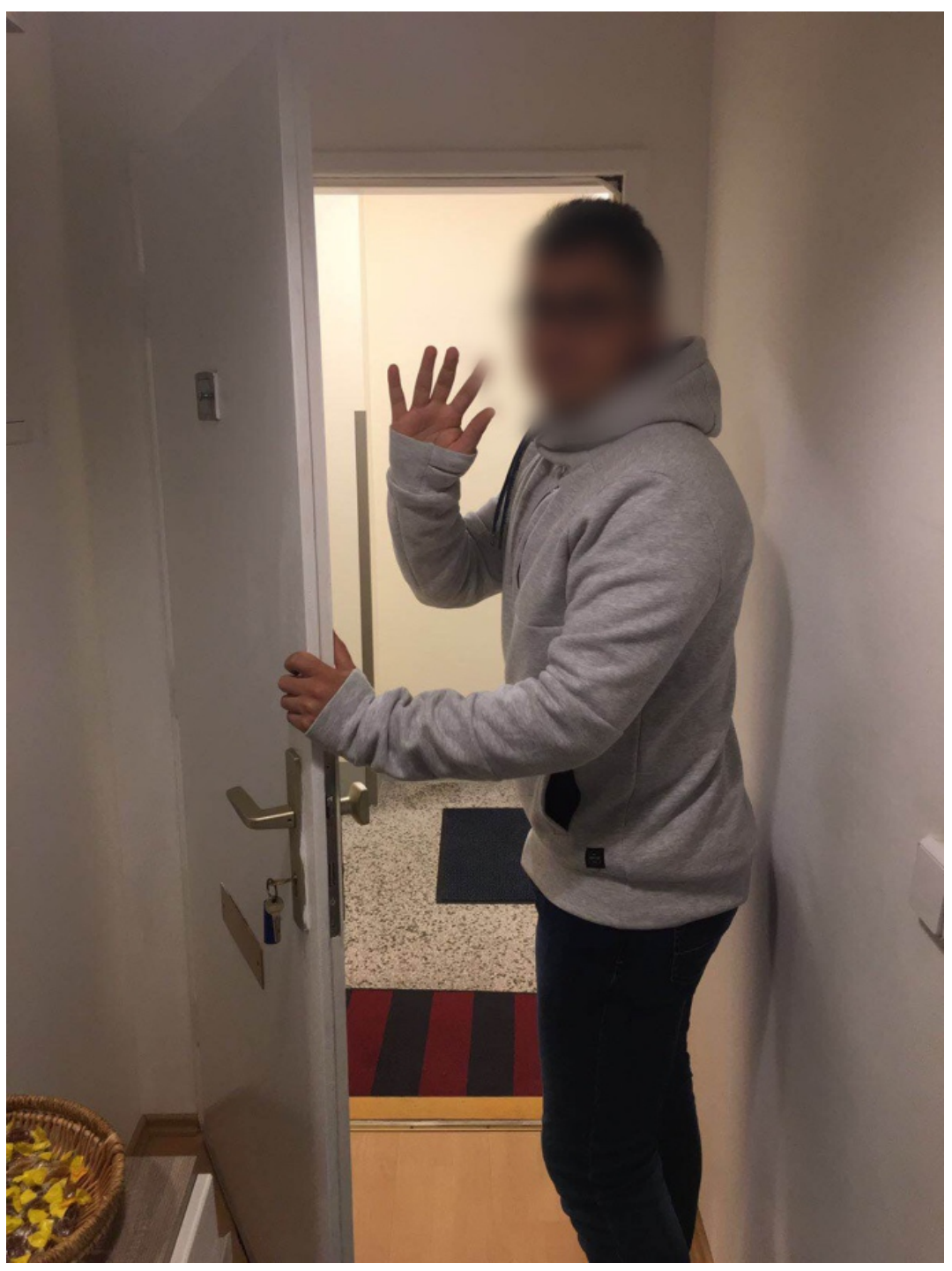

You say:

Why have you used that expression?: 
Appendices

\section{Situation 7}

Scenario: At the supermarket, you start putting all the goods in the conveyor belt, and the cashier greets you: "Hi. How are you?"

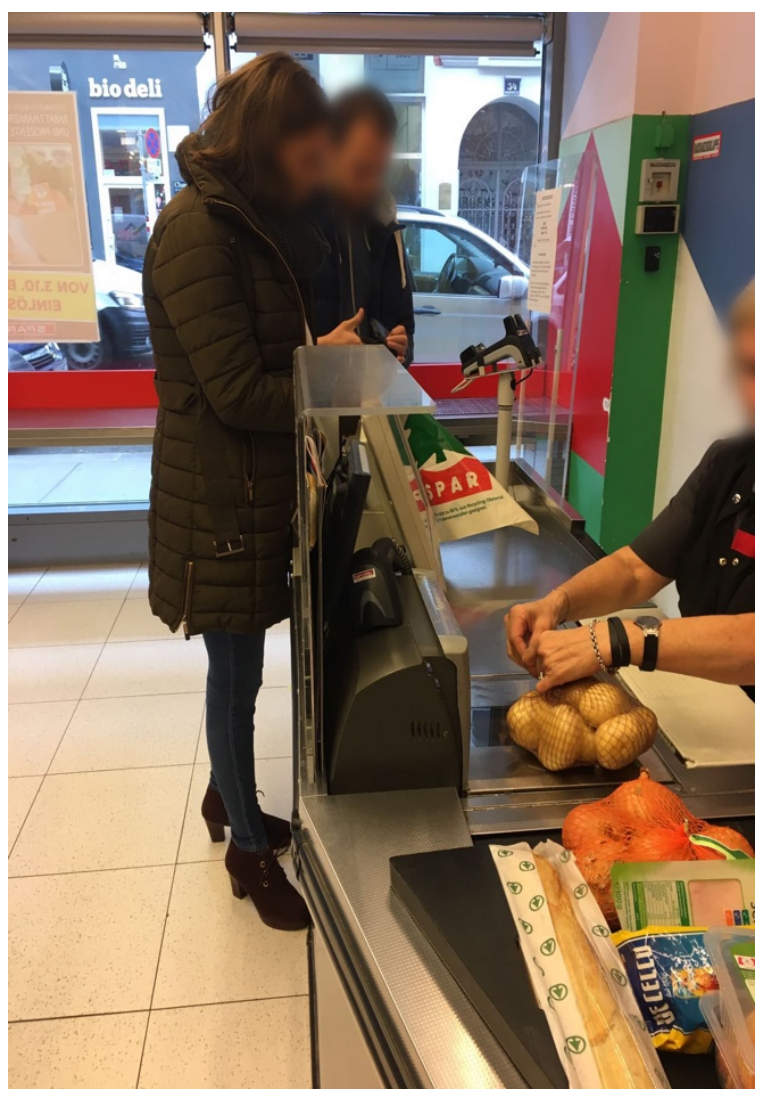

You say:

Why have you used that expression?: 
Appendices

\section{Situation 8}

Scenario: You and your friend are on your way to campus. Your friend is about to cross the street but he does not see a car coming. You already have seen the car and try to stop him.

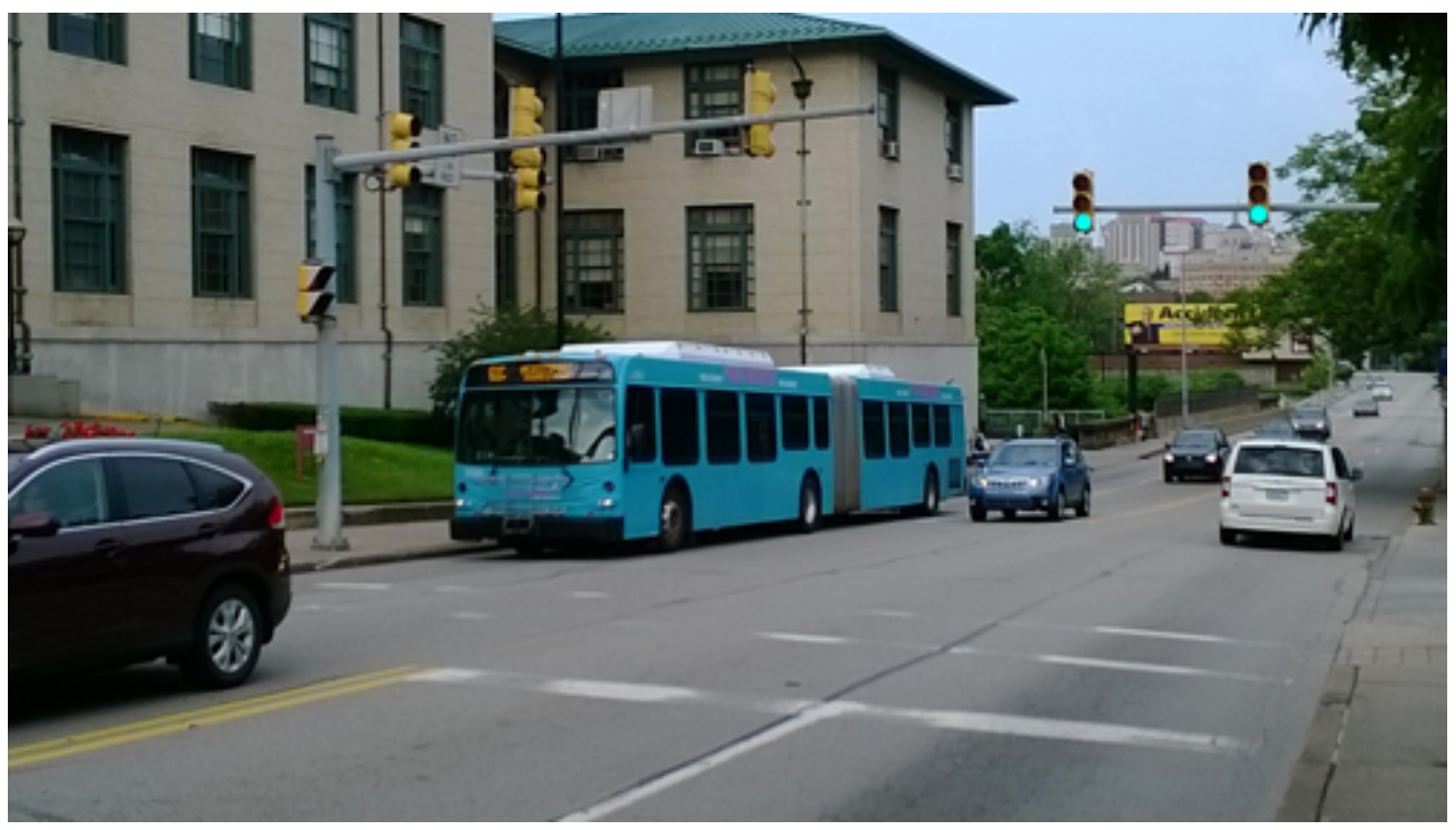

Source: http://www.cmu.edu/news/stories/archives/2014/june/images/buslinephoto_500x281.jpg

You say:

Why have you used that expression?: 


\section{Appendices}

\section{Situation 9}

Scenario: You just finished classes today. It is pouring outside, you do not have an umbrella and you missed the bus. You see a classmate of yours approaching his car.

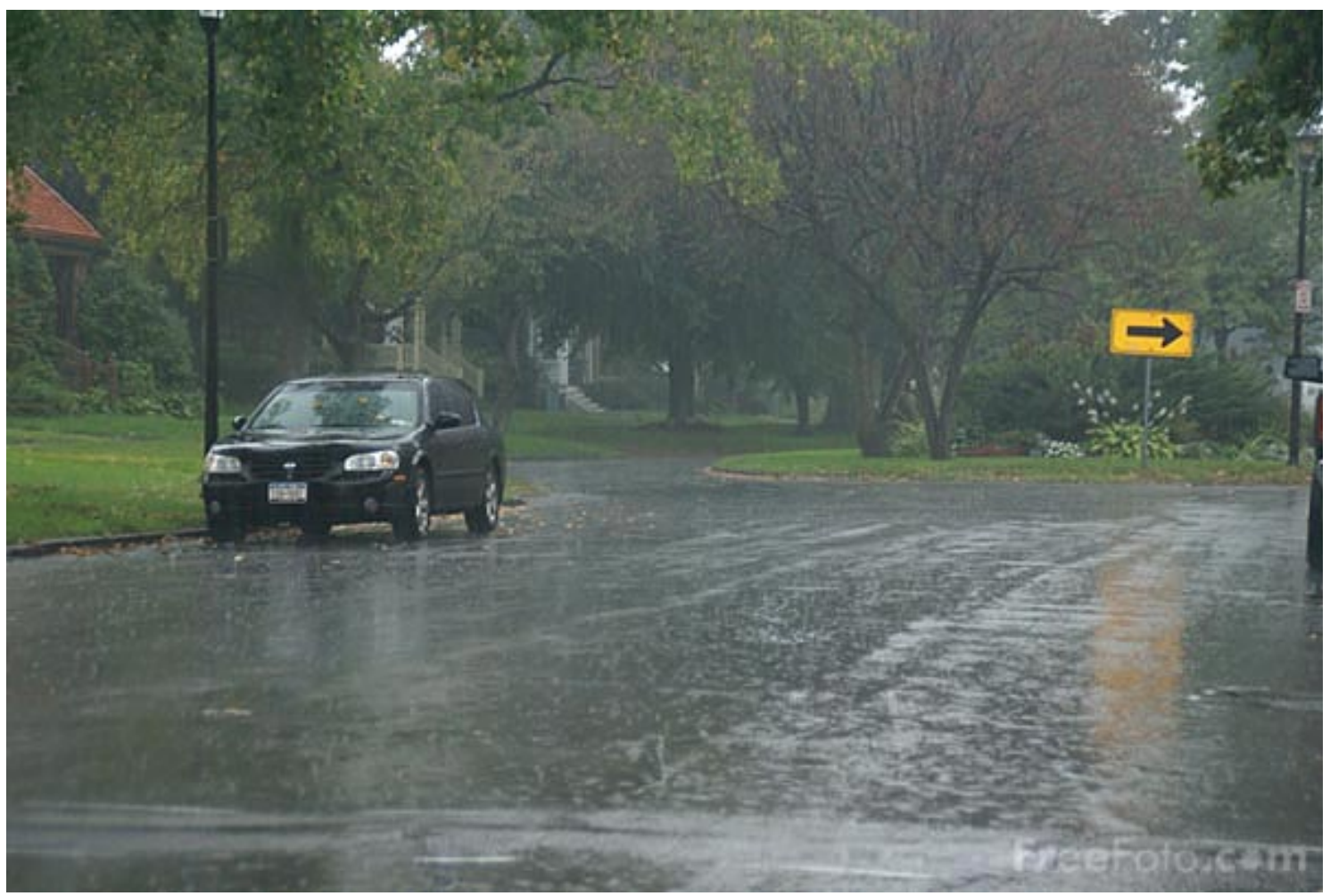

Source: http://injust10.blogspot.com.es/2011 0301 archive.html

You say:

Why have you used that expression?: 
Appendices

\section{Situation 10}

Scenario: You are at your in-laws' Christmas dinner. They offer you more food but you already ate a lot and do not want any more.

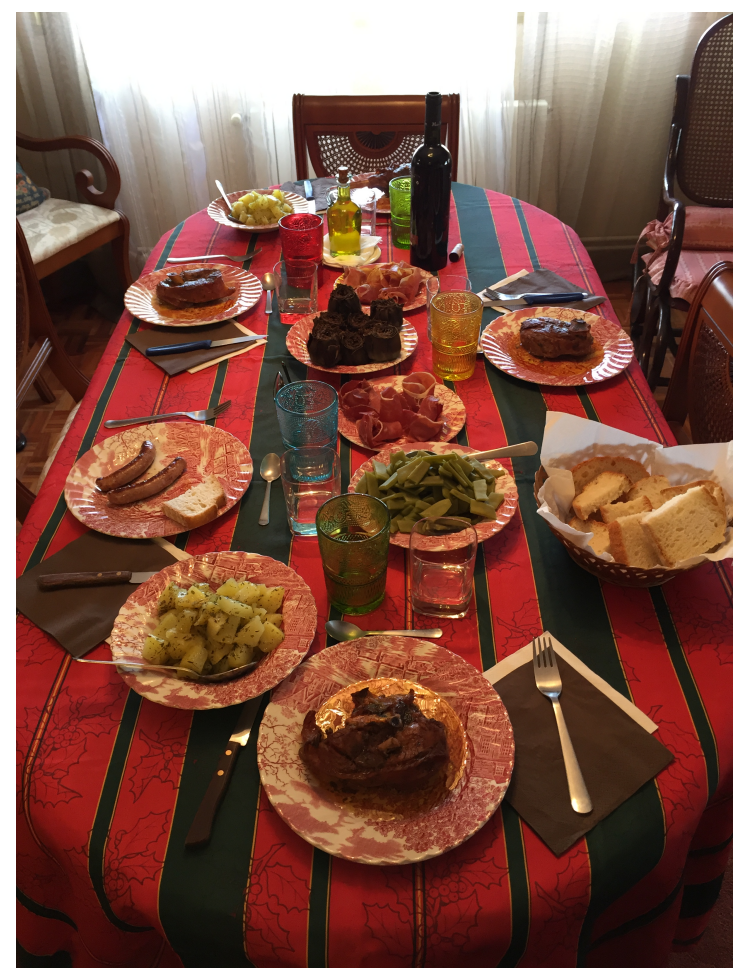

You say:

Why have you used that expression?: 
Appendices

\section{Situation 11}

Scenario: You meet Paula, Silvia's friend, whom you had been introduced before, on campus another day.

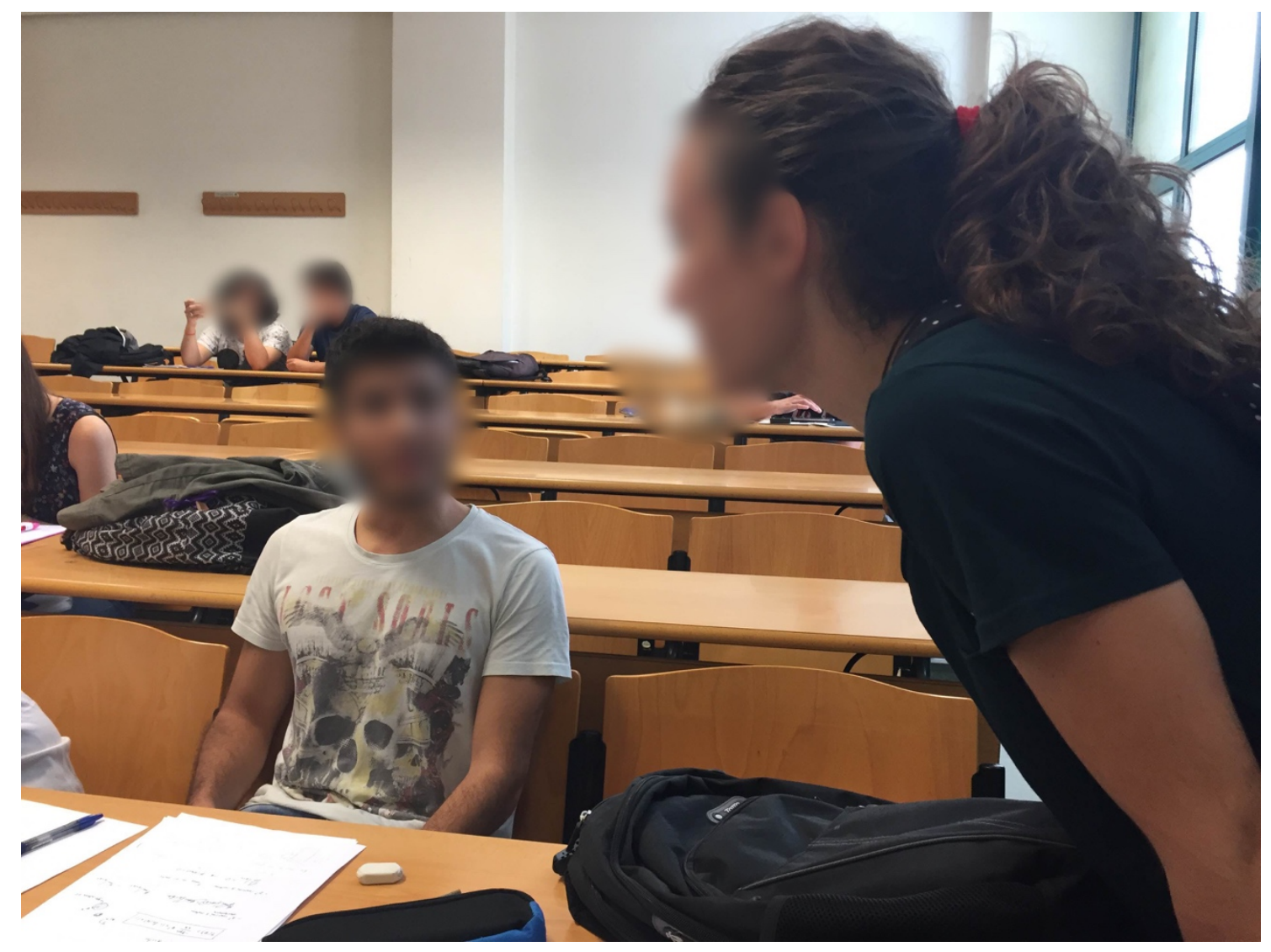

You say:

Why have you used that expression?: 
Appendices

\section{Situation 12}

Scenario: You are in a store looking at some books. A sales person comes up to you and asks you if you need some help. However, you do not need help.

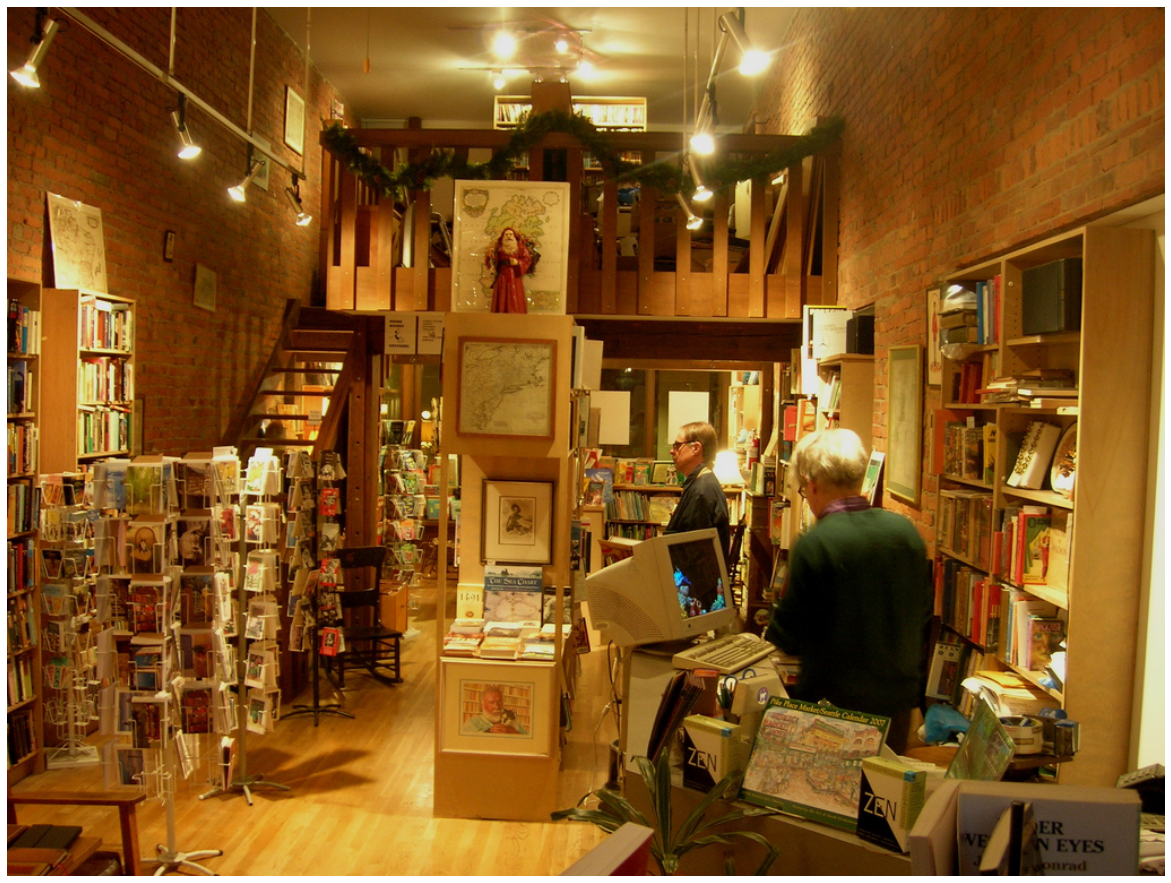

Source: https://www.flickr.com/photos/brewbooks/330665317

You say:

Why have you used that expression?: 


\section{Appendices}

\section{Situation 13}

Scenario: You just finished classes and it is pouring outside. As you go to your car, a classmate of yours asks you if you can give him a ride.

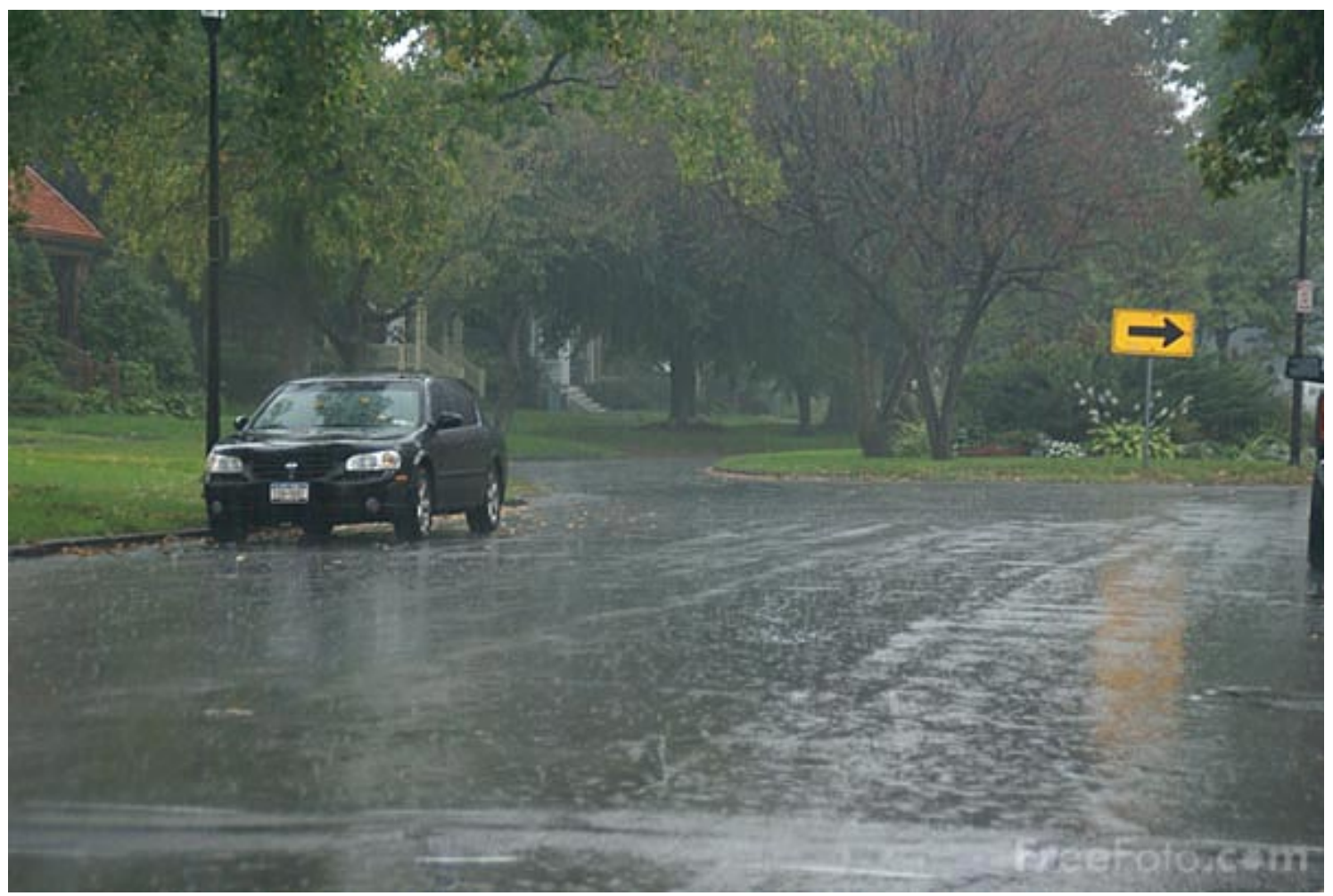

Source: http://injust10.blogspot.com.es/2011 0301 archive.html

You say:

Why have you used that expression?: 


\section{Situation 14}

Scenario: You are in an aisle in a supermarket. There is an old lady slowly pushing a shopping cart in front of you. However, you need to get by her.

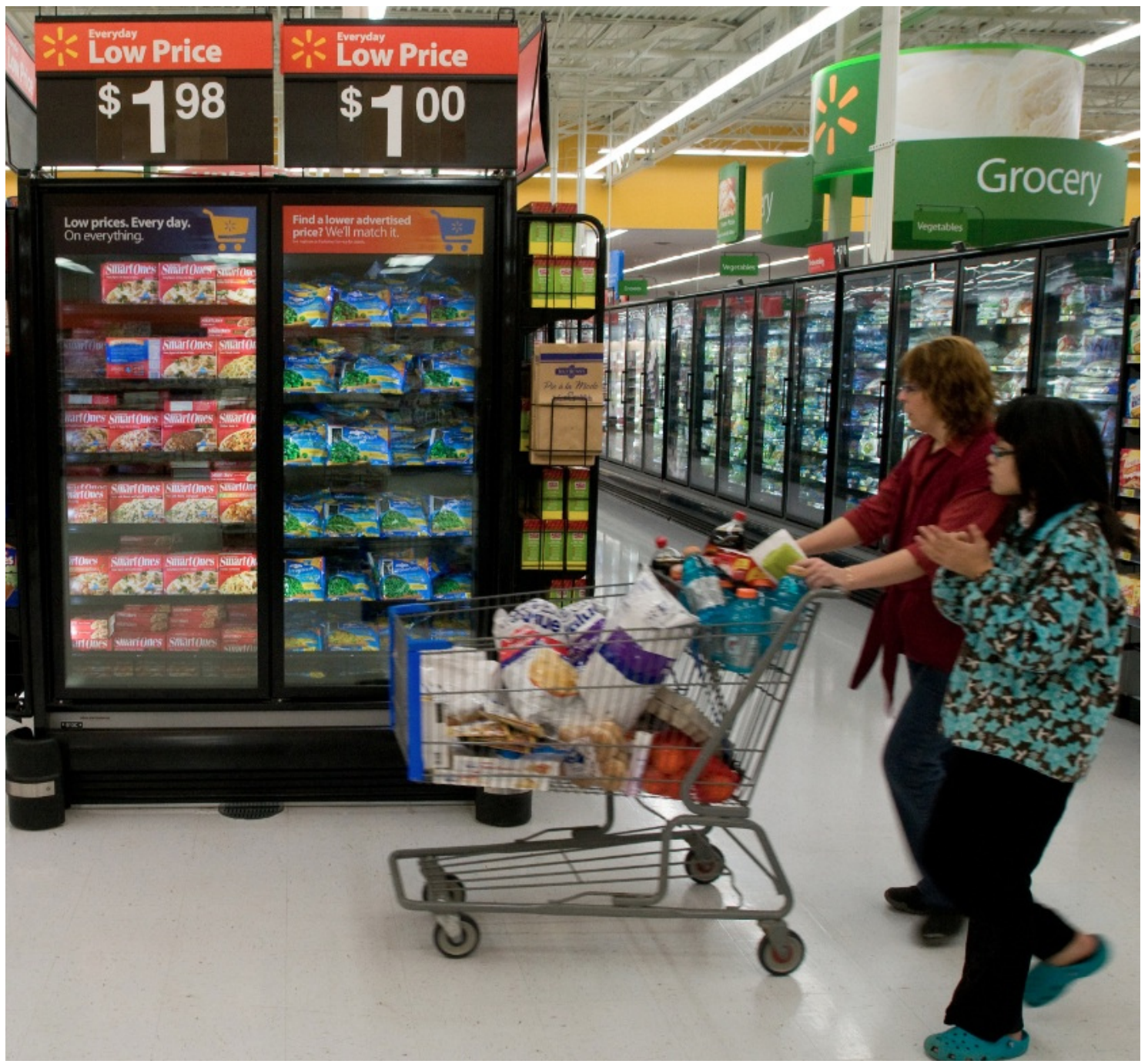

Source: https://www.flickr.com/photos/walmartcorporate/5684145463

You say:

Why have you used that expression?: 
Appendices

\section{Situation 15}

Scenario: Your friend invites you to dinner. Then, he suggests to go dancing afterwards.

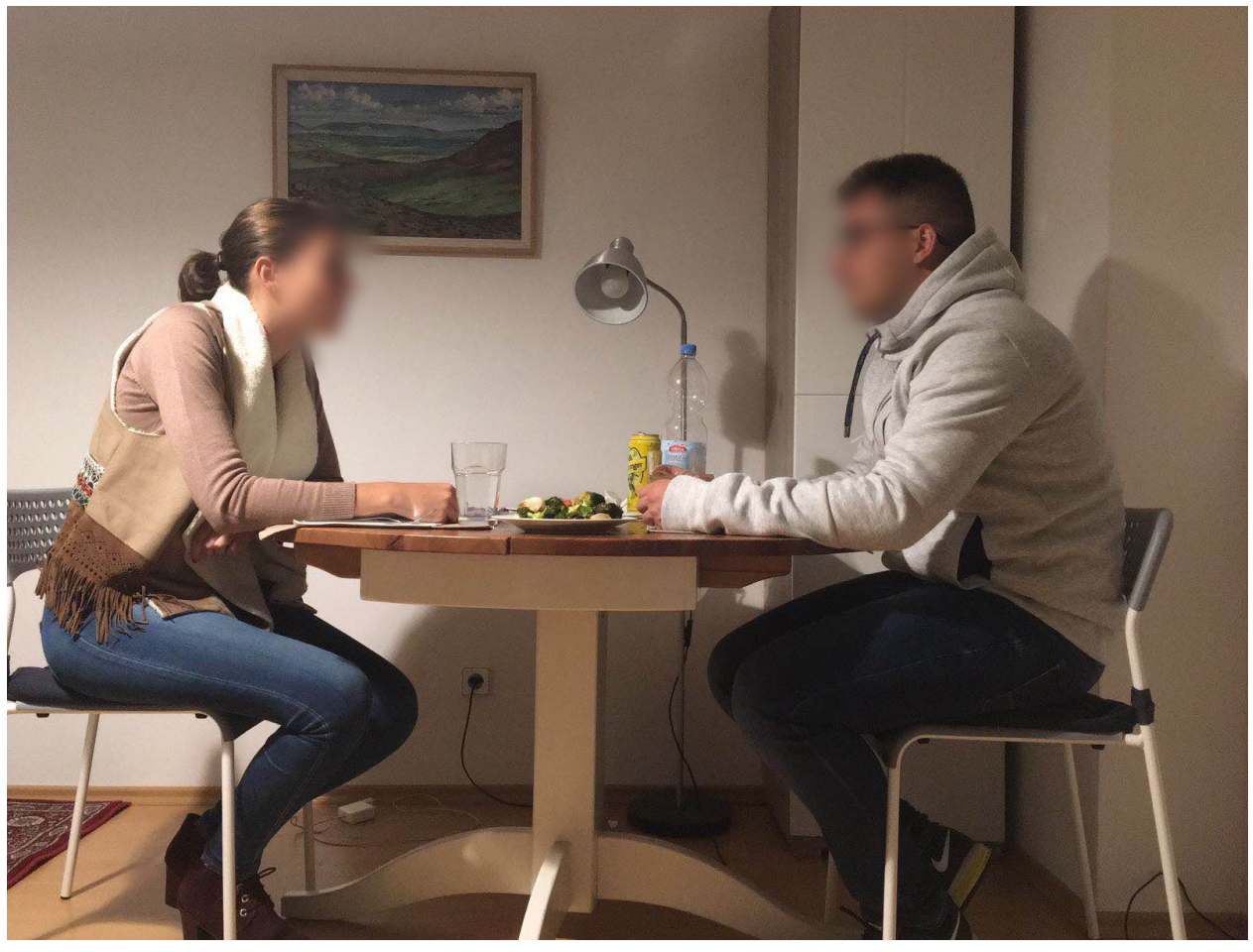

You say:

Why have you used that expression?: 
Appendix 14. Computer-delivered ODCT and RVP Delayed Posttest Version

You are going to work on a series of situations in which there is a situation description, and a picture that shows the situation. Then you are asked two questions: what you would say in each of the situations, and why.

\section{Example}

Scenario: Your mom asks you to help her with dinner. She says: "Would you mind helping me with dinner?"

\section{https://www.youtube.com/watch?v=9 G9uWszJhM\&feature=youtu.be}

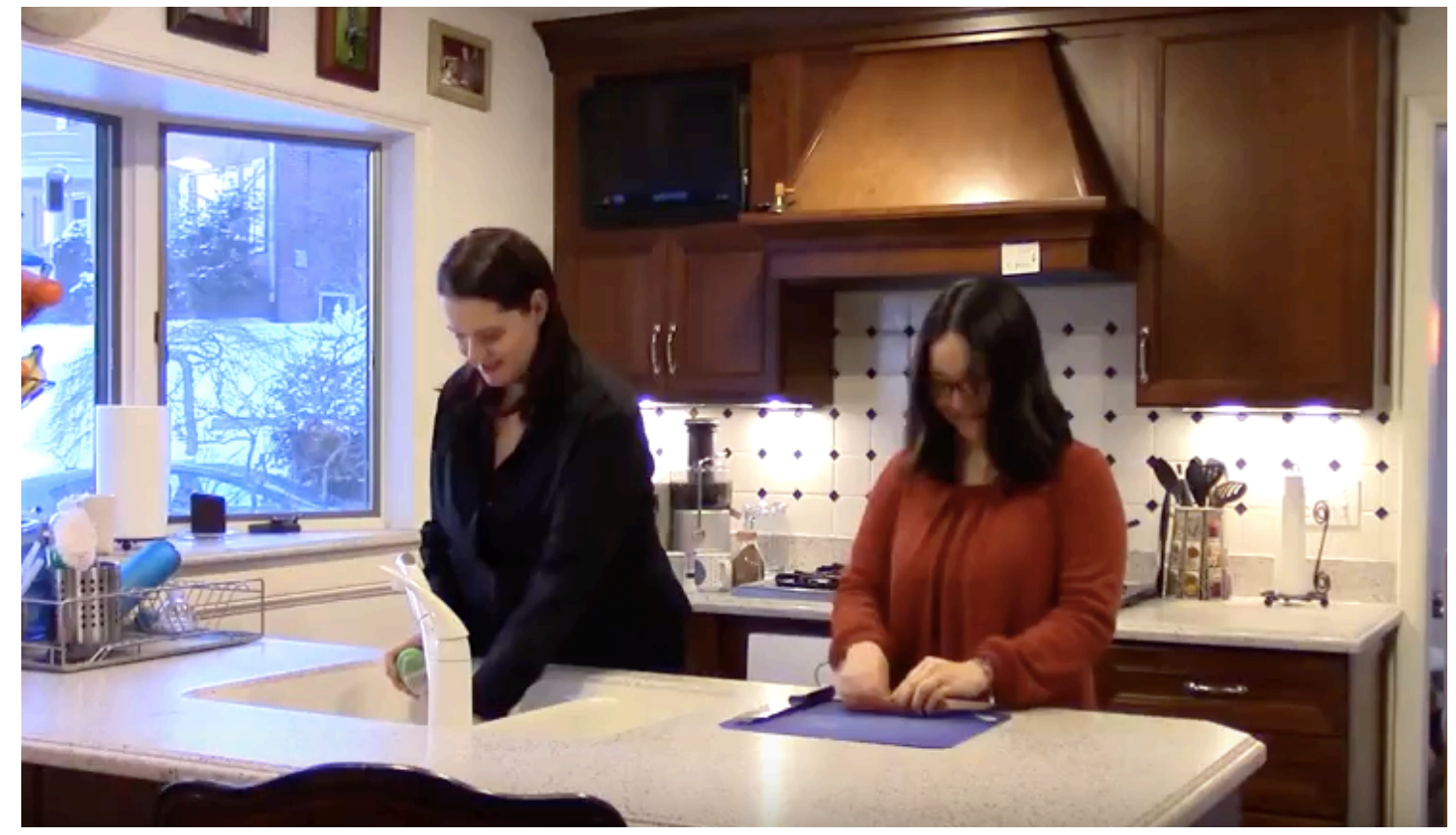

You say: Not at all.

Why have you used that expression?

I have used that expression because it shows that I am willing to help her.

Now, please proceed to complete the following situations. 
Appendices

\section{Situation 1}

Scenario: You and your friend are on your way to campus. Your friend is about to cross the street but he does not see a car coming. You already have seen the car and try to stop him.

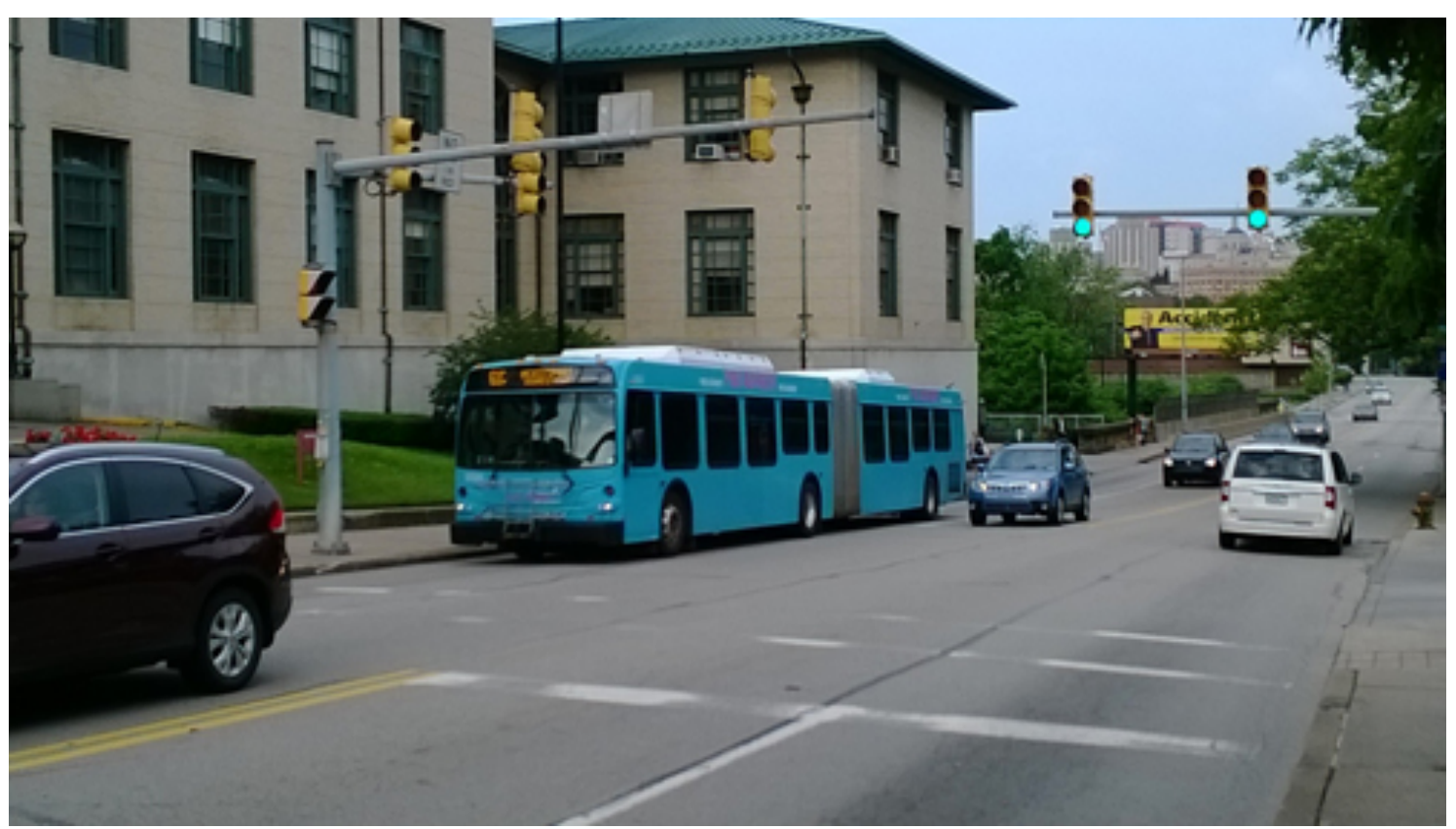

Source: http://www.cmu.edu/news/stories/archives/2014/june/images/buslinephoto 500x281.jpg

You say:

Why have you used that expression?: 


\section{Situation 2}

Scenario: At the supermarket, you start putting all the goods in the conveyor belt and the cashier greets you: "Hi. How are you?"

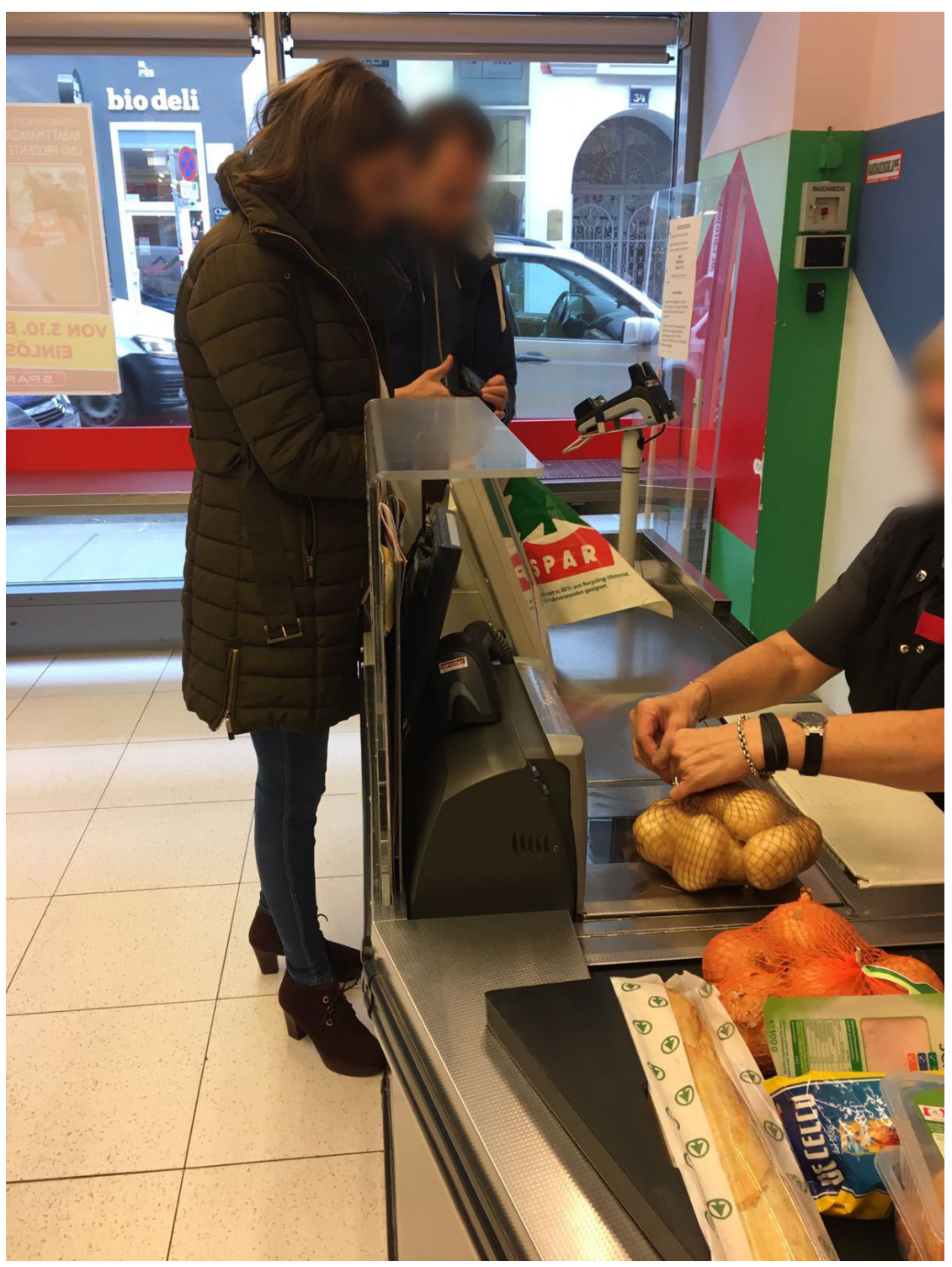

You say:

Why have you used that expression?: 


\section{Appendices}

\section{Situation 3}

Scenario: You just finished classes and it is pouring outside. As you go to your car, a classmate of yours asks you if you can give him a ride.

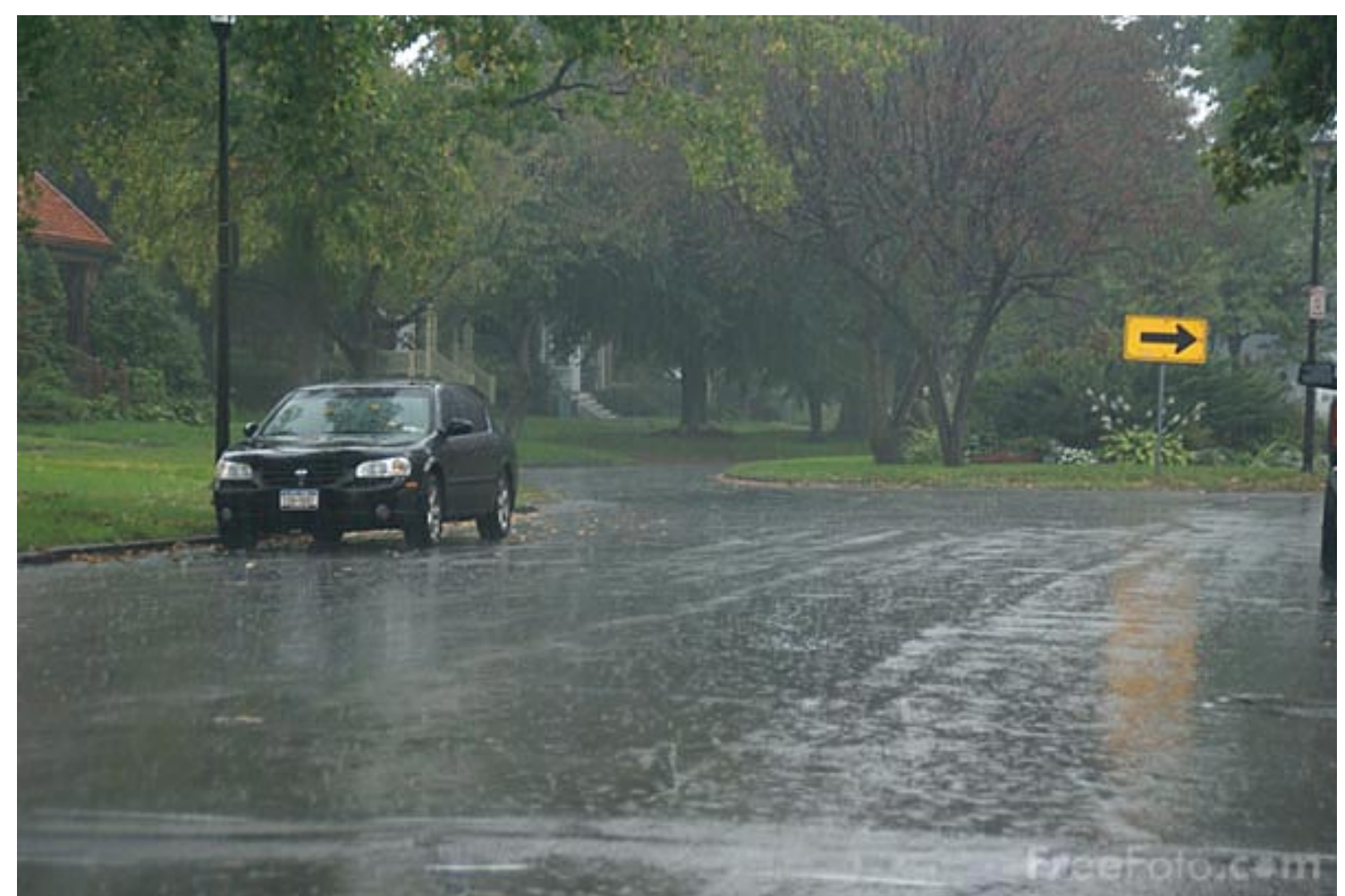

Source: http://injust10.blogspot.com.es/2011_03_01_archive.html

You say:

Why have you used that expression?: 
Appendices

\section{Situation 4}

Scenario: Your friend invites you to dinner. Then, he suggests to go dancing afterwards.

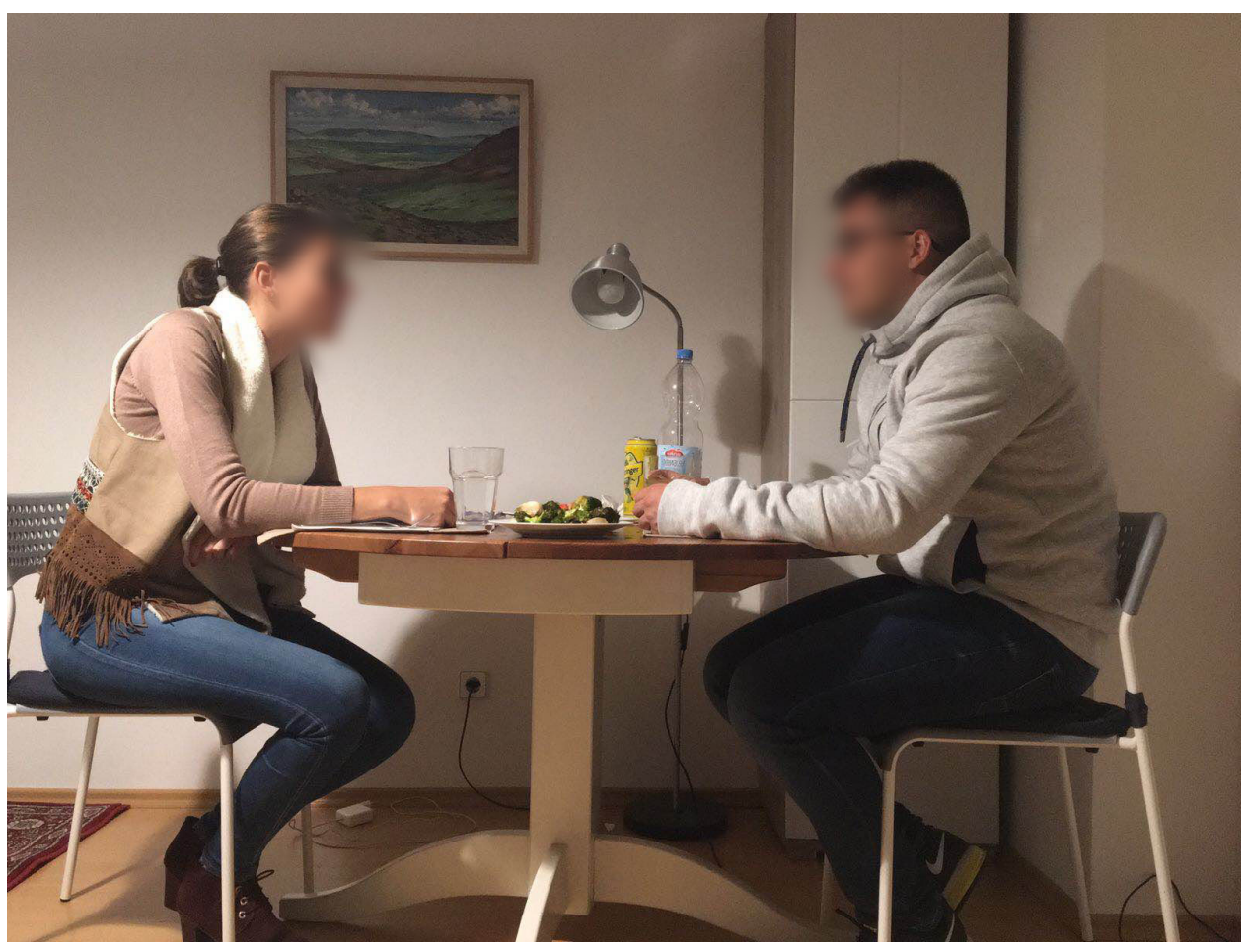

You say:

Why have you used that expression?: 


\section{Appendices}

\section{Situation 5}

Scenario: You just finished classes today. It is pouring outside, you do not have an umbrella and you missed the bus. You see a classmate of yours approaching his car.

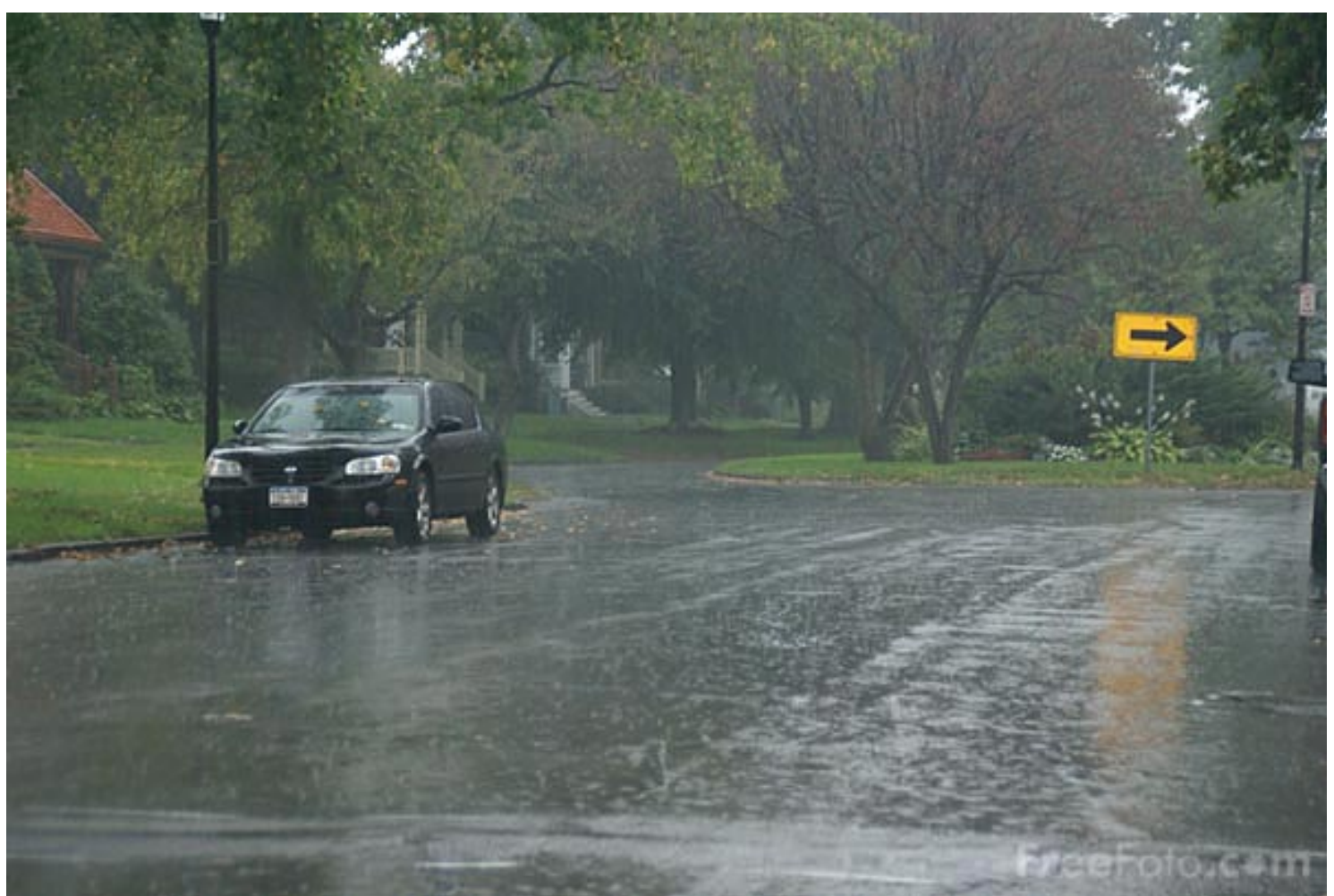

Source: http://injust10.blogspot.com.es/2011_03_01_archive.html

You say:

Why have you used that expression?: 
Appendices

\section{Situation 6}

Scenario: You greet a Professor with whom you have a very good relationship.

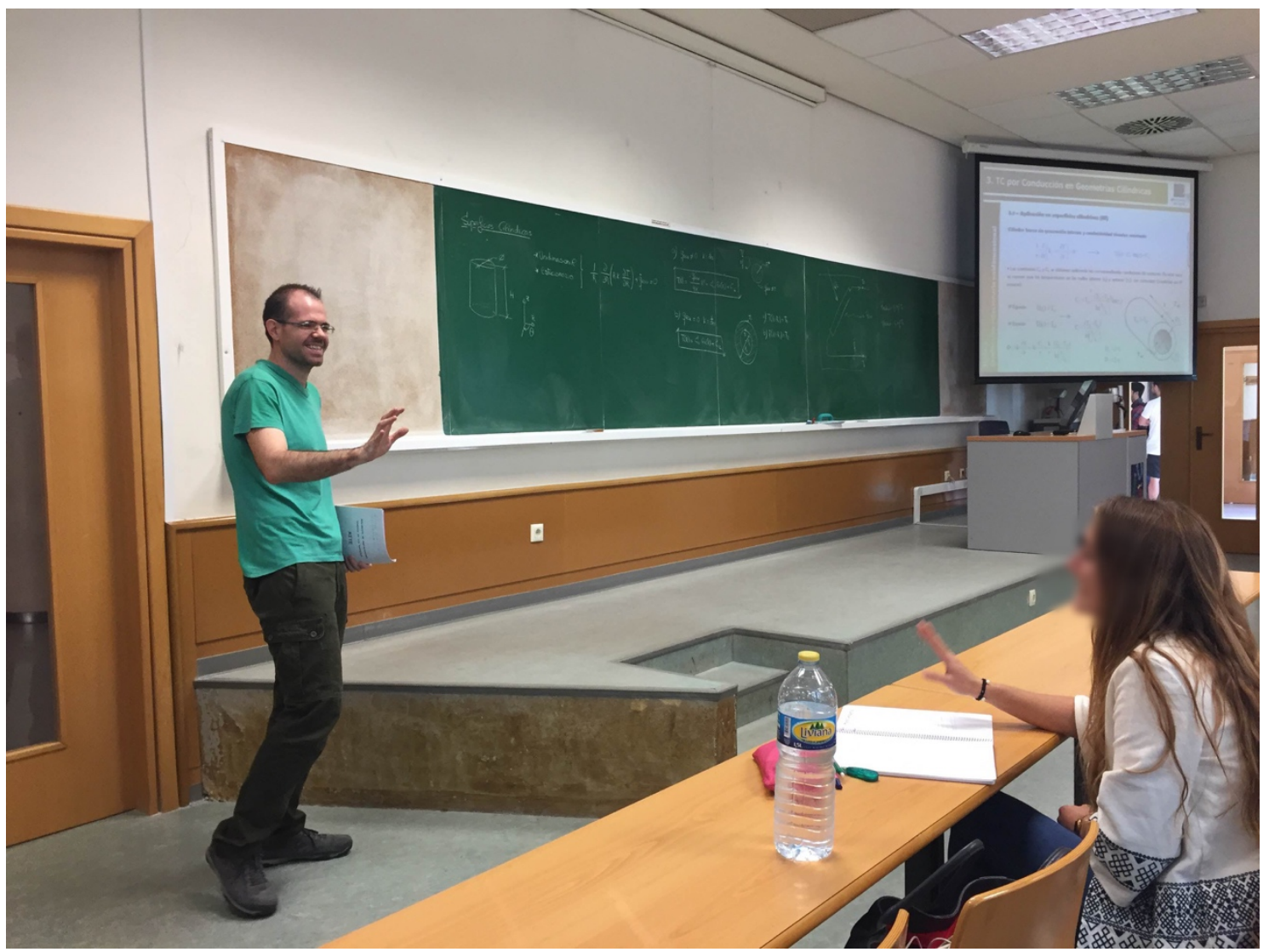

You say:

Why have you used that expression?: 
Appendices

\section{Situation 7}

Scenario: You are at your in-laws' Christmas dinner. They offer you more food but you already ate a lot and do not want any more.

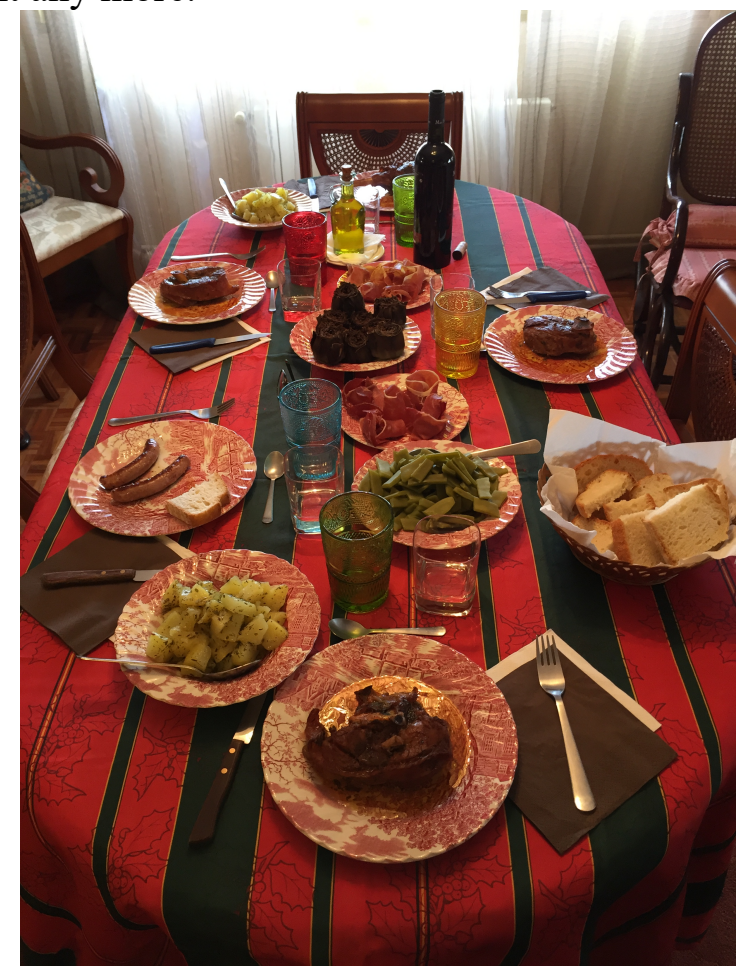

You say:

Why have you used that expression?: 
Appendices

\section{Situation 8}

Scenario: You just finished a long meeting with your professor. You know he is very busy.

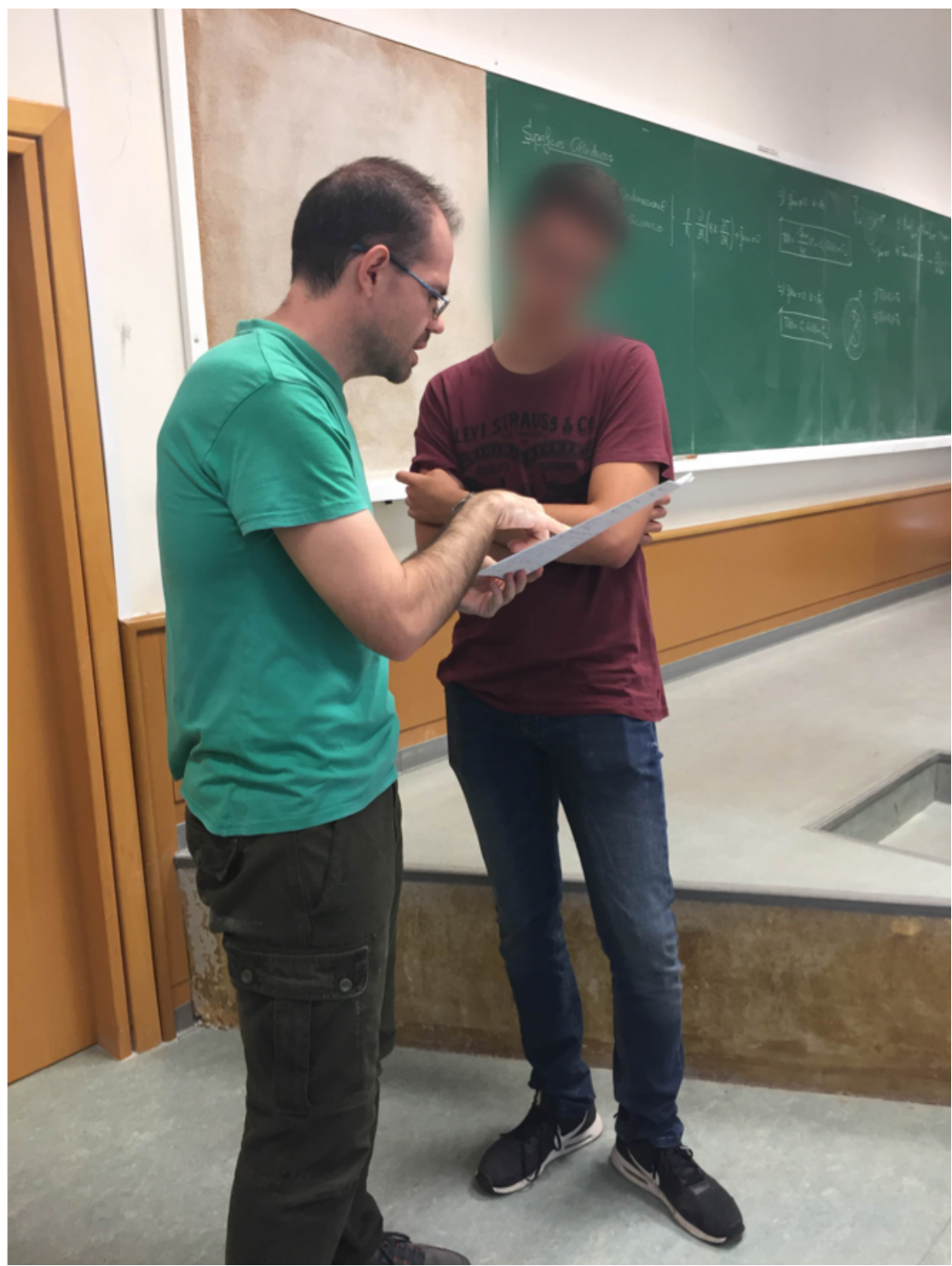

You say:

Why have you used that expression?: 


\section{Situation 9}

Scenario: You are in an aisle in a supermarket. There is an old lady slowly pushing a shopping cart in front of you. However, you need to get by her.

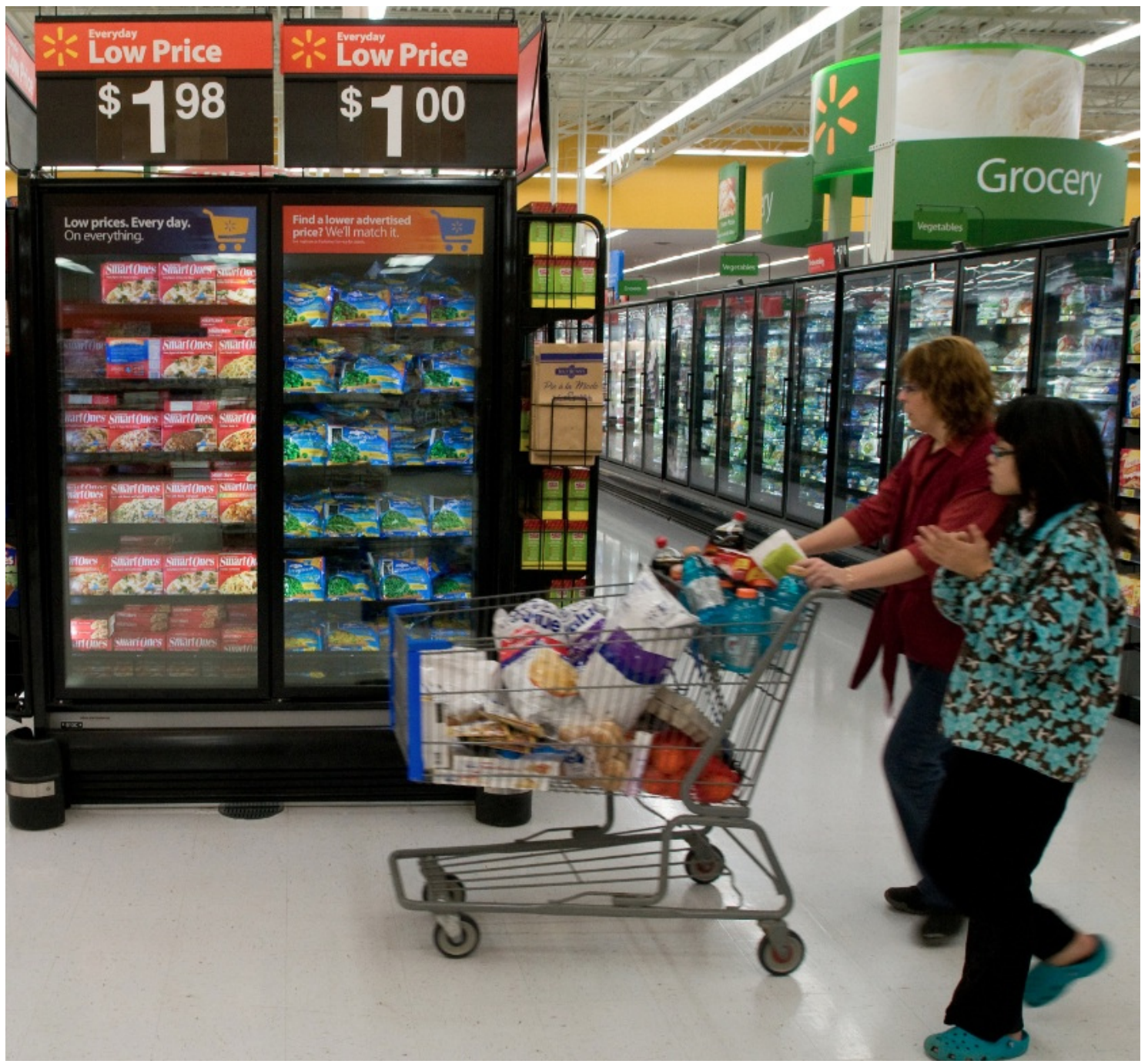

Source: https://www.flickr.com/photos/walmartcorporate/5684145463

You say:

Why have you used that expression?: 
Appendices

\section{Situation 10}

Scenario: You are in a store looking at some books. A sales person comes up to you and asks you if you need some help. However you do not need help.

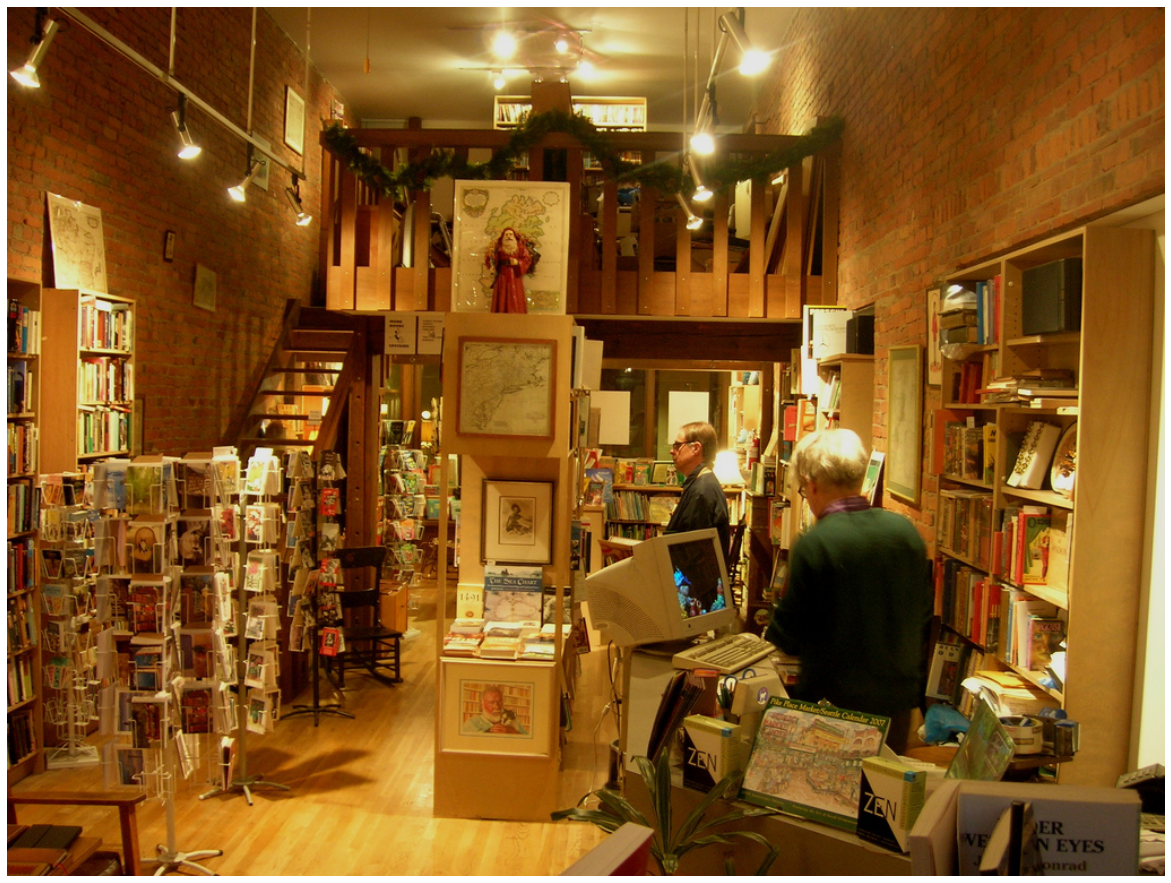

Source: https://www.flickr.com/photos/brewbooks/330665317

You say:

Why have you used that expression?: 


\section{Situation 11}

Scenario: You are in an aisle at a supermarket. You are trying to get around an old lady and accidentally bump into her cart.

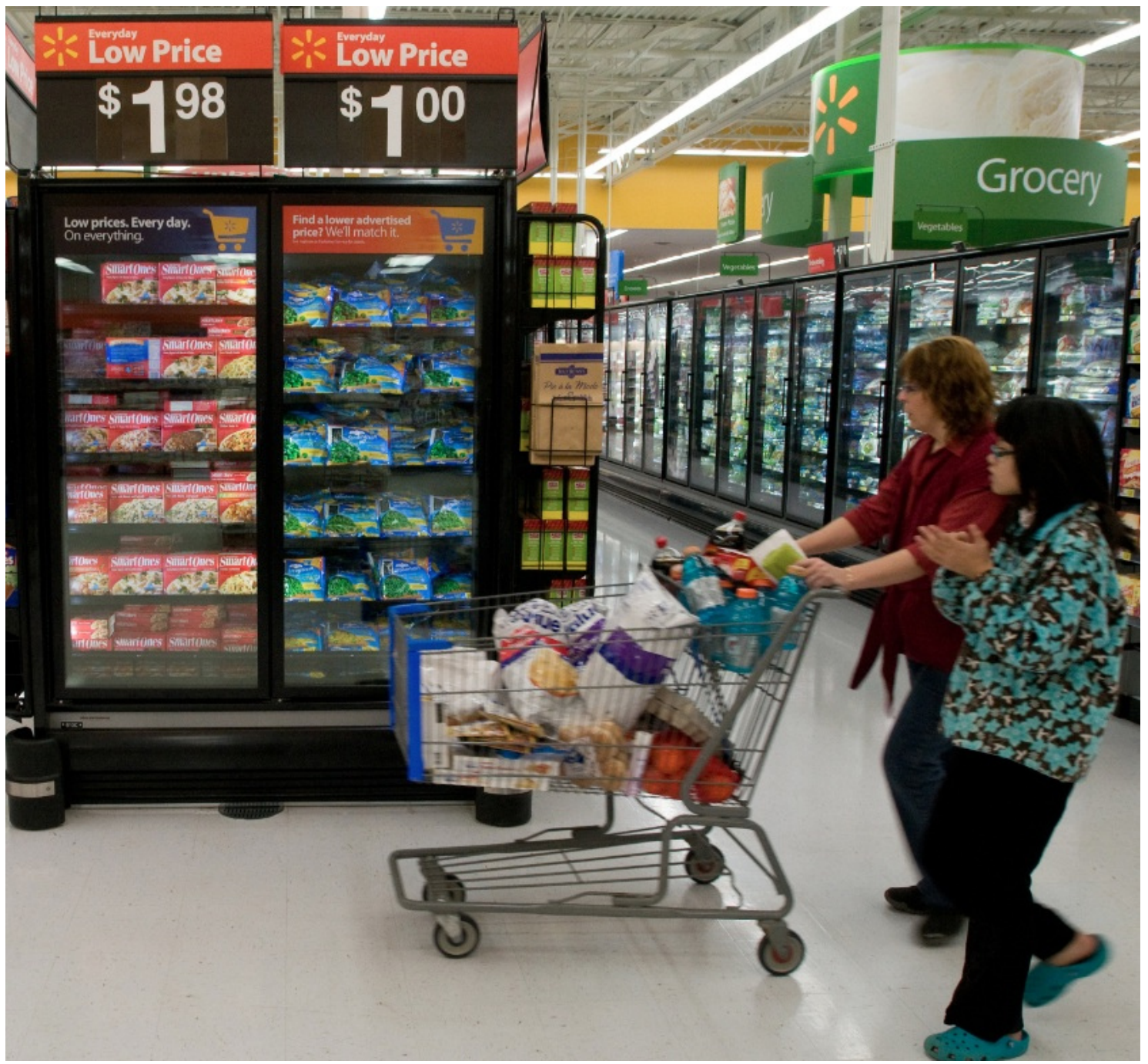

Source: https://www.flickr.com/photos/walmartcorporate/5684145463

You say:

Why have you used that expression?: 
Appendices

\section{Situation 12}

Scenario: Your friend Juan introduces you to a friend of his, Pablo.

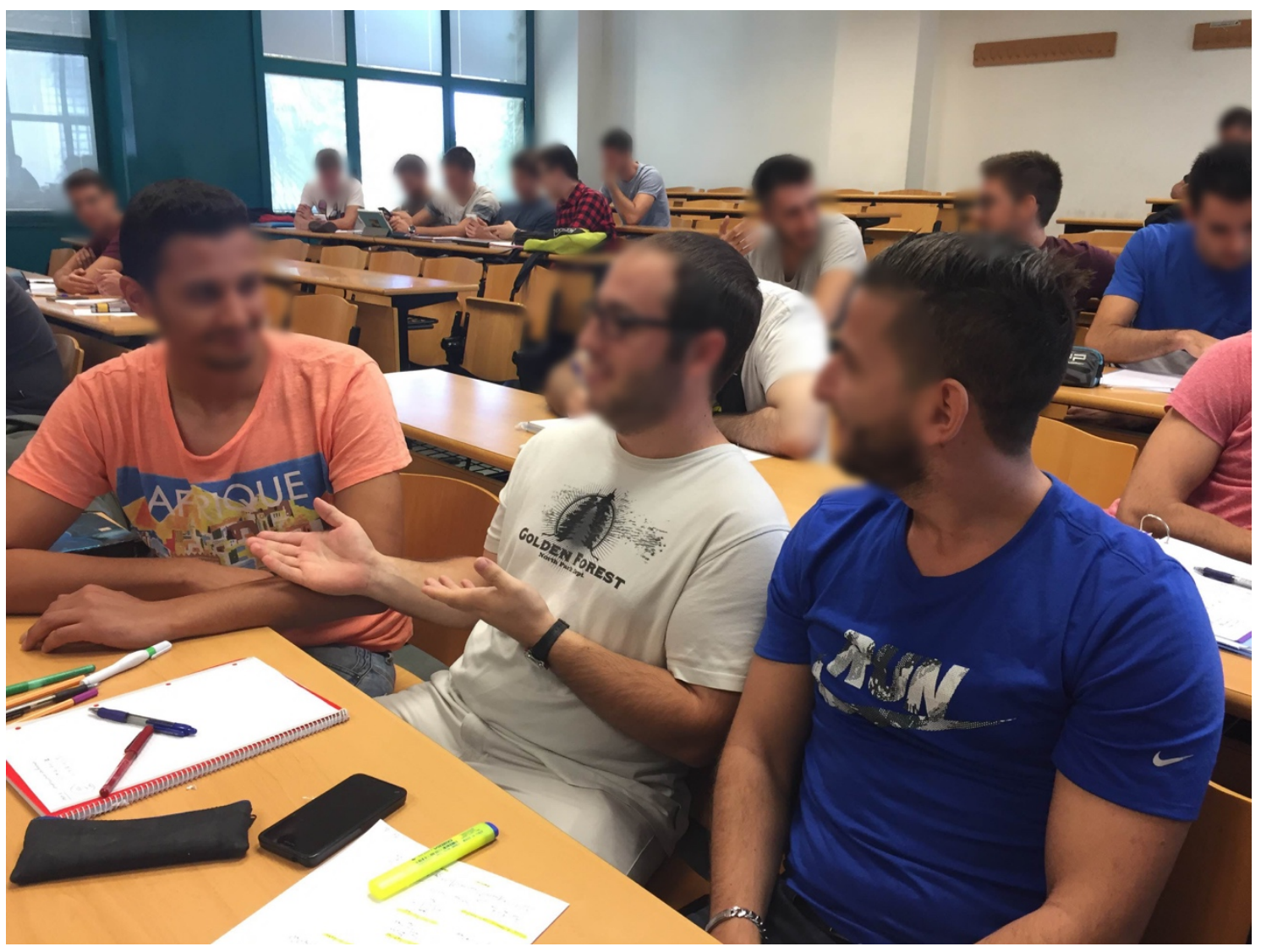

You say:

Why have you used that expression?: 


\section{Situation 13}

Scenario: You are in class and your pen ran out of ink. You ask your friend for a pen.

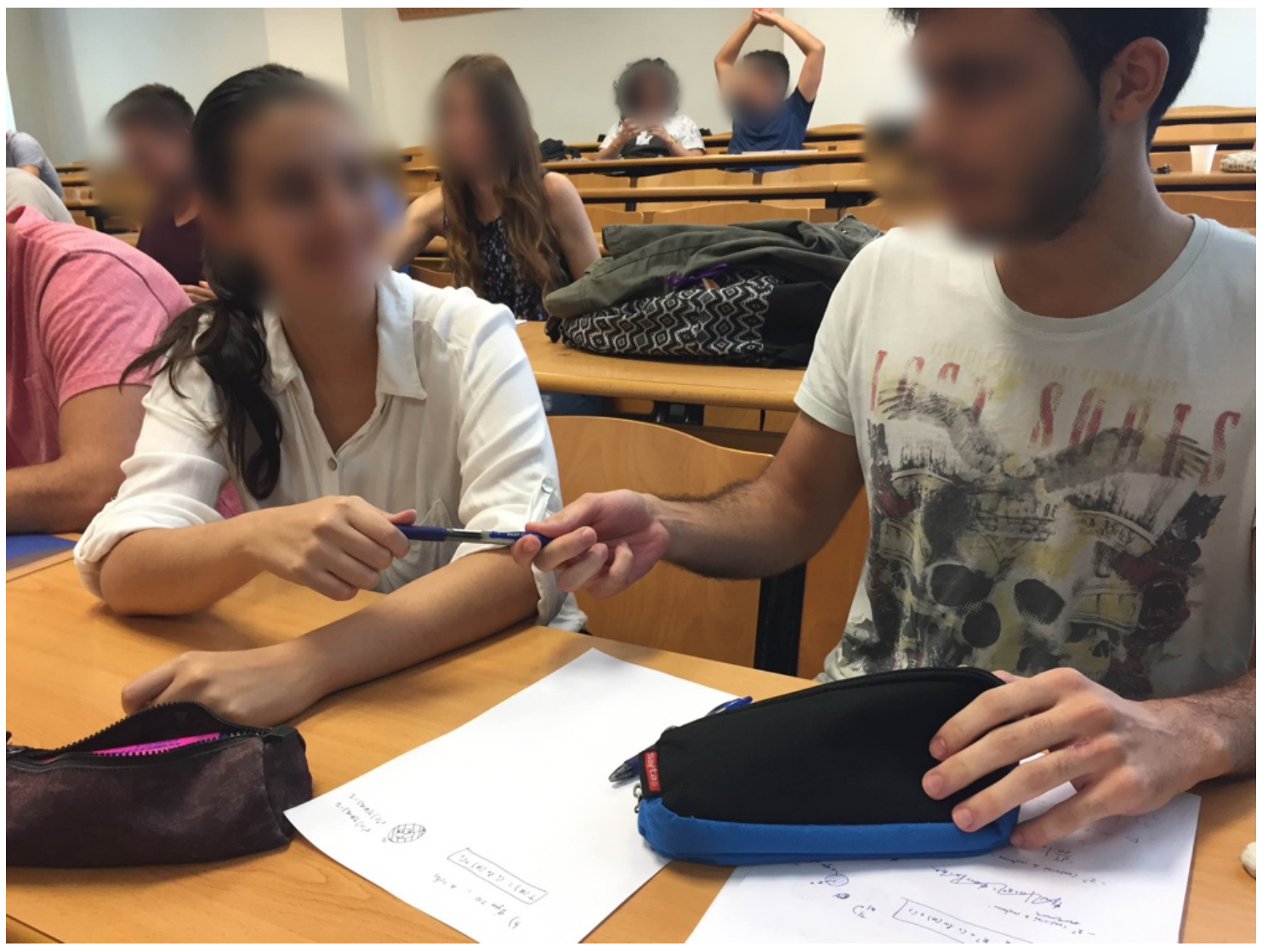

You say:

Why have you used that expression?: 
Appendices

\section{Situation 14}

Scenario: Your friend Ana just threw a wonderful party. As you leave,

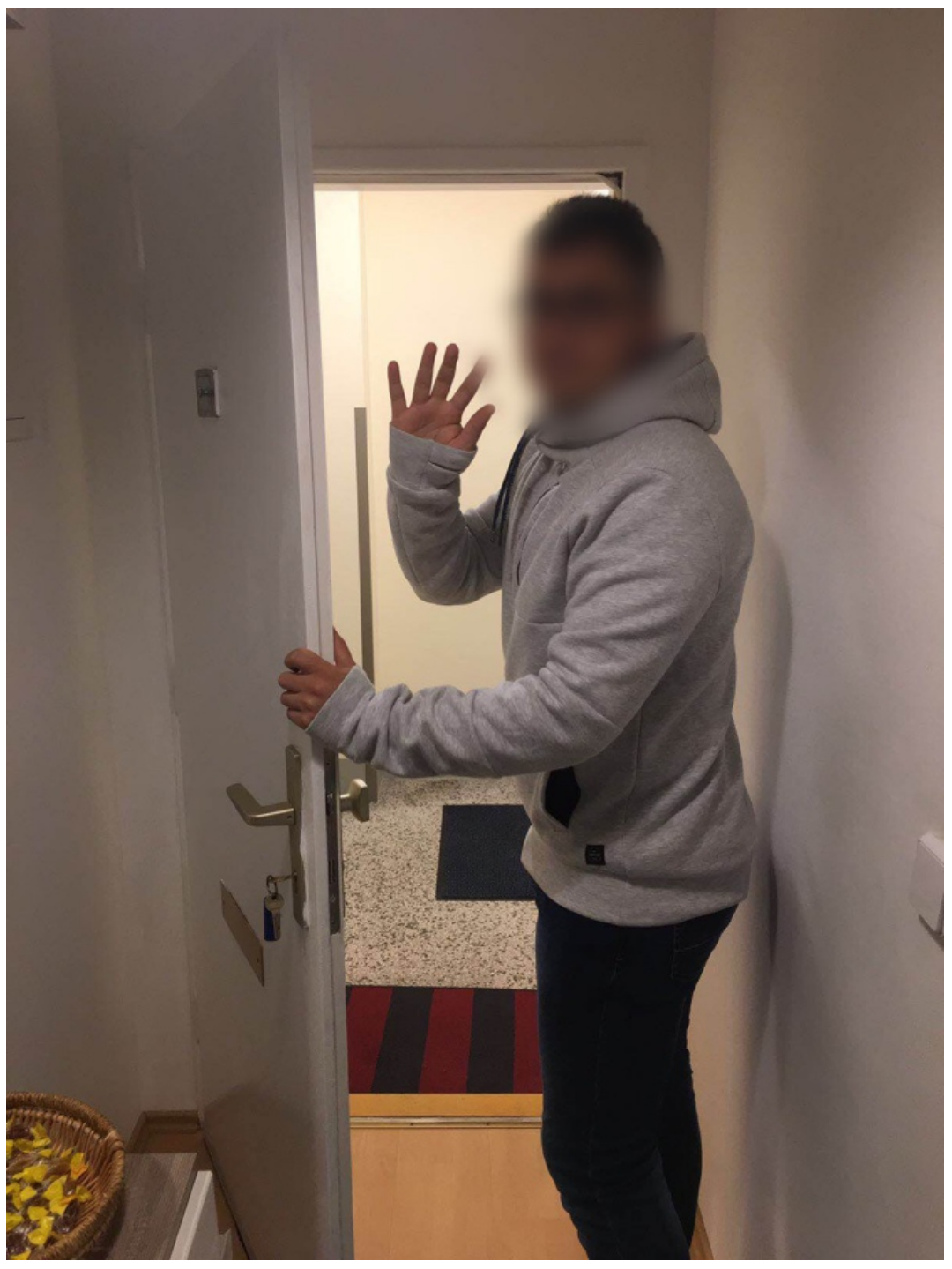

You say:

Why have you used that expression?: 
Appendices

\section{Situation 15}

Scenario: You meet Paula, Silvia's friend, whom you had been introduced before, on campus another day.

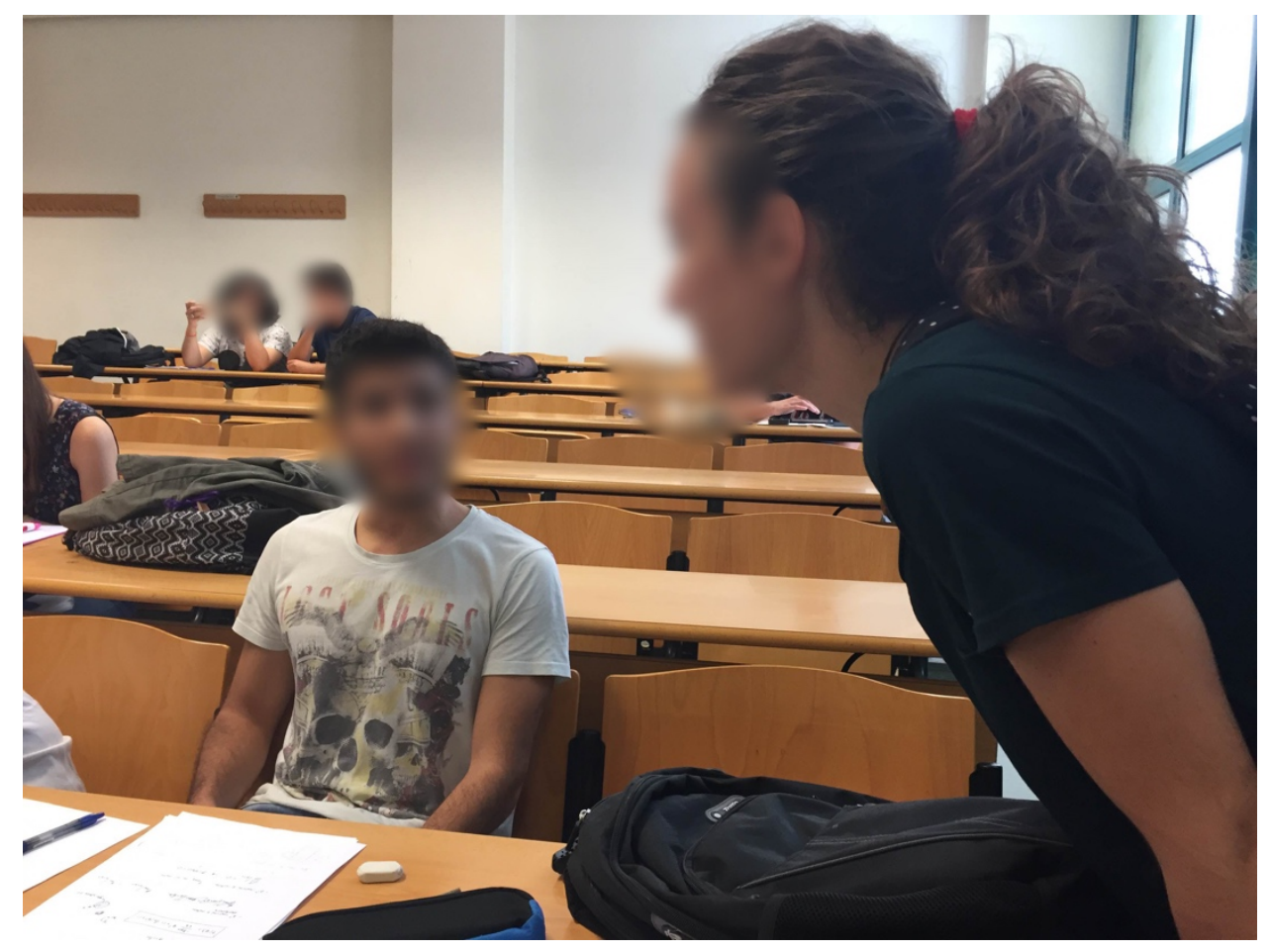

You say:

Why have you used that expression?: 
Appendices

Appendix 15. Quick Placement Test (Oxford University Press, 2001)

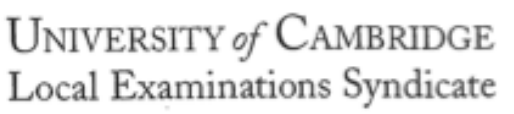

Name:

Date:

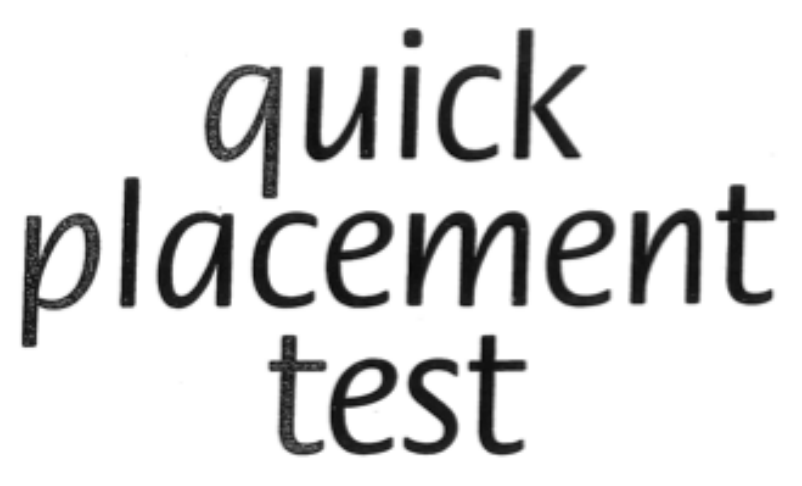

Version 1

The test is divided into two parts:

Part 1 (Questions 1 - 40) - All students.

Part 2 (Questions 41 - 60) - Do not start this part unless told to do so by your test supervisor.

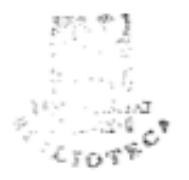

Time: $\mathbf{3 0}$ minutes 
Appendices

\section{Part 1}

Questions 1 - 5

- Where can you see these notices?

- For questions 1 to 5, mark one letter A, B or C on your Answer Sheet.

\begin{tabular}{|c|}
\hline Please leave your \\
room key at \\
Reception.
\end{tabular}

2

Foreign money changed here

3

AFTERNOON
SHOW BEGINS
AT 2PM

4

CLOSED FOR HOLIDAYS

Lessons start again on

8th January
A in a shop
B in a hotel
C in a taxi

A in a library
$\mathbf{B}$ in a bank
$\mathbf{C}$ in a police station

A outside a theatre

B outside a supermarket

C outside a restaurant

5

Price per night: $£ 10$ a tent $£ 5$ a person
A at a cinema
B in a hotel
C at a camp-site 


\section{Appendices}

\section{Questions 6-10}

- In this section you must choose the word which best fits each space in the text below.

- For questions 6 to 10, mark one letter A, B, or C on your Answer Sheet.

\section{Scotland}

Scotland is the north part of the island of Great Britain. The Atlantic Ocean is on the west and the North Sea on the east. Some people (6) Scotland speak a different language called Gaelic.

There are (7) five million people in Scotland, and Edinburgh is

(8) most famous city.

Scotland has many mountains; the highest one is called 'Ben Nevis'. In the south of Scotland, there are a lot of sheep. A long time ago, there (9) many

forests, but now there are only a (10)

Scotland is only a small country, but it is quite beautiful.
6 A on
$\mathbf{B}$ in
C at

$7 \quad$ A about

B between

C among

8 A his

B your

C its

$9 \mathbf{A}$ is

B were

C was

10 A few

B little

C lot 


\section{Appendices}

\section{Questions 11 - 20}

- In this section you must choose the word which best fits each space in the texts.

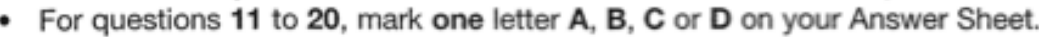

\section{Alice Guy Blaché}

Alice Guy Blaché was the first female film director. She first became involved in cinema whilst working for the Gaumont Film Company in the late 1890s. This was a period of great change in the cinema and Alice was the first to use many new inventions, (11) sound and colour.

In 1907 Alice (12)

to New York where she started her own film company. She was (13) successful, but, when Hollywood became the centre of the film world, the best days of the independent New York film companies were (14) When Alice died in 1968, hardly anybody (15) her name.
11 A bringing
B including
C containing
D supporting
12 A moved
B ran
C entered
D transported
13 A next
B once
C immediately
D recently
14 A after
B down
C behind
D over
15 A remembered
B realised
C reminded
D repeated 


\section{Appendices}

\section{UFOs - do they exist?}

UFO is short for 'unidentified flying object'. UFOs are popularly known as flying saucers, (16) that is often the (17) they are reported to be. The (18) .................. 'flying saucers' were seen in 1947 by an American pilot, but experts who studied his claim decided it had been a trick of the light.

Even people experienced at watching the sky, (19) as pilots, report seeing UFOS.

In 1978 a pilot reported a collection of UFOs off the coast of New Zealand. A television (20) went up with the pilot and filmed the UFOs. Scientists studying this phenomenon later discovered that in this case they were simply lights on boats out fishing.

$\begin{array}{lllll}\text { 16 A because } & \text { B therefore } & \text { C although } & \text { D so } \\ \text { 17 A look } & \text { B shape } & \text { C size } & \text { D type } \\ \text { 18 A last } & \text { B next } & \text { C first } & \text { D oldest } \\ 19 \text { A like } & \text { B that } & \text { C so } & \text { D such } \\ \text { 20 A cameraman } & \text { B director } & \text { C actor } & \text { D announcer }\end{array}$




\section{Appendices}

\section{Questions $21-40$}

In this section you must choose the word or phrase which best completes each sentence. For questions $\mathbf{2 1}$ to $\mathbf{4 0}$, mark one letter A, B, C or D on your Answer Sheet.

21 The teacher encouraged her students to an English pen-friend.
A should write
B write
C wrote
D to write

22 They spent a lot of time at the pictures in the museum.
A looking
B for looking
C to look
D to looking

23 Shirley enjoys science lessons, but all her experiments seem to wrong.
A turn
B come
$C$ end
D go

24 from Michael, all the group arrived on time.
A Except
B Other
C Besides
D Apart

25 She her neighbour's children for the broken window.
A accused
B complained
C blamed
D denied

26 As I had missed the history lesson, my friend went the homework with me.
A by
B after
C over
D on

27 Whether she's a good actress or not is a . of opinion.
A matter
B subject
C point
D case

28 The decorated roof of the ancient palace was up by four thin columns.
A built
B carried
C held
D supported

29 Would it you if we came on Thursday?
A agree
B suit
C like
D fit

30 This form . be handed in until the end of the week.
A doesn't need
B doesn't have
C needn't
D hasn't got 


\section{Appendices}

31 If you make a mistake when you are writing, just it out with your pen.
A cross
B clear
C do
D wipe

32 Although our opinions on many things , we're good friends.
A differ
B oppose
C disagree
D divide

33 This product must be eaten two days of purchase.
A by
B before
C within
D under

34 The newspaper-report contained important information.
A many
B another
C an
D a lot of

35 Have you considered to London?
A move
B to move
C to be moving
D moving

36 It can be a good idea for people who lead an active life to increase their of vitamins.
A upturn
B input
C upkeep
D intake

37 I thought there was a of jealousy in his reaction to my good fortune.
A piece
B part
C shadow
D touch

38 Why didn't you that you were feeling ill?
A advise
B mention
C remark
D tell

39 James was not sure exactly where his best interests
A stood
B rested
C lay
D centred

40 He's still getting the shock of losing his job.
A across
B by
C over
D through 
Appendices

\section{Part 2}

Do not start this part unless told to do so by your test supervisor.

Questions $41-50$

- In this section you must choose the word or phrase which best fits each space in the texts.

- For questions $\mathbf{4 1}$ to $\mathbf{5 0 ,}$ mark one letter A, B, C or D on your Answer Sheet.

\section{The tallest buildings - SKYSCRAPERS}

Nowadays, skyscrapers can be found in most major cities of the world. A building which was many (41) high was first called a skyscraper in the United States at the end of the 19th century, and New York has perhaps the

(42) skyscraper of them all, the Empire State Building. The

(43) beneath the streets of New York is rock, (44) enough to take the heaviest load without sinking, and is therefore well-suited to bearing the (45) of tall buildings.
41 A stages
B steps
C storeys
D levels
42 A first-rate
B top-class
C well-built
D best-known
43 A dirt
B field
C ground
D soil
44 A hard
B stiff
C forceful
D powerful
45 A weight
B height
C size
D scale 


\section{Appendices}

\section{Scrabble}

Scrabble is the world's most popular word game. For its origins, we have to go back to the 1930s in the USA, when Alfred Butts, an architect, found himself out of

(46) . He decided that there was a (47) for a board game based on words, and (48) to design one. Eventually he made a (49) ...................... from it, in spite of the fact that his original (50) was only three cents a game.

$\begin{array}{lllll}\text { 46 } & \text { A earning } & \text { B work } & \text { C income } & \text { D job } \\ \text { 47 } & \text { A market } & \text { B purchase } & \text { C commerce } & \text { D sale } \\ \text { 48 } & \text { A took up } & \text { B set out } & \text { C made for } & \text { D got round } \\ \text { 49 } & \text { A wealth } & \text { B fund } & \text { C cash } & \text { D fortune } \\ \text { 50 } & \text { A receipt } & \text { B benefit } & \text { C profit } & \text { D allowance }\end{array}$




\section{Questions 51-60}

- In this section you must choose the word or phrase which best completes each sentence.

- For questions $\mathbf{5 1}$ to $\mathbf{6 0}$, mark one letter A, B, C or D on your Answer Sheet.

51 Roger's manager to make him stay late if he hadn't finished the work.
A insisted
B warned
C threatened
D announced

52 By the time he has finished his week's work, John has hardly energy left for the weekend.
A any
B much
C no
D same

53 As the game to a close, disappointed spectators started to leave.
A led
B neared
C approached
D drew

54 I don't remember the front door when I left home this morning.
A to lock
B locking
C locked
D to have locked

55 I to other people borrowing my books: they always forget to return them.
A disagree
B avoid
C dislike
D object

56 Andrew's attempts to get into the swimming team have not with much success.
A associated
B concluded
C joined
D met

57 Although Harry had obviously read the newspaper article carefully, he didn't seem to have the main point.
A grasped
B clutched
C clasped
D gripped

58 A lot of the views put forward in the documentary were open to
A enquiry
B query
C question
D wonder

59 The new college for the needs of students with a variety of learning backgrounds.
A deals
B supplies
C furnishes
D caters

60 I find the times of English meals very strange - I'm not used dinner at 6p.m.
A to have
B to having
C having
D have 


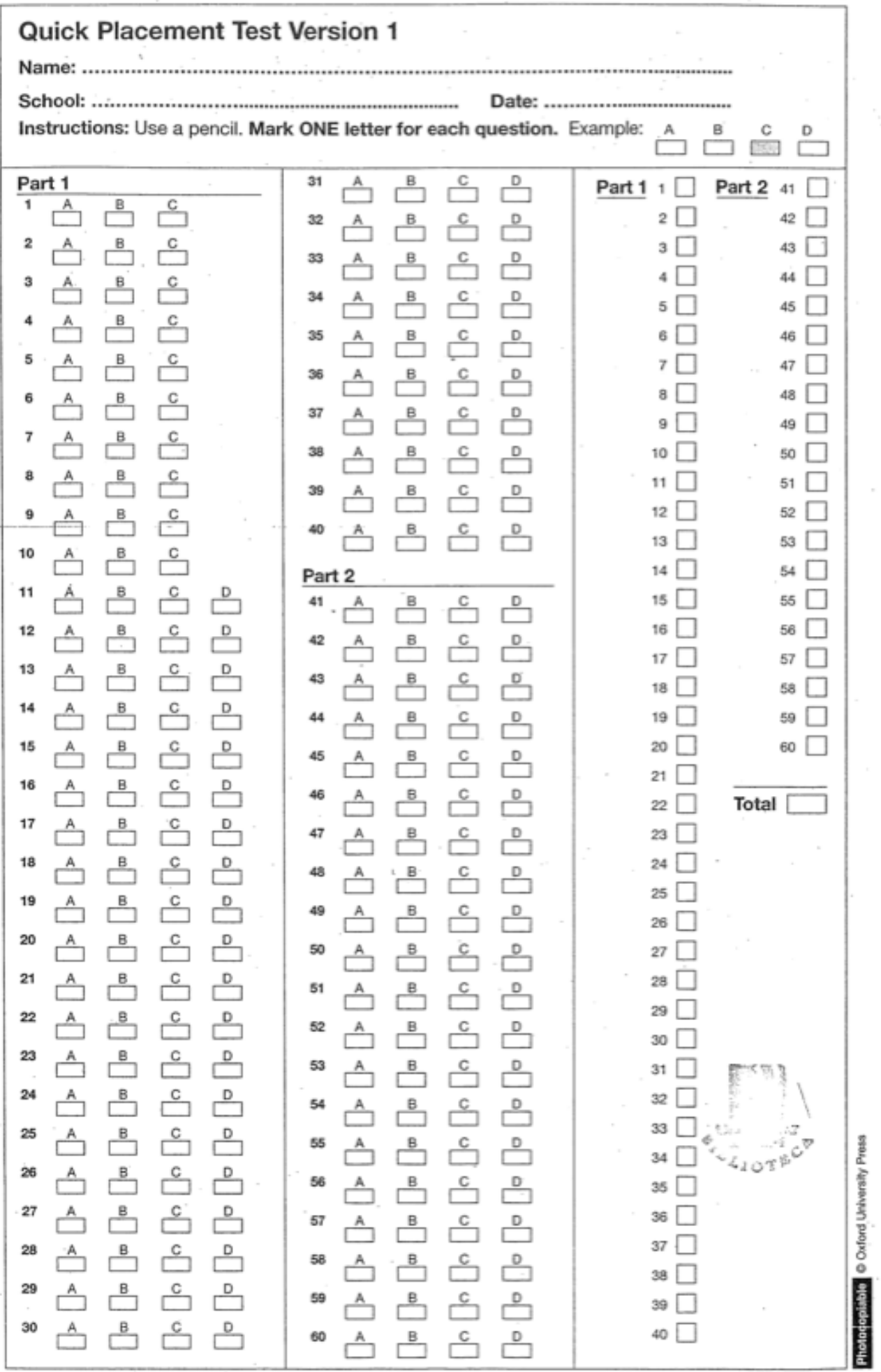


Appendices 
Appendix 16. Extended description of descriptive statistics for experimental and control groups in the VKS

Table 75 shows the descriptive statistics of the scores obtained by the control group in the VKS at Time 1. The control group, conformed by 25 participants $(n=25)$, scored a minimum of 23 and a maximum of 34 , with a range of 11 . The Mean was 29.72 with a SD of 2.716, skewness of -1.035 (SD error .464), and Kurtosis of 1.345 (SD error .902). This means that the scores are normally distributed; there is no significant departure from the Mean score.

Table 75. Descriptive statistics for control group in the VKS at Time 1

\begin{tabular}{cccccc}
\hline Group & Mean & SD & Range & Skewness & Kurtosis \\
\hline Control & 29.72 & 2.716 & 11 & -1.035 & 1.345 \\
$\mathrm{~N}=25$ & & & {$[23-34]$} & $(\mathrm{sd}$ error & (sd error \\
& & & & $.464)$ & $.902)$ \\
\hline
\end{tabular}

Figure 26 below shows the distribution of the scores obtained by the control group in the VKS at Time 1. As shown in the histogram, there is a skewness towards the higher scores, with most of the students in this group obtaining a score of 28,30 , or 31 . Then, there seems to be another large number of participants that scored 27, 29, or 34 . Then, fewer participants scored 23 or 33 . Finally, very few students scored 32.

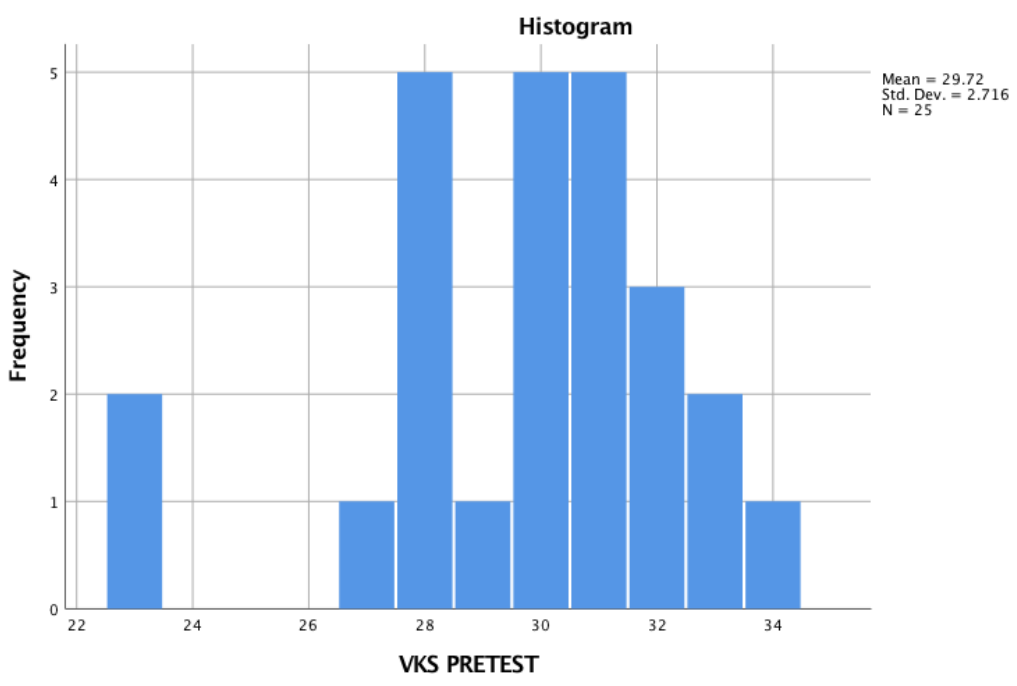


Figure 26. Distribution of the scores by the control group in the VKS at Time 1

Table 76 presents the descriptive statistics from the performance of the VKS by the experimental group at Time 1 . The experimental group, conformed by 21 participants $(n=21)$, scored a minimum of 28 and a maximum of 34 , with a range of 6 . The Mean was 31.00 with a SD of 1.643, skewness of -.075 (sd error .501), and Kurtosis of -.896 (sd error .972). This means that the scores are normally distributed; there is no significant departure from the Mean score.

Table 76. Descriptive statistics for experimental group in the VKS at Time 1

\begin{tabular}{cccccc}
\hline Group & Mean & $S D$ & Range & Skewness & Kurtosis \\
\hline Experimental & 31.00 & 1.643 & 6 & -.075 & -.896 \\
$\mathrm{~N}=21$ & & & {$[28-34]$} & $(\mathrm{sd}$ error & (sd error \\
& & & & $.501)$ & $.972)$ \\
\hline
\end{tabular}

Figure 27 illustrates the distribution of the scores obtained by the experimental group in the VKS at Time 1. It can be seen that the most frequent score obtained was 32, followed by scores of 29 and 31, then 30 and 33. Finally, the least frequent scores obtained by participants in the experimental group in the VKS at Time 1 were 28 and 34.

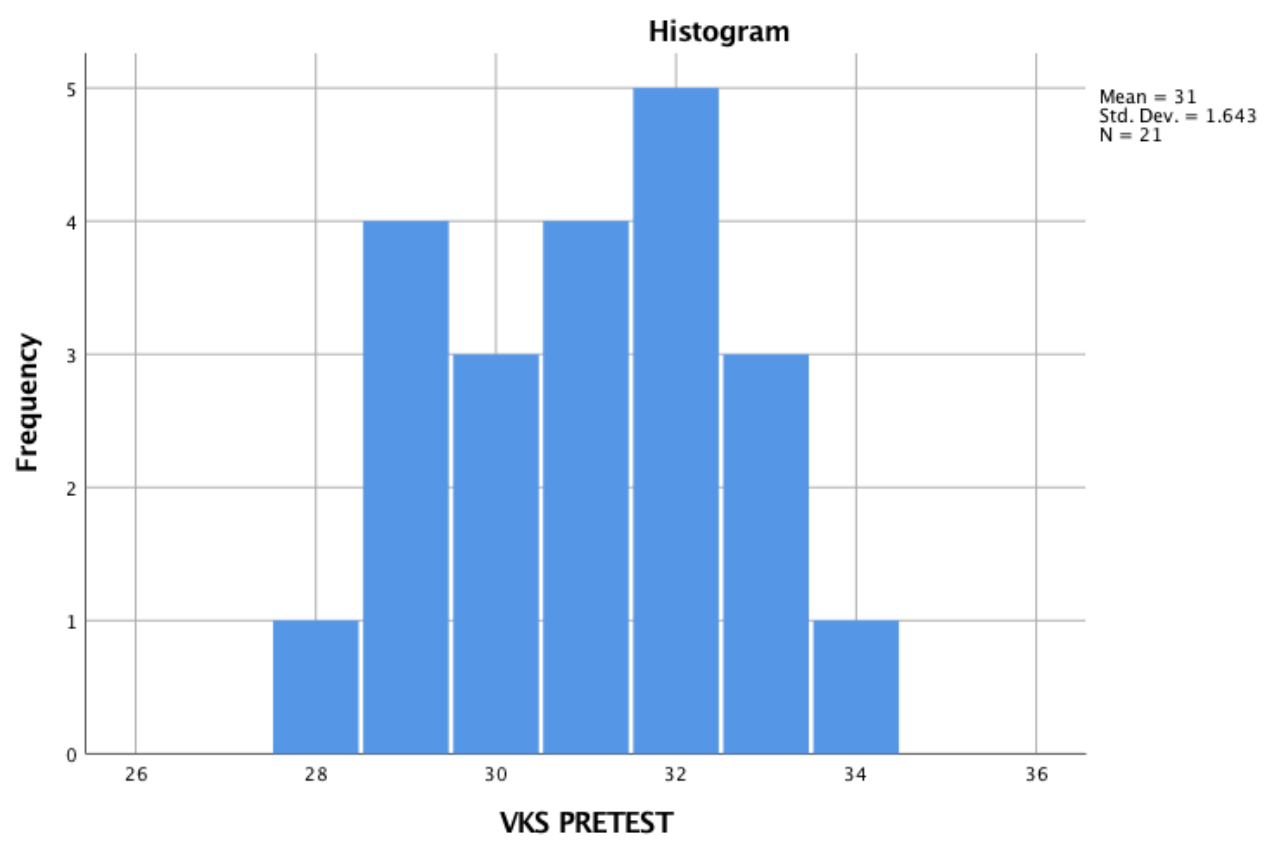


Figure 27. Distribution of the scores by the experimental group in the VKS at Time 1

Table 77 illustrates the descriptive statistics for score performance by the control in the VKS at Time 2. The control group $(n=25)$ scored a minimum of 24 and a maximum of 34 , with a range of 10 . The Mean was higher than the mean at Time 1: 30.44 with a SD of 2.142, a skewness of -1.126 (SD error .464), and Kurtosis of 2.094 (SD error .902). This means that the scores are normally distributed; there is no significant departure from the Mean score.

Table 77. Descriptive statistics for control group in the VKS at Time 2

\begin{tabular}{cccccc}
\hline Group & Mean & SD & Range & Skewness & Kurtosis \\
\hline Control & 30.44 & 2.142 & 10 & -1.126 & 2.094 \\
$\mathrm{~N}=25$ & & & {$[24-34]$} & $(\mathrm{sd}$ error & $(\mathrm{sd}$ error \\
& & & & $.464)$ & $.902)$ \\
\hline
\end{tabular}

Figure 28 below represents the distribution of the scores obtained by the control group in the VKS at Time 2. It shows a skewness towards the higher scores, with the majority of the participants scoring 32 , as in Time 1 . The second highest score is that of 29 , followed by 31 , and then 30 . Finally, a very similar number of students seem to have scored 24, 27, 28, 33, and 34 .

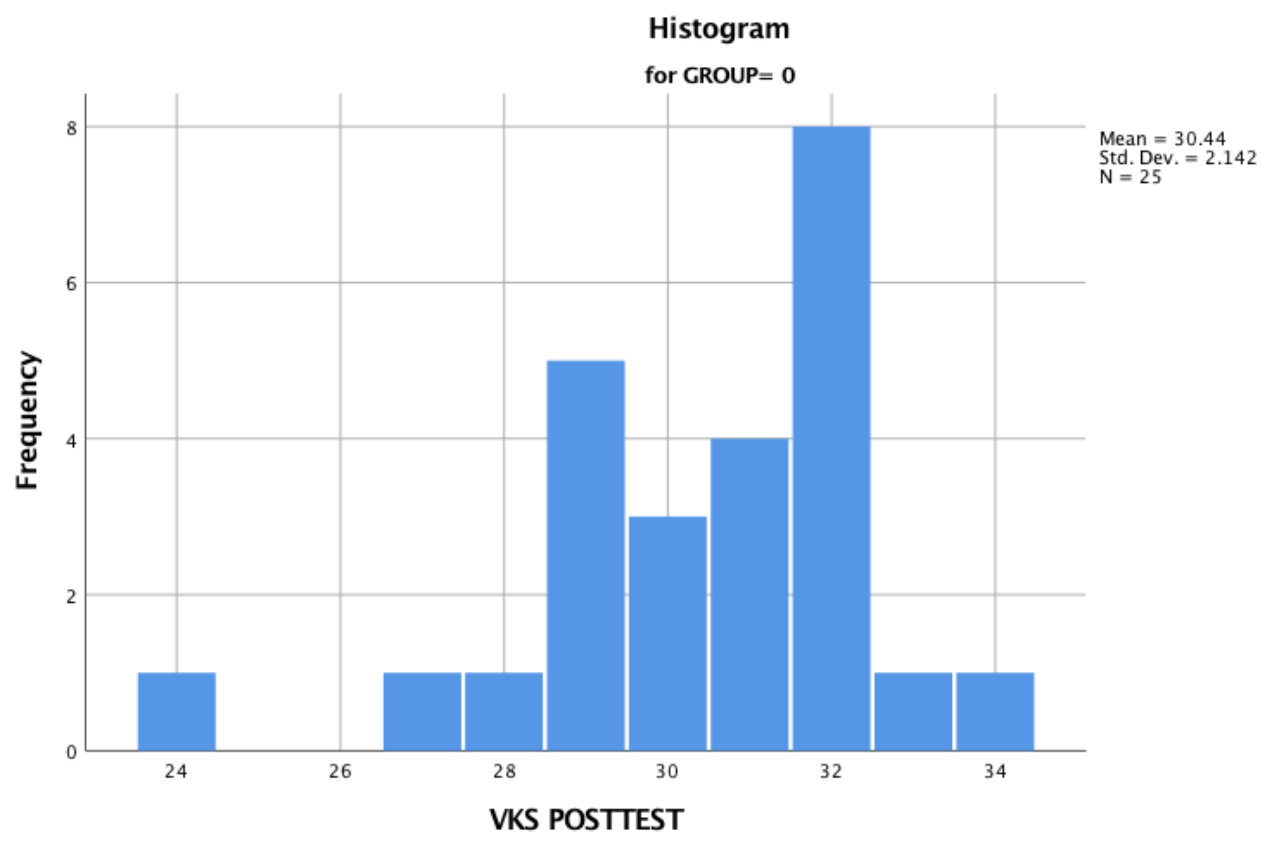


Figure 28. Distribution of the scores by the control group in the VKS at Time 2

Table 78 presents the descriptive statistics from the performance in the VKS by the experimental group at Time 2 . The experimental group $(n=21)$ scored a minimum of 30 and a maximum of 34 , with a range of 4 . The Mean was higher than the Mean at Time 1: 32.81 with a SD of .928 , a skewness of -1.243 (sd error .501), and Kurtosis of 3.083 (sd error .972). This means that the scores are normally distributed; there is no significant departure from the Mean score.

Table 78. Descriptive statistics for experimental group in the VKS at Time 2

\begin{tabular}{cccccc}
\hline Group & Mean & SD & Range & Skewness & Kurtosis \\
\hline Experimental & 32.81 & .928 & 4 & -1.243 & 3.083 \\
$\mathrm{~N}=21$ & & & {$[30-34]$} & $(\mathrm{sd}$ error & (sd error \\
& & & & $.501)$ & $.972)$ \\
\hline
\end{tabular}

Figure 29 illustrates the distribution of the scores obtained by the experimental group in the VKS at Time 2. It can be seen that there is a skewed distribution towards the higher scores. Most of the students scored 33, as they did at Time 1 . There seems to be a very similar number of students that scored 32 and 34. Finally, fewer participants scored 30.

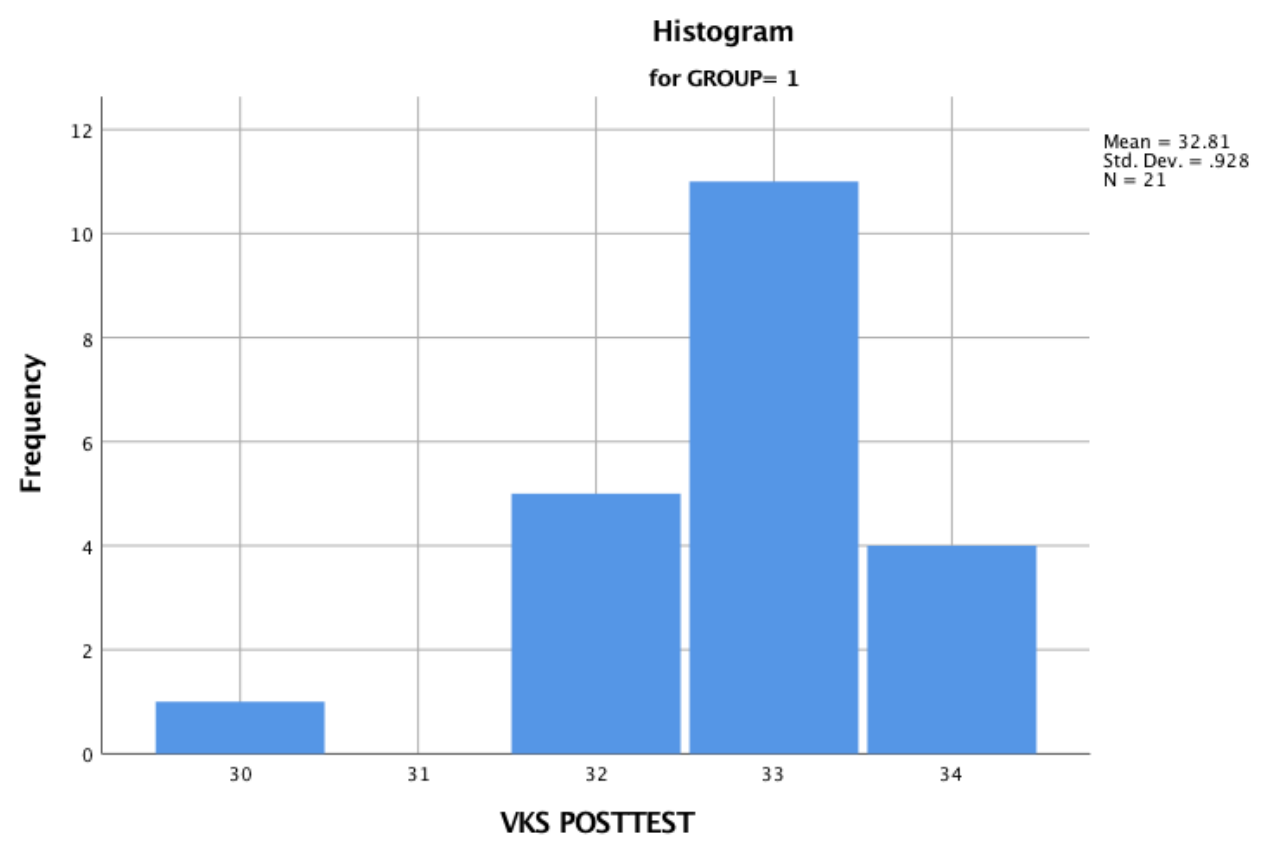




\section{Appendices}

Figure 29. Distribution of the scores by the experimental group in the VKS at Time 2

Table 79 presents the descriptive statistics for score performance by the control in the VKS at Time 3. The control group $(n=25)$ scored a minimum of 25 and a maximum of 33 , with a range of 8 . The Mean was 31.00 with a SD of 2.000. This Mean was higher than the Mean for this group at Time 2. There was a skewness of -1.326 (SD error .464), and Kurtosis of 1.763 (SD error .902). This means that the scores are normally distributed; there is no significant departure from the Mean score.

Table 79. Descriptive statistics for control group in the VKS at Time 3

\begin{tabular}{cccccc}
\hline Group & Mean & SD & Range & Skewness & Kurtosis \\
\hline Control & 31.00 & 2.000 & 8 & -1.326 & 1.763 \\
$\mathrm{~N}=25$ & & & {$[25-33]$} & $(\mathrm{sd}$ error & (sd error \\
& & & & $.464)$ & $.902)$ \\
\hline
\end{tabular}

Figure 30 illustrates the distribution of the scores obtained by the control group in the VKS at Time 3. As can be seen in Figure 19 below, the distribution of the scores is more uneven this time. Even though it is still skewed towards higher scores, there is a difference in the frequency of scores. It seems that there are more students that scored either 29 or 32, the latter being the highest score for the control group at Time 3, same as score performance at Time 1 and Time 2. Then, fewer students scored 33. Less frequent was the score of 31 . Finally, the lowest scores obtained within the range above mentioned were the scores of 25,28 , and 30 , which are still quite high considering that the lowest score for the VKS is 0 and the highest is 34 . 


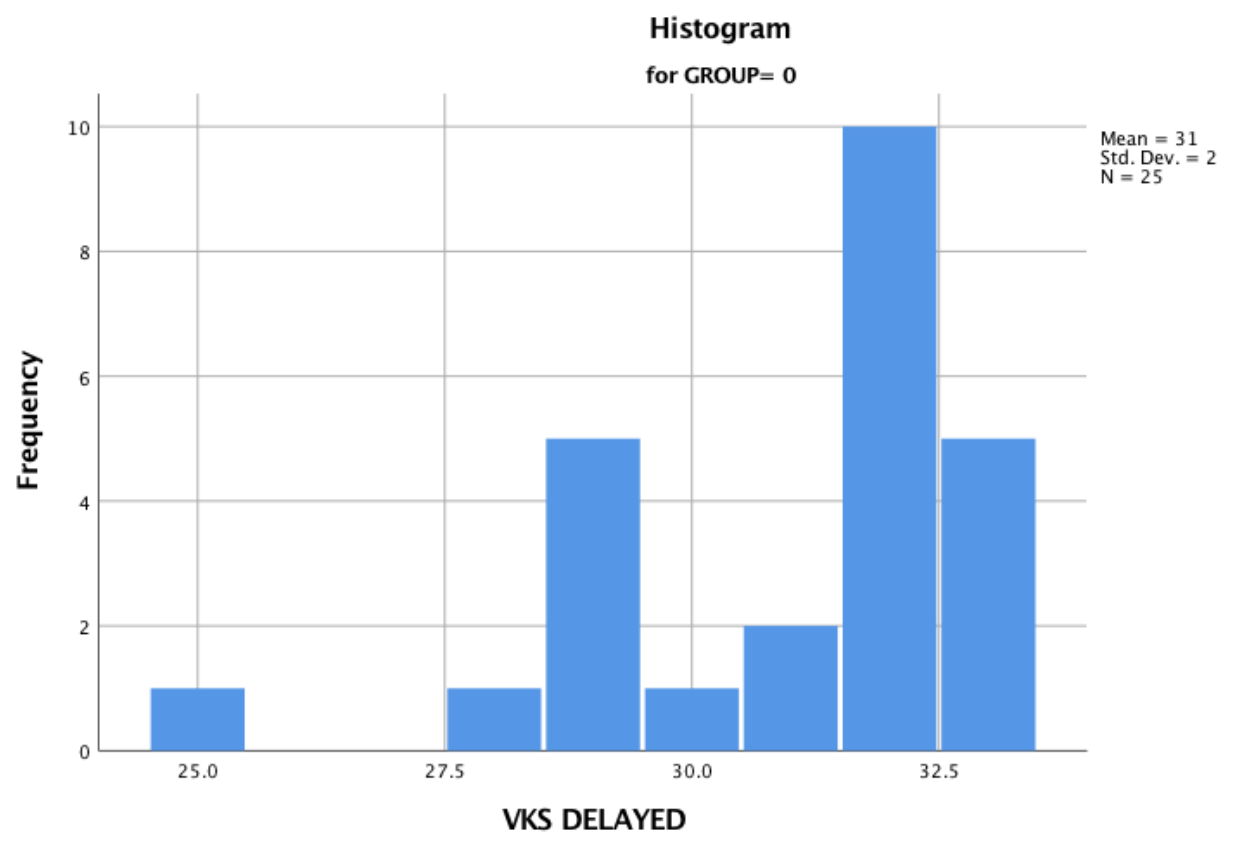

Figure 30. Distribution of the scores by the control group in the VKS at Time 3

Table 80 shows the descriptive statistics from the performance of the VKS task by the experimental group at Time 3 . The experimental group $(n=21)$ scored a minimum of 31 and a maximum of 34 , with a range of 3 . The mean was 33.19 with a SD of .873 . The mean was higher this time as well, being the highest of the Means across times. There was a skewness of -1.400 (sd error .501), and Kurtosis of 2.250 (sd error .972). This means that the scores are normally distributed; there is no significant departure from the Mean score.

Table 80. Descriptive statistics for experimental group in the VKS at Time 3

\begin{tabular}{cccccc}
\hline Group & Mean & SD & Range & Skewness & Kurtosis \\
\hline Experimental & 33.19 & .873 & 3 & -1.400 & 2.250 \\
$\mathrm{~N}=21$ & & & {$[31-34]$} & $(\mathrm{sd}$ error & (sd error \\
& & & & $.501)$ & $.972)$ \\
\hline
\end{tabular}




\section{Appendices}

Figure 31 illustrates the distribution of the scores obtained by the experimental group in the VKS at Time 3. It can be seen that there is a skewed distribution towards the higher scores: 33 and 34. Most of the students obtained 33, the same as they did at Time 1 and Time 2. Then fewer students scored 34. Finally, very few students scored 31.

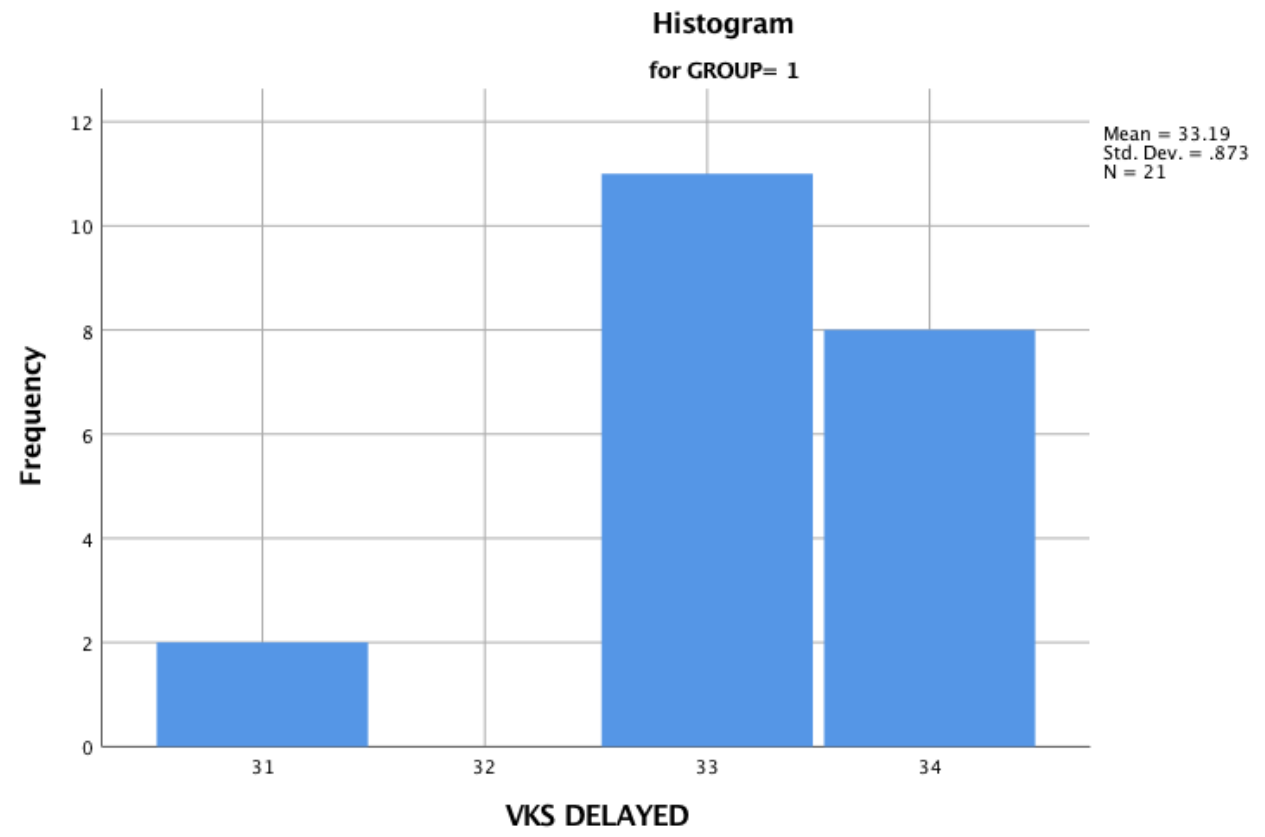

Figure 31. Distribution of the scores by the experimental group in the VKS at Time 3 
Appendices 
Appendix 17. Extended description of descriptive statistics for experimental and control groups in the computer-delivered ODCT and RVP

Table 81 shows the descriptive statistics from the scores obtained by the control group in the computer-delivered ODCT at Time 1 . The control group $(n=25)$ scored a minimum of 0 and a maximum of 10 , with a range of 10 . The Mean was 5.72 with a SD of 2.509, skewness of -.532 (SD error .464), and Kurtosis of -.034 (SD error .902). This means that the scores are normally distributed; there is no significant departure from the Mean score.

Table 81. Descriptive statistics for control group in the computer-delivered ODCT at Time 1

\begin{tabular}{cccccc}
\hline Group & Mean & SD & Range & Skewness & Kurtosis \\
\hline Control & 5.72 & 2.509 & 10 & $-.532(\mathrm{sd}$ & $-.034(\mathrm{sd}$ \\
$\mathrm{N}=25$ & & & {$[0-10]$} & error .464$)$ & error .902$)$ \\
\hline
\end{tabular}

Figure 32 below shows the distribution of the scores obtained by the control group in the computer-delivered ODCT at Time 1. It shows that scores are skewed towards the medium scores, with most of the students in this group scoring 8 , and 5 . Then, there seems to be another large number of participants that scored 4,6 , and 8 . Then, fewer participants scored from 0 to 3 and 10. Finally, even fewer students scored 9. 


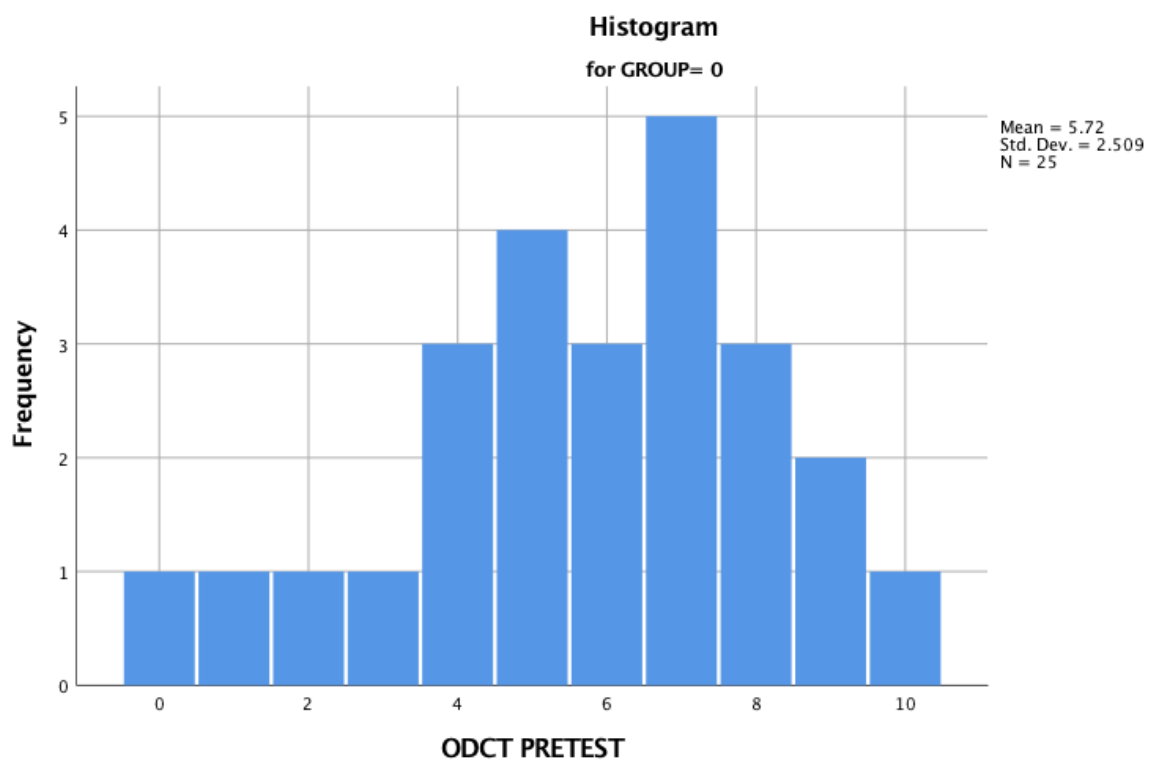

Figure 32. Distribution of the scores by the control group in the computer-delivered ODCT at Time 1

Table 82 illustrates the descriptive statistics from the performance of the computer-delivered ODCT by the experimental group at Time 1. The experimental group $(n=21)$ scored a minimum of 1 and a maximum of 12 , with a range of 11 . The Mean was 7.24 with a SD of 2.644, a skewness of -.374 (sd error .501), and Kurtosis of .185 (sd error .972). This means that the scores are normally distributed; there is no significant departure from the Mean score.

Table 82. Descriptive statistics for experimental group in the computer-delivered ODCT at Time 1

\begin{tabular}{cccccc}
\hline Group & Mean & SD & Range & Skewness & Kurtosis \\
\hline $\begin{array}{c}\text { Experimental } \\
\mathrm{N}=21\end{array}$ & 7.24 & 2.644 & 11 & $-.374(\mathrm{sd}$ & $.185(\mathrm{sd}$ \\
& & & {$[1-12]$} & error .501$)$ & error .972$)$ \\
\hline
\end{tabular}


Figure 33 shows the distribution of the scores obtained by the experimental group in the computer-delivered ODCT at Time 1. It can be seen that there is an uneven distribution because even though the number of participants that scored 5, 8, and 9 seem to be the same, those who scored 6 are dramatically less, and are similar to those who scored 1, 11, and 12. Then, there seems to be a group of students who scored 4 and 10 similarly. Finally, the highest score that most of the students obtained was 7 .

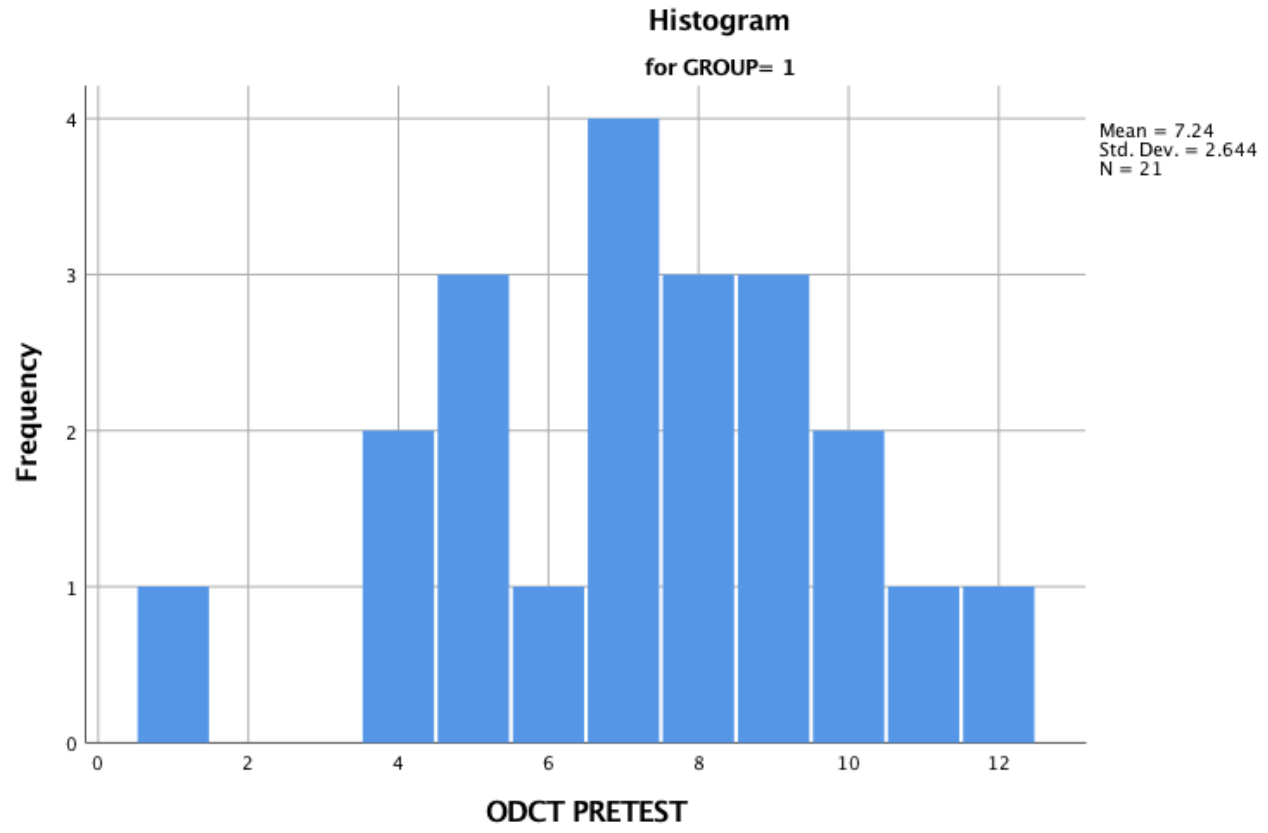

Figure 33. Distribution of the scores by the experimental group in the computerdelivered ODCT at Time 1

Table 83. Descriptive statistics for control group in the computer-delivered ODCT at Time 2

\begin{tabular}{cccccc}
\hline Group & Mean & SD & Range & Skewness & Kurtosis \\
\hline Control & 6.40 & 2.693 & 10 & $.259(\mathrm{sd}$ & $-.580(\mathrm{sd}$ \\
$\mathrm{N}=25$ & & & {$[2-12]$} & error .464$)$ & error .902$)$ \\
\hline
\end{tabular}

Table 83 illustrates the descriptive statistics of the scores obtained by the control group in the computer-delivered ODCT at Time 2. The control group $(n=25)$ scored a minimum of 2 and a maximum of 12 , with a range of 10 . This second time, the range was the same but the scores were higher. The Mean was higher at Time 2 as well: 6.40 
Appendices

with a SD of 2.693, skewness of .259 (sd error .464), and Kurtosis of -.580 (sd error .902). This means that the scores are normally distributed; there is no significant departure from the Mean score.

Figure 34 below shows the distribution of the scores obtained by the control group in the computer-delivered ODCT at Time 2. It can be observed that scores are different from those obtained at Time 1 by this group. At Time 2, there were more participants that scored 4 or 6 , followed by those that scored 5,8 , or 9 . Then fewer students scored $3,10,11$, or 12 . Finally, even fewer students scored 2.

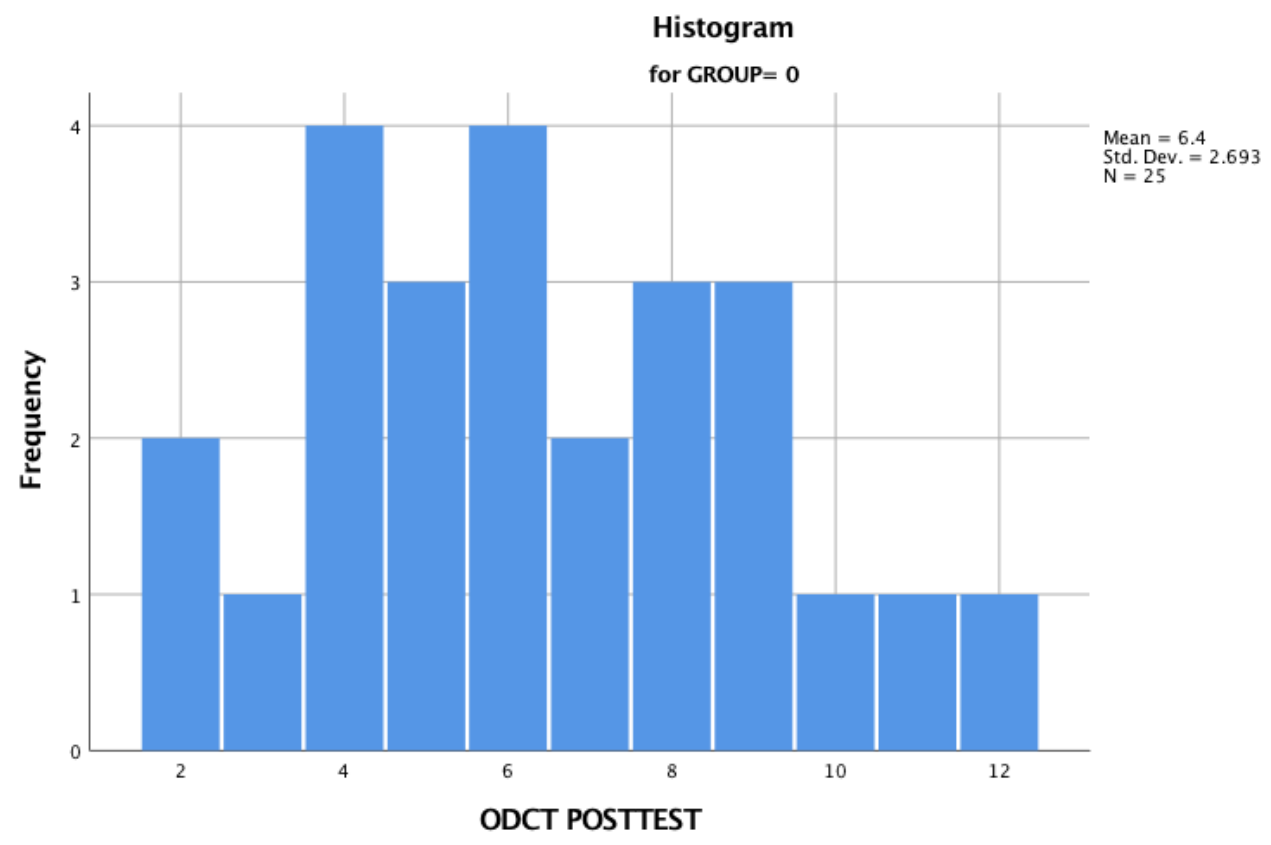

Figure 34. Distribution of the scores by the control group in the computer-delivered ODCT at Time 2 


\section{Appendices}

Table 84 encompasses the descriptive statistics from the performance of the computer-delivered ODCT by the experimental group at Time 2. The experimental group $(n=21)$ scored a minimum of 10 and a maximum of 15 , with a range of 5 . The scores obtained this time were quite different from those at Time 1, since participants' performance improved nearly twice as they did at Time 1 . This is reflected in the Mean, which was 13.38 with a SD of 1.564, a skewness of -.968 (sd error .501), and Kurtosis of .315 (sd error .972). This means that the scores are normally distributed; there is no significant departure from the Mean score.

Table 84. Descriptive statistics for experimental group in the computer-delivered ODCT at Time 2

\begin{tabular}{cccccc}
\hline Group & Mean & SD & Range & Skewness & Kurtosis \\
\hline $\begin{array}{c}\text { Experimental } \\
\mathrm{N}=21\end{array}$ & 13.38 & 1.564 & 5 & $-.968(\mathrm{sd}$ & $.315(\mathrm{sd}$ \\
error .501$)$ & error .972$)$ \\
\hline
\end{tabular}

Figure 35 illustrates the distribution of the scores obtained by the experimental group in the computer-delivered ODCT at Time 2. It can be seen that the scores are skewed towards the three highest scores, with two similar groups of participants scoring 13 and 15 . Then, another the second more frequent score was that of 14 , followed by 10, and finally scores of 11 and 12 . 


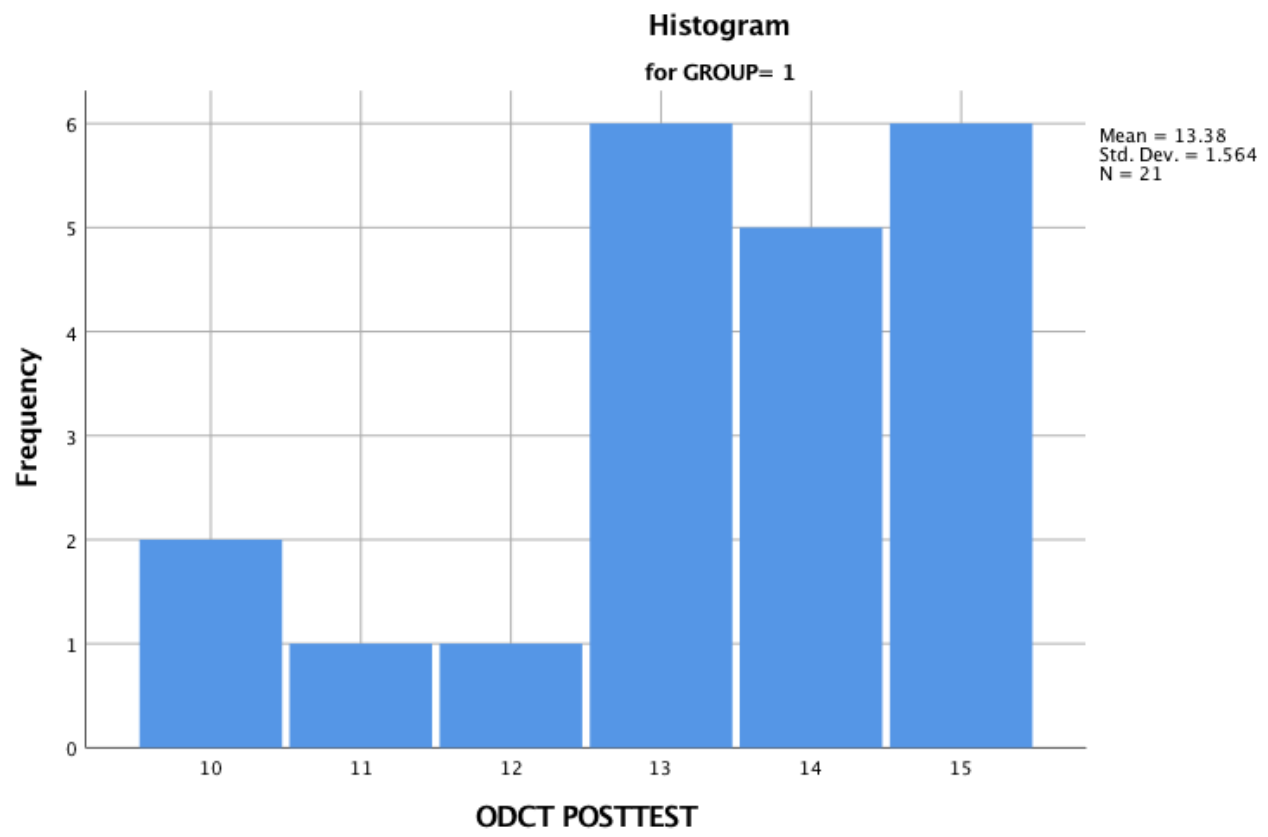

Figure 35. Distribution of the scores by the experimental group in the computerdelivered ODCT at Time 2

Table 85 illustrates the descriptive statistics of the scores obtained by the control group in the computer-delivered ODCT at Time 3 . The control group $(n=25)$ scored a minimum of 0 and a maximum of 12 , with a range of 12 , higher than before. The Mean was also higher at this second time: 6.88 with a SD of 3.087, skewness of -.451 (sd error .464), and Kurtosis of -.133 (sd error .902). This means that the scores are normally distributed; there is no significant departure from the Mean score.

Table 85. Descriptive statistics for control group in the computer-delivered ODCT at Time 3

\begin{tabular}{cccccc}
\hline Group & Mean & SD & Range & Skewness & Kurtosis \\
\hline Control & 6.88 & 3.087 & 12 & $-.451(\mathrm{sd}$ & $-.133(\mathrm{sd}$ \\
$\mathrm{N}=25$ & & & {$[0-12]$} & error .464$)$ & error .902$)$ \\
\hline
\end{tabular}

Figure 36 presents the distribution of the scores obtained by the control group in the computer-delivered ODCT at Time 3. It shows that scores are skewed towards the middle scores. The most frequent score obtained was 6 , followed by 7 , and 10 . Then, less frequent scores were 3, 8, 9, and 11. Finally, the less frequent scored obtained were 
$0,1,4,5$, and 12 . This means that most of the participants scored a medium or higher score, even though very few students obtained the highest score: 12 .

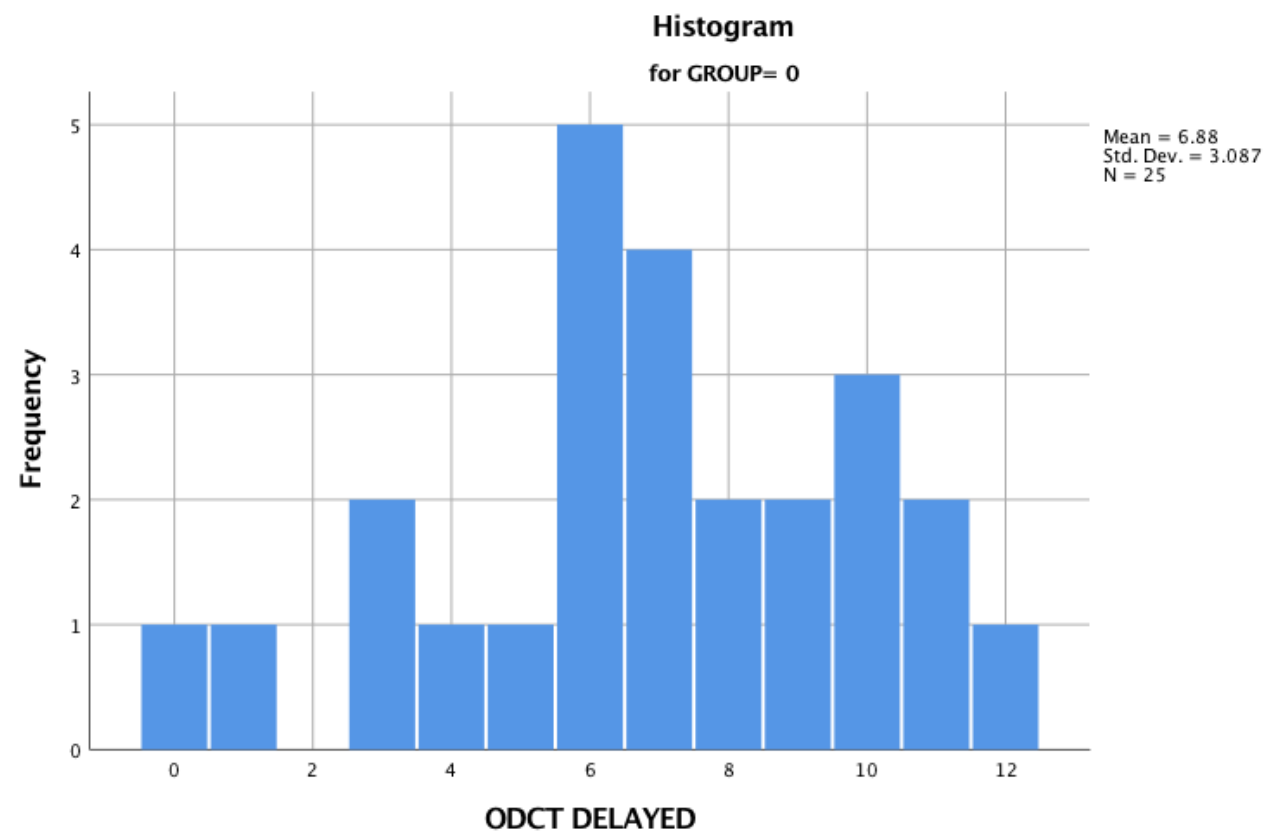

Figure 36. Distribution of the scores by the control group in the computer-delivered ODCT at Time 3

Table 86 encompasses the descriptive statistics from the performance of the computer-delivered ODCT by the experimental group at Time 3. The experimental group $(n=21)$ scored a minimum of 8 and a maximum of 15 , with a range of 7 . The range is higher this time because the minimum scores dropped two points. The Mean was lower at this third and last time: 12.76 with a SD of 1.921 , a skewness of -.935 (sd error .501), and Kurtosis of .218 (sd error .972). This means that the scores are normally distributed; there is no significant departure from the Mean score.

Table 86. Descriptive statistics for experimental group in the computer-delivered ODCT at Time 3

\begin{tabular}{cccccc}
\hline Group & Mean & SD & Range & Skewness & Kurtosis \\
\hline $\begin{array}{c}\text { Experimental } \\
\mathrm{N}=21\end{array}$ & 12.76 & 1.921 & 7 & $-.935(\mathrm{sd}$ & $.218(\mathrm{sd}$ \\
& & & {$[8-15]$} & error .501) & error .972) \\
\hline
\end{tabular}


Appendices

Figure 37 shows the distribution of the scores obtained by the experimental group in the computer-delivered ODCT at Time 3. It can be seen that there is an uneven distribution even though it tends to be skewed towards the higher scores. The most frequent score this time was 14 , in comparison to scores 13 and 15 at Time 2 . The second most frequent score in the experimental group at time 3 was 13 followed by scores 11 and 15. Less frequent was the score of 10, and finally the scores of 8 and 12 were the least frequent ones.

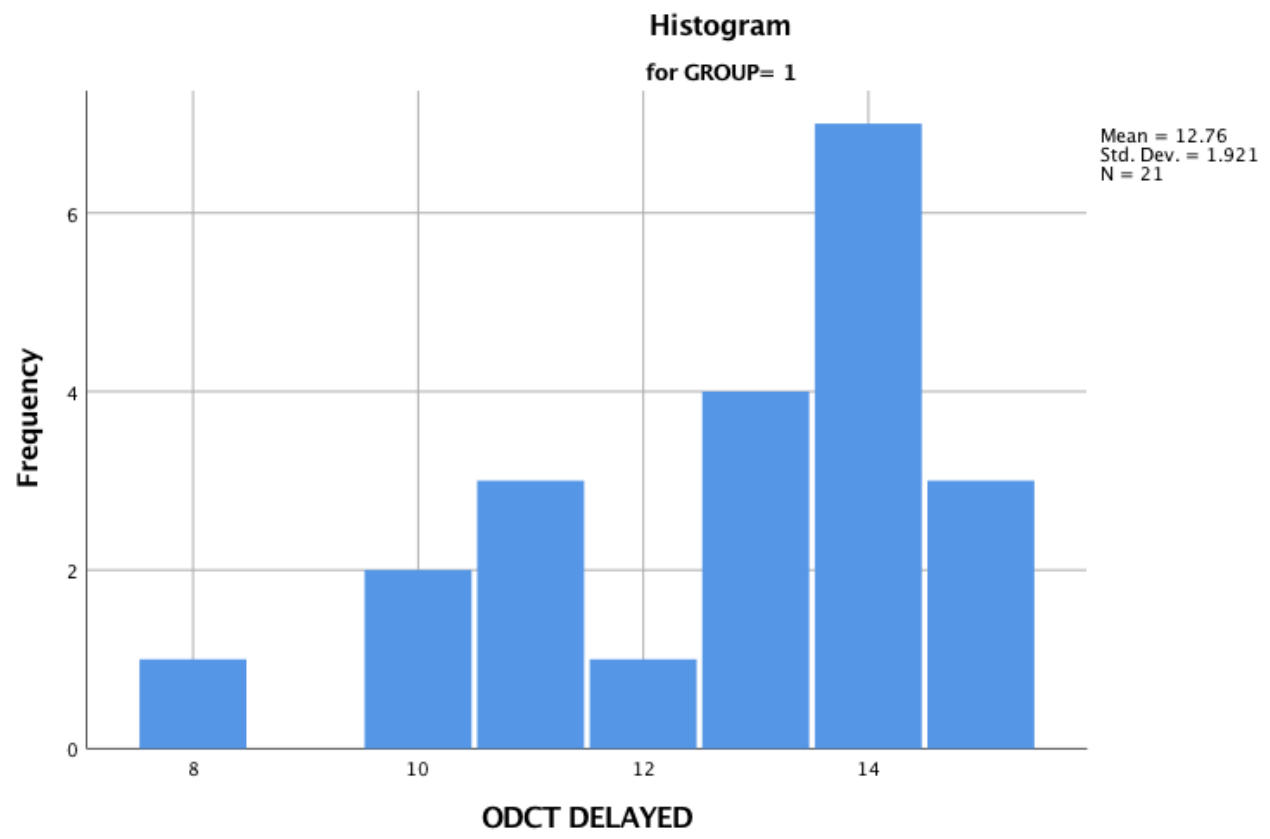

Figure 37. Distribution of the scores by the experimental group in the computerdelivered ODCT at Time 3 
Appendix 18. Test of between-subjects effects across topics

\begin{tabular}{|c|c|c|c|c|c|c|c|}
\hline Source & $\begin{array}{l}\text { Dependent } \\
\text { Variable } \\
\end{array}$ & $\begin{array}{c}\text { Type III Sum } \\
\text { of Squares }\end{array}$ & df & $\begin{array}{l}\text { Mean } \\
\text { Square }\end{array}$ & $\mathrm{F}$ & Sig. & $\begin{array}{c}\text { Partial Eta } \\
\text { Squared }\end{array}$ \\
\hline \multirow{38}{*}{$\begin{array}{l}\text { Corrected } \\
\text { Model }\end{array}$} & LR PRT & $14.026^{\mathrm{a}}$ & 1 & 14.026 & 1.867 & .179 & .041 \\
\hline & LR PST & $7.980^{\mathrm{b}}$ & 1 & 7.980 & 3.001 & .090 & .064 \\
\hline & LR DLY & $11.240^{\mathrm{c}}$ & 1 & 11.240 & 4.759 & .035 & .098 \\
\hline & IIK PRT & $.000^{\mathrm{d}}$ & 1 & .000 & & & \\
\hline & IIR PST & $191.408^{\mathrm{e}}$ & 1 & 191.408 & 33.986 & .000 & .436 \\
\hline & IIR DLY & $444.125^{f}$ & 1 & 444.125 & 82.173 & .000 & .651 \\
\hline & KFT PRT & $.006^{\mathrm{g}}$ & 1 & .006 & .036 & .850 & .001 \\
\hline & KFT PST & $.073^{\mathrm{h}}$ & 1 & .073 & 1.747 & .193 & .038 \\
\hline & KFT DLY & $.292^{\mathrm{i}}$ & 1 & .292 & 3.826 & .057 & .080 \\
\hline & GLK PRT & $2.153^{\mathrm{j}}$ & 1 & 2.153 & 1.920 & .173 & .042 \\
\hline & GLK PST & $.099^{k}$ & 1 & .099 & .254 & .617 & .006 \\
\hline & GLK DLY & $.149^{1}$ & 1 & .149 & .459 & .502 & .010 \\
\hline & IDK PRT & $.711^{\mathrm{m}}$ & 1 & .711 & 1.064 & .308 & .024 \\
\hline & IDK PST & $.144^{\mathrm{n}}$ & 1 & .144 & 1.471 & .232 & .032 \\
\hline & IDK DLY & $.012^{\circ}$ & 1 & .012 & .189 & .666 & .004 \\
\hline & PE PRT & $.197^{\mathrm{p}}$ & 1 & .197 & .318 & .576 & .007 \\
\hline & PE PST & $.175^{\mathrm{q}}$ & 1 & .175 & .447 & .507 & .010 \\
\hline & PE DLY & $.366^{\mathrm{r}}$ & 1 & .366 & 1.228 & .274 & .027 \\
\hline & L1SK PRT & $.073^{\mathrm{s}}$ & 1 & .073 & 1.747 & .193 & .038 \\
\hline & L1SK PST & $.073^{\mathrm{t}}$ & 1 & .073 & 1.747 & .193 & .038 \\
\hline & L1SK DLY & $.457^{\mathrm{u}}$ & 1 & .457 & 3.348 & .074 & .071 \\
\hline & POL PRT & $1.607^{\mathrm{v}}$ & 1 & 1.607 & .246 & .622 & .006 \\
\hline & POL PST & $19.657^{\mathrm{w}}$ & 1 & 19.657 & 4.267 & .045 & .088 \\
\hline & POL DLY & $88.144^{\mathrm{x}}$ & 1 & 88.144 & 17.929 & .000 & .290 \\
\hline & CD PRT & $2.588^{\mathrm{y}}$ & 1 & 2.588 & .734 & .396 & .016 \\
\hline & CD PST & $.538^{z}$ & 1 & .538 & .174 & .679 & .004 \\
\hline & CD DLY & $1.239^{\mathrm{aa}}$ & 1 & 1.239 & .489 & .488 & .011 \\
\hline & SitD PRT & $1.448^{\mathrm{ab}}$ & 1 & 1.448 & 1.331 & .255 & .029 \\
\hline & SitD PST & $8.992^{\mathrm{ac}}$ & 1 & 8.992 & 6.560 & .014 & .130 \\
\hline & SitD DLY & $1.060^{\mathrm{ad}}$ & 1 & 1.060 & .570 & .454 & .013 \\
\hline & PB PRT & $3.316^{\mathrm{ae}}$ & 1 & 3.316 & 1.806 & .186 & .039 \\
\hline & PB PST & $3.177^{\text {af }}$ & 1 & 3.177 & 1.859 & .180 & .041 \\
\hline & PB DLY & $5.072^{\mathrm{ag}}$ & 1 & 5.072 & 1.913 & .174 & .042 \\
\hline & SE PRT & $4.267^{\mathrm{ah}}$ & 1 & 4.267 & 2.131 & .151 & .046 \\
\hline & SE PST & $1.268^{\mathrm{ai}}$ & 1 & 1.268 & .478 & .493 & .011 \\
\hline & SE DLY & $2.041^{\mathrm{aj}}$ & 1 & 2.041 & .819 & .370 & .018 \\
\hline & DIF PRT & $.001^{\mathrm{ak}}$ & 1 & .001 & .015 & .902 & .000 \\
\hline & DIF PST & $.001^{\mathrm{ak}}$ & 1 & .001 & .015 & .902 & .000 \\
\hline
\end{tabular}




\begin{tabular}{|l|l|r|r|r|r|r|r|}
\hline DIF DLY & $.104^{\mathrm{a}}$ & 1 & .104 & 2.517 & .120 & .054 \\
\cline { 2 - 8 } & AWK PRT & $.006^{\mathrm{am}}$ & 1 & .006 & .028 & .867 & .001 \\
\hline AWK PST & $.847^{\mathrm{an}}$ & 1 & .847 & 2.026 & .162 & .044 \\
\hline AWK DLY & $.164^{\mathrm{a}}$ & 1 & .164 & 2.739 & .105 & .059 \\
\hline NA PRT & $.000^{\mathrm{d}}$ & 1 & .000 &. &. & .038 \\
\hline NA PST & $.073^{\mathrm{ap}}$ & 1 & .073 & 1.747 & .193 & .038 \\
\hline & NA DLY & $.012^{\mathrm{aq}}$ & 1 & .012 & .110 & .742 & .002 \\
\hline
\end{tabular}

a. R Squared $=.041$ (Adjusted R Squared $=.019)$

b. $\mathrm{R}$ Squared $=.064$ (Adjusted R Squared $=.043$ )

c. $\mathrm{R}$ Squared $=.098$ (Adjusted R Squared $=.077$ )

d. R Squared $=$. $($ Adjusted R Squared $=$.)

e. $\mathrm{R}$ Squared $=.436$ (Adjusted R Squared $=.423)$

$\mathrm{f}$. $\mathrm{R}$ Squared $=.651$ (Adjusted R Squared $=.643$ )

g. $\mathrm{R}$ Squared $=.001$ (Adjusted R Squared $=-.022)$

h. $\mathrm{R}$ Squared $=.038$ (Adjusted R Squared $=.016)$

i. $\mathrm{R}$ Squared $=.080$ (Adjusted R Squared $=.059$ )

j. R Squared $=.042($ Adjusted R Squared $=.020)$

k. R Squared $=.006$ (Adjusted R Squared $=-.017)$

1. $\mathrm{R}$ Squared $=.010$ (Adjusted R Squared $=-.012$ )

$\mathrm{m}$. $\mathrm{R}$ Squared $=.024$ (Adjusted R Squared $=.001)$

n. $\mathrm{R}$ Squared $=.032$ (Adjusted R Squared $=.010)$

o. $\mathrm{R}$ Squared $=.004$ (Adjusted R Squared $=-.018$ )

p. R Squared $=.007$ (Adjusted R Squared $=-.015$ )

q. $R$ Squared $=.010$ (Adjusted R Squared $=-.012$ )

r. R Squared $=.027$ (Adjusted R Squared $=.005$ )

s. $\mathrm{R}$ Squared $=.038$ (Adjusted R Squared $=.016)$

t. $\mathrm{R}$ Squared $=.038$ (Adjusted R Squared $=.016$ )

u. $\mathrm{R}$ Squared $=.071$ (Adjusted R Squared $=.050)$

v. R Squared $=.006$ (Adjusted R Squared $=-.017$ )

$\mathrm{w} . \mathrm{R}$ Squared $=.088$ (Adjusted R Squared $=.068)$

$\mathrm{x} . \mathrm{R}$ Squared $=.290$ (Adjusted R Squared $=.273$ )

y. R Squared $=.016$ (Adjusted R Squared $=-.006$ )

z. $\mathrm{R}$ Squared $=.004$ (Adjusted R Squared $=-.019$ )

aa. $\mathrm{R}$ Squared $=.011$ (Adjusted R Squared $=-.011)$

ab. R Squared $=.029($ Adjusted R Squared $=.007)$

ac. $\mathrm{R}$ Squared $=.130$ (Adjusted R Squared $=.110$ )

ad. $\mathrm{R}$ Squared $=.013$ (Adjusted $\mathrm{R}$ Squared $=-.010)$

ae. $\mathrm{R}$ Squared $=.039$ (Adjusted R Squared $=.018$ )

af. $\mathrm{R}$ Squared $=.041$ (Adjusted R Squared $=.019)$

ag. $\mathrm{R}$ Squared $=.042$ (Adjusted R Squared $=.020)$

ah. $\mathrm{R}$ Squared $=.046$ (Adjusted R Squared $=.025)$

ai. $\mathrm{R}$ Squared $=.011$ (Adjusted R Squared $=-.012$ ) 
aj. $\mathrm{R}$ Squared $=.018$ (Adjusted R Squared $=-.004)$

ak. R Squared $=.000$ (Adjusted R Squared $=-.022$ )

al. $\mathrm{R}$ Squared $=.054$ (Adjusted R Squared $=.033$ )

am. $\mathrm{R}$ Squared $=.001$ (Adjusted R Squared $=-.022$ )

an. $\mathrm{R}$ Squared $=.044$ (Adjusted R Squared $=.022)$

ao. $\mathrm{R}$ Squared $=.059$ (Adjusted R Squared $=.037)$

ap. R Squared $=.038$ (Adjusted R Squared $=.016)$

aq. $\mathrm{R}$ Squared $=.002$ (Adjusted R Squared $=-.020)$ 
Appendices 
Appendix 19. Extended description of descriptive statistics for experimental and control groups in the Attitudes Questionnaire

Table 87 shows the descriptive statistics for the scores obtained by the control group in the Attitudes Questionnaire at Time 1. The control group $(n=25)$ scored a minimum of 6 and a maximum of 10 , with a range of 4 . The Mean was 8.44 with a SD of 1.083 , skewness of -.367 (sd error .464) and Kurtosis of -.403 (sd error .902). This means that the scores are normally distributed; there is no significant departure from the Mean score.

Table 87. Descriptive statistics for control group in the Attitudes Questionnaire at Time 1

\begin{tabular}{cccccc}
\hline Group & Mean & SD & Range & Skewness & Kurtosis \\
\hline Control & 8.44 & 1.083 & 4 & $-.367(\mathrm{sd}$ & $-.403(\mathrm{sd}$ \\
$\mathrm{N}=25$ & & & {$[6-10]$} & error .464$)$ & error .902$)$ \\
\hline
\end{tabular}

Figure 38 below illustrates the distribution of the scores obtained by the control group in the Attitudes Questionnaire at Time 1. It shows that scores are skewed towards the higher scores. There is a frequency of scores that raises from the lowest -6- to 9, which is the most frequent score obtained. However, the highest score obtained is 10 , which fewer students obtained at this first time. 
Appendices

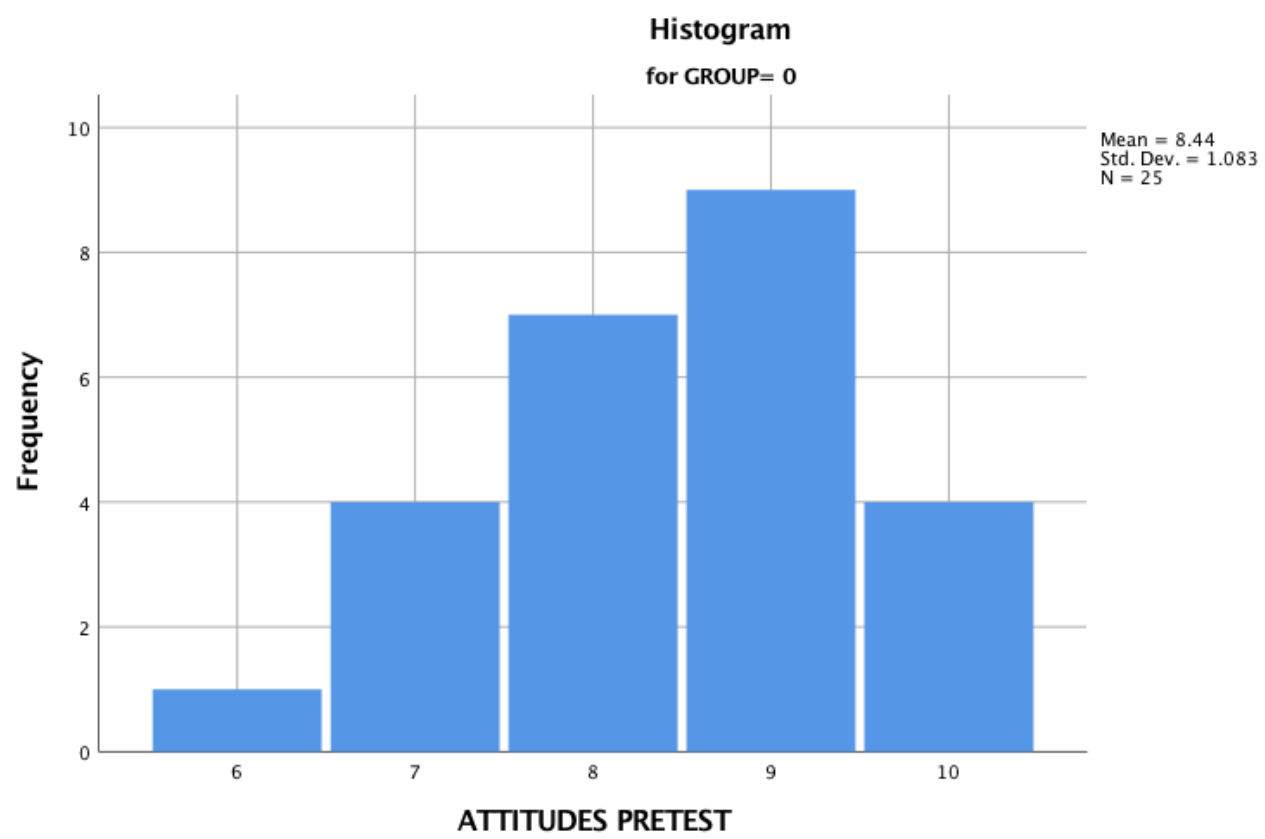

Figure 38. Distribution of the scores by the control group in the Attitudes Questionnaire at Time 1

Table 88 reports the descriptive statistics from the performance of the Attitudes Questionnaire by the experimental group at Time 1 . The experimental group $(n=21)$ scored a minimum of 7 and a maximum of 10 , with a range of 3 . The Mean was 8.43 with a SD of .870 , a skewness of -.010 (sd error .501), and Kurtosis of -.467 (sd error .972). This means that the scores are normally distributed; there is no significant departure from the Mean score.

Table 88. Descriptive statistics for experimental group in the Attitudes Questionnaire at Time 1

\begin{tabular}{cccccc}
\hline Group & Mean & SD & Range & Skewness & Kurtosis \\
\hline $\begin{array}{c}\text { Experimental } \\
\mathrm{N}=21\end{array}$ & 8.43 & .870 & 3 & $-.010(\mathrm{sd}$ & $-.467(\mathrm{sd}$ \\
& & & {$[7-10]$} & error .501$)$ & error .972$)$ \\
\hline
\end{tabular}


Figure 39 illustrates the distribution of the scores obtained by the experimental group in the Attitudes Questionnaire at Time 1. It can be seen that there seems to be a normal distribution of the scores, with the lowest score -7- and the highest score -10being the least frequent ones. Then, the highest scores obtained by participants -8 and 9seem to be equally frequent.

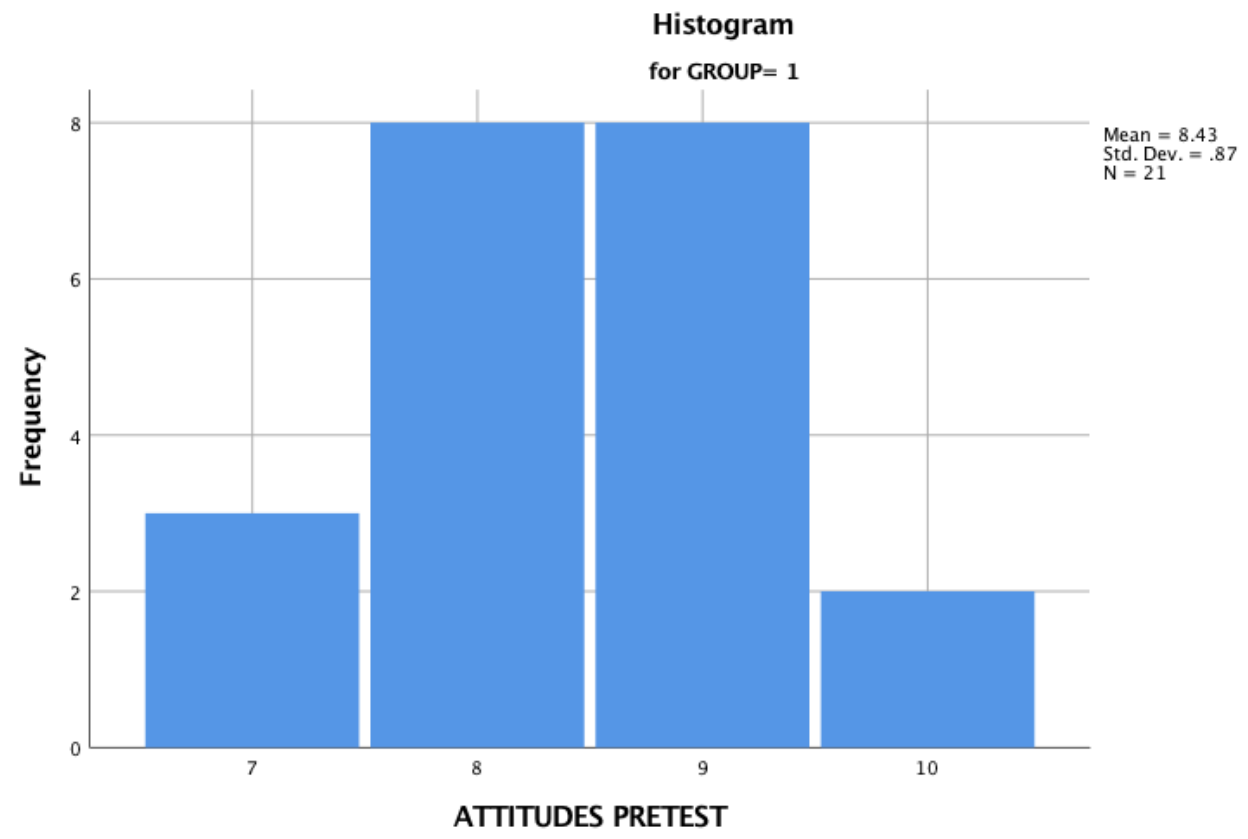

Figure 39. Distribution of the scores by the experimental group in Attitudes Questionnaire at Time 1

Table 89. Descriptive statistics for control group in the Attitudes Questionnaire at Time 2

\begin{tabular}{cccccc}
\hline Group & Mean & SD & Range & Skewness & Kurtosis \\
\hline Control & 8.28 & 1.173 & 5 & $-1.102(\mathrm{sd}$ & $1.423(\mathrm{sd}$ \\
$\mathrm{N}=25$ & & & {$[5-10]$} & error .464) & error .902) \\
\hline
\end{tabular}

Table 89 shows the descriptive statistics for the scores obtained by the control group in the Attitudes Questionnaire at Time 2. The control group $(n=25)$ scored a minimum of 5 and a maximum of 10 , with a range of 5 , being it 1 point higher than at Time 1. The Mean was 8.28 with a SD of 1.173 . The Mean was lower than the Mean at Time 1. There was a skewness of -1.102 (sd error .464), and Kurtosis of 1.423 (sd error 
.902). This means that the scores are normally distributed; there is no significant departure from the Mean score.

Figure 40 below illustrates the distribution of the scores obtained by the control group in the Attitudes Questionnaire at Time 2. Similarly to the scores at Time 1, the most frequent score obtained this second time is that of 9 , and the lowest scores -5 and 6- and the highest score -10- are the less frequent. After score 9, score 8 was the most frequent, followed by score 7, which was the third most frequent. The main difference between the scores from Time 1 to Time 2 is that of having some degree of frequency in score 5, which was inexistent at Time 1.

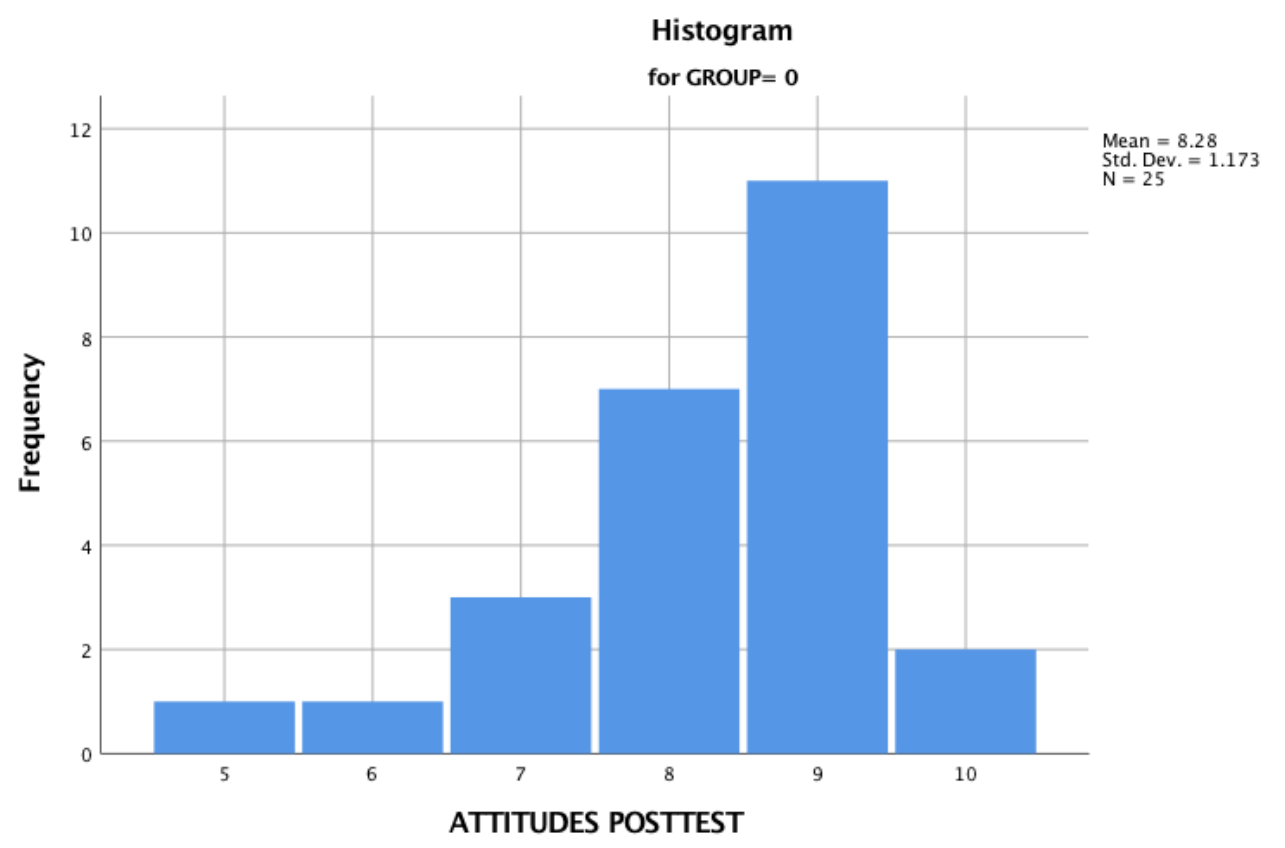

Figure 40. Distribution of the scores by the control group in the Attitudes Questionnaire at Time 2

Table 90 shows the descriptive statistics from the performance of the Attitudes Questionnaire by the experimental group at Time 2. The experimental group $(n=21)$ scored a minimum of 7 and a maximum of 10 , with a range of 3 . The Mean was higher this second time: 8.62 with a SD of .865 , a skewness of -.150 (sd error .501 ), and 
Kurtosis of -.150 (sd error .501). This means that the scores are normally distributed; there is no significant departure from the Mean score.

Table 90. Descriptive statistics for control group in the Attitudes Questionnaire at Time 2

\begin{tabular}{cccccc}
\hline Group & Mean & SD & Range & Skewness & Kurtosis \\
\hline $\begin{array}{c}\text { Experimental } \\
\mathrm{N}=21\end{array}$ & 8.62 & .865 & 3 & $-.150(\mathrm{sd}$ & $-.150(\mathrm{sd}$ \\
& & & {$[7-10]$} & error .501$)$ & error .501$)$ \\
\hline
\end{tabular}

Figure 41 illustrates the distribution of the scores obtained by the experimental group in the Attitudes Questionnaire at Time 2. It can be seen that the scores obtained were the same as in Time 1, but with different frequency. The scores 7 and 10 are still the lowest and highest and the least frequent; and scores 8 and 9 the most frequent. However, the distribution of the scores seems to be more even than it was at Time 1 . Scores 8 and 9 are still the most frequent, but less than what they were at Time 1 . Scores 7 and 10 are still the least frequent. However, the score of 7 was a frequency of 2 -higher at Time 1- and the score of 10 was a frequency of around 3 -higher at Time 2.

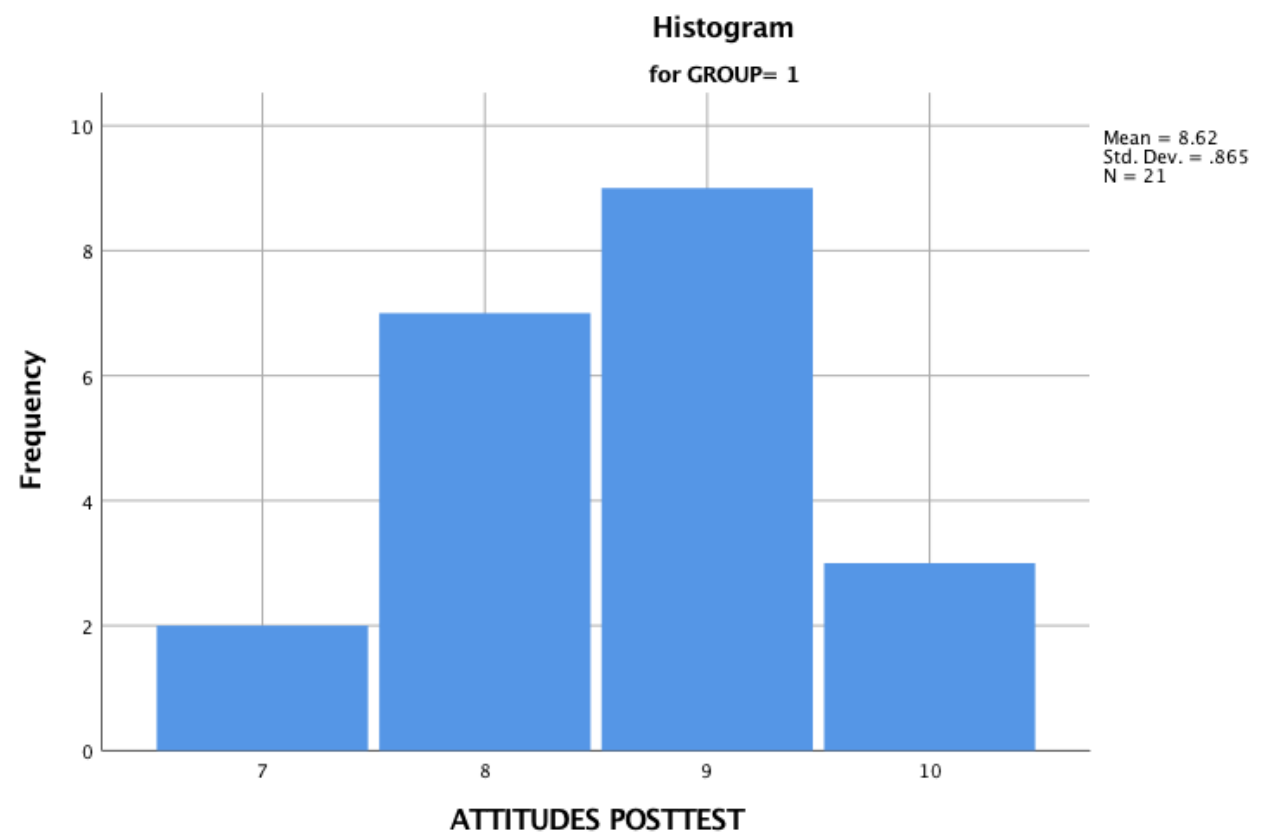

Figure 41. Distribution of the scores by the experimental group in Attitudes Questionnaire at Time 2 
Table 91 shows the descriptive statistics for the scores obtained by the control group in the Attitudes Questionnaire at Time 3. The control group $(n=25)$ scored a minimum of 6 and a maximum of 10, with a range of 4 . The Mean was 8.24 with a SD of 1.052. The mean at Time 3 was the lowest compared to those at Time 1 and Time 2. There was a skewness of -.291 (sd error .464), and Kurtosis of -.709 (sd error .902). This means that the scores are normally distributed; there is no significant departure from the Mean score.

Table 91. Descriptive statistics for control group in the Attitudes Questionnaire at Time 3

\begin{tabular}{cccccc}
\hline Group & Mean & SD & Range & Skewness & Kurtosis \\
\hline Control & 8.24 & 1.052 & 4 & $-.291(\mathrm{sd}$ & $-.709(\mathrm{sd}$ \\
$\mathrm{N}=25$ & & & {$[6-10]$} & error .464) & error .902) \\
\hline
\end{tabular}

Figure 42 below illustrates the distribution of the scores obtained by the control group in the Attitudes Questionnaire at Time 3. It shows that scores are skewed towards the higher scores once more. The distribution of the scores at Time 3 may resemble more those obtained at Time 1 . The minimum and maximum scores are the same. However, the frequency of some of the scores has varied from Time 1 to Time 3 . The score of 6 seems to have remained in the same frequency at around 3 points. Then, the score of 7 was more frequent at this third point than at the first. However, the scores of 8 and 9 were less frequent at this third point. The score of 10 was found less frequent at this third point compared to Time 1, but equally frequent at Time 2 . 
Appendices

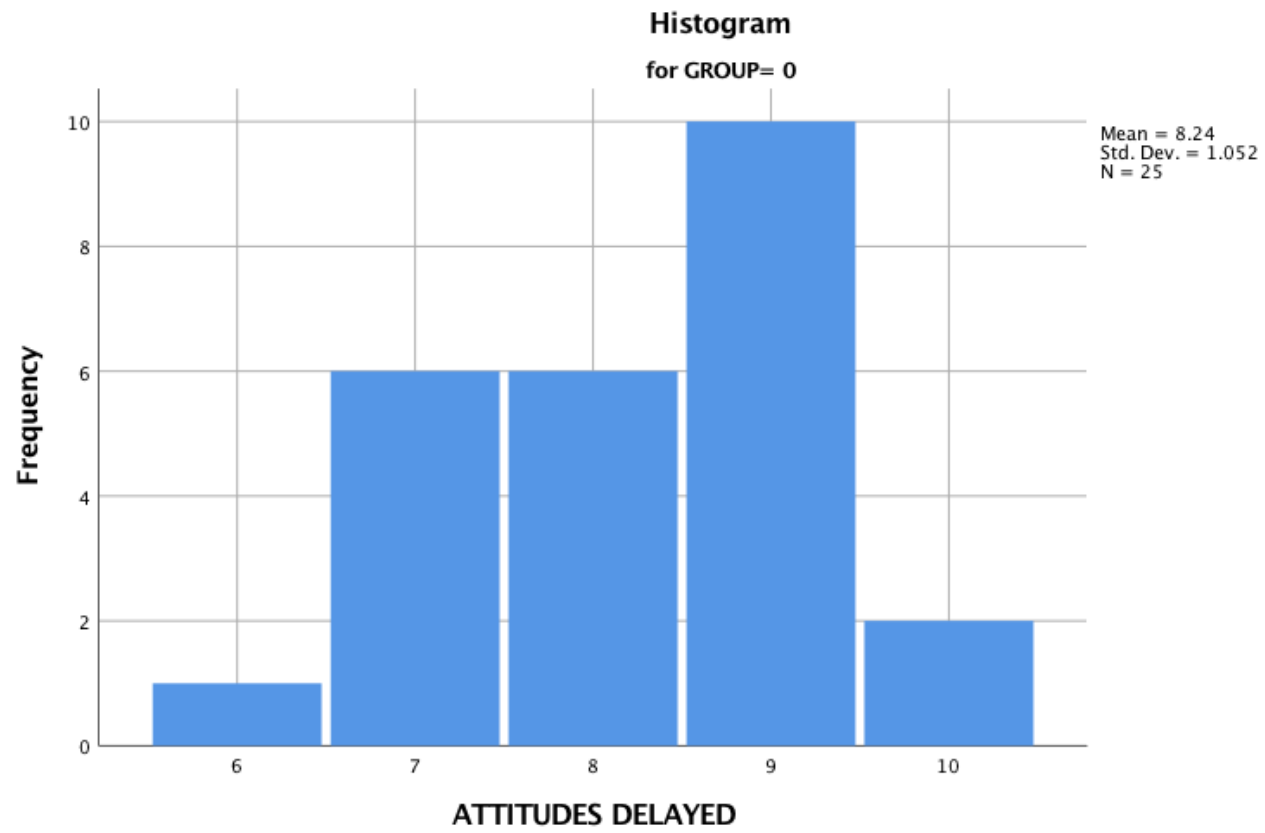

Figure 42. Distribution of the scores by the control group in the Attitudes Questionnaire at Time 3

Table 92 reports the descriptive statistics from the performance of the Attitudes Questionnaire by the experimental group at Time 3. The experimental group $(n=21)$ scored a minimum of 7 and a maximum of 10 , with a range of 3 , same as in Time 1 and Time 2. The Mean was 8.57 with a SD of .870 . The mean at Time 3 was higher than at Time 2 but lower than at Time 1. There was a skewness of .010 (sd error .501), and Kurtosis of -.467 (sd error .972). This means that the scores are normally distributed; there is no significant departure from the Mean score.

Table 92. Descriptive statistics for experimental group in the Attitudes Questionnaire at Time 3

\begin{tabular}{|c|c|c|c|c|c|}
\hline Group & Mean & $S D$ & Range & Skewness & Kurtosis \\
\hline $\begin{array}{c}\text { Experimental } \\
\mathrm{N}=21\end{array}$ & 8.57 & .870 & $\begin{array}{c}3 \\
{[7-10]}\end{array}$ & $\begin{array}{l}.010(\mathrm{sd} \\
\text { error } .501)\end{array}$ & $\begin{array}{l}-.467(\mathrm{sd} \\
\text { error } .972)\end{array}$ \\
\hline
\end{tabular}




\section{Appendices}

Figure 43 illustrates the distribution of the scores obtained by the experimental group in the Attitudes Questionnaire at Time 3. It can be seen that the distribution of the scores is normal, since there is nearly 1 point of SD. Similarly to the distribution of the scores at Time 1 and at Time 2, the scores of 7 and 10 were the lowest and highest as well as the less frequent ones. Scores of 7 and 10 are equally frequent as they were in Time 2. However, their frequency is different from that at Time 1. At that first time, score of 7 was frequent at around three points, and score of 10 was frequent at around two points. Then, this changed at Time 2 , where the score of 7 was frequent at around two points, and the score of 10 was frequent at around three points. And this change was maintained at Time 3. Regarding scores of 8 and 9, their frequency has fluctuated from Time 1 to Time 3. At Time 1, both scores were at frequency eight points. Then, at Time 2, the score of 8 dropped to a frequency of seven points, and the score of 9 rose to a frequency of nine points. Finally, at Time 3, both scores of 8 and 9 came back to being at frequency eight points, same as at Time 1.

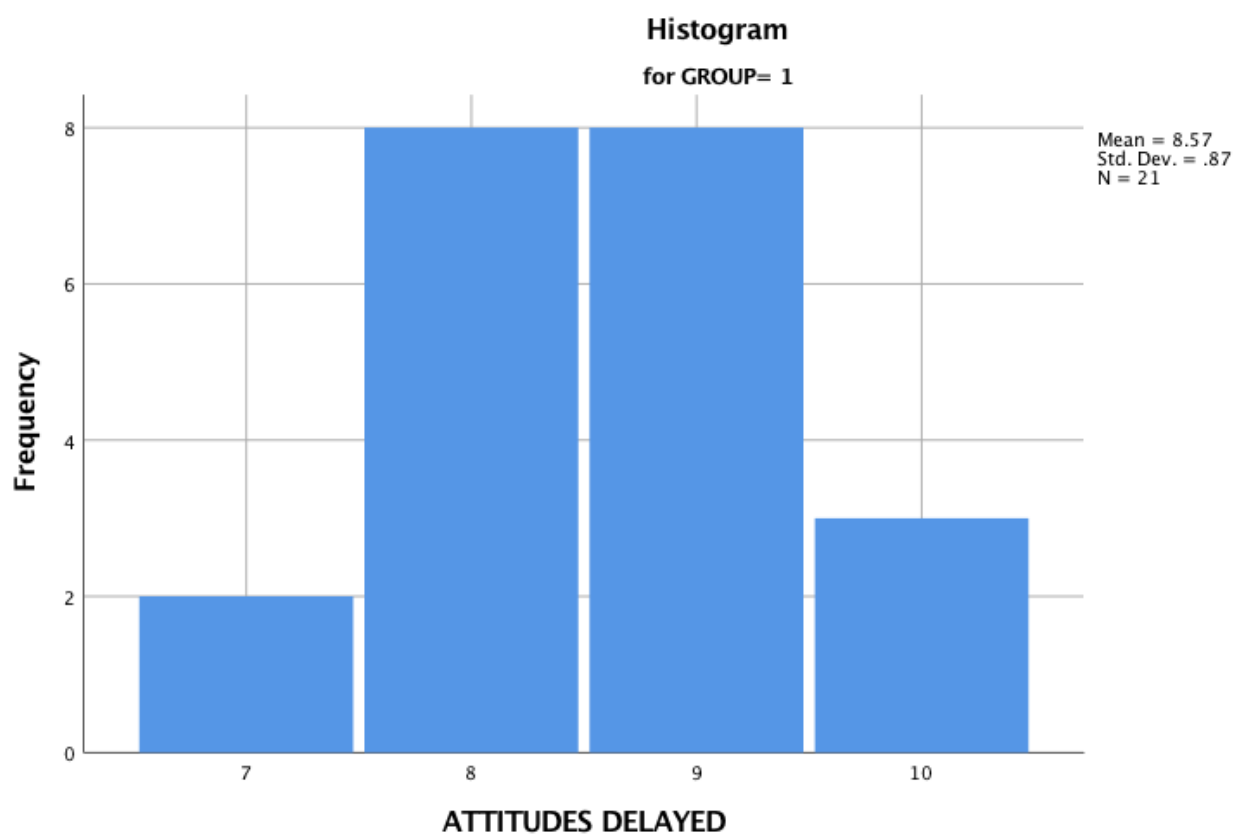

Figure 43. Distribution of the scores by the experimental group in Attitudes Questionnaire at Time 3 
i For the purpose of the present investigation, 'attitudes' and 'motivation' are understood as two different concepts. Attitudes and motivation are two of the individual differences that L2 users experience in the process of learning a second language; and which greatly influence L2 acquisition. Dörnyei and Ottó (1998, p. 65) conceptualized motivation in L2 learning as "the dynamically changing cumulative arousal in a person that initiates, directs, coordinates, amplifies, terminates, and evaluates the cognitive and motor processes whereby initial wishes and desires are selected, prioritised, operationalised and (successfully or unsuccessfully) acted out." Dörnyei and Ushioda (2011) stated that a lack of general agreement to define the term of 'motivation' seems to permeate studies in motivation research. Dörnyei and Ushioda, however, do claim that there are two phenomena which may indicate a consensus among scholars, since most of the definitions available in the literature point to "the direction and magnitude of human behavior" (p. 4) as the issues that motivation explores. Literature on attitudes to languages also experiences the lack of agreement to defining this concept specifically, since scholars seem to disagree both on the more general as well as on the more particular features that characterize the abstract construct that language attitudes are. Newcomb (1950) provided two plausible reasons that may ease the process of differentiating the terms 'motivation' and 'attitudes.' According to Newcomb, motivation seems to be driven by a force, either intrinsic or extrinsic, towards an object, which is absent in attitudes. Secondly, attitudes are to be projected to an object, such as media that uses the L2 to report events and facts, i.e., the New York Times, or a radio station in London. On the other hand, motivation seems to be exerted to reach an aim. For example, L2 learners may be motivated to learn a language because they may desire to be accepted into the L2 community (intrinsic motivation), or because they may need the L2 to get a job or pass a test at school (extrinsic motivation). Despite Newcomb's (1950) efforts to distinguish one term from the other, different understandings of both concepts still remain present in the literature. Additionally, the fact that these concepts have been used interchangeably in the literature may be one of the reasons that perpetuate such lack of agreement. It could be concluded that motivation refers to the driving forces that enhance or obstruct L2 acquisition, thus influencing the learners' attitudes towards the L2. In turn, attitudes may also influence L2 students' motivation (Newcomb, 1950). Therefore, both motivation and attitudes towards language learning are interconnected. In line with such statement relies Gardner's (1985a) conceptualization of the term 'motivation', since he envisioned attitudes as part of motivation, together with a desire to learn a language, as well as motivational intensity, within a more complex model to explain the variables affecting integrative motivation to language learning. 
